University of Rhode Island

DigitalCommons@URI

Open Access Master's Theses

2002

\title{
LECITHIN ORGANOGEL-BASED SYSTEM FOR TOPICAL APPLICATION OF KETOROLAC TROMETHAMINE
}

Angela Attar Nasseri

University of Rhode Island

Follow this and additional works at: https://digitalcommons.uri.edu/theses

\section{Recommended Citation}

Nasseri, Angela Attar, "LECITHIN ORGANOGEL-BASED SYSTEM FOR TOPICAL APPLICATION OF KETOROLAC TROMETHAMINE" (2002). Open Access Master's Theses. Paper 272.

https://digitalcommons.uri.edu/theses/272

This Thesis is brought to you for free and open access by DigitalCommons@URI. It has been accepted for inclusion in Open Access Master's Theses by an authorized administrator of DigitalCommons@URI. For more information, please contact digitalcommons-group@uri.edu. 
LECITHIN ORGANOGEL - BASED SYSTEM FOR TOPICAL APPLICATION OF

KETOROLAC TROMETHAMINE

BY

ANGELA ATTAR NASSERI

A THESIS SUBMTTTED IN PARTIAL FULFILLMENT OF THE

REQUIREMENT FOR THE DEGREE OF

MASTER OF SCIENCE

IN

APPLIED PHARMACEUTICAL SCIENCES

UNIVERSITY OF RHODE ISLAND

2002 


\section{MASTER OF SCIENCE THESIS}

OF

ANGELA ATTAR NASSERI

APPROVED:

Thesis Committee:

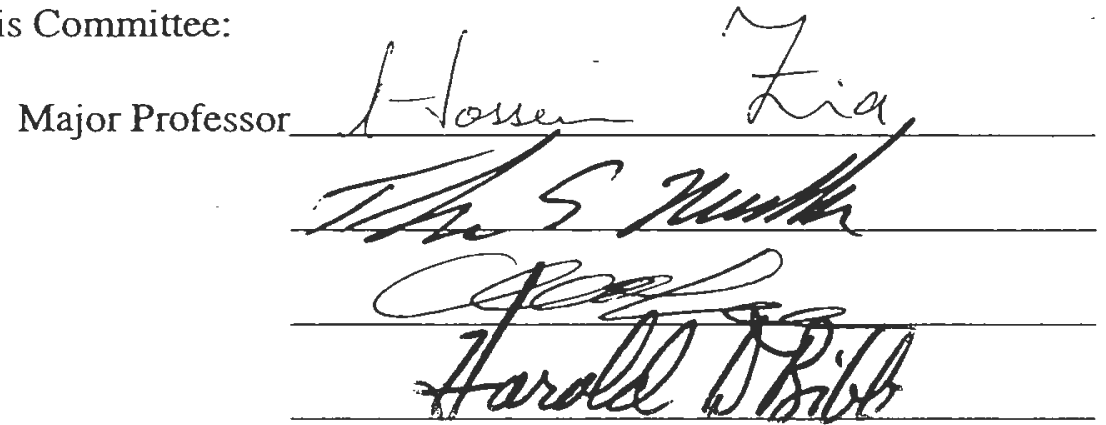

DEAN OF THE GRADUATE SCHOOL

UNIVERSITY OF RHODE ISLAND

2002 


\begin{abstract}
Among various nonsteroidal anti-inflammatory drugs (NSAIDs), ketorolac tromethamine has been widely used for post operative and emergency treatment of pain. However, it accompanies adverse side effects including gastrointestinal irritation when administered orally. Topical administration of ketorolac offers the advantage of enhanced drug delivery to the affected sites with a reduced incidence of gastrointestinal side effects. However, as skin is an exceptionally effective barrier to most chemicals, very few drugs can permeate it in amounts sufficient to deliver a therapeutic dose. Therefore, systems that make the skin locally more permeable and thereby enable transdermal delivery are of great interest. Lecithin organogels are an example of such systems in which solutions of lecithin in organic solvents can be transformed into transparent gels by addition of a critical amount of water. The main objective of this study was to investigate lecithin organogels as carriers for topical application of ketorolac tromethamine. In this research, phase studies were carried out to obtain the concentration of components for the existence range of organogel and the effect of these additives on release rate of ketorolac was also evaluated through the artificial membranes and guinea pig skin. As the lecithin concentration was increased from 40 to 50 and then $60 \% \mathrm{w} / \mathrm{w}$ in formulations, a significant decrease in ketorolac release was obtained. A significant increase in drug release was also observed in formulations containing $6.5 \% \mathrm{w} / \mathrm{w}$ of ketorolac compared to those containing $1 \% \mathrm{w} / \mathrm{w}$ of the drug. Increasing the water content of the organogels also resulted in an increase in ketorolac release. The optimum formulation of the organogel composed of $40 \%$ lecithin, $60 \%$ IPM containing $0.6 \% \mathrm{w} / \mathrm{w}$ of water and $6.5 \% \mathrm{w} / \mathrm{w}$ of ketorolac
\end{abstract}


tromethamine showed the highest drug release rate. Moreover, the viscosity of the different formulations and their rheological behavior were also determined. All formulations showed a slight rheopexy behavior rheogram. It was found that increase in lecithin concentration resulted in an increase in the viscosity of the organogel. Overall, the results have suggested that ketorolac tromethamine could be incorporated with high concentrations into lecithin organogels which makes them interesting for use as a drug delivery vehicle for water soluble drugs. 


\section{ACKNOWLEDGEMENT}

I would like to express my sincere appreciation to my major professor, Dr. $\mathrm{H}$. $\mathrm{Zia}$, for his supervision and guidance throughout the course of this study. I would also like to express my gratitude to Dr. R. Aboofazeli, without his assistance, this project would not have been a success.

I am grateful to the members of my committee, Dr. T.E. Needham, Dr. C. Lee and Dr. K. Parang for their helpful advice during the work and correction of this thesis.

Finally, I would like to thank my parents and my brother for their understanding, love and support. 


\section{TABLE OF CONTENTS}

ABSTRACT

ACKNOWLEDGEMENT iv

TABLE OF CONTENTS $\quad v$

LIST OF TABLES

LIST OF FIGURES $\quad$ xix

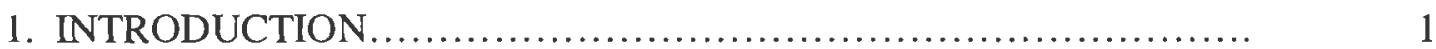

1.1 Microemulsions ............................................. 1

1.1.2 Definition of Microemulsions............................ 1

1.1.3 Emulsion versus Microeulsion............................ 1

1.1.4 Structure of Microemulsions............................ 3

1.1.5 Stability of Microemulsions............................. 5

1.2 Preparation of Microemulsions............................... 6

1.2.1 Pseudo-ternary Phase Diagram........................ 6

1.2.2 Determining the Existence of a Microemulsion Region.... 7

1.3 Choice of Microemulsion Components.......................... 7

1.4 Pharmaceutical Microemulsions................................. 8

1.4.1 Lecithin as a Surfactant................................ 9

1.5 Lecithin Organogels......................................... 9

1.5.1 Lecithin Organogel Components......................... 9

1.6 Structure of Organogels.................................. 11 
1.6.1 Molecular Model of Organogels...................... 12

1.6.2 Rheological Properties of Organogels.................. 16

1.7 Application of Lecithin Organogels......................... 16

1.7.1 Topical Application of Drugs........................ 17

1.7.2 Drug Release from Organogels......................... 18

1.8 Ketorolac Tromethamine.................................... 19

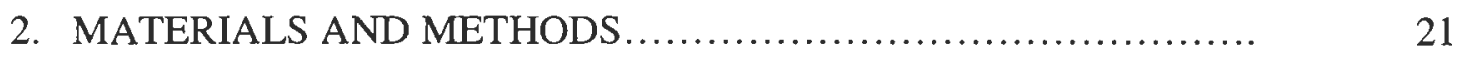

2.1 Materials and Equipments................................ 21

2.2 Methods................................................. 25

2.2.1 Preparation of Organogels.......................... 25

2.2.2 New Method of Preparation............................ 25

2.2.3 Construction of Phase diagrams and Formulation of

Ketorolac Organogels................................. 26

2.2.4 Release/Permeation Studies........................... 37

2.2.5 Release Data Analysis............................. 37

2.2.6 Spectrophotometric and HPLC Analysis of ketorolac........ 38

2.2.7 Spectrophotometric and HPLC data analysis.............. 38

2.2.8 Preparation of Synthetic Membrane and Guinea Pig Skin... 39

2.2.9 Viscosity Measurements.............................. 39

2.2.10 Statistical analysis................................ 39

3. RESULTS AND DISCUSSION ................................ 44

3.1 Organogel Preparation...................................... 44

3.2 Phase Diagram Studies.................................... 44 
3.3 Effect of Membrane on KT Release from Organogels..............

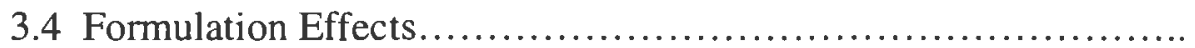

3.4.1 Effect of KT Concentration on Its Release Rates across Cellulose Acetate Membrane from Organogels with Different Composition......................................

3.4.2 Effect of Lecithin Concentration on the Release Rate KT across Cellulose Acetate Membrane from Organogels with Different Composition

3.4.3 Effect of Water Concentration on Release Rate of KT across Cellulose Acetate Membrane from Organogels with Different Composition

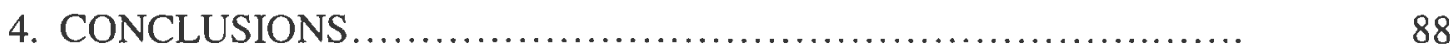

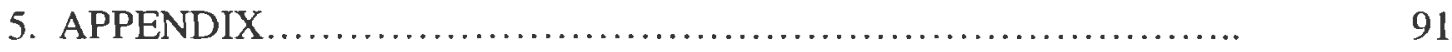

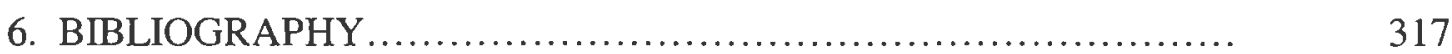




\section{LIST OF TABLES}

Table 1. Comparison of Emulsions and Microemulsions..............

Table 2. Formulation Composed of Lecithin, IPM and Water

Used for Phase Diagram.............................

Table 3. Formulation Composed of Lecithin, IPM and Water

(Containing 2.5\% w/v KT) Used for Phase Diagram........

Table 4. Formulation Composed of Lecithin, IPM and Water

(Containing 5\% w/v KT) Used for Phase Diagram...........

Table 5. Formulation Composed of Lecithin, IPM and Water

(Containing 10\% w/v KT) Used for Phase Diagram.........

Table 6. Formulation Composed of Lecithin, IPM and Water

(Containing 50\% w/v KT) Used for Phase Diagram.........

Table 7. Formulation Composed of Lecithin, IPM and Water

Containing $6.5 \% \mathrm{w} / \mathrm{w}$ KT Used for Phase Diagram...........

Table 8. Data for KT Absorbance in Buffer Solution at Different

Concentration Using Spectrophotometric Method...........

Table 9. Data for KT Absorbance in Buffer Solution at Different

Concentration Using HPLC Method.........................

Table 10. Ketorolac Organogel of Different Compositions..............

Table 11. Cumulative Release of KT across Cellulose Acetate

Membrane from Lecithin:IPM (40:60) Containing 0.1\%

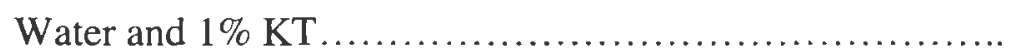


Table 12. Cumulative Release of KT across Silicone Elastomer Membrane from Lecithin:IPM (40:60) Containing 0.1\%

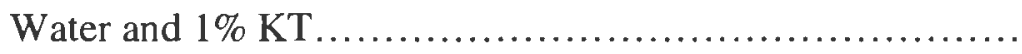

Table 13. Effect of Membrane on KT Release from Lecithin:IPM

Table 14. Cumulative Release of KT across Cellulose Acetate

Membrane from Lecithin:IPM (40:60) Containing 0.1\%

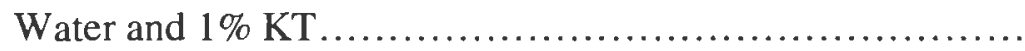

Table 15. Cumulative Release of KT across Cellulose Acetate

Membrane from Lecithin:IPM (40:60) Containing 0.1\%

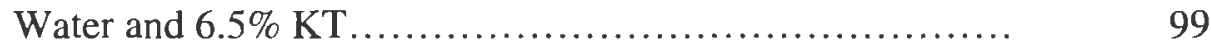

Table 16. Effect of KT Concentration on Its Transdermal Flux from

Lecithin:IPM (40:60) Containing 0.1\% Water............. 101

Table 17. Permeation of KT through Guinea Pig Skin from Lecithin:IPM (40:60) Containing 0.1\% Water and $1 \%$ KT $\ldots \ldots \ldots \ldots \ldots . . . . . .102$

Table 18. Permeation of KT through Guinea Pig Skin from Lecithin:IPM (40:60) Containing $0.1 \%$ Water and $6.5 \% \mathrm{KT}$ by HPLC....

Table 19. Comparison of Cellulose Acetate Membrane with Guinea Pig

Skin on KT Release from Lecithin:IPM (40:60) Containing

$0.1 \%$ Water and $6.5 \% \mathrm{KT}$

106

Table 20. Cumulative Release of KT across Cellulose Acetate

Membrane from Lecithin:IPM (40:60) Containing 0.25\%

Water and $6.5 \% \mathrm{KT}$

107 
Table 21. Cumulative Release of KT from across Cellulose Acetate Membrane Lecithin:IPM (50:50) Containing 0.25\%

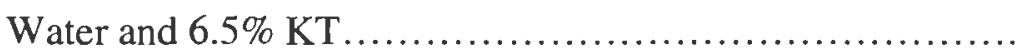

Table 22. Cumulative Release of KT across Cellulose Acetate

Membrane from Lecithin:IPM (60:40) Containing $0.25 \%$

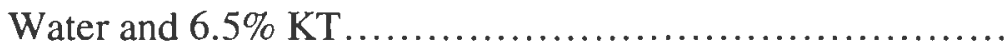

Table 23. Effect of Lecithin Concentration on KT Release from

Lecithin:IPM (40:60), (50:50) and (60:40) Containing $0.25 \%$

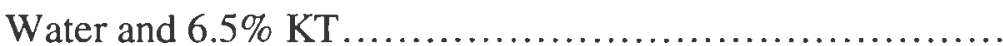

Table 24. Release Profile of KT across Cellulose Acetate

Membrane from Lecithin:IPM (40:60) Containing

Different Water Amounts and 6.5\% KT....................

Table 25. Release Profile of KT across Cellulose Acetate

Membrane from Lecithin:IPM (50:50) Containing

Different Water Amounts and 6.5\% KT....................

Table 26. Release Profile of KT across Cellulose Acetate

Membrane from Lecithin:IPM (60:40) Containing

Different Water Amounts and 6.5\% KT

Table 27. Effect of Water Concentration on KT Release from

Lecithin:IPM (40:60) Containing 6.5\% KT ................

Table 28. Effect of Water Concentration on KT Release from

Lecithin:IPM (50:50) Containing 6.5\% KT 
Table 29. Effect of Water Concentration on KT Release from Lecithin:IPM (60:40) Containing 6.5\% KT............... 119

Table 30. Effect of Viscosity on KT Release from Organogels

With Different Lecithin Concentration by Cylindrical Viscometer 120

Table 31. Effect of Lecithin Concentration on the Viscosity of

Lecithin:IPM (40:60), (50:50) and (60:40) Containing 0.25\%

Water and $6.5 \% \mathrm{KT}$ by Cylindrical Viscometer..............

Table 32. Effect of Lecithin Concentration on the Viscosity of

Lecithin:IPM (40:60), (50:50) and (60:40) Containing 0.25\%

Water and $6.5 \%$ KT by Cone and Plate Viscometer..........

Table 33. Effect of the Shear Rate on Viscosity of Lecithin:IPM

(40:60) Containing $0.25 \%$ Water and $6.5 \%$ KT by Cone

and Plate Viscometer...................................

Table 34. Effect of Water Concentration on the Viscosity of Lecithin:IPM (40:60) Containing 6.5\% KT by Cylindrical

Viscometer................................................

Table 35. Effect of Water Concentration on the Viscosity of Lecithin:IPM (40:60) Containing 6.5\% KT by Cone and Plate

Viscometer.................................................

Table 36. Effect of Viscosity on KT Release from Lecithin:IPM (40:60), (50:50) and (60:40) Containing 0.25\% Water and 6.5\% KT by Cylindrical Viscometer........................ 
Table 37. Viscosity of Organogel Samples with Different Compositions

by Cone and Plate Viscometer.........................

Table 38. Release Profile of KT across Cellulose Acetate from

6.5\% KT Organogels of Different Compositions.............

128

Table 39. Cumulative Release of KT across Cellulose Acetate

Membrane from Lecithin:IPM (40:60) Containing 0.5\%

Water and $6.5 \% \mathrm{KT}$

128

Table 40. Cumulative Release of KT across Cellulose Acetate

Membrane from Lecithin:IPM (40:60) Containing 0.6\%

Water and $6.5 \% \mathrm{KT}$

Table 41. Cumulative Release of KT across Cellulose Acetate

Membrane from Lecithin:IPM (40:60) Containing 0.7\%

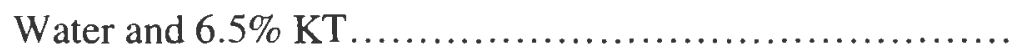

Table 42. Cumulative Release of KT across Cellulose Acetate

Membrane from Lecithin:IPM (40:60) Containing 0.8\%

Water and $6.5 \% \mathrm{KT}$

Table 43. Cumulative Release of KT across Cellulose Acetate

Membrane from Lecithin:IPM (50:50) Containing 0.1\%

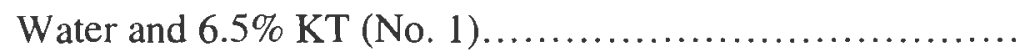

Table 44. Cumulative Release of KT across Cellulose Acetate

Membrane from Lecithin:IPM (50:50) Containing 0.1\%

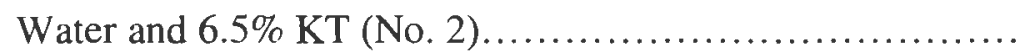


Table 45. Cumulative Release of KT across Cellulose Acetate

Membrane from Lecithin:IPM (50:50) Containing 0.1\%

Water and $6.5 \% \mathrm{KT}($ Mean $\pm \mathrm{SD}, \mathrm{N}=12) \ldots \ldots \ldots \ldots \ldots \ldots \ldots \ldots$

Table 46. Cumulative Release of KT across Cellulose Acetate

Membrane from Lecithin:IPM (50:50) Containing 0.5\%

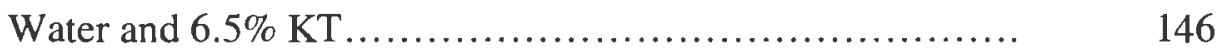

Table 47. Cumulative Release of KT across Cellulose Acetate

Membrane from Lecithin:IPM (50:50) Containing 0.6\%

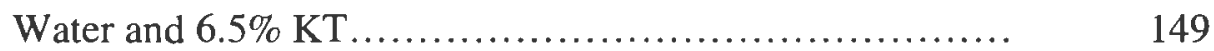

Table 48. Cumulative Release of KT across Cellulose Acetate

Membrane from Lecithin:IPM (50:50) Containing 0.7\%

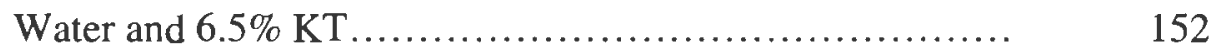

Table 49. Cumulative Release of KT across Cellulose Acetate

Membrane from Lecithin:IPM (50:50) Containing 0.8\%

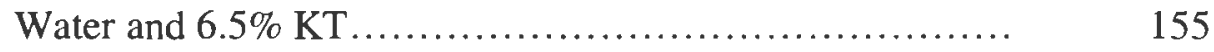

Table 50. Cumulative Release of KT across Cellulose Acetate

Membrane from Lecithin:IPM (60:40) Containing 0.1\%

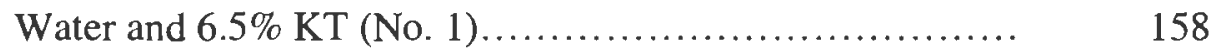

Table 51. Cumulative Release of KT across Cellulose Acetate

Membrane from Lecithin:IPM (60:40) Containing 0.1\%

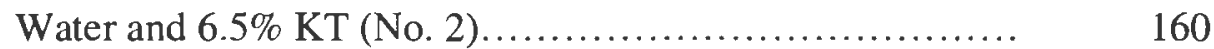


Table 52. Cumulative Release of KT across Cellulose Acetate Membrane from Lecithin:IPM (60:40) Containing 0.1\%

Water and 6.5\% KT (Mean $\pm \mathrm{SD}, \mathrm{N}=12) \ldots \ldots \ldots \ldots \ldots \ldots . . . . .162$

Table 53. Cumulative Release of KT across Cellulose Acetate

Membrane from Lecithin:IPM (60:40) Containing 0.5\%

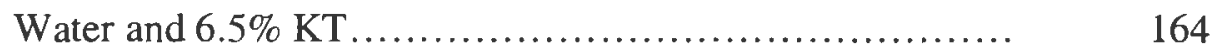

Table 54. Cumulative Release of KT across Cellulose Acetate

Membrane from Lecithin:IPM (60:40) Containing 0.6\%

Water and 6.5\% KT ...................................... 167

Table 55. Cumulative Release of KT across Cellulose Acetate

Membrane from Lecithin:IPM (60:40) Containing 0.7\%

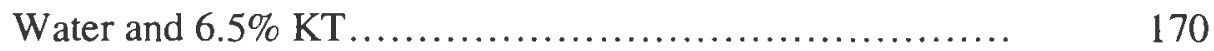

Table 56. Cumulative Release of KT across Cellulose Acetate

Membrane from Lecithin:IPM (60:40) Containing 0.8\%

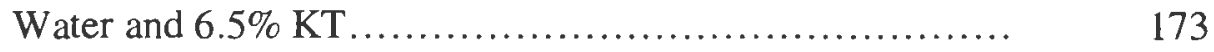

Table 57. Values of Viscosity for KT Organogels with Different

Compositions by Cylindrical Viscometer (NO. 1)........... 176

Table 58. Values of Viscosity for KT Organogels with Different

Compositions by Cylindrical Viscometer (NO. 2)........... 187

Table 59. Viscosity of Lecithin:IPM (40:60) Containing $0.1 \%$

Water and 6.5\% KT by Cone and Plate Viscometer.......... 198

Table 60. Viscosity of Lecithin:IPM (40:60) Containing $0.25 \%$

Water and 6.5\% KT by Cone and Plate Viscometer......... 200 
Table 61. Viscosity of Lecithin:IPM (40:60) Containing 0.5\%

Water and 6.5\% KT by Cone and Plate Viscometer.......... 202

Table 62. Viscosity of Lecithin:IPM (40:60) Containing $0.6 \%$

Water and 6.5\% KT by Cone and Plate Viscometer........ 204

Table 63. Viscosity of Lecithin:IPM (40:60) Containing 0.7\%

Water and 6.5\% KT by Cone and Plate Viscometer.......... 206

Table 64. Viscosity of Lecithin:IPM (40:60) Containing 0.8\%

Water and 6.5\% KT by Cone and Plate Viscometer......... 208

Table 65. Viscosity of Lecithin:IPM (50:50) Containing 0.1\%

Water and $6.5 \%$ KT by Cone and Plate Viscometer......... 210

Table 66. Viscosity of Lecithin:IPM (50:50) Containing 0.25\%

Water and 6.5\% KT by Cone and Plate Viscometer......... 212

Table 67. Viscosity of Lecithin:IPM (50:50) Containing 0.5\%

Water and 6.5\% KT by Cone and Plate Viscometer......... 214

Table 68. Viscosity of Lecithin:IPM (50:50) Containing $0.6 \%$

Water and $6.5 \%$ KT by Cone and Plate Viscometer......... 216

Table 69. Viscosity of Lecithin:IPM (50:50) Containing 0.7\%

Water and $6.5 \%$ KT by Cone and Plate Viscometer......... 218

Table 70. Viscosity of Lecithin:IPM (50:50) Containing 0.8\%

Water and $6.5 \%$ KT by Cone and Plate Viscometer......... 220

Table 71. Viscosity of Lecithin:IPM (60:40) Containing $0.1 \%$

Water and $6.5 \%$ KT by Cone and Plate Viscometer........ 222 
Table 72. Viscosity of Lecithin:IPM (60:40) Containing $0.25 \%$

Water and $6.5 \% \mathrm{KT}$ by Cone and Plate Viscometer.........

Table 73. Viscosity of Lecithin:IPM (60:40) Containing $0.5 \%$

Water and $6.5 \%$ KT by Cone and Plate Viscometer..........

Table 74. Viscosity of Lecithin:IPM (60:40) Containing $0.6 \%$

Water and 6.5\% KT by Cone and Plate Viscometer........... 228

Table 75. Viscosity of Lecithin:IPM (60:40) Containing $0.7 \%$

Water and $6.5 \%$ KT by Cone and Plate Viscometer...........

Table 76. Viscosity of Lecithin:IPM (60:40) Containing $0.8 \%$

Water and $6.5 \% \mathrm{KT}$ by Cone and Plate Viscometer

Table 77. Results of One-Way ANOVA on KT Release from

Formulations with Different Compositions................

Table 77-1. Release Rate Values of KT from Eighteen Organogel

Samples of Different Composition Using One-Way

ANOVA Analysis.......

Table 78. Results of One-Way ANOVA on KT Release through

Hairless Guinea Pig Skin.................................

Table 78-1. Release Rate Values of KT through Guinea Pig Skin

Using One-Way ANOVA Analysis....................... 268

Table 79. Results of One-Way ANOVA on Viscosity of Various

Formulations Containing Different Compositions............

Table 79-1. Viscosity Values of Various Formulations Containing

Different Compositions using One-Way ANOVA Analysis... 
Table 80. Viscosity Values for Lecithin:IPM (40:60) Containing

$0.1 \%$ Water and $6.5 \% \mathrm{KT}$ by Cone and Plate Viscometer...

Table 81. Viscosity Values for Lecithin:IPM (40:60) Containing

$0.25 \%$ Water and $6.5 \%$ KT by Cone and Plate Viscometer...

Table 82. Viscosity Values for Lecithin:IPM (40:60) Containing

$0.5 \%$ Water and $6.5 \% \mathrm{KT}$ by Cone and Plate Viscometer...

Table 83. Viscosity Values for Lecithin:IPM (40:60) Containing

$0.6 \%$ Water and $6.5 \%$ KT by Cone and Plate Viscometer...

Table 84. Viscosity Values for Lecithin:IPM (40:60) Containing

$0.7 \%$ Water and $6.5 \% \mathrm{KT}$ by Cone and Plate Viscometer...

Table 85. Viscosity Values for Lecithin:IPM (40:60) Containing

$0.8 \%$ Water and $6.5 \% \mathrm{KT}$ by Cone AND Plate Viscometer..

Table 86. Viscosity Values for Lecithin:IPM (50:50) Containing

$0.1 \%$ Water and $6.5 \% \mathrm{KT}$ by Cone and Plate Viscometer...

Table 87. Viscosity Values for Lecithin:IPM (50:50) Containing

$0.25 \%$ Water and $6.5 \%$ KT by Cone and Plate Viscometer...

Table 88. Viscosity Values for Lecithin:IPM (50:50) Containing

$0.5 \%$ Water and $6.5 \% \mathrm{KT}$ by Cone and Plate Viscometer...

Table 89. Viscosity Values for Lecithin:IPM (50:50) Containing

$0.6 \%$ Water and $6.5 \% \mathrm{KT}$ by Cone and Plate Viscometer...

Table 90. Viscosity Values for Lecithin:IPM (50:50) Containing

$0.7 \%$ Water and $6.5 \% \mathrm{KT}$ by Cone and Plate Viscometer... 
Table 91. Viscosity Values for Lecithin:IPM (50:50) Containing

$0.8 \%$ Water and $6.5 \% \mathrm{KT}$ by Cone and Plate Viscometer...

Table 92. Viscosity Values for Lecithin:IPM (60:40) Containing

$0.1 \%$ Water and $6.5 \% \mathrm{KT}$ by Cone and Plate Viscometer...

Table 93. Viscosity Values for Lecithin:IPM (60:40) Containing

$0.25 \%$ Water and $6.5 \% \mathrm{KT}$ by Cone and Plate Viscometer...

Table 94. Viscosity Values for Lecithin:IPM (60:40) Containing

$0.5 \%$ Water and $6.5 \% \mathrm{KT}$ by Cone and Plate Viscometer...

Table 95. Viscosity Values for Lecithin:IPM (60:40) Containing

$0.6 \%$ Water and $6.5 \% \mathrm{KT}$ by Cone and Plate Viscometer...

Table 96. Viscosity Values for Lecithin:IPM (60:40) Containing

$0.7 \%$ Water and $6.5 \% \mathrm{KT}$ by Cone and Plate Viscometer...

Table 97. Viscosity Values for Lecithin:IPM (60:40) Containing

$0.8 \%$ Water and $6.5 \% \mathrm{KT}$ by Cone and Plate Viscometer... 


\section{LIST OF FIGURES}

Figure 1. Structure of Microemulsion............................ 4

Figure 2. Structural Formula of Lecithin.......................... 10

Figure 3. A Two Dimensional Schematic Representation of the

Hydrogen Binding Network Formed in Lecithin

Tubular Micelles..........................................

Figure 4. Structure of Lecithin Reverse Micelles as a Function

of Added Water............................................ 15

Figure 5. Chemical Structure of Ketorolac Tromethamine.............. 20

Figure 6. Calibration Curve for Ketorolac Tromethamine Using

Spectrophotometric Method............................. $\quad 41$

Figure 7. Calibration Curve for Ketorolac Tromethamine Using

HPLC Method........................................... 43

Figure 8. Phase Diagram of a System Containing Lecithin, IPM

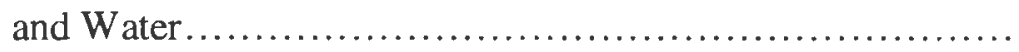

Figure 9. Phase Diagram of a System of Lecithin, IPM

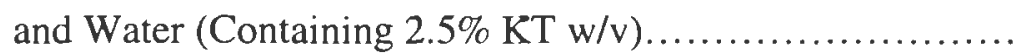

Figure 10. Phase Diagram of a System of Lecithin, IPM

and Water (Containing 5\% KT w/v) ...................... 48

Figure 11. Phase Diagram of a System of Lecithin, IPM

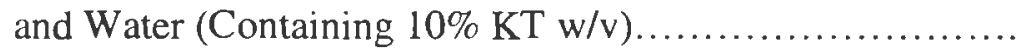

Figure 12. Phase Diagram of a System of Lecithin, IPM

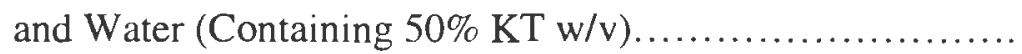


Figure 13. Phase Diagram of a System Containing Lecithin, IPM and Water with $6.5 \%$ w/w KT in a Gel Formulation...........

Figure 14. Release Profile of KT across Cellulose Acetate Membrane from Lecithin:IPM (40:60) Containing 0.1\%

Water and $1 \% \mathrm{KT}$

Figure 15. Release Profile of KT across Silicone Elastomer

Membrane from Lecithin:IPM (40:60) Containing 0.1\%

Water and $1 \% \mathrm{KT}$

Figure 16. Effect of Membrane on KT Release from Lecithin:IPM

(40:60) Containing $0.1 \%$ Water and $1 \% \mathrm{KT} \ldots \ldots \ldots \ldots \ldots . . . . .$.

Figure 17. Release Profile of KT across Cellulose Acetate

Membrane from Lecithin:IPM (40:60) Containing

$0.1 \%$ Water and $1 \% \mathrm{KT}$

58

Figure 18. Release Profile of KT across Cellulose Acetate

Membrane from Lecithin:IPM (40:60) Containing

$0.1 \%$ Water and $6.5 \% \mathrm{KT}$

59

Figure 19. Effect of KT Concentration on Its Release across

Cellulose Acetate Membrane from Lecithin:IPM

(40:60) Containing $0.1 \%$ Water.

60

Figure 20. Permeation Profile of KT through Hairless Guinea

Pig Skin from Lecithin:IPM (40:60) Containing 0.1\%

Water and $1 \% \mathrm{KT}$

62 
Figure 21. Permeation Profile of KT through Hairless Guinea

Pig Skin from Lecithin:IPM (40:60) Containing 0.1\%

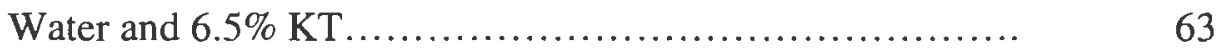

Figure 22. Comparison of Cellulose Acetate Membrane with

Guinea Pig Skin on KT Release from Lecithin:IPM

(40:60) Containing 0.1\% Water and $6.5 \% \mathrm{KT}$

Figure 23. Release Profile of KT across Cellulose Acetate

Membrane from Lecithin:IPM (40:60) Containing

$0.25 \%$ Water and $6.5 \% \mathrm{KT}$

Figure 24. Release Profile of KT across Cellulose Acetate

Membrane from Lecithin:IPM (50:50) Containing

$0.25 \%$ Water and $6.5 \% \mathrm{KT}$

Figure 25. Release Profile of KT across Cellulose Acetate

Membrane from Lecithin:IPM (60:40) Containing

$0.25 \%$ Water and $6.5 \% \mathrm{KT}$

68

Figure 26. Effect of Lecithin Concentration on KT Release across Cellulose Acetate Membrane from lecithin:IPM $(40: 60),(50: 50)$ and $(60: 40)$ Containing $0.25 \%$ Water and $6.5 \% \mathrm{KT}$

Figure 27. Release Profile of KT across Cellulose Acetate Membrane from Lecithin:IPM (40:60) Containing Different Water Amounts and 6.5\% KT 
Figure 28. Release Profile of KT across Cellulose Acetate Membrane from Lecithin:IPM (50:50) Containing Different Water Amounts and 6.5\% KT.

Figure 29. Release Profile of KT across Cellulose Acetate Membrane from Lecithin:IPM (60:40) Containing Different Water Amounts and 6.5\% KT

Figure 30. Effect of Water Concentration on KT Release across Cellulose Acetate Membrane from Lecithin:IPM (40:60) Containing $6.5 \% \mathrm{KT}$

Figure 31. Effect of Water Concentration on KT Release across Cellulose Acetate Membrane from Lecithin:IPM

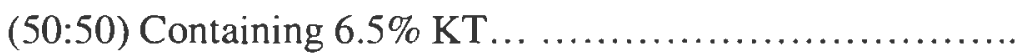

Figure 32. Effect of Water Concentration on KT Release across Cellulose Acetate Membrane from Lecithin:IPM (60:40) Containing $6.5 \% \mathrm{KT}$.

Figure 33. Effect of Viscosity on KT Release from Organogels with Different Lecithin Concentration by Cylindrical Viscometer..............................................

Figure 34. Effect of Lecithin Concentration on Viscosity of Lecithin:IPM (40:60), (50:50) and (60:40) Containing $0.25 \%$ Water and $6.5 \% \mathrm{KT}$ by Cylindrical Viscometer....... 
Figure 35. Effect of Lecithin Concentration on Viscosity of Lecithin:IPM (40:60), (50:50) and (60:40) Containing $0.25 \%$ Water and $6.5 \% \mathrm{KT}$ by Cone and Plate Viscometer...

Figure 36. Rheogram Showing Rheopexy Behavior for

Lecithin:IPM (40:60) Containing 0.25\% Water and

6.5\% KT by Cone and Plate Viscometer.

Figure 37. Effect of Water Concentration on the Viscosity of Lecithin:IPM (40:60) Containing 6.5\% KT by Cylindrical Viscometer.

Figure 38. Effect of Water Concentration on the Viscosity of Lecithin:IPM (40:60) Containing 6.5\% KT by Cone and Plate Viscometer........................................

Figure 39. Effect of Viscosity on KT Release from Lecithin:IPM (40:60), (50:50) and (60:40) Containing 0.25\% Water and $6.5 \% \mathrm{KT}$ by Cylindrical Viscometer..................

Figure 40. Viscosity of Organogel Samples with Different

Compositions by Cone and Plate Viscometer...............

Figure 41. Release Profile of KT across Cellulose Acetate from 6.5\% KT Organogels of Different Compositions..............

Figure 42. Release Profile of KT from Lecithin:IPM (40:60)

Containing $0.5 \%$ Water and $6.5 \% \mathrm{KT} \ldots \ldots \ldots \ldots \ldots \ldots \ldots \ldots$

Figure 43. Release Profile of KT from Lecithin:IPM (40:60)

Containing $0.6 \%$ Water and $6.5 \% \mathrm{KT}$ 
Figure 44. Release Profile of KT from Lecithin:IPM (40:60)

Containing $0.7 \%$ Water and $6.5 \% \mathrm{KT} \ldots \ldots \ldots \ldots \ldots \ldots \ldots \ldots \ldots \ldots \ldots$

Figure 45. Release Profile of KT from Lecithin:IPM (40:60)

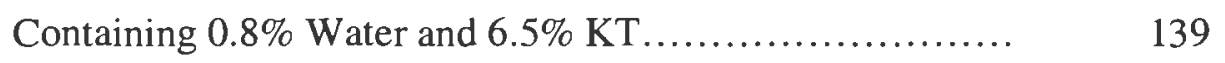

Figure 46. Release Profile of KT from Lecithin:IPM (50:50)

Containing $0.1 \%$ Water and $6.5 \% \mathrm{KT} \ldots \ldots \ldots \ldots \ldots \ldots \ldots \ldots \ldots$

Figure 47. Release Profile of KT from Lecithin:IPM (50:50)

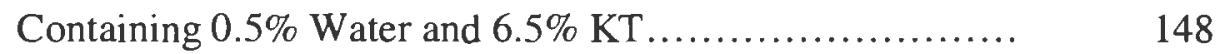

Figure 48. Release Profile of KT from Lecithin:IPM (50:50)

Containing $0.6 \%$ Water and $6.5 \% \mathrm{KT} \ldots \ldots \ldots \ldots \ldots \ldots \ldots \ldots \ldots \ldots \ldots \ldots$

Figure 49. Release Profile of KT from Lecithin:IPM (50:50)

Containing $0.7 \%$ Water and $6.5 \% \mathrm{KT} \ldots \ldots \ldots \ldots \ldots \ldots \ldots \ldots \ldots \ldots$

Figure 50. Release Profile of KT from Lecithin:IPM (50:50)

Containing 0.8\% Water and 6.5\% KT................... 157

Figure 51. Release Profile of KT from Lecithin:IPM (60:40)

Containing $0.1 \%$ Water and $6.5 \% \mathrm{KT} \ldots \ldots \ldots \ldots \ldots \ldots \ldots \ldots \ldots$

Figure 52. Release Profile of KT from Lecithin:IPM (60:40)

Containing $0.5 \%$ Water and $6.5 \% \mathrm{KT} \ldots \ldots \ldots \ldots \ldots \ldots \ldots \ldots \ldots$

Figure 53. Release Profile of KT from Lecithin:IPM (60:40)

Containing $0.6 \%$ Water and $6.5 \% \mathrm{KT} \ldots \ldots \ldots \ldots \ldots \ldots \ldots \ldots \ldots$

Figure 54. Release Profile of KT from Lecithin:IPM (60:40)

Containing $0.7 \%$ Water and $6.5 \% \mathrm{KT} \ldots \ldots \ldots \ldots \ldots \ldots \ldots \ldots \ldots \ldots$ 
Figure 55. Release Profile of KT from Lecithin:IPM (60:40)

Containing $0.8 \%$ Water and $6.5 \% \mathrm{KT}$.

Figure 56. Rheogram for Lecithin:IPM (40:60) Containing 0.1\%

Water and $6.5 \% \mathrm{KT}$ by Cylindrical Viscometer (No. 1).....

178

Figure 57. Rheogram for Lecithin:IPM (40:60) Containing 0.25\%

Water and $6.5 \% \mathrm{KT}$ by Cylindrical Viscometer (No. 1).....

Figure 58. Rheogram for Lecithin:IPM (40:60) Containing 0.5\%

Water and $6.5 \% \mathrm{KT}$ by Cylindrical Viscometer (No. 1)......

Figure 59. Rheogram for Lecithin:IPM (40:60) Containing 0.7\%

Water and $6.5 \% \mathrm{KT}$ by Cylindrical Viscometer (No. 1).....

Figure 60. Rheogram for Lecithin:IPM (40:60) Containing $0.8 \%$

Water and $6.5 \%$ KT by Cylindrical Viscometer (No. 1).....

Figure 61. Rheogram for Lecithin:IPM (50:50) Containing 0.1\%

Water and $6.5 \%$ KT by Cylindrical Viscometer (No. 1).....

Figure 62. Rheogram for Lecithin:IPM (50:50) Containing 0.25\%

Water and $6.5 \%$ KT by Cylindrical Viscometer (No. 1)......

Figure 63. Rheogram for Lecithin:IPM (60:40) Containing $0.1 \%$

Water and $6.5 \%$ KT by Cylindrical Viscometer (No. 1)......

Figure 64. Rheogram for Lecithin:IPM (60:40) Containing 0.25\%

Water and $6.5 \%$ KT by Cylindrical Viscometer (No. 1).....

186

Figure 65. Rheogram for Lecithin:IPM (40:60) Containing 0.1\%

Water and $6.5 \% \mathrm{KT}$ by Cylindrical Viscometer (No. 2)......

189 
Figure 66. Rheogram for Lecithin:IPM (40:60) Containing 0.25\%

Water and $6.5 \% \mathrm{KT}$ by Cylindrical Viscometer (No. 2)......

Figure 67. Rheogram for Lecithin:IPM (40:60) Containing 0.5\%

Water and $6.5 \%$ KT by Cylindrical Viscometer (No. 2)......

Figure 68. Rheogram for Lecithin:IPM (40:60) Containing 0.7\%

Water and $6.5 \%$ KT by Cylindrical Viscometer (No. 2)......

Figure 69. Rheogram for Lecithin:IPM (40:60) Containing 0.8\%

Water and 6.5\% KT by Cylindrical Viscometer (No. 2)......

Figure 70. Rheogram for Lecithin:IPM (50:50) Containing 0.1\%

Water and 6.5\% KT by Cylindrical Viscometer (No. 2)......

Figure 71. Rheogram for Lecithin:IPM (50:50) Containing 0.25\%

Water and 6.5\% KT by Cylindrical Viscometer (No. 2)......

Figure 72. Rheogram for Lecithin:IPM (60:40) Containing 0.1\%

Water and 6.5\% KT by Cylindrical Viscometer (No. 2)......

Figure 73. Rheogram for Lecithin:IPM (60:40) Containing 0.25\%

Water and 6.5\% KT by Cylindrical Viscometer (No. 2)......

Figure 74. Rheogram for Lecithin:IPM (40:60) Containing 0.1\%

Water and $6.5 \%$ KT by Cone and Plate Viscometer ..........

Figure 75. Rheogram for Lecithin:IPM (40:60) Containing 0.25\%

Water and $6.5 \% \mathrm{KT}$ by Cone and Plate Viscometer

Figure 76. Rheogram for Lecithin:IPM (40:60) Containing 0.5\%

Water and $6.5 \% \mathrm{KT}$ by Cone and Plate Viscometer 
Figure 77. Rheogram for Lecithin:IPM (40:60) Containing 0.6\%

Water and $6.5 \% \mathrm{KT}$ by Cone and Plate Viscometer ...........

Figure 78. Rheogram for Lecithin:IPM (40:60) Containing 0.7\%

Water and $6.5 \% \mathrm{KT}$ by Cone and Plate Viscometer.........

Figure 79. Rheogram for Lecithin:IPM (40:60) Containing 0.8\%

Water and $6.5 \%$ KT by Cone and Plate Viscometer .........

Figure 80. Rheogram for Lecithin:IPM (50:50) Containing 0.1\%

Water and $6.5 \%$ KT by Cone and Plate Viscometer ..........

Figure 81. Rheogram for Lecithin:IPM (50:50) Containing 0.25\%

Water and $6.5 \% \mathrm{KT}$ by Cone and Plate Viscometer ..........

Figure 82. Rheogram for Lecithin:IPM (50:50) Containing 0.5\%

Water and $6.5 \% \mathrm{KT}$ by Cone and Plate Viscometer ..........

Figure 83. Rheogram for Lecithin:IPM (50:50) Containing 0.6\%

Water and $6.5 \% \mathrm{KT}$ by Cone and Plate Viscometer ..........

Figure 84. Rheogram for Lecithin:IPM (50:50) Containing 0.7\%

Water and $6.5 \% \mathrm{KT}$ by Cone and Plate Viscometer ..........

Figure 85. Rheogram for Lecithin:IPM (50:50) Containing 0.8\%

Water and $6.5 \% \mathrm{KT}$ by Cone and Plate Viscometer ..........

Figure 86. Rheogram for Lecithin:IPM (60:40) Containing 0.1\%

Water and $6.5 \% \mathrm{KT}$ by Cone and Plate Viscometer .........

Figure 87. Rheogram for Lecithin:IPM (60:40) Containing 0.25\%

Water and $6.5 \%$ KT by Cone and Plate Viscometer ......... 
Figure 88. Rheogram for Lecithin:IPM (60:40) Containing 0.5\%

Water and $6.5 \% \mathrm{KT}$ by Cone and Plate Viscometer .........

Figure 89. Rheogram for Lecithin:IPM (60:40) Containing 0.6\%

Water and $6.5 \%$ KT by Cone and Plate Viscometer ..........

Figure 90. Rheogram for Lecithin:IPM (60:40) Containing 0.7\%

Water and $6.5 \% \mathrm{KT}$ by Cone and Plate Viscometer..........

Figure 91. Rheogram for Lecithin:IPM (60:40) Containing 0.8\%

Water and $6.5 \% \mathrm{KT}$ by Cone and Plate Viscometer ..........

Figure 92. Rheogram Showing Rheopexy Behavior for Lecithin:IPM

(40:60) Containing $0.1 \%$ Water and $6.5 \% \mathrm{KT}$ by Cone and

Plate Viscometer.

Figure 93. Rheogram Showing Rheopexy Behavior for Lecithin:IPM

(40:60) Containing $0.25 \%$ Water and $6.5 \% \mathrm{KT}$ by Cone and

Plate Viscometer.

Figure 94. Rheogram Showing Rheopexy Behavior for Lecithin:IPM

(40:60) Containing $0.5 \%$ Water and $6.5 \% \mathrm{KT}$ by Cone and

Plate Viscometer.

Figure 95. Rheogram Showing Rheopexy Behavior for Lecithin:IPM

(40:60) Containing $0.6 \%$ Water and $6.5 \% \mathrm{KT}$ by Cone and

Plate Viscometer

288

Figure 96. Rheogram Showing Rheopexy Behavior for Lecithin:IPM

(40:60) Containing $0.7 \%$ Water and $6.5 \% \mathrm{KT}$ by Cone and

Plate Viscometer. 
Figure 97. Rheogram Showing Rheopexy Behavior for Lecithin:IPM (40:60) Containing $0.8 \%$ Water and $6.5 \% \mathrm{KT}$ by Cone and Plate Viscometer........................................

Figure 98. Rheogram Showing Rheopexy Behavior for Lecithin:IPM (50:50) Containing 0.1\% Water and $6.5 \% \mathrm{KT}$ by Cone and Plate Viscometer........................................

Figure 99. Rheogram Showing Rheopexy Behavior for Lecithin:IPM (50:50) Containing $0.25 \%$ Water and $6.5 \% \mathrm{KT}$ by Cone and Plate Viscometer.

Figure 100. Rheogram Showing Rheopexy Behavior for Lecithin:IPM (50:50) Containing $0.5 \%$ Water and $6.5 \% \mathrm{KT}$ by Cone and Plate Viscometer

Figure 101. Rheogram Showing Rheopexy Behavior for Lecithin:IPM (50:50) Containing $0.6 \%$ Water and $6.5 \% \mathrm{KT}$ by Cone and Plate Viscometer

Figure 102. Rheogram Showing Rheopexy Behavior for Lecithin:IPM (50:50) Containing $0.7 \%$ Water and $6.5 \% \mathrm{KT}$ by Cone and Plate Viscometer.

Figure 103. Rheogram Showing Rheopexy Behavior for Lecithin:IPM (50:50) Containing 0.8\% Water and 6.5\% KT by Cone and Plate Viscometer. 
Figure 104. Rheogram Showing Rheopexy Behavior for Lecithin:IPM

(60:40) Containing $0.1 \%$ Water and $6.5 \% \mathrm{KT}$ by Cone and

Plate Viscometer.......................................

Figure 105. Rheogram Showing Rheopexy Behavior for Lecithin:IPM

(60:40) Containing $0.25 \%$ Water and $6.5 \% \mathrm{KT}$ by Cone and

Plate Viscometer...................................... 308

Figure 106. Rheogram Showing Rheopexy Behavior for Lecithin:IPM

(60:40) Containing $0.5 \%$ Water and $6.5 \% \mathrm{KT}$ by Cone and

Plate Viscometer.......................................

Figure 107. Rheogram Showing Rheopexy Behavior for Lecithin:IPM

(60:40) Containing $0.6 \%$ Water and $6.5 \% \mathrm{KT}$ by Cone and

Plate Viscometer......................................

Figure 108. Rheogram Showing Rheopexy Behavior for Lecithin:IPM

(60:40) Containing $0.7 \%$ Water and $6.5 \% \mathrm{KT}$ by Cone and

Plate Viscometer.

Figure 109. Rheogram Showing Rheopexy Behavior for Lecithin:IPM

(60:40) Containing $0.8 \%$ Water and $6.5 \% \mathrm{KT}$ by Cone and

Plate Viscometer 


\section{INTRODUCTION}

\subsection{Microemulsions}

\subsubsection{Definition of Microemulsions}

The microemulsion concept was introduced as early as the 1940 s by Hoar and Schulman who generated a clear single-phase solution by titrating a milky emulsion with hexanol. However, the microemulsion definition proposed by Danielsson and Lindman in 1981 who stated a microemulsion as "a system of water, oil and amphiphile which is a single phase optically isotropic and thermodynamically stable liquid solution."

\subsubsection{Emulsion versus Microemulsion}

Recognizing the differences between an emulsion and a microemulsion is important. The major differences between the two are shown in Table 1 (Tenjarla, 1999). The transparency of microemulsions arises from their small droplet diameter, typically less than $140 \mathrm{~nm}$. Such small droplets produce only weak scattering of visible light when compared with that from the droplets $(1-10 \mu \mathrm{m})$ of emulsions. The interfacial tension in a microemulsion is very low compared to that in an emulsion. This low interfacial tension leads to the spontaneous formation of the microemulsion, the small droplet size of the dispersed phase, and the thermodynamic stability of the microemulsion system. From the pharmaceutical manufacturing viewpoint, a microemulsion is very attractive compared with an emulsion. For an emulsion, several factors have to be considered when scaling up an optimum formulation to a manufacturing batch. These include scale-up equipment, compositional changes, 
TABLE 1. COMPARISON OF EMULSIONS AND MICROEMULSIONS (Tenjarla, 1999)

\begin{tabular}{|l|l|l|}
\hline Property & Emulsion & Microemulsion \\
\hline \hline $\begin{array}{l}\text { Droplet size of } \\
\text { dispersed phase }\end{array}$ & $\begin{array}{l}\text { Typically } 0.2 \mu \mathrm{m}-10 \\
\mu \mathrm{m}\end{array}$ & $<0.2 \mu \mathrm{m}$ \\
\hline \hline Appearance & Turbid to milky & $\begin{array}{l}\text { Transparent to } \\
\text { translucent }\end{array}$ \\
\hline \hline Formulation & $\begin{array}{l}\text { Input of external energy } \\
\text { required }\end{array}$ & $\begin{array}{l}\text { Spontaneous; no energy } \\
\text { required }\end{array}$ \\
\hline \hline Stability & $\begin{array}{l}\text { Thermodynamically } \\
\text { unstable }\end{array}$ & $\begin{array}{l}\text { Thermodynamically } \\
\text { stable }\end{array}$ \\
\hline
\end{tabular}


duration of mixing, emulsification time, temperature, order of adding the excipients, heating and cooling rates. Because of spontaneous formation of microemulsions with only mild agitation, many of these factors are avoided in case of their preparation (Tenjarla, 1999; Attwood, 1994).

\subsubsection{Structure of Microemulsions}

A microemulsion can be one of the three types: (1) oil-in-water (o/w), in which water is the continuos phase; (2) water-in-oil (w/o), in which oil is the continuos phase; and (3) bicontinous, in which approximately equal volumes of water and oil exist (Figure 1, Tenjarla, 1999). The surfactant and the phase volume ratio dictate the type of microemulsion formed. Generally, o/w microemulsions are formed in the presence of a small amount of oil, and w/o microemulsions are formed in the presence of a small amount of water. It is generally accepted that surfactants with low hydrophilic lipophilic balance (HLB) [3-6] are favored for the formation of w/o microemulsions whereas surfactants with high HLBs [8-18] are preferred for the formation of $\mathrm{o} / \mathrm{w}$ microemulsion systems (Lawrence et al. 2000). HLB indicates the surface activity of a species based on its molecular constitution. The simplest presentation of the structure of microemulsions is the droplet model in which microemulsion droplets are surrounded by an interfacial monolayer consisting of both surfactant and cosurfactant molecules. The orientation of the amphiphiles at the interface will, of course, differ in o/w and w/o microemulsions. As shown in Figure 1, the hydrophobic portions of these molecules will reside in the dispersed oil droplets of 

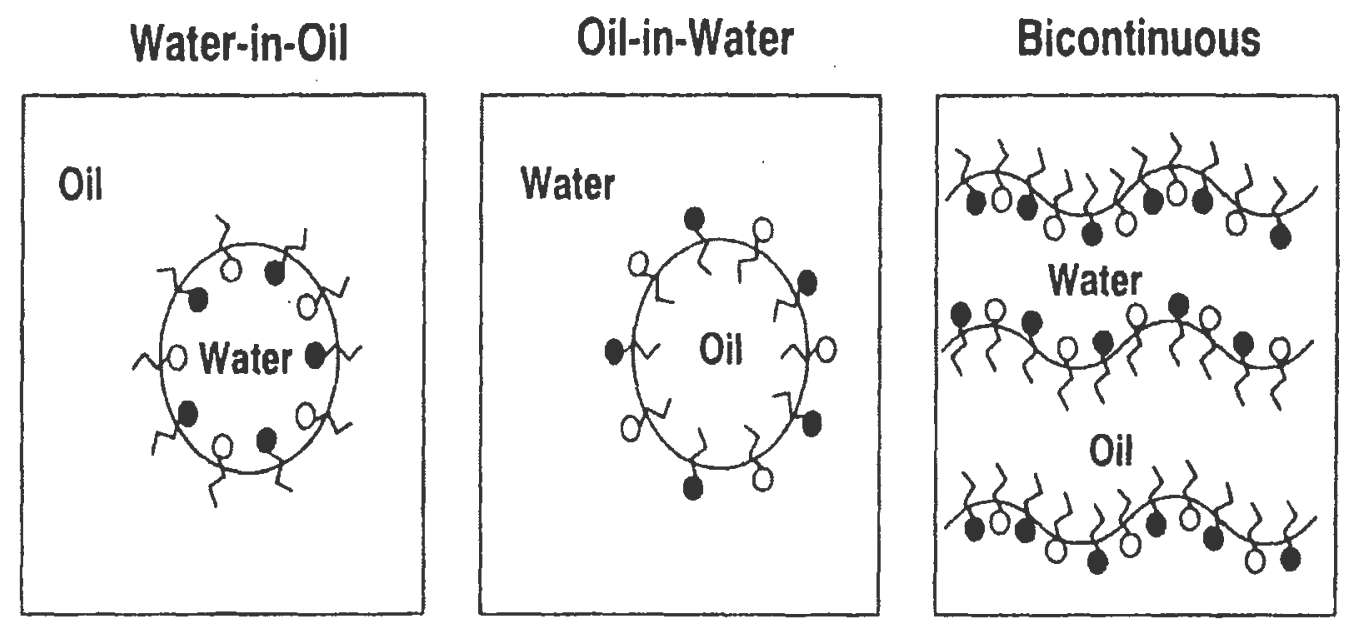

FIGURE 1. STRUCTURE OF MICROEMULSIONS

(Tenjarla, 1999) 
o/w systems, with the hydrophilic groups protruding in the continuos phase, while the opposite situation will be true of w/o microemulsions.

\subsubsection{Stability of Microemulsions}

Since microemulsions have a very large interface between oil and water because of the small droplet size, they can be only thermodynamically stable if the interfacial tension is so low that the positive interfacial energy can be compensated by the negative free energy of mixing. The role of surfactant in the system is thus to reduce the interfacial tension between oil and water. It is generally not possible to obtain this low interfacial tension with a single surfactant; the required low interfacial tension is achieved by adding a second surfactant, called a cosurfactant. Typical cosurfactants are short or long-chain alcohols, glycol, or polyglycerol derivatives (Attwood, 1994).

When a surfactant is added to a mixture of two immiscible phases, its molecules migrate to the interface, which results in lowering of the interfacial tension. When the surfactant occupies the entire interface between the immiscible liquids, adding more surfactant results in micelle formation, and there is no further decrease in the interfacial tension. Under these conditions, adding a second surfactant will further reduce the interfacial tension, resulting in a thermodynamically stable microemulsion. The surfactant preferably should exhibit low solubility in the aqueous and nonaqueous phases of the microemulsion and should be adsorbed at the water-oil interface. The cosurfactant is also amphiphilic with an affinity for both the oil and aqueous phases and partitions into the surfactant interfacial monolayer present at the oil-water interface. In most cases, single-chain surfactants alone are unable to reduce the oil- 
water interfacial tension sufficiently to enable a microemulsion to form. A number of double chain surfactants and a few of nonionic surfactant such as bis (2-ethylhexyl) sodium fosuccinate (AOT) and lecithin are able to form microemulsions without the aid of cosurfactants (Lawrence et al., 2000; Bhatnagar et al., 1994).

\subsection{Preparation of Microemulsions}

\subsubsection{Pseudo-ternary Phase Diagram}

Generally, a pseudo-ternary phase diagram is constructed to determine the composition of polar, nonpolar, and surfactant phases that will yield a microemulsion. For simplicity, the microemulsion is assumed a three-component system: water, oil, and a surfactant mixture. Any combination of these three components can be plotted as a percent on pseudo-ternary phase diagram (Tenjarla, 1999). Following is the rules relating to triangular pseudo-ternary phase diagrams:

1. Each corner of the triangle represents $100 \%$ of one of the components.

2. The points on the three lines joining the corner points represent two component systems of the three possible combinations.

3. Any line drawn through the apex points to a point on the opposite side will have a constant ratio of two of the components.

4. Any point on a line parallel to a side of the triangle has a constant proportion of one of the three components.

5. Any point inside the triangle represents all possible combinations of each component. 


\subsubsection{Determination of the Existence of a Microemulsion Region}

The existence of a microemulsion region can be determined as follows:

1. Prepare a mixture of oil and surfactant blend at a predetermined ratio.

2. Slowly titrate the oil-surfactant mixture with the aqueous phase with continuos mixing. After each addition of the aqueous phase, observe the resulting system for clarity, viscosity, and stability.

3. Upon adding the aqueous phase, the system will clear (beginning of the microemulsion region), on continued titration with the aqueous phase, the system will become cloudy (end of the microemulsion region). The percent of the oil, surfactant, and the aqueous phase at the beginning and end of the microemulsion region are noted.

4. Repeat the whole procedure with a different oil-surfactant mixture ratio. Again, the percentages of the three components are determined at the beginning and end of the microemulsion region.

5. The various points at which the microemulsion regions form and end are connected on a pseudo-ternary phase diagram. The area enclosed by lines connecting the points represents the microemulsion region of the system (Attwood, 1994).

\subsection{Choice of Microemulsion Components}

Different types of aqueous and nonaqueous solvents and surfactants can be used to prepare a microemulsion formulation. A few examples are listed below: 
- Nonaqueous phase: Vegetable oils, synthetic oils, triglycerides, esters of fatty acids and so forth.

- Aqueous phase: Water, sodium chloride solution, buffers and so forth, or a combination of these.

- Surfactant: Ionic and nonionic surfactants, lecithin, and polyglycerol fatty acid esters.

- Cosurfactant: Alcohols, derivatives of glycols polyglycerols or propylene glycols.

\subsection{Pharmaceutical Microemulsions}

The selection of components for microemulsions suitable for pharmaceutical use involves a consideration of their toxicity and, if the systems are to be used topically, their irritancy and sensitizing properties. Importantly, in some cases nonionic surfactants are able to form microemulsions without the need for cosurfactant. This is helpful as it reduces the complexity of the phase behavior, and eliminates the requirement for inclusion of medium chain alcohols, since these cosurfactants have a poor toxicity profile and their evaporation can destabilize the system (Lawrence et al., 2000). Furthermore, the insensitivity of nonionic microemulsions to $\mathrm{pH}$ and ionic strength changes represents an added benefit. Although many nonionic surfactants have suitable properties for topical administration, their potential use in microemulsions use for oral or parenteral administration is very limited (Attwood, 1994). However, one of the problems associated with the use of microemulsions for topical drug delivery is the difficulty of applying these vehicles to the skin because of their fluidity. 


\subsubsection{Lecithin as a Surfactant}

Lecithin, a nontoxic, naturally occurring biological surfactant, is a major component of membrane lipid. When administered in optimum amounts, it does not have a toxicity and sensitivity problems associated with most other surfactants. Hence, it is the ideal surfactant choice for preparing pharmaceutically acceptable microemulsions (Attwood, 1994). The characteristic solution properties of lecithin are:

- Strong hydrophobicity resulting from the two long hydrocarbon chains

- Strong hydrophilicity because of the zwitterionic polar head groups that are strongly hydrated and have dipole moments

- Good balance between hydrophilic and lipophilic properties, with slight partiality to a lipophilic site

\subsection{Lecithin Organogels}

The first description of the lecithin organogels was given by Scartazzini and Luici in 1988. They found that an addition of trace amounts of water into nonequeous solutions of lecithin caused an abrupt rise in the viscosity, producing a transition of the initial nonviscous solution into a jelly-like state.

\subsubsection{Lecithin Organogel Components}

Lecithin is a trivial name for 1,2-diacyl-sn-3-phophocholine. Its structural formula is shown in Figure 2 (Shchipunov, 2001). It belongs to a biologically essential class of substances termed phosphoglycerides or phospholipids. They form the lipid matrix of biological membranes and play a key role in the cellular metabolism. As a 


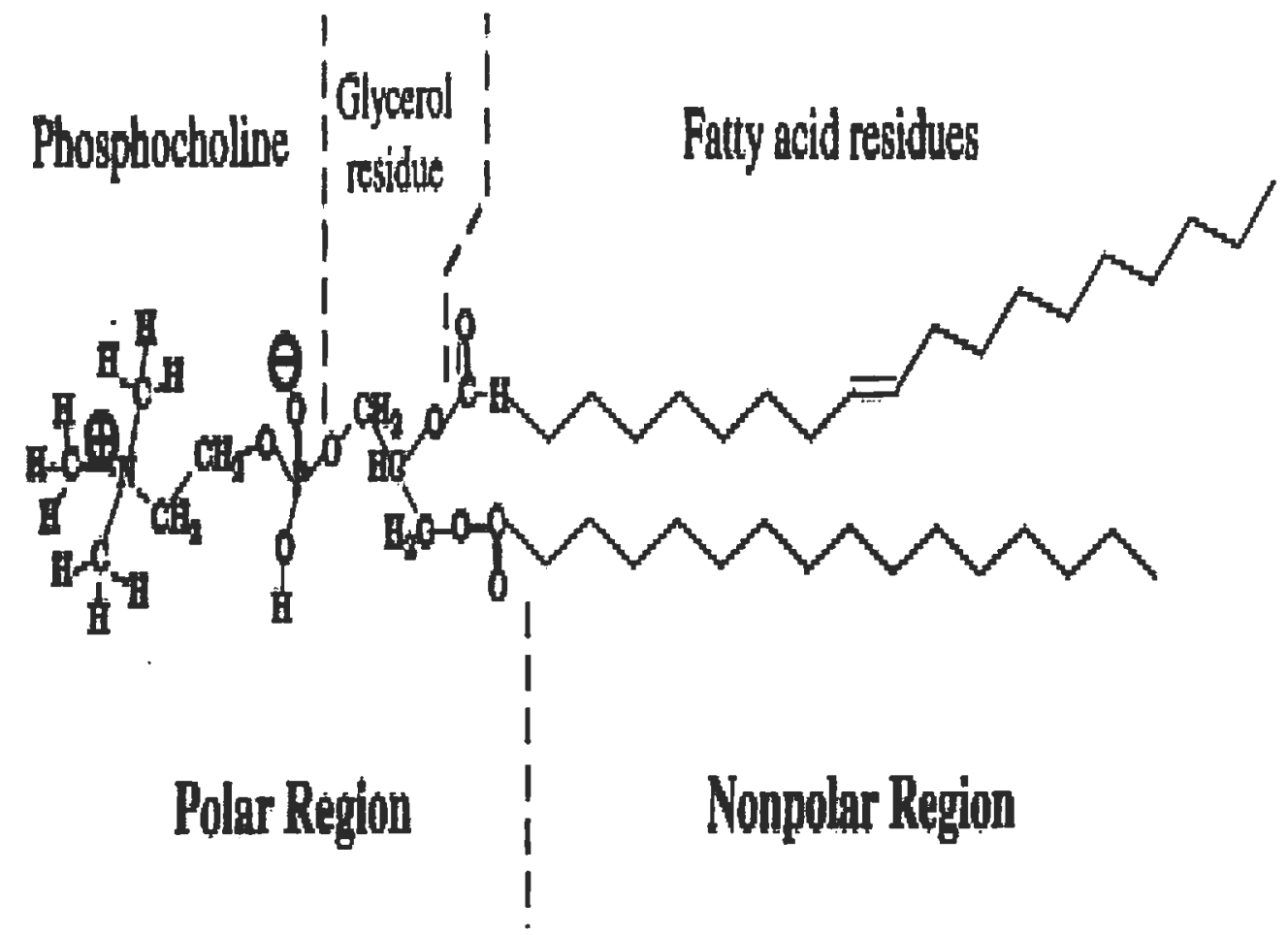

FIGURE 2. STRUCTURAL FORMULA OF LECITHIN. ITS MOLECULES INCLUDE RESIDUES OF CHOLINE, PHOSPHORIC ACID, GLYCEROL AND TWO FATTY ACIDS (Shchipunov, 2001) 
biocompatible surfactant, it is widely used in every day life, including human and animal food, medicine, cosmetics and manifold industrial application.

The second component is an organic solvent, in which lecithin is capable of forming the organogel. Organic solvents could be linear, branched and cyclic alkanes, ethers and esters, fatty acids and amines.

The third component crucial for the organogel formation is water. This polar solvent is added in trace or small amounts that depend on the organic media. Water can be substituted for polar organic substances as glycerol, ethylene glycol and formamide (Shchipunov, 1995).

\subsection{Structure of Organogels}

Gels are an intermediate state of the matter, containing both solid and liquid components. The solid component comprises a three dimensional network of interconnected molecules which immobilizes the liquid continuous phase. Hydrogels have an aqueous continuous phase, and organogels have an organic solvent as the liquid continuos medium. Gels may also be classified based on the nature of the bonds involved in the three-dimensional solid network. Chemical gels arise when strong covalent bonds hold the network together, and physical gels when hydrogen bonds and electrostatic and van der waals interactions maintain the network.

Interest in the physical organogel field has increased with the discovery and synthesis of a number of substances able to gel organic solvents. Examples of such organogelators include, D-homosteroidal nitroxide (SNO), bis (2-ethylhexyl) sodium fosuccinate (AOT), lecithin, 2,3-bis-n-decyloxyanthracene (DDOA), and some 
azobenzene cholesterol derivatives. These organogels exhibit interesting properties such as the ability to solublize guest molecules, uses for purification and separation purposes and as transdermal delivery vehicles (Murdan et al., 1999).

\subsubsection{Molecular Model of Organogels}

The initially spherical reverse micelles that are formed by lecithin molecules in a nonpolar organic solution transform into cylindrical ones, once water has been added. This was established with the help of light scattering and small angle neutron scattering techniques by Luisi and Schurtenberger in 1990. This one-dimensional growth of micelles is caused by the formation of hydrogen bonds between water molecules and phosphate groups of lecithin molecules so that two adjusting lecithin molecules are bridged together by one water molecule. IR and NMR spectroscopies showed that water molecules could interact simultaneously with phosphate groups of neighboring lipid molecules via hydrogen bonding, acting as a bridge between them (Shchipunov et al., 1995). In this case, solvent molecules and lecithin phosphate groups can arrange in such a way that a hydrogen-bonding network will be formed. A possible arrangement is schematically shown in Figure 3 (Shchipunov et al., 1995).

The increase of water amount results in the formation of long tubular and flexible micelles. These so-called polymer-like, wormlike or spaghetti-like micelles can be entangled and therefore build up a transient three-dimensional network that is responsible for the viscoelastic properties of the lecithin organogels. Figure 4 represents the structure of lecithin reverse micelles as a function of added water (Hinze et al., 1996). At the critical concentration of water, the network shrinks and the 


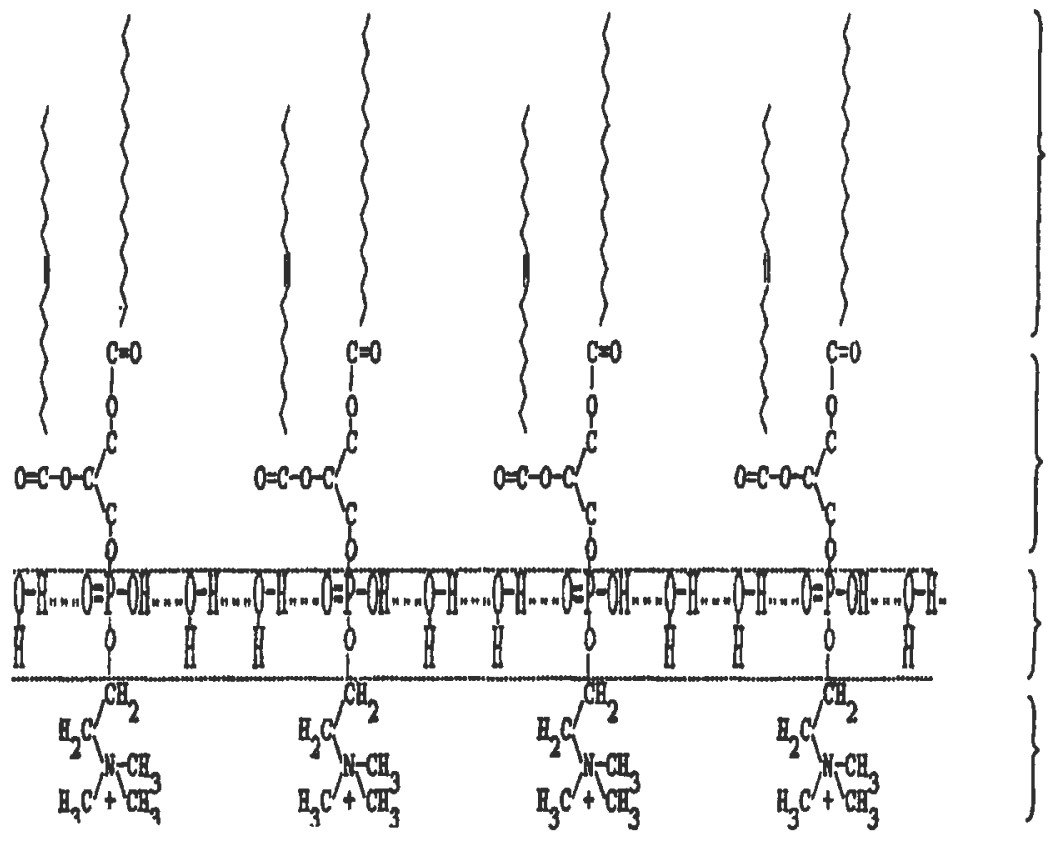

Bydrocarbon

Chain Moiaty

Glyceml

Besidue Holoty

Eydrogen Banding Hetrork

Bnd Heod Group

(Choline)

FIGURE 3. A TWO DIMENSIONA SCHEMATIC REPRESENTATION OF THE HYDROGEN BONDING NETWORK FORMED IN THE LECITHIN TUBULAR MICELLES (Shchipunov et al., 1995) 
phase separation occurs. At still higher concentrations of water, a transformation to a solid, nontransparent precipitate can be observed. This diluted solution is composed of rod-like micelles which their length is not enough to overlap and form a threedimensional network.

It was shown by IR spectroscopic studies that following addition of water to the lecithin solution about three first water molecules are attached to a phosphate group through hydrogen bonds (Shchiponuve, 2001). At this molar ratio, water molecules begin coming to the carbonyl groups. They interact with each other, also forming hydrogen bonds. With increasing further the solvent amount, water molecules are found adjacent to a choline group. At this point the solvent molecules do not interact strongly with lecithin ester groups (Schurtenberger et al., 1990).

A series of polar solvents have been studied to determine how their nature influences the formation of jelly-like hydrogen binding network in lecithin solutions. It has been established (Shchipunov et al., 1995) that glycerol, formamide and ethylene glycol, in addition to water, have the ability to induce organogel formation in the following order: glycerol $>$ water $>$ formamide $>$ ethylene glycol. These polar solvents tend to be located in the most polar moiety of lecithin near the phosphate group. It has been inferred from the results that the organogel formation is sensitive to the structure of polar solvents, and in turn it should be sensitive to their physicochemical properties. 

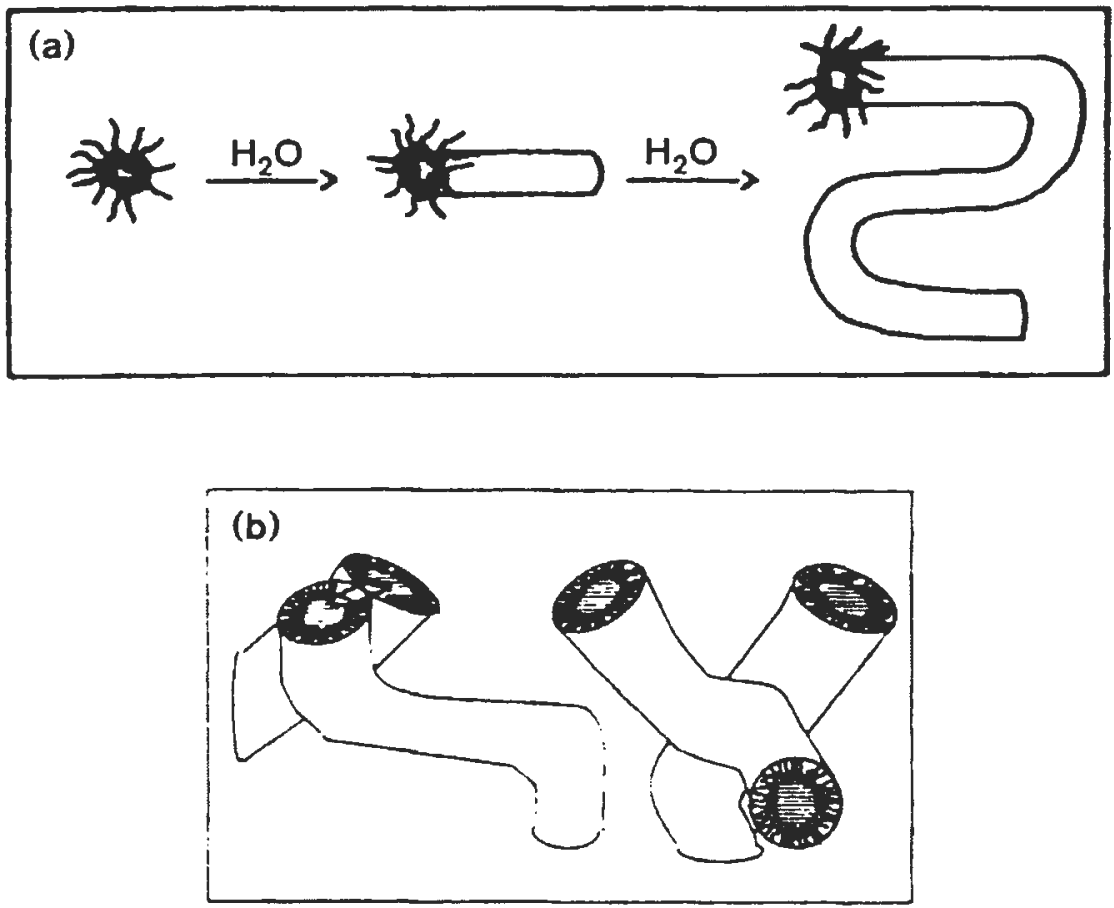

FIGURE 4. STRUCTURE OF LECITHIN REVERSE MICELLES AS A FUNCTION OF ADDED WATER. (a) ADDITION OF WATER INDUCES THE ONE-DIMENSIONAL GROWTH OF THE REVERSE MICELLES INTO LONG AND FLEXIBLE CYLINDRICAL MICELLES. (b) THE OVERLAP OF THESE CYLINDRICAL MICELLES TRANSFORMS THE ORIGINAL ORGANIC MEDIUM INTO A VISCOELASTIC GEL PHASE (Hinze et al., 1996) 


\subsubsection{Rheological Properties of Organogels}

The transition from a low-viscous nonaqueous lecithin solution demonstrating Newtonian behavior to a jelly-like one with Maxwell rheology is caused by the addition of small amounts of polar additives. The transition can be clearly seen by a sharp increase in viscosity if a certain concentration of polar additive has been added (Shchipunov et al., 1999). Further addition of the polar additive results in a maximum of viscosity at a certain concentration. Thereafter a separation of the homogenous organogel into a two-phase system consisting of a low viscous fluid and a compact organogel occurs at a critical concentration. In other words, the viscosity depends on the molecular weight or the micellar length (Kantaria et al., 1999; Bhatnagar et al., 1994).

\subsection{Application of Lecithin Organogels}

Organogels have received a great attention in recent years for various applications, including topical application of drugs. Several mechanisms have been proposed to explain the advantages of organogels for the transdermal delivery of drugs. First, a large amount of drug can be incorporated in the formulation due to the high solubilizing capacity. Second, the permeation rate of the drug from the organogel may be increased, since the affinity of a drug to the internal phase in organogel can be easily modified to favor partitioning into stratum corneum, using different internal phase, changing its portion in organogel or adjusting its property. Third, the surfactant and organic solvent in the organogel may reduce the diffusional barrier of the stratum comeum by acting as permeation enhancers (Rhee et al., 2001). 
The existence of microdomains of different polarity within the same singlephase solution enables both water-soluble and oil-soluble drugs to be solublised. The likely preferred sites of incorporation of a lipophilic, water-insoluble drug into an o/w microemulsion organogel are the disperse oil phase and/or hydrophobic tail region of the surfactant molecule, while a water-soluble drug would be most likely to be incorporated into the dispersed aqueous phase of a water-in-oil droplet (Trotta et al., 1997).

Use of w/o microemulsion organogel for oral or parenteral drug delivery is complicated by the fact that they are destabilized to a much greater extent when diluted by an aqueous phase. This is due to the increase in the volume fraction of the aqueous phase which increases the ratio of water to surfactant leading to droplet growth and eventually percolation (Attwood, 1994).

\subsubsection{Topical Application of Drugs}

Skin has become the subject of much study in the pharmaceutical field because of its role as a route of topical application (Dreher et al., 1996). Recent developments in transdermal drug delivery systems have been extensively studied as drug delivery methods showing promising topical efficacy. However, the stratum corneum in skin provides an effective impermeable barrier to the pecutaneous penetration of topically applied substances. In order to extend the range of drugs which can be administered via the skin and to enhance the effects of locally acting drugs, it is necessary to include penetration enhancers in formulations (Yokomizo, 1996). Generally speaking, since penetration enhancers cause skin problems such as erythema and are mitogenic 
stimulators there is a need for enhancers which do not stimulate and which are safe for skin. Phospholipids such as lecithin are a kind of penetration enhancers that directly influence the lipid bilayer of the cell membrane in the stratum corneum. They slightly disorganize the structure of the skin, and thus, permit the permeation of drugs. It is possible that this disorganization is due to interaction between these lipids and the phospholipids of the skin.

\subsubsection{Drug Release from Organogels}

The release rate of drugs in general from organogel systems depends on the drug partition coefficient, drug solubility in the oil and aqueous phases, dispersed droplet size, phase volume ratio, viscosity and specific drug-excipient interaction. Small droplet size speeds up the drug release and has superior shelf stability (Cordero et al., 1997; Rhee et al., 2001). Delivery of a drug from an organogel is also directly proportional to the concentration of the drug. The intensity of drug partitioning into stratum corneum depends mainly on the lipophilicity of the drug used. Usually, the drug from the external phase is released on the surface of the membrane. Following this, drug from the internal phase partitions into the external phase to maintain the equilibrium. Therefore, there are different partitioning processes occurring: between the internal and external phases of the organogel, and between either the internal or the external phase of the organogel and the skin. Drug transport may be controlled by any of these processes, and the thermodynamic driving force for release will reflect the relative activities of the drug in the different phases (Delgado-Charro et al., 1997). 


\subsection{Ketorolac Tromethamine}

Ketorolac Tromethamine (KT), a potent nonsteroidal anti-inflammatory drug is practically used for the postoperative and emergency treatment of pain. Figure 5 represents the chemical structure of KT (Quadir et al., 2000). However, it has side effects including GI irritation when administered orally. One promising method is to administer the drug via the skin. Novel prepared lecithin organogels incorporated with ketorolac are promising candidate for new drug delivery systems. The objective of this work was to develop a topical formulation of KT. In this study, the in vitro release of KT from various lecithin organogels was evaluated. Furthermore, the effect of lecithin concentration, water content in the vehicle and the viscosity change on the release profile of KT through synthetic membranes and guinea pig skin was examined. 


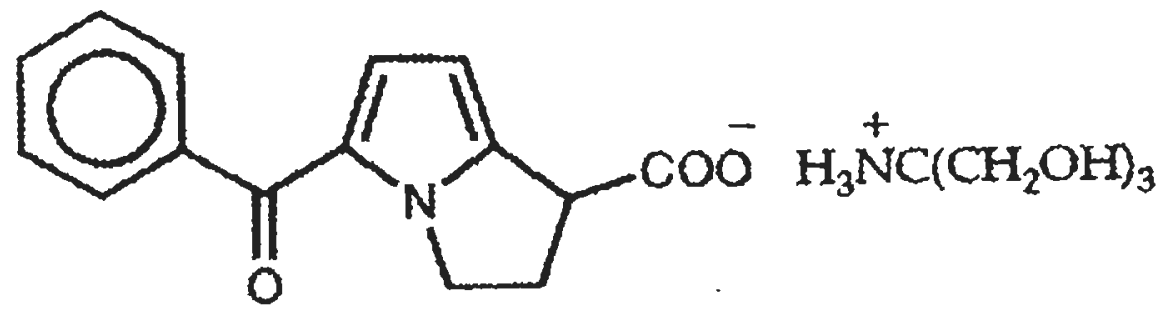

Ketorolac tromethamine

FIGURE 5. CHEMICAL STRUCTURE OF KETOROLAC TROMETHAMINE (Quadir et al., 2000) 


\section{MATERRIALS AND METHODS}

\subsection{Materials and Equipments}

\section{Materials}

Soybean Lecithin, Epikuron 200

Lucas Mayer, Germany

Isopropyl Myristate, Lot \# R36354G14

Ruger Chemical Co. Inc., Irvington, NJ 07111

Ketorolac Tromethamine, Lot \# 6626

Lemmon Company, Sellesville, PA 18960

Acetonitrile, Cat \# 998-4

Fisher Scientific, Fair Lawn, NJ 07410

O- Phosphoric Acid 85\%, Lot \# 920830

Fisher Scientific, Fair Lawn, NJ 07410

Methanol, Cat \# 452- 4

Fisher Scientific, Fair Lawn, NJ 07410

Sodium Chloride, Lot \# 974188

Fisher Scientific, Fair Lawn, NJ 07410 
Sodium Phosphate Dibasic, Lot \# 912230

Fisher Scientific, Fair Lawn, NJ 07410

Potassium Phosphate Monobasic, Lot \# 912104

Fisher Scientific, Fair Lawn, NJ 07410

Cellulose Acetate Membrane, MWCO 3,500, Lot \# 13371

Spectrum Laboratories Inc., CA

Silicon Elastomer Sheeting, Thickness 0.005", Lot \# SM030454

Advanced Biotechnologies Inc., Silverdale, WA 98383

\author{
IAF/HA-HO Guinea Pig Skin \\ Charles River Laboratories, MA, 01887
}

Hamilton Syringe

Waters, Milford, MA 01757

Magnetic Stir Bars, $12 \mathrm{~mm} \times 4 \mathrm{~mm}$

Fisher Scientific, Fair Lawn, NJ 07410 


\section{Equipments}

Mettler Analytical Balance, AE240 Dual range Balance

Electronic Laboratory Equipment, Kansas City, MI

Magnetic Stirrer

Fisher Scientific, Fair Lawn, NJ 07410

Mirak Digital Stirrer

pH Meter, Model IQ-240

Scientific Instruments Inc., San Diego, CA 92127

Vertical Franz Diffusion Cells

$0.9 \mathrm{~cm} \mathrm{ID}, 5.1 \mathrm{ml}$ Volume

Diode Array Spectrophotometer, Model 8451 A

Hewlett Packard, Wilmington, DE

HPLC Pump, Model 515

Waters, Milford, MA

UV Detector, Model 480

Waters, Milford, MA 
Data Module, Model 746

Waters, Milford, MA

717 Plus- Autosampler

Waters, Milford, MA

Automated Gradient Controller

Waters, Milford, MA

Ultrasonic Generator, Model FS1 10

Fisher Scientific, Fair Lawn, NJ 07410

Thelco Oven

Precision Scientific Co., Chicago, IL

Cylindrical Viscometer, Model DV-I, Spindle \#3 LV

Brookfield Engineering Laboratories, MA 02346

Cone/Plate Viscometer, Model DV-II, Cone Spindle CP-52

Brookfield Engineering Laboratories, MA 02346 


\subsection{METHODS}

\subsubsection{Preparation of Organogels}

Lecithin solutions were prepared by first dissolving lecithin in the organic solvent [Isopropyl Myristate (IPM)], with aid of a magnetic stirrer and then while still stirring, the necessary amount of water was added to obtain a clear gel (Williman et al., 1992). Some of the obtained solutions were clear, others were cloudy, but the latter also became clear after addition of a minimal amount of water. The formation of the gels, after the addition of the water by a micropipette syringe, took place within 30 seconds. The drug-containing gels were prepared by dissolving $\mathrm{KT}$ into the water, and then adding the aqueous solution of KT into the mixture of lecithin/ IPM.

\subsubsection{New Method of Preparation}

In this method, the drug-containing gels were prepared by first dissolving KT into the solution of lecithin in organic solvent and then adding water to induce gelation. To facilitate the dissolution and obtain a homogenous mixture of dissolved components, the mixtures were heated for a very short time with constant stirring until solubilisation of the drug was completed. The dissolution was performed by means of a magnetic stirrer. Agitation was then stopped and the samples allowed to cool and set to a gel at room temperature. Formulations gave clear, homogenous, nonbirefringent gels. 


\subsubsection{Construction of Phase Diagram and Formulation of Ketorolac Organogels}

Samples containing different ratio of lecithin/ IPM [(10:90), (20:80), (30:70), (40:60), (50:50), and $(60: 40) \% \mathrm{w} / \mathrm{w}]$ were prepared. Phase studies were carried out by adding solutions of ketorolac or pure water to the mixtures of lecithin/ IPM or lecithin/ IPM/ KT while stirring. After each addition of $5 \mu$ l of aqueous phase containing various percentages of $\mathrm{KT}$ concentration $[2.5,5,10,50 \% \mathrm{w} / \mathrm{v}]$ (in case of old preparation) or pure water (in case of new preparation) to the lecithin solutions, the resulting systems for clarity and viscosity were observed. Then, the percentages of the three components were determined at the beginning and end of the organogel region. Initially, upon adding the aqueous phase, the mixture was cloudy. On continued addition, the system cleared, which indicates the beginning of the organogel region. Upon the continued addition of the aqueous phase, the system eventually will become turbid again, indicating the end of the organogel region. The various points at which the organogel region forms and ends will be connected on a pseudo-ternary phase diagram. The area enclosed by lines connecting the points will represent the organogel region of the system. Based on these results, appropriate concentration ranges of components were used in the preparation of organogels containing ketorolac. The detailed composition of different preparations is given in Tables 2, 3, 4, 5, 6 and 7 . 
TABLE 2. FORMULATIONS COMPOSED OF LECITHIN, IPM AND WATER USED FOR PHASE DIAGRAM

\begin{tabular}{|c|c|c|c|c|c|c|c|}
\hline Sample & Lecithin & IPM & Water & Total Weight & Lecithin & IPM & Water \\
\hline Group & (g) & (g) & $(\mathrm{ml})$ & (g) & $(\% w / w)$ & $(\% w / w)$ & $(\% w / w)$ \\
\hline 1 & 0.05 & 0.45 & 0.005 & 0.505 & 10 & 90 & 1 \\
\hline 1 & 0.05 & 0.45 & 0.01 & 0.51 & 10 & 90 & 2 \\
\hline 1 & 0.05 & 0.45 & 0.015 & 0.515 & 10 & 90 & 3 \\
\hline & & & & & & & \\
\hline 2 & 0.075 & 0.425 & 0.005 & 0.505 & 15 & 85 & 1 \\
\hline 2 & 0.075 & 0.425 & 0.01 & 0.51 & 15 & 85 & 2 \\
\hline 2 & 0.075 & 0.425 & 0.015 & 0.515 & 15 & 85 & 3 \\
\hline & & & & & & & \\
\hline 3 & 0.1 & 0.4 & 0.005 & 0.505 & 20 & 80 & 1 \\
\hline 3 & 0.1 & 0.4 & 0.01 & 0.51 & 20 & 80 & 2 \\
\hline 3 & 0.1 & $\overline{0.4}$ & 0.015 & 0.515 & 20 & 80 & 3 \\
\hline 3 & 0.1 & $\overline{0.4}$ & 0.02 & 0.52 & 20 & 80 & 4 \\
\hline & & & & & & & \\
\hline 4 & 0.125 & 0.375 & 0.005 & 0.505 & 25 & 75 & 1 \\
\hline 4 & 0.125 & 0.375 & 0.01 & 0.51 & 25 & 75 & 2 \\
\hline 4 & 0.125 & 0.375 & 0.015 & 0.515 & 25 & 75 & 3 \\
\hline 4 & 0.125 & 0.375 & 0.02 & 0.52 & 25 & 75 & 4 \\
\hline 4 & 0.125 & 0.375 & 0.025 & 0.525 & 25 & 75 & 5 \\
\hline & & & 000 & 0 & 20 & & \\
\hline$\frac{5}{5}$ & 0.15 & 0.35 & 0.005 & 0.505 & 30 & $\frac{70}{70}$ & $\frac{1}{0}$ \\
\hline & 0.15 & 0.35 & 0.01 & 0.51 & 30 & 70 & 2 \\
\hline$\frac{5}{5}$ & 0.15 & 0.35 & 0.015 & 0.515 & 30 & 70 & 3 \\
\hline$\frac{5}{5}$ & 0.15 & 0.35 & 0.02 & 0.52 & 30 & 70 & 4 \\
\hline 5 & 0.15 & 0.35 & 0.025 & 0.525 & 30 & 70 & 5 \\
\hline & & & & & & & \\
\hline 6 & 0.172 & 0.325 & 0.005 & 0.505 & 35 & 65 & 1 \\
\hline 6 & 0.172 & 0.325 & 0.01 & 0.51 & 35 & 65 & 2 \\
\hline 6 & 0.172 & 0.325 & 0.015 & 0.515 & 35 & 65 & 3 \\
\hline 6 & 0.172 & 0.325 & 0.02 & 0.52 & 35 & 65 & 4 \\
\hline 6 & 0.172 & 0.325 & 0.025 & 0.525 & 35 & 65 & 5 \\
\hline 6 & 0.172 & 0.325 & 0.03 & 0.53 & 35 & 65 & 6 \\
\hline & & & & & & & \\
\hline 7 & 0.2 & 0.3 & 0.005 & 0.505 & 40 & 60 & 1 \\
\hline 7 & 0.2 & 0.3 & 0.01 & 0.51 & 40 & 60 & 2 \\
\hline 7 & 0.2 & 0.3 & 0.015 & 0.515 & 40 & 60 & 3 \\
\hline 7 & 0.2 & 0.3 & 0.02 & 0.52 & 40 & 60 & 4 \\
\hline 7 & 0.2 & 0.3 & 0.025 & 0.525 & 40 & 60 & 5 \\
\hline 7 & 0.2 & 0.3 & 0.03 & 0.53 & 40 & 60 & 6 \\
\hline & & & & & & & \\
\hline 8 & 0.225 & 0.275 & 0.005 & 0.505 & 45 & 55 & 1 \\
\hline 8 & 0.225 & 0.275 & 0.01 & 0.51 & 45 & 55 & 2 \\
\hline 8 & 0.225 & 0.275 & 0.015 & 0.515 & 45 & 55 & 3 \\
\hline 8 & 0.225 & 0.275 & 0.02 & 0.52 & 45 & 55 & 4 \\
\hline 8 & 0.225 & 0.275 & 0.025 & 0.525 & 45 & 55 & 5 \\
\hline 8 & 0.225 & 0.275 & 0.03 & 0.53 & 45 & 55 & 6 \\
\hline 8 & 0.225 & 0.275 & 0.035 & 0.535 & 45 & 55 & 6.5 \\
\hline
\end{tabular}


TABLE 2. CONT'D.

\begin{tabular}{|c|c|c|c|c|c|c|c|}
\hline Sample & Lecithin & IPM & Water & Total Weight & Lecithin & IPM & Water \\
\hline Group & $(\mathbf{g})$ & $\mathbf{( g )}$ & $(\mathbf{m l})$ & $(\mathbf{g})$ & $(\% \mathbf{w} / \mathbf{w})$ & $(\% \mathbf{w} / \mathbf{w})$ & $(\% \mathbf{w} / \mathbf{w})$ \\
\hline 9 & 0.25 & 0.25 & 0.005 & 0.505 & 50 & 50 & 1 \\
\hline 9 & 0.25 & 0.25 & 0.01 & 0.51 & 50 & 50 & 2 \\
\hline 9 & 0.25 & 0.25 & 0.015 & 0.515 & 50 & 50 & 3 \\
\hline 9 & 0.25 & 0.25 & 0.02 & 0.52 & 50 & 50 & 4 \\
\hline 9 & 0.25 & 0.25 & 0.025 & 0.525 & 50 & 50 & 5 \\
\hline 9 & 0.25 & 0.25 & 0.03 & 0.53 & 50 & 50 & 6 \\
\hline 9 & 0.25 & 0.25 & 0.035 & 0.535 & 50 & 50 & 6.5 \\
\hline & & & & & & & \\
\hline 10 & 0.275 & 0.225 & 0.005 & 0.505 & 55 & 45 & 1 \\
\hline 10 & 0.275 & 0.225 & 0.01 & 0.51 & 55 & 45 & 2 \\
\hline 10 & 0.275 & 0.225 & 0.015 & 0.515 & 55 & 45 & 3 \\
\hline 10 & 0.275 & 0.225 & 0.02 & 0.52 & 55 & 45 & 4 \\
\hline 10 & 0.275 & 0.225 & 0.025 & 0.525 & 55 & 45 & 5 \\
\hline 10 & 0.275 & 0.225 & 0.03 & 0.53 & 55 & 45 & 6 \\
\hline 10 & 0.275 & 0.225 & 0.035 & 0.535 & 55 & 45 & 6.5 \\
\hline 10 & 0.275 & 0.225 & 0.04 & 0.54 & 55 & 45 & 7 \\
\hline & & & & & & & \\
\hline 11 & 0.3 & 0.2 & 0.005 & 0.505 & 60 & 40 & 1 \\
\hline 11 & 0.3 & 0.2 & 0.01 & 0.51 & 60 & 40 & 2 \\
\hline 11 & 0.3 & 0.2 & 0.015 & 0.515 & 60 & 40 & 3 \\
\hline 11 & 0.3 & 0.2 & 0.02 & 0.52 & 60 & 40 & 4 \\
\hline 11 & 0.3 & 0.2 & 0.025 & 0.525 & 60 & 40 & 5 \\
\hline 11 & 0.3 & 0.2 & 0.03 & 0.53 & 60 & 40 & 6 \\
\hline 11 & 0.3 & 0.2 & 0.035 & 0.535 & 60 & 40 & 6.5 \\
\hline 11 & 0.3 & 0.2 & 0.04 & 0.54 & 60 & 40 & 7 \\
\hline
\end{tabular}


TABLE 3. FORMULATIONS COMPOSED OF LECITHIN, IPM AND WATER (CONTAINING $2.5 \%$ W/V KT) USED FOR PHASE DIAGRAM

\begin{tabular}{|c|c|c|c|c|c|c|c|}
\hline Sample & Lecithin & IPM & Water & Total Weight & Lecithin & IPM & Water \\
\hline Group & (g) & (g) & $(\mathrm{ml})$ & (g) & $(\% w / w)$ & $(\% w / w)$ & $(\% w / w)$ \\
\hline 1 & 0.05 & 0.45 & 0.005 & 0.505 & 10 & 90 & 1 \\
\hline 1 & 0.05 & 0.45 & 0.01 & 0.51 & 10 & 90 & 2 \\
\hline & & & & & & & \\
\hline 2 & 0.075 & 0.425 & 0.005 & 0.505 & 15 & 85 & 1 \\
\hline 2 & 0.075 & 0.425 & 0.01 & 0.51 & 15 & 85 & 2 \\
\hline & & & & & & & \\
\hline 3 & 0.1 & 0.4 & 0.005 & 0.505 & 20 & 80 & 1 \\
\hline 3 & 0.1 & 0.4 & 0.01 & 0.51 & 20 & 80 & 2 \\
\hline 3 & 0.1 & 0.4 & 0.015 & 0.515 & 20 & 80 & 3 \\
\hline & 0125 & 0375 & 0005 & 0505 & 25 & 75 & 1 \\
\hline$\frac{4}{4}$ & $\frac{0.125}{0.125}$ & $\frac{0.375}{0.375}$ & $\frac{0.005}{0.01}$ & $\frac{0.505}{0.51}$ & $\frac{25}{25}$ & $\frac{75}{75}$ & $\frac{1}{2}$ \\
\hline 4 & 0.125 & 0.375 & 0.015 & 0.515 & 25 & 75 & 3 \\
\hline 4 & 0.125 & 0.375 & 0.02 & 0.52 & 25 & 75 & 4 \\
\hline & & & & & & & \\
\hline 5 & 0.15 & 0.35 & 0.005 & 0.505 & 30 & 70 & 1 \\
\hline 5 & 0.15 & 0.35 & 0.01 & 0.51 & 30 & 70 & 2 \\
\hline 5 & 0.15 & 0.35 & 0.015 & 0.515 & 30 & 70 & 3 \\
\hline 5 & 0.15 & 0.35 & 0.02 & 0.52 & 30 & 70 & 4 \\
\hline & & & & & & & \\
\hline 6 & 0.172 & 0.325 & 0.005 & 0.505 & 35 & 65 & 1 \\
\hline 6 & 0.172 & 0.325 & 0.01 & 0.51 & 35 & 65 & 2 \\
\hline 6 & 0.172 & 0.325 & 0.015 & 0.515 & 35 & 65 & 3 \\
\hline 6 & 0.172 & 0.325 & 0.02 & 0.52 & 35 & 65 & 4 \\
\hline 6 & 0.172 & 0.325 & 0.025 & 0.525 & 35 & 65 & 5 \\
\hline & & & & & & & \\
\hline 7 & 0.2 & 0.3 & 0.005 & 0.505 & 40 & 60 & 1 \\
\hline 7 & 0.2 & 0.3 & 0.01 & 0.51 & 40 & 60 & 2 \\
\hline 7 & 0.2 & 0.3 & 0.015 & 0.515 & 40 & 60 & 3 \\
\hline 7 & 0.2 & 0.3 & 0.02 & 0.52 & 40 & 60 & 4 \\
\hline 7 & 0.2 & 0.3 & 0.025 & 0.525 & 40 & 60 & 5 \\
\hline 7 & 0.2 & 0.3 & 0.03 & 0.53 & 40 & 60 & 6 \\
\hline 7 & 0.2 & 0.3 & 0.035 & 0.535 & 40 & 60 & 6.5 \\
\hline 8 & 0.225 & 0.275 & 0.005 & 0.505 & 45 & 55 & 1 \\
\hline 8 & 0.225 & 0.275 & 0.01 & 0.51 & 45 & 55 & 2 \\
\hline 8 & 0.225 & 0.275 & 0.015 & 0.515 & 45 & 55 & 3 \\
\hline 8 & 0.225 & 0.275 & 0.02 & 0.52 & 45 & 55 & 4 \\
\hline 8 & 0.225 & 0.275 & 0.025 & 0.525 & 45 & 55 & 5 \\
\hline 8 & 0.225 & 0.275 & 0.03 & 0.53 & 45 & 55 & 6 \\
\hline 8 & 0.225 & 0.275 & 0.035 & 0.535 & 45 & 55 & 6.5 \\
\hline
\end{tabular}


TABLE 3. CONT'D.

\begin{tabular}{|c|c|c|c|c|c|c|c|}
\hline Sample & Lecithin & IPM & Water & Total Weight & Lecithin & IPM & Water \\
\hline Group & $(\mathbf{g})$ & $(\mathbf{g})$ & $(\mathbf{m l})$ & $(\mathbf{g})$ & $(\% \mathbf{w} / \mathbf{w})$ & $(\% \mathbf{w} / \mathbf{w})$ & $(\% \mathbf{w} / \mathbf{w})$ \\
\hline 9 & 0.25 & 0.25 & 0.005 & 0.505 & 50 & 50 & 1 \\
\hline 9 & 0.25 & 0.25 & 0.01 & 0.51 & 50 & 50 & 2 \\
\hline 9 & 0.25 & 0.25 & 0.015 & 0.515 & 50 & 50 & 3 \\
\hline 9 & 0.25 & 0.25 & 0.02 & 0.52 & 50 & 50 & 4 \\
\hline 9 & 0.25 & 0.25 & 0.025 & 0.525 & 50 & 50 & 5 \\
\hline 9 & 0.25 & 0.25 & 0.03 & 0.53 & 50 & 50 & 6 \\
\hline 9 & 0.25 & 0.25 & 0.035 & 0.535 & 50 & 50 & 6.5 \\
\hline 9 & 0.25 & 0.25 & 0.04 & 0.54 & 50 & 50 & 7 \\
\hline & & & & & & & \\
\hline 10 & 0.275 & 0.225 & 0.005 & 0.505 & 55 & 45 & 1 \\
\hline 10 & 0.275 & 0.225 & 0.01 & 0.51 & 55 & 45 & 2 \\
\hline 10 & 0.275 & 0.225 & 0.015 & 0.515 & 55 & 45 & 3 \\
\hline 10 & 0.275 & 0.225 & 0.02 & 0.52 & 55 & 45 & 4 \\
\hline 10 & 0.275 & 0.225 & 0.025 & 0.525 & 55 & 45 & 5 \\
\hline 10 & 0.275 & 0.225 & 0.03 & 0.53 & 55 & 45 & 6 \\
\hline 10 & 0.275 & 0.225 & 0.035 & 0.535 & 55 & 45 & 6.5 \\
\hline 10 & 0.275 & 0.225 & 0.04 & 0.54 & 55 & 45 & 7 \\
\hline 10 & 0.275 & 0.225 & 0.045 & 0.545 & 55 & 45 & 8 \\
\hline & & & & & & & \\
\hline 11 & 0.3 & 0.2 & 0.005 & 0.505 & 60 & 40 & 1 \\
\hline 11 & 0.3 & 0.2 & 0.01 & 0.51 & 60 & 40 & 2 \\
\hline 11 & 0.3 & 0.2 & 0.015 & 0.515 & 60 & 40 & 3 \\
\hline 11 & 0.3 & 0.2 & 0.02 & 0.52 & 60 & 40 & 4 \\
\hline 11 & 0.3 & 0.2 & 0.025 & 0.525 & 60 & 40 & 5 \\
\hline 11 & 0.3 & 0.2 & 0.03 & 0.53 & 60 & 40 & 6 \\
\hline 11 & 0.3 & 0.2 & 0.035 & 0.535 & 60 & 40 & 6.5 \\
\hline 11 & 0.3 & 0.2 & 0.04 & 0.54 & 60 & 40 & 7 \\
\hline 11 & 0.3 & 0.2 & 0.045 & 0.545 & 60 & 40 & 8 \\
\hline 11 & 0.3 & 0.2 & 0.05 & 0.55 & 60 & 40 & 9 \\
\hline & & & & & & & \\
\hline
\end{tabular}


TABLE 4. FORMULATIONS COMPOSED OF LECITHIN, IPM AND WATER (CONTAINING 5\% W/N KT) USED FOR PHASE DIAGRAM

\begin{tabular}{|c|c|c|c|c|c|c|c|}
\hline Sample & Lecithin & IPM & Water & Total Weight & Lecithin & IPM & Water \\
\hline Group & (g) & (g) & $(\mathrm{ml})$ & (g) & $(\% w / w)$ & $(\% w / w)$ & $(\% w / w)$ \\
\hline 1 & 0.05 & 0.45 & 0.005 & 0.505 & 10 & 90 & 1 \\
\hline 1 & 0.05 & 0.45 & 0.01 & 0.51 & 10 & 90 & 2 \\
\hline & & & & & & & \\
\hline 2 & 0.075 & 0.425 & 0.005 & 0.505 & 15 & 85 & 1 \\
\hline 2 & 0.075 & 0.425 & 0.01 & 0.51 & 15 & 85 & 2 \\
\hline 2 & 0.075 & 0.425 & 0.015 & 0.515 & 15 & 85 & 3 \\
\hline & & & & & & & \\
\hline 3 & 0.1 & 0.4 & 0.005 & 0.505 & 20 & 80 & 1 \\
\hline 3 & 0.1 & 0.4 & 0.01 & 0.51 & 20 & 80 & 2 \\
\hline 3 & 0.1 & 0.4 & 0.015 & 0.515 & 20 & 80 & 3 \\
\hline & & & & & & & \\
\hline 4 & 0.125 & 0.375 & 0.005 & 0.505 & 25 & 75 & 1 \\
\hline 4 & 0.125 & 0.375 & 0.01 & 0.51 & 25 & 75 & 2 \\
\hline 4 & 0.125 & 0.375 & 0.015 & 0.515 & 25 & 75 & 3 \\
\hline & & & & & & & \\
\hline 5 & 0.15 & 0.35 & 0.005 & 0.505 & 30 & 70 & 1 \\
\hline 5 & 0.15 & 0.35 & 0.01 & 0.51 & 30 & 70 & 2 \\
\hline 5 & 0.15 & 0.35 & 0.015 & 0.515 & 30 & 70 & 3 \\
\hline 5 & 0.15 & 0.35 & 0.02 & 0.52 & 30 & 70 & 4 \\
\hline & & & & & & & \\
\hline 6 & 0.172 & 0.325 & 0.005 & 0.505 & 35 & 65 & 1 \\
\hline 6 & 0.172 & 0.325 & 0.01 & 0.51 & 35 & 65 & 2 \\
\hline 6 & 0.172 & 0.325 & 0.015 & 0.515 & 35 & 65 & 3 \\
\hline 6 & 0.172 & 0.325 & 0.02 & 0.52 & 35 & 65 & 4 \\
\hline & & & & & & & \\
\hline 7 & 0.2 & 0.3 & 0.005 & 0.505 & 40 & 60 & 1 \\
\hline 7 & 0.2 & 0.3 & 0.01 & 0.51 & 40 & 60 & 2 \\
\hline 7 & 0.2 & 0.3 & 0.015 & 0.515 & 40 & 60 & 3 \\
\hline 7 & 0.2 & 0.3 & 0.02 & 0.52 & 40 & 60 & 4 \\
\hline 7 & 0.2 & 0.3 & 0.025 & 0.525 & 40 & 60 & 5 \\
\hline & & & & & & & \\
\hline 8 & 0.225 & 0.275 & 0.005 & 0.505 & 45 & 55 & 1 \\
\hline 8 & 0.225 & 0.275 & 0.01 & 0.51 & 45 & 55 & 2 \\
\hline 8 & 0.225 & 0.275 & 0.015 & 0.515 & 45 & 55 & 3 \\
\hline 8 & 0.225 & 0.275 & 0.02 & 0.52 & 45 & 55 & 4 \\
\hline 8 & 0.225 & 0.275 & 0.025 & 0.525 & 45 & 55 & 5 \\
\hline 9 & 0.25 & 0.25 & 0.005 & 0.505 & 50 & 50 & 1 \\
\hline 9 & 0.25 & 0.25 & 0.01 & 0.51 & 50 & 50 & 2 \\
\hline 9 & 0.25 & 0.25 & 0.015 & 0.515 & 50 & 50 & 3 \\
\hline 9 & 0.25 & 0.25 & 0.02 & 0.52 & 50 & 50 & 4 \\
\hline 9 & 0.25 & 0.25 & 0.025 & 0.525 & 50 & 50 & 5 \\
\hline 9 & 0.25 & 0.25 & 0.03 & 0.53 & 50 & 50 & 6 \\
\hline 9 & 0.25 & 0.25 & 0.035 & 0.535 & 50 & 50 & 6.5 \\
\hline 9 & 0.25 & 0.25 & 0.04 & 0.54 & 50 & 50 & 7 \\
\hline
\end{tabular}


TABLE 4. CONT'D.

\begin{tabular}{|c|c|c|c|c|c|c|c|}
\hline Sample & Lecithin & IPM & Water & Total Weight & Lecithin & IPM & Water \\
\hline Group & $(\mathbf{g})$ & $(\mathbf{g})$ & $(\mathbf{m l})$ & $(\mathbf{g})$ & $(\% \mathbf{w})$ & $(\% \mathbf{w} / \mathbf{w})$ & $(\% \mathbf{w} / \mathbf{w})$ \\
\hline 10 & 0.275 & 0.225 & 0.005 & 0.505 & 55 & 45 & 1 \\
\hline 10 & 0.275 & 0.225 & 0.01 & 0.51 & 55 & 45 & 2 \\
\hline 10 & 0.275 & 0.225 & 0.015 & 0.515 & 55 & 45 & 3 \\
\hline 10 & 0.275 & 0.225 & 0.02 & 0.52 & 55 & 45 & 4 \\
\hline 10 & 0.275 & 0.225 & 0.025 & 0.525 & 55 & 45 & 5 \\
\hline 10 & 0.275 & 0.225 & 0.03 & 0.53 & 55 & 45 & 6 \\
\hline 10 & 0.275 & 0.225 & 0.035 & 0.535 & 55 & 45 & 6.5 \\
\hline 10 & 0.275 & 0.225 & 0.04 & 0.54 & 55 & 45 & 7 \\
\hline 10 & 0.275 & 0.225 & 0.045 & 0.545 & 55 & 45 & 8 \\
\hline & & & & & & & \\
\hline 11 & 0.3 & 0.2 & 0.005 & 0.505 & 60 & 40 & 1 \\
\hline 11 & 0.3 & 0.2 & 0.01 & 0.51 & 60 & 40 & 2 \\
\hline 11 & 0.3 & 0.2 & 0.015 & 0.515 & 60 & 40 & 3 \\
\hline 11 & 0.3 & 0.2 & 0.02 & 0.52 & 60 & 40 & 4 \\
\hline 11 & 0.3 & 0.2 & 0.025 & 0.525 & 60 & 40 & 5 \\
\hline 11 & 0.3 & 0.2 & 0.03 & 0.53 & 60 & 40 & 6 \\
\hline 11 & 0.3 & 0.2 & 0.035 & 0.535 & 60 & 40 & 6.5 \\
\hline 11 & 0.3 & 0.2 & 0.04 & 0.54 & 60 & 40 & 7 \\
\hline 11 & 0.3 & 0.2 & 0.045 & 0.545 & 60 & 40 & 8 \\
\hline
\end{tabular}


TABLE 5. FORMULATIONS COMPOSED OF LECITHIN, IPM AND WATER (CONTAINING 10\% W/N KT) USED FOR PHASE DIAGRAM

\begin{tabular}{|c|c|c|c|c|c|c|c|}
\hline Sample & Lecithin & IPM & Water & Total Weight & Lecithin & IPM & Water \\
\hline Group & (g) & (g) & $(\mathrm{ml})$ & (g) & $(\% w / w)$ & $(\% w / w)$ & $(\% w / w)$ \\
\hline 1 & 0.05 & 0.45 & 0.005 & 0.505 & 10 & 90 & 1 \\
\hline 1 & 0.05 & 0.45 & 0.01 & 0.51 & 10 & 90 & 2 \\
\hline 2 & 0.075 & 0.425 & 0.005 & 0.505 & 15 & 85 & 1 \\
\hline 2 & 0.075 & 0.425 & 0.01 & 0.51 & 15 & 85 & 2 \\
\hline \multirow[t]{2}{*}{2} & 0.075 & 0.425 & 0.015 & 0.515 & 15 & 85 & 3 \\
\hline & & & & & & & \\
\hline 3 & 0.1 & 0.4 & 0.005 & 0.505 & 20 & 80 & 1 \\
\hline 3 & 0.1 & 0.4 & 0.01 & 0.51 & 20 & 80 & 2 \\
\hline 3 & 0.1 & 0.4 & 0.015 & 0.515 & 20 & 80 & 3 \\
\hline 4 & 0.125 & 0.375 & 0.005 & 0.505 & 25 & 75 & 1 \\
\hline 4 & 0.125 & 0.375 & 0.01 & 0.51 & 25 & 75 & 2 \\
\hline 4 & 0.125 & 0.375 & 0.015 & 0.515 & 25 & 75 & 3 \\
\hline \multirow[t]{2}{*}{4} & 0.125 & 0.375 & 0.02 & 0.52 & 25 & 75 & 4 \\
\hline & & & & & & & \\
\hline 5 & 0.15 & 0.35 & 0.005 & 0.505 & 30 & 70 & 1 \\
\hline 5 & 0.15 & 0.35 & 0.01 & 0.51 & 30 & 70 & 2 \\
\hline 5 & 0.15 & 0.35 & 0.015 & 0.515 & 30 & 70 & 3 \\
\hline 5 & 0.15 & 0.35 & 0.02 & 0.52 & 30 & 70 & 4 \\
\hline 6 & 0.172 & 0.325 & 0.005 & 0.505 & 35 & 65 & 1 \\
\hline 6 & 0.172 & 0.325 & 0.01 & 0.51 & 35 & 65 & 2 \\
\hline 6 & 0.172 & 0.325 & 0.015 & 0.515 & 35 & 65 & 3 \\
\hline 6 & 0.172 & 0.325 & 0.02 & 0.52 & 35 & 65 & 4 \\
\hline \multirow[t]{2}{*}{6} & 0.172 & 0.325 & 0.025 & 0.525 & 35 & 65 & 5 \\
\hline & & & & & & & \\
\hline 7 & 0.2 & 0.3 & 0.005 & 0.505 & 40 & 60 & 1 \\
\hline 7 & 0.2 & 0.3 & 0.01 & 0.51 & 40 & 60 & 2 \\
\hline 7 & 0.2 & 0.3 & 0.015 & 0.515 & 40 & 60 & 3 \\
\hline 7 & 0.2 & 0.3 & 0.02 & 0.52 & 40 & 60 & 4 \\
\hline 7 & 0.2 & 0.3 & 0.025 & 0.525 & 40 & 60 & 5 \\
\hline 7 & 0.2 & 0.3 & 0.03 & 0.53 & 40 & 60 & 6 \\
\hline \multirow[t]{2}{*}{7} & 0.2 & 0.3 & 0.035 & 0.535 & 40 & 60 & 6.5 \\
\hline & & & & & & & \\
\hline 8 & 0.225 & 0.275 & 0.005 & 0.505 & 45 & 55 & 1 \\
\hline 8 & 0.225 & 0.275 & 0.01 & 0.51 & 45 & 55 & 2 \\
\hline 8 & 0.225 & 0.275 & 0.015 & 0.515 & 45 & 55 & 3 \\
\hline 8 & 0.225 & 0.275 & 0.02 & 0.52 & 45 & 55 & 4 \\
\hline 8 & 0.225 & 0.275 & 0.025 & 0.525 & 45 & 55 & 5 \\
\hline 8 & 0.225 & 0.275 & 0.03 & 0.53 & 45 & 55 & 6 \\
\hline 8 & 0.225 & 0.275 & 0.035 & 0.535 & 45 & 55 & 6.5 \\
\hline 9 & 0.25 & 0.25 & 0.005 & 0.505 & 50 & 50 & 1 \\
\hline 9 & 0.25 & 0.25 & 0.01 & 0.51 & 50 & 50 & 2 \\
\hline 9 & 0.25 & 0.25 & 0.015 & 0.515 & 50 & 50 & 3 \\
\hline 9 & 0.25 & 0.25 & 0.02 & 0.52 & 50 & 50 & 4 \\
\hline 9 & 0.25 & 0.25 & 0.025 & 0.525 & 50 & 50 & 5 \\
\hline 9 & 0.25 & 0.25 & 0.03 & 0.53 & 50 & 50 & 6 \\
\hline
\end{tabular}


TABLE 5. CONT'D.

\begin{tabular}{|c|c|c|c|c|c|c|c|}
\hline Sample & Lecithin & IPM & Water & Total Weight & Lecithin & IPM & Water \\
\hline Group & $(\mathbf{g})$ & $\mathbf{( g )}$ & $(\mathbf{m l})$ & $(\mathbf{g})$ & $(\% \mathbf{w} / \mathbf{w})$ & $(\% \mathbf{w} / \mathbf{w})$ & $(\% \mathbf{w} / \mathbf{w})$ \\
\hline 9 & 0.25 & 0.25 & 0.035 & 0.535 & 50 & 50 & 6.5 \\
\hline 9 & 0.25 & 0.25 & 0.04 & 0.54 & 50 & 50 & 7 \\
\hline & & & & & & & \\
\hline 10 & 0.275 & 0.225 & 0.005 & 0.505 & 55 & 45 & 1 \\
\hline 10 & 0.275 & 0.225 & 0.01 & 0.51 & 55 & 45 & 2 \\
\hline 10 & 0.275 & 0.225 & 0.015 & 0.515 & 55 & 45 & 3 \\
\hline 10 & 0.275 & 0.225 & 0.02 & 0.52 & 55 & 45 & 4 \\
\hline 10 & 0.275 & 0.225 & 0.025 & 0.525 & 55 & 45 & 5 \\
\hline 10 & 0.275 & 0.225 & 0.03 & 0.53 & 55 & 45 & 6 \\
\hline 10 & 0.275 & 0.225 & 0.035 & 0.535 & 55 & 45 & 6.5 \\
\hline 10 & 0.275 & 0.225 & 0.04 & 0.54 & 55 & 45 & 7 \\
\hline & & & & & & & \\
\hline 11 & 0.3 & 0.2 & 0.005 & 0.505 & 60 & 40 & 1 \\
\hline 11 & 0.3 & 0.2 & 0.01 & 0.51 & 60 & 40 & 2 \\
\hline 11 & 0.3 & 0.2 & 0.015 & 0.515 & 60 & 40 & 3 \\
\hline 11 & 0.3 & 0.2 & 0.02 & 0.52 & 60 & 40 & 4 \\
\hline 11 & 0.3 & 0.2 & 0.025 & 0.525 & 60 & 40 & 5 \\
\hline 11 & 0.3 & 0.2 & 0.03 & 0.53 & 60 & 40 & 6 \\
\hline 11 & 0.3 & 0.2 & 0.035 & 0.535 & 60 & 40 & 6.5 \\
\hline 11 & 0.3 & 0.2 & 0.04 & 0.54 & 60 & 40 & 7 \\
\hline 11 & 0.3 & 0.2 & 0.045 & 0.545 & 60 & 40 & 8 \\
\hline
\end{tabular}


TABLE 6. FORMULATIONS COMPOSED OF LECITHIN, IPM AND WATER (CONTAINING 50\% W/N KT) USED FOR PHASE DIAGRAM

\begin{tabular}{|c|c|c|c|c|c|c|c|}
\hline Sample & Lecithin & IPM & Water & Total Weight & Lecithin & TPM & Water \\
\hline Group & (g) & (g) & $(\mathrm{ml})$ & (g) & $(\% w / w)$ & $(\% w / w)$ & $(\% w / w)$ \\
\hline 1 & 0.05 & 0.45 & 0.005 & 0.505 & 10 & 90 & 1 \\
\hline 1 & 0.05 & 0.45 & 0.01 & 0.51 & 10 & 90 & 2 \\
\hline 1 & 0.05 & 0.45 & 0.015 & 0.515 & 10 & 90 & $\overline{3}$ \\
\hline 2 & 0.075 & 0.425 & 0.005 & 0.505 & 15 & 85 & 1 \\
\hline 2 & 0.075 & 0.425 & 0.01 & 0.51 & 15 & 85 & 2 \\
\hline 2 & 0.075 & 0.425 & 0.015 & 0.515 & 15 & 85 & 3 \\
\hline 3 & 01 & 04 & 0005 & 0505 & 20 & 80 & 1 \\
\hline 3 & 0.1 & 0.4 & 0.01 & 0.51 & 20 & 80 & 2 \\
\hline 3 & 0.1 & 0.4 & 0.015 & 0.515 & 20 & 80 & 3 \\
\hline & & & & & & & \\
\hline 4 & 0.125 & 0.375 & 0.005 & 0.505 & 25 & 75 & 1 \\
\hline 4 & 0.125 & 0.375 & 0.01 & 0.51 & 25 & 75 & 2 \\
\hline 4 & 0.125 & 0.375 & 0.015 & 0.515 & 25 & 75 & 3 \\
\hline 5 & 0.15 & 0.35 & 0.005 & 0.505 & 30 & 70 & $\overline{1}$ \\
\hline 5 & 0.15 & 0.35 & 0.01 & 0.51 & 30 & 70 & 2 \\
\hline 5 & 0.15 & 0.35 & 0.015 & 0.515 & 30 & 70 & 3 \\
\hline 5 & 0.15 & 0.35 & 0.02 & 0.52 & 30 & 70 & 4 \\
\hline & & & & & & & \\
\hline 6 & 0.172 & 0.325 & 0.005 & 0.505 & 35 & 65 & 1 \\
\hline 6 & 0.172 & 0.325 & 0.01 & 0.51 & 35 & 65 & 2 \\
\hline 6 & 0.172 & 0.325 & 0.015 & 0.515 & 35 & 65 & 3 \\
\hline 6 & 0.172 & 0.325 & 0.02 & 0.52 & 35 & 65 & 4 \\
\hline & $0 ?$ & & 0005 & 0505 & & 60 & \\
\hline$\frac{7}{7}$ & $\begin{array}{l}0.2 \\
0.2\end{array}$ & $\frac{0.3}{0.3}$ & $\frac{0.005}{0.01}$ & $\frac{0.505}{0.51}$ & $\frac{40}{40}$ & $\frac{60}{60}$ & $\frac{1}{2}$ \\
\hline 7 & 0.2 & 0.3 & 0.015 & 0.515 & 40 & 60 & 3 \\
\hline 7 & 0.2 & 0.3 & 0.02 & 0.52 & 40 & 60 & 4 \\
\hline 8 & 0.225 & 0.275 & 0.005 & 0.505 & 45 & 55 & 1 \\
\hline 8 & 0.225 & 0.275 & 0.01 & 0.51 & 45 & 55 & 2 \\
\hline 8 & 0.225 & 0.275 & 0.015 & 0.515 & 45 & 55 & $\overline{3}$ \\
\hline 8 & 0.225 & 0.275 & 0.02 & 0.52 & 45 & 55 & 4 \\
\hline & & & & & & & \\
\hline 9 & 0.25 & 0.25 & 0.005 & 0.505 & 50 & 50 & 1 \\
\hline$\overline{9}$ & 0.25 & 0.25 & 0.01 & 0.51 & 50 & 50 & 2 \\
\hline 9 & 0.25 & 0.25 & 0.015 & 0.515 & 50 & 50 & 3 \\
\hline 9 & 0.25 & 0.25 & 0.02 & 0.52 & 50 & 50 & 4 \\
\hline 10 & 0275 & (2020 & 0005 & 0505 & 55 & $\overline{15}$ & 7 \\
\hline$\frac{10}{10}$ & $\frac{0.275}{0.275}$ & $\frac{0.225}{0.225}$ & $\frac{0.005}{0.01}$ & $\frac{0.505}{0.51}$ & 55 & $\frac{45}{45}$ & $\frac{1}{2}$ \\
\hline 10 & $0 . \overline{275}$ & 0.225 & 0.015 & 0.515 & 55 & 45 & 3 \\
\hline 10 & 0.275 & 0.225 & 0.02 & 0.52 & 55 & 45 & 4 \\
\hline & & & & & & & \\
\hline 11 & 0.3 & 0.2 & 0.005 & 0.505 & 60 & 40 & 1 \\
\hline 11 & 0.3 & $\overline{0.2}$ & 0.01 & 0.51 & 60 & 40 & 2 \\
\hline 11 & 0.3 & 0.2 & 0.015 & 0.515 & 60 & 40 & 3 \\
\hline 11 & 0.3 & 0.2 & 0.02 & 0.52 & 60 & 40 & 4 \\
\hline
\end{tabular}


TABLE 7. FORMULATIONS COMPOSED OF LECITHIN, IPM AND WATER CONTAINING $6.5 \%$ W/W KT USED FOR PHASE DIAGRAM

\begin{tabular}{|c|c|c|c|c|c|c|c|}
\hline Sample & Lecithin & IPM & Water & Total Weight & Lecithin & IPM & Water \\
\hline Group & $(\mathbf{g})$ & $(\mathbf{g})$ & $(\mathbf{m l})$ & $(\mathbf{g})$ & $(\% \mathbf{w} / \mathbf{w})$ & $(\% \mathbf{w} / \mathbf{w})$ & $(\% \mathbf{w} / \mathbf{w})$ \\
\hline 1 & 0.4 & 0.6 & 0.005 & 1.075 & 40 & 60 & 0.46 \\
\hline 1 & 0.4 & 0.6 & 0.01 & 1.08 & 40 & 60 & 0.93 \\
\hline 1 & 0.4 & 0.6 & 0.015 & 1.085 & 40 & 60 & 1.4 \\
\hline 1 & 0.4 & 0.6 & 0.02 & 1.09 & 40 & 60 & 1.8 \\
\hline & & & & & & & \\
\hline 2 & 0.5 & 0.5 & 0.005 & 1.075 & 50 & 50 & 0.46 \\
\hline 2 & 0.5 & 0.5 & 0.01 & 1.08 & 50 & 50 & 0.93 \\
\hline 2 & 0.5 & 0.5 & 0.015 & 1.085 & 50 & 50 & 1.4 \\
\hline 2 & 0.5 & 0.5 & 0.02 & 1.09 & 50 & 50 & 1.8 \\
\hline & & & & & & & \\
\hline 3 & 0.6 & 0.4 & 0.005 & 1.075 & 60 & 40 & 0.46 \\
\hline 3 & 0.6 & 0.4 & 0.01 & 1.08 & 60 & 40 & 0.93 \\
\hline 3 & 0.6 & 0.4 & 0.015 & 1.085 & 60 & 40 & 1.4 \\
\hline 3 & 0.6 & 0.4 & 0.02 & 1.09 & 60 & 40 & 1.8 \\
\hline 3 & 0.6 & 0.4 & 0.025 & 1.095 & 60 & 40 & 2.3 \\
\hline
\end{tabular}




\subsubsection{Release/Permeation Studies}

The release/permeation of ketorolac from the lecithin gel through various selected membranes was determined using vertical Franz-diffusion cells having a diameter of $9 \mathrm{~mm}$ and a volume of $5.1 \mathrm{ml}$. Permeation studies were performed using guinea pig skin, cellulose acetate and silicone elastomer as synthetic membranes. In these cells, the skin or artificial membrane was placed between the donor and receptor compartments of the cells with the dermal side in direct contact with the receptor medium. The effective area of membrane available for diffusion was $0.64 \mathrm{~cm}^{2}$. In all experiments, a 0.3-gram amount of each formulation containing the drug was placed onto the membrane, and then covered with parafilm. The receptor compartment was filled with $5.1 \mathrm{ml}$ of degassed phosphate buffer solution (pH 7.4). The cells were thermostated at $32{ }^{\circ} \mathrm{C}$ in an incubator, and the receptor solution was stirred with a magnetic stirrer at $200 \mathrm{rpm}$ throughout the experiment. The receptor phase was withdrawn at various times $(0.5,1,2,4, \ldots, 12 \mathrm{~h})$ for synthetic membranes and $(0.5,1$, $2,4, \ldots, 24 \mathrm{~h}$ ) for guinea pig skin, and replaced with equal volumes of fresh phosphate buffer equilibrated to $32^{\circ} \mathrm{C}$. The concentration of the drug in each receptor solution was determined either using a spectrophotometer (in case of artificial membranes) or HPLC method (in case of guinea pig skin).

\subsubsection{Release Data Analysis}

The cumulative amount of ketorolac permeated through guinea pig skin or synthetic membranes was plotted as a function of time. The slope and intercept of the linear portion of the plot was derived by regression. The release rate $\left(\mu \mathrm{g} / \mathrm{cm}^{2} / \mathrm{h}\right)$ was 
calculated as the slope and the intercept on the X-axis was taken as the lag time (h). All release studies were the average of six individual cells.

\subsubsection{Spectrophotometric and HPLC Analysis of Ketorolac}

The amount of ketorolac released into the receptor medium was determined with either a spectrophotometric or HPLC method. For those samples analyzed by spectrophotometer, the UV detector was set at the specific absorbance wavelength (322 nm) for KT and concentrations were determined from a calibration curve obtained with known amounts of drug under identical analytical conditions.

An HPLC method was also utilized when guinea pig skin was used as a membrane for permeation studies. In this case, a C-18 column $(3.9 \mathrm{~mm}$ i.d. $\times 300 \mathrm{~mm})$ was eluted at $37{ }^{\circ} \mathrm{C}$ with a mobile phase consisting of acetonitrile-phosphoric acid solution (1.3 mM, pH 3.02) with a ratio of $34: 66(\mathrm{v} / \mathrm{v})$ at a flow rate of $1.5 \mathrm{ml} / \mathrm{min}$ and injection volume of $20 \mu \mathrm{l}$ (Quadir et al., 2000). The retention time of ketorolac was 10 minutes and the detection wavelength was set at $322 \mathrm{~nm}$. The concentration of KT was determined by comparing the absorbance of the unknown from a calibration curve. All operations were carried out at room temperature.

\subsubsection{Spectrophotometric and HPLC Data Analysis}

Two series of different concentrations, $8,16,24,32,40 \mu \mathrm{g} / \mathrm{ml}$ and $1,5,10,15$, $20,25,50 \mu \mathrm{g} / \mathrm{ml}$ of $\mathrm{KT}$ in phosphate buffer $(\mathrm{pH} 7.4)$ were prepared to construct the calibration curves. Solutions were analyzed using the standard spectrophotometric and HPLC methods respectively. The peak area of the drug versus known concentrations 
was plotted. Linear regression analysis of the peak areas gave a correlation coefficient of 0.9999 by spectrophotometry and 0.9997 by HPLC method. Data is tabulated in Tables 8, 9 and Figures 6, 7 respectively.

\subsubsection{Preparation of Synthetic Membrane and Guinea Pig Skin}

Cellulose acetate and silicone elastomer membranes soaked in distilled water for $24 \mathrm{~h}$ were used as artificial membranes. For guinea pig skin the whole skin was used as experimental skin.

\subsubsection{Viscosity Measurements}

The viscosity of the lecithin/ IPM/ water system depends on the amount of lecithin and added water into the organogel. An attempt was therefore made to observe the effect of added water and lecithin on the viscosity of the system. Viscosity of each sample was measured, using both cylindrical and cone \& plate viscometers at a controlled temperature $\left(25^{\circ} \mathrm{C}\right)$.

\subsubsection{Statistical Analysis}

All the release experiments were repeated six times and their mean values with standard deviation are presented. A one-way ANOVA was used to test the statistical difference in the release profile between organogels of different compositions. The multiple comparisons within the formulations were also determined. Differences were assumed to be significant at $\mathrm{p}<0.05$. 
TABLE 8. DATA FOR KT ABSORBANCE IN BUFFER SOLUTION AT DIFFERENT CONCENTRATION USING SPECTROPHOTOMETRIC METHOD

\begin{tabular}{|c|c|c|c|}
\hline Sample & Conc. $(\mathbf{u g} / \mathrm{ml})$ & Mean Abs. $(\mathbf{n}=\mathbf{3})$ & Std.Dev. \\
\hline & & & \\
\hline 1 & 8 & 0.396 & 0.039 \\
\hline 2 & 16 & 0.841 & 0.044 \\
\hline 3 & 24 & 1.262 & 0.049 \\
\hline 4 & 32 & 1.722 & 0.061 \\
\hline 5 & 40 & 2.156 & 0.063 \\
\hline
\end{tabular}




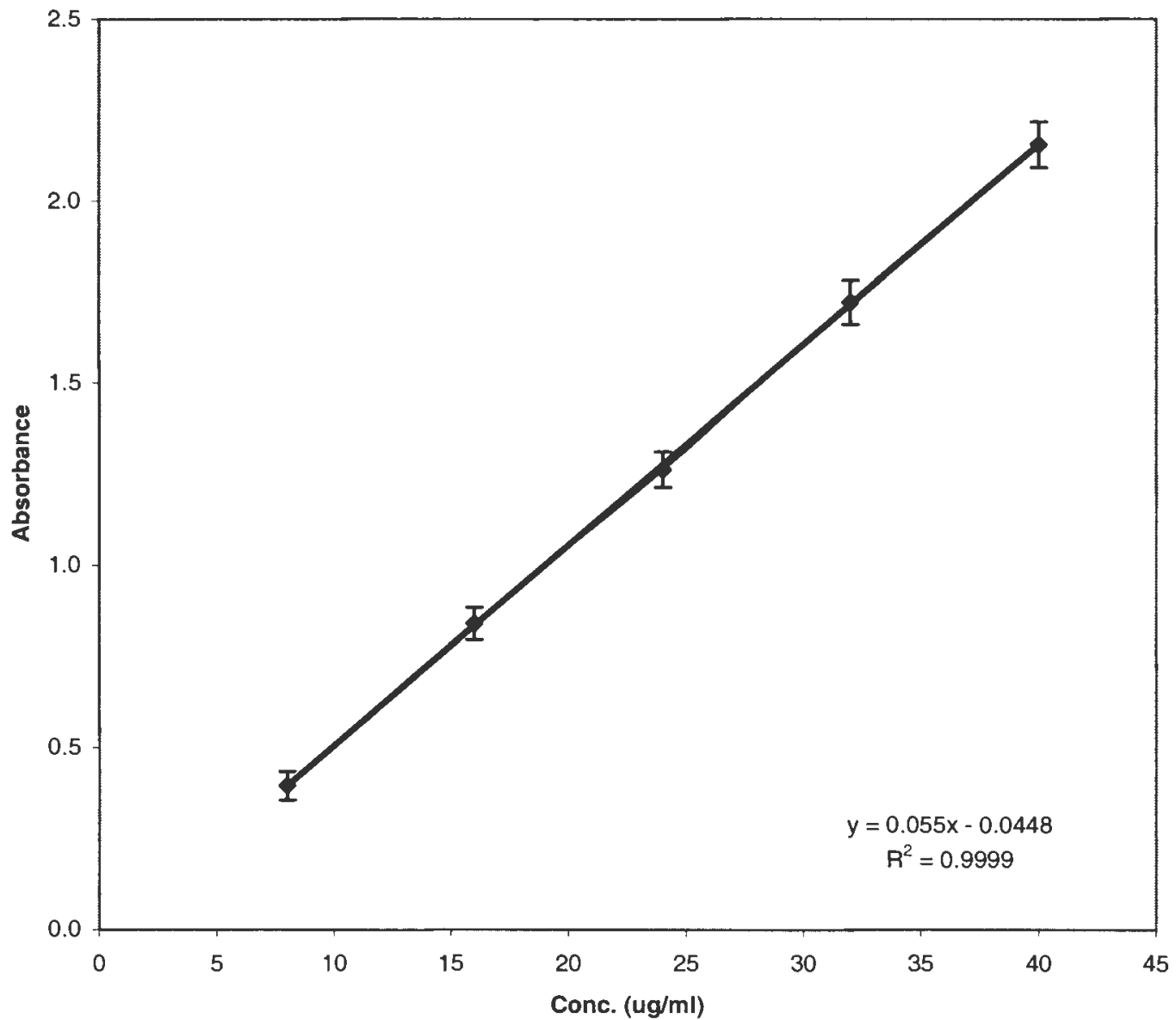

FIGURE 6. CALIBRATION CURVE FOR KETOROLAC TROMETHAMINE USING THE SPECTROPHOTOMETRIC METHOD $(M E A N \pm S D, N=3)$ 
TABLE 9. DATA FOR KETOROLAC ABSORBANCE IN BUFFER SOLUTION AT DIFFERENT CONCENTRATION USING HPLC METHOD

\begin{tabular}{|c|c|c|}
\hline Sample & Concentration (ug/ml) & Area Under Peak \\
\hline & & \\
\hline 1 & 1 & 45416 \\
\hline 2 & 5 & 245081 \\
\hline 3 & 10 & 513500 \\
\hline 4 & 15 & 718649 \\
\hline 5 & 20 & 976095 \\
\hline 6 & 25 & 1200978 \\
\hline 7 & 50 & 2416148 \\
\hline
\end{tabular}




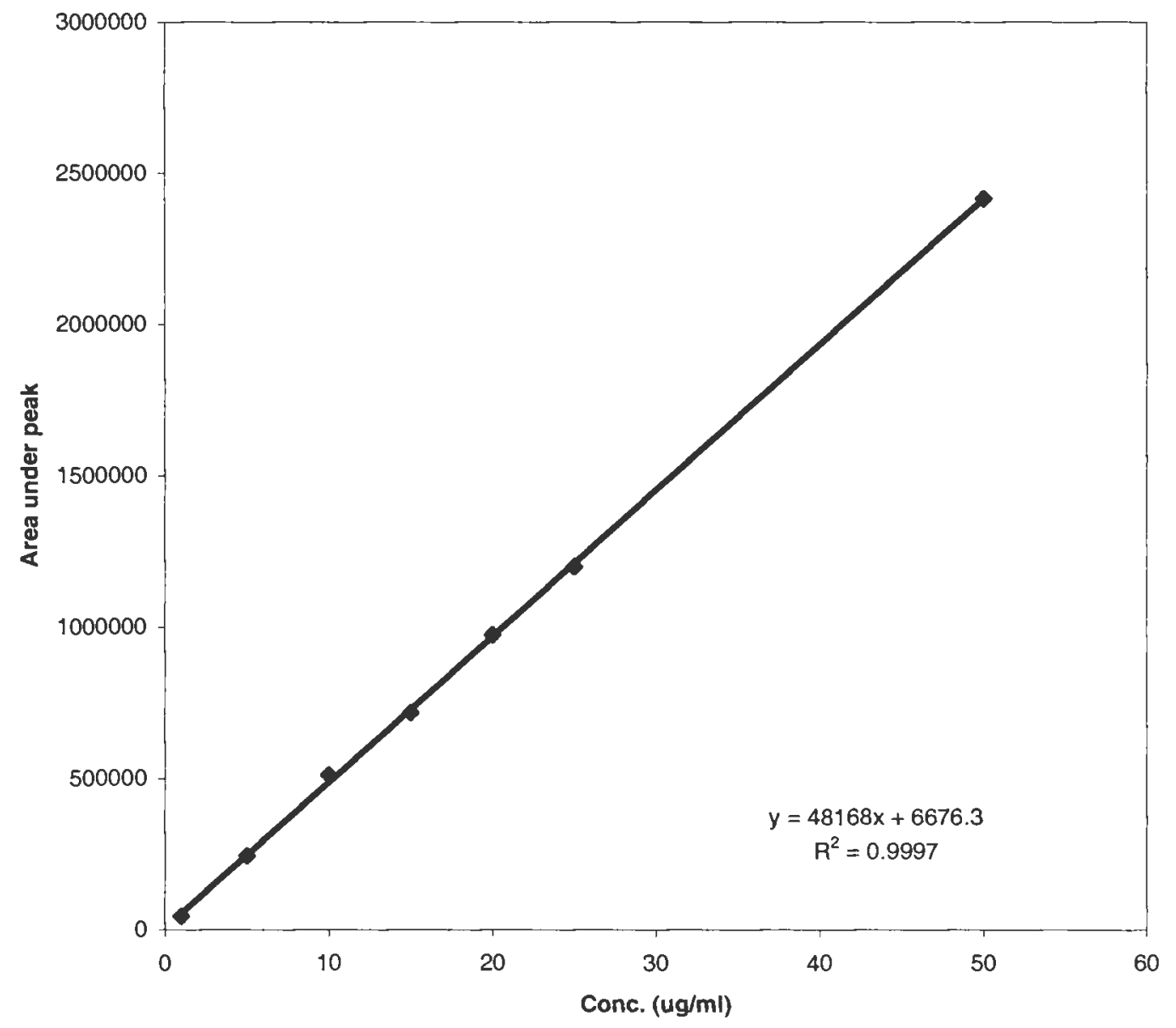

FIGURE 7. CALIBRATION CURVE FOR KETOROLAC TROMETHAMINE USING HPLC METHOD 


\section{RESULTS AND DISCUSION}

\subsection{Organogel Preparation}

Poorly purified lecithin did not possess gel-forming properties. When synthetic lecithin containing residues of saturated fatty acids were examined, the organogel formation was not observed. The gelation took place only when a soybean lecithin (Epikuron 200) containing at least $95 \%$ phosphatidylcholine was used.

\subsection{Phase Diagram Studies}

The construction of a phase diagram made it easy to determine the concentration range of lecithin, IPM, KT and water for the existing range of organogels. Figure 8 shows the phase diagram, constructed to determine the optimum formulation of organogel. As shown in this figure, organogels exist in a narrow water concentration region. Decrease of viscosity, cloudiness and two-phase system appearance occurred at water excess. This figure shows the existence of the organogel occurred along the lecithin/IPM axis, where its extent increased as the weight percent of lecithin increased. Compared to the phase diagram constructed in the absence of $\mathrm{KT}$, a relatively large gel region was observed when KT solution was incorporated into the organogel.

No significant differences in phase behavior were noted when altering the concentration of KT solution from 2.5 to 5 and then $10 \%$ w/v (Figures 9, 10, and 11). However, a small decrease in the extent of the gel region was observed when $50 \% \mathrm{w} / \mathrm{v}$ of the drug solution was incorporated into the system (Figure 12). 
The phase diagram resulting from the new method of preparation showed a smaller existence area of organogel compared to those from the old method (Figure 13). However, by using the new method of preparation it is possible to incorporate a higher amount of drug into the organogel. In this case, for each of the organogel samples, up to $6.5 \% \mathrm{w} / \mathrm{w}$ of $\mathrm{KT}$ could be dissolved compared to $1 \% \mathrm{w} / \mathrm{w}$ in case of the old method. The detailed composition of eighteen different organogels is shown in Table 10.

It seems that the presence of lecithin in the organic solution brings about an increase in solubility with respect to that observed in either water or isopropyl myristate. This finding is confirmed by Williman et al., 1991 who reported a considerably high solubility of several drugs in lecithin gel than in water or isopropyl palmitate. 


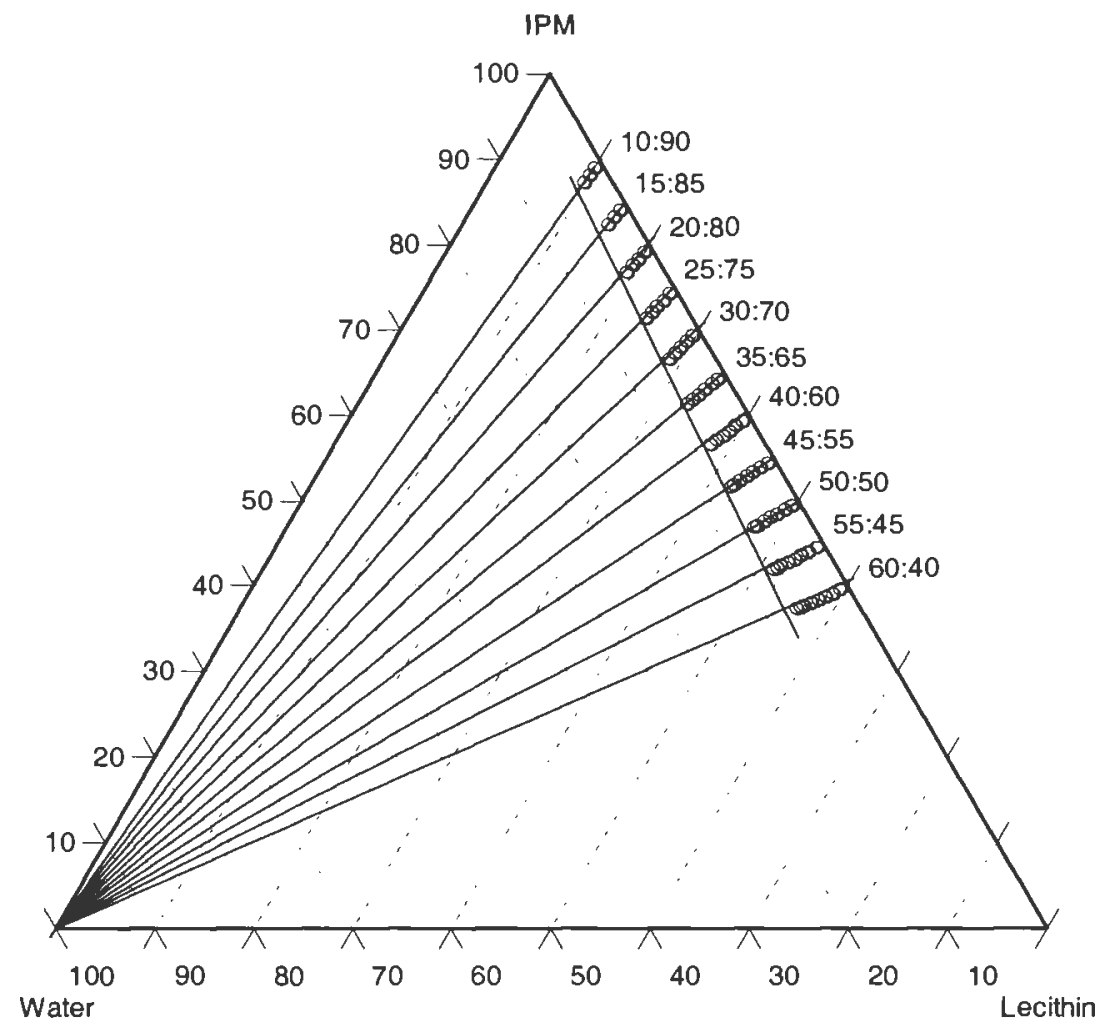

FIGURE 8. PHASE DIAGRAM OF A SYSTEM CONTAINING LECITHIN, IPM AND WATER 


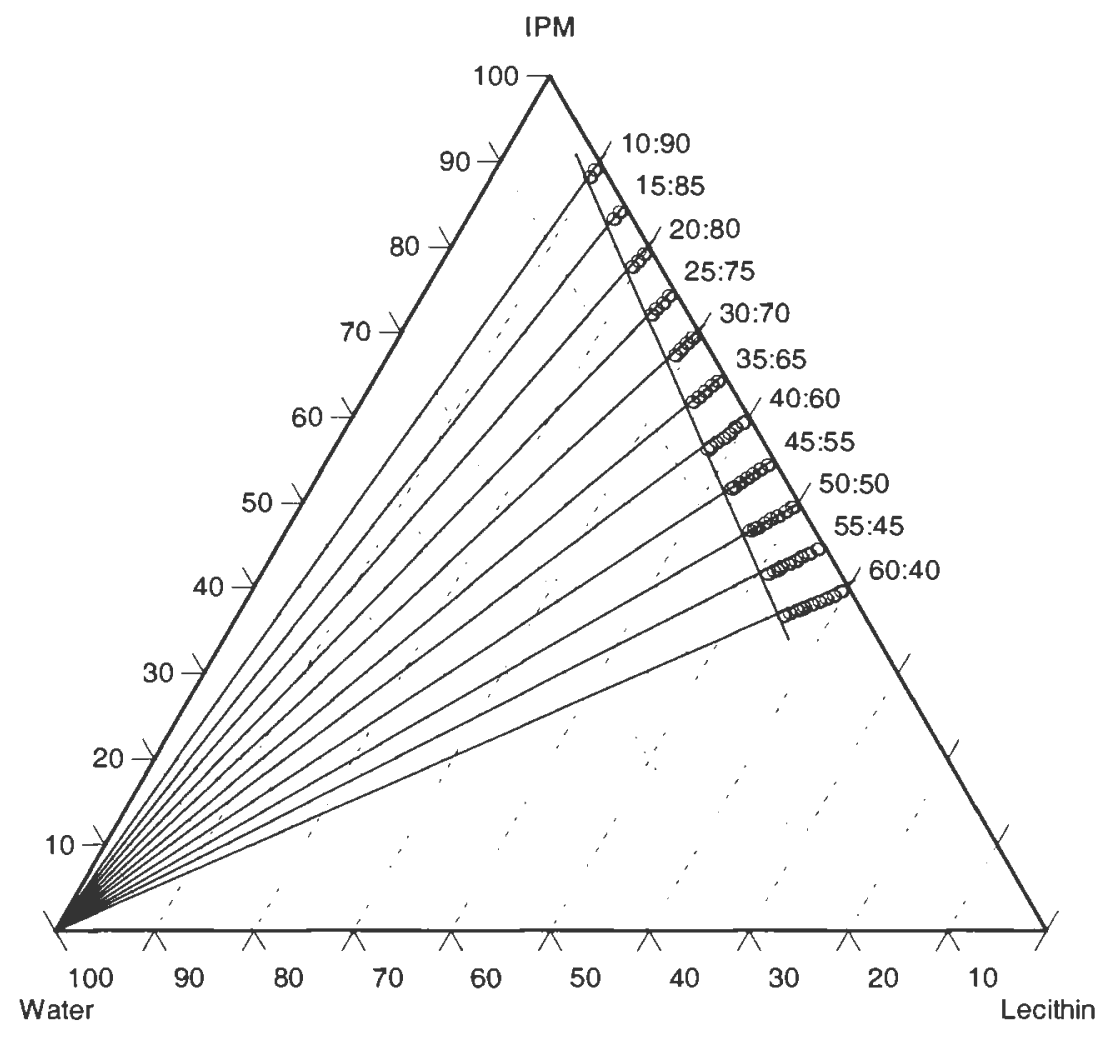

FIGURE 9. PHASE DIAGRAM OF A SYSTEM OF LECITHIN, IPM AND WATER (CONTAINING 2.5\% KT W/V) 


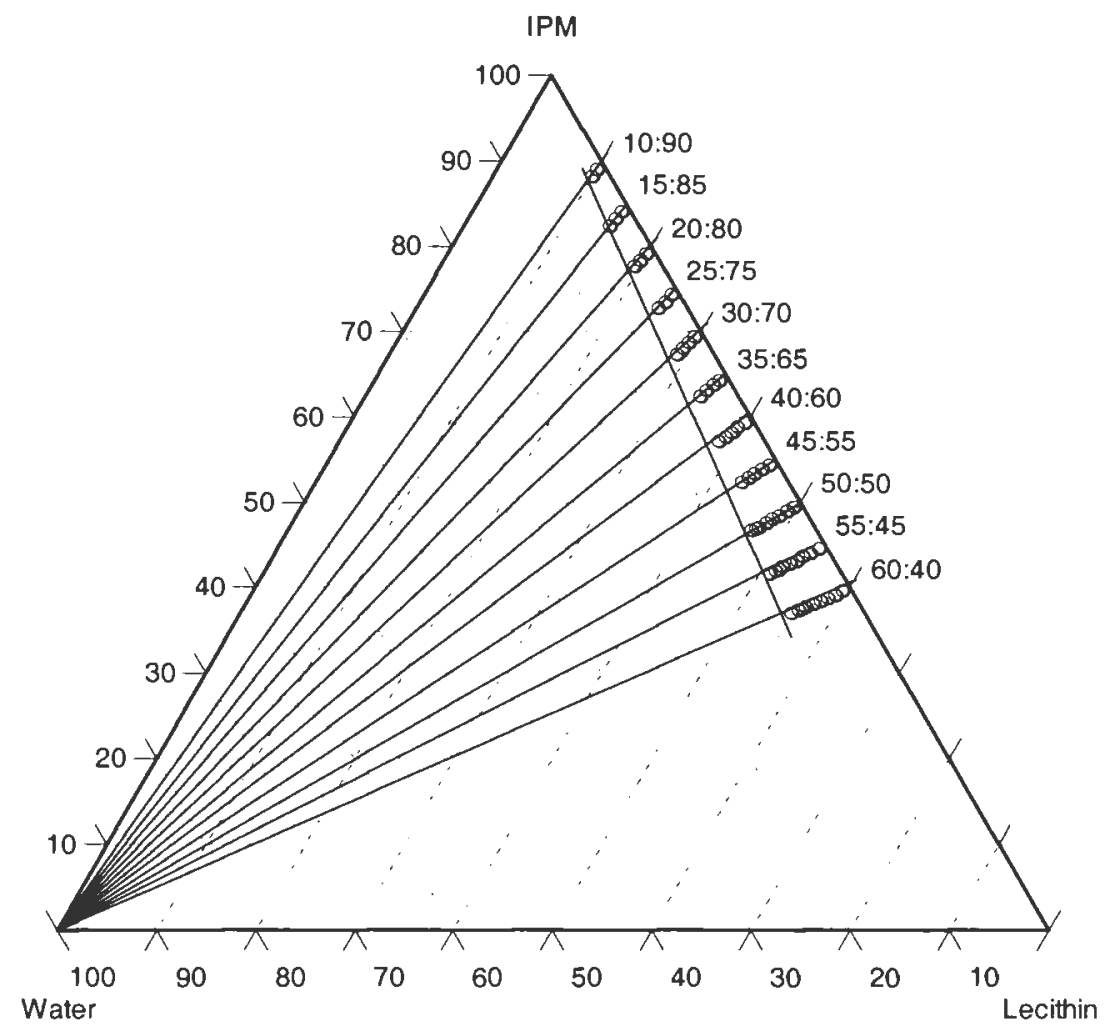

FIGURE 10. PHASE DIAGRAM OF A SYSTEM OF LECITHIN, IPM AND WATER (CONTAINING 5\% KT W/V) 


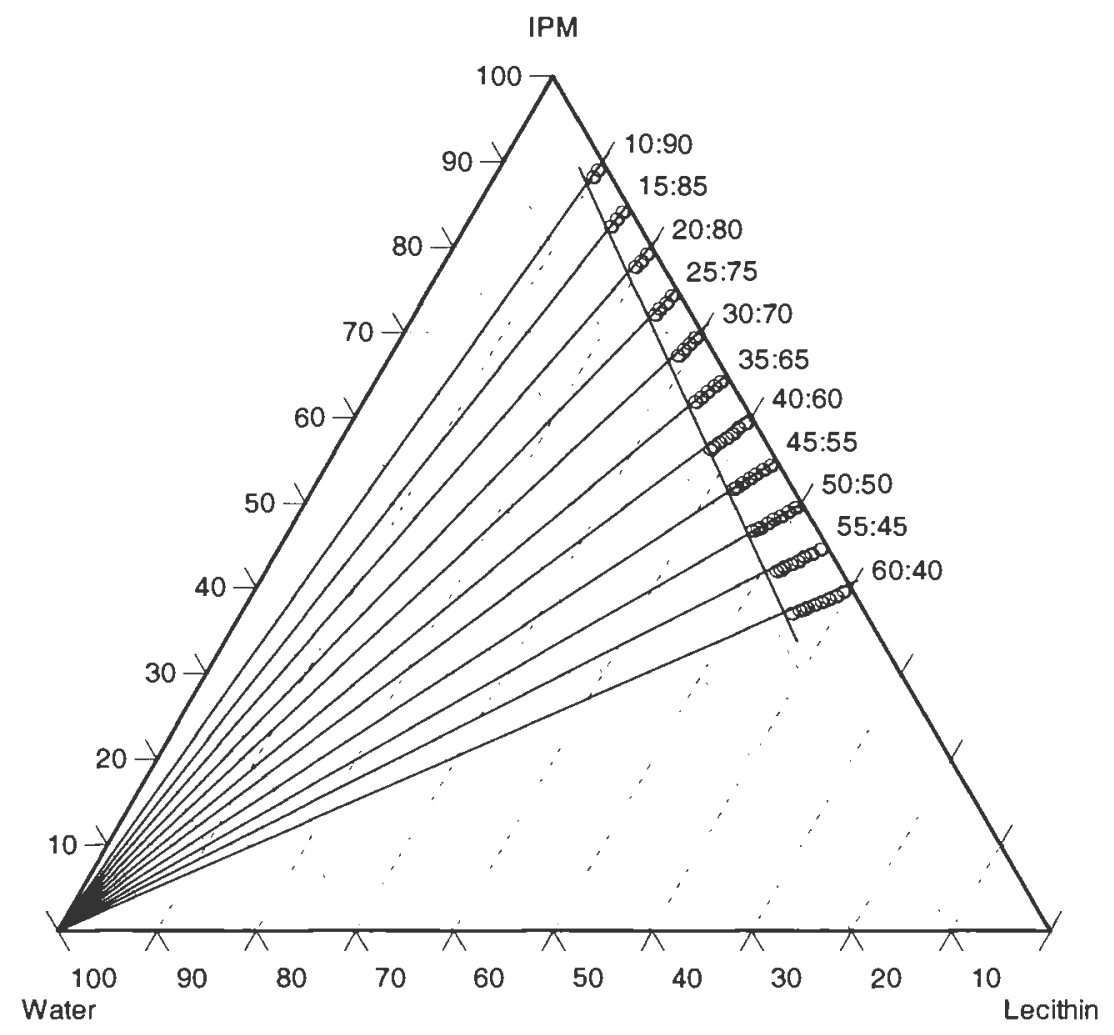

FIGURE 11. PHASE DIAGRAM OF A SYSTEM OF LECITHIN, IPM AND WATER (CONTAINING 10\% KT W/V) 


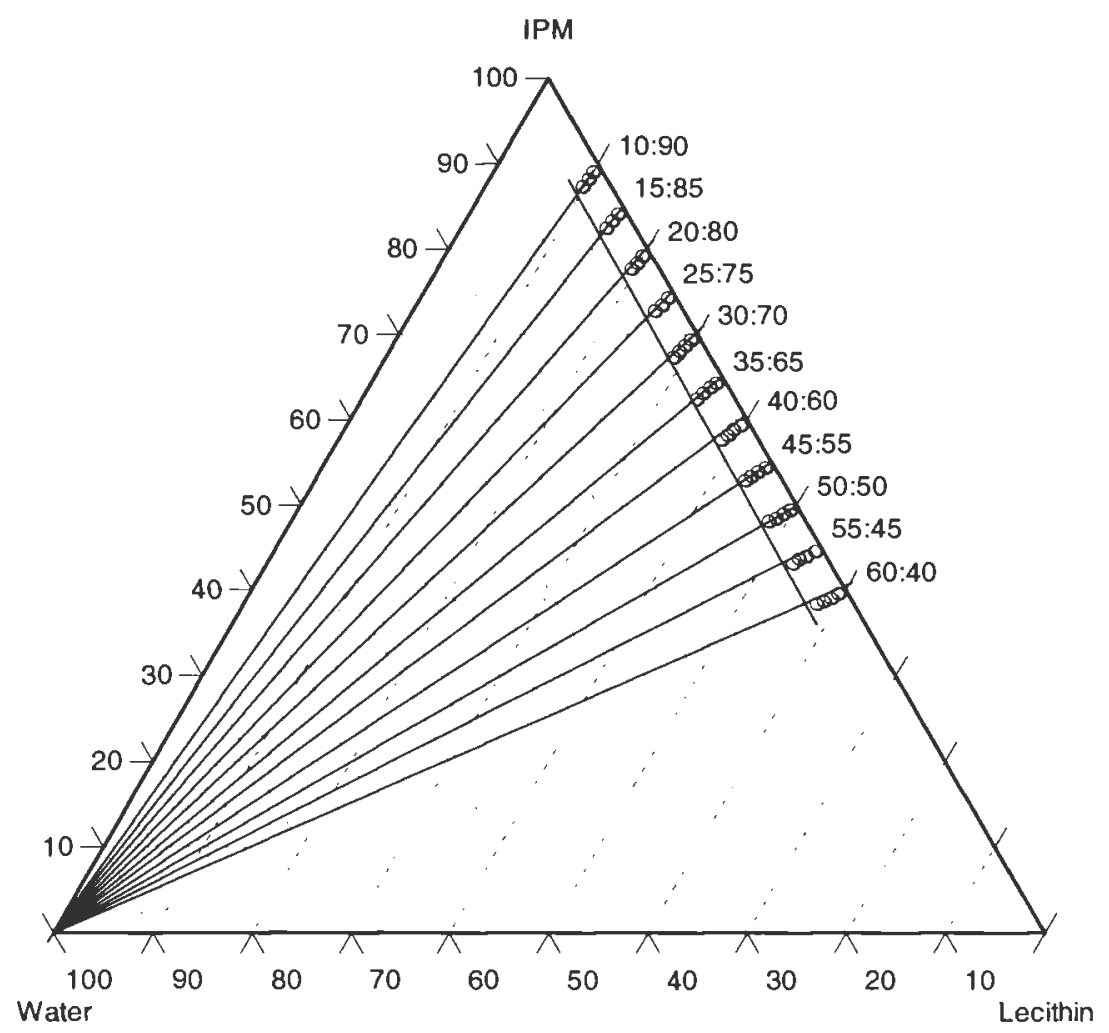

FIGURE 12. PHASE DIAGRAM OF A SYSTEM OF LECITHIN, IPM AND WATER (CONTAINING 50\% KT W/V) 


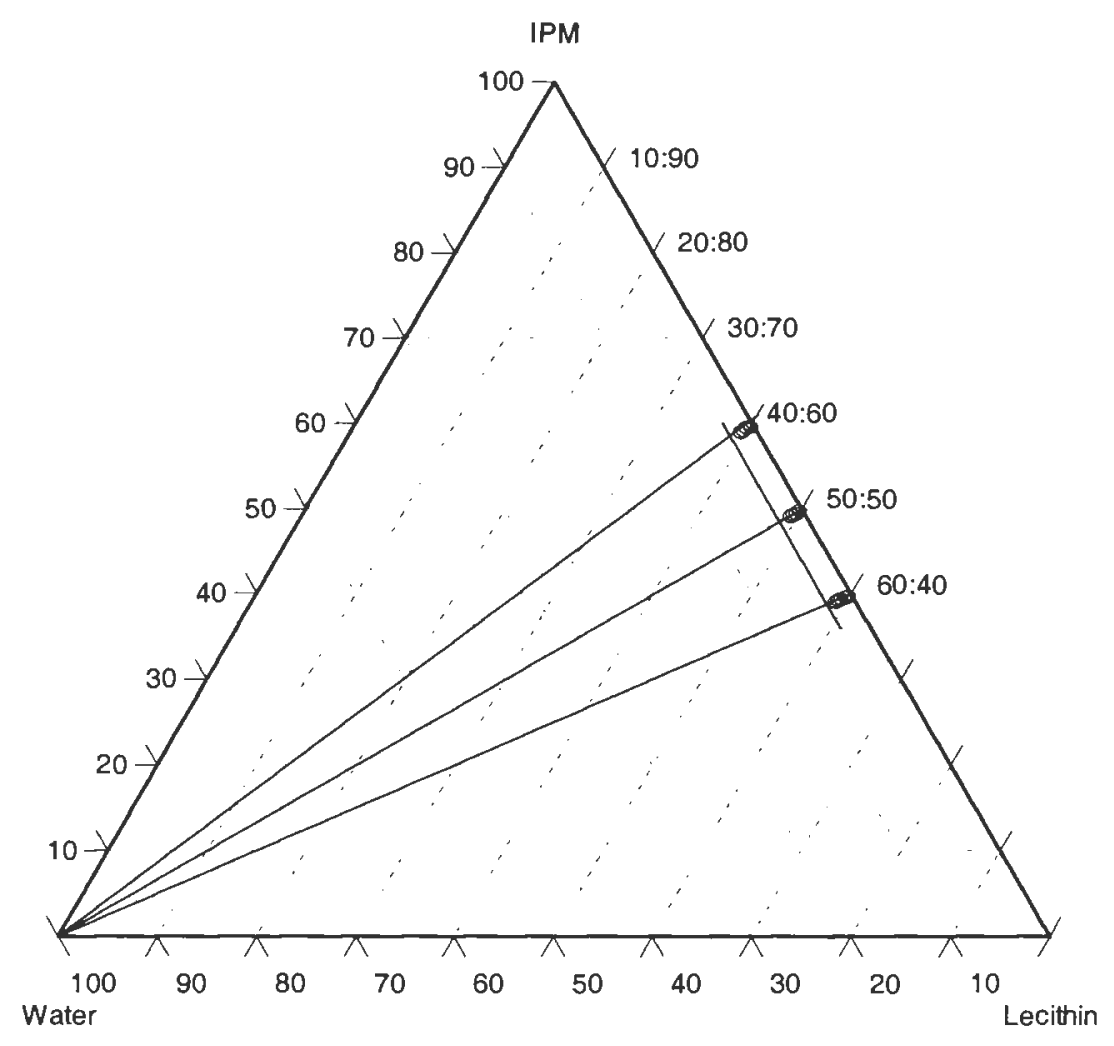

FIGURE 13. PHASE DIAGRAM OF A SYSTEM CONTAINING LECITHIN, IPM AND WATER WITH 6.5\% W/W OF KT IN A GEL FORMULATION (NEW METHOD) 
TABLE 10. KETOROLAC ORGANOGEL OF DIFFERENT COMPOSITIONS (NEW METHOD)

\begin{tabular}{|c|c|c|c|c|c|c|c|c|c|}
\hline Formu- & Lecithin & IPM & Water & KT & Total Weight & Lecithin & IPM & Water & KT \\
\hline lation & $\mathbf{( g )}$ & $\mathbf{( g )}$ & $\mathbf{( m l )}$ & $(\mathbf{g})$ & $\mathbf{( g )}$ & $(\% \mathbf{w} / \mathbf{w})$ & $(\% \mathbf{w} / \mathbf{w})$ & $(\% \mathbf{w} / \mathbf{w})$ & $\mathbf{\% w} / \mathbf{w})$ \\
\hline $\mathbf{1}$ & 1.2 & 1.8 & 0.003 & 0.21 & 3.213 & $\mathbf{4 0}$ & $\mathbf{6 0}$ & 0.1 & 6.5 \\
\hline $\mathbf{2}$ & 1.2 & 1.8 & 0.0075 & 0.21 & 3.2175 & $\mathbf{4 0}$ & $\mathbf{6 0}$ & 0.25 & 6.5 \\
\hline $\mathbf{3}$ & 1.2 & 1.8 & 0.015 & 0.21 & 3.225 & $\mathbf{4 0}$ & $\mathbf{6 0}$ & 0.5 & 6.5 \\
\hline $\mathbf{4}$ & 1.2 & 1.8 & 0.018 & 0.21 & 3.228 & $\mathbf{4 0}$ & $\mathbf{6 0}$ & 0.6 & 6.5 \\
\hline $\mathbf{5}$ & 1.2 & 1.8 & 0.021 & 0.21 & 3.231 & $\mathbf{4 0}$ & $\mathbf{6 0}$ & 0.7 & 6.5 \\
\hline $\mathbf{6}$ & 1.2 & 1.8 & 0.024 & 0.21 & 3.234 & $\mathbf{4 0}$ & $\mathbf{6 0}$ & 0.8 & 6.5 \\
\hline & & & & & & & & & \\
\hline $\mathbf{7}$ & 1.5 & 1.5 & 0.003 & 0.21 & 3.213 & $\mathbf{5 0}$ & $\mathbf{5 0}$ & 0.1 & 6.5 \\
\hline $\mathbf{8}$ & 1.5 & 1.5 & 0.0075 & 0.21 & 3.2175 & $\mathbf{5 0}$ & $\mathbf{5 0}$ & 0.25 & 6.5 \\
\hline $\mathbf{9}$ & 1.5 & 1.5 & 0.015 & 0.21 & 3.225 & $\mathbf{5 0}$ & $\mathbf{5 0}$ & 0.5 & 6.5 \\
\hline $\mathbf{1 0}$ & 1.5 & 1.5 & 0.018 & 0.21 & 3.228 & $\mathbf{5 0}$ & $\mathbf{5 0}$ & 0.6 & 6.5 \\
\hline $\mathbf{1 1}$ & 1.5 & 1.5 & 0.021 & 0.21 & 3.231 & $\mathbf{5 0}$ & $\mathbf{5 0}$ & 0.7 & 6.5 \\
\hline $\mathbf{1 2}$ & 1.5 & 1.5 & 0.024 & 0.21 & 3.234 & $\mathbf{5 0}$ & $\mathbf{5 0}$ & 0.8 & 6.5 \\
\hline & & & & & & & & & \\
\hline $\mathbf{1 3}$ & 1.8 & 1.2 & 0.003 & 0.21 & 3.213 & $\mathbf{6 0}$ & $\mathbf{4 0}$ & 0.1 & 6.5 \\
\hline $\mathbf{1 4}$ & 1.8 & 1.2 & 0.0075 & 0.21 & 3.2175 & $\mathbf{6 0}$ & $\mathbf{4 0}$ & 0.25 & 6.5 \\
\hline $\mathbf{1 5}$ & 1.8 & 1.2 & 0.015 & 0.21 & 3.225 & $\mathbf{6 0}$ & $\mathbf{4 0}$ & 0.5 & 6.5 \\
\hline $\mathbf{1 6}$ & 1.8 & 1.2 & 0.018 & 0.21 & 3.228 & $\mathbf{6 0}$ & $\mathbf{4 0}$ & 0.6 & 6.5 \\
\hline $\mathbf{1 7}$ & 1.8 & 1.2 & 0.021 & 0.21 & 3.231 & $\mathbf{6 0}$ & $\mathbf{4 0}$ & 0.7 & 6.5 \\
\hline $\mathbf{1 8}$ & 1.8 & 1.2 & 0.024 & 0.21 & 3.234 & $\mathbf{6 0}$ & $\mathbf{4 0}$ & 0.8 & 6.5 \\
\hline
\end{tabular}




\subsection{Effect of Membrane on KT Release from Organogels}

Release studies were performed using, both cellulose acetate and silicone elastomer in order to find out if the release rates were influenced, by different artificial membranes. A significant $(p<0.05)$ decrease in $\mathrm{KT}$ release was obtained when using silicone as a synthetic membrane. The release rate with the cellulose acetate membrane was $\sim 3$ times $\left(22.746 \mu \mathrm{g} / \mathrm{cm}^{2} / \mathrm{h}\right)$ higher than with the silicone membrane $\left(7.6779 \mu \mathrm{g} / \mathrm{cm}^{2} / \mathrm{h}\right)$. This may be due to the differences in molecular weight cut-offs (MWCO) between cellulose acetate (3,500 Dalton) and silicone elastomer membrane. As the drug molecular weight approaches the MWCO, the diffusion through the membrane slows dramatically.

The plot of cumulative release of KT through both membranes per unit area versus time is given in Figures 14, and 15. The effect of membrane on the release rate of KT from lecithin:IPM $(40: 60)$ containing $0.1 \% \mathrm{w} / \mathrm{w}$ of water and $1 \% \mathrm{w} / \mathrm{w}$ of KT is shown in Figure 16 (The experiment was done up to 10 hours when silicone elastomer was used as a membrane). 


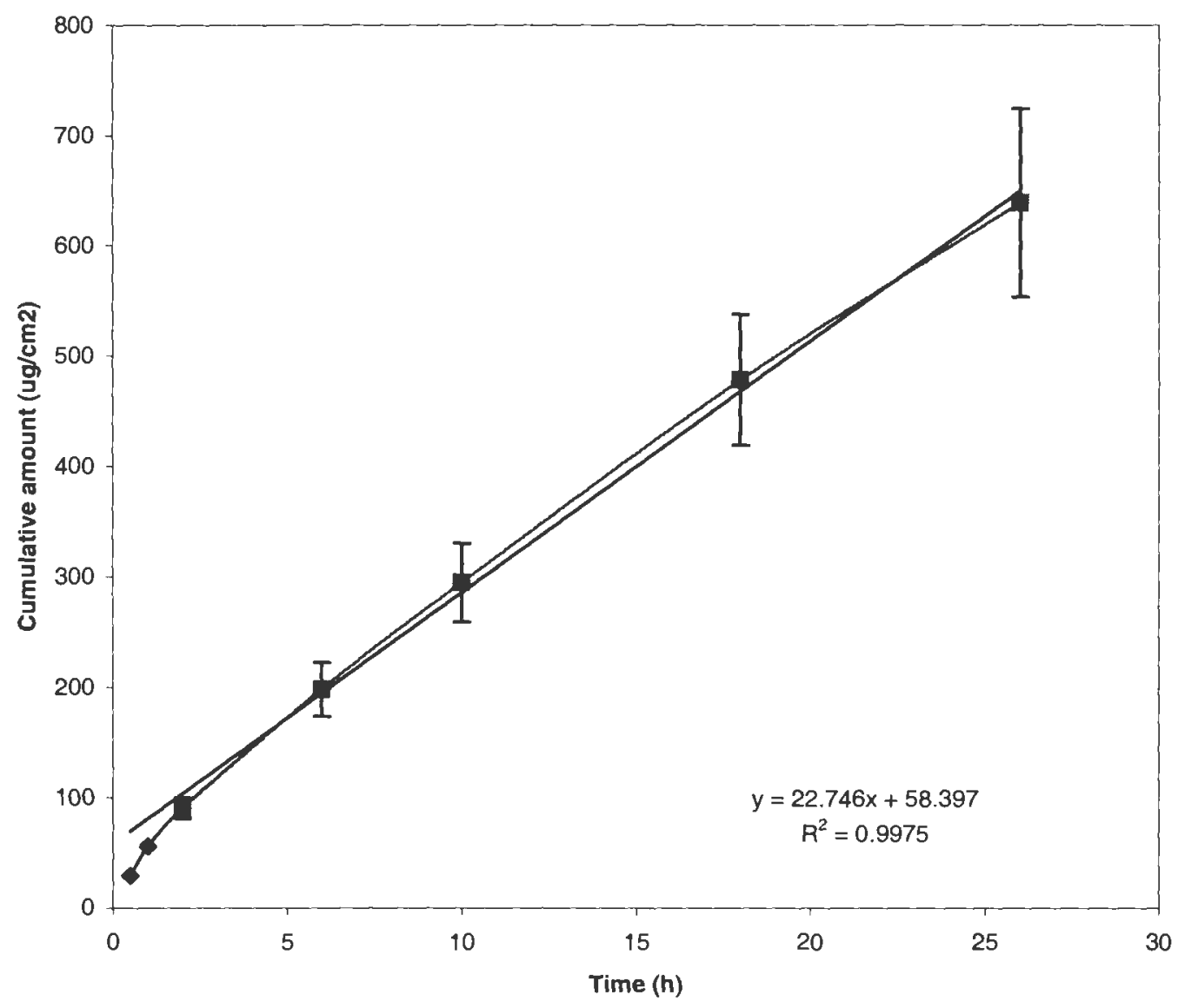

FIGURE 14. RELEASE PROFILE OF KT ACROSS CELLULOSE ACETATE MEMBRANE FROM LECITHIN:IPM (40:60) CONTAINING $0.1 \%$ WATER AND $1 \% \mathrm{KT}(\mathrm{MEAN} \pm \mathrm{SD}, \mathrm{N}=6)$ 


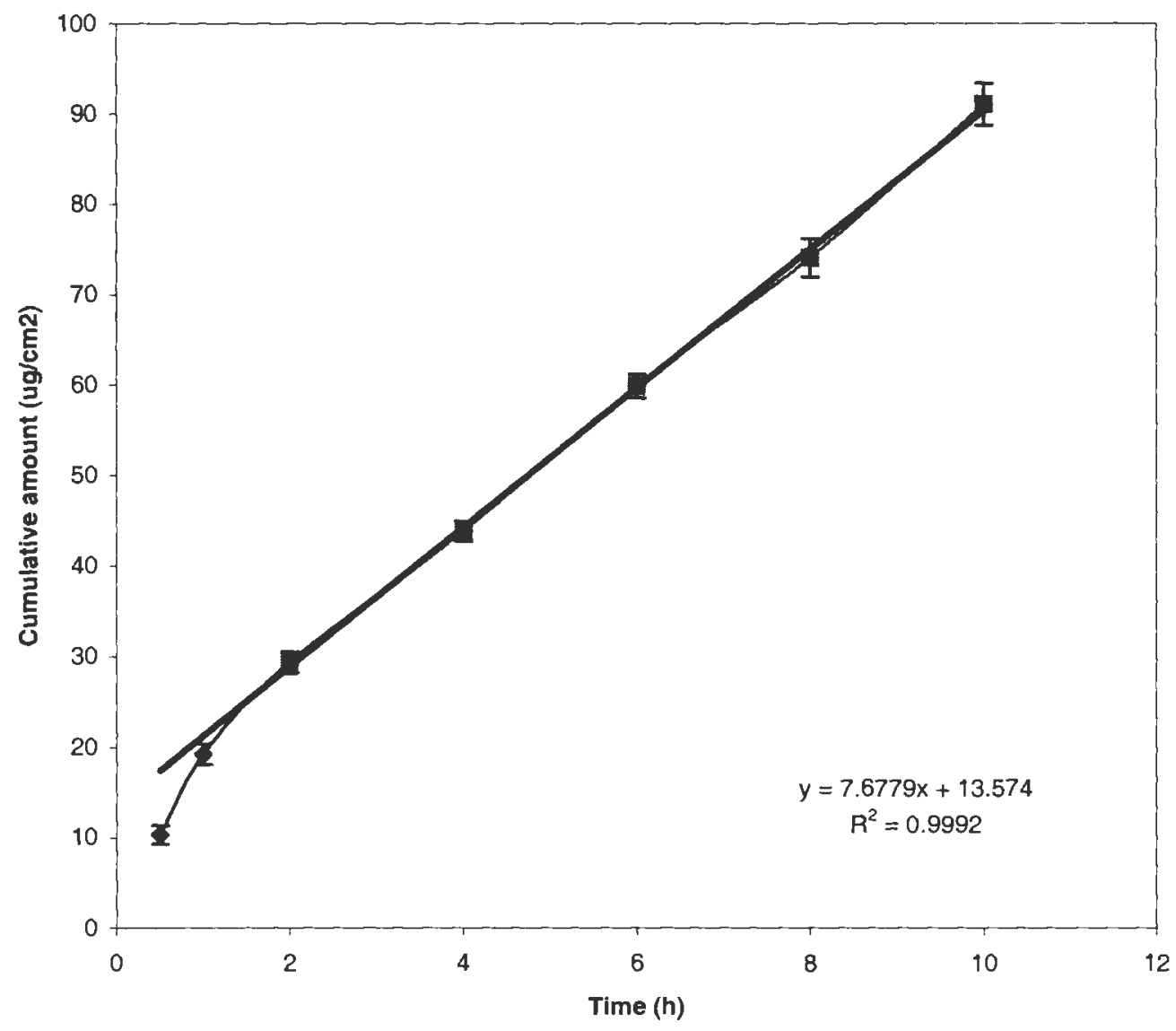

FIGURE 15. RELEASE PROFILE OF KT ACROSS SILICONE ELASTOMER FROM LECITHIN:IPM (40:60) CONTAINING 0.1\% WATER AND $1 \% \mathrm{KT}(\mathrm{MEAN} \pm \mathrm{SD}, \mathrm{N}=6)$ 


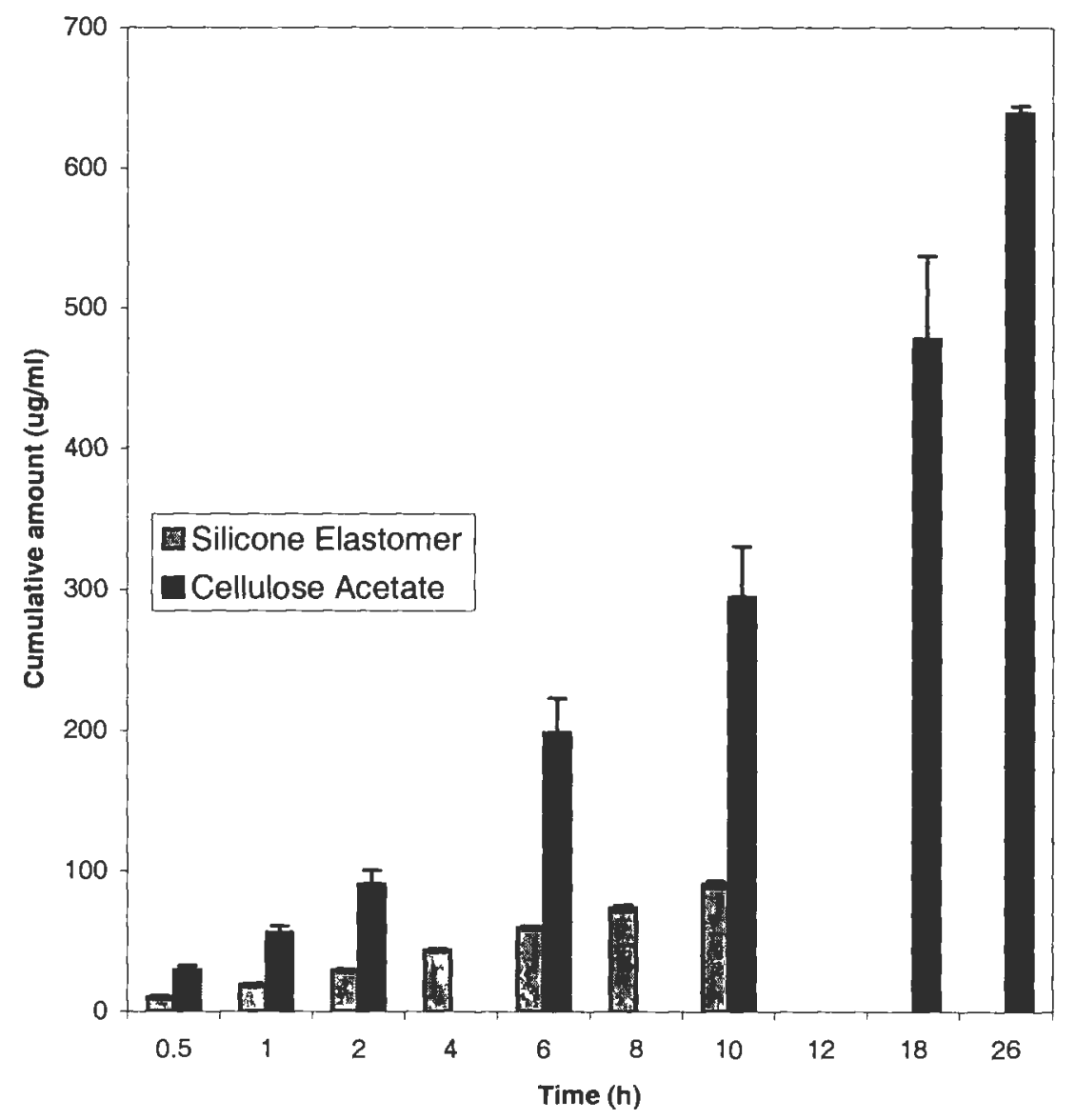

FIGURE 16. EFFECT OF MEMBRANE ON KT RELEASE FROM LECITHIN:IPM (40:60) CONTAINING 0.1\% WATER AND 1\% KT (MEAN $\pm S D, N=6$ ) 


\subsection{Formulation Effects}

It was found from this study that $\mathrm{KT}$ release from organogels was highly variable and extremely dependent upon following factors:

- KT concentration

- Lecithin concentration

- Water concentration

\subsubsection{Effect of KT Concentration on Its Release Rate across Cellulose Acetate Membrane from Organogels with Different Compositions}

The effect of the concentration on drug release rate from lecithin:IPM (40:60) containing $0.1 \%$ water and both $1 \%$ and $6.5 \% \mathrm{w} / \mathrm{w}$ of $\mathrm{KT}$ was evaluated. A significant $(p<0.05)$ increase in drug release was obtained in formulations containing $6.5 \% \mathrm{w} / \mathrm{w}$ of KT compared to those containing $1 \% \mathrm{w} / \mathrm{w}$ of the drug. The release rate of the formulation containing $6.5 \% \mathrm{KT}$ was $\sim 10$ times $\left(223.12 \mu \mathrm{g} / \mathrm{cm}^{2} / \mathrm{h}\right)$ higher than the one containing $1 \%$ of the drug $\left(22.746 \mu \mathrm{g} / \mathrm{cm}^{2} / \mathrm{h}\right)$. Plot of cumulative release of $\mathrm{KT}$ for both concentrations versus time is given in Figures 17, and 18. The effect of KT concentration on its release from lecithin:IPM (40:60) containing $0.1 \%$ water is shown in Figure 19 (The experiment was done up to 12 hours when the formulation containing $6.5 \% \mathrm{w} / \mathrm{w}$ of $\mathrm{KT}$ was used).

The data revealed that there is a positive correlation between drug concentration and release rate of the drug due to the increase in the thermodynamic activity. In this case, thermodynamic activity of the drug increases with concentration 


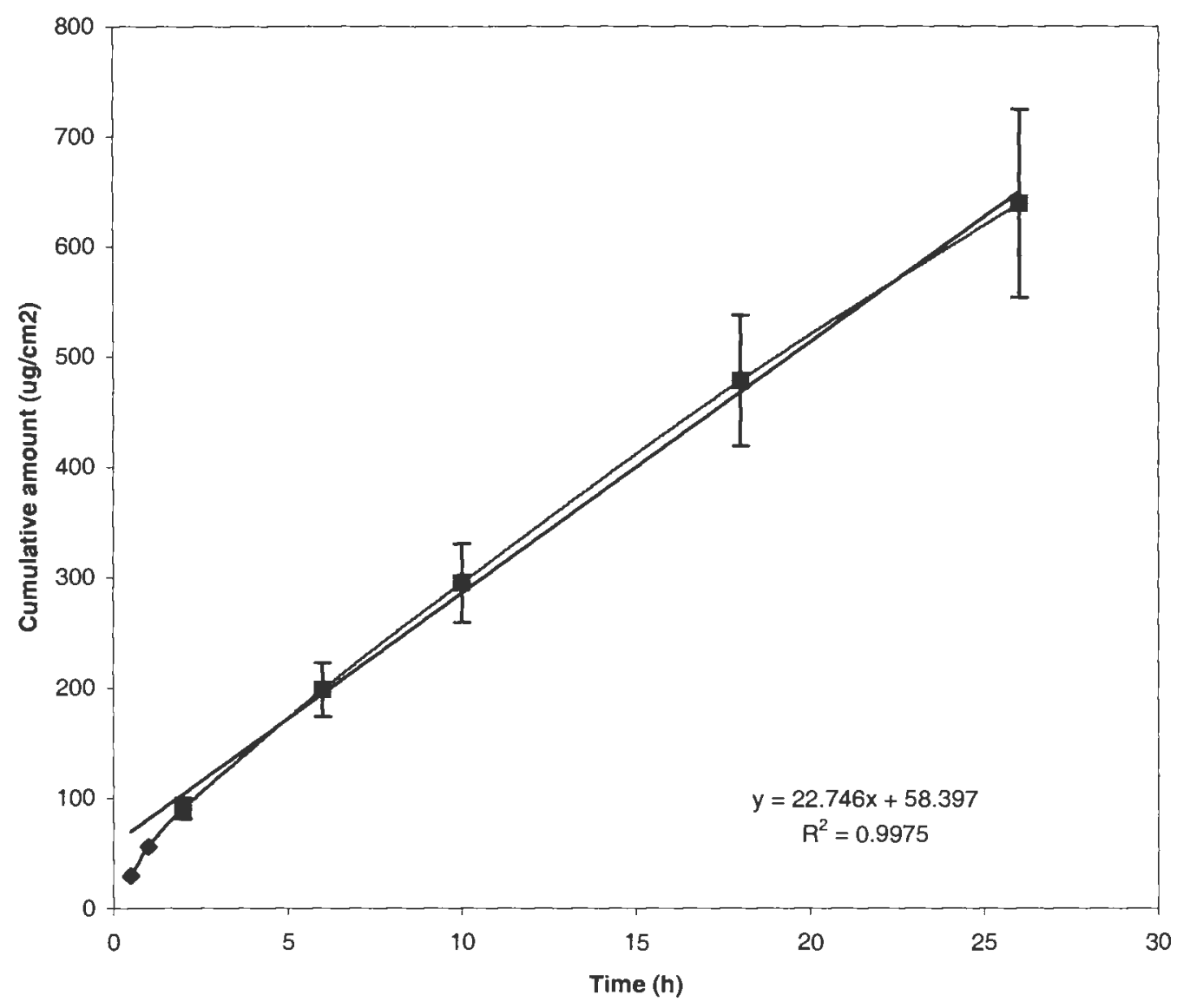

FIGURE 17. RELEASE PROFILE OF KT ACROSS CELLULOSE ACETATE MEMBRANE FROM LECITHIN:IPM (40:60) CONTAINING $0.1 \%$ WATER AND $1 \% \mathrm{KT}(\mathrm{MEAN} \pm \mathrm{SD}, \mathrm{N}=6)$ 


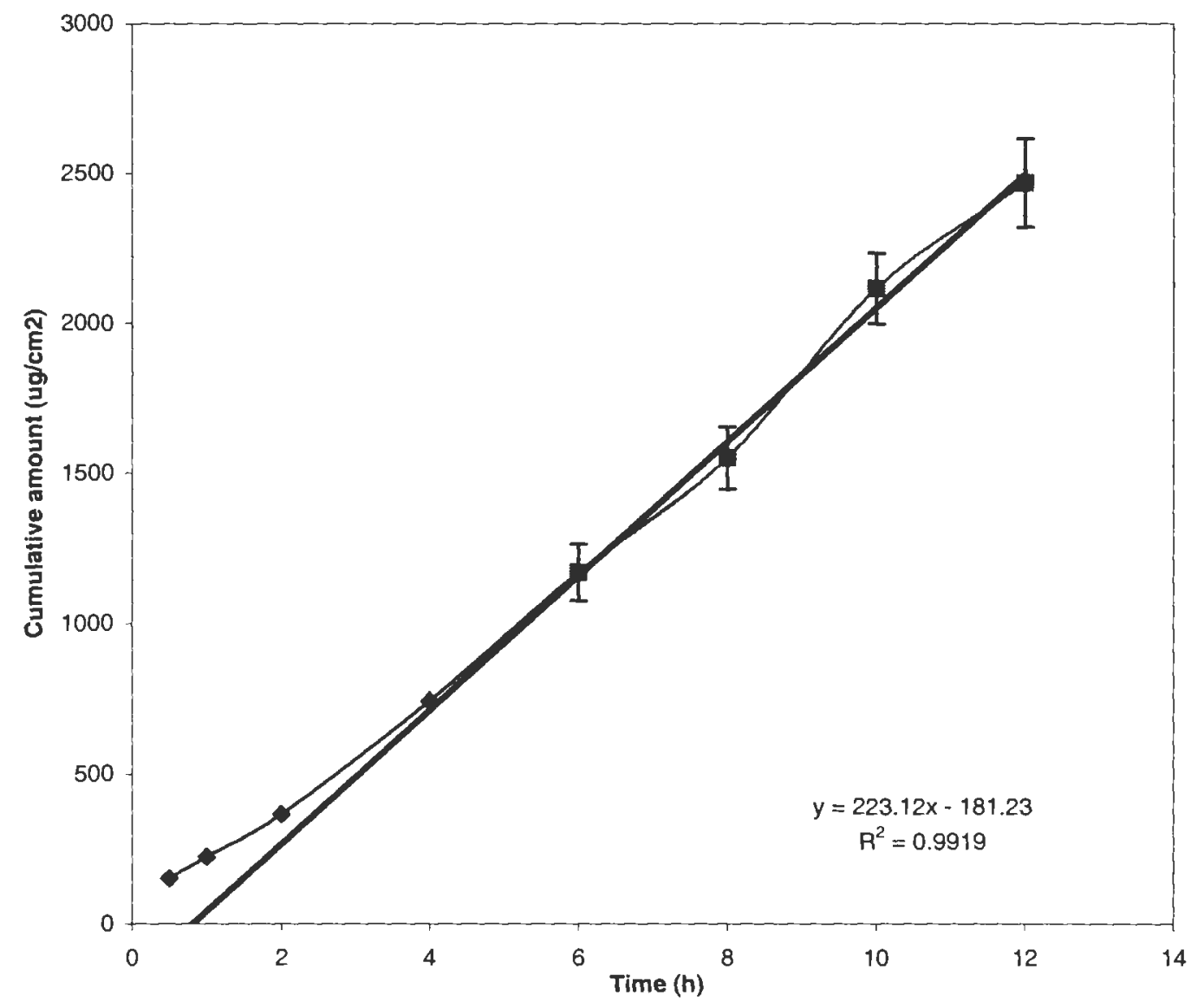

FIGURE 18. RELEASE PROFILE OF KT ACROSS CELLULOSE ACETATE MEMBRANE FROM LECITHIN:IPM (40:60)

CONTAINING 0.1\% WATER AND 6.5\% KT (MEAN \pm SD, $N=6$ ) 


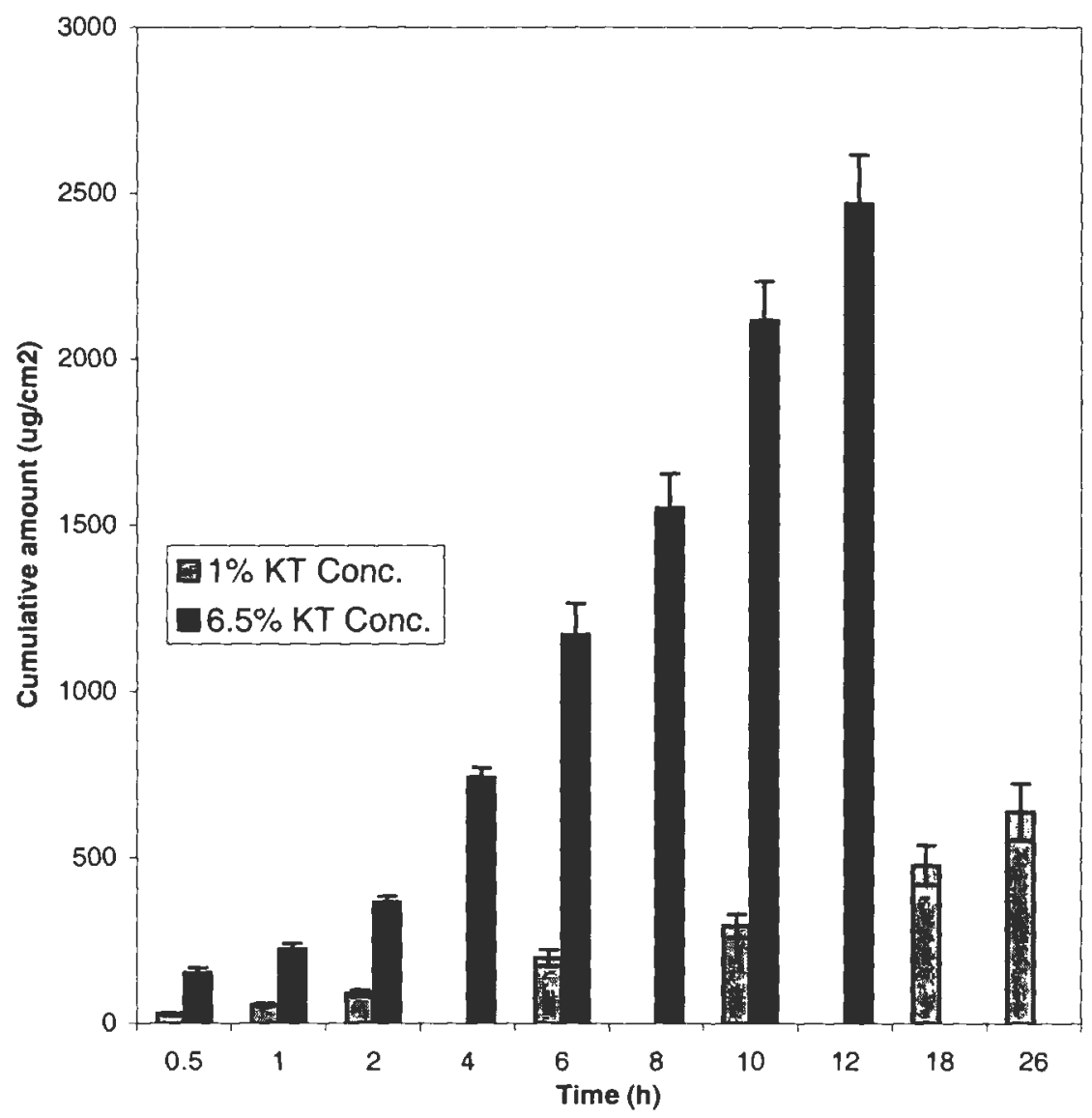

FIGURE 19. EFFECT OF KT CONCENTRATION ON ITS RELEASE ACROSS CELLULOSE ACETATE MEMBRANE FROM LECITHIN:IPM $(40: 60)$ CONTAINING 0.1\% WATER (MEAN $\pm S D, N=6$ ) 
until it reaches the limiting value which is the value of the saturated solution. This finding is in agreement with the results of Santoyo et al., 1996 who reported a direct relationship between piroxicam concentration and its release rate from propylene glycol gel. Henmi et al., 1994 also reported that the release rate of indomethacin from an oily gel formed by hydrogenated soybean phospholipids (HSL) was proportional to the drug concentration in the vehicle.

Similar results were obtained using guinea pig skin with the same formulation. There was a significant $(p<0.05)$ increase in KT release from organogels containing $6.5 \% \mathrm{w} / \mathrm{w}$ of $\mathrm{KT}$ compared to $1 \% \mathrm{w} / \mathrm{w}$ of the drug. The permeation profile of KT through guinea pig skin from lecithin:IPM (40:60) containing $0.1 \% \mathrm{w} / \mathrm{w}$ of water is shown in Figures 20, and 21. The plot of cumulative release of KT through both membranes, guinea pig skin and cellulose acetate, per unit area versus time is also given in Figure 22. 


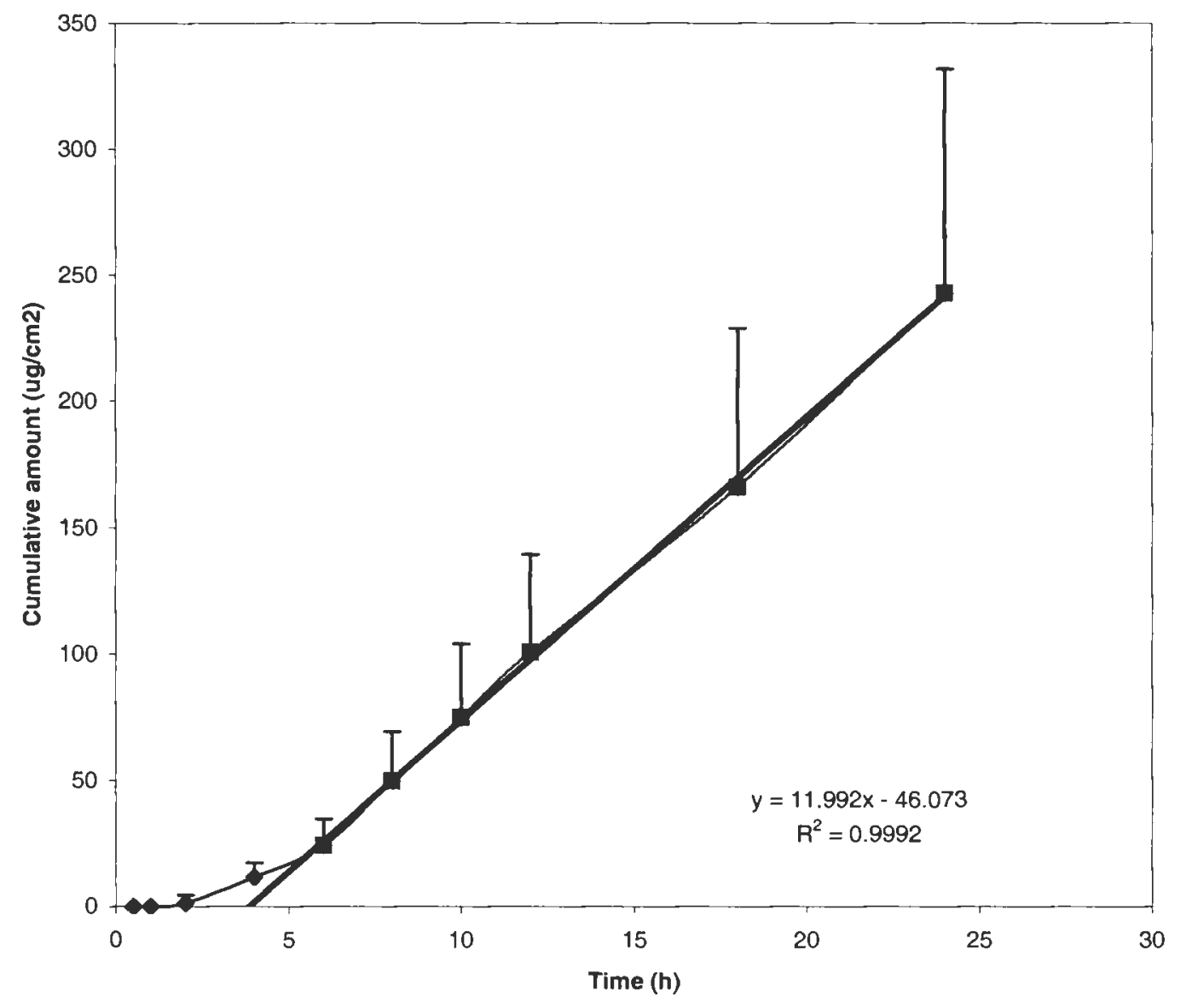

FIGURE 20. PERMEATION PROFILE OF KT THROUGH HAIRLESS GUINEA PIG SKIN FROM LECITHIN:IPM (40:60) CONTAINING $0.1 \%$ WATER AND $1 \% \mathrm{KT}(\mathrm{MEAN} \pm \mathrm{SD}, \mathrm{N}=6)$ 


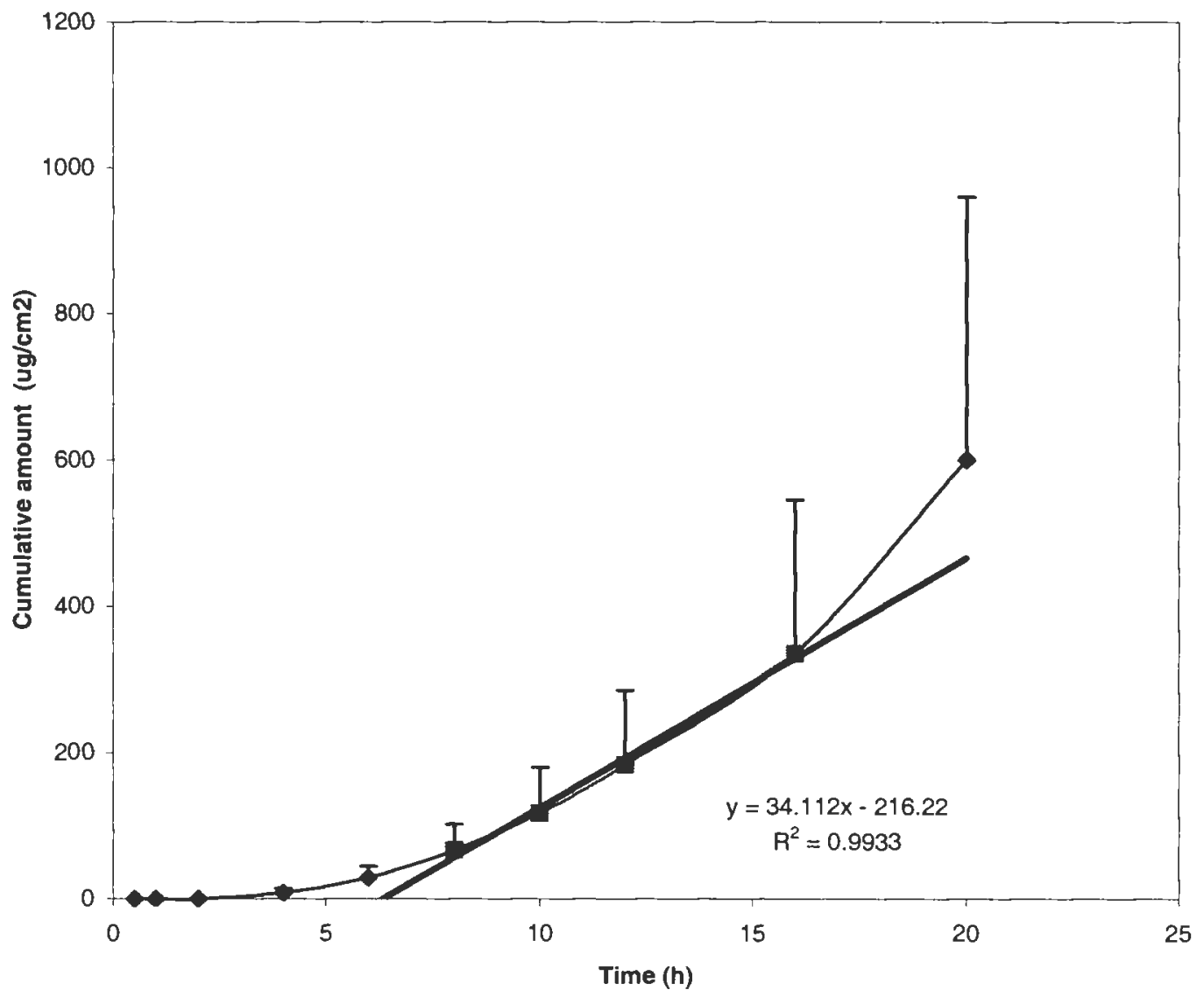

FIGURE 21. PERMEATION PROFILE OF KT THROUGH HAIRLESS GUINEA PIG SKIN FROM LECITHIN:IPM (40:60)

CONTAINING 0.1\% WATER AND 6.5\% KT (MEAN $\pm \mathrm{SD}, \mathrm{N}=6$ ) 


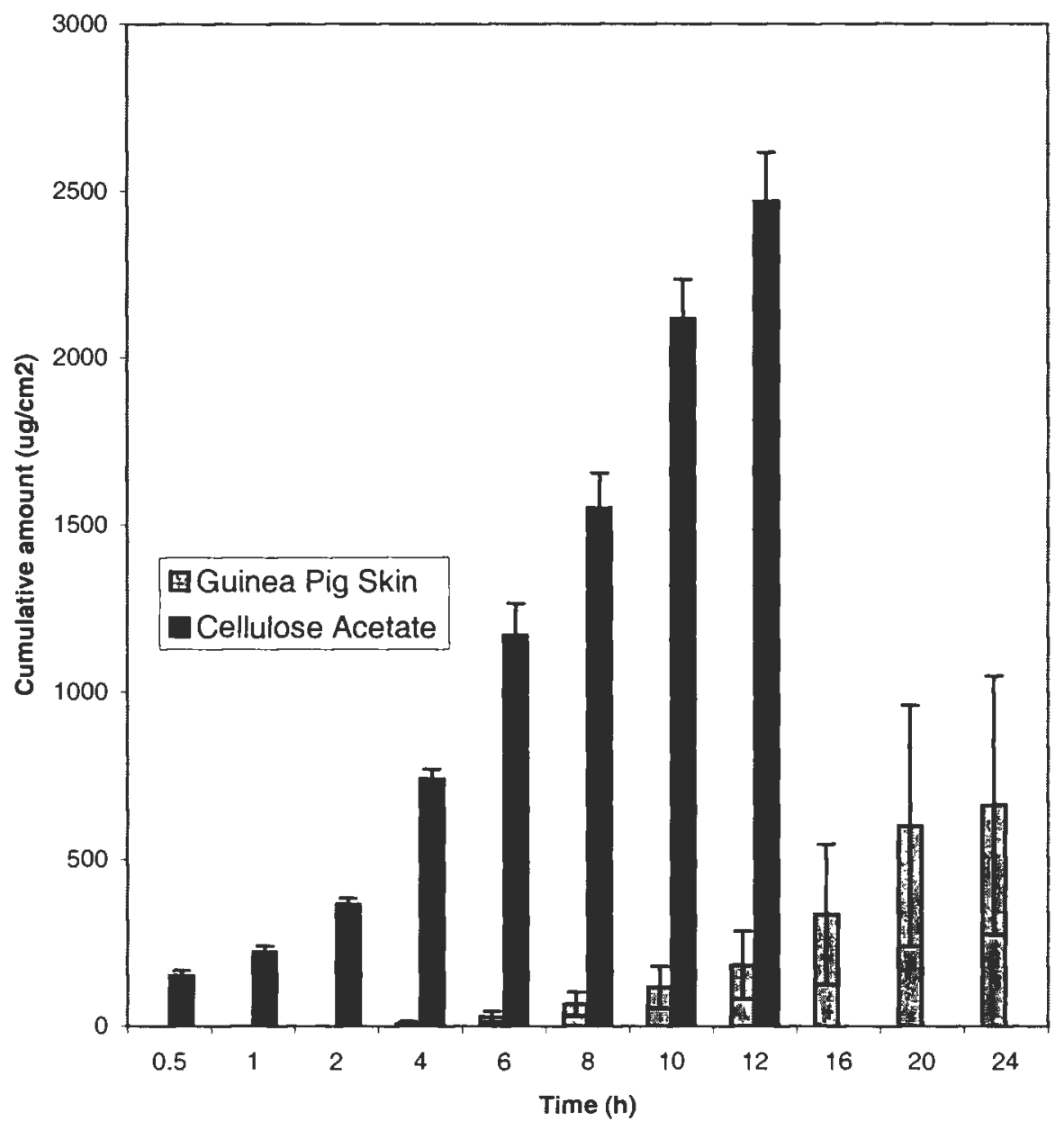

FIGURE 22. COMPARISON OF CELLULOSE ACETATE MEMBRANE WITH GUINEA PIG SKIN ON KT RELEASE FROM LECITHIN:IPM (40:60) CONTAINING 0.1\% WATER AND $6.5 \%$ $\mathrm{KT}(\mathrm{MEAN} \pm \mathrm{SD}, \mathrm{N}=6)$ 


\subsubsection{Effect of Lecithin Concentration on the Release Rate of KT across Cellulose Acetate Membrane from Organogels with Different Compositions}

The effect of lecithin concentration on the release rate of ketorolac from lecithin:IPM (40:60), (50:50) and (60:40) containing $0.25 \% \mathrm{w} / \mathrm{w}$ of water and $6.5 \%$ w/w of KT was evaluated. A significant $(p<0.05)$ decrease in KT release was obtained as the lecithin concentration was increased from 40 to 50 and then $60 \% \mathrm{w} / \mathrm{w}$ in formulations. The release rates of KT were $\left(229.27 \mu \mathrm{g} / \mathrm{cm}^{2} / \mathrm{h}\right),\left(104.15 \mu \mathrm{g} / \mathrm{cm}^{2} / \mathrm{h}\right)$ and $\left(84.987 \mu \mathrm{g} / \mathrm{cm}^{2} / \mathrm{h}\right)$ for formulations composed of 40,50 and $60 \% \mathrm{w} / \mathrm{w}$ of lecithin respectively. The release profile of KT from organogels with different lecithin concentration is shown in Figures 23, 24, and 25.

This result may be due to a decreased thermodynamic activity of the drug in the organogel at the higher concentration of lecithin. At higher lecithin concentrations there is a more extensive entanglement of the long cylindrical micelles with each other, forming a network-like structure with a very high viscosity. The entrapment of the drug within this network lowers the amount of free drug available for release, causing a decrease in the release rate of KT across the membrane (Shchipunov et al., 1998). The effect of lecithin concentration on the release of KT from lecithin:IPM $(40: 60),(50: 50)$ and $(60: 40)$ containing $0.25 \% \mathrm{w} / \mathrm{w}$ of water and $6.5 \% \mathrm{w} / \mathrm{w}$ of KT is given in Figure 26. 


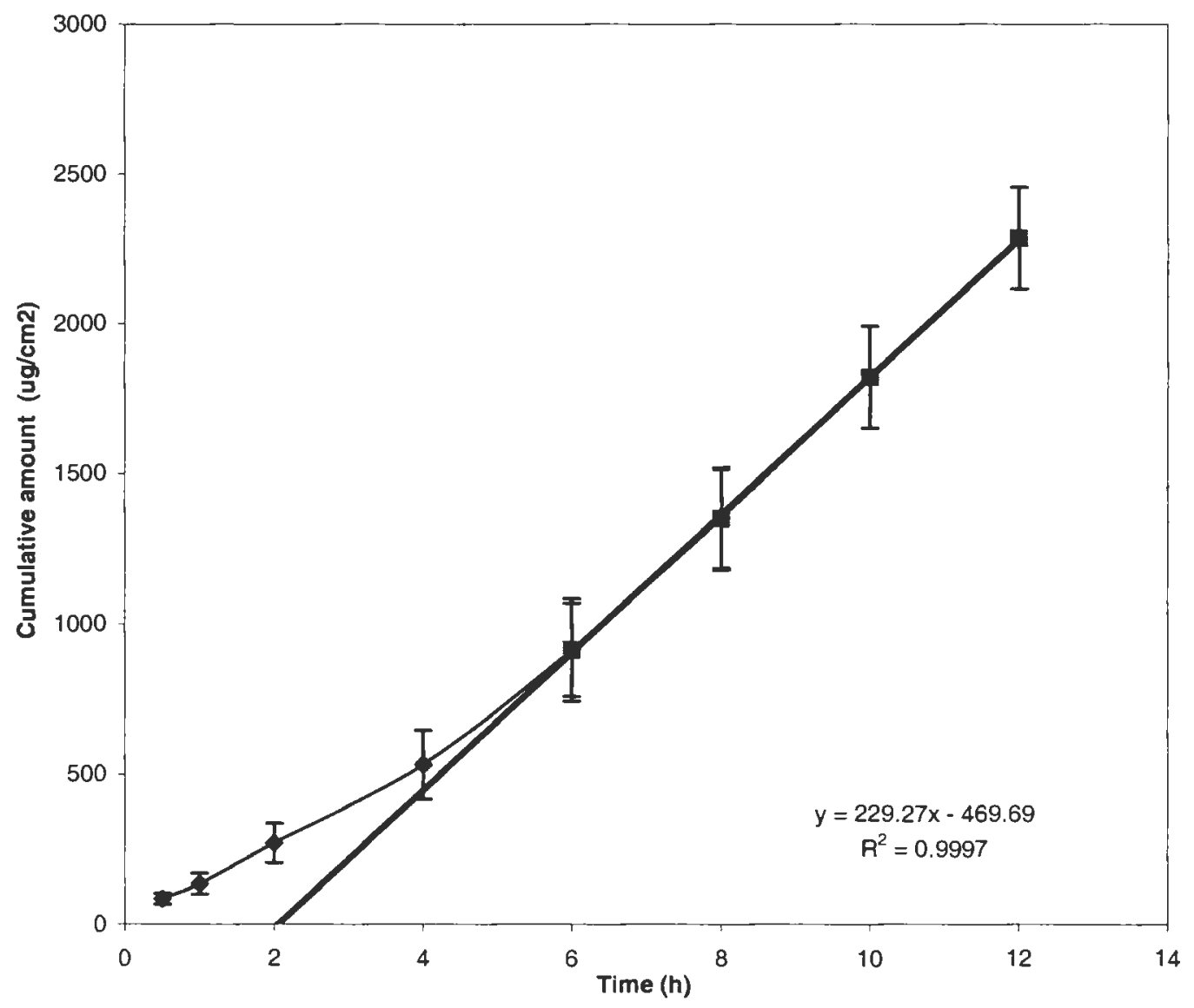

FIGURE 23. RELEASE PROFILE OF KT ACROSS CELLULOSE ACETATE MEMBRANE FROM LECITHIN:IPM (40:60)

CONTAINING $0.25 \%$ WATER AND $6.5 \% \mathrm{KT}(\mathrm{MEAN} \pm \mathrm{SD}, \mathrm{N}=6)$ 


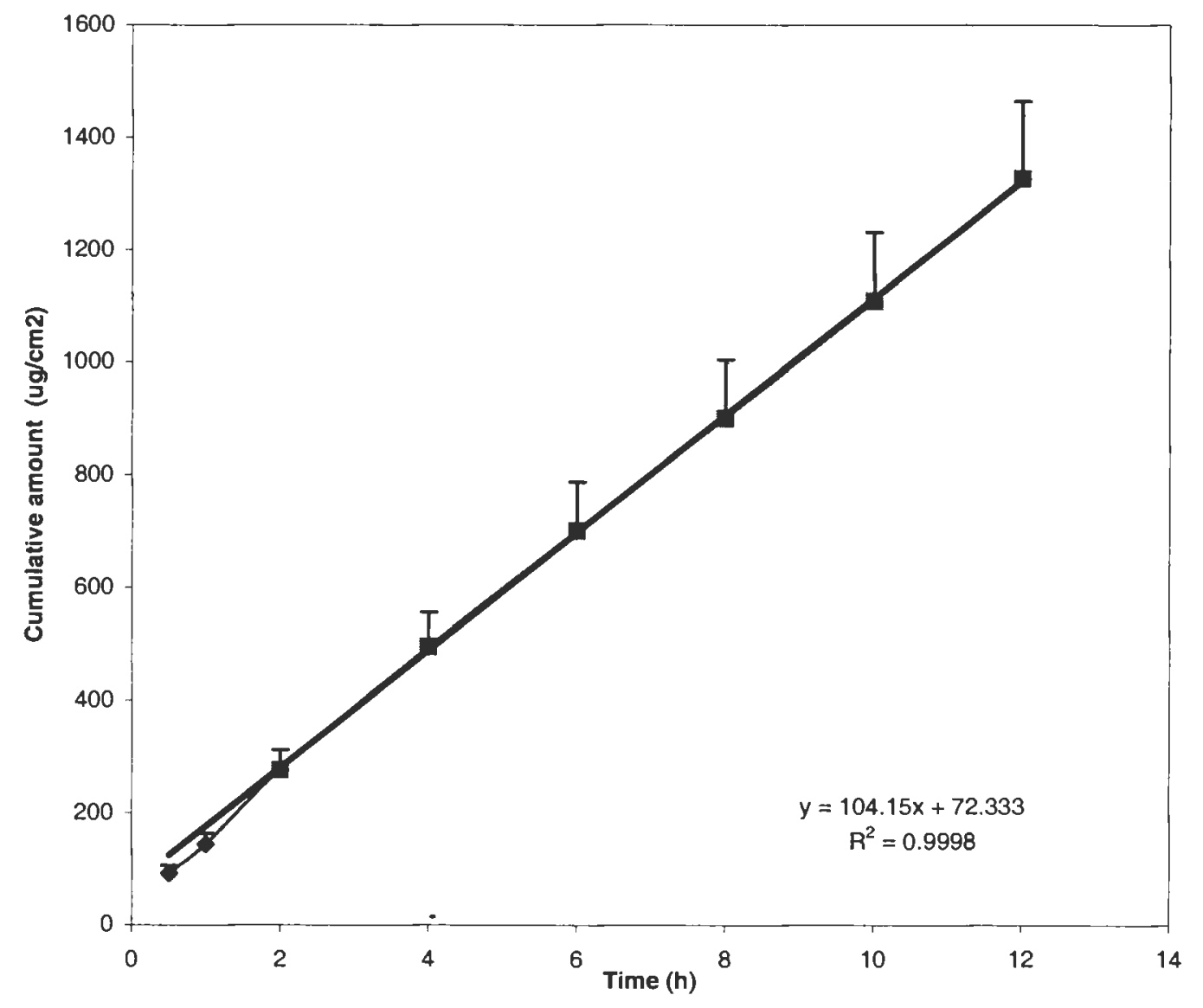

FIGURE 24. RELEASE PROFILE OF KT ACROSS CELLULOSE ACETATE MEMBRANE FROM LECITHIN:IPM (50:50) CONTAINING $0.25 \%$ WATER AND $6.5 \% \mathrm{KT}(\mathrm{MEAN} \pm \mathrm{SD}, \mathrm{N}=6)$ 


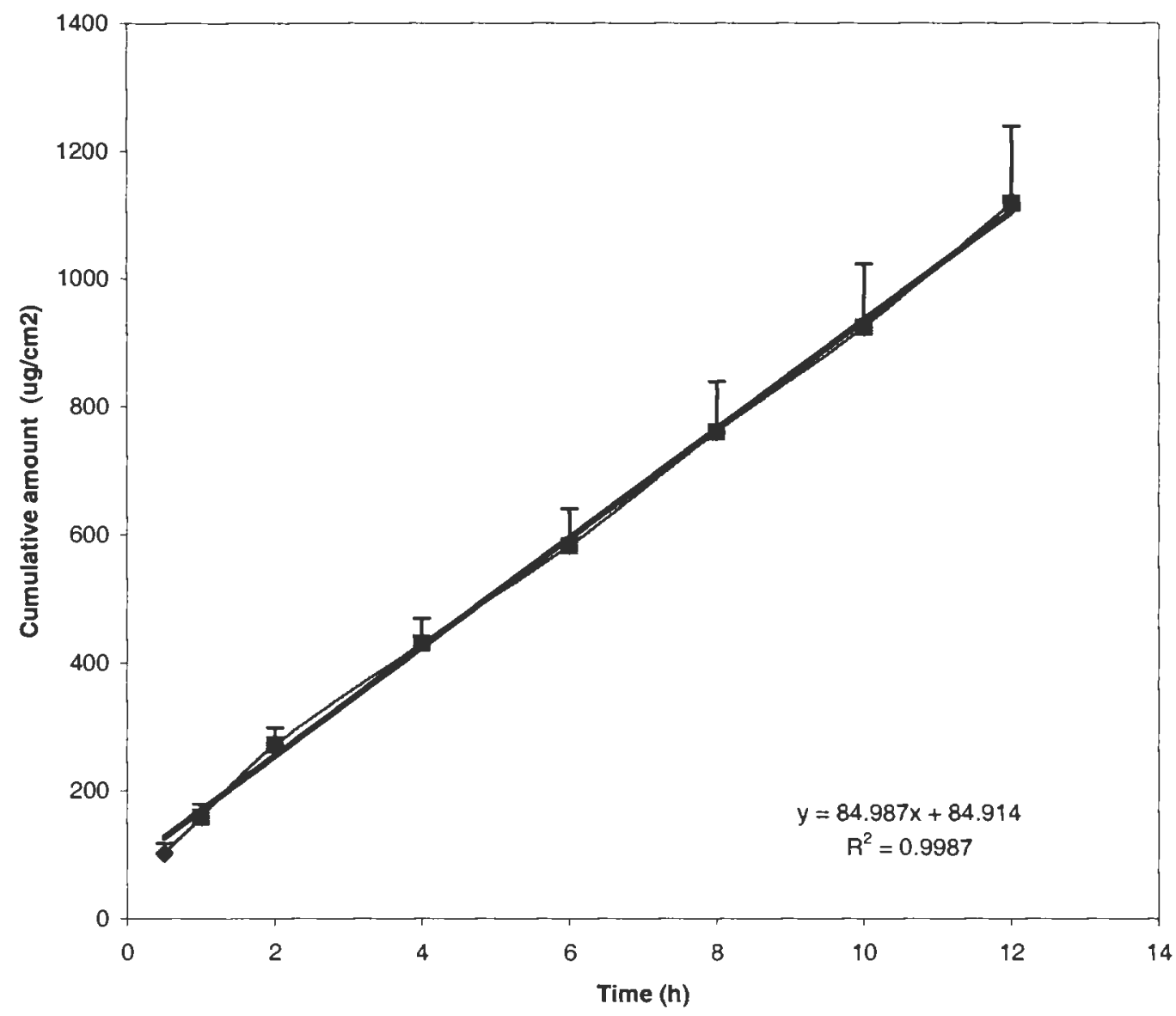

FIGURE 25. RELEASE PROFILE OF KT ACROSS CELLULOSE ACETATE MEMBRANE FROM LECITHIN:IPM (60:40) CONTAINING $0.25 \%$ WATER AND $6.5 \% \mathrm{KT}(\mathrm{MEAN} \pm \mathrm{SD}, \mathrm{N}=6)$ 


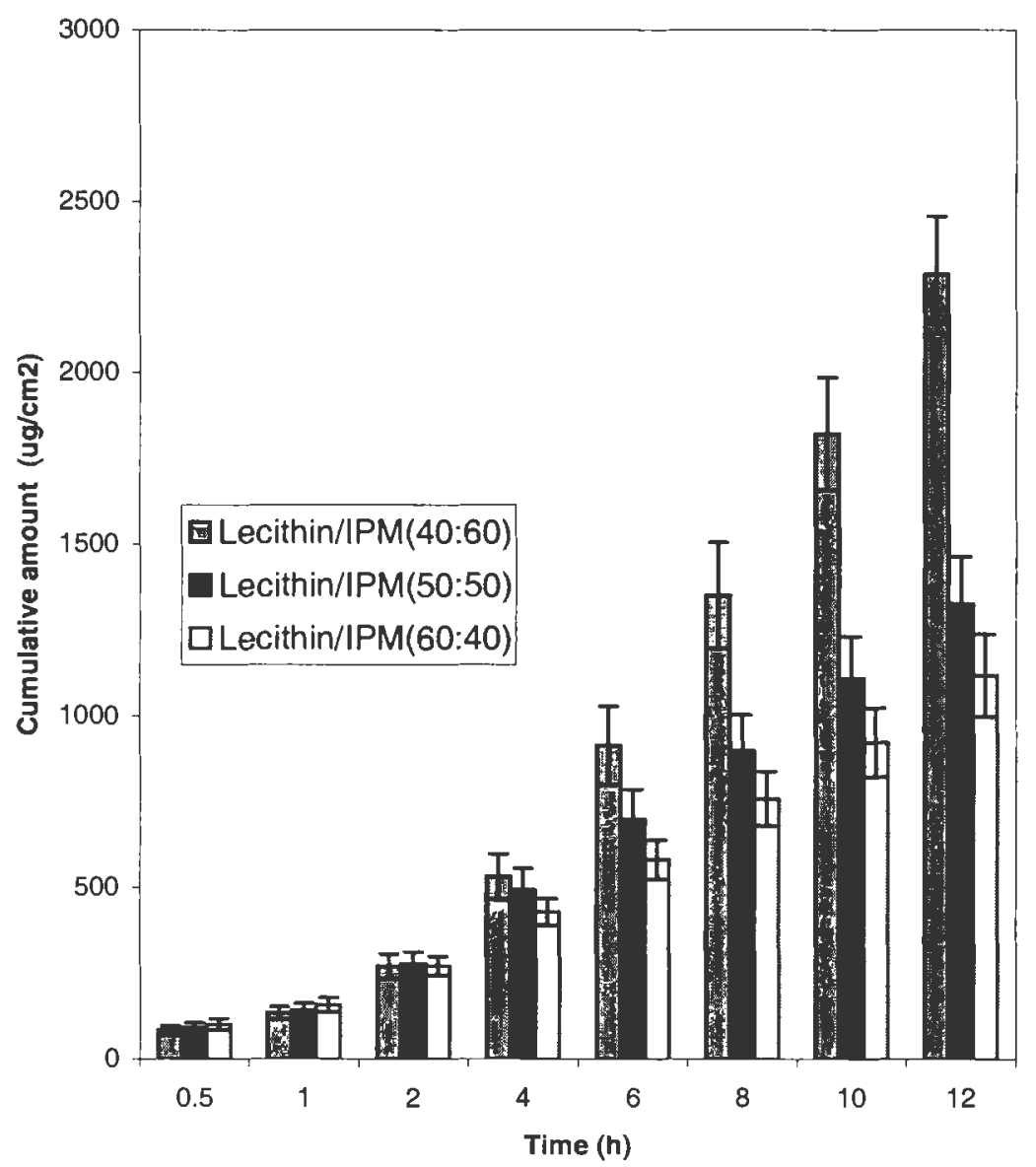

FIGURE 26. EFFECT OF LECITHIN CONCENTRATION ON KT RELEASE ACROSS CELLULOSE ACETATE MEMBRANE FROM LECITHIN:IPM (40:60),(50:50) AND (60:40) CONTAINING $0.25 \%$ WATER AND $6.5 \% \mathrm{KT}($ MEAN $\pm \mathrm{SD}, \mathrm{N}=6)$ 


\subsubsection{Effect of Water Concentration on Release Rate of KT across Cellulose Acetate Membrane from Organogels with Different Compositions}

The effect of the organogel water concentration on the release rate of KT from different formulations containing $6.5 \% \mathrm{w} / \mathrm{w}$ of KT was also determined. While each of the organogels evaluated had the same ratio of lecithin/ IPM, differences in water concentration caused the release rate of KT to vary.

A significant $(p<0.05)$ decrease in release rate of KT from lecithin:IPM (40:60) containing $0.5 \% \mathrm{w} / \mathrm{w}$ of water compared to those containing higher amounts of water was obtained. A significant $(p<0.05)$ decrease in release rate of KT from lecithin:IPM (50:50) and (60:40) containing $0.25 \% \mathrm{w} / \mathrm{w}$ of water compared to those containing higher amounts of water was also observed. The release rates of KT were (180.39 $\left.\mu \mathrm{g} / \mathrm{cm}^{2} / \mathrm{h}\right),\left(104.15 \mu \mathrm{g} / \mathrm{cm}^{2} / \mathrm{h}\right)$ and $\left(84.987 \mu \mathrm{g} / \mathrm{cm}^{2} / \mathrm{h}\right)$ for lecithin:IPM (40:60), (50:50) and (60:40) respectively. The release profile of KT from above formulations is given in Figures 27, 28, and 29 respectively.

The data revealed that increasing the water content of the organogel (lecithin:IPM 40:60) from $0.1 \%$ to $0.25 \%$ and then $0.5 \% \mathrm{w} / \mathrm{w}$ resulted in a decrease in $\mathrm{KT}$ release. Once increasing the water amount of the system, the initially spherical reverse micelles transform into cylindrical micelles and then into long tubular and flexible micelles with the ability to entangle and build up a three-dimensional network with a high viscosity. This network is responsible for the entrapment and unavailability of the drug molecules for their release from the organogel system, causing a significant decrease in release rate of KT from lecithin:IPM (40:60) containing $0.5 \% \mathrm{w} / \mathrm{w}$ of water. The increase of water amount from $0.5 \%$ to $0.6 \% \mathrm{w} / \mathrm{w}$ 


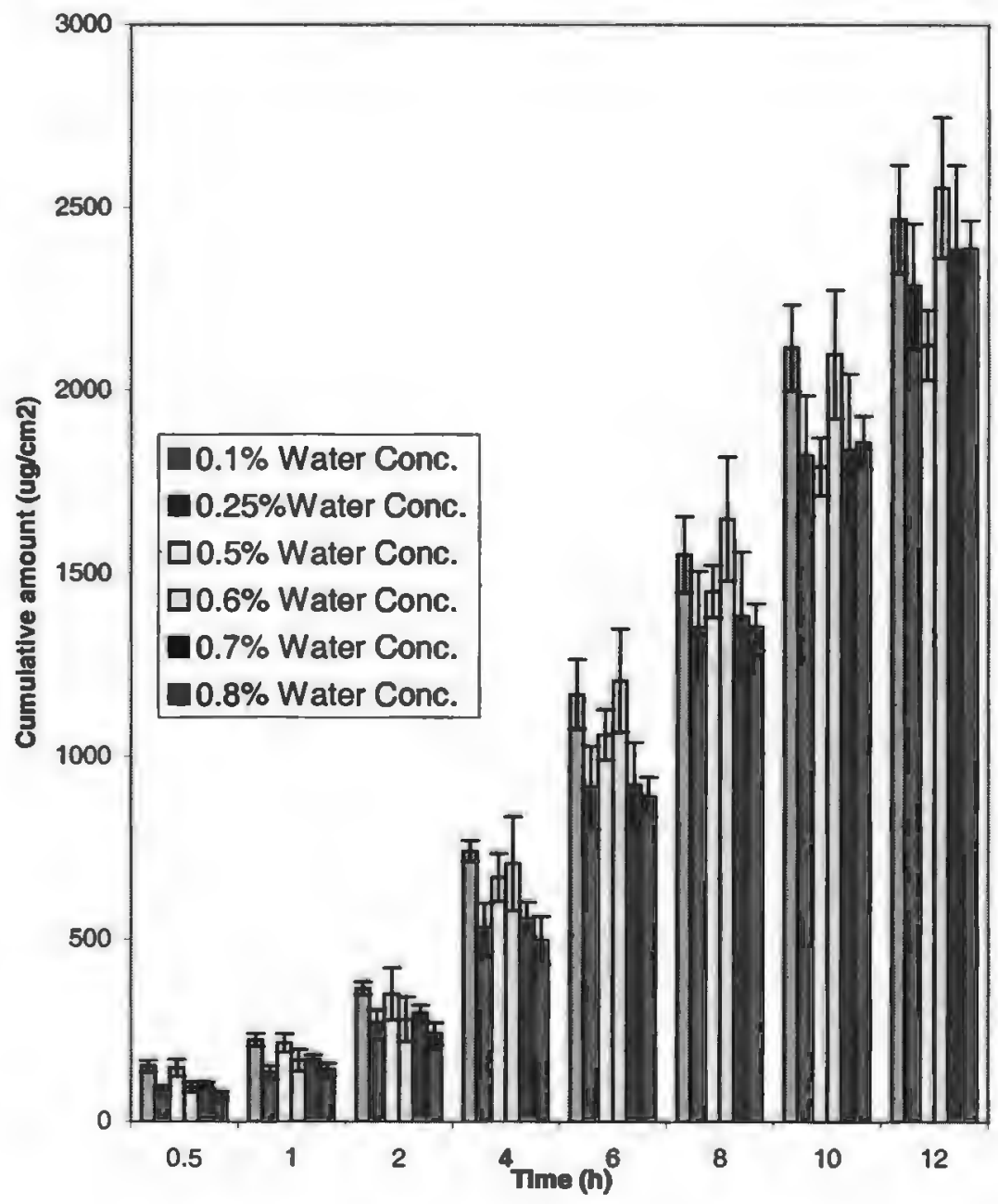

FIGURE 27. RELEASE PROFILE OF KT ACROSS CELLULOSE ACETATE MEMBRANE FROM LECITHIN:IPM (40:60) CONTAINING DIFFERENT WATER AMOUNTS AND 6.5\% KT $(M E A N \pm S D, N=6)$ 


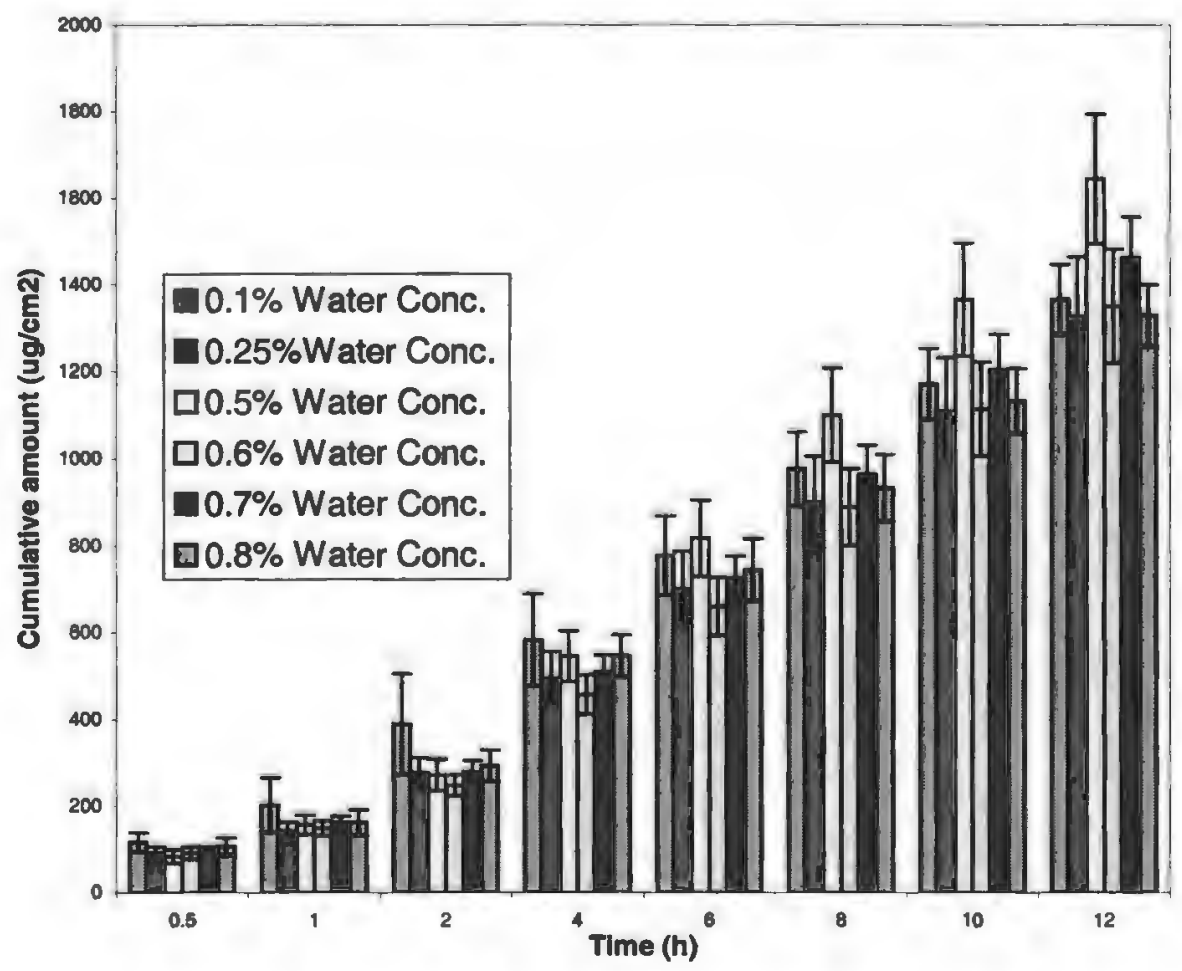

FIGURE 28. RELEASE PROFILE OF KT ACROSS CELLULOSE ACETATE MEMBRANE FROM LECITHIN:IPM (50:50) CONTAINING DIFFERENT WATER AMOUNTS AND $6.5 \% \mathrm{KT}$ $(M E A N \pm S D, N=6)$ 


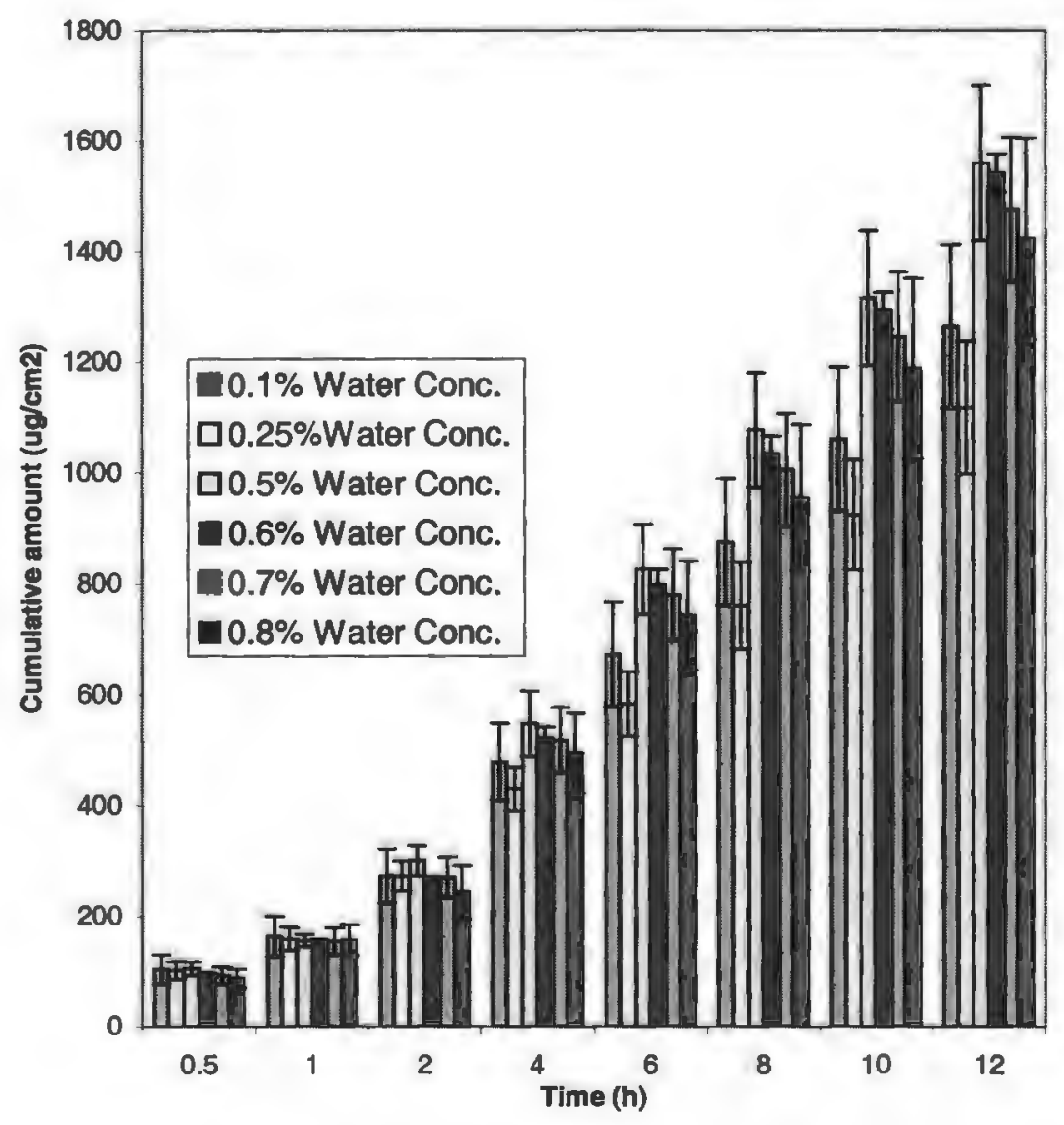

FIGURE 29. RELEASE PROFILE OF KT ACROSS CELLULOSE ACETATE MEMBRANE FROM LECITHIN:IPM (60:40) CONTAINING DIFFERENT WATER AMOUNTS AND $6.5 \% \mathrm{KT}$ $(M E A N \pm S D, N=6)$ 
made the additional water and therefore, KT available within the system for partitioning into the membrane. A decrease in release rate of the drug at higher concentration of water $(0.7 \%$ and $0.8 \% \mathrm{w} / \mathrm{w})$ was observed, which suggests that at this concentration of water the three-dimensional network shrinks and organogel region ends. The same result was found for lecithin:IPM (50:50) and (60:40) except for the lowest release rate of $\mathrm{KT}$, which happened at $0.25 \% \mathrm{w} / \mathrm{w}$ of water concentration. This finding is confirmed by Osborne et al., 1991 who reported a high dependency of the release of glucose as a model hydrophilic drug across human skin from microemulsions containing different concentrations of water. The effect of water concentration on the release of KT from lecithin:IPM (40:60), (50:50) and (60:40) containing $6.5 \%$ w/w of KT is shown in Figures 30, 31, and 32 . 


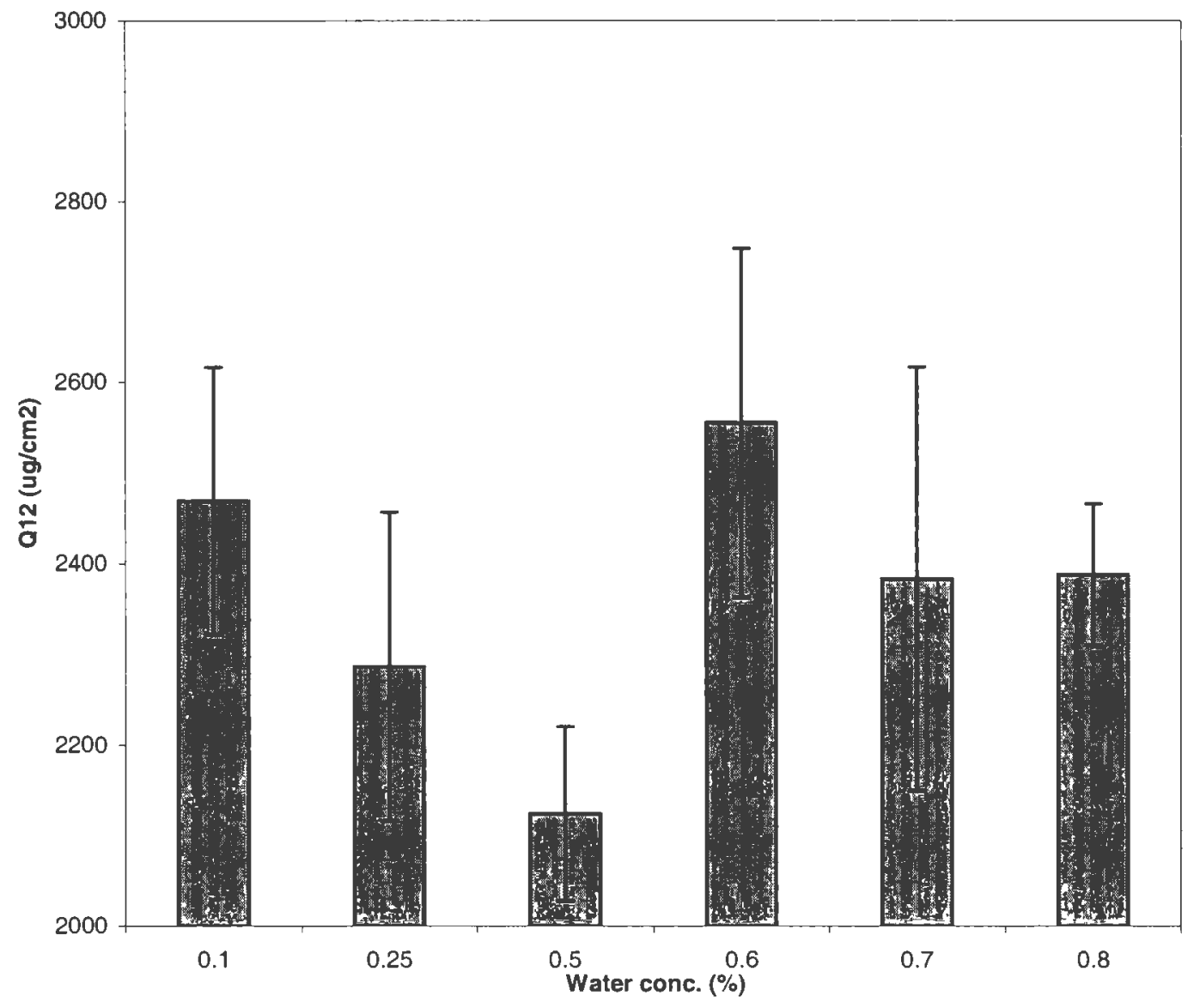

FIGURE 30. EFFECT OF WATER CONCENTRATION ON KT RELEASE ACROSS CELLULOSE ACETATE MEMBRANE FROM LECITHIN:IPM (40:60) CONTAINING 6.5\% KT (MEAN \pm $S D, N=6)$ 


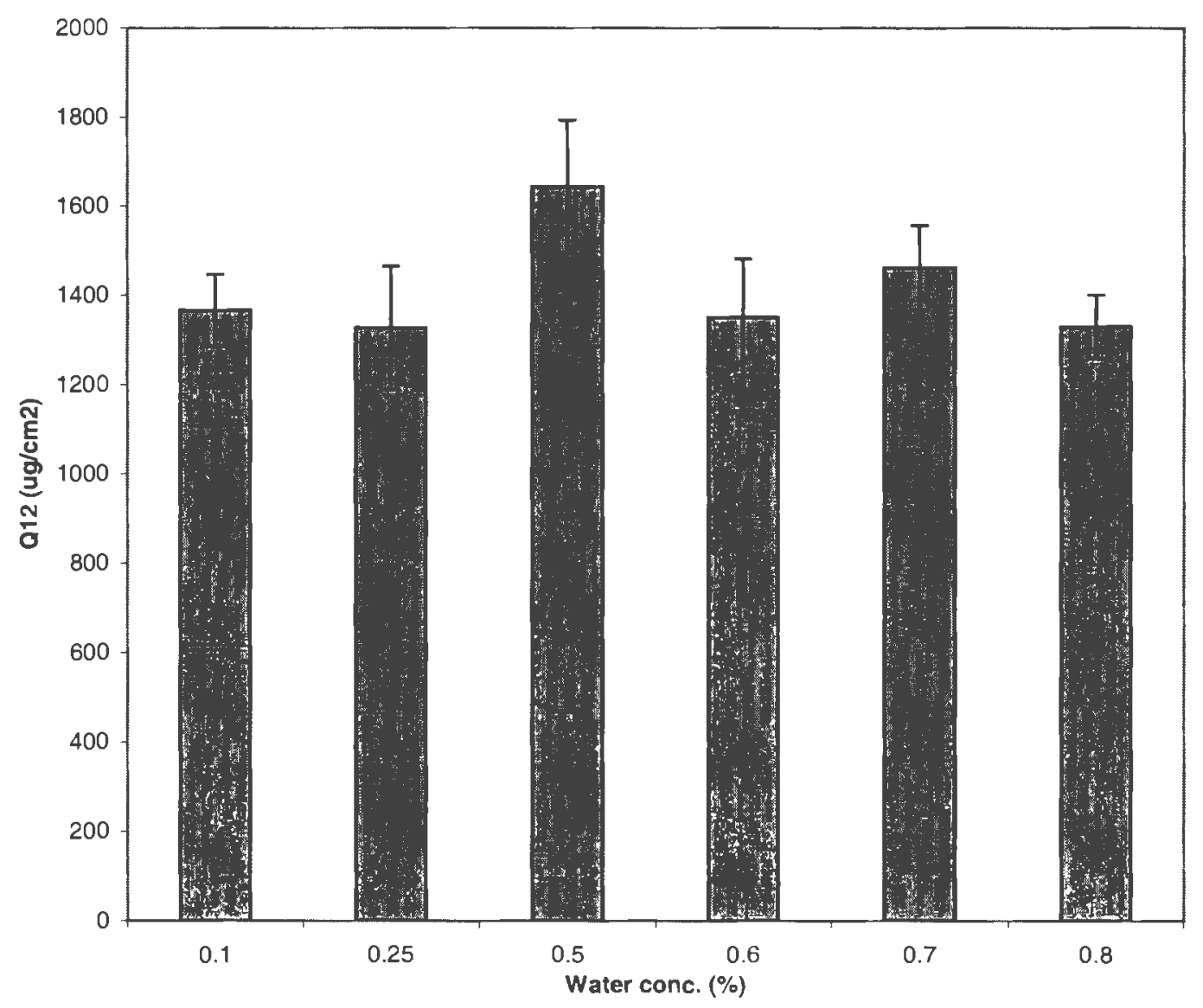

FIGURE 31. EFFECT OF WATER CONCENTRATION ON KT RELEASE ACROSS CELLULOSE ACETATE MEMBRANE FROM LECITHIN:IPM (50:50) CONTAINING 6.5\% KT (MEAN \pm $\mathrm{SD}, \mathrm{N}=6$ ) 


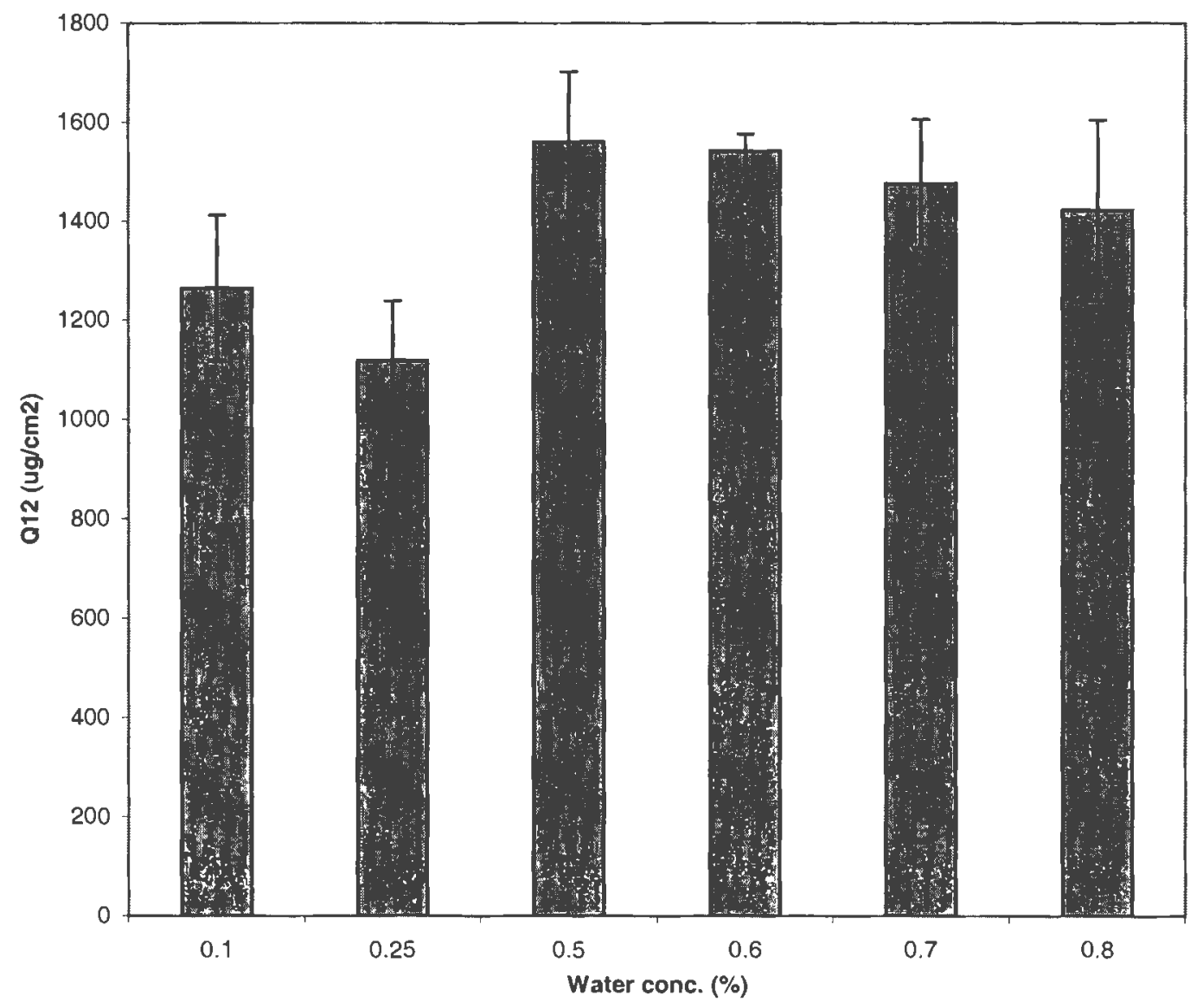

FIGURE 32. EFFECT OF WATER CONCENTRATION ON KT RELEASE ACROSS CELLULOSE ACETATE MEMBRANE FROM LECITHIN:IPM (60:40) CONTAINING 6.5\% KT (MEAN \pm $S D, N=6$ ) 


\subsection{Rheological Measurements}

Increase in lecithin concentration produced a significant increase $(p<0.05)$ in the viscosity of the organogel. The average viscosity of the organogels were $(418.80 \pm$ $114.15),(951.76 \pm 25.70)$ and $(1832.70 \pm 358.93)$ poise for lecithin:IPM (40:60), (50:50) and (60:40) containing $0.25 \% \mathrm{w} / \mathrm{w}$ of water and $6.5 \% \mathrm{w} / \mathrm{w}$ of KT respectively. Figure 33 shows the values of the viscosity for above formulations using cylindrical viscometer. The effect of lecithin concentration on the viscosity of the organogels containing $0.25 \% \mathrm{w} / \mathrm{w}$ of water and $6.5 \% \mathrm{w} / \mathrm{w}$ of KT using both cylindrical and cone \& plate viscometer is also given in Figures 34, and 35.

Organogels viscosity measurements were determined by applying increasing and decreasing values of the shear rate, in order to reveal any possible thixotropy of the system. All formulations surprisingly gave a slight rheopexy behavior rheogram. This is essentially the opposite of thixotropic behavior, in that the viscosity of the gel increased with an increase in the shear rate. A plot of shear rate versus shear stress was made (Figure 36) as the shear rate was increased to a certain value, then immediately decreased to the starting point. As shown in Figure 36 the up and down curves do not coincide and a hysteresis loop is caused by the increase in the viscosity of the organogel with increasing time of shearing. 


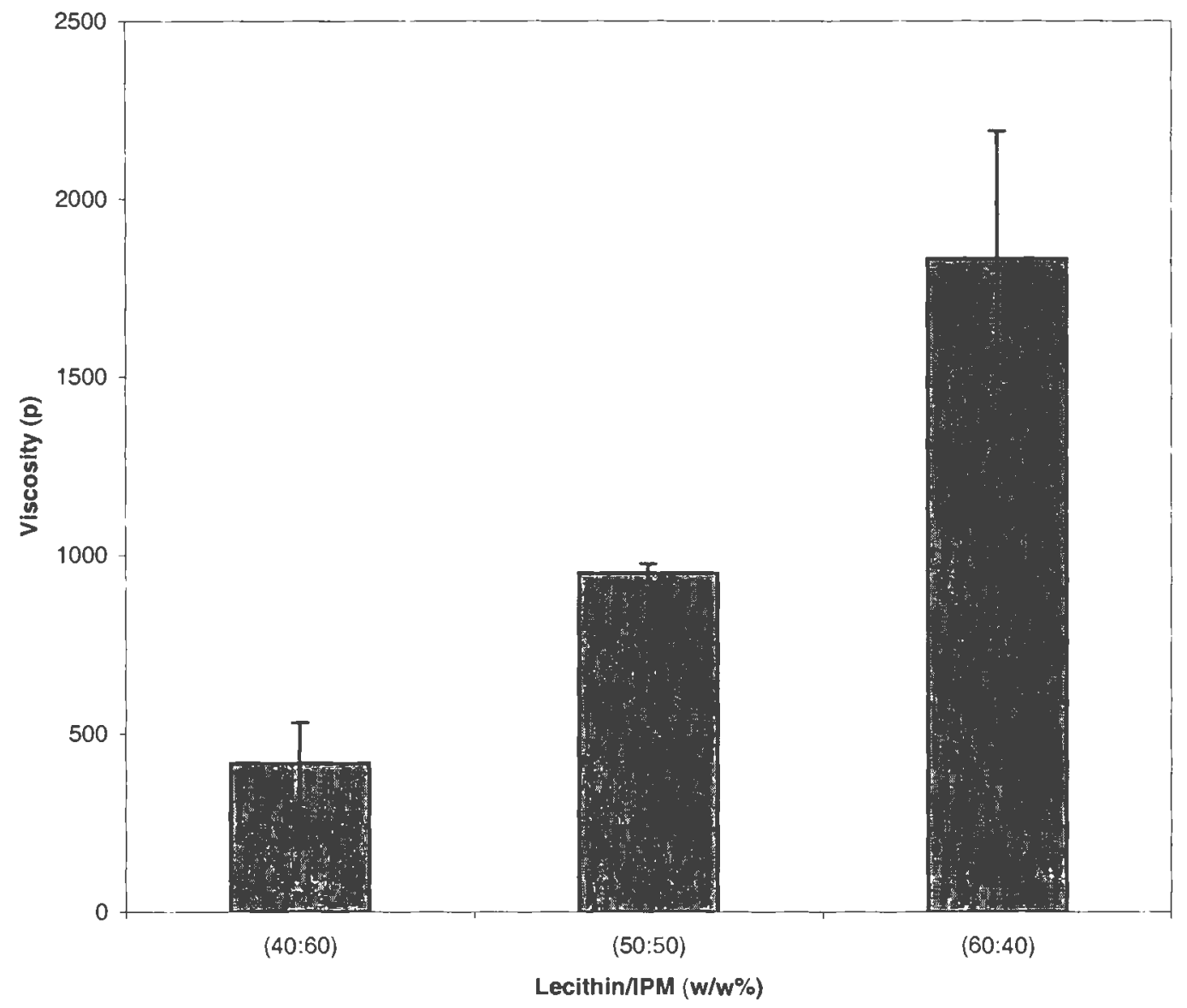

FIGURE 33. EFFECT OF LECITHIN CONCECNTRATION ON VISCOSITY OF LECITHIN:IPM (40:60), (50:50) AND (60:40) CONTAINING $0.25 \%$ WATER AND $6.5 \% \mathrm{KT}$ BY CYLINDRICAL VISCOMETER (MEAN $\pm S D, N=2)$ 


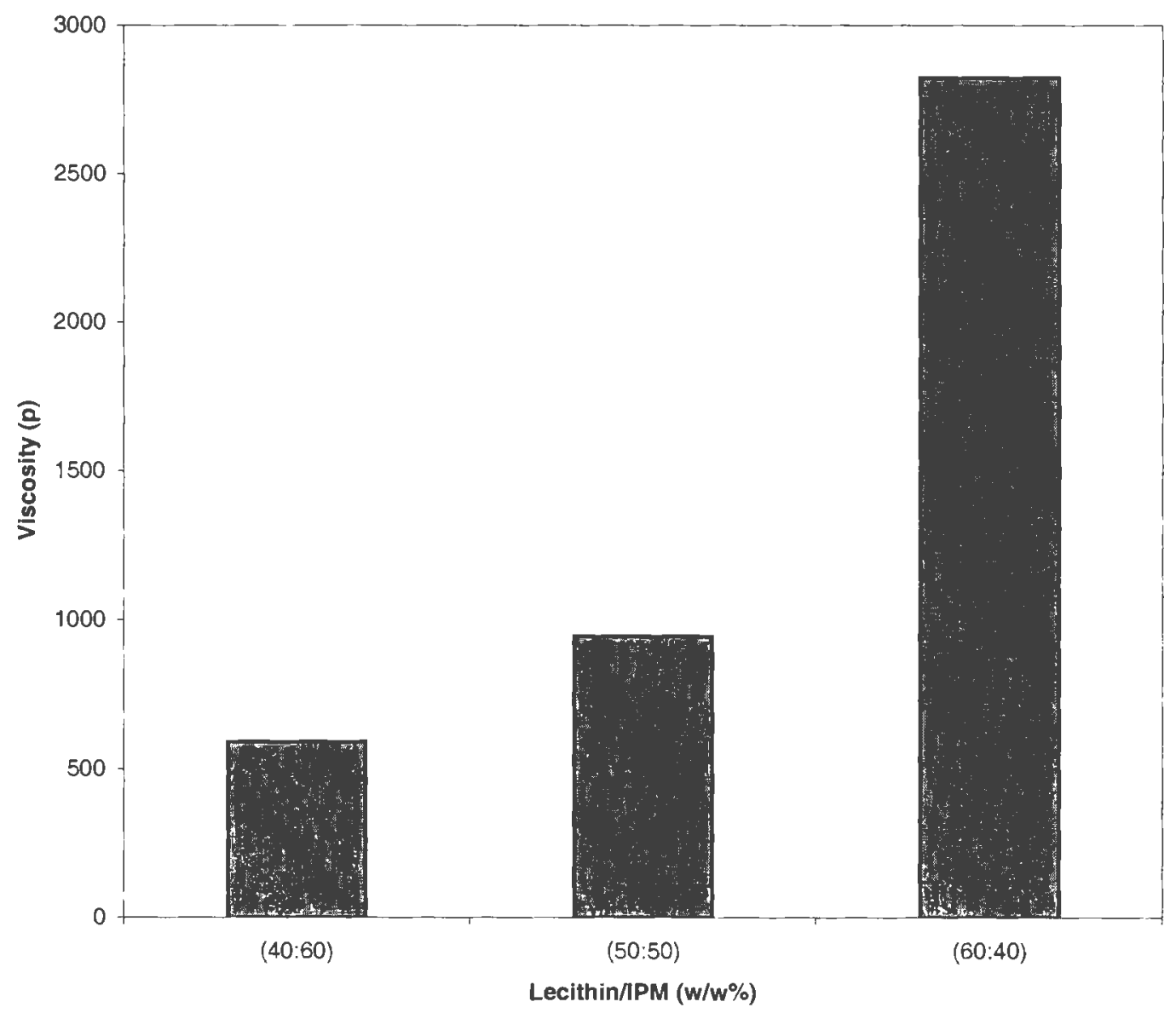

FIGURE 34. EFFECT OF LECITHIN CONCENTRATION ON THE VISCOSITY OF LECITHIN:IPM (40:60), (50:50) AND (60:40) CONTAINING $0.25 \%$ WATER AND $6.5 \%$ KT BY CONE AND PLATE VISCOMETER 


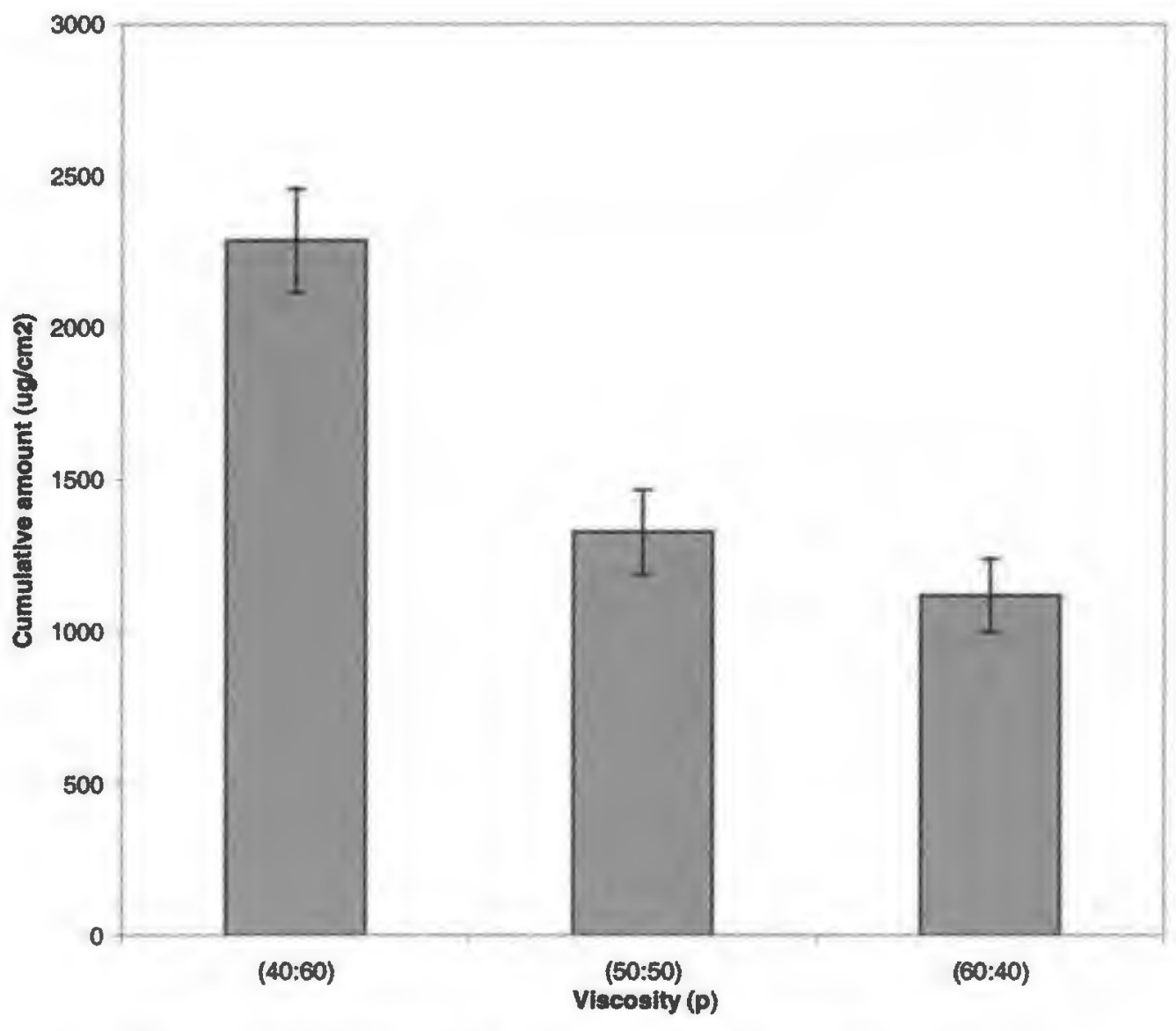

FIGURE 35. EFFECT OF VISCOSITY ON KT RELEASE ACROSS CELLULOSE ACTATE FROM ORGANOGELS WITH DIFFERENT LECITHIN CONCENTARTION BY CYLINDRICAL VISCOMETER (MEAN $\pm \mathrm{SD}, \mathrm{N}=2$ ) 


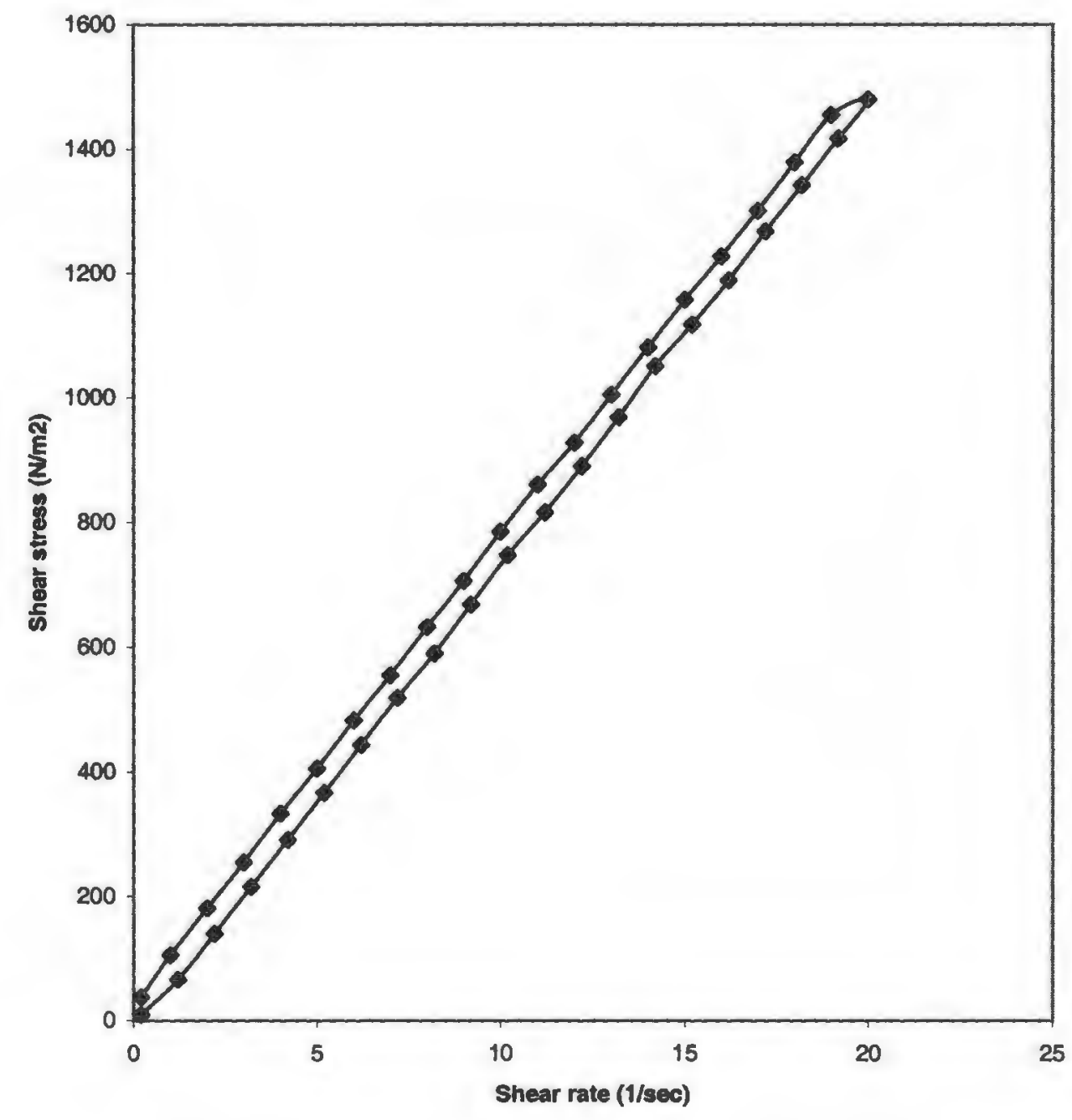

FIGURE 36. RHEOGRAM SHOWING THE RHEOPEXY BEHAVIOR FOR LECITHIN:IPM (40:60) CONTAINING 0.25\% WATER AND $6.5 \% \mathrm{KT}$ BY CONE AND PLATE VISCOMETER 
It was found (using both cylindrical and cone \& plate viscometer) that there was a significant $(p<0.05)$ increase in viscosity of lecithin:IPM (40:60) containing $0.5 \% \mathrm{w} / \mathrm{w}$ of water compared to the other concentrations of water (Figures 37, and 38). This result explained the significant decrease in the release of KT from this formulation which was mentioned at section 3.4.3. Therefore, at this specific concentration of water, long tubular micelles can be entangled and from a threedimensional network with a very high viscosity which affects the release rate of KT from the system. The effect of viscosity on cumulative release of KT from above formulation is given in Figure 39.

As KT release decreased with an increase in lecithin concentration, an inverse correlation existed between the release rate and the gel viscosity values. These data are confirmed by Santoyo et al., 1996 who reported that the drug release rate is inversely related to the viscosity of the continuous phase.

Viscosity profile of the organogel samples with eighteen different compositions obtained by cone and plate viscometer is given in Figure 40. Lecithin:IPM (60:40) containing different amounts of water showed the highest viscosity compared to the other ratios of lecithin:IPM. 


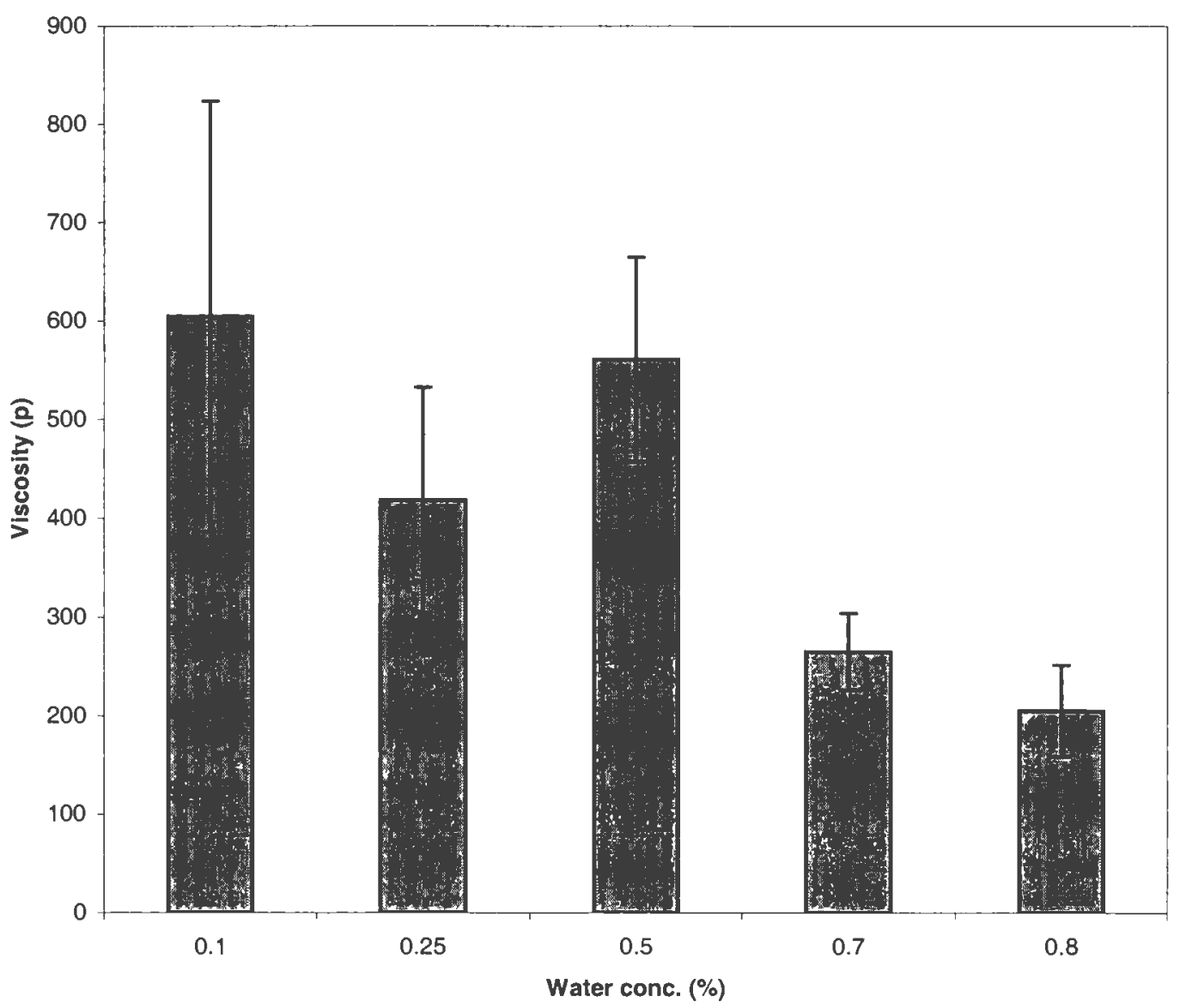

FIGURE 37. EFFECT OF WATER CONCENTRATION ON VISCOSITY OF THE LECITHIN:IPM (40:60) CONTAINING 6.5\% KT BY CYLINDRICAL VISCOMETER (MEAN $\pm S D, N=2$ ) 


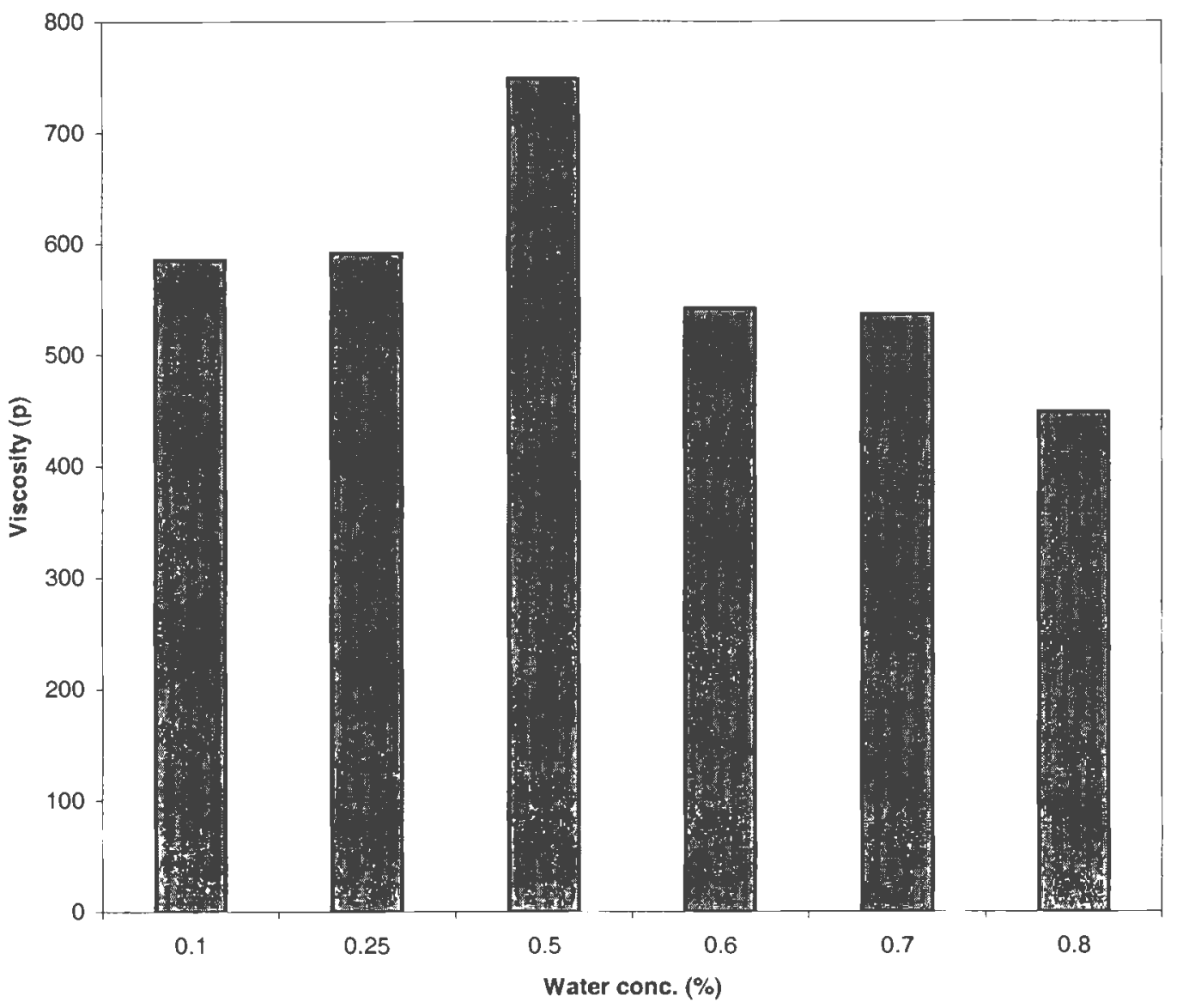

FIGURE 38. EFFECT OF WATER CONCENTRATION ON THE VISCOSITY OF LECITHIN:IPM (40:60) CONTAINING 6.5\% KT BY CONE AND PLATE 


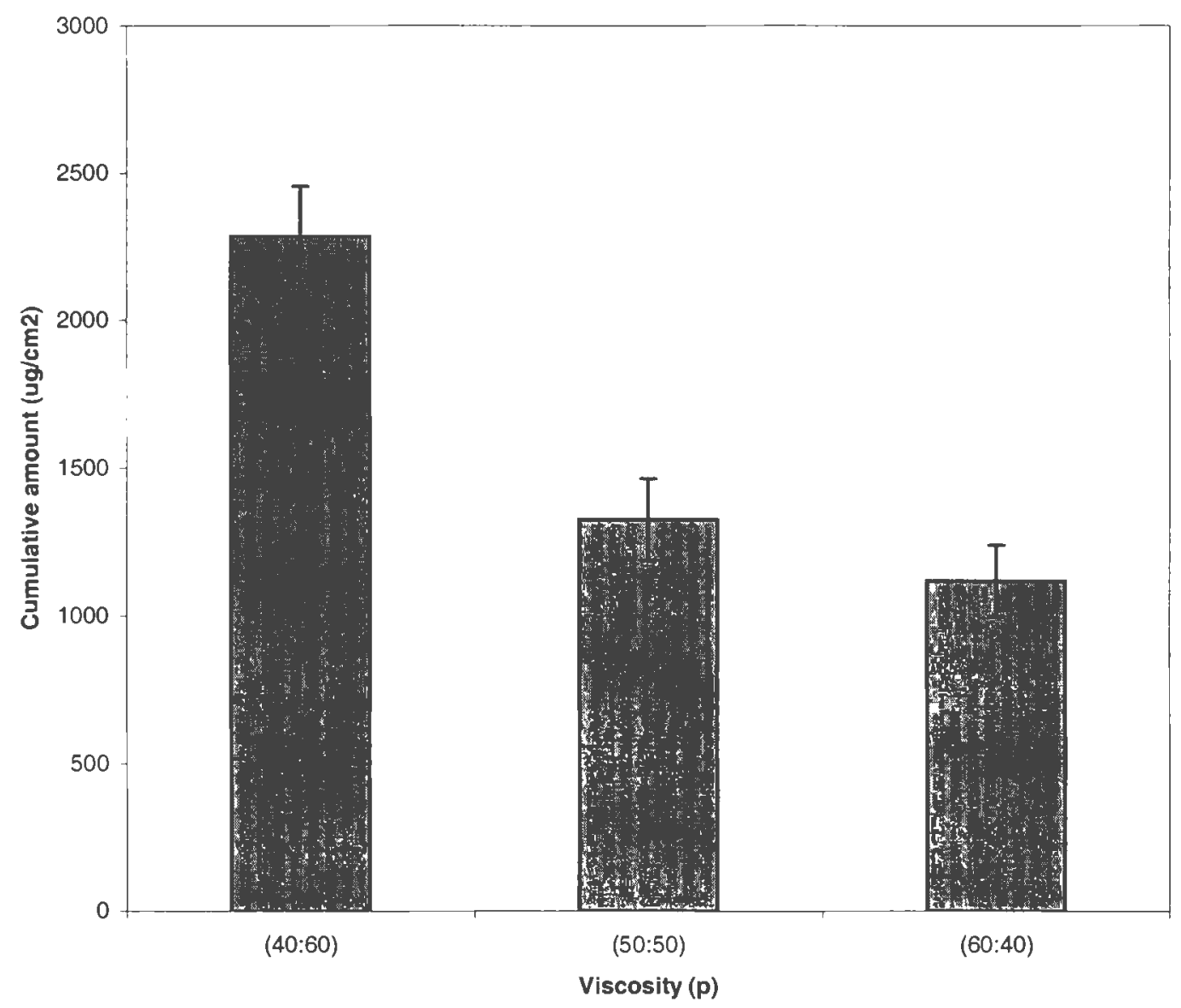

FIGURE 39. EFFECT OF VISCOSITY ON KT RELEASE ACROSS CELLULOSE ACETATE MEMBRANE FROM LECITHIN:IPM (40:60), (50:50) AND $(60: 40)$ CONTAINING $0.25 \%$ WATER AND $6.5 \%$ KT BY CYLINDRICAL VISCOMETER (MEAN $\pm S D, N=2$ ) 


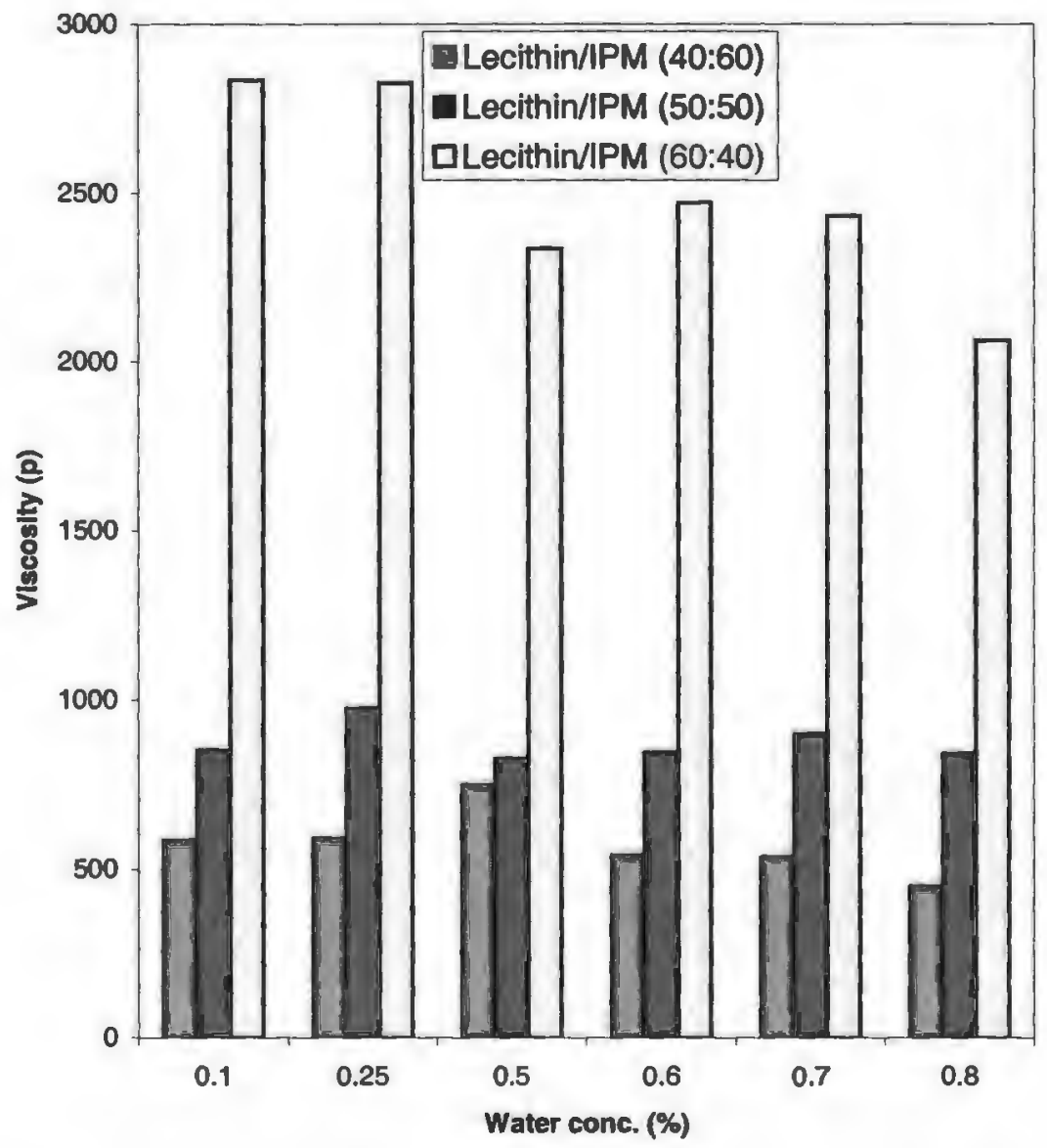

FIGURE 40. VISCOSITY OF ORGANOGEL SAMPLES WITH DIFFERENT COMPOSITIONS BY CONE AND PLATE VISCOMETER 


\section{CONCLUSION}

As shown in Figure 41, among all the different organogel formulations tested, Formula 4 , which is composed of $40 \%$ lecithin, $60 \%$ IPM containing $0.6 \%$ w/w of water and $6.5 \% \mathrm{w} / \mathrm{w}$ of ketorolac tromethamine showed the highest release profile. This formulation is the most desirable one based on the in vitro release studies. The mean cumulative amount of ketorolac from this optimum formula was 2555.757 $\pm 192.55\left(\mu \mathrm{g} / \mathrm{cm}^{2}\right)$.

Our study demonstrates that lecithin organogels are promising candidates for topical application of KT since they reduce the possibility of GI irritation, and side effects associated with oral administration of the drug. Other advantages of these organogels arising from their solubilization capacity, transparency, high thermodynamic stability and simplicity of manufacture. They have the ability to solubilize guest molecules of different chemico-physical properties (ware-insoluble, amphiphilic or water-soluble compounds). The transparency of organogels enables them to be visually assessed for microorganism growth and presence of undissolved drug. Their transparency is also of benefit in topical preparation when clear systems are more aesthetically pleasing. They are quickly absorbed by the skin without greasy shine. There is no significant change in the viscosity, color or appearance of organogels after a very long time at room temperature. Organogels are isotropic and thermoreversibe. At temperature $>40^{\circ} \mathrm{C}$, they become liquids with much lower viscosity, and high viscosity gels are again formed by cooling. The formation of organogels requires only the most basic mixing equipment. Their manufacture is not 


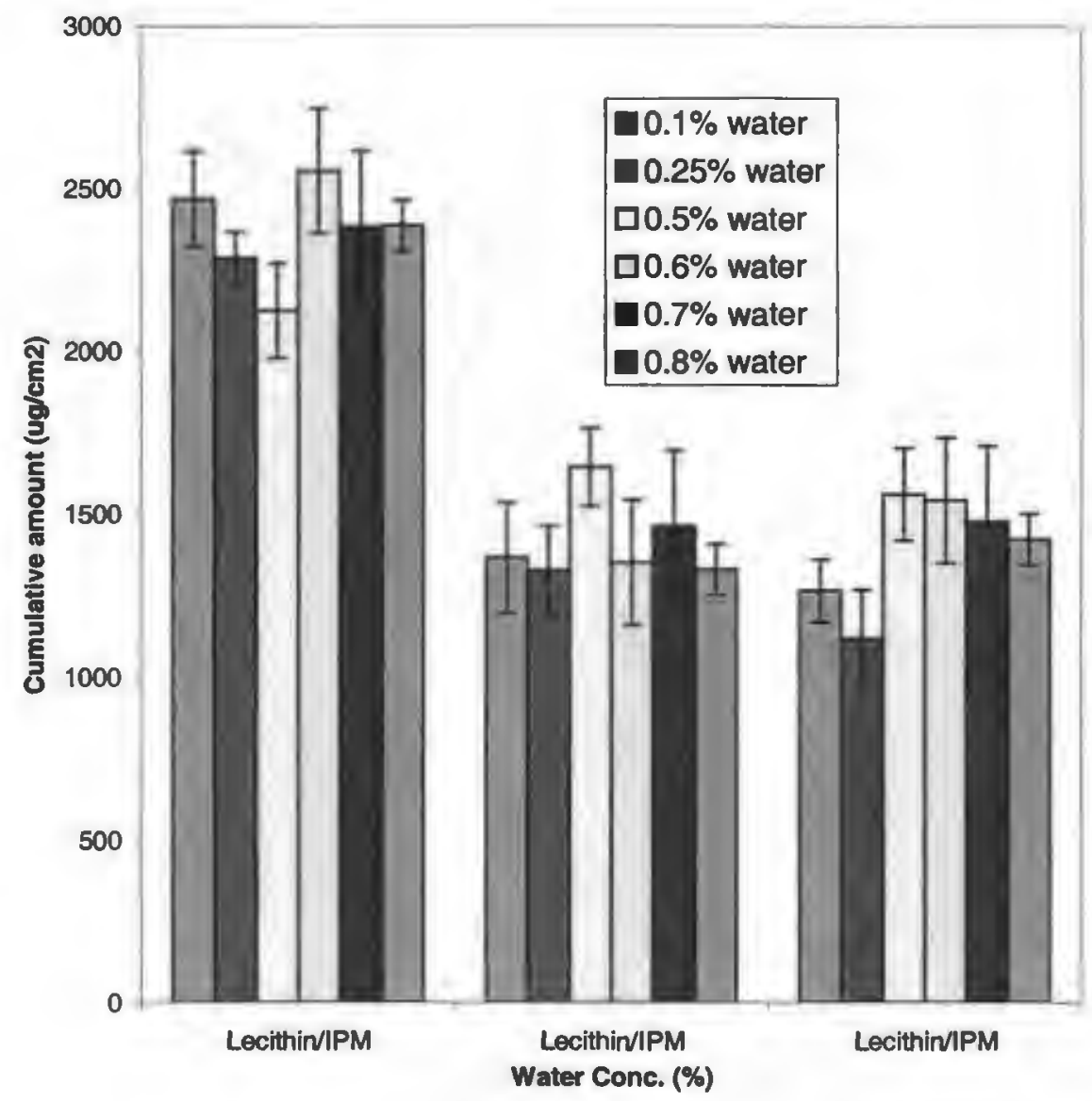

FIGURE 41. RELEASE PROFILE OF KT ACROSS CELLULOSE ACETATE MEMBRANE FROM $6.5 \%$ KT ORGANOGELS OF DIFFERENT COMPOSITIONS (MEAN $\pm S D, N=6$ ) 
so dependent on the careful control of manufacturing process. Composition of organogels is made of harmless compounds such as lecithin, fatty acid esters and water with no toxicity or irritation potential. And finally, Lecithin organogels have a high affinity for epidermal tissue, change the fluidity of tissue by hydration of stratum corneum and enhance the percutaneous absorption of drugs. 
5. APPENDIX 
TABLE 11. CUMULATIVE RELEASE OF KT ACROSS CELLULOSE ACETATE FROM LECITHIN:IPM (40:60) CONTAINING 0.1\% WATER AND 1\% KT

\begin{tabular}{|c|c|c|c|c|c|c|c|}
\hline Sample & Time & Abs. & $\mathrm{ug} / \mathrm{ml}$ & $\mathrm{ug} / 5.1$ & $\mathrm{ug} / \mathrm{cm}^{2}$ & Cumulative amount & \\
\hline & (h) & & & & & & \\
\hline 1 & 0.5 & 0.198 & 4.418 & 22.534 & 35.439 & 35.438 & Average \\
\hline 2 & 0.5 & 0.161 & 3.737 & 19.060 & 29.976 & 29.976 & 29.681 \\
\hline 3 & 0.5 & 0.152 & 3.579 & 18.251 & 28.703 & 28.703 & \\
\hline 4 & 0.5 & 0.135 & 3.267 & 16.663 & 26.206 & 26.206 & Std.Dev. \\
\hline 5 & 0.5 & 0.160 & 3.727 & 19.008 & 29.894 & 29.894 & 3.149 \\
\hline \multirow[t]{2}{*}{6} & 0.5 & 0.146 & 3.475 & 17.720 & 27.869 & 27.869 & \\
\hline & & & & & & & \\
\hline \multirow[t]{2}{*}{ Sample } & Time & Abs. & $\mathrm{ug} / \mathrm{ml}$ & $u g / 5.1$ & $\mathrm{ug} / \mathrm{cm}^{2}$ & Cumulative amount & \\
\hline & (h) & & & & & & \\
\hline 1 & 1 & 0.151 & 3.563 & 18.173 & 28.581 & 64.019 & Average \\
\hline 2 & 1 & 0.120 & 2.998 & 15.292 & 24.050 & 54.026 & 56.391 \\
\hline$\overline{3}$ & 1 & 0.169 & 3.880 & 19.790 & 31.124 & 59.827 & \\
\hline 4 & 1 & 0.129 & 3.162 & 16.127 & 25.363 & 51.569 & Std.Dev. \\
\hline 5 & 1 & 0.139 & 3.343 & 17.050 & 26.814 & 56.707 & 4.828 \\
\hline \multirow[t]{3}{*}{6} & 1 & 0.122 & 3.033 & 15.468 & 24.326 & 52.195 & \\
\hline & & & & & & & \\
\hline & Time & Abs. & $\mathrm{ua} / \mathrm{ml}$ & $4 a / 5.1$ & $4 \mathrm{a} / \mathrm{cm}^{2}$ & Cumulative amount & \\
\hline Sample & (h) & & & & & & \\
\hline 1 & 2 & 0.247 & 5.301 & 27.035 & 42.517 & 106.536 & Average \\
\hline 2 & 2 & 0.178 & 4.054 & 20.675 & 32.515 & 86.541 & 91.132 \\
\hline 3 & 2 & 0.221 & 4.833 & 24.646 & 38.761 & 98.588 & \\
\hline 4 & 2 & 0.159 & 3.711 & 18.926 & 29.764 & 81.334 & Std.Dev. \\
\hline 5 & 2 & 0.162 & 3.769 & 19.221 & 30.230 & 86.937 & 9.443 \\
\hline \multirow[t]{3}{*}{6} & 2 & 0.193 & 4.322 & 22.040 & 34.662 & 86.857 & \\
\hline & & & & & & & \\
\hline & & & & & & & \\
\hline \multirow[t]{2}{*}{ Sample } & Time & Abs. & $\mathrm{ug} / \mathrm{ml}$ & ug/5.1 & $\mathrm{ug} / \mathrm{cm}^{2}$ & Cumulative amount & \\
\hline & (h) & & & & & & \\
\hline 1 & 6 & 0.807 & 15.496 & 79.028 & 124.287 & 230.823 & Average \\
\hline 2 & 6 & 0.687 & 13.309 & 67.876 & 106.748 & 193.289 & 198.636 \\
\hline 3 & 6 & 0.822 & 15.765 & 80.401 & 126.446 & 225.034 & \\
\hline 4 & 6 & 0.571 & 11.192 & 57.079 & 89.768 & 171.101 & Std.Dev. \\
\hline 5 & 6 & 0.572 & 11.218 & 57.213 & 89.979 & 176.916 & 24.524 \\
\hline 6 & 6 & 0.694 & 13.440 & 68.542 & 107.796 & 194.653 & \\
\hline \multirow{2}{*}{ Sample } & Time & Abs. & $\mathrm{ug} / \mathrm{ml}$ & ug/5.1 & $\mathrm{ug} / \mathrm{cm}^{2}$ & Cumulative amount & \\
\hline & (h) & & & & & & \\
\hline 1 & 10 & 0.723 & 13.953 & 71.160 & 111.913 & 342.736 & Average \\
\hline 2 & 10 & 0.645 & 12.541 & 63.959 & 100.589 & 293.878 & 295.036 \\
\hline 3 & 10 & 0.634 & 12.338 & 62.925 & 98.962 & 323.996 & \\
\hline 4 & 10 & 0.554 & 10.895 & 55.563 & 87.384 & 258.486 & Std.Dev. \\
\hline 5 & 10 & 0.469 & 9.344 & 47.655 & 74.948 & 251.863 & 35.589 \\
\hline 6 & 10 & 0.673 & 13.042 & 66.513 & 104.605 & 299.258 & \\
\hline
\end{tabular}


TABLE 11. CONT'D.

\begin{tabular}{|c|c|c|c|c|c|c|c|}
\hline Sample & Time & Abs. & ug/ml & ug/5.1 & ug/ $\mathbf{c m}^{\mathbf{2}}$ & Cumulative amount & \\
\hline & (h) & & & & & & \\
\hline 1 & 18 & 1.380 & 25.914 & 132.163 & 207.853 & 550.589 & Average \\
\hline 2 & 18 & 1.229 & 23.157 & 118.099 & 185.735 & 479.612 & 478.320 \\
\hline 3 & 18 & 1.443 & 27.059 & 138.002 & 217.036 & 541.032 & \\
\hline 4 & 18 & 1.128 & 21.316 & 108.710 & 170.968 & 429.453 & Std.Dev. \\
\hline 5 & 18 & 0.978 & 18.595 & 94.833 & 149.143 & 401.006 & 59.371 \\
\hline 6 & 18 & 1.114 & 21.067 & 107.439 & 168.970 & 468.228 & \\
\hline & & & & & & & \\
\hline & & & & & & & \\
\hline Sample & Time & Abs. & ug/ml & ug/5.1 & ug/cm & Cumulative amount & \\
\hline & (h) & & & & & & \\
\hline 1 & 26 & 1.206 & 22.737 & 115.956 & 182.364 & 732.953 & Average \\
\hline 2 & 26 & 1.075 & 20.354 & 103.804 & 163.253 & 642.865 & 639.101 \\
\hline 3 & 26 & 1.303 & 24.505 & 124.975 & 196.548 & 737.580 & \\
\hline 4 & 26 & 1.127 & 21.305 & 108.656 & 170.883 & 600.336 & Std.Dev. \\
\hline 5 & 26 & 0.739 & 14.254 & 72.696 & 114.330 & 515.336 & 85.402 \\
\hline 6 & 26 & 0.897 & 17.119 & 87.308 & 137.309 & 605.538 & \\
\hline
\end{tabular}

\begin{tabular}{|c|c|c|c|}
\hline Time & \multicolumn{2}{|c|}{ Average cum. amount } & Std.Dev. \\
\hline (h) & & & \\
\hline 0.5 & 29.681 & & 3.149 \\
\hline 1 & 56.391 & & 4.828 \\
\hline 2 & 91.132 & 91.132 & 9.443 \\
\hline 6 & 198.636 & 198.636 & 24.524 \\
\hline 10 & 295.036 & 295.036 & 35.589 \\
\hline 18 & 478.320 & 478.320 & 59.371 \\
\hline 26 & 639.102 & 639.102 & 85.402 \\
\hline
\end{tabular}


TABLE 12. CUMULATIVE RELEASE OF KT ACROSS SILICONE ELASTOMER MEMBRANE FROM LECITHIN:IPM (40:60) CONTAINING 0.1\% WATER AND $1 \% \mathrm{KT}$

\begin{tabular}{|c|c|c|c|c|c|c|c|}
\hline Sample & Time & Abs. & $\mathrm{ug} / \mathrm{ml}$ & $\mathrm{ug} / 5.1$ & $\mathrm{ug} / \mathrm{cm}^{2}$ & Cumulative amount & \\
\hline & (h) & & & & & & \\
\hline 1 & 0.5 & 0.035 & 1.442 & 7.355 & 11.567 & 11.567 & Average \\
\hline 2 & 0.5 & 0.024 & 1.256 & 6.405 & 10.073 & 10.073 & 10.312 \\
\hline 3 & 0.5 & 0.020 & 1.185 & 6.044 & 9.506 & 9.506 & \\
\hline$\overline{4}$ & 0.5 & 0.019 & 1.164 & 5.934 & 9.333 & 9.333 & Std.Dev \\
\hline 5 & 0.5 & 0.035 & 1.448 & 7.383 & 11.611 & 11.611 & 1.021 \\
\hline \multirow[t]{2}{*}{6} & 0.5 & 0.022 & 1.219 & 6.218 & 9.780 & 9.780 & \\
\hline & & & & & & & \\
\hline \multirow[t]{2}{*}{ Sample } & Time & Abs. & $\mathrm{ug} / \mathrm{ml}$ & $\mathrm{ug} / 5.1$ & $\mathrm{ug} / \mathrm{cm}^{2}$ & Cumulative amount & \\
\hline & (h) & & & & & & \\
\hline 1 & 1 & 0.019 & 1.157 & 5.900 & 9.279 & 20.846 & Average \\
\hline 2 & 1 & 0.016 & 1.105 & 5.636 & 8.863 & 18.936 & 19.258 \\
\hline 3 & 1 & 0.018 & 1.146 & 5.842 & 9.188 & 18.694 & \\
\hline 4 & $\overline{1}$ & 0.014 & 1.067 & 5.442 & 8.558 & 17.891 & Std.Dev \\
\hline 5 & 1 & 0.016 & 1.102 & 5.619 & 8.836 & 20.447 & 1.141 \\
\hline \multirow[t]{2}{*}{6} & 1 & 0.017 & 1.116 & 5.692 & 8.952 & 18.732 & \\
\hline & & & & & & & \\
\hline \multirow{3}{*}{ Sample } & & & & & & & \\
\hline & Time & Abs. & $\mathrm{ug} / \mathrm{ml}$ & ug/5.1 & $\mathrm{ug} / \mathrm{cm}^{2}$ & Cumulative amount & \\
\hline & (h) & & & & & & \\
\hline 1 & 2 & 0.024 & 1.251 & 6.381 & 10.036 & 30.882 & Average \\
\hline 2 & 2 & 0.025 & 1.276 & 6.509 & 10.236 & 29.172 & 29.391 \\
\hline 3 & 2 & 0.030 & 1.358 & 6.926 & 10.892 & 29.586 & \\
\hline 4 & 2 & 0.020 & 1.176 & 5.999 & 9.435 & 27.326 & Std.Dev. \\
\hline 5 & 2 & 0.020 & 1.177 & 6.002 & 9.439 & 29.887 & 1.169 \\
\hline \multirow[t]{2}{*}{6} & 2 & 0.029 & 1.342 & 6.844 & 10.763 & 29.495 & \\
\hline & & & & & & & \\
\hline \multirow[t]{2}{*}{ Sample } & Time & Abs. & $\mathrm{ug} / \mathrm{ml}$ & $u g / 5.1$ & $\mathrm{ug} / \mathrm{cm}^{2}$ & Cumulative amount & \\
\hline & (h) & & & & & & \\
\hline 1 & 4 & 0.054 & 1.800 & 9.181 & 14.439 & 45.321 & Average \\
\hline 2 & 4 & 0.052 & 1.753 & 8.938 & 14.057 & 43.229 & 43.841 \\
\hline 3 & 4 & 0.059 & 1.879 & 9.585 & 15.074 & 44.660 & \\
\hline 4 & 4 & 0.058 & 1.871 & 9.542 & 15.007 & 42.332 & Std.Dev \\
\hline 5 & $\overline{4}$ & 0.053 & 1.769 & 9.023 & 14.190 & 44.077 & 1.0713 \\
\hline \multirow[t]{2}{*}{6} & 4 & 0.051 & 1.737 & 8.859 & 13.932 & 43.427 & \\
\hline & & & & & & & \\
\hline \multirow[t]{2}{*}{ Sample } & Time & Abs. & $\mathrm{ug} / \mathrm{ml}$ & $u g / 5.1$ & $\mathrm{ug} / \mathrm{cm}^{2}$ & Cumulative amount & \\
\hline & (h) & & & & & & \\
\hline 1 & 6 & 0.068 & 2.043 & 10.419 & 16.386 & 61.707 & Average \\
\hline 2 & 6 & 0.062 & 1.934 & 9.863 & 15.512 & 58.741 & 59.867 \\
\hline 3 & 6 & 0.069 & 2.077 & 10.592 & 16.658 & 61.318 & \\
\hline 4 & 6 & 0.071 & 2.107 & 10.745 & 16.898 & 59.231 & Std.Dev. \\
\hline 5 & 6 & 0.059 & 1.890 & 9.640 & 15.160 & 59.237 & 1.293 \\
\hline 6 & 6 & 0.062 & 1.938 & 9.883 & 15.543 & 58.970 & \\
\hline
\end{tabular}


TABLE 12. CONT'D

\begin{tabular}{|c|c|c|c|c|c|c|c|}
\hline Sample & Time & Abs. & $\mathrm{ug} / \mathrm{ml}$ & $u g / 5.1$ & $\mathrm{ug} / \mathrm{cm}^{2}$ & Cumulative amount & \\
\hline & (h) & & & & & & \\
\hline 1 & 8 & 0.057 & 1.843 & 9.398 & 14.780 & 76.487 & Average \\
\hline 2 & 8 & 0.051 & 1.737 & 8.857 & 13.930 & 72.671 & 74.035 \\
\hline 3 & 8 & 0.062 & 1.945 & 9.920 & 15.601 & 76.919 & \\
\hline 4 & 8 & 0.054 & 1.804 & 9.200 & 14.468 & 73.699 & Std.Dev. \\
\hline 5 & 8 & 0.045 & 1.640 & 8.362 & 13.151 & 72.388 & 2.144 \\
\hline 6 & 8 & 0.045 & 1.630 & 8.313 & 13.073 & 72.043 & \\
\hline & & & & & & & \\
\hline Sample & Time & Abs. & $\mathrm{ug} / \mathrm{ml}$ & $u g / 5.1$ & $\mathrm{ug} / \mathrm{cm}^{2}$ & Cumulative amount & \\
\hline & (h) & & & & & & \\
\hline 1 & 10 & 0.064 & 1.975 & 10.074 & 15.843 & 92.331 & Average \\
\hline 2 & 10 & 0.064 & 1.973 & 10.060 & 15.821 & 88.492 & 91.074 \\
\hline 3 & 10 & 0.079 & 2.252 & 11.486 & 18.064 & 94.983 & \\
\hline 4 & 10 & 0.072 & 2.123 & 10.830 & 17.032 & 90.731 & Std.Dev. \\
\hline 5 & 10 & 0.080 & 2.270 & 11.578 & 18.209 & 90.597 & 2.323 \\
\hline 6 & 10 & 0.074 & 2.153 & 10.978 & 17.265 & 89.309 & \\
\hline
\end{tabular}

\begin{tabular}{|c|c|c|c|}
\hline Time & \multicolumn{2}{|c|}{ Average cum. amount } & Std.Dev. \\
\hline (h) & & & \\
\hline 0.5 & 10.312 & & 1.021 \\
\hline 1 & 19.258 & & 1.141 \\
\hline 2 & 29.391 & 29.391 & 1.169 \\
\hline 4 & 43.841 & 43.841 & 1.071 \\
\hline 6 & 59.867 & 59.867 & 1.293 \\
\hline 8 & 74.035 & 74.035 & 2.144 \\
\hline 10 & 91.074 & 91.074 & 2.323 \\
\hline
\end{tabular}


TABLE 13. EFFECT OF MEMBRANE ON KT RELEASE FROM LECITHIN:IPM (40:60) CONTAINING 0.1\% WATER AND 1\% KT

\begin{tabular}{|c|c|c|c|c|}
\hline & Silicone Elastomer & & Cellulose Acetate & \\
\hline Time & Average Cum.Amount & Std.Dev. & Average Cum.Amount & Std.Dev. \\
\hline & & & & \\
\hline 0.5 & 10.31 & 1.02 & 29.68 & 3.15 \\
\hline 1 & 19.26 & 1.14 & 56.39 & 4.83 \\
\hline 2 & 29.39 & 1.17 & 91.13 & 9.44 \\
\hline 4 & 43.84 & 1.07 & & \\
\hline 6 & 59.87 & 1.29 & 198.63 & 24.52 \\
\hline 8 & 74.03 & 2.14 & & \\
\hline 10 & 91.07 & 2.32 & 295.04 & 35.59 \\
\hline 12 & & & & \\
\hline 18 & & & 478.32 & 59.37 \\
\hline 26 & & & 639.1 & 5.4 \\
\hline
\end{tabular}


TABLE 14. CUMULATIVE RELEASE OF KT ACROSS CELLULOSE ACETATE FROM LECITHIN:IPM (40:60) CONTAINING 0.1\% WATER AND $1 \%$ KT

\begin{tabular}{|c|c|c|c|c|c|c|c|}
\hline Sample & Time & Abs. & $\mathrm{ug} / \mathrm{ml}$ & ug/ 5.1 & $\mathrm{ug} / \mathrm{cm}^{2}$ & Cumulative amount & \\
\hline & (h) & & & & & & \\
\hline 1 & 0.5 & 0.198 & 4.418 & 22.534 & 35.439 & 35.438 & Average \\
\hline 2 & 0.5 & 0.161 & 3.737 & 19.060 & 29.976 & 29.976 & 29.681 \\
\hline 3 & 0.5 & 0.152 & 3.579 & 18.251 & 28.703 & 28.703 & \\
\hline 4 & 0.5 & 0.135 & 3.267 & 16.663 & 26.206 & 26.206 & Std.Dev. \\
\hline 5 & 0.5 & 0.160 & 3.727 & 19.008 & 29.894 & 29.894 & 3.149 \\
\hline \multirow[t]{2}{*}{6} & 0.5 & 0.146 & 3.475 & 17.720 & 27.869 & 27.869 & \\
\hline & & & & & & & \\
\hline & & & & & & & \\
\hline \multirow[t]{2}{*}{ Sample } & Time & Abs. & $\mathrm{ug} / \mathrm{ml}$ & $\mathrm{ug} / 5.1$ & $\mathrm{ug} / \mathrm{cm}^{2}$ & Cumulative amount & \\
\hline & (h) & & & & & & \\
\hline 1 & $\frac{1}{1}$ & 0.151 & 3.563 & 18.173 & 28.581 & 64.019 & Average \\
\hline 2 & 1 & 0.120 & 2.998 & 15.292 & 24.050 & 54.026 & 56.391 \\
\hline 3 & 1 & 0.169 & 3.880 & 19.790 & 31.124 & 59.827 & \\
\hline 4 & 1 & 0.129 & 3.162 & 16.127 & 25.363 & 51.569 & Std.Dev. \\
\hline 5 & 1 & 0.139 & 3.343 & 17.050 & 26.814 & 56.707 & 4.828 \\
\hline \multirow[t]{3}{*}{6} & 1 & 0.122 & 3.033 & 15.468 & 24.326 & 52.195 & \\
\hline & & & & & & & \\
\hline & Time & Abs. & $\mathrm{ua} / \mathrm{ml}$ & $4 a / 5.1$ & $\mathrm{ua} / \mathrm{cm}^{2}$ & Cumulative amount & \\
\hline Sample & (h) & & & & & & \\
\hline 1 & $\frac{1}{2}$ & 0.247 & 5.301 & 27.035 & 42.517 & 106.536 & Average \\
\hline 2 & 2 & 0.178 & 4.054 & 20.675 & 32.515 & 86.541 & 91.132 \\
\hline 3 & 2 & 0.221 & 4.833 & 24.646 & 38.761 & 98.588 & \\
\hline 4 & 2 & 0.159 & 3.711 & 18.926 & 29.764 & 81.334 & Std.Dev. \\
\hline 5 & 2 & 0.162 & 3.769 & 19.221 & 30.230 & 86.937 & 9.443 \\
\hline \multirow[t]{3}{*}{6} & 2 & 0.193 & 4.322 & 22.040 & 34.662 & 86.857 & \\
\hline & & & & & & & \\
\hline & & & & & & & \\
\hline \multirow[t]{2}{*}{ Sample } & Time & Abs. & $\mathrm{ug} / \mathrm{ml}$ & ug/5.1 & $\mathrm{ug} / \mathrm{cm}^{2}$ & Cumulative amount & \\
\hline & (h) & & & & & & \\
\hline 1 & 6 & 0.807 & 15.496 & 79.028 & 124.287 & 230.823 & Average \\
\hline 2 & 6 & 0.687 & 13.309 & 67.876 & 106.748 & 193.289 & 198.636 \\
\hline 3 & 6 & 0.822 & 15.765 & 80.401 & 126.446 & 225.034 & \\
\hline 4 & 6 & 0.571 & 11.192 & 57.079 & 89.768 & 171.101 & Std.Dev. \\
\hline 5 & 6 & 0.572 & 11.218 & 57.213 & 89.979 & 176.916 & 24.524 \\
\hline 6 & 6 & 0.694 & 13.440 & 68.542 & 107.796 & 194.653 & \\
\hline \multirow[t]{2}{*}{ Sample } & Time & Abs. & $\mathrm{ug} / \mathrm{ml}$ & $\mathrm{ug} / 5.1$ & $\mathrm{ug} / \mathrm{cm}^{2}$ & Cumulative amount & \\
\hline & (h) & & & & & & \\
\hline 1 & 10 & 0.723 & 13.953 & 71.160 & 111.913 & 342.736 & Average \\
\hline 2 & 10 & 0.645 & 12.541 & 63.959 & 100.589 & 293.878 & 295.036 \\
\hline 3 & 10 & 0.634 & 12.338 & 62.925 & 98.962 & 323.996 & \\
\hline 4 & 10 & 0.554 & 10.895 & 55.563 & 87.384 & 258.486 & Std.Dev. \\
\hline 5 & 10 & 0.469 & 9.344 & 47.655 & 74.948 & 251.863 & 35.589 \\
\hline 6 & 10 & 0.673 & 13.042 & 66.513 & 104.605 & 299.258 & \\
\hline
\end{tabular}


TABLE 14. CONT'D.

\begin{tabular}{|c|c|c|c|c|c|c|c|}
\hline Sample & Time & Abs. & ug/ml & ug/5.1 & ug/cm & Cumulative amount & \\
\hline & (h) & & & & & & \\
\hline 1 & 18 & 1.380 & 25.914 & 132.163 & 207.853 & 550.589 & Average \\
\hline 2 & 18 & 1.229 & 23.157 & 118.099 & 185.735 & 479.612 & 478.320 \\
\hline 3 & 18 & 1.443 & 27.059 & 138.002 & 217.036 & 541.032 & \\
\hline 4 & 18 & 1.128 & 21.316 & 108.710 & 170.968 & 429.453 & Std.Dev. \\
\hline 5 & 18 & 0.978 & 18.595 & 94.833 & 149.143 & 401.006 & 59.371 \\
\hline 6 & 18 & 1.114 & 21.067 & 107.439 & 168.970 & 468.228 & \\
\hline & & & & & & & \\
\hline & & & & & & & \\
\hline Sample & Time & Abs. & ug/ml & ug/5.1 & ug/cm & Cumulative amount & \\
\hline & (h) & & & & & & \\
\hline 1 & 26 & 1.206 & 22.737 & 115.956 & 182.364 & 732.953 & Average \\
\hline 2 & 26 & 1.075 & 20.354 & 103.804 & 163.253 & 642.865 & 639.101 \\
\hline 3 & 26 & 1.303 & 24.505 & 124.975 & 196.548 & 737.580 & \\
\hline 4 & 26 & 1.127 & 21.305 & 108.656 & 170.883 & 600.336 & Std.Dev. \\
\hline 5 & 26 & 0.739 & 14.254 & 72.696 & 114.330 & 515.336 & 85.402 \\
\hline 6 & 26 & 0.897 & 17.119 & 87.308 & 137.309 & 605.538 & \\
\hline
\end{tabular}

\begin{tabular}{|c|c|c|c|}
\hline Time & \multicolumn{2}{|c|}{ Average cum. amount } & Std.Dev. \\
\hline$(\mathrm{h})$ & & & \\
\hline 0.5 & 29.681 & & 3.149 \\
\hline 1 & 56.391 & & 4.828 \\
\hline 2 & 91.132 & 91.132 & 9.443 \\
\hline 6 & 198.636 & 198.636 & 24.524 \\
\hline 10 & 295.036 & 295.036 & 35.589 \\
\hline 18 & 478.320 & 478.320 & 59.371 \\
\hline 26 & 639.102 & 639.102 & 85.402 \\
\hline
\end{tabular}


TABLE 15. CUMULATIVE RELEASE OF KT ACROSS

CELLULOSE ACETATE MEMBRANE FROM LECITHIN:IPM (40:60) CONTAINING 0.1\% WATER AND $6.5 \%$ KT

\begin{tabular}{|c|c|c|c|c|c|c|c|c|}
\hline \multirow[t]{2}{*}{ Sample } & \multirow{2}{*}{\begin{tabular}{|c|} 
Time \\
(h) \\
\end{tabular}} & \multirow{2}{*}{\begin{tabular}{|l|} 
Abs. \\
\end{tabular}} & \multirow{2}{*}{$\mathrm{ug} / \mathrm{ml}$} & & \multirow{2}{*}{ ug/5.1 } & \multirow[t]{2}{*}{$\mathrm{ug} / \mathrm{cm}^{2}$} & \multicolumn{2}{|c|}{ Cumulative amount } \\
\hline & & & & & & & & \\
\hline 1 & 0.5 & 0.948 & 18.044 & & 92.022 & 144.723 & 144.723 & \\
\hline 2 & 0.5 & 1.133 & 21.421 & & 109.246 & 171.811 & 171.811 & Average \\
\hline 3 & 0.5 & 0.856 & 16.374 & & 83.506 & 131.330 & 131.330 & 152.822 \\
\hline 4 & 0.5 & 1.123 & 21.233 & & 108.286 & 170.301 & 170.301 & Std.Dev. \\
\hline 5 & 0.5 & 0.962 & 18.301 & & 93.333 & 146.784 & 146.784 & 15.689 \\
\hline 6 & 0.5 & 0.997 & 18.948 & & 96.636 & 151.980 & 151.980 & \\
\hline & & & & & & & & \\
\hline & & & & & & & & \\
\hline Sample & Time & Abs. & $\mathrm{ug} / \mathrm{ml}$ & & ug/5.1 & $\mathrm{ug} / \mathrm{cm}^{2}$ & \multicolumn{2}{|c|}{ Cumulative amount } \\
\hline & (h) & & & & & & & \\
\hline 1 & 1 & 0.456 & 9.101 & & 46.415 & 72.996 & 217.720 & \\
\hline 2 & 1 & 0.452 & 9.034 & & 46.072 & 72.458 & 244.268 & Average \\
\hline 3 & 1 & 0.427 & 8.574 & & 43.728 & 68.770 & 200.101 & 224.110 \\
\hline 4 & 1 & 0.456 & 9.101 & & 46.414 & 72.995 & 243.296 & Std.Dev. \\
\hline 5 & 1 & 0.411 & 8.288 & & 42.267 & 66.473 & 213.257 & 17.396 \\
\hline 6 & 1 & 0.463 & 9.231 & & 47.078 & 74.039 & 226.019 & \\
\hline & & & & & & & & \\
\hline Sample & Time & Abs. & $\mathrm{ug} / \mathrm{ml}$ & & $u q / 5.1$ & $\mathrm{ug} / \mathrm{cm}^{2}$ & \multicolumn{2}{|c|}{ Cumulative amount } \\
\hline & (h) & & & & & & & \\
\hline 1 & 2 & 0.948 & 18.053 & & 92.068 & 144.796 & 362.516 & \\
\hline 2 & 2 & 0.952 & 18.124 & & 92.434 & 145.371 & 389.639 & Average \\
\hline 3 & 2 & 0.927 & 17.665 & & 90.090 & 141.684 & 341.785 & 366.315 \\
\hline 4 & 2 & 0.905 & 17.272 & & 88.085 & 138.531 & 381.828 & Std.Dev. \\
\hline 5 & 2 & 0.913 & 17.418 & & 88.834 & 139.709 & 352.966 & 17.816 \\
\hline 6 & 2 & 0.937 & 17.846 & & 91.014 & 143.137 & 369.156 & \\
\hline & & & & & & & & \\
\hline & & & & & & & & \\
\hline Sample & Time & Abs. & $\mathrm{ug} / \mathrm{ml}$ & $2^{*}(\mathrm{ug} / \mathrm{ml})$ & ug/5.1 & $\mathrm{ug} / \mathrm{cm}^{2}$ & \multicolumn{2}{|c|}{ Cumulative amount } \\
\hline & (h) & & & & & & & \\
\hline 1 & 4 & 1.123 & 21.240 & 42.480 & 216.650 & 340.725 & 703.241 & \\
\hline 2 & 4 & 1.073 & 20.327 & 40.653 & 207.331 & 326.069 & 715.708 & Average \\
\hline 3 & 4 & 1.334 & 25.061 & 50.121 & 255.619 & 402.012 & 743.797 & 742.302 \\
\hline 4 & 4 & 1.265 & 23.822 & 47.644 & 242.984 & 382.141 & 763.969 & Std.Dev. \\
\hline 5 & 4 & 1.423 & 26.689 & 53.379 & 272.232 & 428.139 & 781.105 & 29.066 \\
\hline 6 & 4 & 1.247 & 23.491 & 46.983 & 239.613 & 376.839 & 745.994 & \\
\hline Sample & Time & Abs. & $\mathrm{ug} / \mathrm{ml}$ & $2^{*}(u g / m l)$ & ug/5.1 & $\mathrm{ug} / \mathrm{cm}^{2}$ & \multicolumn{2}{|c|}{ Cumulative amount } \\
\hline & (h) & & & & & & & \\
\hline 1 & 6 & 1.221 & 23.022 & 46.045 & 234.828 & 369.314 & 1072.554 & \\
\hline 2 & 6 & 1.225 & 23.081 & 46.163 & 235.431 & 370.262 & 1085.970 & Average \\
\hline 3 & 6 & 1.784 & 33.257 & 66.514 & 339.222 & 533.494 & 1277.291 & 1170.373 \\
\hline 4 & 6 & 1.514 & 28.348 & 56.695 & 289.146 & 454.739 & 1218.708 & Std.Dev. \\
\hline 5 & 6 & 1.618 & 30.237 & 60.473 & 308.413 & 485.040 & 1266.146 & 94.198 \\
\hline 6 & 6 & 1.174 & 22.166 & 44.332 & 226.091 & \begin{tabular}{|l|}
355.573 \\
\end{tabular} & 1101.568 & \\
\hline
\end{tabular}


TABLE 15. CONT'D.

\begin{tabular}{|c|c|c|c|c|c|c|c|c|}
\hline Sample & Time & Abs. & $\mathrm{ug} / \mathrm{ml}$ & $2^{*}(\mathrm{ug} / \mathrm{ml})$ & ug/5.1 & $\mathrm{ug} / \mathrm{cm}^{2}$ & \multicolumn{2}{|c|}{ Cumulative amount } \\
\hline & (h) & & & & & & & \\
\hline 1 & 8 & 1.313 & 24.768 & 49.536 & 252.635 & 397.319 & 1469.873 & \\
\hline 2 & 8 & 1.439 & 27.047 & 54.095 & 275.884 & 433.882 & 1519.852 & Average \\
\hline 3 & 8 & 1.095 & 20.798 & 41.596 & 212.140 & 333.632 & 1610.923 & 1551.097 \\
\hline 4 & 8 & 1.026 & 19.537 & 39.073 & 199.273 & 313.396 & 1532.104 & Std.Dev. \\
\hline 5 & 8 & 1.534 & 28.780 & 57.561 & 293.560 & 461.681 & 1727.826 & 103.722 \\
\hline 6 & 8 & 1.132 & 21.472 & 42.943 & 219.011 & 344.438 & 1446.005 & \\
\hline & & & & & & & & \\
\hline Sample & Time & Abs. & $\mathrm{ug} / \mathrm{ml}$ & $3^{*}(\mathrm{ug} / \mathrm{ml})$ & $u g / 5.1$ & $\mathrm{ug} / \mathrm{cm}^{2}$ & \multicolumn{2}{|c|}{ Cumulative amount } \\
\hline & (h) & & & & & & & \\
\hline 1 & 10 & 1.172 & 22.124 & 66.371 & 338.494 & 532.349 & 2002.223 & \\
\hline 2 & 10 & \begin{tabular}{|l|}
1.012 \\
\end{tabular} & 19.216 & 57.647 & 293.999 & 462.372 & 1982.224 & Average \\
\hline 3 & 10 & \begin{tabular}{|l|}
1.327 \\
\end{tabular} & 24.948 & 74.843 & 381.702 & 600.301 & 2211.224 & 2116.640 \\
\hline 4 & 10 & 1.313 & 24.681 & 74.044 & 377.623 & 593.888 & 2125.992 & Std.Dev. \\
\hline 5 & 10 & 1.231 & 23.197 & 69.592 & 354.918 & 558.179 & 2286.006 & 117.878 \\
\hline 6 & 10 & 1.432 & 26.854 & 80.562 & 410.866 & 646.168 & 2092.174 & \\
\hline & & & & & & & & \\
\hline Sample & Time & Abs. & $u g / m l$ & 2*(ug/ml) & $u g / 5.1$ & $\mathrm{ug} / \mathrm{cm}^{2}$ & \multicolumn{2}{|c|}{ Cumulative amount } \\
\hline & (h) & & & & & & & \\
\hline 1 & 12 & 1.102 & 20.854 & 41.707 & 212.707 & 334.524 & 2336.747 & \\
\hline 2 & 12 & 1.039 & 19.705 & 39.409 & 200.988 & 316.094 & 2298.318 & Average \\
\hline 3 & 12 & 1.265 & 23.823 & 47.645 & 242.990 & 382.150 & 2593.374 & 2469.334 \\
\hline 4 & 12 & 1.032 & 19.581 & 39.162 & 199.725 & 314.108 & 2440.099 & Std.Dev. \\
\hline 5 & 12 & 1.315 & 24.732 & 49.463 & 252.263 & 396.733 & 2682.739 & 147.397 \\
\hline 6 & 12 & \begin{tabular}{|l|}
1.233 \\
\end{tabular} & 23.225 & 46.449 & 236.890 & 372.557 & 2464.731 & \\
\hline
\end{tabular}

\begin{tabular}{|c|c|c|c|}
\hline Time & \multicolumn{2}{|c|}{ Average cum. amnt. } & Std.Dev. \\
\hline (h) & & & \\
\hline 0.5 & 152.822 & & 15.689 \\
\hline 1 & 224.110 & & 17.396 \\
\hline 2 & 366.315 & & 17.816 \\
\hline 4 & 742.302 & & 29.066 \\
\hline 6 & 1170.373 & 1170.373 & 94.198 \\
\hline 8 & 1551.097 & 1551.097 & 103.722 \\
\hline 10 & 2116.640 & 2116.640 & 117.878 \\
\hline 12 & 2469.334 & 2469.334 & 147.397 \\
\hline
\end{tabular}


TABLE 16. EFFECT OF KT CONCENTRATION ON ITS TRANSDERMAL FLUX ACROSS CELLULOSE ACETATE MEMBRANE FROM LECITHIN:IPM (40:60) CONTAINING 0.1\% WATER

\begin{tabular}{|c|c|c|c|c|}
\hline & 1\% KT Conc. & & 6.5\% KT Conc. & \\
\hline & & & & \\
\hline Time & Average Cum.Amount & Std.Dev. & Average Cum.Amount & Std.Dev. \\
\hline & & & & \\
\hline 0.5 & 29.68 & 3.15 & 152.82 & 15.69 \\
\hline 1 & 56.39 & 4.83 & 224.11 & 17.4 \\
\hline 2 & 91.13 & 9.44 & 366.31 & 17.82 \\
\hline 4 & & & 742.3 & 29.07 \\
\hline 6 & 198.64 & 24.52 & 1170.37 & 94.2 \\
\hline 8 & & & 1551.1 & 103.72 \\
\hline 10 & 295.04 & 35.59 & 2116.64 & 117.88 \\
\hline 12 & & & 2469.33 & 147.4 \\
\hline 18 & 478.32 & 59.37 & & \\
\hline 26 & 639.1 & 85.402 & & \\
\hline
\end{tabular}


TABLE 17. PERMEATION OF KT THROUGH GUINEA PIG

SKIN FROM LECITHIN:IPM (40:60) CONTAINING 0.1\% WATER AND $1 \% \mathrm{KT}$

\begin{tabular}{|c|c|c|c|c|c|c|c|}
\hline Sample & Time & Abs. & $\mathrm{ug} / \mathrm{ml}$ & ug/5.1 & $\mathrm{ug} / \mathrm{cm}^{2}$ & Cumulative amount & \\
\hline & (h) & & & & & & \\
\hline 1 & 0.5 & 0 & 0 & 0 & 0 & 0 & \\
\hline 2 & 0.5 & 0 & 0 & 0 & 0 & 0 & Average \\
\hline 3 & 0.5 & 0 & $\overline{0}$ & $\overline{0}$ & $\overline{0}$ & 0 & 0 \\
\hline 4 & 0.5 & 0 & 0 & $\overline{0}$ & $\overline{0}$ & 0 & Std.Dev. \\
\hline 5 & 0.5 & $\overline{0}$ & 0 & 0 & 0 & 0 & 0 \\
\hline 6 & 0.5 & 0 & 0 & 0 & 0 & 0 & \\
\hline Sample & Time & Abs. & $\mathrm{ug} / \mathrm{ml}$ & $u g / 5.1$ & $\mathrm{ug} / \mathrm{cm}^{2}$ & Cumulative amount & \\
\hline & (h) & & & & & & \\
\hline 1 & 1 & 0 & 0 & 0 & 0 & 0 & \\
\hline 2 & 1 & 0 & 0 & 0 & 0 & 0 & Average \\
\hline 3 & 1 & 0 & 0 & 0 & $\overline{0}$ & 0 & 0 \\
\hline 4 & 1 & 0 & $\overline{0}$ & 0 & 0 & 0 & Std.Dev. \\
\hline 5 & $\overline{1}$ & $\overline{0}$ & 0 & 0 & $\overline{0}$ & 0 & 0 \\
\hline 6 & $\overline{1}$ & 0 & 0 & 0 & 0 & 0 & \\
\hline Sample & Time & Abs. & $\mathrm{ug} / \mathrm{ml}$ & ug/5.1 & $\mathrm{ug} / \mathrm{cm}^{2}$ & Cumulative amount & \\
\hline & (h) & & & & & & \\
\hline 1 & 2 & 0 & 0 & 0 & 0 & 0 & \\
\hline 2 & 2 & 0 & 0 & 0 & 0 & 0 & Average \\
\hline 3 & 2 & 0 & 0 & 0 & 0 & 0 & 1.346 \\
\hline 4 & 2 & 0 & 0 & 0 & 0 & 0 & Std.Dev. \\
\hline 5 & 2 & 0 & 0 & 0 & 0 & 0 & 3.298 \\
\hline 6 & 2 & 0.011 & 1.007 & 5.136 & 8.077 & 8.077 & \\
\hline Sample & Time & Abs. & $\mathrm{ug} / \mathrm{ml}$ & ug/5.1 & $\mathrm{ug} / \mathrm{cm}^{2}$ & Cumulative amount & \\
\hline & (h) & & & & & & \\
\hline 1 & 4 & 0.022 & 1.211 & 6.175 & 9.711 & 9.711 & \\
\hline 2 & 4 & 0.033 & 1.411 & 7.196 & 11.317 & 11.317 & Average \\
\hline 3 & 4 & 0.054 & 1.801 & 9.184 & 14.444 & 14.444 & 11.723 \\
\hline 4 & 4 & 0.000 & 0.815 & 4.154 & 6.533 & 6.533 & Std.Dev. \\
\hline 5 & 4 & 0.000 & 0.815 & 4.154 & 6.533 & 6.533 & 5.780 \\
\hline 6 & 4 & 0.049 & 1.711 & 8.726 & 13.723 & 21.800 & \\
\hline Sample & Time & Abs. & $\mathrm{ug} / \mathrm{ml}$ & ug/5.1 & $\mathrm{ug} / \mathrm{cm}^{2}$ & Cumulative amount & \\
\hline & (h) & & & & & & \\
\hline$\overline{1}$ & 6 & 0.022 & 1.215 & 6.194 & 9.742 & 19.453 & \\
\hline 2 & 6 & 0.041 & 1.557 & 7.940 & 12.488 & 23.805 & Average \\
\hline 3 & 6 & 0.074 & 2.158 & 11.007 & 17.310 & 31.754 & 24.207 \\
\hline 4 & 6 & 0.021 & 1.202 & 6.132 & 9.644 & 16.177 & Std.Dev. \\
\hline 5 & 6 & 0.000 & 0.815 & 4.154 & 6.533 & 13.067 & 10.487 \\
\hline 6 & 6 & 0.087 & 2.392 & 12.201 & 19.188 & 40.988 & \\
\hline Sample & Time & Abs. & $\mathrm{ug} / \mathrm{ml}$ & ug/5.1 & $\mathrm{ug} / \mathrm{cm}^{2}$ & Cumulative amount & \\
\hline 1 & 8 & 0.150 & 3.611 & 18.415 & 28.962 & 48.414 & \\
\hline 2 & 8 & 0.133 & 3.307 & 16.866 & 26.525 & 50.330 & Average \\
\hline 3 & 8 & 0.111 & 2.911 & 14.848 & 23.352 & 55.106 & 49.762 \\
\hline 4 & 8 & 0.084 & 2.420 & 12.341 & 19.409 & 35.586 & Std.Dev. \\
\hline 5 & 8 & 0.039 & 1.597 & 8.143 & 12.806 & 25.873 & 19.619 \\
\hline 6 & 8 & 0.241 & 5.270 & 26.879 & 42.273 & 83.261 & \\
\hline
\end{tabular}


TABLE 17. CONT'D.

\begin{tabular}{|c|c|c|c|c|c|c|c|}
\hline Sample & Time & Abs. & $\mathrm{ug} / \mathrm{ml}$ & $u g / 5.1$ & $\mathrm{ug} / \mathrm{cm}^{2}$ & Cumulative amount & \\
\hline & (h) & & & & & & \\
\hline 1 & 10 & 0.130 & 3.181 & 16.223 & 25.514 & 73.929 & \\
\hline 2 & 10 & 0.162 & 3.761 & 19.183 & 30.169 & 80.500 & Average \\
\hline$\overline{3}$ & 10 & 0.132 & 3.220 & 16.423 & 25.828 & 80.934 & 75.118 \\
\hline 4 & 10 & 0.099 & 2.623 & 13.375 & 21.035 & 56.621 & Std.Dev. \\
\hline 5 & 10 & 0.024 & 1.243 & 6.340 & 9.971 & 35.844 & 29.086 \\
\hline 6 & 10 & 0.227 & 4.939 & 25.191 & 39.618 & 122.879 & \\
\hline \multirow[t]{2}{*}{ Sample } & Time & Abs. & $\mathrm{ug} / \mathrm{ml}$ & $u g / 5.1$ & $\mathrm{ug} / \mathrm{cm}^{2}$ & Cumulative amount & \\
\hline & (h) & & & & & & \\
\hline$\overline{1}$ & 12 & 0.125 & 3.091 & 15.765 & 24.793 & 98.722 & \\
\hline 2 & 12 & 0.172 & 3.946 & 20.124 & 31.649 & 112.149 & Average \\
\hline 3 & 12 & 0.134 & 3.250 & 16.573 & 26.064 & 106.998 & 100.790 \\
\hline 4 & 12 & 0.099 & 2.623 & 13.375 & 21.035 & 77.656 & Std.Dev. \\
\hline 5 & 12 & 0.027 & 1.314 & 6.700 & 10.536 & 46.380 & 38.774 \\
\hline 6 & 12 & 0.229 & 4.982 & 25.407 & 39.958 & 162.837 & \\
\hline \multirow[t]{2}{*}{ Sample } & Time & Abs. & $\mathrm{ug} / \mathrm{ml}$ & $\mathrm{ug} / 5.1$ & $\mathrm{ug} / \mathrm{cm}^{2}$ & Cumulative amount & \\
\hline & (h) & & & & & & \\
\hline 1 & 18 & 0.433 & 8.693 & 44.333 & 69.723 & 168.445 & \\
\hline 2 & 18 & 0.497 & 9.851 & 50.242 & 79.015 & 191.164 & Average \\
\hline 3 & 18 & 0.358 & 7.327 & 37.368 & 58.768 & 165.765 & 166.146 \\
\hline 4 & 18 & 0.255 & 5.443 & 27.762 & 43.661 & 121.317 & Std.Dev. \\
\hline 5 & 18 & 0.206 & 4.566 & 23.288 & 36.625 & 83.005 & 62.868 \\
\hline 6 & 18 & 0.671 & 13.009 & 66.348 & 104.345 & 267.182 & \\
\hline \multirow[t]{2}{*}{ Sample } & Time & Abs. & $\mathrm{ug} / \mathrm{ml}$ & ug/5.1 & $\mathrm{ug} / \mathrm{cm}^{2}$ & Cumulative amount & \\
\hline & (h) & & & & & & \\
\hline 1 & 24 & 0.481 & 9.563 & 48.773 & 76.705 & 245.150 & \\
\hline 2 & 24 & 0.569 & 11.156 & 56.898 & 89.483 & 280.647 & Average \\
\hline 3 & 24 & 0.444 & 8.895 & 45.363 & 71.343 & 237.108 & 242.886 \\
\hline 4 & 24 & 0.341 & 7.013 & 35.765 & 56.247 & 177.564 & Std.Dev. \\
\hline 5 & 24 & 0.272 & 5.766 & 29.409 & 46.251 & 129.256 & 88.974 \\
\hline 6 & 24 & 0.781 & 15.012 & 76.561 & 120.407 & 387.589 & \\
\hline
\end{tabular}

\begin{tabular}{|c|c|c|c|}
\hline Time & \multicolumn{2}{|l|}{ Average cum. amount } & Std.Dev. \\
\hline (h) & & & \\
\hline 0.5 & 0.000 & & 0.000 \\
\hline 1 & 0.000 & & 0.000 \\
\hline 2 & 1.346 & & 3.298 \\
\hline 4 & 11.723 & & 5.780 \\
\hline 6 & 24.207 & 24.207 & 10.487 \\
\hline 8 & 49.762 & 49.762 & 19.619 \\
\hline 10 & 75.118 & 75.118 & 29.086 \\
\hline 12 & 100.790 & 100.790 & 38.774 \\
\hline 18 & 166.146 & 166.146 & 62.868 \\
\hline 24 & 242.886 & 242.886 & 88.974 \\
\hline
\end{tabular}


TABLE 18. PERMEATION OF KT THROUGH

GUINEA PIG SKIN FROM LECITHIN:IPM (40:60)

CONTAINING 0.1\% WATER AND 6.5\% KT BY HPLC

\begin{tabular}{|c|c|c|c|c|c|c|c|}
\hline Sample & Time & AUP & $\mathrm{ug} / \mathrm{ml}$ & $\mathrm{ug} / 5.1$ & $\mathrm{ug} / \mathrm{cm}^{2}$ & Cumulative amount & \\
\hline & (h) & & & & & & \\
\hline 1 & 0.5 & 0 & 0 & 0 & 0 & 0 & \\
\hline 2 & 0.5 & 0 & 0 & 0 & 0 & 0 & Average \\
\hline 3 & 0.5 & 0 & 0 & 0 & 0 & 0 & 0 \\
\hline 4 & 0.5 & 0 & 0 & 0 & 0 & 0 & Std.Dev. \\
\hline 5 & 0.5 & 0 & 0 & 0 & 0 & 0 & 0 \\
\hline 6 & 0.5 & 0 & 0 & 0 & 0 & 0 & \\
\hline Sample & Time & AUP & $\mathrm{ug} / \mathrm{ml}$ & ug/5.1 & $\mathrm{ug} / \mathrm{cm}^{2}$ & Cumulative amount & \\
\hline & (h) & & & & & & \\
\hline 1 & 1 & 0 & 0 & 0 & 0 & 0 & \\
\hline 2 & 1 & 0 & $\overline{0}$ & 0 & $\overline{0}$ & 0 & Average \\
\hline 3 & 1 & $\overline{0}$ & 0 & 0 & 0 & 0 & 0 \\
\hline 4 & 1 & 0 & 0 & 0 & 0 & 0 & Std.Dev. \\
\hline 5 & 1 & 0 & 0 & 0 & 0 & 0 & 0 \\
\hline 6 & 1 & 0 & 0 & 0 & 0 & 0 & \\
\hline Sample & Time & AUP & $\mathrm{ug} / \mathrm{ml}$ & $\mathrm{ug} / 5.1$ & $\mathrm{ug} / \mathrm{cm}^{2}$ & Cumulative amount & \\
\hline & (h) & & & & & & \\
\hline 1 & 2 & 0 & 0 & 0 & 0 & 0 & \\
\hline 2 & 2 & 0 & 0 & 0 & 0 & 0 & Average \\
\hline 3 & 2 & 0 & 0 & 0 & 0 & 0 & 0 \\
\hline 4 & 2 & 0 & 0 & 0 & 0 & 0 & Std.Dev. \\
\hline 5 & 2 & 0 & 0 & 0 & 0 & 0 & 0 \\
\hline 6 & 2 & 0 & 0 & 0 & 0 & 0 & \\
\hline Sample & Time & AUP & $\mathrm{ug} / \mathrm{ml}$ & $\mathrm{ug} / 5.1$ & $\mathrm{ug} / \mathrm{cm}^{2}$ & Cumulative amount & \\
\hline & (h) & & & & & & \\
\hline 1 & 4 & 50330 & 0.906 & 4.622 & 7.269 & 7.269 & \\
\hline 2 & 4 & 80761 & 1.538 & 7.844 & 12.336 & 12.336 & Average \\
\hline 3 & 4 & 92046 & 1.772 & 9.039 & 14.215 & 14.215 & 8.562 \\
\hline 4 & 4 & 14698 & 0.167 & 0.849 & 1.336 & 1.336 & Std.Dev. \\
\hline 5 & 4 & 93672 & 1.806 & 9.211 & 14.486 & 14.486 & 6.032 \\
\hline 6 & 4 & 17054 & 0.215 & 1.099 & 1.728 & 1.728 & \\
\hline Sample & Time & AUP & $\mathrm{ug} / \mathrm{ml}$ & $u g / 5.1$ & $\mathrm{ug} / \mathrm{cm}^{2}$ & Cumulative amount & \\
\hline & (h) & & & & & & \\
\hline 1 & 6 & 109619 & 2.137 & 10.900 & 17.142 & 24.411 & \\
\hline 2 & 6 & 144452 & 2.860 & 14.588 & 22.942 & 35.278 & Average \\
\hline 3 & 6 & 218999 & 4.408 & 22.481 & 35.355 & 49.571 & 29.204 \\
\hline 4 & 6 & 61445 & 1.137 & 5.799 & 9.120 & 10.456 & Std.Dev. \\
\hline 5 & 6 & 175260 & 3.500 & 17.850 & 28.072 & 42.558 & 15.929 \\
\hline 6 & 6 & 74072 & 1.399 & 7.136 & 11.222 & 12.951 & \\
\hline Sample & Time & AUP & $\mathrm{ug} / \mathrm{ml}$ & $u g / 5.1$ & $\mathrm{ug} / \mathrm{cm}^{2}$ & Cumulative amount & \\
\hline 1 & 8 & 179690 & 3.592 & 18.319 & 28.810 & 53.220 & \\
\hline 2 & 8 & 232315 & 4.684 & 23.890 & 37.573 & 72.851 & Average \\
\hline 3 & 8 & 437608 & 8.946 & 45.627 & 71.757 & 121.328 & 66.642 \\
\hline 4 & 8 & 135966 & 2.684 & 13.689 & 21.529 & 31.984 & Std.Dev. \\
\hline 5 & 8 & 297030 & 6.028 & 30.742 & 48.349 & 90.907 & 35.704 \\
\hline 6 & 8 & 106442 & 2.071 & 10.563 & 16.613 & 29.563 & \\
\hline
\end{tabular}


TABLE 18. CONT'D.

\begin{tabular}{|c|c|c|c|c|c|c|c|}
\hline Sample & Time & AUP & $\mathrm{ug} / \mathrm{ml}$ & $\mathrm{ug} / 5.2$ & $\mathrm{ug} / \mathrm{cm}^{2}$ & Cumulative amount & \\
\hline 1 & 10 & 228223 & 4.599 & 23.457 & 36.891 & 90.111 & \\
\hline 2 & 10 & 266200 & 5.388 & \begin{tabular}{|l|}
27.478 \\
\end{tabular} & 43.215 & 116.066 & Average \\
\hline 3 & 10 & 566058 & 11.613 & 59.227 & 93.146 & 214.474 & 117.707 \\
\hline 4 & 10 & 180632 & 3.611 & 18.418 & 28.966 & 60.951 & Std.Dev. \\
\hline 5 & 10 & 475256 & 9.728 & 49.613 & 78.026 & 168.933 & 62.957 \\
\hline 6 & 10 & 163665 & 3.259 & 16.622 & 26.141 & 55.704 & \\
\hline Sample & Time & AUP & $\mathrm{ug} / \mathrm{ml}$ & ug/5.1 & $\mathrm{ug} / \mathrm{cm}^{2}$ & Cumulative amount & \\
\hline 1 & 12 & 237952 & 4.801 & 24.487 & 38.511 & 128.623 & \\
\hline 2 & 12 & 284574 & 5.769 & 29.424 & 46.275 & 162.340 & Average \\
\hline 3 & 12 & 671185 & 13.796 & \begin{tabular}{|l|}
70.358 \\
\end{tabular} & 110.652 & 325.126 & 183.970 \\
\hline 4 & 12 & 166660 & 3.321 & 16.939 & 26.640 & 87.591 & Std.Dev. \\
\hline 5 & 12 & 775652 & 15.964 & \begin{tabular}{|l|}
81.419 \\
\end{tabular} & 128.047 & 296.980 & 102.026 \\
\hline 6 & 12 & 291654 & 5.916 & \begin{tabular}{|l|}
30.173 \\
\end{tabular} & 47.453 & 103.158 & \\
\hline Sample & Time & AUP & $\mathrm{ug} / \mathrm{ml}$ & $\mathrm{ug} / 5.1$ & $\mathrm{ug} / \mathrm{cm}^{2}$ & Cumulative amount & \\
\hline 1 & 16 & 570962 & 11.715 & 59.746 & 93.963 & 222.585 & \\
\hline 2 & 16 & 579779 & 11.898 & \begin{tabular}{|l|}
60.680 \\
\end{tabular} & 95.431 & 257.771 & Average \\
\hline 3 & 16 & $2 \mathrm{E}+06$ & 35.778 & 182.466 & 286.964 & 612.090 & 335.940 \\
\hline 4 & 16 & 368976 & 7.522 & 38.360 & 60.329 & 147.920 & Std.Dev. \\
\hline 5 & 16 & $2 \mathrm{E}+06$ & 36.858 & \begin{tabular}{|l|l|}
187.975 \\
\end{tabular} & 295.627 & 592.607 & 209.734 \\
\hline 6 & 16 & 484142 & 9.913 & 50.554 & 79.506 & 182.664 & \\
\hline Sample & Time & AUP & $\mathrm{ug} / \mathrm{ml}$ & $u g / 5.1$ & $\mathrm{ug} / \mathrm{cm}^{2}$ & Cumulative amount & \\
\hline 1 & 20 & $1 \mathrm{E}+06$ & 22.762 & 116.085 & 182.566 & 405.152 & \\
\hline 2 & 20 & $1 \mathrm{E}+06$ & 23.441 & 119.550 & 188.016 & 445.787 & Average \\
\hline 3 & 20 & $3 E+06$ & 61.692 & 314.631 & 494.820 & 1106.909 & 600.377 \\
\hline 4 & 20 & 829010 & 17.072 & 87.068 & 136.932 & 284.852 & Std.Dev. \\
\hline 5 & 20 & $3 E+06$ & 52.073 & 265.574 & 417.668 & 1010.276 & 360.335 \\
\hline 6 & 20 & $1 \mathrm{E}+06$ & 20.774 & 105.946 & 166.622 & 349.285 & \\
\hline Sample & Time & AUP & $\mathrm{ug} / \mathrm{ml}$ & $\mathrm{ug} / 5.1$ & $\mathrm{ug} / \mathrm{cm}^{2}$ & Cumulative amount & \\
\hline 1 & 24 & 205604 & 4.130 & 21.062 & 33.125 & 438.276 & \\
\hline 2 & 24 & 196584 & 3.943 & 20.107 & 31.623 & 477.410 & Average \\
\hline 3 & 24 & 927927 & 19.126 & 97.541 & 153.403 & 1260.313 & 662.528 \\
\hline 4 & 24 & 526784 & 10.798 & 55.069 & 86.606 & 371.458 & Std.Dev. \\
\hline 5 & 24 & 193912 & 3.887 & 19.824 & 31.178 & 1041.454 & \begin{tabular}{|l|}
386.403 \\
\end{tabular} \\
\hline 6 & 24 & 228719 & 4.610 & 23.510 & 36.974 & 386.259 & \\
\hline
\end{tabular}

\begin{tabular}{|c|c|c|c|}
\hline Time & Average Cum. amount & Std.Dev. \\
\hline & & & \\
\hline 0.5 & 0.000 & & 0.000 \\
\hline 1 & 0.000 & & 0.000 \\
\hline 2 & 0.000 & & 0.000 \\
\hline 4 & 8.562 & & 6.032 \\
\hline 6 & 29.204 & & 15.929 \\
\hline 8 & 66.642 & 66.642 & 35.704 \\
\hline 10 & 117.707 & 117.707 & 62.957 \\
\hline 12 & 183.970 & 183.970 & 102.026 \\
\hline 16 & 335.940 & 335.940 & 209.734 \\
\hline 20 & 600.377 & & 360.335 \\
\hline 24 & 662.53 & & 386.403 \\
\hline
\end{tabular}


TABLE 19. COMPARISON OF CELLULOSE ACETATE MEMBRANE WITH GUINEA PIG SKIN ON KT RELEASE FROM LECITHIN:IPM (40:60) CONTAINING 0.1\% WATER AND $6.5 \% \mathrm{KT}$

\begin{tabular}{|c|c|c|c|c|}
\hline & Guinea Pig Skin & & Cellulose Acetate & \\
\hline & & & & \\
\hline Time & Average Cum.Amount & Std.Dev. & Average Cum.Amount & Std.Dev. \\
\hline & & & & \\
\hline 0.5 & 0.000 & 0.000 & 152.822 & 15.689 \\
\hline 1 & 0.000 & 0.000 & 224.110 & 17.396 \\
\hline 2 & 0.000 & 0.000 & 366.315 & 17.816 \\
\hline 4 & 8.562 & 6.032 & 742.302 & 29.066 \\
\hline 6 & 29.204 & 15.929 & 1170.373 & 94.198 \\
\hline 8 & 66.642 & 35.704 & 1551.097 & 103.722 \\
\hline 10 & 117.707 & 62.957 & 2116.640 & 117.878 \\
\hline 12 & 183.970 & 102.026 & 2469.334 & 147.397 \\
\hline 16 & 335.940 & 209.734 & & \\
\hline 20 & 600.377 & 360.335 & & \\
\hline 24 & 662.530 & 386.403 & & \\
\hline
\end{tabular}


TABLE 20. CUMULATIVE RELEASE OF KT ACROSS CELLULOSE ACETATE MEMBRANE FROM LECITHIN:IPM (40:60) CONTAINING 0.25\% WATER AND $6.5 \% \mathrm{KT}$

\begin{tabular}{|c|c|c|c|c|c|c|c|c|}
\hline Sample & Time & Abs. & $\mathrm{ug} / \mathrm{ml}$ & & ug/5.1 & $\mathrm{ug} / \mathrm{cm}^{2}$ & \multicolumn{2}{|c|}{ Cumulative amount } \\
\hline & (h) & & & & & & & \\
\hline 1 & 0.5 & 0.440 & 8.811 & & 44.937 & 70.673 & 70.673 & \\
\hline$\overline{2}$ & 0.5 & 0.563 & 11.055 & & 56.380 & 88.668 & 88.668 & Average \\
\hline 3 & 0.5 & 0.509 & 10.075 & & 51.384 & 80.811 & 80.811 & 84.797 \\
\hline 4 & 0.5 & 0.624 & 12.166 & & 62.046 & 97.580 & 97.580 & Std.Dev. \\
\hline 5 & 0.5 & 0.651 & 12.655 & & 64.538 & 101.499 & 101.499 & 13.455 \\
\hline 6 & 0.5 & 0.432 & 8.671 & & 44.223 & 69.549 & 69.549 & \\
\hline & & & & & & & & \\
\hline Sample & Time & Abs. & $\mathrm{ug} / \mathrm{ml}$ & & $u g / 5.1$ & $\mathrm{ug} / \mathrm{cm}^{2}$ & \multicolumn{2}{|c|}{ Cumulative amount } \\
\hline & (h) & & & & & & & \\
\hline 1 & 1 & 0.262 & 5.580 & & 28.459 & 44.758 & 115.431 & \\
\hline 2 & 1 & 0.330 & 6.808 & & 34.720 & 54.605 & 143.273 & Average \\
\hline 3 & 1 & 0.276 & 5.834 & & 29.755 & 46.796 & 127.607 & 135.350 \\
\hline 4 & 1 & 0.327 & 6.768 & & 34.517 & 54.284 & 151.864 & Std.Dev. \\
\hline 5 & 1 & 0.343 & 7.045 & & 35.927 & 56.503 & 158.002 & 18.346 \\
\hline 6 & 1 & 0.273 & 5.781 & & 29.485 & 46.371 & 115.921 & \\
\hline & & & & & & & & \\
\hline Sample & Time & Abs. & $\mathrm{ug} / \mathrm{ml}$ & & $u g / 5.1$ & $\mathrm{ug} / \mathrm{cm}^{2}$ & \multicolumn{2}{|c|}{ Cumulative amount } \\
\hline & (h) & & & & & & & \\
\hline 1 & $\frac{1}{2}$ & 0.802 & 15.404 & & 78.558 & 123.549 & 238.980 & \\
\hline 2 & 2 & 0.942 & 17.935 & & 91.467 & 143.849 & 287.122 & Average \\
\hline 3 & 2 & 0.827 & 15.853 & & 80.849 & 127.151 & 254.759 & 271.488 \\
\hline 4 & 2 & 1.009 & 19.153 & & 97.682 & 153.624 & 305.488 & Std.Dev. \\
\hline 5 & 2 & 1.016 & 19.295 & & 98.403 & 154.758 & 312.760 & 35.148 \\
\hline 6 & 2 & 0.736 & 14.200 & & 72.422 & 113.898 & 229.818 & \\
\hline & & & & & & & & \\
\hline & & & & & & & & \\
\hline Sample & Time & Abs. & $\mathrm{ug} / \mathrm{ml}$ & & ug/5.1 & $\mathrm{ug} / \mathrm{cm}^{2}$ & \multicolumn{2}{|c|}{ Cumulative amount } \\
\hline 1 & $\frac{(h)}{4}$ & 1.593 & 29.777 & & 151.863 & 238.835 & 477.814 & \\
\hline 2 & 4 & 1.994 & 37.066 & & 189.037 & 297.297 & 584.420 & Average \\
\hline 3 & 4 & 1.608 & 30.057 & & 153.289 & 241.078 & 495.836 & 533.034 \\
\hline 4 & 4 & 2.001 & 37.203 & & 189.737 & 298.399 & 603.887 & Std.Dev. \\
\hline 5 & 4 & 1.823 & 33.962 & & 173.205 & 272.400 & 585.160 & 65.614 \\
\hline 6 & 4 & 1.472 & 27.587 & & 140.692 & 221.267 & 451.085 & \\
\hline Sample & Time & Abs. & $\mathrm{ug} / \mathrm{ml}$ & $2^{\star}(u g / m l)$ & $u q / 5.1$ & $\mathrm{ug} / \mathrm{cm}^{2}$ & \multicolumn{2}{|c|}{ Cumulative amount } \\
\hline & (h) & & & & & & & \\
\hline 1 & 6 & 1.198 & 22.599 & 45.197 & 230.505 & 362.515 & 840.329 & \\
\hline 2 & 6 & 1.519 & 28.441 & 56.881 & 290.094 & 456.230 & 1040.649 & Average \\
\hline 3 & 6 & 1.136 & 21.474 & 42.949 & 219.039 & 344.481 & 840.318 & 915.320 \\
\hline 4 & 6 & 1.454 & 27.252 & 54.504 & 277.969 & 437.161 & 1041.047 & Std.Dev. \\
\hline 5 & 6 & 1.229 & 23.156 & 46.312 & 236.193 & 371.460 & 956.620 & 113.787 \\
\hline 6 & 6 & 1.059 & 20.065 & 40.129 & 204.660 & 321.869 & 772.954 & \\
\hline
\end{tabular}


TABLE 20. CONT'D.

\begin{tabular}{|c|c|c|c|c|c|c|c|c|}
\hline Sample & Time & Abs. & $\mathrm{ug} / \mathrm{ml}$ & $2^{*}(\mathrm{ug} / \mathrm{ml})$ & ug/5.1 & $\mathrm{ug} / \mathrm{cm}^{2}$ & \multicolumn{2}{|c|}{ Cumulative amount } \\
\hline & (h) & & & & & & & \\
\hline 1 & 8 & 1.493 & 28.038 & 56.077 & 285.991 & 449.778 & 1290.107 & \\
\hline 2 & 8 & 1.631 & 30.545 & 61.090 & 311.558 & 489.987 & 1530.636 & Average \\
\hline 3 & 8 & 1.393 & 26.222 & 52.445 & 267.468 & 420.647 & 1260.964 & 1351.132 \\
\hline 4 & 8 & 1.585 & 29.701 & 59.401 & 302.947 & 476.445 & 1517.492 & Std.Dev. \\
\hline 5 & 8 & 1.384 & 26.054 & 52.107 & 265.747 & 417.940 & 1374.560 & 154.835 \\
\hline 6 & 8 & 1.186 & 22.447 & 44.893 & 228.955 & 360.077 & 1133.030 & \\
\hline & & & & & & & & \\
\hline ample & Time & Abs. & $\mathrm{ug} / \mathrm{ml}$ & $2^{\star}(u g / m l)$ & $u g / 5.1$ & $\mathrm{ug} / \mathrm{cm}^{2}$ & \multicolumn{2}{|c|}{ Cumulative amount } \\
\hline & (h) & & & & & & & \\
\hline 1 & 10 & 1.630 & 30.445 & 60.889 & 310.536 & 488.380 & .487 & \\
\hline 2 & 10 & 1.653 & 30.867 & $1.7 \overline{34}$ & 314.844 & 495.155 & 791 & \\
\hline 3 & 10 & 1.637 & 30.577 & 24 & 311.884 & 490.500 & 464 & 655 \\
\hline 4 & 10 & 1.564 & 29.254 & 8.509 & 298.395 & 469.284 & 777 & Dev. \\
\hline 5 & 10 & 1.443 & 27.048 & 36 & 275.891 & 433.894 & 54 & 97 \\
\hline 6 & 10 & 1.484 & 27.798 & 55.597 & 283.543 & 445.928 & 58 & \\
\hline & & & & & & & & \\
\hline & & & & & & & & \\
\hline Sample & Time & Abs. & $\mathrm{ug} / \mathrm{ml}$ & $2^{\star}(\mathrm{ug} / \mathrm{ml})$ & $u g / 5.1$ & $\mathrm{ug} / \mathrm{cm}^{2}$ & \multicolumn{2}{|c|}{ Cumulative amount } \\
\hline & (h) & & & & & & & \\
\hline 1 & 12 & 1.564 & 29.256 & 58.512 & 298.409 & 469.308 & 2247.795 & \\
\hline 2 & 12 & 1.616 & 30.197 & 60.393 & 308.005 & 484.398 & 2510.189 & Average \\
\hline 3 & 12 & 1.680 & 31.354 & 62.707 & 319.807 & 502.960 & 2254.424 & 2286.971 \\
\hline 4 & 12 & 1.504 & 28.151 & 56.302 & 287.139 & 451.583 & 2438.360 & Std.Dev. \\
\hline 5 & 12 & 1.450 & 27.171 & 54.341 & 277.140 & 435.857 & 2244.311 & 170.221 \\
\hline 6 & 12 & 1.490 & 27.914 & 55.829 & 284.727 & 447.789 & 2026.747 & \\
\hline
\end{tabular}

\begin{tabular}{|c|c|c|c|}
\hline Time & Average cum. amnt & Std.Dev. \\
\hline (h) & & & \\
\hline 0.5 & 84.797 & & 13.455 \\
\hline 1 & 135.350 & & 18.346 \\
\hline 2 & 271.488 & & 35.148 \\
\hline 4 & 533.034 & & 65.614 \\
\hline 6 & 915.320 & 915.320 & 113.787 \\
\hline 8 & 1351.132 & 1351.132 & 154.835 \\
\hline 10 & 1821.655 & 1821.655 & 164.197 \\
\hline 12 & 2286.971 & 2286.971 & 170.221 \\
\hline
\end{tabular}


TABLE 21. CUMULATIVE RELEASE OF KT ACROSS CELLULOSE ACETATE MEMBRANEFROM LECITHIN:IPM (50:50) CONTAINING $0.25 \%$ WATER AND $6.5 \% \mathrm{KT}$

\begin{tabular}{|c|c|c|c|c|c|c|c|}
\hline Sample & Time & Abs. & $\mathrm{ug} / \mathrm{ml}$ & $u g / 5.1$ & $\mathrm{ug} / \mathrm{cm}^{2}$ & Cumulative amount & \\
\hline & (h) & & & & & & \\
\hline 1 & 0.5 & 0.602 & 11.753 & 59.941 & 94.269 & 94.269 & \\
\hline 2 & 0.5 & 0.614 & 11.971 & 61.055 & 96.020 & 96.020 & Average \\
\hline 3 & 0.5 & 0.513 & 10.149 & 51.761 & 81.405 & 81.405 & 92.550 \\
\hline 4 & 0.5 & 0.763 & 14.683 & 74.884 & 117.770 & 117.770 & Std.Dev. \\
\hline 5 & 0.5 & 0.558 & 10.962 & 55.904 & 87.921 & 87.921 & 14.219 \\
\hline \multirow[t]{2}{*}{6} & 0.5 & 0.489 & 9.714 & 49.541 & 77.914 & 77.914 & \\
\hline & & & & & & & \\
\hline \multirow[t]{2}{*}{ Sample } & Time & Abs. & $\mathrm{ug} / \mathrm{ml}$ & ug/5.1 & $\mathrm{ug} / \mathrm{cm}^{2}$ & Cumulative amount & \\
\hline & (h) & & & & & & \\
\hline 1 & 1 & 0.329 & 6.789 & 34.623 & 54.451 & 148.720 & \\
\hline 2 & 1 & 0.288 & 6.054 & 30.877 & 48.561 & 144.581 & Average \\
\hline 3 & 1 & 0.257 & 5.493 & 28.012 & 44.055 & 125.460 & 144.023 \\
\hline 4 & 1 & 0.375 & 7.624 & 38.884 & 61.153 & 178.923 & Std.Dev. \\
\hline 5 & 1 & 0.324 & 6.714 & 34.242 & 53.853 & 141.773 & 19.820 \\
\hline \multirow[t]{3}{*}{6} & 1 & 0.276 & 5.831 & 29.736 & 46.765 & 124.679 & \\
\hline & & & & & & & \\
\hline & & & & & & & \\
\hline \multirow[t]{2}{*}{ Sample } & Time & Abs. & $\mathrm{ug} / \mathrm{ml}$ & ug/5.1 & $\mathrm{ug} / \mathrm{cm}^{2}$ & Cumulative amount & \\
\hline & (h) & & & & & & \\
\hline 1 & 2 & 0.932 & 17.762 & 90.588 & 142.467 & 291.188 & \\
\hline 2 & 2 & 0.856 & 16.377 & 83.522 & 131.355 & 275.936 & Average \\
\hline 3 & 2 & \begin{tabular}{|l|}
0.709 \\
\end{tabular} & 13.713 & 69.939 & 109.993 & 235.453 & 277.002 \\
\hline 4 & 2 & 0.984 & 18.699 & 95.365 & 149.980 & 328.903 & Std.Dev \\
\hline 5 & 2 & 0.984 & 18.702 & 95.379 & 150.002 & 291.775 & 35.506 \\
\hline \multirow[t]{2}{*}{6} & 2 & 0.737 & 14.223 & 72.535 & 114.076 & 238.755 & \\
\hline & & & & & & & \\
\hline \multirow{2}{*}{ Sample } & Time & Abs. & $\mathrm{ua} / \mathrm{ml}$ & ua/5.1 & $4 \mathrm{c} / \mathrm{cm}^{2}$ & Cumulative amount & \\
\hline & (h) & & & & & & \\
\hline 1 & 4 & 1.589 & 29.709 & 151.515 & 238.287 & 529.474 & \\
\hline 2 & $\overline{4}$ & 1.494 & 27.976 & 142.678 & 224.389 & 500.325 & Average \\
\hline 3 & 4 & 1.201 & 22.651 & 115.522 & 181.682 & 417.134 & 494.806 \\
\hline 4 & 4 & 1.606 & 30.014 & 153.072 & 240.737 & 569.639 & Std.Dev. \\
\hline 5 & 4 & 1.582 & 29.585 & 150.885 & 237.296 & 529.072 & 61.915 \\
\hline 6 & 4 & 1.220 & 22.995 & 117.276 & 184.440 & 423.194 & \\
\hline \multirow[t]{2}{*}{ Sample } & Time & Abs. & $\mathrm{ug} / \mathrm{ml}$ & $4 \mathrm{~g} / 5.1$ & $\mathrm{ug} / \mathrm{cm}^{2}$ & Cumulative amount & \\
\hline & (h) & & & & & & \\
\hline 1 & 6 & 1.497 & 28.034 & 142.972 & 224.851 & 754.325 & \\
\hline 2 & 6 & 1.409 & 26.433 & 134.808 & 212.012 & 712.337 & Average \\
\hline 3 & 6 & 1.180 & 22.261 & 113.531 & 178.549 & 595.684 & 700.962 \\
\hline 4 & 6 & 1.501 & 28.096 & 143.291 & 225.354 & 794.994 & Std.Dev \\
\hline 5 & 6 & 1.501 & 28.099 & 143.304 & 225.375 & 754.446 & 86.264 \\
\hline 6 & 6 & 1.126 & 21.293 & 108.597 & 170.790 & 593.984 & \\
\hline
\end{tabular}


TABLE 21. CONT'D.

\begin{tabular}{|c|c|c|c|c|c|c|c|}
\hline Sample & Time & Abs. & ug/ml & ug/5.2 & ug/cm & Cumulative amount & \\
\hline & (h) & & & & & & \\
\hline 1 & 8 & 1.367 & 25.745 & 131.297 & 206.491 & 960.816 & \\
\hline 2 & 8 & 1.355 & 25.528 & 130.192 & 204.752 & 917.089 & Average \\
\hline 3 & 8 & 1.167 & 22.099 & 112.707 & 177.254 & 772.938 & 899.919 \\
\hline 4 & 8 & 1.464 & 27.511 & 140.307 & 220.661 & 1015.655 & Std.Dev. \\
\hline 5 & 8 & 1.395 & 26.245 & 133.850 & 210.506 & 964.952 & 105.012 \\
\hline 6 & 8 & 1.145 & 21.703 & 110.687 & 174.077 & 768.061 & \\
\hline & & & & & & & \\
\hline & & & & & & & \\
\hline Sample & Time & Abs. & ug/ml & ug/5.1 & ug/cm & Cumulative amount & \\
\hline & (h) & & & & & & \\
\hline 1 & 10 & 1.425 & 26.717 & 136.256 & 214.290 & 1175.106 & \\
\hline 2 & 10 & 1.397 & 26.215 & 133.694 & 210.261 & 1127.350 & Average \\
\hline 3 & 10 & 1.255 & 23.632 & 120.521 & 189.544 & 962.482 & 1108.63 \\
\hline 4 & 10 & 1.571 & 29.380 & 149.840 & 235.653 & 1251.308 & Std.Dev. \\
\hline 5 & 10 & 1.438 & 26.955 & 137.469 & 216.197 & 1181.149 & 122.904 \\
\hline 6 & 10 & 1.233 & 23.234 & 118.492 & 186.353 & 954.414 & \\
\hline & & & & & & & \\
\hline & & & & & & & \\
\hline Sample & Time & Abs. & ug/ml & ug/5.1 & ug/cm & Cumulative amount & \\
\hline & (h) & & & & & & \\
\hline 1 & 12 & 1.397 & 26.220 & 133.721 & 210.303 & 1385.409 & \\
\hline 2 & 12 & 1.488 & 27.869 & 142.130 & 223.527 & 1350.877 & Average \\
\hline 3 & 12 & 1.334 & 25.077 & 127.890 & 201.133 & 1163.615 & 1327.03 \\
\hline 4 & 12 & 1.640 & 30.633 & 156.231 & 245.704 & 1497.011 & Std.Dev. \\
\hline 5 & 12 & 1.511 & 28.283 & 144.242 & 226.849 & 1407.998 & 137.800 \\
\hline 6 & 12 & 1.346 & 25.293 & 128.995 & 202.870 & 1157.283 & \\
\hline & & & & & & & \\
\hline & & & & & \\
\hline & & & & & & \\
\hline & & & & & & \\
\hline & & & & & & \\
\hline & & & & & & \\
\hline & & & & & & \\
\hline & & & & & & \\
\hline & & & & & & \\
\hline
\end{tabular}

\begin{tabular}{|c|c|c|c|}
\hline Time & Average cum. amount & Std.Dev. \\
\hline (h) & & & \\
\hline 0.5 & 92.550 & & 14.219 \\
\hline 1 & 144.023 & & 19.820 \\
\hline 2 & 277.002 & 277.002 & 35.506 \\
\hline 4 & 494.806 & 494.806 & 61.915 \\
\hline 6 & 700.962 & 700.962 & 86.264 \\
\hline 8 & 899.919 & 899.919 & 105.012 \\
\hline 10 & 1108.635 & 1108.635 & 122.904 \\
\hline 12 & 1327.032 & 1327.032 & 137.800 \\
\hline
\end{tabular}


TABLE 22. CUMULATIVE RELEASE OF KT ACROSS CELLULOSE ACETATE MEMBRANE FROM LECITHIN:IPM $(60: 40)$ CONTAINING $0.25 \%$ WATER AND $6.5 \% \mathrm{KT}$

\begin{tabular}{|c|c|c|c|c|c|c|c|}
\hline Sample & Time & Abs. & $\mathrm{ug} / \mathrm{ml}$ & ug/5.1 & $\mathrm{ug} / \mathrm{cm}^{2}$ & Cumulative amount & \\
\hline & (h) & & & & & & \\
\hline 1 & 0.5 & 0.557 & 10.949 & 55.841 & 87.820 & 87.820 & \\
\hline 2 & 0.5 & 0.426 & 8.554 & 43.624 & 68.608 & 114.332 & Average \\
\hline 3 & 0.5 & 0.515 & 10.179 & 51.914 & 81.645 & 101.361 & 102.362 \\
\hline 4 & 0.5 & 0.355 & 7.262 & 37.035 & 58.245 & 84.583 & Std.Dev. \\
\hline 5 & 0.5 & 0.448 & 8.956 & 45.676 & 71.835 & 98.688 & 16.196 \\
\hline \multirow[t]{2}{*}{6} & 0.5 & 0.501 & 9.928 & 50.632 & 79.629 & 127.387 & \\
\hline & & & & & & & \\
\hline \multirow[t]{2}{*}{ Sample } & Time & Abs. & $\mathrm{ug} / \mathrm{ml}$ & ug/5.1 & $\mathrm{ug} / \mathrm{cm}^{2}$ & Cumulative amount & \\
\hline & (h) & & & & & & \\
\hline 1 & $\frac{1-1}{1}$ & 0.395 & 7.998 & 40.790 & 64.151 & 151.971 & \\
\hline 2 & 1 & 0.328 & 6.786 & 34.609 & 54.429 & 168.761 & Average \\
\hline$\overline{3}$ & 1 & 0.369 & 7.526 & 38.381 & 60.361 & 161.722 & 159.353 \\
\hline 4 & 1 & 0.277 & 5.851 & 29.839 & 46.927 & 131.510 & Std.Dev. \\
\hline 5 & 1 & 0.305 & 6.362 & 32.448 & 51.031 & 149.719 & 20.547 \\
\hline \multirow[t]{3}{*}{6} & 1 & 0.401 & 8.110 & 41.359 & 65.045 & 192.433 & \\
\hline & & & & & & & \\
\hline & & & & & & & \\
\hline \multirow[t]{2}{*}{ Sample } & Time & Abs. & $\mathrm{ug} / \mathrm{ml}$ & ug/5.1 & $\mathrm{ug} / \mathrm{cm}^{2}$ & Cumulative amount & \\
\hline & (h) & & & & & & \\
\hline 1 & 2 & 0.766 & 14.739 & 75.170 & 118.220 & 270.191 & \\
\hline 2 & 2 & 0.695 & 13.442 & 68.554 & 107.815 & 276.576 & Average \\
\hline 3 & 2 & 0.735 & 14.174 & 72.288 & 113.688 & 275.410 & 272.616 \\
\hline$\overline{4}$ & 2 & 0.671 & 13.019 & 66.396 & 104.420 & 235.930 & Std.Dev. \\
\hline 5 & 2 & 0.708 & 13.685 & 69.795 & 109.766 & 259.486 & 26.894 \\
\hline \multirow[t]{2}{*}{6} & 2 & 0.817 & 15.668 & 79.906 & 125.668 & 318.100 & \\
\hline & & & & & & & \\
\hline \multirow[t]{2}{*}{ Sample } & Time & Abs. & $\mathrm{ug} / \mathrm{ml}$ & $u g / 5.1$ & $\mathrm{ug} / \mathrm{cm}^{2}$ & Cumulative amount & \\
\hline & (h) & & & & & & \\
\hline 1 & 4 & 1.177 & 22.221 & 113.328 & 178.230 & 448.421 & \\
\hline 2 & 4 & 1.068 & 20.225 & 103.149 & 162.222 & 438.798 & Average \\
\hline 3 & 4 & 1.206 & 22.744 & 115.996 & 182.427 & 457.837 & 430.863 \\
\hline 4 & 4 & 0.865 & 16.546 & 84.384 & 132.710 & 368.640 & Std.Dev. \\
\hline 5 & 4 & 0.913 & 17.422 & 88.850 & 139.735 & 399.221 & 39.206 \\
\hline 6 & 4 & 1.012 & 19.220 & 98.022 & 154.159 & 472.259 & \\
\hline \multirow[t]{2}{*}{ Sample } & Time & Abs. & $\mathrm{ug} / \mathrm{ml}$ & $u g / 5.1$ & $\mathrm{ug} / \mathrm{cm}^{2}$ & Cumulative amount & \\
\hline & (h) & & & & & & \\
\hline 1 & $\frac{17}{6}$ & 1.060 & 20.086 & 102.437 & 161.102 & 609.523 & \\
\hline 2 & 6 & 1.092 & 20.678 & 105.457 & 165.852 & 604.649 & Average \\
\hline 3 & 6 & 1.156 & 21.834 & 111.353 & 175.125 & 632.962 & 583.120 \\
\hline$\overline{4}$ & 6 & 0.796 & 15.286 & 77.957 & 122.602 & 491.242 & Std.Dev. \\
\hline 5 & 6 & 0.868 & 16.598 & 84.650 & 133.129 & 532.349 & 57.754 \\
\hline 6 & 6 & 1.023 & 19.416 & 99.023 & 155.734 & 627.993 & \\
\hline
\end{tabular}


TABLE 22. CONT'D.

\begin{tabular}{|c|c|c|c|c|c|c|c|}
\hline Sample & Time & Abs. & ug/ml & ug/5.2 & ug/ $\mathbf{c m}^{2}$ & Cumulative amount & \\
\hline & (h) & & & & & & \\
\hline 1 & 8 & 1.225 & 23.158 & 118.106 & 185.745 & 795.268 & \\
\hline 2 & 8 & 1.285 & 24.260 & 123.724 & 194.581 & 799.230 & Average \\
\hline 3 & 8 & 1.309 & 24.685 & 125.896 & 197.996 & 830.958 & 760.484 \\
\hline 4 & 8 & 0.909 & 17.409 & 88.788 & 139.637 & 630.879 & Std.Dev. \\
\hline 5 & 8 & 1.075 & 20.438 & 104.235 & 163.930 & 696.279 & 78.839 \\
\hline 6 & 8 & 1.201 & 22.728 & 115.912 & 182.294 & 810.288 & \\
\hline & & & & & & & \\
\hline & & & & & & & \\
\hline Sample & Time & Abs. & ug/ml & ug/5.1 & ug/cm & Cumulative amount & \\
\hline & (h) & & & & & & \\
\hline 1 & 10 & 1.133 & 21.415 & 109.216 & 171.764 & 967.032 & \\
\hline 2 & 10 & 1.170 & 22.087 & 112.645 & 177.157 & 976.387 & Average \\
\hline 3 & 10 & 1.222 & 23.036 & 117.482 & 184.763 & 1015.722 & 923.934 \\
\hline 4 & 10 & 0.819 & 15.698 & 80.058 & 125.907 & 756.786 & Std.Dev. \\
\hline 5 & 10 & 1.011 & 19.200 & 97.920 & 153.999 & 850.278 & 99.253 \\
\hline 6 & 10 & 1.101 & 20.835 & 106.257 & 167.110 & 977.398 & \\
\hline & & & & & & & \\
\hline & & & & & & & \\
\hline Sample & Time & Abs. & ug/ml & ug/5.1 & ug/cm & Cumulative amount & \\
\hline & (h) & & & & & & \\
\hline 1 & 12 & 1.302 & 24.489 & 124.893 & 196.420 & 1163.452 & \\
\hline 2 & 12 & 1.365 & 25.642 & 130.772 & 205.665 & 1182.052 & Average \\
\hline 3 & 12 & 1.485 & 27.811 & 141.837 & 223.066 & 1238.788 & 1118.46 \\
\hline 4 & 12 & 1.021 & 19.370 & 98.785 & 155.359 & 912.145 & Std.Dev. \\
\hline 5 & 12 & 1.249 & 23.528 & 119.993 & 188.712 & 1038.990 & 120.549 \\
\hline 6 & 12 & 1.312 & 24.675 & 125.845 & 197.916 & 1175.314 & \\
\hline & & & & & & & \\
\hline
\end{tabular}

\begin{tabular}{|c|c|c|c|}
\hline Time & Average cum. amount & Std.Dev. \\
\hline (h) & & & \\
\hline 0.5 & 102.362 & & 16.196 \\
\hline 1 & 159.353 & 159.353 & 20.547 \\
\hline 2 & 272.616 & 272.616 & 26.894 \\
\hline 4 & 430.863 & 430.863 & 39.206 \\
\hline 6 & 583.120 & 583.120 & 57.754 \\
\hline 8 & 760.484 & 760.484 & 78.839 \\
\hline 10 & 923.934 & 923.934 & 99.253 \\
\hline 12 & 1118.457 & 1118.457 & 120.549 \\
\hline
\end{tabular}


TABLE 23. EFFECT OF LECITHIN CONCENTRATION ON KT RELEASE FROM LECITHIN:IPM (40:60), (50:50) AND (60:40) CONTAINING $0.25 \%$ WATER AND $6.5 \%$ KT

\begin{tabular}{|c|c|c|c|c|c|c|}
\hline & Lecithin/IPM(40:60) & \multicolumn{3}{|c|}{ Lecithin/IPM(50:50) } & Lecithin/IPM(60:40) \\
\hline Time & Average Cum.Amnt.Std.Dev & Average Cum.Amnt & Std.Dev & Average Cum.Amnt. & Std.Dev. \\
\hline & & & & & & \\
\hline 0.5 & 84.8 & 13.46 & 92.55 & 14.22 & 102.36 & 16.2 \\
\hline 1 & 135.35 & 18.35 & 144.02 & 19.82 & 159.35 & 20.55 \\
\hline 2 & 271.49 & 35.15 & 277 & 35.51 & 272.62 & 26.89 \\
\hline 4 & 533.03 & 65.61 & 494.81 & 61.92 & 430.86 & 39.21 \\
\hline 6 & 915.32 & 113.8 & 700.96 & 86.26 & 583.12 & 57.75 \\
\hline 8 & 1351.13 & 154.8 & 899.92 & 105 & 760.48 & 78.84 \\
\hline 10 & 1821.66 & 164.2 & 1108.63 & 122.9 & 923.93 & 99.25 \\
\hline 12 & 2286.97 & 170.2 & 1327.03 & 137.8 & 1118.46 & 120.55 \\
\hline
\end{tabular}


TABLE 24. RELEASE PROFILE OF KT FROM LECITHIN:IPM (40:60) CONTAINING DIFFERENT WATER AMOUNTS AND 6.5\% KT

\begin{tabular}{|c|c|c|c|c|c|c|}
\hline & $\mathbf{0 . 1 \%}$ Water Conc. & & $\mathbf{0 . 2 5} \%$ Water Conc. & & $\mathbf{0 . 5 \%}$ Water Conc. & \\
\hline Time Average Cum.Amnt & Std.Dev & Average Cum.Amnt & Std.Dev & Average Cum.Amn & Std.Dev. \\
\hline & & & & & & \\
\hline 0.5 & 152.82 & 15.69 & 84.80 & 13.46 & 147.35 & 23.07 \\
\hline 1 & 224.11 & 17.40 & 135.35 & 18.35 & 216.45 & 24.88 \\
\hline 2 & 366.31 & 17.82 & 271.49 & 35.15 & 350.71 & 71.59 \\
\hline 4 & 742.30 & 29.07 & 533.03 & 65.61 & 669.21 & 65.25 \\
\hline 6 & 1170.37 & 94.20 & 915.32 & 113.79 & 1059.35 & 68.71 \\
\hline 8 & 1551.10 & 103.72 & 1351.13 & 154.83 & 1450.72 & 71.91 \\
\hline 10 & 2116.64 & 117.88 & 1821.66 & 164.20 & 1791.67 & 79.43 \\
\hline 12 & 2469.33 & 147.40 & 2286.97 & 170.22 & 2124.48 & 96.22 \\
\hline
\end{tabular}

\begin{tabular}{|c|r|c|c|c|c|c|}
\hline & $\mathbf{0 . 6 \%}$ Water Conc. & & $\mathbf{0 . 7 \%}$ Water Conc. & & $\mathbf{0 . 8 \%}$ Water Conc. & \\
\hline Time Average Cum.Amn & Std.Dev & Average Cum.Amn & Std.Dev & Average Cum.Amnt & Std.Dev. \\
\hline & & & & & & \\
\hline 0.5 & 95.18 & 13.61 & 99.41 & 8.94 & 73.46 & 9.40 \\
\hline 1 & 169.16 & 29.77 & 170.8 & 13.76 & 142.88 & 17.74 \\
\hline 2 & 280.84 & 61.54 & 297.02 & 22.55 & 241.26 & 29.70 \\
\hline 4 & 707.52 & 128.77 & 555.85 & 46.06 & 496.84 & 65.61 \\
\hline 6 & 1206.9 & 140.92 & 920.36 & 117.91 & 889.09 & 54.30 \\
\hline 8 & 1648.37 & 168.74 & 1382.10 & 176.01 & 1353.16 & 63.14 \\
\hline 10 & 2099.12 & 176.10 & 1835.81 & 209.67 & 1856.69 & 72.37 \\
\hline 12 & 2555.76 & 192.55 & 2383.48 & 233.56 & 2388.26 & 78.07 \\
\hline
\end{tabular}


TABLE 25. RELEASE PROFILE OF KT FROM LECITHIN:IPM (50:50) CONTAINING DIFFERENT WATER AMOUNTS AND 6.5\% KT

\begin{tabular}{|c|c|c|c|c|c|c|}
\hline & $\mathbf{0 . 1 \%}$ Water Conc. & & $\mathbf{0 . 2 5} \%$ Water Conc. & & $\mathbf{0 . 5 \%}$ Water Conc. & \\
\hline Time & Average Cum.AmntStd.Dev & Average Cum.Amnt & Std.Dev & Average Cum.Amnt & Std.Dev. \\
\hline & & & & & & \\
\hline 0.5 & 116.94 & 22.11 & 92.55 & 14.22 & 84.26 & 15.51 \\
\hline 1 & 202.57 & 62.90 & 144.02 & 19.82 & 157.67 & 22.48 \\
\hline 2 & 389.43 & 116.22 & 277.00 & 35.51 & 272.20 & 36.59 \\
\hline 4 & 583.20 & 105.74 & 494.81 & 61.92 & 546.53 & 57.92 \\
\hline 6 & 777.58 & 90.90 & 700.96 & 86.26 & 817.24 & 87.52 \\
\hline 8 & 976.58 & 85.22 & 899.92 & 105.01 & 1099.93 & 108.09 \\
\hline 10 & 1172.10 & 81.21 & 1108.63 & 122.90 & 1365.74 & 130.31 \\
\hline 12 & 1366.66 & 80.86 & 1327.03 & 137.80 & 1644.62 & 149.33 \\
\hline
\end{tabular}

\begin{tabular}{|c|c|c|c|c|c|c|}
\hline & $\mathbf{0 . 6 \%}$ Water Conc. & & $\mathbf{0 . 7 \%}$ Water Conc. & & $\mathbf{0 . 8 \%}$ Water Conc. & \\
\hline Time & Average Cum.Amnt & Std.Dev & Average Cum.Amnt & Std.Dev & Average Cum.Amnt & Std.Dev. \\
\hline & & & & & & \\
\hline 0.5 & 92.33 & 14.20 & 98.22 & 7.69 & 107.16 & 19.60 \\
\hline 1 & 149.56 & 17.17 & 162.98 & 14.17 & 162.62 & 29.11 \\
\hline 2 & 247.79 & 24.33 & 278.84 & 25.44 & 293.45 & 36.11 \\
\hline 4 & 457.98 & 46.01 & 509.53 & 38.90 & 547.21 & 48.06 \\
\hline 6 & 660.79 & 66.40 & 725.08 & 51.25 & 744.85 & 70.65 \\
\hline 8 & 888.64 & 88.53 & 964.41 & 66.70 & 933.25 & 76.53 \\
\hline 10 & 1113.83 & 108.04 & 1204.05 & 82.16 & 1133.17 & 74.98 \\
\hline 12 & 1351.01 & 131.06 & 1462.15 & 94.67 & 1329.88 & 71.20 \\
\hline
\end{tabular}


TABLE 26. RELEASE PROFILE OF KT FROM LECITHIN:IPM (60:40) CONTAINING DIFFERENT WATER AMOUNTS AND 6.5\% KT

\begin{tabular}{|c|c|c|c|c|c|c|}
\hline & $\mathbf{0 . 1 \%}$ Water Conc. & & $\mathbf{0 . 2 5 \% W a t e r ~ C o n c . ~}$ & & $\mathbf{0 . 5 \%}$ Water Conc. & \\
\hline Time & Average Cum.Amnt & Std.Dev & Average Cum.Amnt & Std.Dev & Average Cum.Amnt & Std.Dev. \\
\hline & & & & & & \\
\hline 0.5 & 104.35 & 26.52 & 102.36 & 16.20 & 105.14 & 12.23 \\
\hline 1 & 163.72 & 35.64 & 159.35 & 20.55 & 156.46 & 11.26 \\
\hline 2 & 272.98 & 49.18 & 272.62 & 26.89 & 300.39 & 27.50 \\
\hline 4 & 478.67 & 69.40 & 430.86 & 39.21 & 548.08 & 59.23 \\
\hline 6 & 672.72 & 93.93 & 583.12 & 57.75 & 825.60 & 81.40 \\
\hline 8 & 874.93 & 114.91 & 760.48 & 78.84 & 1077.48 & 102.89 \\
\hline 10 & 1061.90 & 129.98 & 923.93 & 99.25 & 1316.70 & 122.77 \\
\hline 12 & 1264.94 & 147.28 & 1118.46 & 120.55 & 1560.72 & 141.37 \\
\hline
\end{tabular}

\begin{tabular}{|c|c|c|c|c|c|c|}
\hline & $\mathbf{0 . 6 \%}$ Water Conc. & & $\mathbf{0 . 7 \%}$ Water Conc. & & $\mathbf{0 . 8 \%}$ Water Conc. & \\
\hline Time & Average Cum.Amnt Std.Dev & Average Cum.Amnt & Std.Dev & Average Cum.Amnt & Std.Dev. \\
\hline & & & & & & \\
\hline 0.5 & 94.20 & 3.23 & 92.92 & 15.00 & 87.57 & 17.09 \\
\hline 1 & 151.33 & 6.11 & 154.70 & 24.05 & 157.00 & 28.24 \\
\hline 2 & 265.73 & 5.84 & 269.96 & 36.36 & 243.10 & 48.10 \\
\hline 4 & 522.33 & 19.06 & 518.56 & 58.67 & 494.29 & 72.39 \\
\hline 6 & 797.86 & 27.37 & 780.38 & 82.31 & 742.56 & 98.60 \\
\hline 8 & 1033.75 & 32.79 & 1005.79 & 102.30 & 954.29 & 132.15 \\
\hline 10 & 1293.00 & 33.45 & 1246.81 & 116.81 & 1188.49 & 163.50 \\
\hline 12 & 1542.80 & 34.13 & 1476.27 & 130.26 & 1423.23 & 181.94 \\
\hline
\end{tabular}


TABLE 27. EFFECT OF WATER CONCENTRATION ON KT RELEASE FROM LECITHIN:IPM (40:60) CONTAINING 6.5\% KT

\begin{tabular}{|c|c|c|}
\hline Water Conc. (\%) & Q12 $\left(\mathbf{u g} / \mathbf{c m}^{2}\right)$ & Std.Dev. \\
\hline & & \\
\hline 0.1 & 2469.33 & 147.4 \\
\hline 0.25 & 2286.97 & 170.22 \\
\hline 0.5 & 2124.48 & 96.22 \\
\hline 0.6 & 2555.757 & 192.55 \\
\hline 0.7 & 2383.48 & 233.56 \\
\hline 0.8 & 2388.26 & 78.07 \\
\hline
\end{tabular}


TABLE 28. EFFECT OF WATER CONCENTRATION ON KT RELEASE FROM LECITHIN:IPM (50:50) CONTAINING 6.5\% KT

\begin{tabular}{|c|c|c|}
\hline Water Conc.(\%) & Q12(ug/cm $\left.{ }^{2}\right)$ & Std.Dev. \\
\hline & & \\
\hline 0.1 & 1366.66 & 80.86 \\
\hline 0.25 & 1327.03 & 137.80 \\
\hline 0.5 & 1644.62 & 149.33 \\
\hline 0.6 & 1351.01 & 131.06 \\
\hline 0.7 & 1462.15 & 94.66 \\
\hline 0.8 & 1329.88 & 71.20 \\
\hline
\end{tabular}


TABLE 29. EFFECT OF WATER CONCENTRATION ON KT RELEASE FROM LECITHIN:IPM (60:40) CONTAINING 6.5\% KT

\begin{tabular}{|c|c|c|}
\hline Water Conc.(\%) & Q12 (ug// $\left.\mathbf{c m}^{2}\right)$ & Std.Dev. \\
\hline & & \\
\hline 0.1 & 1264.94 & 147.28 \\
\hline 0.25 & 1118.46 & 120.55 \\
\hline 0.5 & 1560.72 & 141.37 \\
\hline 0.6 & 1542.80 & 34.13 \\
\hline 0.7 & 1476.27 & 130.26 \\
\hline 0.8 & 1423.23 & 181.94 \\
\hline
\end{tabular}


TABLE 30. EFFECT OF VISCOSITY ON KT RELEASE FROM

ORGANOGELS WITH DIFFERENT LECITHIN

CONCENTRATION BY CYLINDRICAL VISCOMETER

\begin{tabular}{|c|c|c|c|}
\hline Lecithin/IPM & Mean Viscosity (p) & Mean Cum.Amount (ug/cm2) & Std.Dev. \\
\hline & & & \\
\hline$(40: 60)$ & 418.8 & 2286.97 & 170.22 \\
\hline$(50: 50)$ & 951.76 & 1327.032 & 137.8 \\
\hline$(60: 40)$ & 1832.7 & 1118.46 & 120.55 \\
\hline
\end{tabular}


TABLE 31. EFFECT OF LECITHIN CONCENTRATION ON VISCOSITY C LECITHIN:IPM (40:60), (50:50) AND (60:40) CONTAINING $0.25 \%$

WATER AND 6.5\% KT BY CYLINDRICAL VISCOMETER

\begin{tabular}{|c|c|c|c|r|}
\hline Sample & Viscosity 1 ( $p)$ & Viscosity 2 ( $p)$ & Mean viscosity (p) & Std.Dev. \\
\hline Lecithin/IPM & & & & \\
\hline$(40: 60)$ & 338.08 & 499.51 & 418.80 & 114.15 \\
\hline$(50: 50)$ & 933.58 & 969.93 & 951.76 & 25.70 \\
\hline$(60: 40)$ & 1578.9 & 2086.5 & 1832.70 & 358.93 \\
\hline
\end{tabular}

\begin{tabular}{|c|c|c|}
\hline Sample & Mean Viscosity (p) & Std.Dev. \\
\hline Lecithin/IPM & & \\
\hline$(40: 60)$ & 418.80 & 114.15 \\
\hline$(50: 50)$ & 951.76 & 25.70 \\
\hline$(60: 40)$ & 1832.70 & 358.93 \\
\hline
\end{tabular}


TABLE 32. EFFECT OF LECITHIN CONCENTRATION ON THE VISCOSITY OF LECITHIN:IPM (40:60), (50:50) AND (60:40) CONTAINING $0.25 \%$ WATER AND $6.5 \% \mathrm{KT}$ BY CONE AND PLATE VISCOMETER

\begin{tabular}{|c|c|}
\hline Sample & Viscosity (p) \\
\hline Lecithin/IPM & \\
\hline$(40: 60)$ & 591.98 \\
\hline$(50: 50)$ & 947.61 \\
\hline$(60: 40)$ & 2825 \\
\hline
\end{tabular}


TABLE 33. EFFECT OF THE SHEAR RATE ON VISCOSITY OF LECITHIN:IPM (40:60) CONTAINING 0.25\% WATER AND 6.5\% KT BY CONE AND PLATE VISCOMETER

\begin{tabular}{|c|c|c|c|c|}
\hline$\overline{R P M}$ & Torque (\%) & Sh Str (N/m2) & Sh Rt (1/Sec) & Viscosity (mPas) \\
\hline 01 & 06 & 944 & $0 ?$ & 47184 \\
\hline 0.6 & 4.2 & 66.1 & 1.2 & 55048 \\
\hline 1.1 & 8.9 & 140 & 2.2 & 63627 \\
\hline 1.6 & 13.7 & 215.5 & 3.2 & 67336 \\
\hline 2.1 & 18.5 & 291 & 4.2 & 69278 \\
\hline 2.6 & 23.3 & 366.5 & 5.2 & 70474 \\
\hline 3.1 & 28.2 & 443.5 & 6.2 & 71537 \\
\hline 3.6 & 33 & 519 & 7.2 & 72087 \\
\hline 4.1 & 37.5 & 589.8 & 8.2 & 71927 \\
\hline 4.6 & 42.5 & 668.4 & 9.2 & 72657 \\
\hline 5.1 & 47.5 & 747.1 & 10.2 & 73243 \\
\hline 5.6 & 51.9 & 816.3 & 11.2 & 72882 \\
\hline 6.1 & 56.6 & 890.2 & 12.2 & 72968 \\
\hline 6.6 & 61.6 & 968.8 & 13.2 & 73397 \\
\hline 7.1 & 66.8 & 1051 & 14.2 & 73988 \\
\hline 7.6 & 71.1 & 1118 & 15.2 & 73570 \\
\hline 8.1 & 75.6 & 1189 & 16.2 & 73397 \\
\hline 8.6 & 80.6 & 1268 & 17.2 & 73702 \\
\hline 9.1 & 85.3 & 1342 & 18.2 & 73714 \\
\hline 9.6 & 90.1 & 1417 & 19.2 & 73807 \\
\hline 10.0 & 94.1 & 1480 & 20.0 & 74000 \\
\hline 9.5 & 92.5 & 1455 & 19.0 & 76571 \\
\hline 9.0 & 87.7 & 1379 & 18.0 & 76630 \\
\hline 8.5 & 82.7 & 1301 & 17.0 & 76512 \\
\hline 8.0 & 78.1 & 1228 & 16.0 & 76772 \\
\hline 7.5 & 73.6 & 1158 & 15.0 & 77172 \\
\hline 7.0 & 68.7 & 1081 & 14.0 & 77180 \\
\hline 6.5 & 63.9 & 1005 & 13.0 & 77309 \\
\hline 6.0 & 59.0 & 928 & 12.0 & 77329 \\
\hline 5.5 & 54.7 & 860.3 & 11.0 & 78211 \\
\hline 5.0 & 49.9 & 784.8 & 10.0 & 78483 \\
\hline 4.5 & 44.9 & 706.2 & 9.0 & 78465 \\
\hline 4.0 & 40.2 & 632.3 & 8.0 & 79033 \\
\hline 3.5 & 35.3 & 555.2 & 7.0 & 79314 \\
\hline 3.0 & 30.7 & 482.8 & 6.0 & 80475 \\
\hline 2.5 & 25.8 & 405.8 & 5.0 & 81156 \\
\hline 2.0 & 21.2 & 333.4 & 4.0 & 83358 \\
\hline 1.5 & 16.2 & 254.8 & 3.0 & 84931 \\
\hline 1.0 & 11.5 & 180.9 & 2.0 & 90436 \\
\hline 0.5 & 6.7 & 105.4 & 1.0 & 105378 \\
\hline 0.1 & 2.4 & 37.7 & 0.2 & 188736 \\
\hline
\end{tabular}


TABLE 34. EFFECT OF WATER CONCENTRATION ON VISCOSITY OF LECITHIN:IPM (40:60) CONTAINING 6.5\% KT BY CYLINDRICAL VISCOMETER

\begin{tabular}{|c|c|c|c|c|}
\hline Water Conc.(\%) & Viscosity 1 ( $p$ ) & Viscosity 2 (p) & Mean Viscosity (p) & Std.Dev. \\
\hline & & & & \\
\hline 0.1 & 450.46 & 759.92 & 605.19 & 218.82 \\
\hline 0.25 & 338.08 & 499.51 & 418.80 & 114.15 \\
\hline 0.5 & 488 & 634.69 & 561.35 & 103.73 \\
\hline 0.7 & 293 & 238.11 & 265.56 & 38.81 \\
\hline 0.8 & 172.89 & 238.55 & 205.72 & 46.43 \\
\hline
\end{tabular}

\begin{tabular}{|c|c|c|}
\hline Water Conc.(\%) & Mean Viscosity (p) & Std.Dev. \\
\hline & & \\
\hline 0.1 & 605.19 & 218.82 \\
\hline 0.25 & 418.80 & 114.15 \\
\hline 0.5 & 561.35 & 103.73 \\
\hline 0.7 & 265.56 & 38.81 \\
\hline 0.8 & 205.72 & 46.43 \\
\hline
\end{tabular}


TABLE 35. EFFECT OF WATER CONCENTRATION ON THE VISCOSITY OF LECITHIN:IPM (40:60) CONTAINING 6.5\% KT BY CONE AND PLATE VISCOMETER

\begin{tabular}{|c|c|}
\hline Water Conc. (\%) & Viscosity (p) \\
\hline & \\
\hline 0.1 & 585.91 \\
\hline 0.25 & 591.98 \\
\hline 0.5 & 748.96 \\
\hline 0.6 & 541.68 \\
\hline 0.7 & 536.66 \\
\hline 0.8 & 448.86 \\
\hline
\end{tabular}


TABLE 36. EFFECT OF VISCOSITY ON KT RELEASE FROM LECITHIN:IPM (40:60), (50:50) AND (60:40) CONTAINING 0.25\% WATER AND 6.5\% KT BY CONE AND PLATE VISCOMETER

\begin{tabular}{|c|c|c|c|}
\hline Lecithin/IPM & Viscosity (p) & Mean Cum. Amount (ug/cm2) & Std.Dev. \\
\hline & & & \\
\hline$(40: 60)$ & 591.98 & 2286.97 & 170.22 \\
\hline$(50: 50)$ & 947.61 & 1327.03 & 137.8 \\
\hline$(60: 40)$ & 2825 & 1118.46 & 120.55 \\
\hline
\end{tabular}


TABLE 37. VISCOSITY OF ORGANOGEL SAMPLES WITH DIFFERENT COMPOSITIONS BY CONE AND PLATE VISCOMETER

\begin{tabular}{|c|c|c|c|}
\hline & Lecithin/IPM (40:60) & Lecithin/IPM (50:50) & Lecithin/IPM (60:40) \\
\hline & & & \\
\hline Water Conc.(\%) & Viscosity (p) & Viscosity (p) & Viscosity (p) \\
\hline & & & \\
\hline 0.1 & 585.91 & 851.35 & 2834.80 \\
\hline 0.25 & 591.98 & 974.61 & 2825.00 \\
\hline 0.5 & 748.96 & 827.20 & 2335.90 \\
\hline 0.6 & 541.68 & 844.70 & 2472.40 \\
\hline 0.7 & 536.66 & 900.22 & 2432.00 \\
\hline 0.8 & 448.86 & 842.30 & 2063.60 \\
\hline
\end{tabular}


TABLE 38. RELEASE PROFILE OF KT ACROSS CELLULOSE ACETATE FROM 6.5\% KT ORGANOGELS OF DIFFERENT COMPOSITIONS

\begin{tabular}{|c|c|c|c|c|c|c|}
\hline & Lecithin/IPM & & Lecithin/IPM & & Lecithin/IPM & \\
\hline & $(\mathbf{4 0 : 6 0 )}$ & & $\mathbf{( 5 0 : 5 0 )}$ & & $\mathbf{6 0 : 4 0 )}$ & \\
\hline Water Conc. & Cum.Amount & Std.Dev & Cum.Amount & Std.Dev & Cum.Amount & Std.Dev. \\
\hline & & & & & & \\
\hline $0.1 \%$ water & 2469.33 & 147.4 & 1366.664 & 80.858 & 1264.94 & 147.28 \\
\hline $0.25 \%$ water & 2286.97 & 170.22 & 1327.03 & 137.8 & 1118.46 & 120.55 \\
\hline $0.5 \%$ water & 2124.48 & 96.22 & 1644.62 & 149.33 & 1560.72 & 141.37 \\
\hline $0.6 \%$ water & 2555.757 & 192.55 & 1351.01 & 131.06 & 1542.8 & 34.13 \\
\hline $0.7 \%$ water & 2383.48 & 233.56 & 1462.15 & 94.66 & 1476.27 & 130.26 \\
\hline $0.8 \%$ water & 2388.26 & 78.07 & 1329.88 & 71.2 & 1423.23 & 181.94 \\
\hline
\end{tabular}




\section{TABLE 39. CUMULATIVE RELAESE OF KT ACROSS CELLULOS ACETATE MEMBRANE FROM LECITHIN:IPM (40:60) CONTAINING $0.5 \%$ WATER AND $6.5 \% \mathrm{KT}$}

\begin{tabular}{|c|c|c|c|c|c|c|c|c|}
\hline \multicolumn{2}{|c|}{ Sample Time } & Abs. & $\mathrm{ug} / \mathrm{ml}$ & & ug/5.1 & $\mathrm{ug} / \mathrm{cm}^{2}$ & \multicolumn{2}{|l|}{ Cumulative amount } \\
\hline & (h) & & & & & & & \\
\hline 1 & 0.5 & 0.722 & 13.950 & & 71.143 & 111.886 & 111.886 & \\
\hline 2 & 0.5 & 0.871 & 16.646 & & 84.894 & 133.513 & 171.811 & Average \\
\hline 3 & 0.5 & 0.628 & 12.234 & & 62.393 & 98.126 & 131.330 & 147.349 \\
\hline 4 & 0.5 & 0.725 & 13.993 & & 71.364 & 112.233 & 170.301 & Std.Dev. \\
\hline 5 & 0.5 & 0.564 & 11.075 & & 56.484 & \begin{tabular}{|l|}
88.833 \\
\end{tabular} & 146.784 & 23.070 \\
\hline 6 & 0.5 & 0.585 & 11.445 & & 58.372 & 91.801 & 151.980 & \\
\hline & & & & & & & & \\
\hline Sample & Time & Abs. & $\mathrm{ug} / \mathrm{ml}$ & & $u g / 5.1$ & $\mathrm{ug} / \mathrm{cm}^{2}$ & Cumulative amount & \\
\hline & (h) & & & & & & & \\
\hline 1 & 1 & 0.463 & 9.238 & & 47.116 & 74.100 & 185.986 & \\
\hline 2 & 1 & 0.495 & 9.814 & & 50.051 & 78.715 & 250.525 & Average \\
\hline 3 & 1 & 0.397 & 8.024 & & 40.925 & 64.362 & 195.692 & 216.447 \\
\hline 4 & 1 & 0.429 & 8.609 & & 43.906 & 69.051 & 239.352 & Std.Dev. \\
\hline 5 & 1 & 0.385 & 7.808 & & 39.818 & 62.622 & 209.406 & 24.883 \\
\hline 6 & 1 & 0.406 & 8.196 & & 41.801 & 65.740 & 217.719 & \\
\hline & & & & & & & & \\
\hline Sample & Time & Abs. & $\mathrm{ug} / \mathrm{ml}$ & & ug/5.1 & $\mathrm{ug} / \mathrm{cm}^{2}$ & Cumulative amoun & \\
\hline & (h) & & & & & & & \\
\hline 1 & 2 & 1.305 & 24.536 & & 125.135 & 196.800 & 382.786 & \\
\hline 2 & 2 & 0.286 & 6.017 & & 30.686 & 48.260 & 298.786 & Average \\
\hline 3 & 2 & 0.197 & 4.391 & & 22.392 & 35.216 & 230.908 & 350.714 \\
\hline 4 & 2 & 1.212 & 22.851 & & 116.540 & 183.282 & 422.633 & Std.Dev. \\
\hline 5 & 2 & 1.113 & 21.049 & & 107.349 & 168.827 & 378.233 & 71.591 \\
\hline 6 & 2 & 1.143 & 21.596 & & 110.141 & 173.218 & 390.937 & \\
\hline & & & & & & & & \\
\hline Sample & Time & Abs. & $\mathrm{ug} / \mathrm{ml}$ & $2^{*}(\mathrm{ug} / \mathrm{ml})$ & $u g / 5.1$ & $\mathrm{ug} / \mathrm{cm}^{2}$ & Cumulative amount & \\
\hline & (h) & & & & & & & \\
\hline 1 & 4 & 1.134 & 21.427 & 42.855 & 218.560 & 343.729 & 726.515 & \\
\hline 2 & 4 & 1.154 & 21.801 & 43.602 & 222.369 & 349.720 & 648.505 & Average \\
\hline 3 & 4 & 1.059 & 20.075 & 40.149 & 204.762 & 322.029 & 552.937 & 669.208 \\
\hline 4 & 4 & 1.007 & 19.124 & 38.248 & 195.063 & 306.775 & 729.409 & Std.Dev. \\
\hline 5 & 4 & 0.948 & 18.058 & 36.116 & 184.190 & 289.675 & 667.908 & 65.251 \\
\hline 6 & 4 & 0.980 & 18.642 & 37.283 & 190.144 & 299.038 & 689.976 & \\
\hline Sample & Time & Abs. & $\mathrm{ug} / \mathrm{ml}$ & $2^{*}(\mathrm{ug} / \mathrm{ml})$ & $u g / 5.1$ & $\mathrm{ug} / \mathrm{cm}^{2}$ & Cumulative amount & \\
\hline & (h) & & & & & & & \\
\hline 1 & 6 & 1.407 & 26.389 & 52.778 & 269.169 & 423.321 & 1149.836 & \\
\hline 2 & 6 & 1.343 & 25.238 & 50.476 & 257.429 & 404.859 & 1053.364 & Average \\
\hline 3 & 6 & 1.311 & 24.647 & 49.293 & 251.397 & 395.371 & 948.308 & 1059.347 \\
\hline 4 & 6 & 1.240 & 23.366 & 46.732 & 238.335 & 374.829 & 1104.238 & Std.Dev. \\
\hline 5 & 6 & 1.194 & 22.530 & 45.059 & 229.802 & 361.410 & 1029.317 & 68.712 \\
\hline 6 & 6 & 1.262 & 23.753 & 47.507 & 242.285 & 381.041 & 1071.017 & \\
\hline
\end{tabular}


TABLE 39. CONT'D.

\begin{tabular}{|c|c|c|c|c|c|c|c|c|}
\hline \multicolumn{2}{|c|}{ Sample Time } & Abs. & $\mathrm{ug} / \mathrm{ml}$ & $2^{*}(\mathrm{ug} / \mathrm{ml})$ & $\mathrm{ug} / 5.2$ & $\mathrm{ug} / \mathrm{cm}^{2}$ & \multicolumn{2}{|l|}{ Cumulative amount } \\
\hline & (h) & & & & & & & \\
\hline 1 & 8 & 1.348 & 25.396 & 50.793 & 259.043 & 407.396 & 1557.233 & \\
\hline 2 & 8 & 1.309 & 24.687 & 49.373 & 251.805 & 396.013 & 1449.377 & Average \\
\hline 3 & 8 & 1.494 & 28.050 & 56.101 & 286.114 & 449.970 & 1398.278 & 1450.724 \\
\hline 4 & 8 & 1.347 & 25.370 & 50.741 & 258.778 & 406.979 & 1511.217 & Std.Dev. \\
\hline 5 & 8 & 1.102 & 20.930 & 41.860 & 213.486 & 335.749 & 1365.066 & 71.905 \\
\hline 6 & 8 & 1.159 & 21.953 & 43.906 & 223.920 & 352.158 & 1423.175 & \\
\hline & & & & & & & & \\
\hline & & & & & & & & \\
\hline Sample & Time & Abs. & $\mathrm{ug} / \mathrm{ml}$ & $2^{*}(\mathrm{ug} / \mathrm{ml})$ & $\mathrm{ug} / 5.1$ & $\mathrm{ug} / \mathrm{cm}^{2}$ & Cumulative amoun & \\
\hline & (h) & & & & & & & \\
\hline 1 & 10 & 1.134 & 21.439 & 42.877 & 218.673 & 343.907 & 1901.139 & \\
\hline 2 & 10 & 1.085 & 20.541 & 41.081 & 209.514 & 329.502 & 1778.878 & Average \\
\hline 3 & 10 & 1.277 & 24.038 & 48.076 & 245.188 & 385.606 & 1783.884 & 1791.674 \\
\hline 4 & 10 & 1.163 & 21.967 & 43.933 & 224.061 & 352.380 & 1863.596 & Std.Dev. \\
\hline 5 & 10 & 1.057 & 20.032 & 40.064 & 204.328 & 321.347 & 1686.413 & 79.429 \\
\hline 6 & 10 & 1.028 & 19.509 & 39.019 & 198.995 & 312.958 & 1736.133 & \\
\hline & & & & & & & & \\
\hline Sample & Time & Abs. & $4 \mathbf{a} / \mathbf{m l}$ & $2^{\star}(\mathrm{ug} / \mathrm{ml})$ & 4a/5.1 & $4 \mathrm{~d} / \mathrm{cm}^{2}$ & Cumulative amoun & \\
\hline & (h) & & & & & & & \\
\hline 1 & 12 & 1.110 & 21.002 & 42.005 & 214.224 & 336.910 & 2238.049 & \\
\hline 2 & 12 & 1.038 & 19.681 & 39.362 & 200.745 & 315.712 & 2094.590 & Average \\
\hline 3 & 12 & 1.235 & 23.274 & 46.548 & 237.393 & 373.347 & 2157.232 & 2124.476 \\
\hline 4 & 12 & 1.175 & 22.173 & 44.347 & 226.169 & 355.696 & 2219.292 & Std.Dev. \\
\hline 5 & 12 & 1.068 & 20.236 & 40.472 & 206.405 & 324.613 & 2011.026 & 96.221 \\
\hline 6 & 12 & 0.951 & 18.111 & 36.223 & 184.736 & 290.533 & 2026.667 & \\
\hline
\end{tabular}

\begin{tabular}{|c|c|c|c|}
\hline Time & \multicolumn{2}{|c|}{ Average cum.amnt. } & Std.Dev. \\
\hline (h) & & & \\
\hline 0.5 & 147.349 & & 23.070 \\
\hline 1 & 216.447 & & 24.883 \\
\hline 2 & 350.714 & 350.714 & 71.591 \\
\hline 4 & 669.208 & 669.208 & 65.251 \\
\hline 6 & 1059.347 & 1059.347 & 68.712 \\
\hline 8 & 1450.724 & 1450.724 & 71.905 \\
\hline 10 & 1791.674 & 1791.674 & 79.429 \\
\hline 12 & 2124.476 & 2124.476 & 96.221 \\
\hline
\end{tabular}




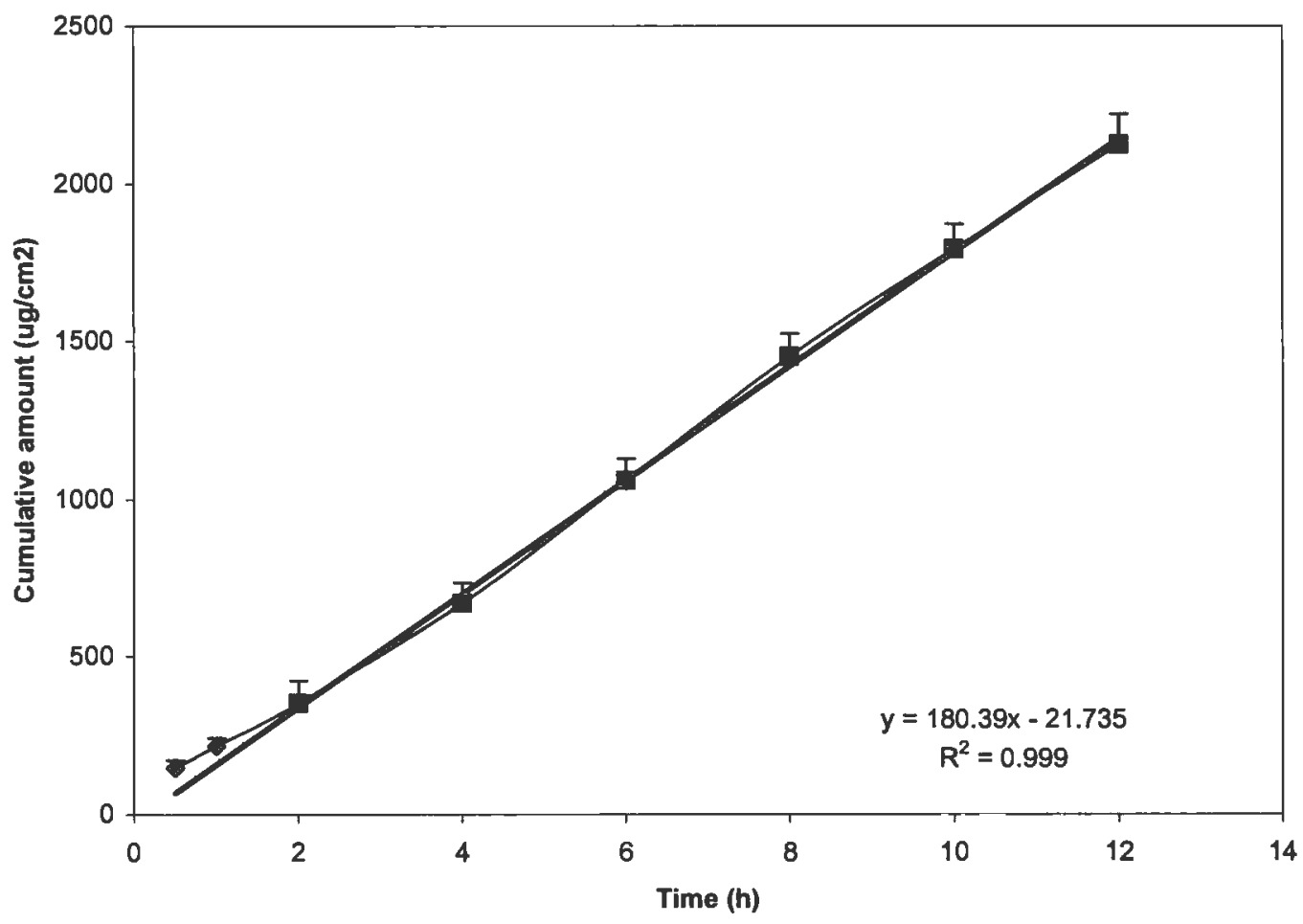

FIGURE 42. RELEASE PROFILE OF KT FROM LECITHIN:IPM (40:60) CONTAINING 0.5\% WATER AND 6.5\% KT (MEAN \pm SD, $\mathrm{N}=6$ ) 
TABLE 40. CUMULATIVE RELEASE OF KT ACROSS CELLULOSE ACETATE MEMBRANE FROM LECITHIN:IPM (40:60) CONTAINING $0.6 \%$ WATER AND $6.5 \% \mathrm{KT}$

\begin{tabular}{|c|c|c|c|c|c|c|c|c|}
\hline \multicolumn{2}{|c|}{ SampleTime } & Abs. & $\mathrm{ug} / \mathrm{ml}$ & & $\mathrm{ug} / 5.1$ & $\mathrm{ug} / \mathrm{cm}^{2}$ & \multicolumn{2}{|l|}{ Cumulative amount } \\
\hline & (h) & & & & & & & \\
\hline 1 & 0.5 & 0.618 & 12.044 & & 61.425 & 96.603 & 96.603 & \\
\hline 2 & 0.5 & 0.598 & 11.681 & & 59.575 & 93.693 & 93.693 & Average \\
\hline 3 & 0.5 & 0.500 & 9.899 & & 50.484 & 79.396 & 79.396 & 95.183 \\
\hline 4 & 0.5 & 0.563 & 11.058 & & 56.395 & 88.693 & 88.693 & Std.Dev. \\
\hline 5 & 0.5 & 0.590 & 11.541 & & 58.857 & 92.565 & 92.565 & 13.608 \\
\hline \multirow[t]{2}{*}{6} & 0.5 & 0.779 & 14.980 & & 76.398 & 120.151 & 120.151 & \\
\hline & & & & & & & & \\
\hline \multicolumn{2}{|c|}{ Sample Time } & Abs. & $\mathrm{ug} / \mathrm{ml}$ & & $u g / 5.1$ & $\mathrm{ug} / \mathrm{cm}^{2}$ & \multicolumn{2}{|l|}{ Cumulative amount } \\
\hline & (h) & & & & & & & \\
\hline 1 & 1 & 0.437 & 8.758 & & 44.667 & 70.248 & 166.851 & \\
\hline 2 & 1 & 0.438 & 8.773 & & 44.744 & 70.368 & 164.061 & Average \\
\hline 3 & 1 & 0.384 & 7.792 & & 39.738 & 62.495 & 141.891 & 169.157 \\
\hline 4 & 1 & 0.421 & $8 . \overline{477}$ & & 43.234 & 67.994 & 156.687 & Std.Dev. \\
\hline 5 & 1 & 0.405 & 8.177 & & 41.701 & 65.584 & 158.149 & 29.775 \\
\hline \multirow[t]{2}{*}{6} & 1 & 0.690 & 13.360 & & 68.135 & 107.155 & 227.306 & \\
\hline & & & & & & & & \\
\hline \multicolumn{2}{|c|}{ SampleTime } & Abs. & $\mathrm{ug} / \mathrm{ml}$ & & ug/5.1 & $\mathrm{ug} / \mathrm{cm}^{2}$ & \multicolumn{2}{|l|}{ Cumulative amount } \\
\hline & (h) & & & & & & & \\
\hline 1 & 2 & 0.681 & 13.196 & & 67.299 & 105.840 & 272.692 & \\
\hline 2 & 2 & 0.633 & 12.319 & & 62.829 & 98.811 & 262.872 & Average \\
\hline 3 & 2 & 0.566 & 11.104 & & 56.632 & 89.064 & 230.955 & 280.843 \\
\hline 4 & 2 & 0.640 & 12.458 & & 63.535 & 99.921 & 256.608 & Std.Dev. \\
\hline 5 & 2 & 0.645 & 12.536 & & 63.934 & 100.549 & 258.697 & 61.540 \\
\hline \multirow[t]{2}{*}{6} & 2 & 1.162 & 21.934 & & 111.865 & 175.930 & 403.236 & \\
\hline & & & & & & & & \\
\hline \multicolumn{2}{|c|}{ SampleTime } & Abs. & $\mathrm{ug} / \mathrm{ml}$ & $2^{\star}(\mathrm{ug} / \mathrm{ml})$ & $u g / 5.1$ & $\mathrm{ug} / \mathrm{cm}^{2}$ & \multicolumn{2}{|l|}{ Cumulative amount } \\
\hline & (h) & & & & & & & \\
\hline 1 & 4 & 1.379 & 25.885 & 51.771 & 264.032 & 415.242 & 687.934 & \\
\hline 2 & 4 & 1.451 & 27.190 & 54.380 & 277.340 & 436.172 & 699.043 & Average \\
\hline 3 & 4 & 1.130 & 21,364 & 42.728 & 217.911 & 342.708 & 573.664 & 707.524 \\
\hline 4 & 4 & 1.354 & 25.440 & 50.879 & 259.484 & 408.090 & 664.698 & Std.Dev. \\
\hline 5 & 4 & 1.350 & 25.356 & 50.712 & 258.633 & 406.752 & 665.449 & 128.768 \\
\hline 6 & 4 & 1.845 & 34.356 & 68.712 & 350.431 & 551.122 & 954.359 & \\
\hline \multicolumn{2}{|c|}{ SampleTime } & Abs. & $\mathrm{ug} / \mathrm{ml}$ & $2^{\star}(\mathrm{ug} / \mathrm{ml})$ & $\mathrm{ug} / 5.1$ & $\mathrm{ug} / \mathrm{cm}^{2}$ & \multicolumn{2}{|l|}{ Cumulative amount } \\
\hline & (h) & & & & & & & \\
\hline 1 & 6 & 1.630 & 30.455 & 60.911 & 310.644 & 488.549 & 1176.483 & \\
\hline 2 & 6 & 1.865 & 34.727 & 69.455 & 354.220 & 557.081 & 1256.125 & Average \\
\hline 3 & 6 & 1.585 & 29.631 & 59.262 & 302.237 & 475.328 & 1048.991 & 1206.9 \\
\hline 4 & 6 & 1.560 & 29.177 & 58.355 & 297.610 & 468.051 & 1132.749 & Std.Dev. \\
\hline 5 & 6 & 1.676 & 31.285 & 62.570 & 319.108 & 501.860 & 1167.309 & 140.918 \\
\hline 6 & 6 & 1.688 & 31.506 & 63.012 & 321.361 & 505.404 & 1459.763 & \\
\hline
\end{tabular}


TABLE 40. CONT'D.

\begin{tabular}{|c|c|c|c|c|c|c|c|c|}
\hline \multicolumn{2}{|c|}{ SampleTime } & Abs. & $\mathrm{ug} / \mathrm{ml}$ & $2^{\star}(\mathrm{ug} / \mathrm{ml})$ & $u g / 5.2$ & $\mathrm{ug} / \mathrm{cm}^{2}$ & \multicolumn{2}{|l|}{ Cumulative amount } \\
\hline & (h) & & & & & & & \\
\hline 1 & 8 & 1.455 & 27.336 & 54.672 & 278.829 & 438.514 & 1614.996 & \\
\hline 2 & 8 & 1.592 & 29.827 & 59.654 & 304.236 & 478.472 & 1734.596 & Average \\
\hline 3 & 8 & 1.346 & 25.368 & 50.737 & 258.757 & 406.947 & 1455.938 & 1648.37 \\
\hline 4 & 8 & 1.401 & 26.365 & 52.731 & 268.926 & 422.939 & 1555.688 & Std.Dev. \\
\hline 5 & 8 & 1.399 & 26.322 & 52.643 & 268.481 & 422.239 & 1589.548 & 168.737 \\
\hline 6 & 8 & 1.596 & 29.903 & 59.807 & 305.013 & 479.694 & 1939.457 & \\
\hline & & & & & & & & \\
\hline Sample & Time & Abs. & $\mathrm{ug} / \mathrm{ml}$ & $2^{*}(\mathrm{ug} / \mathrm{ml})$ & $u g / 5.1$ & $\mathrm{ug} / \mathrm{cm}^{2}$ & Cumulative amount & \\
\hline & (h) & & & & & & & \\
\hline 1 & 10 & 1.517 & 28.394 & 56.789 & 289.623 & 455.489 & 2070.485 & \\
\hline 2 & 10 & 1.594 & 29.796 & 59.593 & 303.923 & 477.979 & 2212.575 & Average \\
\hline 3 & 10 & 1.443 & 27.059 & 54.117 & 275.999 & 434.063 & 1890.001 & 2099.12 \\
\hline 4 & 10 & 1.451 & 27.198 & 54.396 & 277.420 & 436.297 & 1991.985 & Std.Dev. \\
\hline 5 & 10 & 1.508 & 28.238 & 56.476 & 288.029 & 452.983 & 2042.532 & 176.100 \\
\hline 6 & 10 & 1.490 & 27.907 & 55.815 & 284.656 & 447.678 & 2387.135 & \\
\hline & & & & & & & & \\
\hline & & & & & & & & \\
\hline Sample & Time & Abs. & ug/ml & $2^{*}(\mathrm{ug} / \mathrm{ml})$ & ug/5.1 & $\mathrm{ug} / \mathrm{cm}^{2}$ & Cumulative amount & \\
\hline & (h) & & & & & & & \\
\hline 1 & 12 & 1.494 & 27.986 & 55.972 & 285.457 & 448.938 & 2519.423 & \\
\hline 2 & 12 & 1.482 & 27.768 & 55.537 & 283.237 & 445.447 & 2658.022 & Average \\
\hline 3 & 12 & 1.554 & 29.070 & 58.140 & 296.516 & 466.330 & 2356.331 & 2555.76 \\
\hline 4 & 12 & 1.434 & 26.894 & 53.788 & 274.321 & 431.424 & 2423.409 & Std.Dev. \\
\hline 5 & 12 & 1.481 & 27.736 & 55.471 & 282.903 & 444.922 & 2487.453 & 192.554 \\
\hline 6 & 12 & 1.679 & 31.342 & 62.684 & 319.687 & 502.770 & 2889.905 & \\
\hline
\end{tabular}

\begin{tabular}{|c|c|c|c|}
\hline Time & \multicolumn{2}{|c|}{ Average cum.amnt } & Std.Dev. \\
\hline (h) & & & \\
\hline 0.5 & 95.183 & & 13.608 \\
\hline 1 & 169.157 & & 29.775 \\
\hline 2 & 280.843 & & 61.540 \\
\hline 4 & 707.524 & & 128.768 \\
\hline 6 & 1206.903 & 1206.903 & 140.918 \\
\hline 8 & 1648.371 & 1648.371 & 168.737 \\
\hline 10 & 2099.119 & 2099.119 & 1455.938 \\
\hline 12 & 2555.757 & 2555.757 & 176.100 \\
\hline
\end{tabular}




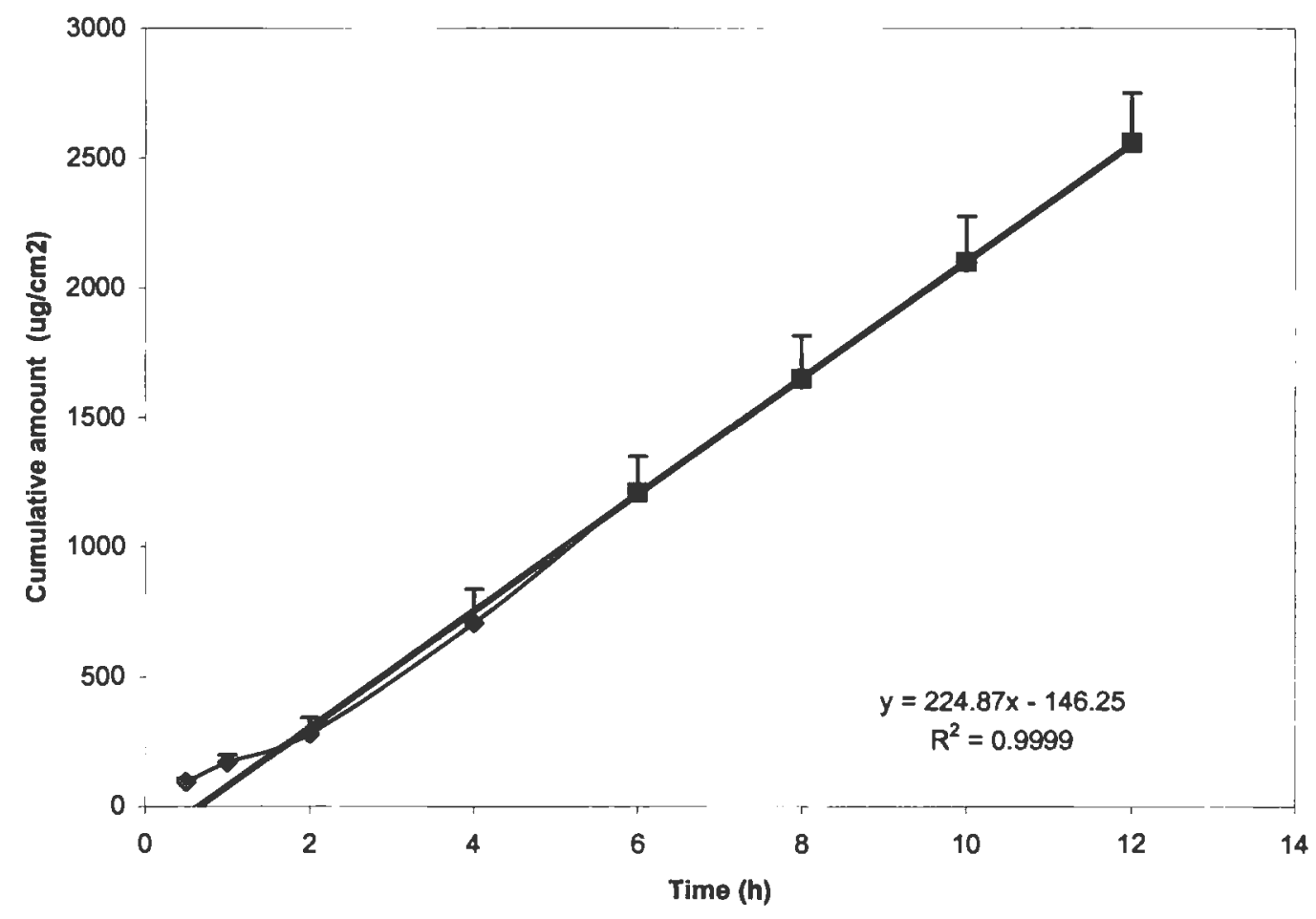

FIGURE 43. RELEASE PROFILE OF KT FROM LECITHIN:IPM (40:60) CONTAINING 0.6\% WATER AND 6.5\% KT (MEAN \pm SD, $N=6$ ) 
TABLE 41. CUMULATIVE RELEASE OF KT ACROSS CELLULOSE ACETATE MEMBRANE FROM LECITHIN:IPM (40:60) CONTAINING $0.7 \%$ WATER AND $6.5 \% \mathrm{KT}$

\begin{tabular}{|c|c|c|c|c|c|c|c|c|}
\hline \multicolumn{2}{|c|}{ Sample/Time } & Abs. & $\mathrm{ug} / \mathrm{ml}$ & & ug/5.1 & $\mathrm{ug} / \mathrm{cm}^{2}$ & Cumulative amount & \\
\hline & (h) & & & & & & & \\
\hline 1 & 0.5 & 0.675 & 13.087 & & 66.746 & 104.971 & 104.971 & \\
\hline 2 & 0.5 & 0.692 & 13.401 & & 68.344 & 107.485 & 107.485 & Average \\
\hline 3 & 0.5 & 0.628 & 12.230 & & 62.373 & 98.094 & 98.094 & 99.406 \\
\hline 4 & 0.5 & 0.609 & 11.882 & & 60.598 & 95.302 & 95.302 & Std.Dev. \\
\hline 5 & 0.5 & 0.532 & 10.485 & & 53.474 & 84.098 & 84.098 & 8.936 \\
\hline 6 & 0.5 & 0.685 & 13.276 & & 67.708 & 106.483 & 106.484 & \\
\hline & & & & & & & & \\
\hline & & & & & & & & \\
\hline Sample & Time & Abs. & $\mathrm{ug} / \mathrm{ml}$ & & $\mathrm{ug} / 5.1$ & $\mathrm{ug} / \mathrm{cm}^{2}$ & Cumulative amount & \\
\hline & (h) & & & & & & & \\
\hline 1 & 1 & 0.464 & 9.250 & & 47.174 & 74.190 & 179.161 & \\
\hline 2 & 1 & 0.462 & 9.219 & & 47.017 & 73.944 & 181.429 & Average \\
\hline 3 & 1 & 0.456 & 9.112 & & 46.471 & 73.085 & 171.179 & 170.804 \\
\hline 4 & 1 & 0.458 & 9.141 & & 46.618 & 73.316 & 168.618 & Std.Dev. \\
\hline 5 & 1 & 0.371 & 7.559 & & 38.551 & 60.628 & 144.726 & 13.763 \\
\hline 6 & 1 & 0.457 & 9.130 & & 46.563 & 73.230 & 179.713 & \\
\hline & & & & & & & & \\
\hline & & & & & & & & \\
\hline Sample & Time & Abs. & $\mathrm{ug} / \mathrm{ml}$ & & $\mathrm{ug} / 5.1$ & $\mathrm{ug} / \mathrm{cm}^{2}$ & Cumulative amount & \\
\hline & (h) & & & & & & & \\
\hline 1 & 2 & 0.871 & 16.648 & & 84.905 & 133.530 & 312.691 & \\
\hline 2 & 2 & 0.885 & 16.897 & & 86.175 & 135.527 & 316.956 & Average \\
\hline 3 & 2 & 0.824 & 15.791 & & 80.535 & 126.657 & 297.837 & 297.016 \\
\hline 4 & 2 & 0.868 & 16.600 & & 84.661 & 133.146 & 301.764 & Std.Dev. \\
\hline 5 & 2 & 0.703 & 13.594 & & 69.330 & 109.036 & 253.762 & 22.547 \\
\hline 6 & 2 & \begin{tabular}{|l|}
0.774 \\
\end{tabular} & 14.883 & & 75.905 & 119.376 & 299.090 & \\
\hline & & & & & & & & \\
\hline Sample & Time & Abs. & $\mathrm{ug} / \mathrm{ml}$ & & ug/5.1 & $\mathrm{ug} / \mathrm{cm}^{2}$ & Cumulative amount & \\
\hline & (h) & & & & & & & \\
\hline 1 & $\frac{1}{4}$ & 1.859 & 34.621 & & 176.566 & 277.685 & 590.375 & \\
\hline 2 & 4 & 1.892 & 35.215 & & 179.597 & 282.452 & 599.407 & Average \\
\hline 3 & 4 & 1.598 & 29.875 & & 152.365 & 239.624 & 537.460 & 555.852 \\
\hline 4 & 4 & 1.835 & 34.183 & & 174.333 & 274.173 & 575.937 & Std.Dev. \\
\hline 5 & 4 & 1.462 & 27.403 & & 139.756 & 219.794 & 473.555 & 46.065 \\
\hline 6 & 4 & 1.733 & 32.327 & & 164.867 & 259.286 & 558.376 & \\
\hline Sample & Time & Abs. & $\mathrm{ug} / \mathrm{ml}$ & $2^{*}(\mathrm{ug} / \mathrm{ml})$ & $u g / 5.1$ & $\mathrm{ug} / \mathrm{cm}^{2}$ & Cumulative amount & \\
\hline & (h) & & & & & & & \\
\hline 1 & 6 & 1.431 & 26.835 & 53.670 & 273.718 & 430.476 & 1020.851 & \\
\hline 2 & 6 & 1.588 & 29.691 & 59.381 & 302.844 & 476.281 & 1075.689 & Average \\
\hline 3 & 6 & 0.916 & 17.461 & 34.922 & 178.103 & 280.102 & 817.562 & 920.356 \\
\hline 4 & 6 & 1.268 & 23.867 & 47.735 & 243.448 & 382.870 & 958.807 & Std.Dev. \\
\hline 5 & 6 & 0.989 & 18.795 & 37.591 & 191.714 & 301.508 & 775.063 & 117.912 \\
\hline 6 & 6 & 1.038 & 19.686 & 39.371 & 200.793 & 315.788 & 874.163 & \\
\hline
\end{tabular}


TABLE 41. CONT'D.

\begin{tabular}{|c|c|c|c|c|c|c|c|c|}
\hline Sample & Time & Abs. & $\mathrm{ug} / \mathrm{ml}$ & $2^{*}(\mathrm{ug} / \mathrm{ml})$ & $u g / 5.2$ & $\mathrm{ug} / \mathrm{cm}^{2}$ & Cumulative amount & \\
\hline & (h) & & & & & & & \\
\hline 1 & 8 & 1.554 & 29.143 & 58.287 & 297.263 & 467.505 & 1488.356 & \\
\hline 2 & 8 & 1.907 & 35.562 & 71.125 & 362.736 & 570.474 & 1646.163 & Average \\
\hline 3 & 8 & 1.157 & 21.923 & 43.846 & 223.614 & 351.677 & 1169.239 & 1382.1 \\
\hline 4 & 8 & 1.590 & 29.803 & 59.606 & 303.990 & 478.084 & 1436.891 & Std.Dev. \\
\hline 5 & 8 & 1.535 & 28.794 & 57.588 & 293.697 & 461.897 & 1236.960 & 176.012 \\
\hline 6 & 8 & 1.463 & 27.480 & 54.960 & 280.298 & 440.824 & 1314.987 & \\
\hline & & & & & & & & \\
\hline Sample & Time & Abs. & $\mathrm{ug} / \mathrm{ml}$ & $2^{*}(\mathrm{ug} / \mathrm{ml})$ & $u g / 5.1$ & $\mathrm{ug} / \mathrm{cm}^{2}$ & Cumulative amount & \\
\hline & (h) & & & & & & & \\
\hline 1 & 10 & 1.366 & 25.657 & 51.314 & 261.702 & 411.579 & 1899.935 & \\
\hline 2 & 10 & 1.702 & 31.768 & 63.537 & 324.037 & 509.613 & 2155.776 & Average \\
\hline 3 & 10 & 1.242 & 23.404 & 46.809 & 238.725 & 375.442 & 1544.680 & 1835.81 \\
\hline 4 & 10 & 1.624 & 30.335 & 60.671 & 309.420 & 486.624 & 1923.515 & Std.Dev \\
\hline 5 & 10 & 1.535 & 28.727 & 57.455 & 293.020 & 460.832 & 1697.792 & 209.670 \\
\hline 6 & 10 & 1.595 & 29.808 & 59.617 & 304.045 & \begin{tabular}{|l|l|}
478.171 \\
\end{tabular} & 1793.159 & \\
\hline & & & & & & & & \\
\hline Sample & Time & Abs. & $\mathrm{ug} / \mathrm{ml}$ & $2^{*}(\mathrm{ug} / \mathrm{ml})$ & $u g / 5.1$ & $\mathrm{ug} / \mathrm{cm}^{2}$ & Cumulative amount & \\
\hline & (h) & & & & & & & \\
\hline 1 & 12 & 1.711 & 31.930 & 63.860 & 325.688 & 512.209 & 2412.143 & \\
\hline 2 & 12 & 1.991 & 37.017 & 74.034 & 377.572 & 593.807 & 2749.583 & Average \\
\hline 3 & 12 & 1.769 & 32.972 & 65.944 & 336.314 & 528.921 & 2073.601 & 2383.48 \\
\hline 4 & 12 & 1.926 & 35.836 & 71.672 & 365.525 & 574.861 & 2498.376 & Std.Dev \\
\hline 5 & 12 & 1.737 & 32.405 & 64.809 & 330.526 & 519.818 & 2217.610 & 233.556 \\
\hline 6 & 12 & 1.863 & 34.685 & 69.370 & 353.788 & 556.402 & 2349.560 & \\
\hline
\end{tabular}

\begin{tabular}{|c|c|c|c|}
\hline Time & \multicolumn{2}{|c|}{ Average cum.amnt } & Std.Dev \\
\hline (h) & & & \\
\hline 0.5 & 99.406 & & 8.936 \\
\hline 1 & 170.804 & & 13.763 \\
\hline 2 & 297.016 & & 22.547 \\
\hline$\overline{4}$ & \begin{tabular}{|l|}
555.852 \\
\end{tabular} & & 46.065 \\
\hline 6 & 920.356 & 920.356 & 117.912 \\
\hline 8 & 1382.099 & 1382.099 & 176.012 \\
\hline 10 & 1835.809 & 1835.809 & 209.670 \\
\hline 12 & 2383.479 & 2383.479 & 233.556 \\
\hline
\end{tabular}




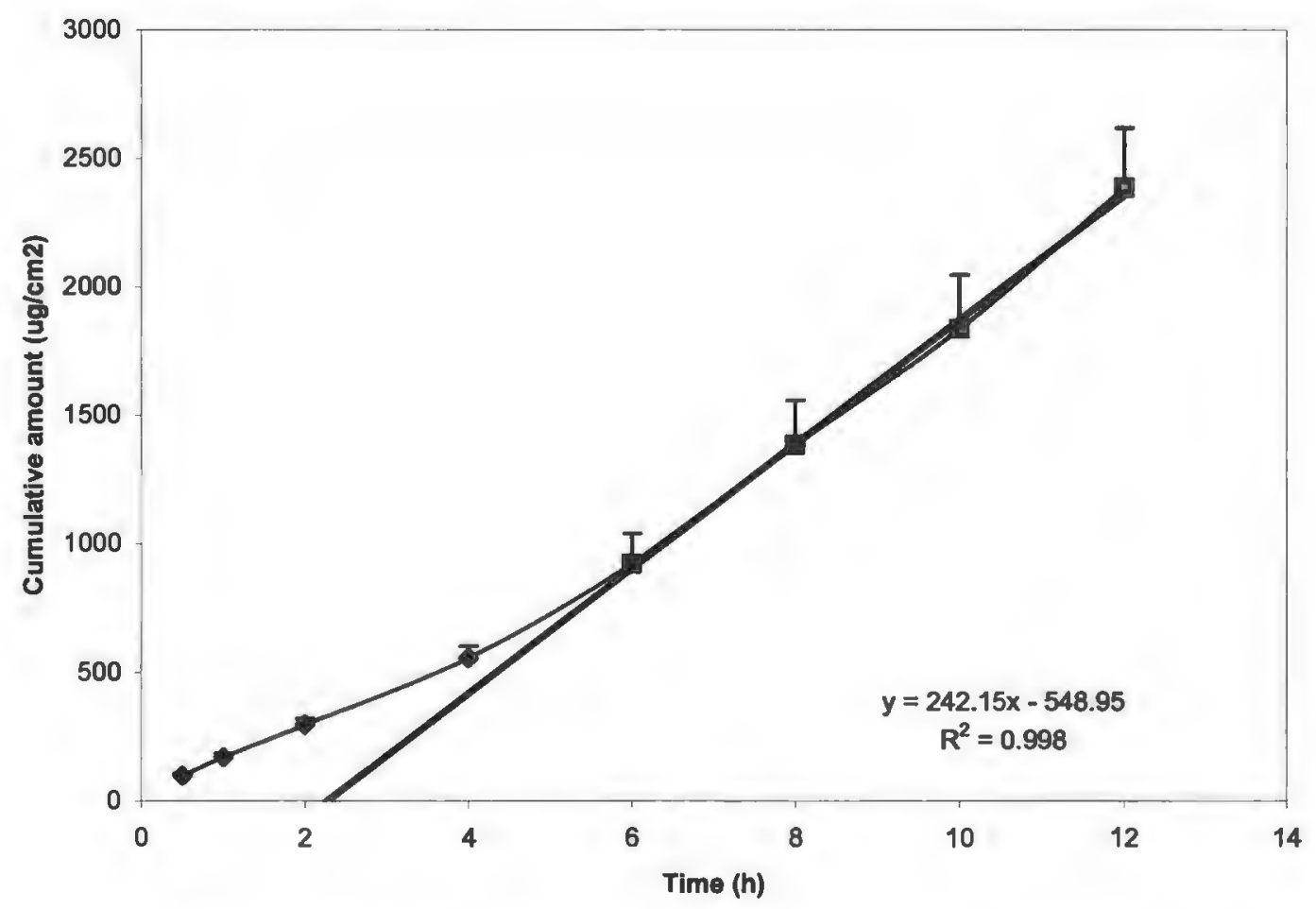

FIGURE 44. RELEASE PROFILE OF KT FROM LECITHIN:IPM (40:60) CONTAINING 0.7\% WATER AAND 6.5\% KT (MEAN \pm $\mathrm{SD}, \mathrm{N}=6$ ) 
TABLE 42. CUMULATIVE RELEASE OF KT ACROSS CELLULOSE ACETATE MEMBRANE FROM LECITHIN:IPM (40:60) CONTAINING $0.8 \%$ WATER AND $6.5 \% \mathrm{KT}$

\begin{tabular}{|c|c|c|c|c|c|c|c|c|}
\hline \multicolumn{2}{|c|}{ SampleTime } & Abs. & $\mathrm{ug} / \mathrm{ml}$ & & $\mathrm{ug} / 5.1$ & $\mathrm{ug} / \mathrm{cm}^{2}$ & Cumulative amount & \\
\hline & (h) & & & & & & & \\
\hline 1 & 0.5 & 0.431 & 8.656 & & 44.145 & 69.427 & 69.427 & \\
\hline 2 & 0.5 & 0.520 & 10.261 & & 52.329 & 82.298 & 82.298 & Average \\
\hline 3 & 0.5 & 0.475 & 9.450 & & 48.197 & 75.800 & 75.800 & 73.465 \\
\hline 4 & 0.5 & 0.391 & 7.926 & & 40.422 & 63.572 & 63.572 & Std.Dev. \\
\hline 5 & 0.5 & 0.393 & 7.966 & & 40.626 & \begin{tabular}{|l|}
63.893 \\
\end{tabular} & 63.893 & 9.396 \\
\hline 6 & 0.5 & 0.544 & 10.697 & & 54.556 & 85.800 & 85.800 & \\
\hline & & & & & & & & \\
\hline Sample & Time & Abs. & $\mathrm{ug} / \mathrm{ml}$ & & $\mathrm{ug} / 5.1$ & $\mathrm{ug} / \mathrm{cm}^{2}$ & Cumulative amount & \\
\hline & (h) & & & & & & & \\
\hline 1 & 1 & 0.395 & 8.001 & & 40.804 & 64.173 & 133.600 & \\
\hline 2 & 1 & 0.495 & 9.819 & & 50.076 & 78.755 & 161.052 & Average \\
\hline 3 & 1 & 0.453 & 9.044 & & 46.123 & 72.538 & 148.338 & 142.882 \\
\hline 4 & 1 & 0.359 & 7.344 & & 37.455 & 58.906 & 122.478 & Std.Dev. \\
\hline 5 & 1 & 0.390 & 7.906 & & 40.319 & 63.410 & 127.302 & 17.739 \\
\hline 6 & 1 & 0.495 & 9.815 & & 50.055 & 78.722 & 164.522 & \\
\hline & & & & & & & & \\
\hline & & & & & & & & \\
\hline Sample & Time & Abs. & $\mathrm{ug} / \mathrm{ml}$ & & $u g / 5.1$ & $\mathrm{ug} / \mathrm{cm}^{2}$ & Cumulative amount & \\
\hline & (h) & & & & & & & \\
\hline 1 & 2 & 0.734 & 14.169 & & 72.261 & 113.644 & 247.244 & \\
\hline 2 & 2 & 0.734 & 14.161 & & 72.221 & 113.582 & 274.634 & Average \\
\hline 3 & 2 & 0.599 & 11.707 & & 59.706 & 93.900 & 242.237 & 241.262 \\
\hline 4 & 2 & 0.520 & 10.273 & & 52.391 & 82.395 & 204.874 & Std.Dev. \\
\hline 5 & 2 & 0.510 & 10.092 & & 51.467 & 80.942 & 208.245 & 29.699 \\
\hline 6 & 2 & 0.681 & 13.193 & & 67.283 & 105.816 & 270.337 & \\
\hline & & & & & & & & \\
\hline & & & & & & & & \\
\hline Sample & Time & Abs. & $\mathrm{ug} / \mathrm{ml}$ & & $\mathrm{ug} / 5.1$ & $\mathrm{ug} / \mathrm{cm}^{2}$ & Cumulative amount & \\
\hline & (h) & & & & & & & \\
\hline 1 & 4 & 1.965 & 36.540 & & 186.352 & 293.076 & 540.319 & \\
\hline 2 & 4 & 1.950 & 36.269 & & 184.973 & 290.907 & 565.541 & Average \\
\hline 3 & 4 & 1.701 & 31.740 & & 161.876 & 254.582 & 496.819 & 496.838 \\
\hline 4 & 4 & 1.440 & 27.003 & & 137.717 & 216.587 & 421.460 & Std.Dev. \\
\hline 5 & 4 & 1.359 & 25.532 & & 130.215 & 204.789 & 413.034 & 65.614 \\
\hline 6 & 4 & 1.831 & 34.101 & & 173.916 & 273.517 & 543.854 & \\
\hline Sample & Time & Abs. & $\mathrm{ug} / \mathrm{ml}$ & $2^{\star}(\mathrm{ug} / \mathrm{ml})$ & $u q / 5.1$ & $\mathrm{uq} / \mathrm{cm}^{2}$ & Cumulative amount & \\
\hline & (h) & & & & & & & \\
\hline 1 & 6 & 1.325 & 24.913 & 49.827 & 254.117 & 399.650 & 939.969 & \\
\hline 2 & 6 & 1.284 & 24.165 & 48.329 & 246.478 & 387.636 & 953.177 & Average \\
\hline 3 & 6 & 1.053 & 19.956 & 39.912 & 203.551 & 320.125 & 816.944 & 889.092 \\
\hline 4 & 6 & 1.492 & 27.950 & 55.900 & 285.092 & 4448.363 & 869.824 & Std.Dev. \\
\hline 5 & 6 & 1.433 & 26.877 & 53.755 & 274.150 & 431.155 & 844.189 & 54.304 \\
\hline 6 & 6 & \begin{tabular}{|l|}
1.212 \\
\end{tabular} & 22.853 & 45.705 & \begin{tabular}{|l|}
233.098 \\
\end{tabular} & 366.592 & 910.446 & \\
\hline
\end{tabular}


TABLE 42. CONT'D

\begin{tabular}{|c|c|c|c|c|c|c|c|c|}
\hline Sample & Time & Abs. & ug/ml & $2^{*}(\mathbf{u g} / \mathbf{m l})$ & ug/5.2 & ug/cm & Cumulative amount & \\
\hline & (h) & & & & & & & \\
\hline 2 & 8 & 1.487 & 27.930 & 55.861 & 284.890 & 448.045 & 1388.015 & \\
\hline 3 & 8 & 1.446 & 27.176 & 54.353 & 277.199 & 435.950 & 1389.128 & Average \\
\hline 4 & 8 & 1.370 & 25.789 & 51.578 & 263.049 & 413.696 & 1230.640 & 1353.160 \\
\hline 5 & 8 & 1.776 & 33.173 & 66.347 & 338.369 & 532.153 & 1401.976 & Std.Dev. \\
\hline 6 & 8 & 1.461 & 27.456 & 54.912 & 280.053 & 440.439 & 1350.885 & \\
\hline & & & & & & & & \\
\hline & & & & & & & & \\
\hline Sample & & & & & & & \\
\hline & (h) & & & & & & & \\
\hline 1 & 10 & 1.678 & 31.319 & 62.639 & 319.457 & 502.409 & 1890.423 & \\
\hline 2 & 10 & 1.668 & 31.142 & 62.283 & 317.645 & 499.559 & 1888.687 & Average \\
\hline 3 & 10 & 1.626 & 30.377 & 60.755 & 309.850 & 487.301 & 1717.940 & 1856.69 \\
\hline 4 & 10 & 1.702 & 31.763 & 63.525 & 323.978 & 509.519 & 1911.496 & Std.Dev. \\
\hline 5 & 10 & 1.792 & 33.403 & 66.805 & 340.708 & 535.830 & 1894.144 & 72.373 \\
\hline 6 & 10 & 1.624 & 30.333 & 60.666 & 309.398 & 486.589 & 1837.475 & \\
\hline & & & & & & & & \\
\hline & & & & & & & & \\
\hline SampleTime & Abs. & ug/ml & $\mathbf{2}^{*}(\mathbf{u g} / \mathbf{m l})$ & ug/5.1 & ug/cm & Cumulative amount & \\
\hline & (h) & & & & & & & \\
\hline 1 & 12 & 1.798 & 33.514 & 67.027 & 341.840 & 537.611 & 2428.035 & \\
\hline 2 & 12 & 1.730 & 32.263 & 64.527 & 329.085 & 517.552 & 2406.239 & Average \\
\hline 3 & 12 & 1.777 & 33.115 & 66.231 & 337.776 & 531.219 & 2249.160 & 2388.26 \\
\hline 4 & 12 & 1.803 & 33.600 & 67.200 & 342.720 & 538.995 & 2450.491 & Std.Dev. \\
\hline 5 & 12 & 1.856 & 34.568 & 69.135 & 352.590 & 554.517 & 2448.662 & 78.074 \\
\hline 6 & 12 & 1.702 & 31.763 & 63.525 & 323.979 & 509.521 & 2346.995 & \\
\hline
\end{tabular}

\begin{tabular}{|c|c|c|c|}
\hline Time & Average & um.amnt & Std.Dev \\
\hline (h) & & & \\
\hline 0.5 & 73.465 & & 9.396 \\
\hline$\overline{1}$ & 142.882 & & 17.739 \\
\hline 2 & 241.262 & & 29.699 \\
\hline$\overline{4}$ & 496.838 & 496.838 & 65.614 \\
\hline 6 & 889.092 & 889.092 & 54.304 \\
\hline 8 & 1353.160 & 1353.160 & 63.142 \\
\hline 10 & 1856.694 & 1856.694 & 72.373 \\
\hline 12 & 2388.263 & 2388.263 & 78.074 \\
\hline
\end{tabular}




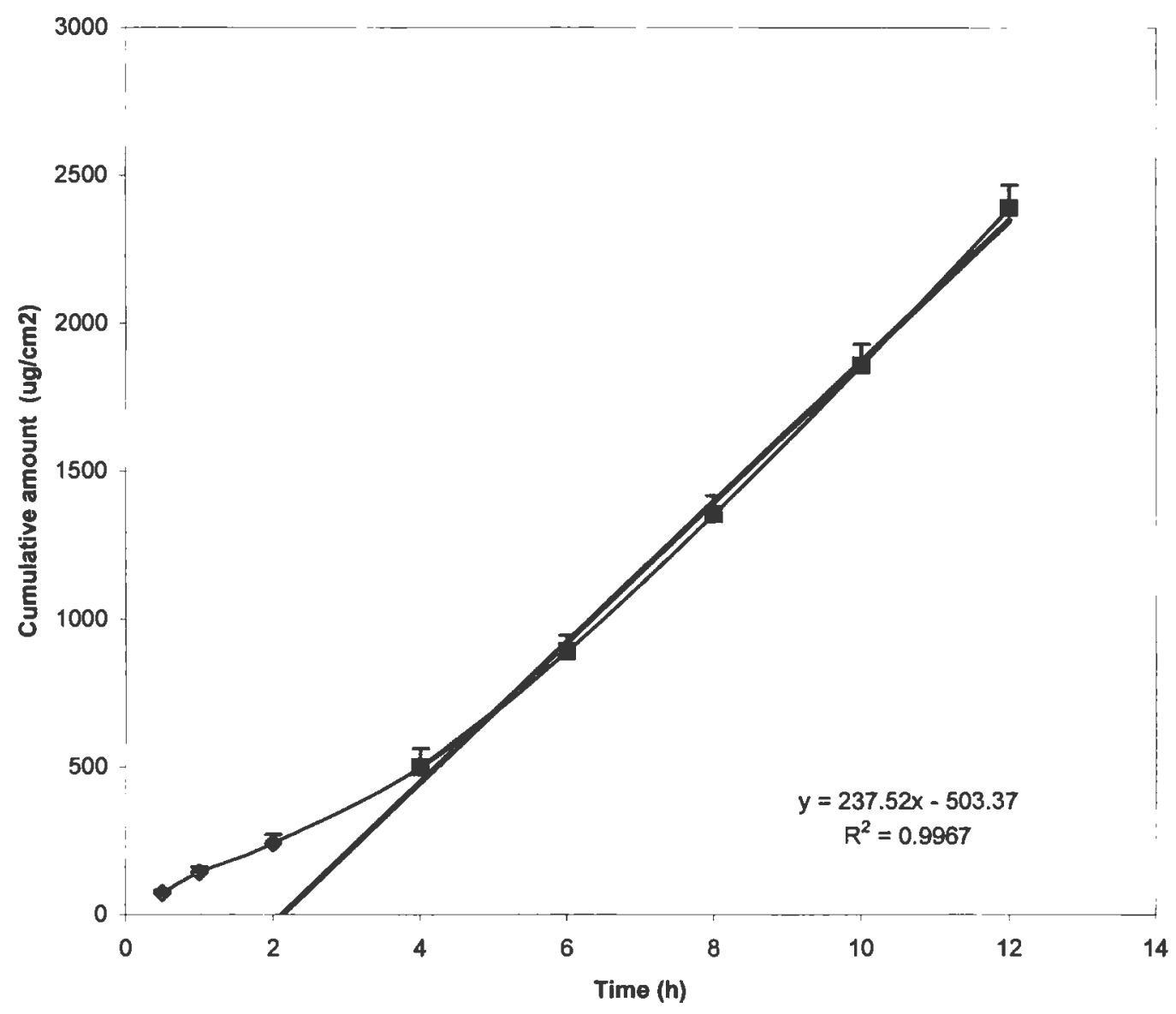

FIGURE 45. RELEASE PROFILE OF KT FROM LECITHIN:IPM (40:60) CONTAINING 0.8\% WATER AND 6.5\% KT (MEAN \pm SD, $\mathrm{N}=6$ ) 
TABLE 43. CUMULATIVE RELEASE OF KT ACROSS CELLULOSE ACETATE MEMBRANE FROM LECITHIN:IPM (50:50) CONTAINING $0.1 \%$ WATER AND $6.5 \% \mathrm{KT}$ (NO. 1 )

\begin{tabular}{|c|c|c|c|c|c|c|c|}
\hline Sample & Time & Abs & $\mathrm{ug} / \mathrm{ml}$ & $\mathrm{ug} / 5.1$ & $\mathrm{ug} / \mathrm{cm}^{2}$ & Cumulative amount & \\
\hline & (h) & & & & & & \\
\hline 1 & 0.5 & 0.541 & 10.650 & 54.313 & 85.417 & 85.417 & \\
\hline 2 & 0.5 & 0.552 & 10.844 & 55.306 & 86.979 & 86.979 & Average \\
\hline 3 & 0.5 & 0.556 & 10.919 & 55.688 & 87.580 & 87.580 & 96.026 \\
\hline 4 & 0.5 & 0.671 & 13.013 & 66.366 & 104.374 & 104.374 & Std.Dev. \\
\hline 5 & 0.5 & 0.668 & 12.962 & 66.104 & 103.962 & 103.962 & 10.374 \\
\hline \multirow[t]{2}{*}{6} & 0.5 & 0.695 & 13.446 & 68.573 & 107.845 & 107.845 & \\
\hline & & & & & & & \\
\hline \multirow[t]{2}{*}{ Sample } & Time & Abs & $\mathrm{ug} / \mathrm{ml}$ & $\mathrm{ug} / 5.1$ & $\mathrm{ug} / \mathrm{cm}^{2}$ & Cumulative amount & \\
\hline & (h) & & & & & & \\
\hline 1 & $\frac{1}{1}$ & 0.268 & 5.693 & 29.034 & 45.661 & 131.079 & \\
\hline 2 & 1 & 0.237 & 5.116 & 26.094 & 41.037 & 128.017 & Average \\
\hline 3 & 1 & 0.260 & 5.544 & 28.275 & 44.468 & 132.048 & 140.275 \\
\hline 4 & 1 & 0.287 & 6.033 & 30.768 & 48.390 & 152.763 & Std.Dev. \\
\hline 5 & 1 & 0.235 & 5.093 & 25.973 & 40.848 & 144.810 & 11.308 \\
\hline \multirow[t]{2}{*}{6} & 1 & 0.264 & 5.622 & 28.670 & 45.090 & 152.935 & \\
\hline & & & & & & & \\
\hline \multirow{2}{*}{ Sample } & Time & Abs & $\mathrm{ug} / \mathrm{ml}$ & $u g / 5.1$ & $\mathrm{ug} / \mathrm{cm}^{2}$ & Cumulative amount & \\
\hline & (h) & & & & & & \\
\hline 1 & 2 & 0.891 & 17.014 & 86.773 & 136.468 & 267.547 & \\
\hline 2 & 2 & 0.864 & 16.519 & 84.245 & 132.492 & 260.508 & Average \\
\hline 3 & 2 & 0.865 & 16.545 & 84.382 & 132.707 & 264.755 & 273.861 \\
\hline 4 & 2 & 0.959 & 18.254 & 93.094 & 146.408 & 299.172 & Std.Dev. \\
\hline 5 & 2 & 0.839 & 16.066 & 81.935 & 128.859 & 273.670 & 13.821 \\
\hline \multirow[t]{2}{*}{6} & 2 & 0.809 & 15.532 & 79.215 & 124.581 & 277.516 & \\
\hline & & & & & & & \\
\hline \multirow[t]{2}{*}{ Sample } & Time & Abs & $\mathrm{ug} / \mathrm{ml}$ & $\mathrm{ug} / 5.1$ & $\mathrm{ug} / \mathrm{cm}^{2}$ & Cumulative amount & \\
\hline & (h) & & & & & & \\
\hline 1 & 4 & 1.452 & 27.217 & 138.809 & 218.305 & 485.852 & \\
\hline 2 & 4 & 1.330 & 24.993 & 127.467 & 200.466 & 460.975 & Average \\
\hline 3 & 4 & \begin{tabular}{|l|}
1.359 \\
\end{tabular} & 25.519 & 130.146 & 204.681 & 469.436 & 479.189 \\
\hline 4 & 4 & 1.507 & 28.206 & 143.852 & 226.235 & 525.407 & Std.Dev. \\
\hline 5 & 4 & 1.284 & 24.166 & 123.245 & 193.827 & 467.497 & 24.161 \\
\hline 6 & 4 & 1.247 & 23.495 & 119.827 & 188.451 & 465.967 & \\
\hline \multirow[t]{2}{*}{ Sample } & Time & Abs & $\mathrm{ug} / \mathrm{ml}$ & $u g / 5.1$ & $\mathrm{ug} / \mathrm{cm}^{2}$ & Cumulative amount & \\
\hline & (h) & & & & & & \\
\hline 1 & 6 & 1.574 & 29.428 & 150.085 & 236.038 & 721.890 & \\
\hline 2 & 6 & 1.401 & 26.278 & 134.020 & 210.772 & 671.747 & Average \\
\hline 3 & 6 & 1.417 & 26.570 & 135.507 & 213.112 & 682.548 & 692.606 \\
\hline 4 & 6 & 1.606 & 30.012 & 153.060 & 240.718 & 766.124 & Std.Dev. \\
\hline 5 & 6 & 1.225 & 23.083 & 117.721 & 185.140 & 652.636 & 43.393 \\
\hline 6 & 6 & 1.290 & 24.277 & 123.815 & 194.724 & 660.691 & \\
\hline
\end{tabular}


TABLE 43. CONT'D.

\begin{tabular}{|c|c|c|c|c|c|c|c|}
\hline Sample & Time & Abs & $\mathrm{ug} / \mathrm{ml}$ & ug/5.3 & $\mathrm{ug} / \mathrm{cm}^{2}$ & Cumulative amount & \\
\hline & (h) & & & & & & \\
\hline 1 & 8 & 1.599 & 29.956 & 152.776 & 240.270 & 962.159 & \\
\hline 2 & 8 & 1.327 & 25.012 & 127.563 & 200.618 & 872.366 & Average \\
\hline 3 & 8 & 1.321 & 24.913 & 127.057 & 199.822 & 882.370 & 904.655 \\
\hline 4 & 8 & 1.550 & 29.067 & 148.239 & 233.136 & 999.260 & Std.Dev. \\
\hline 5 & 8 & 1.292 & 24.377 & 124.323 & 195.523 & 848.159 & 61.110 \\
\hline \multirow[t]{2}{*}{6} & 8 & 1.343 & 25.300 & 129.032 & 202.928 & 863.619 & \\
\hline & & & & & & & \\
\hline \multirow[t]{2}{*}{ Sample } & Time & Abs & $\mathrm{ug} / \mathrm{ml}$ & ug/5.1 & $\mathrm{ug} / \mathrm{cm}^{2}$ & Cumulative amount & \\
\hline & (h) & & & & & & \\
\hline 1 & 10 & 1.625 & 30.364 & 154.856 & 243.542 & 1205.702 & \\
\hline 2 & 10 & 1.284 & 24.164 & 123.236 & 193.814 & 1066.179 & Average \\
\hline 3 & 10 & 1.323 & 24.863 & 126.799 & 199.417 & 1081.786 & 1117.1 \\
\hline 4 & 10 & 1.542 & 28.851 & 147.139 & 231.405 & 1230.665 & Std.Dev. \\
\hline 5 & 10 & 1.328 & 24.959 & 127.289 & 200.186 & 1048.345 & 79.422 \\
\hline \multirow[t]{2}{*}{6} & 10 & 1.370 & 25.722 & 131.184 & 206.313 & 1069.932 & \\
\hline & & & & & & & \\
\hline \multirow{2}{*}{ Sample } & Time & Abs & $\mathrm{ug} / \mathrm{ml}$ & ug/5.1 & $\mathrm{ug} / \mathrm{cm}^{2}$ & Cumulative amount & \\
\hline & (h) & & & & & & \\
\hline$\overline{1}$ & 12 & 1.391 & 26.107 & 133.147 & 209.400 & 1415.102 & \\
\hline 2 & 12 & 1.371 & 25.745 & 131.299 & 206.494 & 1272.673 & Average \\
\hline 3 & 12 & 1.229 & 23.163 & 118.133 & 185.787 & 1267.573 & 1320.67 \\
\hline 4 & 12 & $\overline{1.334}$ & 25.075 & 127.882 & 201.120 & 1431.785 & Std.Dev. \\
\hline 5 & 12 & 1.410 & 26.456 & 134.927 & 212.200 & 1260.546 & 79.961 \\
\hline 6 & 12 & 1.370 & 25.731 & 131.230 & 206.386 & 1276.318 & \\
\hline
\end{tabular}

\begin{tabular}{|c|c|c|c|}
\hline Time & \multicolumn{2}{|c|}{ Average cum. amount } & Std.Dev. \\
\hline (h) & & & \\
\hline 0.5 & 96.026 & & 10.374 \\
\hline 1 & 140.275 & & 11.308 \\
\hline 2 & 273.861 & 273.861 & 13.821 \\
\hline 4 & 479.189 & 479.189 & 24.161 \\
\hline 6 & 692.606 & 692.606 & 43.393 \\
\hline 8 & 904.655 & 904.655 & 61.110 \\
\hline 10 & 1117.102 & 1117.102 & 79.422 \\
\hline 12 & 1320.666 & 1320.666 & 79.961 \\
\hline
\end{tabular}


TABLE 44. CUMULATIVE RELEASE OF KT ACROSS CELLULOSE ACETATE MEMBRANE FROM LECITHIN:IPM (50:50) CONTAINING $0.1 \%$ WATER AND $6.5 \% \mathrm{KT}$ (NO. 2)

\begin{tabular}{|c|c|c|c|c|c|c|c|}
\hline Sample & Time & Abs. & $\mathrm{ug} / \mathrm{ml}$ & ug/5.1 & $\mathrm{ug} / \mathrm{cm}^{2}$ & Cumulative amount & \\
\hline & (h) & & & & & & \\
\hline 1 & 0.5 & 0.904 & 17.247 & 87.962 & 138.338 & 138.338 & \\
\hline 2 & 0.5 & 0.909 & 17.345 & 88.461 & 139.123 & 139.123 & Average \\
\hline 3 & 0.5 & 0.865 & 16.546 & 84.382 & 132.708 & 132.708 & 137.762 \\
\hline 4 & 0.5 & 0.870 & 16.637 & 84.850 & 133.444 & 133.444 & Std.Dev. \\
\hline 5 & 0.5 & 0.923 & 17.595 & 89.733 & 141.124 & 141.124 & 3.855 \\
\hline \multirow[t]{2}{*}{6} & 0.5 & 0.928 & 17.684 & 90.188 & 141.839 & 141.839 & \\
\hline & & & & & & & \\
\hline \multirow[t]{2}{*}{ Sample } & Time & Abs. & $\mathrm{ug} / \mathrm{ml}$ & $\mathrm{ug} / 5.1$ & $\mathrm{ug} / \mathrm{cm}^{2}$ & Cumulative amount & \\
\hline & (h) & & & & & & \\
\hline 1 & 1 & 0.878 & 16.779 & 85.574 & 134.583 & 272.920 & \\
\hline 2 & 1 & 0.779 & 14.986 & 76.430 & 120.202 & 259.325 & Average \\
\hline 3 & 1 & 0.810 & 15.539 & 79.251 & 124.638 & 257.346 & 264.873 \\
\hline 4 & 1 & 0.816 & 15.647 & 79.800 & 125.502 & 258.946 & Std.Dev. \\
\hline 5 & 1 & 0.857 & 16.387 & 83.575 & 131.438 & 272.562 & 7.171 \\
\hline \multirow[t]{2}{*}{6} & 1 & 0.821 & 15.746 & 80.306 & 126.298 & 268.137 & \\
\hline & & & & & & & \\
\hline \multirow[t]{2}{*}{ Sample } & Time & Abs. & $\mathrm{ug} / \mathrm{ml}$ & $\mathrm{ug} / 5.1$ & $\mathrm{ug} / \mathrm{cm}^{2}$ & Cumulative amount & \\
\hline & (h) & & & & & & \\
\hline 1 & $\frac{1}{2}$ & 1.637 & 30.576 & 155.937 & 245.241 & 518.161 & \\
\hline 2 & 2 & 1.561 & 29.198 & 148.910 & 234.190 & 493.515 & Average \\
\hline 3 & 2 & 1.647 & 30.754 & 156.847 & 246.673 & 504.019 & 504.998 \\
\hline 4 & 2 & 1.537 & 28.755 & 146.653 & 230.641 & 489.586 & Std.Dev. \\
\hline 5 & 2 & 1.528 & 28.603 & 145.878 & 229.421 & 501.983 & 13.167 \\
\hline \multirow[t]{2}{*}{6} & 2 & 1.701 & 31.741 & 161.878 & 254.585 & 522.721 & \\
\hline & & & & & & & \\
\hline \multirow[t]{2}{*}{ Sample } & Time & Abs. & $\mathrm{ug} / \mathrm{ml}$ & $\mathrm{ug} / 5.1$ & $\mathrm{ug} / \mathrm{cm}^{2}$ & \begin{tabular}{|l|} 
Cumulative amount \\
\end{tabular} & \\
\hline & (h) & & & & & & \\
\hline 1 & 4 & 1.234 & 23.243 & 118.542 & 186.430 & 704.592 & \\
\hline 2 & 4 & 1.132 & 21.396 & 109.120 & 171.612 & 665.127 & Average \\
\hline 3 & 4 & 1.238 & 23.322 & 118.940 & 187.057 & 691.077 & 687.219 \\
\hline 4 & 4 & 1.331 & 25.012 & 127.560 & 200.614 & 690.200 & Std.Dev. \\
\hline 5 & 4 & 1.099 & 20.790 & 106.031 & 166.755 & 668.738 & 16.870 \\
\hline 6 & 4 & 1.195 & 22.549 & 115.000 & 180.861 & 703.582 & \\
\hline \multirow[t]{2}{*}{ Sample } & Time & Abs. & $\mathrm{ug} / \mathrm{ml}$ & $\mathrm{ug} / 5.1$ & $\mathrm{ug} / \mathrm{cm}^{2}$ & \begin{tabular}{|l|} 
Cumulative amount \\
\end{tabular} & \\
\hline & (h) & & & & & & \\
\hline 1 & 6 & 1.203 & 22.679 & 115.661 & 181.899 & 886.491 & \\
\hline 2 & 6 & 1.122 & 21.215 & 108.197 & 170.161 & 835.288 & Average \\
\hline 3 & 6 & 1.184 & 22.337 & 113.918 & 179.159 & 870.236 & 862.562 \\
\hline 4 & 6 & 1.261 & 23.749 & 121.119 & 190.483 & 880.683 & Std.Dev. \\
\hline 5 & 6 & 1.045 & 19.814 & 101.053 & 158.926 & 827.664 & 24.805 \\
\hline 6 & 6 & 1.131 & 21.373 & 109.001 & 171.426 & 875.008 & \\
\hline
\end{tabular}


TABLE 44. CONT'D.

\begin{tabular}{|c|c|c|c|c|c|c|c|}
\hline Sample & Time & Abs. & ug/ml & ug/5.2 & ug/cm & Cumulative amount & \\
\hline & (h) & & & & & & \\
\hline 1 & 8 & 1.322 & 24.925 & 127.119 & 199.920 & 1086.410 & \\
\hline 2 & 8 & 1.146 & 21.720 & 110.774 & 174.214 & 1009.502 & Average \\
\hline 3 & 8 & 1.257 & 23.734 & 121.042 & 190.363 & 1060.599 & 1048.420 \\
\hline 4 & 8 & 1.296 & 24.443 & 124.660 & 196.052 & 1076.735 & Std.Dev. \\
\hline 5 & 8 & 1.125 & 21.342 & 108.844 & 171.179 & 998.843 & 35.961 \\
\hline 6 & 8 & 1.209 & 22.868 & 116.629 & 183.422 & 1058.429 & \\
\hline & & & & & & & \\
\hline & & & & & & & \\
\hline Sample & Time & Abs. & ug/ml & ug/5.1 & ug/cm & Cumulative amount & \\
\hline & (h) & & & & & & \\
\hline 1 & 10 & 1.357 & 25.489 & 129.992 & 204.437 & 1290.848 & \\
\hline 2 & 10 & 1.107 & 20.937 & 106.780 & 167.933 & 1177.435 & Average \\
\hline 3 & 10 & 1.188 & 22.407 & 114.273 & 179.718 & 1240.316 & 1227.088 \\
\hline 4 & 10 & 1.196 & 22.563 & 115.073 & 180.975 & 1257.710 & Std.Dev. \\
\hline 5 & 10 & 1.106 & 20.920 & 106.690 & 167.791 & 1166.634 & 47.548 \\
\hline 6 & 10 & 1.129 & 21.339 & 108.828 & 171.154 & 1229.584 & \\
\hline & & & & & & & \\
\hline & & & & & & & \\
\hline Sample & Time & Abs. & ug/ml & ug/5.1 & ug/cm & Cumulative amount & \\
\hline & (h) & & & & & & \\
\hline 1 & 12 & 1.521 & 28.463 & 145.161 & 228.294 & 1519.142 & \\
\hline 2 & 12 & 1.174 & 22.163 & 113.032 & 177.765 & 1355.200 & Average \\
\hline 3 & 12 & 1.218 & 22.954 & 117.064 & 184.107 & 1424.423 & 1412.663 \\
\hline 4 & 12 & 1.185 & 22.362 & 114.045 & 179.359 & 1437.068 & Std.Dev. \\
\hline 5 & 12 & 1.128 & 21.328 & 108.774 & 171.068 & 1337.703 & 64.957 \\
\hline 6 & 12 & 1.141 & 21.551 & 109.911 & 172.856 & 1402.440 & \\
\hline & & & & & & & \\
\hline
\end{tabular}

\begin{tabular}{|c|c|c|c|}
\hline Time & Average Cum. amount & Std.Dev. \\
\hline (h) & & & \\
\hline 0.5 & 137.762 & & 3.855 \\
\hline 1 & 264.873 & & 7.171 \\
\hline 2 & 504.998 & & 13.167 \\
\hline 4 & 687.219 & & 16.870 \\
\hline 6 & 862.562 & 862.562 & 24.805 \\
\hline 8 & 1048.420 & 1048.420 & 35.961 \\
\hline 10 & 1227.088 & 1227.088 & 47.548 \\
\hline 12 & 1412.663 & 1412.663 & 94.957 \\
\hline
\end{tabular}


TABLE 45. CUMULATIVE RELEASE OF KT ACROSS CELLULOSE MEMBRANE FROM LECITHIN:IPM (50:50) CONTAINING 0.1\% WATER AND $6.5 \% \mathrm{KT}$

\begin{tabular}{|c|c|c|c|}
\hline Time (h) & \multicolumn{2}{|c|}{ Average cumulative amount } & Std.Dev. \\
\hline & & & \\
\hline 0.5 & 116.943 & & 22.107 \\
\hline 1 & 202.574 & & 62.895 \\
\hline 2 & 389.429 & 389.429 & 116.223 \\
\hline 4 & 583.204 & 583.204 & 105.74 \\
\hline 6 & 777.584 & 777.584 & 90.897 \\
\hline 8 & 976.538 & 976.538 & 85.217 \\
\hline 10 & 1172.095 & 1172.095 & 81.207 \\
\hline 12 & 1366.664 & 1366.664 & 80.858 \\
\hline
\end{tabular}




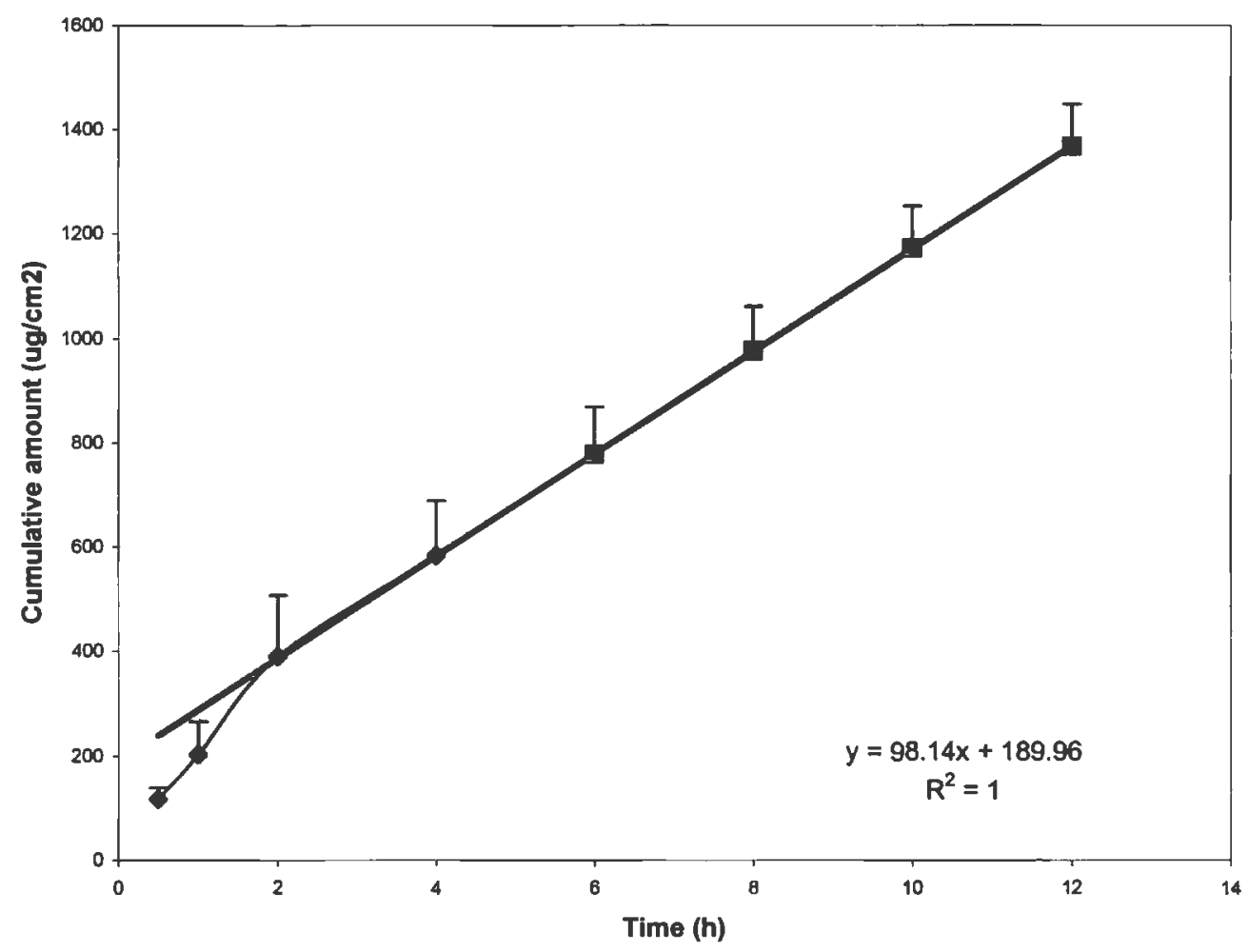

FIGURE 46. RELEASE PROFILE OF KT FROM LECITHIN:IPM $(50: 50)$ CONTAINING 0.1\% WATER AND 6.5\% KT (MEAN \pm SD, $N=12$ ) 
TABLE 46. CUMULATIVE RELEASE OF KT ACROSS CELLULOSE ACETATE MEMBRANE FROM LECITHIN:IPM (50:50) CONTAINING $0.5 \%$ WATER AND $6.5 \% \mathrm{KT}$

\begin{tabular}{|c|c|c|c|c|c|c|c|}
\hline Sample & Time & Abs. & $\mathrm{ug} / \mathrm{ml}$ & $\mathrm{ug} / 5.1$ & $\mathrm{ug} / \mathrm{cm}^{2}$ & Cumulative amount & \\
\hline & (h) & & & & & & \\
\hline 1 & 0.5 & 0.688 & 13.322 & 67.942 & 106.853 & 106.853 & \\
\hline 2 & 0.5 & 0.477 & 9.492 & 48.408 & 76.131 & 76.131 & Average \\
\hline 3 & 0.5 & 0.375 & 7.636 & 38.942 & 61.245 & 61.245 & 84.256 \\
\hline 4 & 0.5 & 0.543 & 10.695 & 54.545 & 85.782 & 85.782 & Std.Dev. \\
\hline 5 & 0.5 & 0.598 & 11.681 & 59.573 & 93.691 & 93.691 & 15.514 \\
\hline \multirow[t]{2}{*}{6} & 0.5 & 0.516 & 10.203 & 52.034 & 81.834 & 81.834 & \\
\hline & & & & & & & \\
\hline \multirow[t]{2}{*}{ Sample } & Time & Abs. & $\mathrm{ug} / \mathrm{ml}$ & $\mathrm{ug} / 5.1$ & $\mathrm{ug} / \mathrm{cm}^{2}$ & Cumulative amount & \\
\hline & (h) & & & & & & \\
\hline 1 & 1 & 0.437 & 8.755 & 44.650 & 70.221 & 177.074 & \\
\hline 2 & 1 & 0.431 & 8.646 & 44.096 & 69.349 & 145.480 & Average \\
\hline 3 & 1 & 0.348 & 7.149 & 36.458 & 57.337 & 118.582 & 157.665 \\
\hline 4 & 1 & 0.522 & 10.305 & 52.555 & 82.653 & 168.436 & Std.Dev. \\
\hline 5 & 1 & 0.522 & 10.314 & 52.599 & 82.722 & 176.413 & 22.475 \\
\hline \multirow[t]{2}{*}{6} & 1 & 0.491 & 9.746 & 49.706 & 78.172 & 160.005 & \\
\hline & & & & & & & \\
\hline \multirow[t]{2}{*}{ Sample } & Time & Abs. & $\mathrm{ug} / \mathrm{ml}$ & $\mathrm{ug} / 5.1$ & $\mathrm{ug} / \mathrm{cm}^{2}$ & Cumulative amount & \\
\hline & (h) & & & & & & \\
\hline 1 & 2 & 0.637 & 12.396 & 63.219 & 99.425 & 276.499 & \\
\hline 2 & 2 & 0.695 & 13.444 & 68.563 & 107.830 & 253.310 & Average \\
\hline 3 & 2 & 0.570 & 11.177 & 57.004 & 89.650 & 208.231 & 272.196 \\
\hline 4 & 2 & 0.827 & 15.853 & 80.849 & 127.151 & 295.587 & Std.Dev. \\
\hline 5 & 2 & 0.862 & 16.494 & 84.120 & 132.296 & 308.709 & 36.591 \\
\hline \multirow[t]{3}{*}{6} & 2 & 0.852 & 16.312 & 83.191 & 130.835 & 290.840 & \\
\hline & & & & & & & \\
\hline & & & & & & & \\
\hline \multirow[t]{2}{*}{ Sample } & Time & Abs. & $\mathrm{ug} / \mathrm{ml}$ & ug/5.1 & $\mathrm{ug} / \mathrm{cm}^{2}$ & Cumulative amount & \\
\hline & (h) & & & & & & \\
\hline 1 & 4 & 1.647 & 30.751 & 156.831 & 246.647 & 523.146 & \\
\hline 2 & 4 & 1.964 & 36.521 & 186.255 & 292.923 & 546.233 & Average \\
\hline 3 & 4 & 1.567 & 29.307 & 149.463 & 235.061 & 443.292 & 546.533 \\
\hline$\overline{4}$ & 4 & 1.946 & 36.201 & 184.627 & 290.363 & 585.950 & Std.Dev. \\
\hline 5 & 4 & 1.952 & 36.311 & 185.187 & 291.243 & 599.952 & 57.923 \\
\hline 6 & 4 & 1.942 & 36.129 & 184.259 & 289.784 & 580.624 & \\
\hline \multirow[t]{2}{*}{ Sample } & Time & Abs. & $\mathrm{ug} / \mathrm{ml}$ & $\mathrm{ug} / 5.1$ & $\mathrm{ug} / \mathrm{cm}^{2}$ & Cumulative amount & \\
\hline & (h) & & & & & & \\
\hline 1 & 6 & 1.705 & 31.818 & 162.274 & 255.207 & 778.353 & \\
\hline 2 & 6 & 1.767 & 32.939 & 167.988 & 264.195 & 810.428 & Average \\
\hline 3 & 6 & 1.472 & 27.571 & 140.613 & 221.141 & 664.433 & 817.243 \\
\hline 4 & 6 & 1.980 & 36.808 & 187.719 & 295.225 & 881.175 & Std.Dev. \\
\hline 5 & 6 & 1.983 & 36.861 & 187.992 & 295.654 & 895.605 & 87.519 \\
\hline 6 & 6 & 1.963 & 36.510 & 186.201 & 292.838 & 873.462 & \\
\hline
\end{tabular}


TABLE 46. CONT'D.

\begin{tabular}{|c|c|c|c|c|c|c|c|}
\hline Sample & Time & Abs. & ug/ml & ug/5.2 & ug/cm & Cumulative amount & \\
\hline & (h) & & & & & & \\
\hline 1 & 8 & 1.903 & 35.483 & 180.965 & 284.603 & 1062.956 & \\
\hline 2 & 8 & 1.874 & 34.960 & 178.296 & 280.406 & 1090.833 & Average \\
\hline 3 & 8 & 1.610 & 30.155 & 153.789 & 241.864 & 906.297 & 1099.93 \\
\hline 4 & 8 & 1.985 & 36.986 & 188.629 & 296.656 & 1177.831 & Std.Dev. \\
\hline 5 & 8 & 1.994 & 37.135 & 189.387 & 297.849 & 1193.454 & 108.094 \\
\hline 6 & 8 & 1.972 & 36.748 & 187.417 & 294.750 & 1168.212 & \\
\hline & & & & & & & \\
\hline & & & & & & & \\
\hline Sample & Time & Abs. & ug/ml & ug/5.1 & ug/cm & Cumulative amount & \\
\hline & (h) & & & & & & \\
\hline 1 & 10 & 1.768 & 32.959 & 168.091 & 264.357 & 1327.313 & \\
\hline 2 & 10 & 1.747 & 32.579 & 166.155 & 261.312 & 1352.145 & Average \\
\hline 3 & 10 & 1.493 & 27.956 & 142.577 & 224.230 & 1130.527 & 1365.74 \\
\hline 4 & 10 & 1.891 & 35.193 & 179.485 & 282.275 & 1460.106 & Std.Dev. \\
\hline 5 & 10 & 1.897 & 35.299 & 180.025 & 283.126 & 1476.580 & 130.315 \\
\hline 6 & 10 & 1.872 & 34.857 & 177.772 & 279.582 & 1447.794 & \\
\hline & & & & & & & \\
\hline & & & & & & & \\
\hline Sample & Time & Abs. & ug/ml & ug/5.1 & ug/cm & Cumulative amount & \\
\hline & (h) & & & & & & \\
\hline 1 & 12 & 1.844 & 34.339 & 175.131 & 275.429 & 1602.742 & \\
\hline 2 & 12 & 1.730 & 32.261 & 164.529 & 258.754 & 1610.899 & Average \\
\hline 3 & 12 & 1.671 & 31.189 & 159.066 & 250.163 & 1380.690 & 1644.62 \\
\hline 4 & 12 & 1.993 & 37.050 & 188.953 & 297.166 & 1757.273 & Std.Dev. \\
\hline 5 & 12 & 1.996 & 37.099 & 189.203 & 297.559 & 1774.138 & 149.325 \\
\hline 6 & 12 & 1.972 & 36.675 & 187.045 & 294.165 & 1741.959 & \\
\hline & & & & & & & \\
\hline
\end{tabular}

\begin{tabular}{|c|c|c|c|}
\hline Time & \multicolumn{2}{|c|}{ Average cum. amount } & Std.Dev. \\
\hline (h) & & & \\
\hline 0.5 & 84.256 & & 15.514 \\
\hline 1 & 157.665 & & 22.475 \\
\hline 2 & 272.196 & & 36.591 \\
\hline 4 & 546.533 & 546.533 & 57.923 \\
\hline 6 & 817.243 & 817.243 & 87.519 \\
\hline 8 & 1099.931 & 1099.931 & 108.094 \\
\hline 10 & 1365.744 & 1365.744 & 130.315 \\
\hline 12 & 1644.617 & 1644.617 & 149.325 \\
\hline
\end{tabular}




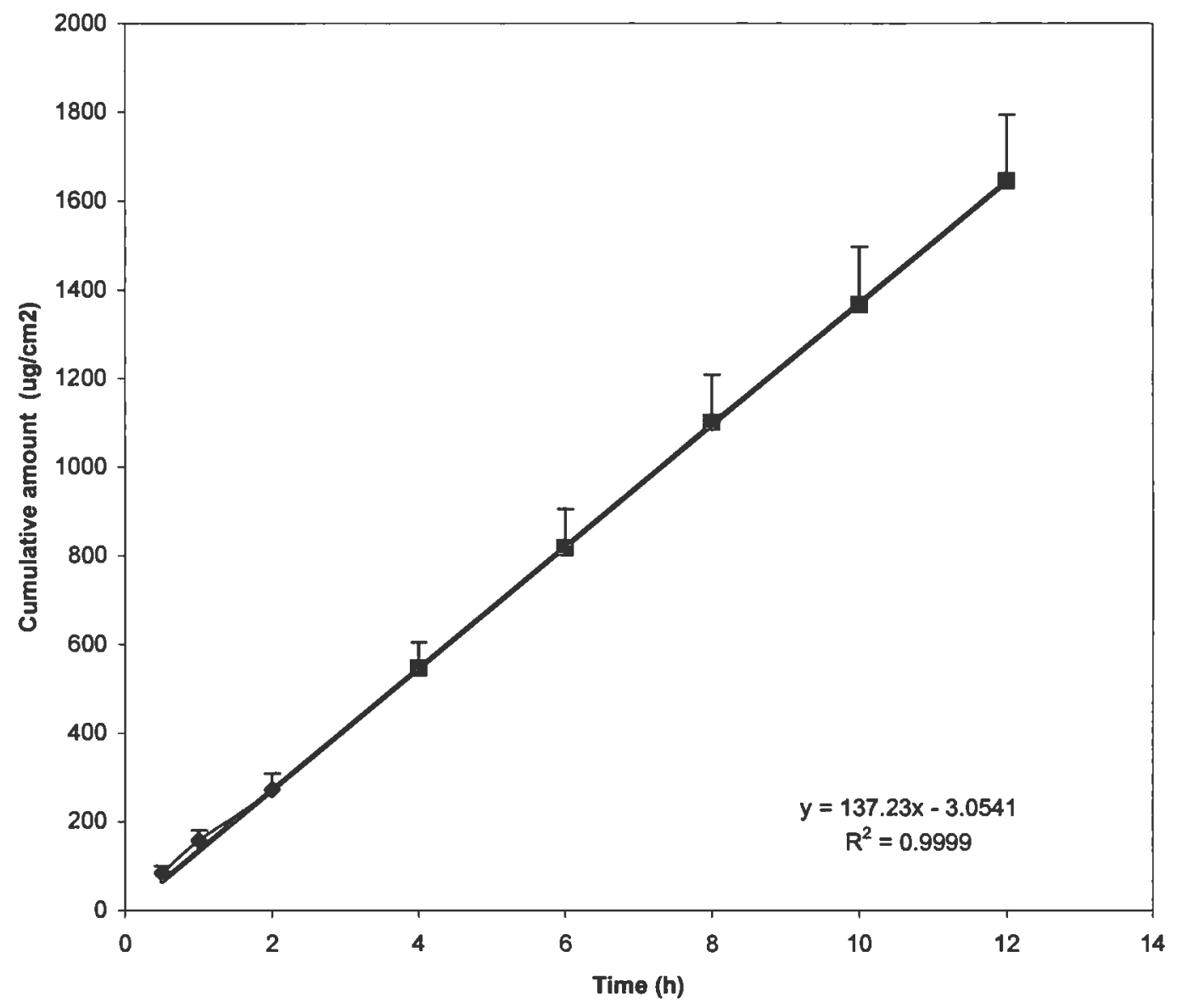

FIGURE 47. RELEASE PROFILE OF LECITHIN:IPM (50:50) CONTAINING 0.5\% WATER AND 6.5\% KT (MEAN \pm SD, $\mathrm{N}=6$ ) 
TABLE 47. CUMULATIVE RELEASE OF KT ACROSS CELLULOSE ACETATE MEMBRANE FROM LECITHIN:IPM (50:50) CONTAINING $0.6 \%$ WATER AND $6.5 \% \mathrm{KT}$

\begin{tabular}{|c|c|c|c|c|c|c|c|}
\hline Sample & Time & Abs. & $\mathrm{ug} / \mathrm{ml}$ & $\mathrm{ug} / 5.1$ & $\mathrm{ug} / \mathrm{cm}^{2}$ & Cumulative amount & \\
\hline & (h) & & & & & & \\
\hline 1 & 0.5 & 0.593 & 11.588 & 59.101 & 92.947 & 92.947 & \\
\hline 2 & 0.5 & 0.568 & 11.141 & 56.820 & 89.360 & 96.020 & Average \\
\hline 3 & 0.5 & 0.558 & 10.960 & 55.894 & 87.905 & 81.405 & 92.330 \\
\hline 4 & 0.5 & 0.508 & 10.054 & 51.273 & 80.638 & 117.770 & Std.Dev. \\
\hline 5 & 0.5 & 0.558 & 10.962 & 55.904 & 87.921 & 87.921 & 14.197 \\
\hline \multirow[t]{2}{*}{6} & 0.5 & 0.485 & 9.640 & 49.167 & 77.324 & 77.914 & \\
\hline & & & & & & & \\
\hline \multirow[t]{2}{*}{ Sample } & Time & Abs. & $\mathrm{ug} / \mathrm{ml}$ & $u g / 5.1$ & $\mathrm{ug} / \mathrm{cm}^{2}$ & Cumulative amount & \\
\hline & (h) & & & & & & \\
\hline 1 & 1 & 0.324 & 6.700 & 34.169 & 53.737 & 146.684 & \\
\hline 2 & 1 & 0.387 & 7.842 & 39.995 & 62.900 & 158.921 & Average \\
\hline 3 & 1 & 0.372 & 7.576 & 38.640 & 60.768 & 142.174 & 149.557 \\
\hline 4 & 1 & 0.373 & 7.590 & 38.708 & 60.875 & 178.645 & Std.Dev. \\
\hline 5 & 1 & 0.324 & 6.714 & 34.242 & 53.853 & 141.773 & 17.169 \\
\hline \multirow[t]{2}{*}{6} & 1 & 0.307 & 6.387 & 32.575 & 51.231 & 129.145 & \\
\hline & & & & & & & \\
\hline \multirow[t]{2}{*}{ Sample } & Time & Abs. & $\mathrm{ug} / \mathrm{ml}$ & $\mathrm{ug} / 5.1$ & $\mathrm{ug} / \mathrm{cm}^{2}$ & Cumulative amount & \\
\hline & (h) & & & & & & \\
\hline 1 & 2 & 0.559 & 10.987 & 56.032 & 88.121 & 234.805 & \\
\hline 2 & 2 & 0.703 & 13.598 & 69.350 & 109.067 & 267.988 & Average \\
\hline 3 & 2 & 0.696 & 13.466 & 68.677 & 108.008 & 250.181 & 247.792 \\
\hline 4 & 2 & 0.675 & 13.095 & 66.786 & 105.035 & 283.680 & Std.Dev. \\
\hline 5 & 2 & 0.562 & 11.035 & 56.279 & 88.510 & 230.283 & 24.329 \\
\hline \multirow[t]{2}{*}{6} & 2 & 0.577 & 11.304 & 57.652 & 90.669 & 219.814 & \\
\hline & & & & & & & \\
\hline \multirow[t]{2}{*}{ Sample } & \begin{tabular}{|l|} 
Time \\
\end{tabular} & Abs. & $\mathrm{ug} / \mathrm{ml}$ & $\mathrm{ug} / 5.1$ & $\mathrm{ug} / \mathrm{cm}^{2}$ & Cumulative amount & \\
\hline & (h) & & & & & & \\
\hline 1 & 4 & 1.269 & 23.883 & 121.806 & 191.563 & 426.368 & \\
\hline 2 & 4 & 1.541 & 28.830 & 147.034 & 231.240 & 499.228 & Average \\
\hline 3 & 4 & 1.559 & 29.161 & 148.723 & 233.897 & 484.078 & 457.980 \\
\hline 4 & 4 & 1.523 & 28.513 & 145.415 & 228.694 & 512.373 & Std.Dev. \\
\hline 5 & 4 & 1.273 & 23.962 & 122.205 & 192.192 & 422.475 & 46.010 \\
\hline 6 & 4 & 1.214 & 22.883 & 116.706 & 183.543 & 403.356 & \\
\hline \multirow[t]{2}{*}{ Sample } & \begin{tabular}{|l|} 
Time \\
\end{tabular} & Abs. & $\mathrm{ug} / \mathrm{ml}$ & $\mathrm{ug} / 5.1$ & $\mathrm{ug} / \mathrm{cm}^{2}$ & Cumulative amount & \\
\hline & (h) & & & & & & \\
\hline 1 & 6 & 1.278 & 24.043 & 122.621 & 192.845 & 619.214 & \\
\hline 2 & 6 & 1.489 & 27.896 & 142.269 & 223.746 & 722.973 & Average \\
\hline 3 & 6 & 1.460 & 27.366 & 139.568 & 219.498 & 703.576 & 660.785 \\
\hline 4 & 6 & 1.457 & 27.312 & 139.291 & 219.063 & 731.436 & Std.Dev. \\
\hline 5 & 6 & 1.252 & 23.584 & 120.277 & 189.160 & 611.635 & 66.398 \\
\hline 6 & 6 & 1.138 & 21.509 & 109.697 & 172.521 & 575.877 & \\
\hline
\end{tabular}


TABLE 47. CONT'D.

\begin{tabular}{|c|c|c|c|c|c|c|c|}
\hline Sample & Time & Abs. & $\mathrm{ug} / \mathrm{ml}$ & $u g / 5.2$ & $\mathrm{ug} / \mathrm{cm}^{2}$ & Cumulative amount & \\
\hline & (h) & & & & & & \\
\hline 1 & 8 & 1.441 & 27.088 & 138.147 & 217.263 & 836.477 & \\
\hline 2 & 8 & 1.693 & 31.671 & 161.524 & 254.029 & 977.002 & Average \\
\hline 3 & 8 & 1.567 & 29.386 & 149.870 & 235.701 & 939.277 & 888.639 \\
\hline$\overline{4}$ & 8 & 1.663 & 31.118 & 158.703 & 249.591 & 981.028 & Std.Dev. \\
\hline 5 & 8 & 1.424 & 26.769 & 136.522 & 214.708 & 826.344 & 88.525 \\
\hline \multirow[t]{2}{*}{6} & 8 & 1.294 & 24.415 & 124.516 & 195.826 & 771.703 & \\
\hline & & & & & & & \\
\hline \multirow[t]{2}{*}{ Sample } & Time & Abs. & $\mathrm{ug} / \mathrm{ml}$ & $u g / 5.1$ & $\mathrm{ug} / \mathrm{cm}^{2}$ & Cumulative amount & \\
\hline & (h) & & & & & & \\
\hline 1 & 10 & 1.370 & 25.725 & 131.198 & 206.335 & 1042.812 & \\
\hline 2 & 10 & 1.686 & 31.471 & 160.503 & 252.424 & 1229.426 & Average \\
\hline 3 & 10 & 1.512 & 28.302 & 144.338 & 227.001 & 1166.278 & 1113.829 \\
\hline 4 & 10 & 1.642 & 30.671 & 156.423 & 246.007 & 1227.035 & Std.Dev. \\
\hline 5 & 10 & 1.438 & 26.955 & 137.469 & 216.197 & 1042.541 & 108.038 \\
\hline \multirow[t]{2}{*}{6} & 10 & 1.348 & 25.332 & 129.191 & 203.179 & 974.882 & \\
\hline & & & & & & & \\
\hline \multirow[t]{2}{*}{ Sample } & Time & Abs. & $\mathrm{ug} / \mathrm{ml}$ & $u g / 5.1$ & $\mathrm{ug} / \mathrm{cm}^{2}$ & Cumulative amount & \\
\hline & (h) & & & & & & \\
\hline 1 & 12 & 1.437 & 26.937 & 137.378 & 216.054 & 1258.866 & \\
\hline 2 & 12 & 1.821 & 33.923 & 173.009 & 272.090 & 1501.516 & Average \\
\hline 3 & 12 & 1.521 & 28.471 & 145.204 & 228.363 & 1394.640 & 1351.013 \\
\hline 4 & 12 & 1.775 & 33.090 & 168.760 & 265.408 & 1492.443 & Std.Dev. \\
\hline 5 & 12 & 1.511 & 28.283 & 144.242 & 226.849 & 1269.390 & 131.062 \\
\hline 6 & 12 & 1.425 & 26.723 & 136.289 & 214.341 & 1189.223 & \\
\hline
\end{tabular}

\begin{tabular}{|c|c|c|c|}
\hline Time & \multicolumn{2}{|c|}{ Average cum. amount } & Std.Dev. \\
\hline (h) & & & \\
\hline 0.5 & 92.330 & & 14.197 \\
\hline 1 & 149.557 & & 17.169 \\
\hline 2 & 247.792 & & 24.329 \\
\hline 4 & 457.980 & & 46.010 \\
\hline 6 & 660.785 & 660.785 & 66.398 \\
\hline 8 & 888.639 & 888.639 & 88.525 \\
\hline 10 & 1113.829 & 1113.829 & 108.038 \\
\hline 12 & 1351.013 & 1351.013 & 131.062 \\
\hline
\end{tabular}




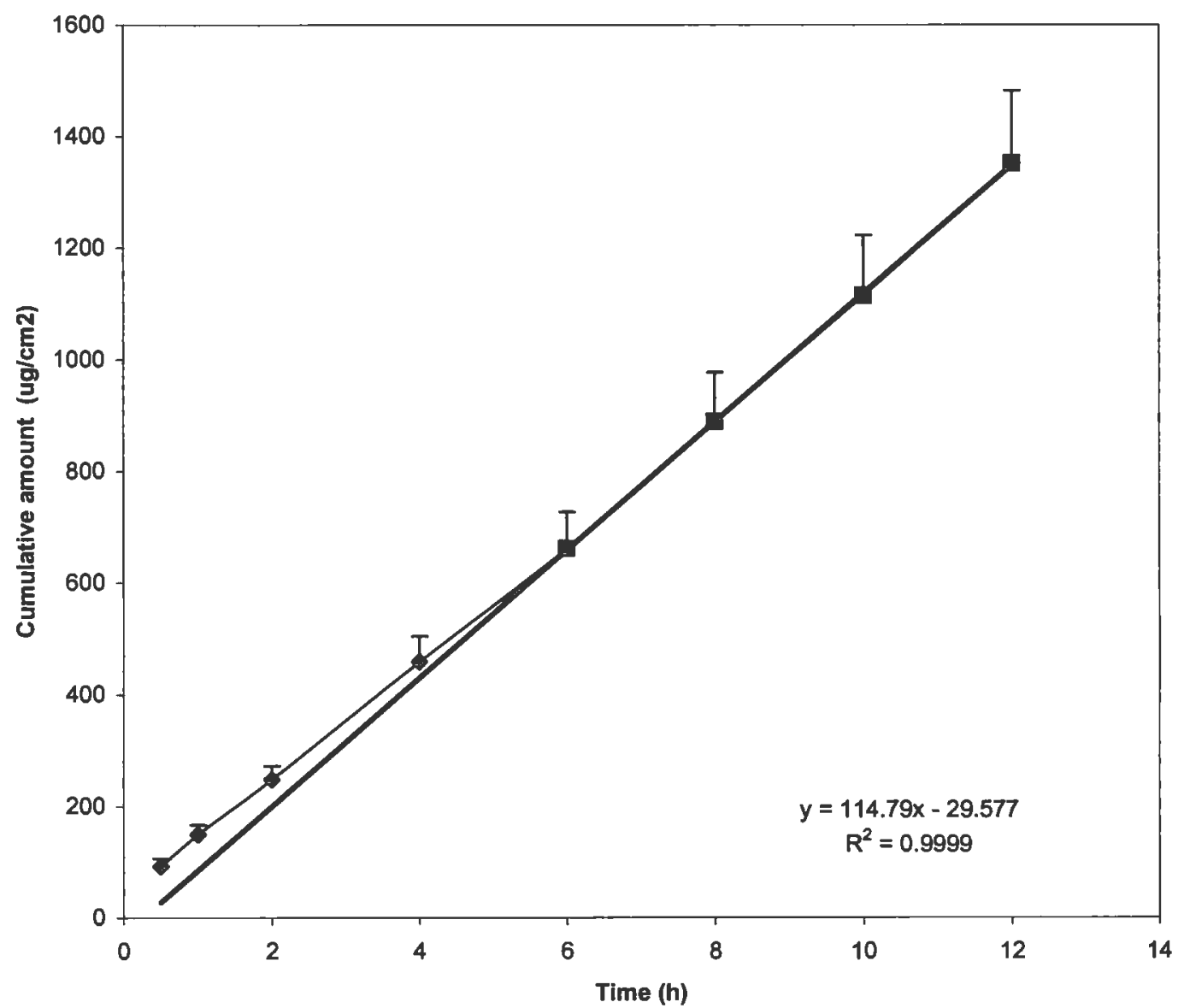

FIGURE 48. RELEASE PROFILE OF LECITHIN:IPM (50:50) CONTAINING $0.6 \%$ WATER AND $6.5 \% \mathrm{KT}$ (MEAN $\pm \mathrm{SD}, \mathrm{N}=6$ ) 
TABLE 48. CUMULATIVE RELEASE OF KT ACROSS CELLULOSE ACETATE MEMBRANE FROM LECITHIN:IPM (50:50) CONTAINING $0.7 \%$ WATER AND $6.5 \% \mathrm{KT}$

\begin{tabular}{|c|c|c|c|c|c|c|c|}
\hline Sample & Time & Abs. & $\mathrm{ug} / \mathrm{ml}$ & $\mathrm{ug} / 5.1$ & $\mathrm{ug} / \mathrm{cm}^{2}$ & Cumulative amount & \\
\hline & (h) & & & & & & \\
\hline 1 & 0.5 & 0.558 & 10.952 & 55.853 & 87.840 & 87.840 & \\
\hline 2 & 0.5 & 0.638 & 12.410 & 63.290 & 99.536 & 99.536 & Average \\
\hline 3 & 0.5 & 0.596 & 11.656 & 59.447 & 93.493 & 93.493 & 98.217 \\
\hline 4 & 0.5 & 0.663 & 12.875 & 65.664 & 103.270 & 103.270 & Std.Dev. \\
\hline 5 & 0.5 & 0.707 & 13.671 & 69.722 & 109.652 & 109.652 & 7.686 \\
\hline \multirow[t]{2}{*}{6} & 0.5 & 0.610 & 11.908 & 60.729 & 95.509 & 95.509 & \\
\hline & & & & & & & \\
\hline \multirow[t]{2}{*}{ Sample } & Time & Abs. & $\mathrm{ug} / \mathrm{ml}$ & ug/5.1 & $\mathrm{ug} / \mathrm{cm}^{2}$ & Cumulative amount & \\
\hline & (h) & & & & & & \\
\hline 1 & 1 & 0.339 & 6.972 & 35.557 & 55.920 & 143.760 & \\
\hline 2 & 1 & 0.413 & 8.332 & 42.491 & 66.825 & 166.362 & Average \\
\hline 3 & 1 & 0.360 & 7.352 & 37.495 & 58.968 & 152.461 & 162.982 \\
\hline 4 & 1 & 0.417 & 8.394 & 42.808 & 67.324 & 170.594 & Std.Dev. \\
\hline 5 & 1 & 0.466 & 9.290 & 47.378 & 74.511 & 184.163 & 14.171 \\
\hline \multirow[t]{2}{*}{6} & 1 & 0.401 & 8.110 & 41.359 & 65.045 & 160.554 & \\
\hline & & & & & & & \\
\hline \multirow[t]{2}{*}{ Sample } & Time & Abs. & $\mathrm{ug} / \mathrm{ml}$ & $\mathrm{ug} / 5.1$ & $\mathrm{ug} / \mathrm{cm}^{2}$ & Cumulative amount & \\
\hline & (h) & & & & & & \\
\hline 1 & 2 & 0.621 & 12.109 & 61.755 & 97.122 & 240.882 & \\
\hline 2 & 2 & 0.799 & 15.343 & 78.249 & 123.061 & 289.423 & Average \\
\hline 3 & 2 & 0.696 & 13.460 & 68.647 & 107.961 & 260.422 & 278.835 \\
\hline 4 & 2 & 0.777 & 14.939 & 76.188 & 119.821 & 290.416 & Std.Dev. \\
\hline 5 & 2 & 0.843 & 16.139 & 82.311 & 129.450 & 313.613 & 25.438 \\
\hline \multirow[t]{2}{*}{6} & 2 & 0.762 & 14.675 & 74.841 & 117.702 & 278.257 & \\
\hline & & & & & & & \\
\hline \multirow[t]{2}{*}{ Sample } & Time & Abs. & ug/ml & $\mathrm{ug} / 5.1$ & $\mathrm{ug} / \mathrm{cm}^{2}$ & Cumulative amount & \\
\hline & (h) & & & & & & \\
\hline 1 & 4 & 1.411 & 26.466 & 134.976 & 212.276 & 453.158 & \\
\hline 2 & 4 & 1.619 & 30.257 & 154.310 & 242.683 & 532.107 & Average \\
\hline 3 & 4 & 1.453 & 27.235 & 138.900 & 218.448 & 478.869 & 509.533 \\
\hline 4 & 4 & 1.543 & 28.878 & 147.277 & 231.622 & 522.038 & Std.Dev. \\
\hline 5 & 4 & 1.660 & 31.004 & 158.119 & 248.673 & 562.286 & 38.905 \\
\hline 6 & 4 & 1.536 & 28.736 & 146.552 & 230.482 & 508.738 & \\
\hline \multirow[t]{2}{*}{ Sample } & Time & Abs. & $\mathrm{ug} / \mathrm{ml}$ & $\mathrm{ug} / 5.1$ & $\mathrm{ug} / \mathrm{cm}^{2}$ & Cumulative amount & \\
\hline & (h) & & & & & & \\
\hline 1 & 6 & 1.315 & 24.719 & 126.069 & 198.269 & 651.427 & \\
\hline 2 & 6 & 1.505 & 28.187 & 143.751 & 226.078 & 758.184 & Average \\
\hline 3 & 6 & 1.347 & 25.309 & 129.077 & 203.000 & 681.869 & 725.083 \\
\hline 4 & 6 & 1.459 & 27.350 & 139.487 & 219.371 & 741.408 & Std.Dev. \\
\hline 5 & 6 & 1.530 & 28.640 & 146.065 & 229.716 & 792.002 & 51.251 \\
\hline 6 & 6 & 1.442 & 27.038 & 137.895 & 216.867 & 725.605 & \\
\hline
\end{tabular}


TABLE 48. CONT'D.

\begin{tabular}{|c|c|c|c|c|c|c|c|}
\hline Sample & Time & Abs. & ug/ml & ug/5.2 & ug/cm & Cumulative amount & \\
\hline & (h) & & & & & & \\
\hline 1 & 8 & 1.430 & 26.882 & 137.097 & 215.613 & 867.039 & \\
\hline 2 & 8 & 1.678 & 31.392 & 160.101 & 251.791 & 1009.975 & Average \\
\hline 3 & 8 & 1.488 & 27.939 & 142.488 & 224.090 & 905.959 & 964.408 \\
\hline 4 & 8 & 1.635 & 30.617 & 156.144 & 245.568 & 986.976 & Std.Dev. \\
\hline 5 & 8 & 1.696 & 31.724 & 161.791 & 254.449 & 1046.451 & 66.702 \\
\hline 6 & 8 & 1.627 & 30.477 & 155.430 & 244.445 & 970.050 & \\
\hline & & & & & & & \\
\hline & & & & & & & \\
\hline Sample & Time & Abs. & ug/ml & ug/5.1 & ug/cm ${ }^{2}$ & Cumulative amount & \\
\hline & (h) & & & & & & \\
\hline 1 & 10 & 1.416 & 26.552 & 135.417 & 212.970 & 1080.010 & \\
\hline 2 & 10 & 1.700 & 31.729 & 161.817 & 254.488 & 1264.463 & Average \\
\hline 3 & 10 & 1.493 & 27.960 & 142.594 & 224.258 & 1130.216 & 1204.049 \\
\hline 4 & 10 & 1.674 & 31.246 & 159.354 & 250.615 & 1237.591 & Std.Dev. \\
\hline 5 & 10 & 1.646 & 30.744 & 156.793 & 246.587 & 1293.038 & 82.163 \\
\hline 6 & 10 & 1.662 & 31.035 & 158.279 & 248.925 & 1218.975 & \\
\hline & & & & & & & \\
\hline & & & & & & & \\
\hline Sample & Time & Abs. & ug/ml & ug/5.1 & ug/cm ${ }^{2}$ & Cumulative amount & \\
\hline & (h) & & & & & & \\
\hline 1 & 12 & 1.561 & 29.196 & 148.901 & 234.177 & 1314.187 & \\
\hline 2 & 12 & 1.814 & 33.801 & 172.383 & 271.106 & 1535.569 & Average \\
\hline 3 & 12 & 1.666 & 31.103 & 158.623 & 249.466 & 1379.682 & 1462.154 \\
\hline 4 & 12 & 1.807 & 33.667 & 171.703 & 270.037 & 1507.629 & Std.Dev. \\
\hline 5 & 12 & 1.737 & 32.389 & 165.183 & 259.782 & 1552.821 & 94.668 \\
\hline 6 & 12 & 1.766 & 32.923 & 167.905 & 264.064 & 1483.039 & \\
\hline & & & & & & & \\
\hline
\end{tabular}

\begin{tabular}{|c|c|c|c|}
\hline Time & \multicolumn{2}{|c|}{ Average cum. amount } & Std.Dev. \\
\hline (h) & & & \\
\hline 0.5 & 98.217 & & 7.686 \\
\hline 1 & 162.982 & & 14.171 \\
\hline 2 & 278.835 & & 25.438 \\
\hline 4 & 509.533 & 509.533 & 38.905 \\
\hline 6 & 725.083 & 725.083 & 51.251 \\
\hline 8 & 964.408 & 964.408 & 66.702 \\
\hline 10 & 1204.049 & & 82.163 \\
\hline 12 & 1462.154 & & 94.668 \\
\hline
\end{tabular}




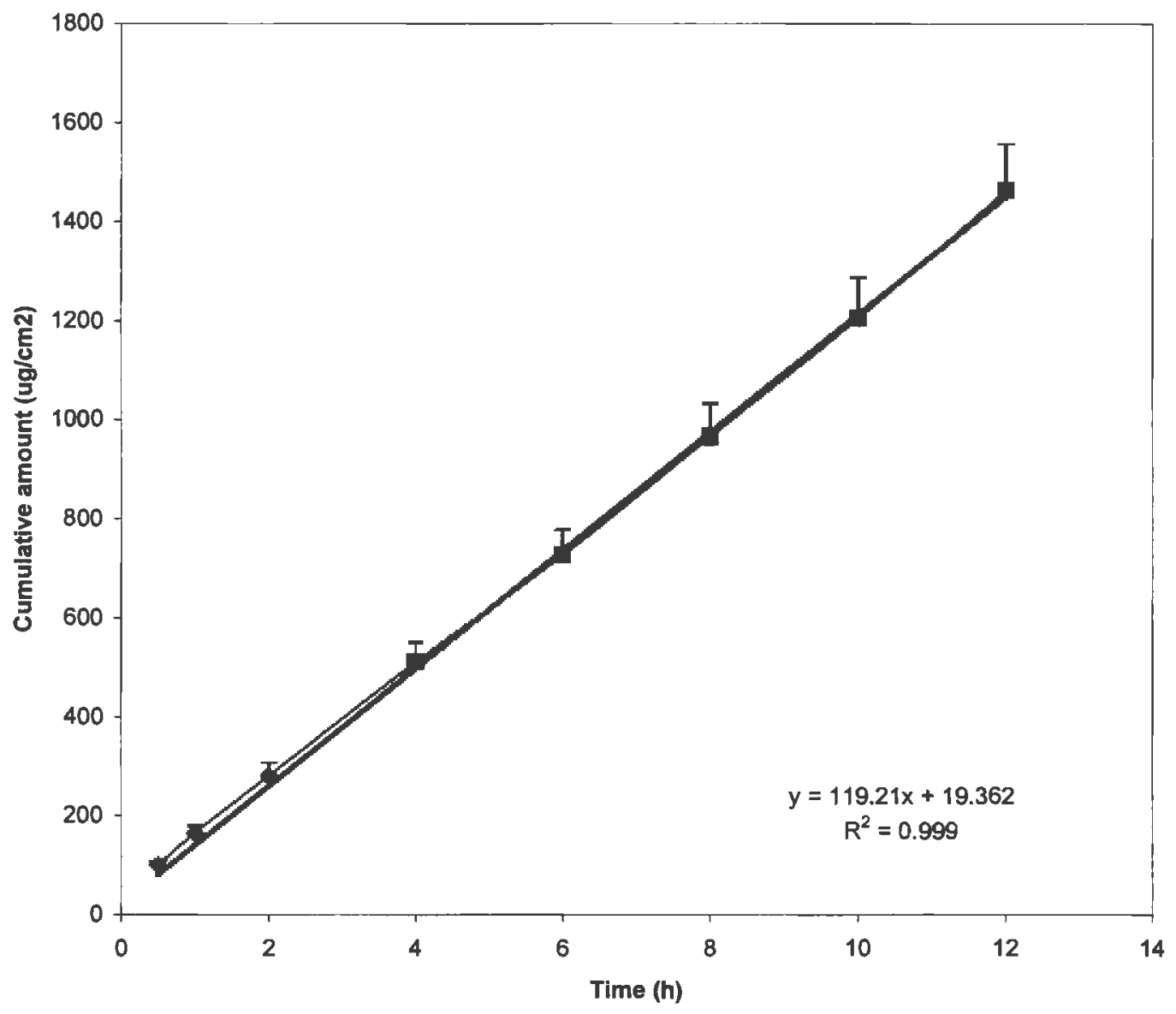

FIGURE 49. RELEASE PROFILE OF KT FROM LECITHIN:IPM $(50: 50)$ CONTAINING $0.7 \%$ WATER AND $6.5 \% \mathrm{KT}$ (MEAN \pm SD, $\mathrm{N}=6$ ) 
TABLE 49. CUMULATIVE RELEASE OF KT ACROSS CELLULOSE ACETATE MEMBRANE FROM LECITHIN:IPM (50:50) CONTAINING $0.8 \%$ WATER AND $6.5 \% \mathrm{KT}$

\begin{tabular}{|c|c|c|c|c|c|c|c|}
\hline Sample & Time & Abs. & $\mathrm{ug} / \mathrm{ml}$ & $\mathrm{ug} / 5.1$ & $\mathrm{ug} / \mathrm{cm}^{2}$ & Cumulative amount & \\
\hline & (h) & & & & & & \\
\hline 1 & 0.5 & 0.888 & 16.966 & 86.527 & 136.080 & 136.080 & \\
\hline 2 & 0.5 & 0.789 & 15.161 & 77.322 & 121.604 & 121.604 & Average \\
\hline 3 & 0.5 & 0.645 & 12.539 & 63.951 & 100.575 & 100.575 & 107.163 \\
\hline 4 & 0.5 & 0.699 & 13.519 & 68.948 & 108.435 & 108.435 & Std.dev. \\
\hline 5 & 0.5 & 0.509 & 10.071 & 51.362 & 80.778 & 80.778 & 19.605 \\
\hline \multirow[t]{2}{*}{6} & 0.5 & 0.610 & 11.908 & 60.729 & 95.509 & 95.509 & \\
\hline & & & & & & & \\
\hline \multirow[t]{2}{*}{ Sample } & Time & Abs. & $\mathrm{ug} / \mathrm{ml}$ & $\mathrm{ug} / 5.1$ & $\mathrm{ug} / \mathrm{cm}^{2}$ & \begin{tabular}{|c|} 
Cumulative amount \\
\end{tabular} & \\
\hline & (h) & & & & & & \\
\hline 1 & 1 & 0.438 & 8.775 & 44.752 & 70.381 & 206.462 & \\
\hline 2 & 1 & 0.365 & 7.456 & 38.025 & 59.801 & 181.405 & Average \\
\hline 3 & 1 & 0.280 & 5.909 & 30.135 & 47.393 & 147.968 & 162.620 \\
\hline 4 & 1 & 0.297 & 6.208 & 31.660 & 49.791 & 158.226 & Std.dev. \\
\hline 5 & 1 & 0.232 & 5.028 & 25.641 & 40.325 & 121.103 & 29.110 \\
\hline \multirow[t]{2}{*}{6} & 1 & 0.401 & 8.110 & 41.359 & 65.045 & 160.554 & \\
\hline & & & & & & & \\
\hline \multirow[t]{2}{*}{ Sample } & Time & Abs. & $\mathrm{ug} / \mathrm{ml}$ & $\mathrm{ug} / 5.1$ & $\mathrm{ug} / \mathrm{cm}^{2}$ & Cumulative amount & \\
\hline & (h) & & & & & & \\
\hline 1 & $\frac{1}{2}$ & 0.887 & 16.948 & 86.433 & 135.933 & 342.395 & \\
\hline 2 & 2 & 0.876 & 16.740 & 85.373 & 134.266 & 315.671 & Average \\
\hline 3 & 2 & 0.859 & 16.425 & 83.765 & 131.737 & 279.706 & 293.452 \\
\hline 4 & 2 & 0.971 & 18.474 & 94.216 & 148.173 & 306.399 & Std.dev. \\
\hline 5 & 2 & 0.759 & 14.610 & 74.509 & 117.180 & 238.283 & 36.111 \\
\hline \multirow[t]{3}{*}{6} & 2 & 0.762 & 14.675 & 74.841 & 117.702 & 278.257 & \\
\hline & & & & & & & \\
\hline & & & & & & & \\
\hline \multirow[t]{2}{*}{ Sample } & Time & Abs. & $\mathrm{ug} / \mathrm{ml}$ & $\mathrm{ug} / 5.1$ & $\mathrm{ug} / \mathrm{cm}^{2}$ & Cumulative amount & \\
\hline & (h) & & & & & & \\
\hline 1 & 4 & 1.712 & 31.948 & 162.936 & 256.249 & 598.643 & \\
\hline 2 & 4 & 1.706 & 31.827 & 162.317 & 255.276 & 570.947 & Average \\
\hline 3 & 4 & 1.697 & 31.672 & 161.526 & 254.032 & 533.738 & 547.207 \\
\hline 4 & 4 & 1.899 & 35.346 & 180.265 & 283.502 & 589.901 & Std.dev. \\
\hline 5 & 4 & 1.571 & 29.386 & 149.870 & 235.700 & 473.983 & 48.057 \\
\hline 6 & 4 & 1.586 & 29.645 & 151.188 & 237.773 & 516.030 & \\
\hline \multirow[t]{2}{*}{ Sample } & Time & Abs. & $\mathrm{ug} / \mathrm{ml}$ & $\mathrm{ug} / 5.1$ & $\mathrm{ug} / \mathrm{cm}^{2}$ & Cumulative amount & \\
\hline & (h) & & & & & & \\
\hline 1 & 6 & 1.483 & 27.781 & 141.681 & 222.821 & 821.464 & \\
\hline 2 & 6 & 1.465 & 27.452 & 140.003 & 220.183 & 791.130 & Average \\
\hline 3 & 6 & 1.393 & 26.133 & 133.281 & 209.610 & 743.348 & 744.848 \\
\hline 4 & 6 & 1.312 & 24.678 & 125.857 & 197.935 & 787.836 & Std.dev. \\
\hline 5 & 6 & 1.056 & 20.014 & 102.070 & 160.525 & 634.507 & 70.652 \\
\hline 6 & 6 & 1.154 & 21.790 & 111.128 & 174.771 & 690.801 & \\
\hline
\end{tabular}


TABLE 49. CONT'D.

\begin{tabular}{|c|c|c|c|c|c|c|c|}
\hline Sample & Time & Abs. & $\mathrm{ug} / \mathrm{ml}$ & $\mathrm{ug} / 5.2$ & $\mathrm{ug} / \mathrm{cm}^{2}$ & Cumulative amount & \\
\hline & (h) & & & & & & \\
\hline 1 & 8 & 1.217 & 23.022 & 117.410 & 184.651 & 1006.115 & \\
\hline 2 & 8 & 1.293 & 24.403 & 124.454 & 195.728 & 986.858 & Average \\
\hline 3 & 8 & 1.191 & 22.534 & 114.925 & 180.743 & 924.090 & 933.247 \\
\hline 4 & 8 & 1.342 & 25.295 & 129.007 & 202.889 & 990.724 & Std.dev. \\
\hline 5 & 8 & 1.161 & 22.000 & 112.202 & 176.460 & 810.967 & 76.528 \\
\hline \multirow[t]{2}{*}{6} & 8 & 1.254 & 23.679 & 120.764 & 189.926 & 880.727 & \\
\hline & & & & & & & \\
\hline \multirow[t]{2}{*}{ Sample } & Time & Abs. & $\mathrm{ug} / \mathrm{ml}$ & $u g / 5.1$ & $\mathrm{ug} / \mathrm{cm}^{2}$ & Cumulative amount & \\
\hline & (h) & & & & & & \\
\hline 1 & 10 & 1.367 & 25.675 & 130.944 & 205.935 & 1212.051 & \\
\hline 2 & 10 & 1.280 & 24.083 & 122.825 & 193.166 & 1180.025 & Average \\
\hline 3 & 10 & 1.281 & 24.101 & 122.913 & 193.305 & 1117.395 & 1133.17 \\
\hline 4 & 10 & 1.318 & 24.774 & 126.347 & 198.706 & 1189.431 & Std.dev. \\
\hline 5 & 10 & 1.354 & 25.435 & 129.718 & 204.007 & 1014.974 & 74.977 \\
\hline \multirow[t]{2}{*}{6} & 10 & 1.357 & 25.487 & 129.983 & 204.424 & 1085.151 & \\
\hline & & & & & & & \\
\hline \multirow{2}{*}{ Sample } & Time & Abs. & $\mathrm{ug} / \mathrm{ml}$ & $u g / 5.1$ & $\mathrm{ug} / \mathrm{cm}^{2}$ & Cumulative amount & \\
\hline & (h) & & & & & & \\
\hline 1 & 12 & 1.249 & 23.515 & 119.927 & 188.609 & 1400.659 & \\
\hline 2 & 12 & 1.282 & 24.120 & 123.014 & 193.464 & 1373.488 & Average \\
\hline 3 & 12 & 1.289 & 24.249 & 123.669 & 194.495 & 1311.890 & 1329.882 \\
\hline 4 & 12 & 1.319 & 24.803 & 126.494 & 198.937 & 1388.367 & Std.dev. \\
\hline 5 & 12 & 1.332 & 25.029 & 127.649 & 200.754 & 1215.728 & 71.197 \\
\hline 6 & 12 & 1.354 & 25.435 & 129.718 & 204.007 & 1289.158 & \\
\hline
\end{tabular}

\begin{tabular}{|c|c|c|c|}
\hline Time & \multicolumn{2}{|c|}{ Average cum. amount } & Std.Dev. \\
\hline (h) & & & \\
\hline 0.5 & 107.163 & & 19.605 \\
\hline 1 & 162.620 & & 29.110 \\
\hline 2 & 293.452 & & 36.111 \\
\hline 4 & 547.207 & 547.207 & 48.057 \\
\hline 6 & 744.848 & 744.848 & 70.652 \\
\hline 8 & 933.247 & 933.247 & 76.528 \\
\hline 10 & 1133.171 & 1133.171 & 74.977 \\
\hline 12 & 1329.882 & 1329.882 & 71.197 \\
\hline
\end{tabular}




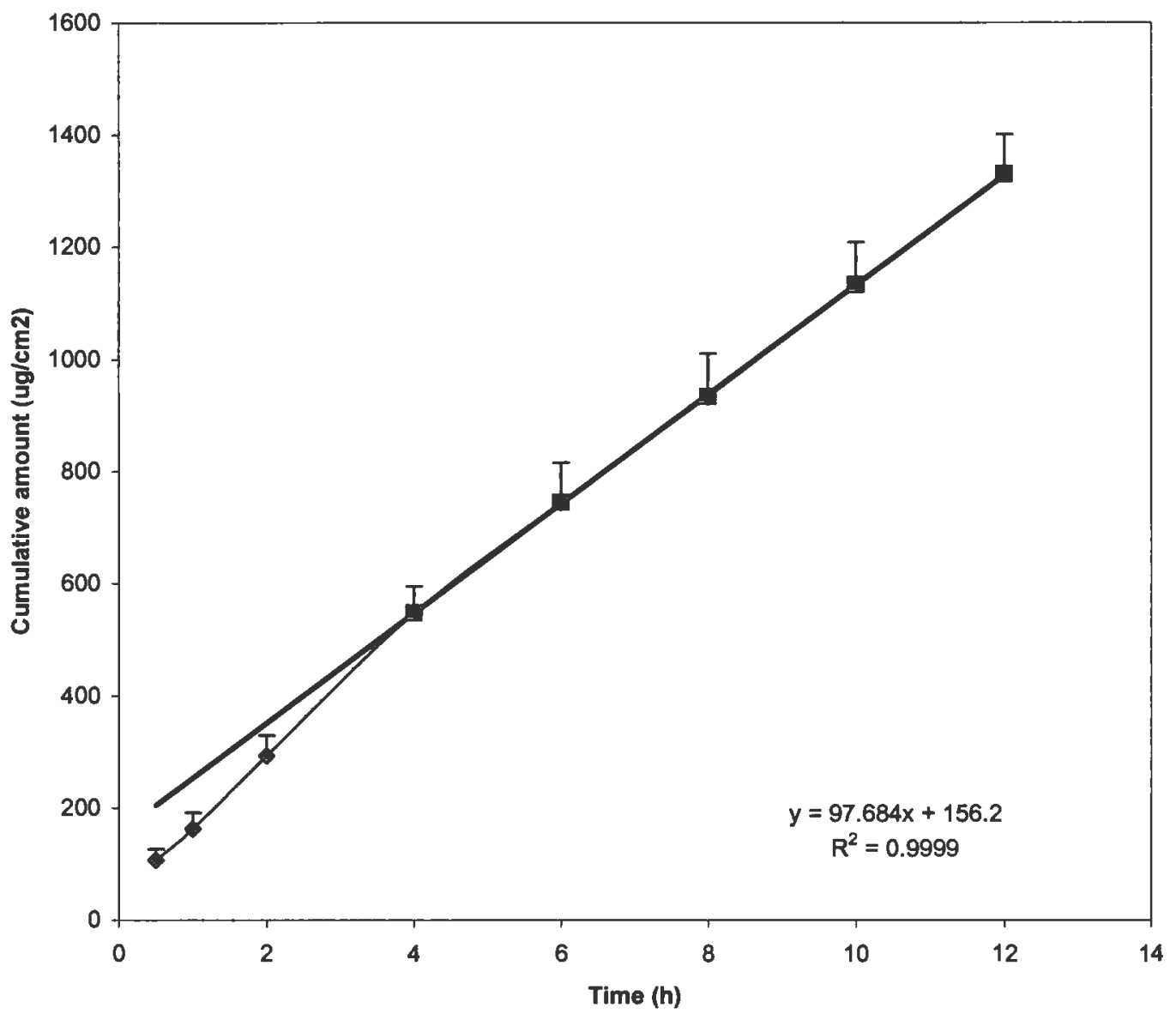

FIGURE 50. RELEASE PROFILE OF KT FROM LECITHIN:IPM (50:50) CONTAINING $0.8 \%$ WATER AND $6.5 \% \mathrm{KT}$ (MEAN \pm SD, $\mathrm{N}=6)$ 
TABLE 50. CUMULATIVE RELEASE OF KT ACROSS CELLULOSE ACETATE MEMBRANE FROM LECITHIN:IPM (60:40) CONTAINING $0.1 \%$ WATER AND $6.5 \% \mathrm{KT}$ (NO. 1 )

\begin{tabular}{|c|c|c|c|c|c|c|c|}
\hline Sample & Time & Abs. & $\mathrm{ug} / \mathrm{ml}$ & ug/5.1 & $\mathrm{ug} / \mathrm{cm}^{2}$ & Cumulative amount & \\
\hline & (h) & & & & & & \\
\hline 1 & 0.5 & 1.204 & 22.702 & 115.780 & 182.087 & 182.087 & \\
\hline 2 & 0.5 & 0.739 & 14.254 & 72.698 & 114.332 & 114.332 & Average \\
\hline 3 & 0.5 & 0.650 & 12.637 & 64.450 & 101.361 & 101.361 & 118.073 \\
\hline 4 & 0.5 & 0.535 & 10.545 & 53.782 & 84.583 & 84.583 & Std.Dev. \\
\hline 5 & 0.5 & 0.632 & 12.304 & 62.751 & 98.688 & 98.688 & 34.569 \\
\hline \multirow[t]{2}{*}{6} & 0.5 & 0.829 & 15.882 & 80.999 & 127.387 & 127.387 & \\
\hline & & & & & & & \\
\hline \multirow[t]{2}{*}{ Sample } & Time & Abs. & $\mathrm{ug} / \mathrm{ml}$ & $\mathrm{ug} / 5.1$ & $\mathrm{ug} / \mathrm{cm}^{2}$ & Cumulative amount & \\
\hline & (h) & & & & & & \\
\hline 1 & 1 & 0.501 & 9.920 & 50.593 & 79.567 & 261.654 & \\
\hline 2 & 1 & 0.375 & 7.629 & 38.907 & 61.189 & 175.521 & Average \\
\hline 3 & 1 & 0.391 & 7.929 & 40.438 & 63.597 & 164.958 & 183.389 \\
\hline 4 & 1 & 0.290 & 6.094 & 31.081 & 48.881 & 133.464 & Std.Dev. \\
\hline 5 & 1 & 0.389 & 7.882 & 40.196 & 63.216 & 161.905 & 44.405 \\
\hline \multirow[t]{2}{*}{6} & 1 & 0.473 & 9.406 & 47.971 & 75.444 & 202.831 & \\
\hline & & & & & & & \\
\hline \multirow[t]{2}{*}{ Sample } & Time & Abs. & $\mathrm{ug} / \mathrm{ml}$ & $u g / 5.1$ & $\mathrm{ug} / \mathrm{cm}^{2}$ & Cumulative amount & \\
\hline & (h) & & & & & & \\
\hline 1 & $\frac{1}{2}$ & 0.861 & 16.467 & 83.980 & 132.076 & 393.730 & \\
\hline 2 & 2 & 0.775 & 14.914 & 76.064 & 119.626 & 295.146 & Average \\
\hline 3 & 2 & 0.807 & 15.489 & 78.994 & 124.234 & 289.192 & 305.153 \\
\hline 4 & 2 & 0.620 & 12.083 & 61.622 & 96.913 & 230.377 & Std.Dev. \\
\hline 5 & 2 & 0.757 & 14.569 & 74.302 & 116.855 & 278.760 & 56.526 \\
\hline \multirow[t]{2}{*}{6} & 2 & 0.921 & 17.565 & 89.579 & 140.881 & 343.712 & \\
\hline & & & & & & & \\
\hline \multirow[t]{2}{*}{ Sample } & Time & Abs. & $\mathrm{ug} / \mathrm{ml}$ & $\mathrm{ug} / 5.1$ & $\mathrm{ug} / \mathrm{cm}^{2}$ & Cumulative amount & \\
\hline & (h) & & & & & & \\
\hline 1 & 4 & 1.471 & 27.558 & 140.544 & 221.033 & 614.763 & \\
\hline 2 & 4 & 1.573 & 29.407 & 149.977 & 235.869 & 531.015 & Average \\
\hline 3 & 4 & 1.659 & 30.974 & 157.969 & 248.438 & 537.630 & 531.671 \\
\hline 4 & 4 & 1.227 & 23.116 & 117.890 & 185.405 & 415.782 & Std.Dev. \\
\hline 5 & 4 & 1.524 & 28.523 & 145.469 & 228.778 & 507.538 & 68.729 \\
\hline 6 & 4 & 1.598 & 29.871 & 152.343 & 239.589 & 583.301 & \\
\hline \multirow[t]{2}{*}{ Sample } & Time & Abs. & $\mathrm{ug} / \mathrm{ml}$ & $\mathrm{ug} / 5.1$ & $\mathrm{ug} / \mathrm{cm}^{2}$ & Cumulative amount & \\
\hline & (h) & & & & & & \\
\hline 1 & 6 & 1.368 & 25.679 & 130.962 & 205.963 & 820.726 & \\
\hline 2 & 6 & 1.684 & 31.434 & 160.312 & 252.122 & 783.137 & Average \\
\hline 3 & 6 & 1.532 & 28.668 & 146.209 & 229.942 & 767.572 & 747.894 \\
\hline 4 & 6 & 1.133 & 21.417 & 109.224 & 171.777 & 587.559 & Std.Dev. \\
\hline 5 & 6 & 1.391 & 26.105 & 133.138 & 209.386 & 716.924 & 86.763 \\
\hline 6 & 6 & 1.520 & 28.444 & 145.065 & 228.144 & 811.445 & \\
\hline
\end{tabular}


TABLE 50. CONT'D.

\begin{tabular}{|c|c|c|c|c|c|c|c|}
\hline Sample & Time & Abs. & ug/ml & ug/5.3 & ug/cm & Cumulative amount & \\
\hline & (h) & & & & & & \\
\hline 1 & 8 & 1.360 & 25.622 & 130.672 & 205.508 & 1026.234 & \\
\hline 2 & 8 & 1.705 & 31.883 & 162.601 & 255.722 & 1038.859 & Average \\
\hline 3 & 8 & 1.548 & 29.028 & 148.043 & 232.827 & 1000.398 & 968.611 \\
\hline 4 & 8 & 1.235 & 23.334 & 119.004 & 187.158 & 774.716 & Std.Dev. \\
\hline 5 & 8 & 1.438 & 27.037 & 137.886 & 216.854 & 933.777 & 102.806 \\
\hline 6 & 8 & 1.503 & 28.207 & 143.853 & 226.238 & 1037.683 & \\
\hline & & & & & & & \\
\hline & & & & & & & \\
\hline Sample & Time & Abs. & ug/ml & ug/5.1 & ug/cm & Cumulative amount & \\
\hline & (h) & & & & & & \\
\hline 1 & 10 & 1.182 & 22.301 & 113.733 & 178.867 & 1205.101 & \\
\hline 2 & 10 & 1.537 & 28.768 & 146.717 & 230.741 & 1269.600 & Average \\
\hline 3 & 10 & 1.465 & 27.444 & 139.963 & 220.120 & 1220.519 & 1167.930 \\
\hline 4 & 10 & 1.146 & 21.659 & 110.461 & 173.722 & 948.439 & Std.Dev. \\
\hline 5 & 10 & 1.338 & 25.136 & 128.195 & 201.613 & 1135.390 & 116.096 \\
\hline 6 & 10 & 1.264 & 23.794 & 121.350 & 190.847 & 1228.530 & \\
\hline & & & & & & & \\
\hline & & & & & & & \\
\hline Sample & Time & Abs. & ug/ml & ug/5.1 & ug/cm & Cumulative amount & \\
\hline & (h) & & & & & & \\
\hline 1 & 12 & 1.226 & 23.113 & 117.879 & 185.387 & 1390.489 & \\
\hline 2 & 12 & 1.661 & 31.010 & 158.152 & 248.725 & 1518.325 & Average \\
\hline 3 & 12 & 1.582 & 29.585 & 150.881 & 237.291 & 1457.809 & 1384.242 \\
\hline 4 & 12 & 1.256 & 23.656 & 120.645 & 189.738 & 1138.176 & Std.Dev. \\
\hline 5 & 12 & 1.453 & 27.231 & 138.879 & 218.415 & 1353.806 & 133.284 \\
\hline 6 & 12 & 1.452 & 27.219 & 138.816 & 218.315 & 1446.845 & \\
\hline & & & & & & \\
\hline
\end{tabular}

\begin{tabular}{|c|c|c|c|}
\hline Time & Average cum. amount & Std.Dev. \\
\hline$(\mathrm{h})$ & & & \\
\hline 0.5 & 118.087 & & 34.569 \\
\hline 1 & 183.389 & & 44.405 \\
\hline 2 & 305.153 & & 56.526 \\
\hline 4 & 531.671 & 531.671 & 68.729 \\
\hline 6 & 747.894 & 747.894 & 86.763 \\
\hline 8 & 968.611 & 968.611 & 102.806 \\
\hline 10 & 1167.930 & 1167.930 & 116.096 \\
\hline 12 & 1384.242 & 1384.242 & 133.284 \\
\hline
\end{tabular}


TABLE 51. CUMULATIVE RELEASE OF KT ACROSS CELLULOSE ACETATE MEMBRANE FROM LECITHIN:IPM $(60: 40)$ CONTAINING $0.1 \%$ WATER AND $6.5 \% \mathrm{KT}$ (NO. 2)

\begin{tabular}{|c|c|c|c|c|c|c|c|}
\hline Sample & Time & Abs. & $\mathrm{ug} / \mathrm{ml}$ & $\mathrm{ug} / 5.1$ & $\mathrm{ug} / \mathrm{cm}^{2}$ & Cumulative amount & \\
\hline & (h) & & & & & & \\
\hline 1 & 0.5 & 0.535 & 10.545 & 53.782 & 84.583 & 84.583 & \\
\hline 2 & 0.5 & 0.532 & 10.486 & 53.478 & 84.105 & 84.105 & Average \\
\hline 3 & 0.5 & 0.550 & 10.819 & 55.178 & 86.778 & 86.778 & 90.628 \\
\hline 4 & 0.5 & 0.621 & 12.114 & 61.780 & 97.161 & 97.161 & Std.Dev. \\
\hline 5 & 0.5 & 0.631 & 12.295 & 62.707 & 98.619 & 98.619 & 6.388 \\
\hline \multirow[t]{2}{*}{6} & 0.5 & 0.590 & 11.535 & 58.830 & 92.522 & 92.522 & \\
\hline & & & & & & & \\
\hline \multirow[t]{2}{*}{ Sample } & Time & Abs. & $\mathrm{ug} / \mathrm{ml}$ & $\mathrm{ug} / 5.1$ & $\mathrm{ug} / \mathrm{cm}^{2}$ & Cumulative amount & \\
\hline & (h) & & & & & & \\
\hline 1 & 1 & 0.290 & 6.094 & 31.081 & 48.881 & 133.464 & \\
\hline 2 & 1 & 0.285 & 5.992 & 30.561 & 48.063 & 132.169 & \begin{tabular}{|l|} 
Average \\
\end{tabular} \\
\hline 3 & 1 & 0.302 & 6.297 & 32.117 & 50.510 & 137.288 & 144.053 \\
\hline 4 & 1 & 0.386 & 7.826 & 39.914 & 62.772 & 159.933 & Std.Dev. \\
\hline 5 & 1 & 0.362 & 7.399 & 37.735 & 59.346 & 157.964 & 12.208 \\
\hline \multirow[t]{2}{*}{6} & 1 & 0.305 & 6.356 & 32.416 & 50.981 & 143.502 & \\
\hline & & & & & & & \\
\hline \multirow[t]{2}{*}{ Sample } & Time & Abs. & $\mathrm{ug} / \mathrm{ml}$ & $\mathrm{ug} / 5.1$ & $\mathrm{ug} / \mathrm{cm}^{2}$ & Cumulative amount & \\
\hline & (h) & & & & & & \\
\hline 1 & 2 & 0.615 & 11.992 & 61.162 & 96.189 & 229.653 & \\
\hline 2 & 2 & 0.635 & 12.369 & 63.081 & 99.208 & 231.377 & Average \\
\hline 3 & 2 & 0.652 & 12.675 & 64.641 & 101.662 & 238.949 & 240.816 \\
\hline 4 & 2 & 0.621 & 12.114 & 61.781 & 97.163 & 257.096 & Std.Dev. \\
\hline 5 & 2 & 0.599 & 11.699 & 59.664 & 93.833 & 251.797 & 11.188 \\
\hline \multirow[t]{3}{*}{6} & 2 & 0.590 & 11.535 & 58.829 & 92.520 & 236.023 & \\
\hline & & & & & & & \\
\hline & & & & & & & \\
\hline \multirow[t]{2}{*}{ Sample } & Time & Abs. & $\mathrm{ug} / \mathrm{ml}$ & $\mathrm{ug} / 5.1$ & $\mathrm{ug} / \mathrm{cm}^{2}$ & Cumulative amount & \\
\hline & (h) & & & & & & \\
\hline 1 & 4 & 1.227 & 23.116 & 117.890 & 185.405 & 415.058 & \\
\hline 2 & 4 & 1.246 & 23.467 & 119.680 & 188.221 & 419.598 & Average \\
\hline 3 & 4 & 1.264 & 23.796 & 121.360 & 190.863 & 429.812 & 425.675 \\
\hline 4 & 4 & 1.205 & 22.720 & 115.871 & 182.230 & 439.326 & Std.Dev. \\
\hline 5 & 4 & 1.196 & 22.566 & 115.086 & 180.996 & 432.793 & 9.708 \\
\hline 6 & 4 & 1.199 & 22.621 & 115.368 & 181.439 & 417.462 & \\
\hline \multirow[t]{2}{*}{ Sample } & Time & Abs. & $\mathrm{ug} / \mathrm{ml}$ & $\mathrm{ug} / 5.1$ & $\mathrm{ug} / \mathrm{cm}^{2}$ & Cumulative amount & \\
\hline & (h) & & & & & & \\
\hline 1 & 6 & 1.133 & 21.417 & 109.224 & 171.777 & 586.835 & \\
\hline 2 & 6 & 1.142 & 21.585 & 110.081 & 173.124 & 592.722 & Average \\
\hline 3 & 6 & 1.154 & 21.801 & 111.183 & 174.857 & 604.669 & 597.551 \\
\hline 4 & 6 & 1.124 & 21.245 & 108.347 & 170.397 & 609.724 & Std.Dev. \\
\hline 5 & 6 & 1.114 & 21.063 & 107.424 & 168.945 & 601.738 & 9.138 \\
\hline 6 & 6 & 1.136 & 21.464 & 109.464 & 172.154 & 589.616 & \\
\hline
\end{tabular}


TABLE 51. CONT'D.

\begin{tabular}{|c|c|c|c|c|c|c|c|}
\hline Sample & Time & Abs. & ug/ml & ug/5.3 & ug/cm & Cumulative amount & \\
\hline & (h) & & & & & & \\
\hline 1 & 8 & 1.235 & 23.350 & 119.086 & 187.286 & 774.121 & \\
\hline 2 & 8 & 1.246 & 23.536 & 120.034 & 188.777 & 781.499 & Average \\
\hline 3 & 8 & 1.251 & 23.641 & 120.570 & 189.621 & 794.290 & 781.247 \\
\hline 4 & 8 & 1.146 & 21.716 & 110.753 & 174.182 & 783.905 & Std.Dev. \\
\hline 5 & 8 & 1.137 & 21.560 & 109.954 & 172.925 & 774.662 & 7.435 \\
\hline 6 & 8 & 1.250 & 23.612 & 120.422 & 189.388 & 779.004 & \\
\hline & & & & & & & \\
\hline & & & & & & & \\
\hline Sample & Time & Abs. & ug/ml & ug/5.2 & ug/cm & Cumulative amount & \\
\hline & (h) & & & & & & \\
\hline 1 & 10 & 1.149 & 21.697 & 110.657 & 174.030 & 948.151 & \\
\hline 2 & 10 & 1.169 & 22.069 & 112.550 & 177.006 & 958.505 & Average \\
\hline 3 & 10 & 1.176 & 22.191 & 113.173 & 177.988 & 972.278 & 955.874 \\
\hline 4 & 10 & 1.139 & 21.523 & 109.766 & 172.629 & 956.535 & Std.Dev. \\
\hline 5 & 10 & 1.125 & 21.265 & 108.452 & 170.562 & 945.225 & 9.500 \\
\hline 6 & 10 & 1.159 & 21.887 & 111.621 & 175.547 & 954.550 & \\
\hline & & & & & & & \\
\hline & & & & & & & \\
\hline Sample & Time & Abs. & ug/ml & ug/5.2 & ug/cm & Cumulative amount & \\
\hline & (h) & & & & & & \\
\hline 1 & 12 & 1.256 & 23.656 & 120.645 & 189.738 & 1137.889 & \\
\hline 2 & 12 & 1.269 & 23.887 & 121.822 & 191.590 & 1150.095 & Average \\
\hline 3 & 12 & 1.275 & 23.989 & 122.343 & 192.408 & 1164.686 & 1145.640 \\
\hline 4 & 12 & 1.247 & 23.495 & 119.823 & 188.446 & 1144.980 & Std.Dev. \\
\hline 5 & 12 & 1.226 & 23.100 & 117.808 & 185.277 & 1130.501 & 11.596 \\
\hline 6 & 12 & 1.266 & 23.831 & 121.537 & 191.141 & 1145.691 & \\
\hline & & & & & & & \\
\hline
\end{tabular}

\begin{tabular}{|c|c|c|c|}
\hline Time & Average cum. amount & Std.Dev. \\
\hline (h) & & & \\
\hline 0.5 & 90.628 & & 6.388 \\
\hline 1 & 144.053 & & 12.208 \\
\hline 2 & 240.815 & 240.815 & 11.188 \\
\hline 4 & 425.675 & 425.675 & 9.708 \\
\hline 6 & 597.551 & 597.551 & 9.138 \\
\hline 8 & 781.247 & 781.247 & 7.435 \\
\hline 10 & 955.874 & 955.874 & 9.500 \\
\hline 12 & 1145.640 & 1145.640 & 11.596 \\
\hline
\end{tabular}


TABLE 52. CUMULATIVE RELAESE OF KT FROM LECITIN:IPM (60:40) CONTAINING 0.1\% WATER AND $6.5 \% \mathrm{KT}$

\begin{tabular}{|c|c|c|c|}
\hline Time (h) & Average cumulative amount & Std.Dev. \\
\hline & & & \\
\hline 0.5 & 104.351 & & 27.698 \\
\hline 1 & 163.721 & & 37.229 \\
\hline 2 & 272.984 & & 51.363 \\
\hline 4 & 478.673 & 478.673 & 72.486 \\
\hline 6 & 672.722 & 672.722 & 98.103 \\
\hline 8 & 874.929 & 874.929 & 120.014 \\
\hline 10 & 1061.902 & 1061.902 & 135.762 \\
\hline 12 & 1264.941 & 1264.941 & 153.826 \\
\hline
\end{tabular}




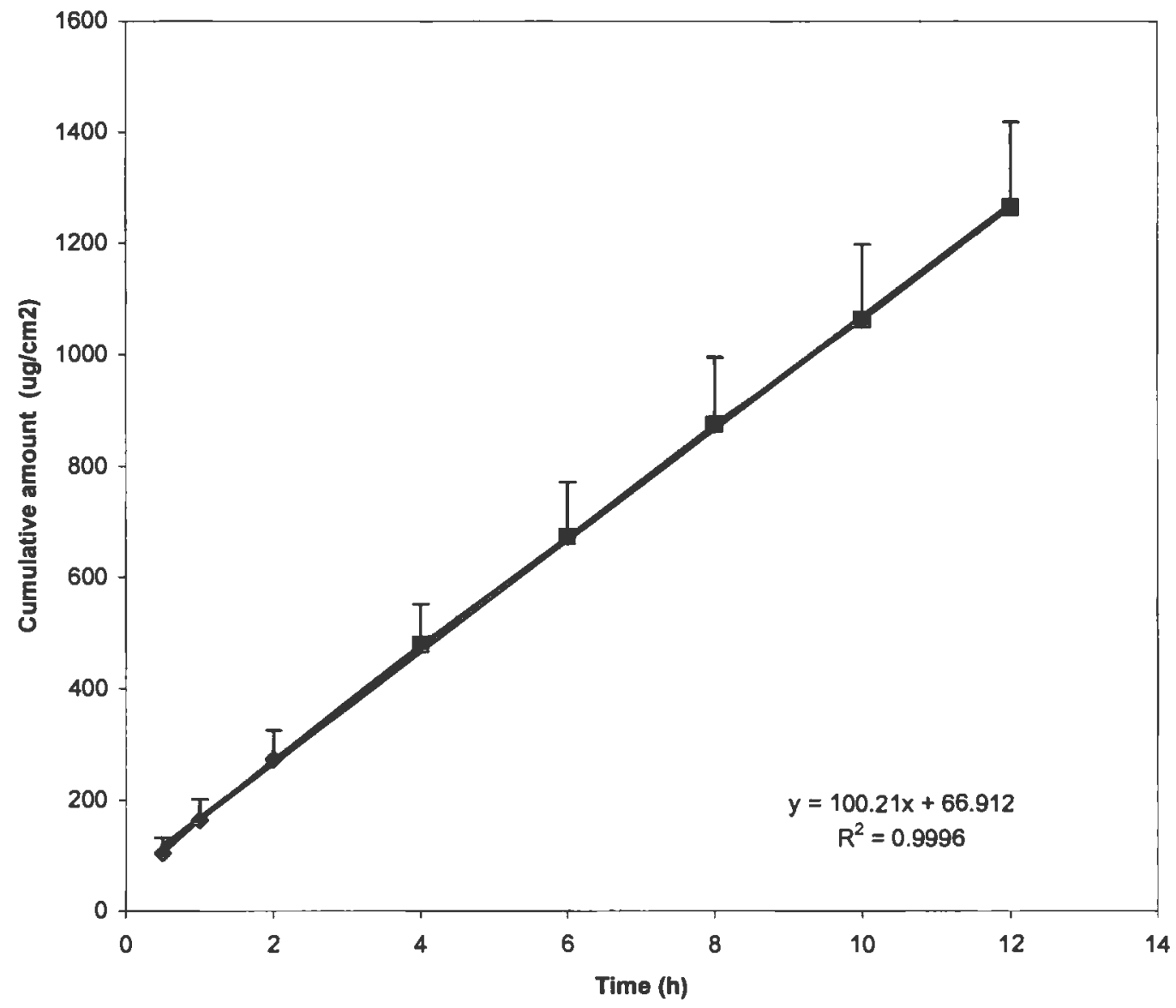

FIGURE 51. RELEASE PROFILE OF KT FROM LECITHIN:IPM (60:40) CONTAINING 0.1\% WATER AND 6.5\% KT (MEAN \pm SD, $N=12$ ) 
TABLE 53. CUMULATIVE RELEASE OF KT ACROSS CELLULOSE ACETATE MEMBRANE FROM LECITHIN:IPM (60:40) CONTAINING $0.5 \%$ WATER AND $6.5 \% \mathrm{KT}$

\begin{tabular}{|c|c|c|c|c|c|c|c|}
\hline Sample & Time & Abs. & $\mathrm{ug} / \mathrm{ml}$ & $\mathrm{ug} / 5.1$ & $\mathrm{ug} / \mathrm{cm}^{2}$ & Cumulative amount & \\
\hline & (h) & & & & & & \\
\hline 1 & 0.5 & 0.649 & 12.606 & 64.292 & 101.112 & 101.112 & \\
\hline 2 & 0.5 & 0.838 & 16.043 & 81.817 & 128.673 & 128.673 & Average \\
\hline 3 & 0.5 & 0.688 & 13.323 & 67.947 & 106.859 & 106.859 & 105.139 \\
\hline 4 & 0.5 & 0.634 & 12.340 & 62.934 & 98.975 & 98.975 & Std.Dev. \\
\hline 5 & 0.5 & 0.648 & 12.592 & 64.221 & 101.001 & 101.001 & 12.227 \\
\hline \multirow[t]{2}{*}{6} & 0.5 & 0.601 & 11.746 & 59.905 & 94.212 & 94.212 & \\
\hline & & & & & & & \\
\hline \multirow[t]{2}{*}{ Sample } & Time & Abs. & $\mathrm{ug} / \mathrm{ml}$ & ug/5.1 & $\mathrm{ug} / \mathrm{cm}^{2}$ & Cumulative amount & \\
\hline & (h) & & & & & & \\
\hline 1 & 1 & 0.297 & 6.219 & 31.715 & 49.878 & 150.990 & \\
\hline 2 & 1 & 0.282 & 5.948 & 30.334 & 47.706 & 176.380 & Average \\
\hline 3 & 1 & 0.224 & 4.882 & 24.897 & 39.155 & 146.014 & 156.461 \\
\hline 4 & 1 & 0.353 & 7.236 & 36.902 & 58.036 & 157.011 & Std.Dev. \\
\hline 5 & 1 & 0.365 & 7.453 & 38.012 & 59.781 & 160.782 & 11.256 \\
\hline \multirow[t]{2}{*}{6} & 1 & 0.321 & 6.655 & 33.941 & 53.379 & 147.591 & \\
\hline & & & & & & & \\
\hline \multirow{2}{*}{ Sample } & Time & Abs. & ua/ml & $u a / 5.1$ & $\mathrm{Ha} / \mathrm{cm}^{2}$ & Cumulative amount & \\
\hline & (h) & & & & & & \\
\hline 1 & $\frac{1}{2}$ & 0.938 & 17.861 & 91.090 & 143.257 & 294.247 & \\
\hline 2 & 2 & 0.875 & 16.731 & 85.327 & 134.194 & 310.574 & Average \\
\hline 3 & 2 & 0.660 & 12.815 & 65.357 & 102.787 & 248.802 & 300.388 \\
\hline 4 & 2 & 1.005 & 19.096 & 97.388 & 153.162 & 310.173 & Std.Dev. \\
\hline 5 & 2 & 1.105 & 20.914 & 106.660 & 167.745 & 328.527 & 27.505 \\
\hline \multirow[t]{2}{*}{6} & 2 & 1.069 & 20.249 & 103.270 & 162.413 & 310.004 & \\
\hline & & & & & & & \\
\hline \multirow{2}{*}{ Sample } & Time & ahs $>$, & $40 / \mathbf{m l}$ & $\mu / 51$ & $4 a / \mathrm{cm}^{2}$ & Cumulative amount & \\
\hline & (h) & & & & & & \\
\hline$\overline{1}$ & 4 & \begin{tabular}{|l|}
1.722 \\
\end{tabular} & 32.123 & 163.826 & 257.649 & 551.896 & \\
\hline 2 & 4 & 1.668 & 31.143 & 158.827 & 249.787 & 560.361 & Average \\
\hline 3 & 4 & 1.220 & 22.996 & 117.281 & 184.448 & 433.250 & 548.075 \\
\hline 4 & 4 & 1.703 & 31.784 & 162.098 & 254.932 & 565.105 & Std.Dev. \\
\hline 5 & 4 & 1.856 & 34.564 & 176.275 & 277.227 & 605.753 & 59.235 \\
\hline 6 & 4 & 1.752 & 32.676 & 166.646 & 262.083 & 572.087 & \\
\hline \multirow[t]{2}{*}{ Sample } & Time & Abs. & $\mathrm{ug} / \mathrm{ml}$ & $u g / 5.1$ & $\mathrm{ug} / \mathrm{cm}^{2}$ & Cumulative amount & \\
\hline & (h) & & & & & & \\
\hline 1 & 6 & 1.903 & 35.409 & 180.586 & 284.008 & 835.904 & \\
\hline 2 & 6 & 1.938 & 36.060 & 183.905 & 289.227 & 849.588 & Average \\
\hline 3 & 6 & 1.539 & 28.805 & 146.905 & 231.037 & 664.287 & 825.604 \\
\hline 4 & 6 & 1.905 & 35.448 & 180.787 & 284.323 & 849.427 & Std.Dev. \\
\hline 5 & 6 & \begin{tabular}{|c|}
1.928 \\
\end{tabular} & 35.878 & 182.978 & 287.769 & 893.522 & 81.400 \\
\hline 6 & 6 & 1.936 & 36.007 & 183.637 & 288.806 & 860.893 & \\
\hline
\end{tabular}


TABLE 53. CONT'D.

\begin{tabular}{|c|c|c|c|c|c|c|c|}
\hline Sample & Time & Abs. & ug/ml & ug/5.2 & ug/cm & Cumulative amount & \\
\hline & (h) & & & & & & \\
\hline 1 & 8 & 1.836 & 34.262 & 174.736 & 274.807 & 1110.711 & \\
\hline 2 & 8 & 1.761 & 32.899 & 167.783 & 263.871 & 1113.459 & Average \\
\hline 3 & 8 & 1.361 & 25.624 & 130.681 & 205.521 & 869.808 & 1077.48 \\
\hline 4 & 8 & 1.714 & 32.051 & 163.462 & 257.077 & 1106.504 & Std.Dev. \\
\hline 5 & 8 & 1.704 & 31.863 & 162.500 & 255.563 & 1149.085 & 102.886 \\
\hline 6 & 8 & 1.696 & 31.721 & 161.778 & 254.429 & 1115.322 & \\
\hline & & & & & & & \\
\hline & & & & & & & \\
\hline Sample & Time & Abs. & ug/ml & ug/5.1 & ug/cm & Cumulative amount & \\
\hline & (h) & & & & & & \\
\hline 1 & 10 & 1.699 & 31.702 & 161.682 & 254.277 & 1364.988 & \\
\hline 2 & 10 & 1.653 & 30.862 & 157.396 & 247.537 & 1360.996 & Average \\
\hline 3 & 10 & 1.316 & 24.735 & 126.147 & 198.391 & 1068.200 & 1316.700 \\
\hline 4 & 10 & 1.673 & 31.236 & 159.305 & 250.539 & 1357.044 & Std.Dev. \\
\hline 5 & 10 & 1.655 & 30.901 & 157.597 & 247.853 & 1396.938 & 122.769 \\
\hline 6 & 10 & 1.578 & 29.513 & 150.515 & 236.714 & 1352.036 & \\
\hline & & & & & & & \\
\hline & & & & & & & \\
\hline Sample & Time & Abs. & ug/ml & ug/5.1 & ug/cm & Cumulative amount & \\
\hline & (h) & & & & & & \\
\hline 1 & 12 & 1.677 & 31.306 & 159.661 & 251.098 & 1616.086 & \\
\hline 2 & 12 & 1.690 & 31.545 & 160.879 & 253.014 & 1614.010 & Average \\
\hline 3 & 12 & 1.371 & 25.733 & 131.238 & 206.397 & 1274.597 & 1560.72 \\
\hline 4 & 12 & 1.745 & 32.537 & 165.940 & 260.974 & 1618.017 & Std.Dev. \\
\hline 5 & 12 & 1.687 & 31.495 & 160.623 & 252.612 & 1649.550 & 141.371 \\
\hline 6 & 12 & 1.601 & 29.928 & 152.633 & 240.045 & 1592.081 & \\
\hline
\end{tabular}

\begin{tabular}{|c|c|c|c|}
\hline Time & \multicolumn{2}{|c|}{ Average cum. amount } & Std.Dev. \\
\hline (h) & & & \\
\hline 0.5 & 105.139 & & 12.227 \\
\hline 1 & 156.461 & & 11.254 \\
\hline 2 & 300.388 & & 27.505 \\
\hline 4 & 548.075 & & 59.235 \\
\hline 6 & 825.604 & 825.604 & 81.400 \\
\hline 8 & 1077.482 & 1077.482 & 102.886 \\
\hline 10 & 1316.700 & 1316.700 & 122.769 \\
\hline 12 & 1560.724 & 1560.724 & 141.371 \\
\hline
\end{tabular}




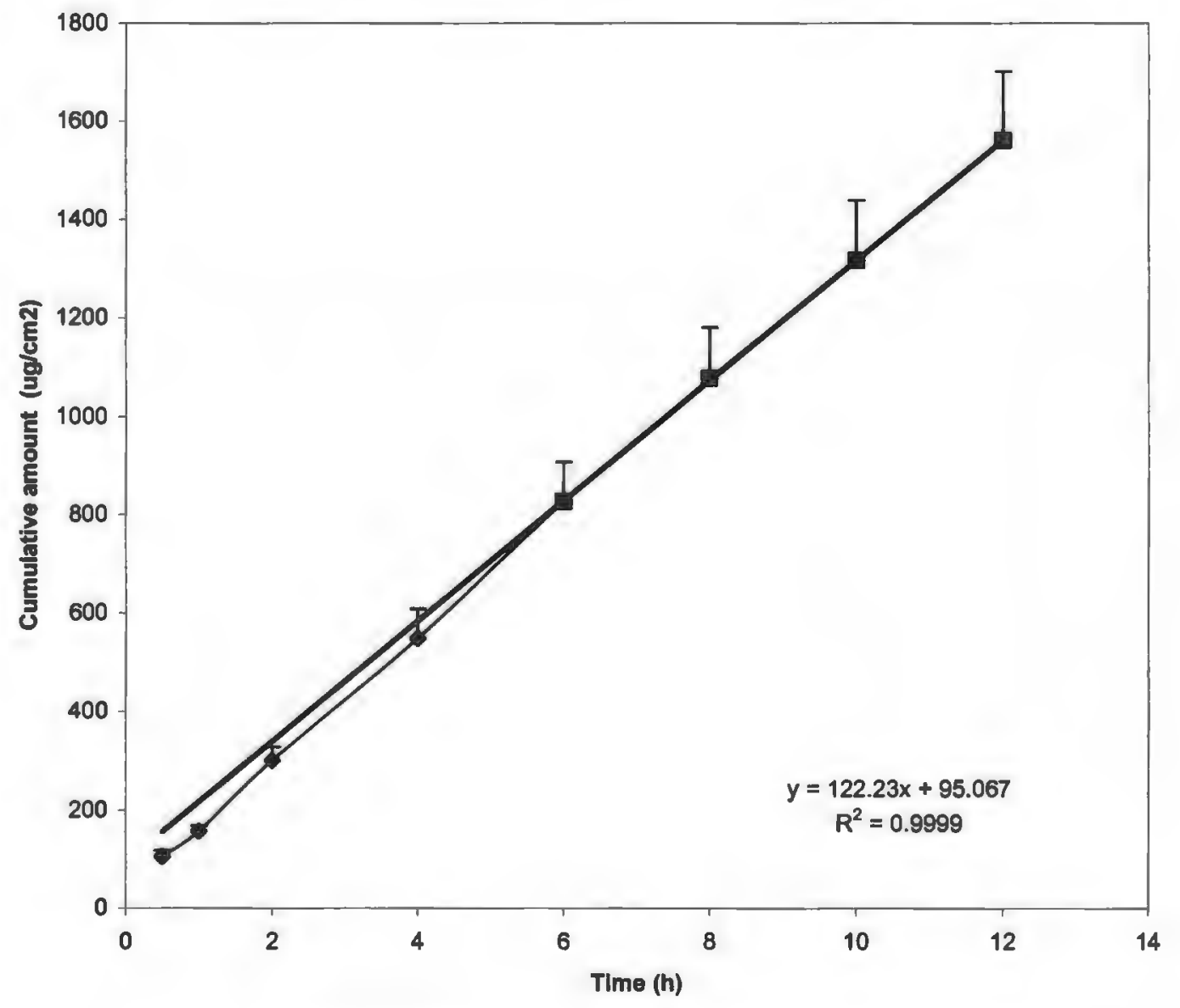

FIGURE 52. RELEASE PROFILE OF KT FROM LECITHIN:IPM (60:40) CONTAINING 0.5\% WATER AND 6.5\% KT (MEAN \pm SD, $N=6)$ 
TABLE 54. CUMULATIVE RELEASE OF KT ACROSS CELLULOSE ACETATE MEMBRANE FROM LECITHIN:IPM $(60: 40)$ CONTAINING $0.6 \%$ WATER AND $6.5 \% \mathrm{KT}$

\begin{tabular}{|c|c|c|c|c|c|c|c|}
\hline Sample & Time & Abs. & $\mathrm{ug} / \mathrm{ml}$ & $\mathrm{ug} / 5.1$ & $\mathrm{ug} / \mathrm{cm}^{2}$ & Cumulative amount & \\
\hline & (h) & & & & & & \\
\hline 1 & 0.5 & 0.600 & 11.724 & 59.794 & 94.038 & 94.038 & \\
\hline 2 & 0.5 & 0.626 & 12.190 & 62.170 & 97.774 & 97.774 & Average \\
\hline 3 & 0.5 & 0.608 & 11.872 & 60.548 & 95.224 & 95.224 & 94.199 \\
\hline 4 & 0.5 & 0.560 & 10.997 & 56.087 & 88.208 & 88.208 & Std.Dev. \\
\hline 5 & 0.5 & 0.612 & 11.937 & 60.876 & 95.740 & 95.740 & 3.229 \\
\hline \multirow[t]{2}{*}{6} & 0.5 & 0.601 & 11.746 & 59.905 & 94.212 & 94.212 & \\
\hline & & & & & & & \\
\hline \multirow[t]{2}{*}{ Sample } & Time & Abs. & $\mathrm{ug} / \mathrm{ml}$ & $\mathrm{ug} / 5.1$ & $\mathrm{ug} / \mathrm{cm}^{2}$ & Cumulative amount & \\
\hline & (h) & & & & & & \\
\hline 1 & 1 & 0.343 & 7.044 & 35.924 & 56.498 & 150.536 & \\
\hline 2 & 1 & 0.352 & 7.206 & 36.751 & 57.798 & 155.572 & Average \\
\hline 3 & 1 & 0.325 & 6.724 & 34.294 & 53.935 & 149.159 & 151.329 \\
\hline 4 & 1 & 0.338 & 6.956 & 35.476 & 55.793 & 144.000 & Std.Dev. \\
\hline 5 & 1 & 0.404 & 8.151 & 41.570 & 65.377 & 161.117 & 6.113 \\
\hline \multirow[t]{2}{*}{6} & 1 & 0.321 & 6.655 & 33.941 & 53.379 & 147.591 & \\
\hline & & & & & & & \\
\hline \multirow[t]{2}{*}{ Sample } & Time & Abs. & $\mathrm{ug} / \mathrm{ml}$ & $\mathrm{ug} / 5.1$ & $\mathrm{ug} / \mathrm{cm}^{2}$ & Cumulative amount & \\
\hline & (h) & & & & & & \\
\hline 1 & 2 & 0.769 & 14.792 & 75.439 & 118.642 & 269.178 & \\
\hline 2 & 2 & 0.731 & 14.107 & 71.948 & 113.152 & 268.724 & Average \\
\hline 3 & 2 & 0.736 & 14.192 & 72.378 & 113.829 & 262.987 & 265.725 \\
\hline 4 & 2 & 0.735 & 14.178 & 72.306 & 113.715 & 257.716 & Std.Dev. \\
\hline 5 & 2 & 0.727 & 14.040 & 71.602 & 112.609 & 273.726 & 5.836 \\
\hline \multirow[t]{2}{*}{6} & 2 & 0.740 & 14.267 & 72.759 & 114.429 & 262.019 & \\
\hline & & & & & & & \\
\hline \multirow[t]{2}{*}{ Sample } & Time & Abs. & $\mathrm{ug} / \mathrm{ml}$ & $\mathrm{ug} / 5.1$ & $\mathrm{ug} / \mathrm{cm}^{2}$ & Cumulative amount & \\
\hline & (h) & & & & & & \\
\hline 1 & 4 & 1.834 & 34.157 & 174.203 & 273.969 & 543.147 & \\
\hline 2 & 4 & 1.466 & 27.461 & 140.050 & 220.256 & 488.980 & Average \\
\hline 3 & $\overline{4}$ & 1.739 & 32.426 & 165.371 & 260.078 & 523.066 & 522.334 \\
\hline 4 & 4 & 1.733 & 32.318 & 164.821 & 259.213 & 516.929 & Std.Dev. \\
\hline 5 & 4 & 1.766 & 32.921 & 167.898 & 264.054 & 537.780 & 19.063 \\
\hline 6 & 4 & 1.752 & 32.676 & 166.646 & 262.083 & 524.103 & \\
\hline \multirow[t]{2}{*}{ Sample } & Time & Abs. & $\mathrm{ug} / \mathrm{ml}$ & $\mathrm{ug} / 5.1$ & $\mathrm{ug} / \mathrm{cm}^{2}$ & Cumulative amount & \\
\hline & (h) & & & & & & \\
\hline 1 & 6 & 1.870 & 34.812 & 177.539 & 279.216 & 822.363 & \\
\hline 2 & 6 & 1.724 & 32.169 & 164.061 & 258.018 & 746.998 & Average \\
\hline 3 & 6 & 1.824 & 33.972 & 173.259 & 272.484 & 795.550 & 797.861 \\
\hline 4 & 6 & 1.887 & 35.129 & 179.160 & 281.765 & 798.694 & Std.Dev. \\
\hline 5 & 6 & 1.897 & 35.297 & 180.014 & 283.108 & 820.888 & 27.374 \\
\hline 6 & 6 & 1.865 & 34.731 & 177.129 & 278.571 & 802.674 & \\
\hline
\end{tabular}


TABLE 54. CONT'D.

\begin{tabular}{|c|c|c|c|c|c|c|c|}
\hline Sample & Time & Abs. & ug/ml & ug/5.2 & ug/cm & Cumulative amount & \\
\hline & (h) & & & & & & \\
\hline 1 & 8 & 1.654 & 30.959 & 157.890 & 248.313 & 1070.675 & \\
\hline 2 & 8 & 1.520 & 28.528 & 145.493 & 228.816 & 975.814 & Average \\
\hline 3 & 8 & 1.558 & 29.223 & 149.036 & 234.388 & 1029.938 & 1033.75 \\
\hline 4 & 8 & 1.553 & 29.131 & 148.570 & 233.656 & 1032.350 & Std.Dev. \\
\hline 5 & 8 & 1.584 & 29.691 & 151.425 & 238.145 & 1059.033 & 32.792 \\
\hline 6 & 8 & 1.542 & 28.930 & 147.544 & 232.042 & 1034.716 & \\
\hline & & & & & & & \\
\hline & & & & & & & \\
\hline Sample & Time & Abs. & ug/ml & ug/5.1 & ug/cm & Cumulative amount & \\
\hline & (h) & & & & & & \\
\hline 1 & 10 & 1.769 & 32.975 & 168.171 & 264.482 & 1335.157 & \\
\hline 2 & 10 & 1.746 & 32.556 & 166.036 & 261.124 & 1236.938 & Average \\
\hline 3 & 10 & 1.696 & 31.653 & 161.428 & 253.877 & 1283.816 & 1293 \\
\hline 4 & 10 & 1.699 & 31.699 & 161.666 & 254.252 & 1286.602 & Std.Dev. \\
\hline 5 & 10 & 1.712 & 31.948 & 162.936 & 256.249 & 1315.281 & 33.448 \\
\hline 6 & 10 & 1.776 & 33.100 & 168.808 & 265.484 & 1300.200 & \\
\hline & & & & & & & \\
\hline & & & & & & & \\
\hline Sample & Time & Abs. & ug/ml & ug/5.1 & ug/cm & Cumulative amount & \\
\hline & (h) & & & & & & \\
\hline 1 & 12 & 1.603 & 29.963 & 152.811 & 240.325 & 1575.483 & \\
\hline 2 & 12 & 1.720 & 32.091 & 163.666 & 257.398 & 1494.336 & Average \\
\hline 3 & 12 & 1.608 & 30.049 & 153.248 & 241.012 & 1524.828 & 1542.8 \\
\hline 4 & 12 & 1.567 & 29.304 & 149.449 & 235.037 & 1521.639 & Std.Dev. \\
\hline 5 & 12 & 1.759 & 32.790 & 167.228 & 262.999 & 1578.281 & 34.132 \\
\hline 6 & 12 & 1.752 & 32.671 & 166.624 & 262.050 & 1562.250 & \\
\hline & & & & & & & \\
\hline
\end{tabular}

\begin{tabular}{|c|c|c|c|}
\hline Time & Average cum. amount & Std.Dev \\
\hline (h) & & & \\
\hline 0.5 & 94.199 & & 3.229 \\
\hline 1 & 151.329 & 151.329 & 6.113 \\
\hline 2 & 265.725 & 265.725 & 5.836 \\
\hline 4 & 522.334 & 522.334 & 19.063 \\
\hline 6 & 797.861 & 797.861 & 27.374 \\
\hline 8 & 1033.754 & 1033.754 & 32.792 \\
\hline 10 & 1292.999 & 1292.999 & 33.448 \\
\hline 12 & 1542.803 & 1542.803 & 34.132 \\
\hline
\end{tabular}




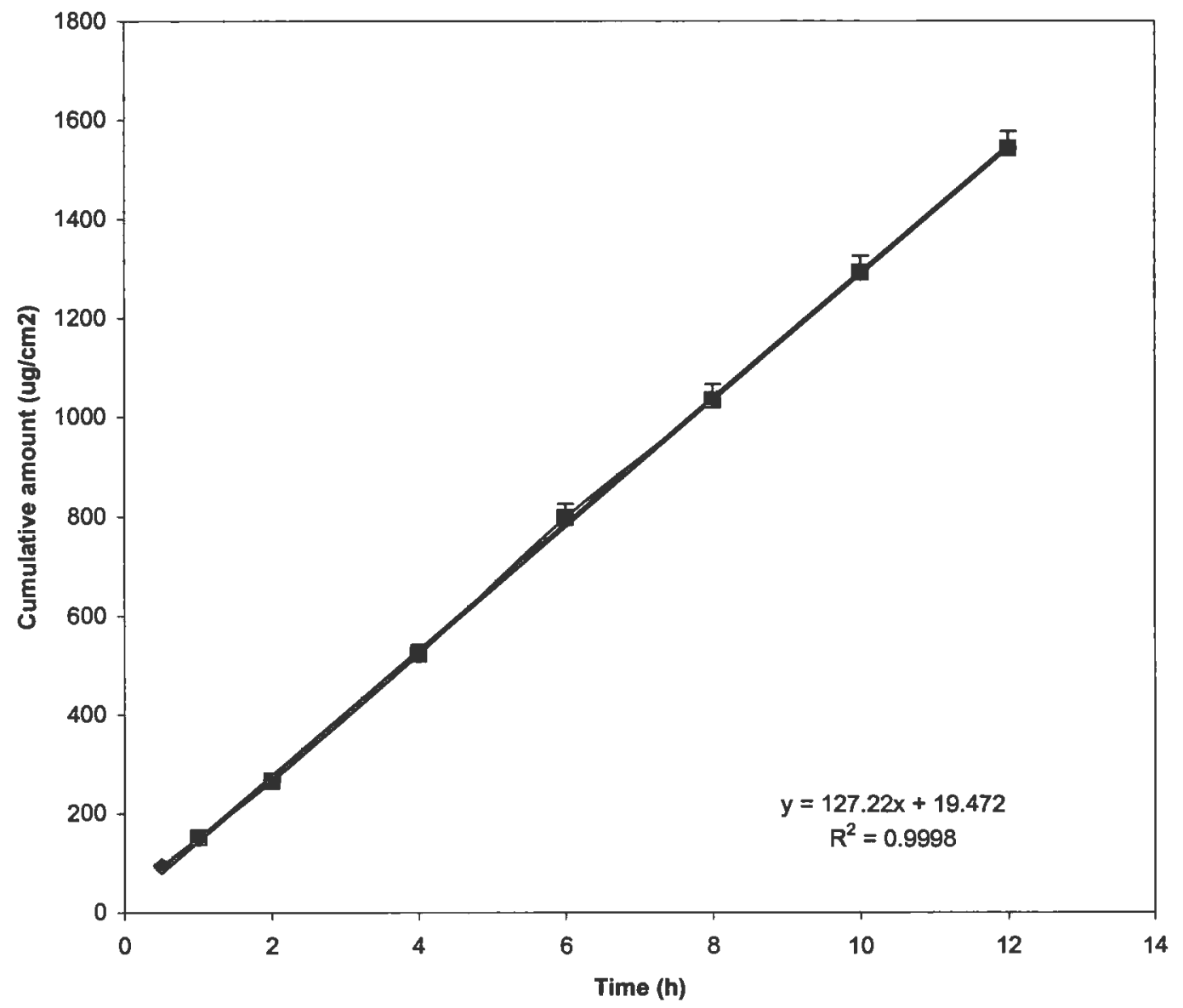

FIGURE 53. RELEASE PROFILE OF KT FROM (LECITHIN:IPM $(60: 40)$ CONTAINING 0.6\% WATER AND 6.5\% KT (MEAN \pm SD, $\mathrm{N}=6$ ) 
TABLE 55. CUMULATIVE RELEASE OF KT ACROSS CELLULOSE ACETATE MEMBRANE FROM LECITHIN:IPM (60:40) CONTAINING $0.7 \%$ WATER AND $6.5 \% \mathrm{KT}$

\begin{tabular}{|c|c|c|c|c|c|c|c|}
\hline Sample & Time & Abs. & $\mathrm{ug} / \mathrm{ml}$ & $u g / 5.1$ & $\mathrm{ug} / \mathrm{cm}^{2}$ & Cumulative amount & \\
\hline & (h) & & & & & & \\
\hline 1 & 0.5 & 0.774 & 14.890 & 75.941 & 119.432 & 119.432 & \\
\hline 2 & 0.5 & 0.577 & 11.300 & 57.630 & 90.635 & 90.635 & Average \\
\hline 3 & 0.5 & 0.483 & 9.603 & 48.975 & 77.024 & 77.024 & 92.917 \\
\hline 4 & 0.5 & 0.507 & 10.031 & 51.159 & 80.457 & 80.457 & Std.Dev. \\
\hline 5 & 0.5 & 0.612 & 11.937 & 60.876 & 95.740 & 95.740 & 15.005 \\
\hline \multirow[t]{2}{*}{6} & 0.5 & 0.601 & 11.746 & 59.905 & 94.212 & 94.212 & \\
\hline & & & & & & & \\
\hline \multirow[t]{2}{*}{ Sample } & Time & Abs. & $\mathrm{ug} / \mathrm{ml}$ & $\mathrm{ug} / 5.1$ & $\mathrm{ug} / \mathrm{cm}^{2}$ & Cumulative amount & \\
\hline & (h) & & & & & & \\
\hline 1 & 1 & 0.480 & 9.539 & 48.650 & 76.512 & 195.944 & \\
\hline 2 & 1 & 0.365 & 7.458 & 38.037 & 59.821 & 150.456 & Average \\
\hline 3 & 1 & 0.297 & 6.223 & 31.736 & 49.912 & 126.935 & 154.701 \\
\hline 4 & 1 & 0.336 & 6.919 & 35.288 & 55.497 & 135.954 & Std.Dev. \\
\hline 5 & 1 & 0.404 & 8.151 & 41.570 & 65.377 & 161.117 & 24.050 \\
\hline \multirow[t]{3}{*}{6} & 1 & 0.391 & 7.928 & 40.432 & 63.587 & 157.799 & \\
\hline & & & & & & & \\
\hline & Time & Abs. & $\mathrm{ug} / \mathrm{ml}$ & $u q / 5.1$ & $\mathrm{uq} / \mathrm{cm}^{2}$ & Cumulative amount & \\
\hline Sample & (h) & & & & & & \\
\hline 1 & 2 & 0.896 & 17.099 & 87.203 & 137.143 & 333.087 & \\
\hline 2 & 2 & 0.767 & 14.761 & 75.279 & 118.390 & 268.846 & Average \\
\hline 3 & 2 & 0.620 & 12.096 & 61.691 & 97.022 & 223.957 & 269.955 \\
\hline 4 & 2 & 0.723 & 13.955 & 71.173 & 111.933 & 247.887 & Std.Dev. \\
\hline 5 & 2 & 0.727 & 14.040 & 71.602 & 112.609 & 273.726 & 36.357 \\
\hline \multirow[t]{3}{*}{6} & 2 & 0.740 & 14.267 & 72.759 & 114.429 & 272.227 & \\
\hline & & & & & & & \\
\hline & & & & & & & \\
\hline \multirow[t]{2}{*}{ Sample } & Time & Abs. & $\mathrm{ug} / \mathrm{ml}$ & $\mathrm{ug} / 5.1$ & $\mathrm{ug} / \mathrm{cm}^{2}$ & Cumulative amount & \\
\hline & (h) & & & & & & \\
\hline 1 & 4 & 1.834 & 34.157 & 174.203 & 273.969 & 607.056 & \\
\hline 2 & 4 & 1.727 & 32.209 & 164.265 & 258.338 & 527.185 & Average \\
\hline 3 & 4 & 1.374 & 25.805 & 131.604 & 206.974 & 430.930 & 518.561 \\
\hline 4 & 4 & 1.566 & 29.295 & 149.405 & 234.969 & 482.856 & Std.Dev. \\
\hline 5 & 4 & 1.736 & 32.376 & 165.117 & 259.679 & 533.405 & 58.668 \\
\hline 6 & 4 & 1.722 & 32.130 & 163.864 & 257.708 & 529.936 & \\
\hline \multirow[t]{2}{*}{ Sample } & Time & Abs. & $\mathrm{ug} / \mathrm{ml}$ & $u g / 5.1$ & $\mathrm{ug} / \mathrm{cm}^{2}$ & Cumulative amount & \\
\hline & (h) & & & & & & \\
\hline 1 & 6 & 1.870 & 34.812 & 177.539 & 279.216 & 886.272 & \\
\hline 2 & 6 & 1.796 & 33.470 & 170.695 & 268.452 & 795.637 & Average \\
\hline 3 & 6 & 1.444 & 27.062 & 138.016 & 217.058 & 647.988 & 780.384 \\
\hline 4 & 6 & 1.632 & 30.487 & 155.486 & 244.533 & 727.389 & Std.Dev. \\
\hline 5 & 6 & 1.897 & 35.297 & 180.014 & 283.108 & 816.513 & 82.314 \\
\hline 6 & 6 & 1.865 & 34.731 & 177.129 & 278.571 & 808.507 & \\
\hline
\end{tabular}


TABLE 55. CONT'D.

\begin{tabular}{|c|c|c|c|c|c|c|c|}
\hline Sample & Time & Abs. & $\mathrm{ug} / \mathrm{ml}$ & $\mathrm{ug} / 5.2$ & $\mathrm{ug} / \mathrm{cm}^{2}$ & Cumulative amount & \\
\hline & (h) & & & & & & \\
\hline 1 & 8 & 1.665 & 31.159 & 158.913 & 249.922 & 1136.194 & \\
\hline 2 & 8 & 1.518 & 28.480 & 145.247 & 228.430 & 1024.067 & Average \\
\hline 3 & 8 & 1.286 & 24.277 & 123.812 & 194.719 & 842.708 & 1005.790 \\
\hline 4 & 8 & 1.386 & 26.079 & 133.003 & 209.174 & 936.563 & Std.Dev. \\
\hline 5 & 8 & 1.584 & 29.691 & 151.425 & 238.145 & 1054.658 & 102.297 \\
\hline 6 & 8 & 1.542 & 28.930 & 147.544 & 232.042 & 1040.549 & \\
\hline & & & & & & & \\
\hline Sample & Time & Abs. & $\mathrm{ug} / \mathrm{ml}$ & ug/5.1 & $\mathrm{ug} / \mathrm{cm}^{2}$ & Cumulative amount & \\
\hline & (h) & & & & & & \\
\hline 1 & 10 & 1.768 & 32.961 & 168.101 & 264.372 & 1400.566 & \\
\hline 2 & 10 & 1.663 & 31.050 & 158.353 & 249.042 & 1273.108 & Average \\
\hline 3 & 10 & 1.464 & 27.440 & 139.944 & 220.090 & 1062.797 & 1246.812 \\
\hline 4 & 10 & 1.534 & 28.710 & 146.421 & 230.276 & 1166.839 & Std.Dev. \\
\hline 5 & 10 & 1.612 & 30.130 & 153.663 & 241.665 & 1296.323 & 116.812 \\
\hline 6 & 10 & 1.606 & 30.009 & 153.045 & 240.693 & 1281.242 & \\
\hline & & & & & & & \\
\hline Sample & Time & Abs. & $\mathrm{ug} / \mathrm{ml}$ & $u g / 5.1$ & $\mathrm{ug} / \mathrm{cm}^{2}$ & Cumulative amount & \\
\hline & (h) & & & & & & \\
\hline 1 & 12 & 1.640 & 30.631 & 156.217 & 245.682 & 1646.247 & \\
\hline 2 & 12 & 1.593 & 29.774 & 151.847 & 238.810 & 1511.918 & Average \\
\hline 3 & 12 & 1.392 & 26.118 & 133.203 & 209.488 & 1272.285 & 1476.267 \\
\hline 4 & 12 & 1.437 & 26.934 & 137.364 & 216.033 & 1382.871 & Std.Dev. \\
\hline 5 & 12 & 1.559 & 29.153 & 148.683 & 233.833 & 1530.156 & 130.256 \\
\hline 6 & 12 & 1.552 & 29.035 & 148.079 & 232.883 & 1514.125 & \\
\hline
\end{tabular}

\begin{tabular}{|c|c|c|c|}
\hline Time & Average cum. amount & Std.Dev. \\
\hline (h) & & & \\
\hline 0.5 & 92.917 & & 15.005 \\
\hline 1 & 154.701 & & 24.050 \\
\hline 2 & 269.955 & & 36.357 \\
\hline 4 & 518.561 & & 58.668 \\
\hline 6 & 780.384 & 780.384 & 82.314 \\
\hline 8 & 1005.790 & 1005.790 & 102.297 \\
\hline 10 & 1246.812 & 1246.812 & 116.812 \\
\hline 12 & 1476.267 & 1476.267 & 130.256 \\
\hline
\end{tabular}




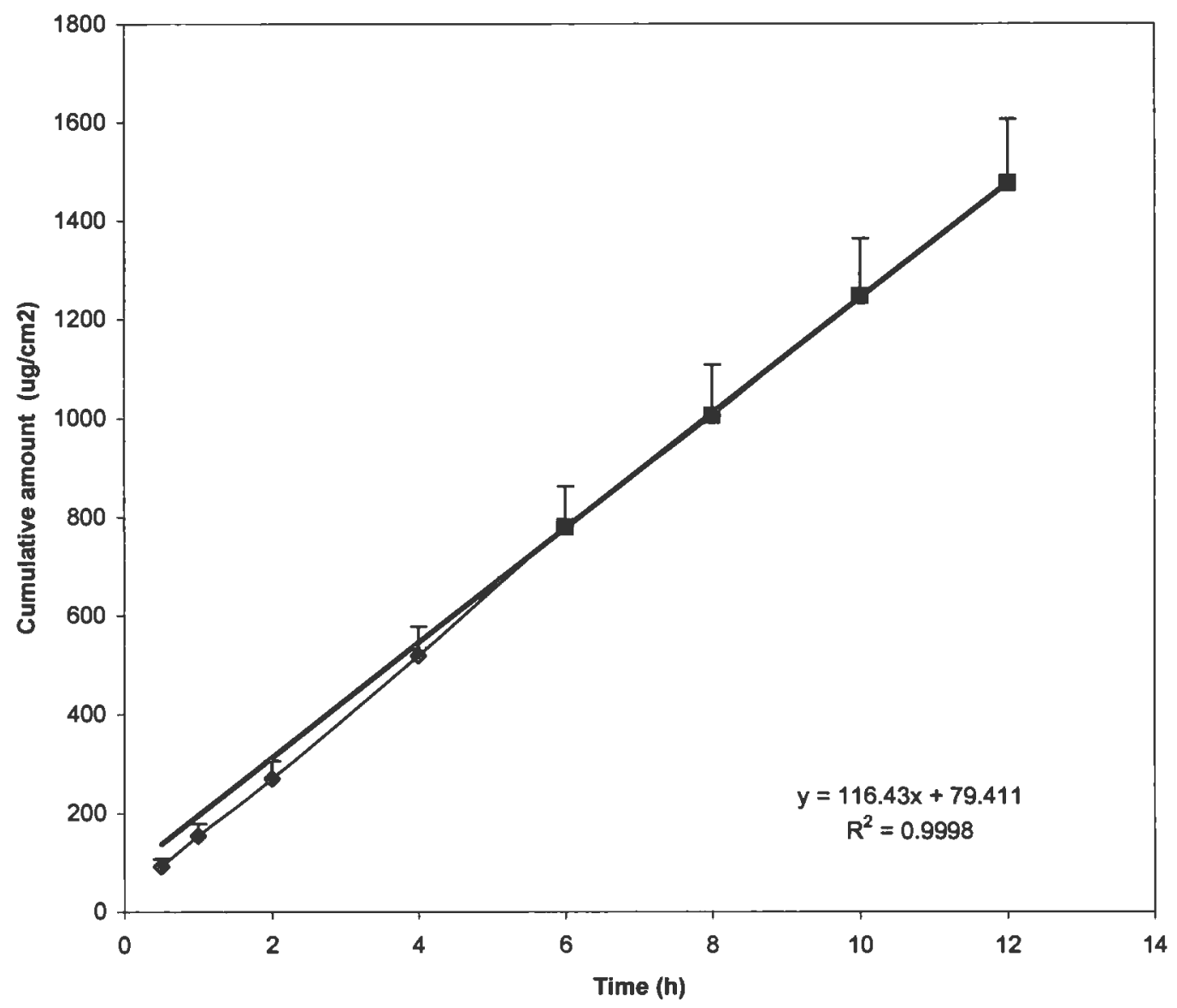

FIGURE 54. RELEASE PROFILE OF KT FROM LECITHIN:IPM (60:40) CONTAINING 0.7\% WATER AND 6.5\% KT (MEAN \pm SD, $\mathrm{N}=6$ ) 
TABLE 56. CUMULATIVE RELEASE OF KT ACROSS CELLULOSE ACETATE MEMBRANE FROM LECITHIN:IPM (60:40) CONTAINING $0.8 \%$ WATER AND $6.5 \% \mathrm{KT}$

\begin{tabular}{|c|c|c|c|c|c|c|c|}
\hline Sample & Time & Abs. & $\mathrm{ug} / \mathrm{ml}$ & $\mathrm{ug} / 5.1$ & $\mathrm{ug} / \mathrm{cm}^{2} /$ & Cumulative amount & \\
\hline & (h) & & & & & & \\
\hline 1 & 0.5 & 0.703 & 13.599 & 69.357 & 109.078 & 109.078 & \\
\hline 2 & 0.5 & 0.700 & 13.548 & 69.093 & 108.662 & 108.663 & Average \\
\hline 3 & 0.5 & \begin{tabular}{|l|}
0.515 \\
\end{tabular} & 10.175 & 51.894 & 81.614 & 81.614 & 87.573 \\
\hline 4 & 0.5 & 0.517 & 10.223 & 52.135 & 81.993 & 81.993 & Std.Dev. \\
\hline 5 & 0.5 & 0.459 & 9.169 & 46.760 & 73.539 & 73.539 & 17.091 \\
\hline \multirow[t]{2}{*}{6} & 0.5 & 0.439 & 8.796 & 44.860 & 70.551 & 70.551 & \\
\hline & & & & & & & \\
\hline \multirow[t]{2}{*}{ Sample } & Time & Abs. & $\mathrm{ug} / \mathrm{ml}$ & $\mathrm{ug} / 5.1$ & $\mathrm{ug} / \mathrm{cm}^{2} /$ & Cumulative amount & \\
\hline & (h) & & & & & & \\
\hline 1 & 1 & \begin{tabular}{|l|}
0.538 \\
\end{tabular} & 10.593 & 54.027 & 84.968 & 194.046 & \\
\hline 2 & 1 & \begin{tabular}{|l|}
0.507 \\
\end{tabular} & 10.035 & 51.178 & 80.487 & 189.150 & Average \\
\hline 3 & 1 & 0.430 & 8.626 & 43.995 & 69.191 & 150.805 & 156.998 \\
\hline 4 & 1 & 0.409 & 8.245 & 42.048 & 66.129 & 148.122 & Std.Dev. \\
\hline 5 & 1 & \begin{tabular}{|l|}
0.345 \\
\end{tabular} & 7.094 & 36.178 & 56.897 & 130.436 & 28.245 \\
\hline \multirow[t]{2}{*}{6} & 1 & 0.359 & 7.341 & 37.440 & 58.882 & 129.432 & \\
\hline & & & & & & & \\
\hline \multirow[t]{2}{*}{ Sample } & Time & Abs. & $\mathrm{ug} / \mathrm{ml}$ & $\mathrm{ug} / 5.1$ & $\mathrm{ug} / \mathrm{cm}^{2} \mathrm{I}$ & Cumulative amount & \\
\hline & (h) & & & & & & \\
\hline 1 & 2 & 0.716 & 13.828 & 70.522 & 110.909 & 304.955 & \\
\hline 2 & 2 & 0.707 & 13.670 & 69.715 & 109.641 & 298.791 & Average \\
\hline 3 & 2 & 0.511 & 10.114 & 51.580 & 81.120 & 231.926 & 243.102 \\
\hline 4 & 2 & 0.516 & 10.202 & 52.030 & 81.828 & 229.949 & Std.Dev. \\
\hline 5 & 2 & 0.405 & 8.185 & 41.744 & 65.651 & 196.086 & 48.103 \\
\hline \multirow[t]{2}{*}{6} & 2 & 0.418 & 8.412 & 42.903 & 67.473 & 196.905 & \\
\hline & & & & & & & \\
\hline \multirow[t]{2}{*}{ Sample } & Time & Abs. & $\mathrm{ug} / \mathrm{ml}$ & $\mathrm{ug} / 5.1$ & $\mathrm{ug} / \mathrm{cm}^{2} \mathrm{I}$ & Cumulative amount & \\
\hline & (h) & & & & & & \\
\hline 1 & 4 & 1.934 & 35.976 & 183.476 & 288.552 & 593.507 & \\
\hline 2 & 4 & 1.827 & 34.027 & 173.537 & 272.922 & 571.712 & Average \\
\hline 3 & 4 & 1.632 & 30.482 & 155.458 & 244.489 & 476.414 & 494.291 \\
\hline 4 & 4 & 1.629 & 30.424 & 155.161 & 244.021 & 473.970 & Std.Dev. \\
\hline 5 & 4 & 1.491 & 27.922 & 142.404 & 223.959 & 420.045 & 72.393 \\
\hline 6 & 4 & \begin{tabular}{|l|}
1.554 \\
\end{tabular} & 29.074 & 148.276 & 233.193 & 430.098 & \\
\hline \multirow[t]{2}{*}{ Sample } & Time & Abs. & $\mathrm{ug} / \mathrm{ml}$ & $\mathrm{ug} / 5.1$ & $\mathrm{ug} / \mathrm{cm}^{2} \mathrm{I}$ & Cumulative amount & \\
\hline & (h) & & & & & & \\
\hline 1 & 6 & 1.930 & 35.903 & 183.103 & 287.966 & 881.473 & \\
\hline 2 & 6 & 1.816 & 33.833 & 172.550 & 271.369 & 843.081 & Average \\
\hline 3 & 6 & 1.621 & 30.289 & 154.472 & 242.937 & 719.351 & 742.564 \\
\hline 4 & 6 & 1.606 & 30.013 & 153.065 & 240.725 & 714.695 & Std.Dev. \\
\hline 5 & 6 & 1.461 & 27.375 & 139.613 & 219.569 & 639.614 & 98.596 \\
\hline 6 & 6 & 1.512 & 28.310 & 144.383 & 227.071 & 657.169 & \\
\hline
\end{tabular}


TABLE 56. CONT'D.

\begin{tabular}{|c|c|c|c|c|c|c|c|}
\hline Sample & Time & Abs. & ug/ml & ug/5.2 & ug/cm $/$ & Cumulative amount & \\
\hline & (h) & & & & & & \\
\hline 1 & 8 & 1.719 & 32.146 & 163.943 & 257.832 & 1139.305 & \\
\hline 2 & 8 & 1.618 & 30.298 & 154.520 & 243.013 & 1086.094 & Average \\
\hline 3 & 8 & 1.357 & 25.568 & 130.399 & 205.078 & 924.429 & 954.292 \\
\hline 4 & 8 & 1.329 & 25.058 & 127.794 & 200.981 & 915.676 & Std.Dev. \\
\hline 5 & 8 & 1.015 & 19.350 & 98.686 & 155.204 & 794.818 & 132.146 \\
\hline 6 & 8 & 1.379 & 25.965 & 132.423 & 208.261 & 865.430 & \\
\hline & & & & & & & \\
\hline & & & & & & & \\
\hline Sample & Time & Abs. & ug/ml & ug/5.1 & ug/cm $/ 1$ & Cumulative amount & \\
\hline & (h) & & & & & & \\
\hline 1 & 10 & 1.835 & 34.179 & 174.312 & 274.139 & 1413.444 & \\
\hline 2 & 10 & 1.763 & 32.868 & 167.626 & 263.625 & 1349.719 & Average \\
\hline 3 & 10 & 1.577 & 29.483 & 150.361 & 236.472 & 1160.902 & 1188.490 \\
\hline 4 & 10 & 1.367 & 25.675 & 130.943 & 205.934 & 1121.610 & Std.Dev. \\
\hline 5 & 10 & 1.187 & 22.404 & 114.261 & 179.699 & 974.516 & 163.500 \\
\hline 6 & 10 & 1.637 & 30.586 & 155.988 & 245.321 & 1110.751 & \\
\hline & & & & & & & \\
\hline & & & & & & & \\
\hline Sample & Time & Abs. & ug/ml & ug/5.1 & ug/cm 21 & Cumulative amount & \\
\hline & (h) & & & & & & \\
\hline 1 & 12 & 1.699 & 31.704 & 161.689 & 254.287 & 1667.732 & \\
\hline 2 & 12 & 1.653 & 30.865 & 157.411 & 247.560 & 1597.279 & Average \\
\hline 3 & 12 & 1.612 & 30.118 & 153.603 & 241.571 & 1402.472 & 1423.229 \\
\hline 4 & 12 & 1.496 & 28.011 & 142.856 & 224.669 & 1346.279 & Std.Dev. \\
\hline 5 & 12 & 1.289 & 24.244 & 123.646 & 194.458 & 1168.975 & 181.938 \\
\hline 6 & 12 & 1.641 & 30.656 & 156.347 & 245.887 & 1356.639 & \\
\hline & & & & & & \\
\hline
\end{tabular}

\begin{tabular}{|c|c|c|c|}
\hline Time & \multicolumn{2}{|c|}{ Average cum. amount } & Std.Dev. \\
\hline (h) & & & \\
\hline 0.5 & 87.573 & & 17.091 \\
\hline 1 & 156.998 & & 28.245 \\
\hline 2 & 243.102 & & 48.103 \\
\hline 4 & 494.291 & 497.708 & 72.393 \\
\hline 6 & 742.564 & 713.397 & 98.596 \\
\hline 8 & 954.292 & 954.292 & 132.146 \\
\hline 10 & 1188.490 & 1188.490 & 163.500 \\
\hline 12 & 1423.229 & 1423.229 & 181.938 \\
\hline
\end{tabular}




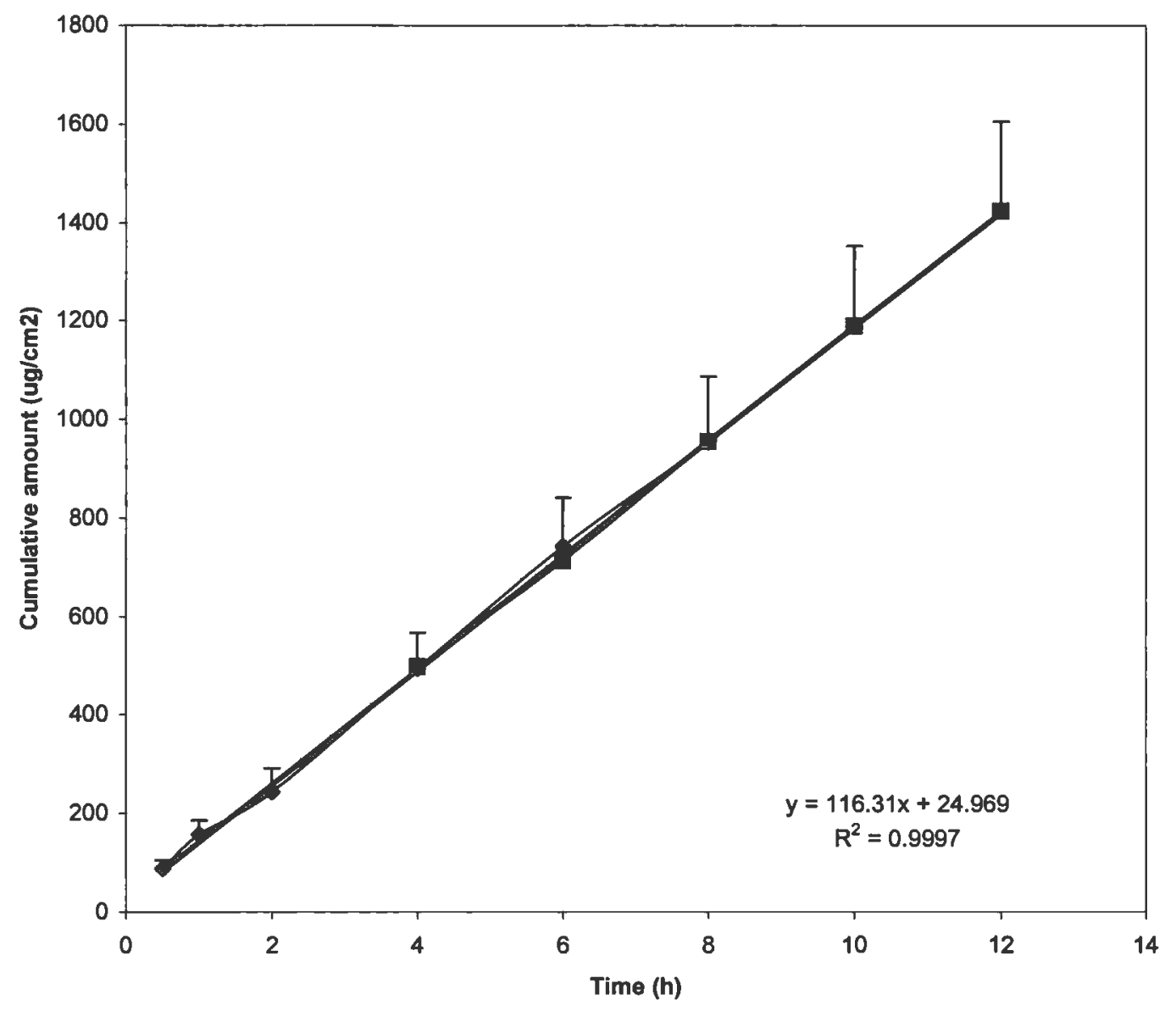

FIGURE 55. RELEASE PROFILE OF KT FROM LECITHIN:IPM (60:40) CONTAINING 0.8\% WATER AND 6.5\% KT (MEAN \pm SD, $\mathrm{N}=6)$ 
TABLE 57. VALUES OF VISCOSITY FOR KT ORGANOGELS WITH DIFFERENT COMPOSITIONS BY CYLINDRICAL VISCOMETER (NO.1)

\begin{tabular}{|c|c|c|c|c|c|c|}
\hline \multicolumn{4}{|c|}{ 40:60 $0.1 \%$} & \multirow{2}{*}{ Viscosity } & \multirow{2}{*}{ Reading Visco. } & \multirow{2}{*}{$(3.1 / 1.6)^{\star}$ Reading Visco. } \\
\hline Reading & Sh Str & RPM & Sh Rt & & & \\
\hline$(\%)$ & (dyne/cm2) & & $(1 / \mathrm{sec})$ & (p) & (cp) & \\
\hline 1.2 & 31.43 & 0.3 & 0.07 & 450.46 & 24000 & 46500 \\
\hline 2.4 & 62.86 & 0.6 & 0.14 & 450.46 & 24000 & 46500 \\
\hline 6 & 157.16 & 1.5 & 0.35 & 450.46 & 24000 & 46500 \\
\hline 12 & 314.32 & 3 & 0.70 & 450.46 & 24000 & 46500 \\
\hline 24 & 628.65 & 6 & 1.40 & 450.46 & 24000 & 46500 \\
\hline 48 & 1257.29 & 12 & 2.79 & 450.46 & 24000 & 46500 \\
\hline & & & & & & \\
\hline \multicolumn{7}{|c|}{$40: 600.25 \%$} \\
\hline & & & & & & \\
\hline \begin{tabular}{|l|} 
Reading \\
\end{tabular} & Sh Str & RPM & Sh Rt & Viscosity & Reading Visco. & $(3.1 / 1.6)^{\star}$ Reading Visco. \\
\hline$(\%)$ & (dyne/cm2) & & $(1 / \mathrm{sec})$ & (p) & (cp) & \\
\hline 1 & 26.19 & 0.3 & 0.07 & 375.39 & 20000 & 38750 \\
\hline 1.9 & 49.77 & 0.6 & 0.14 & 356.62 & 19000 & 36812.5 \\
\hline 4.7 & 123.11 & 1.5 & 0.35 & 352.86 & 18800 & 36425 \\
\hline 9.3 & 243.60 & 3 & 0.70 & 349.11 & 18600 & 36037.5 \\
\hline 18.4 & 481.96 & 6 & 1.40 & 345.36 & 18400 & 35650 \\
\hline 36.1 & 945.59 & 12 & 2.79 & 338.79 & 18400 & 35650 \\
\hline & & & & & & \\
\hline \multicolumn{7}{|c|}{$40: 60 \quad 0.5 \%$} \\
\hline & & & & & & \\
\hline Reading & Sh Str & RPM & Sh Rt & Viscosity & Reading Visco. & $(3.1 / 1.6)^{\star}$ Reading Visco. \\
\hline$(\%)$ & (dyne/cm2) & & $(1 / \mathrm{sec})$ & (p) & (cp) & \\
\hline 1.3 & 34.05 & 0.3 & 0.07 & 488.00 & 26000 & 50375 \\
\hline 2.6 & 68.10 & 0.6 & 0.14 & 488.00 & 26000 & 50375 \\
\hline 6.5 & 170.26 & 1.5 & 0.35 & 488.00 & 26000 & 50375 \\
\hline 13 & 340.52 & 3 & 0.70 & 488.00 & 26000 & 50375 \\
\hline 26 & 681.03 & 6 & 1.40 & 488.00 & 26000 & 50375 \\
\hline 52 & 1362.07 & 12 & 2.79 & 488.00 & 26000 & 50375 \\
\hline & & & & & & \\
\hline \multicolumn{7}{|c|}{$40: 60 \quad 0.7 \%$} \\
\hline & & & & & & \\
\hline Reading & Sh Str & RPM & Sh Rt & Viscosity & Reading Visco. & $(3.1 / 1.6)^{\star}$ Reading Visco. \\
\hline$(\%)$ & (dyne/cm2) & & $(1 / \mathrm{sec})$ & (p) & (cp) & \\
\hline 0.9 & 23.57 & 0.3 & 0.07 & 337.85 & 18000 & 34875 \\
\hline 1.6 & 41.91 & 0.6 & 0.14 & 300.31 & 16000 & 31000 \\
\hline 3.9 & 102.16 & 1.5 & 0.35 & 292.80 & 15600 & 30225 \\
\hline 7.7 & 201.69 & 3 & 0.70 & 289.05 & 15600 & 30225 \\
\hline 15.6 & 408.62 & 6 & 1.40 & 292.80 & 15600 & 30225 \\
\hline 31.3 & 819.86 & 12 & 2.79 & 293.74 & 15500 & 30031.25 \\
\hline
\end{tabular}




\section{TABLE 57. CONT'D.}

\begin{tabular}{|c|c|c|c|c|c|c|}
\hline \multicolumn{2}{|c|}{$40: 60 \quad 0.8 \%$} & & & \multirow[b]{2}{*}{ Viscosity } & \multirow[b]{2}{*}{ Reading Visco. } & \multirow[b]{2}{*}{$(3.1 / 1.6)^{\star}$ Reading Visco } \\
\hline Reading & Sh Str & RPM & Sh Rt & & & \\
\hline$(\%)$ & (dyne/cm2) & & (1/sec) & (p) & (cp) & \\
\hline 6 & 157.16 & 3 & 0.70 & 225.23 & 12000 & 23250 \\
\hline 10 & 261.94 & 6 & 1.40 & 187.69 & 10000 & 19375 \\
\hline 18.9 & 495.06 & 12 & 2.79 & 177.37 & 9450 & 18309.375 \\
\hline & & & & & & \\
\hline \multicolumn{7}{|c|}{$50: 500.1 \%$} \\
\hline & & & & & & \\
\hline Reading & Sh Str & RPM & Sh Rt & Viscosity & Reading Visco. & $(3.1 / 1.6)^{\star}$ Reading Visco. \\
\hline$(\%)$ & (dyne/cm2) & & $(1 / \mathrm{sec})$ & (p) & (cp) & \\
\hline 3 & 80.14 & 0.3 & 0.07 & 1148.49 & 60000 & 116250 \\
\hline 5.8 & 154.93 & 0.6 & 0.14 & 1110.20 & 58000 & 112375 \\
\hline 14.5 & 387.34 & 1.5 & 0.35 & 1110.20 & 58000 & 112375 \\
\hline 28.5 & 761.32 & 3 & 0.70 & 1091.06 & 57000 & 110437.5 \\
\hline 56.8 & 1517.29 & 6 & 1.40 & 1087.23 & 56800 & 110050 \\
\hline & & & & & & \\
\hline & & & & & & \\
\hline \multicolumn{7}{|c|}{$50: 50 \quad 0.25 \%$} \\
\hline & & & & & & \\
\hline Reading & Sh Str & RPM & Sh Rt & Viscosity & Reading Visco. & $(3.1 / 1.6)^{\star}$ Reading Visco. \\
\hline (\%) & (dyne/cm2) & & (1/sec) & (p) & (cp) & \\
\hline 2.6 & 68.10 & 0.3 & 0.07 & 976.00 & 52000 & 100750 \\
\hline 5 & 130.97 & 0.6 & 0.14 & 938.47 & 50000 & 96875 \\
\hline 12.5 & 327.42 & 1.5 & 0.35 & 938.47 & 50000 & 96875 \\
\hline 25 & 654.84 & 3 & 0.70 & 938.47 & 50000 & 96875 \\
\hline 49.8 & 1304.44 & 6 & 1.40 & 934.71 & 49800 & 96487.5 \\
\hline & & & & & & \\
\hline & & & & & & \\
\hline \multicolumn{7}{|c|}{ 60:40 0.1\% } \\
\hline & & & & & & \\
\hline Reading & Sh Str & RPM & Sh Rt & Viscosity & Reading Visco. & $(3.1 / 1.6)^{\star}$ Reading Visco. \\
\hline$(\%)$ & (dyne/cm2) & & $(1 / \mathrm{sec})$ & (p) & (cp) & \\
\hline 6.8 & 178.12 & 0.3 & 0.07 & 2552.63 & 136000 & 263500 \\
\hline 12.5 & 327.42 & 0.6 & 0.14 & 2346.16 & 125000 & 242187.5 \\
\hline 29 & 759.62 & 1.5 & 0.35 & 2177.24 & 116000 & 224750 \\
\hline 59 & 1545.42 & 3 & 0.70 & 2214.78 & 116000 & 224750 \\
\hline & & & & & & \\
\hline \multirow{2}{*}{\multicolumn{7}{|c|}{$60: 40 \quad 0.25 \%$}} \\
\hline & & & & & & \\
\hline Reading & Sh Str & RPM & Sh Rt & Viscosity & Reading Visco. & $(3.1 / 1.6)^{\star}$ Reading Visco \\
\hline (\%) & (dyne/cm2) & & (1/sec) & (p) & $(c p)$ & \\
\hline 6.4 & 167.64 & 0.3 & 0.07 & 2402.47 & 128000 & 248000 \\
\hline 11.4 & 298.61 & $\overline{0.6}$ & 0.14 & 2139.70 & 114000 & 220875 \\
\hline 24.5 & 641.74 & 1.5 & 0.35 & 1839.39 & 98000 & 189875 \\
\hline 44.5 & 1165.62 & 3 & 0.70 & 1670.47 & 98000 & 189875 \\
\hline
\end{tabular}




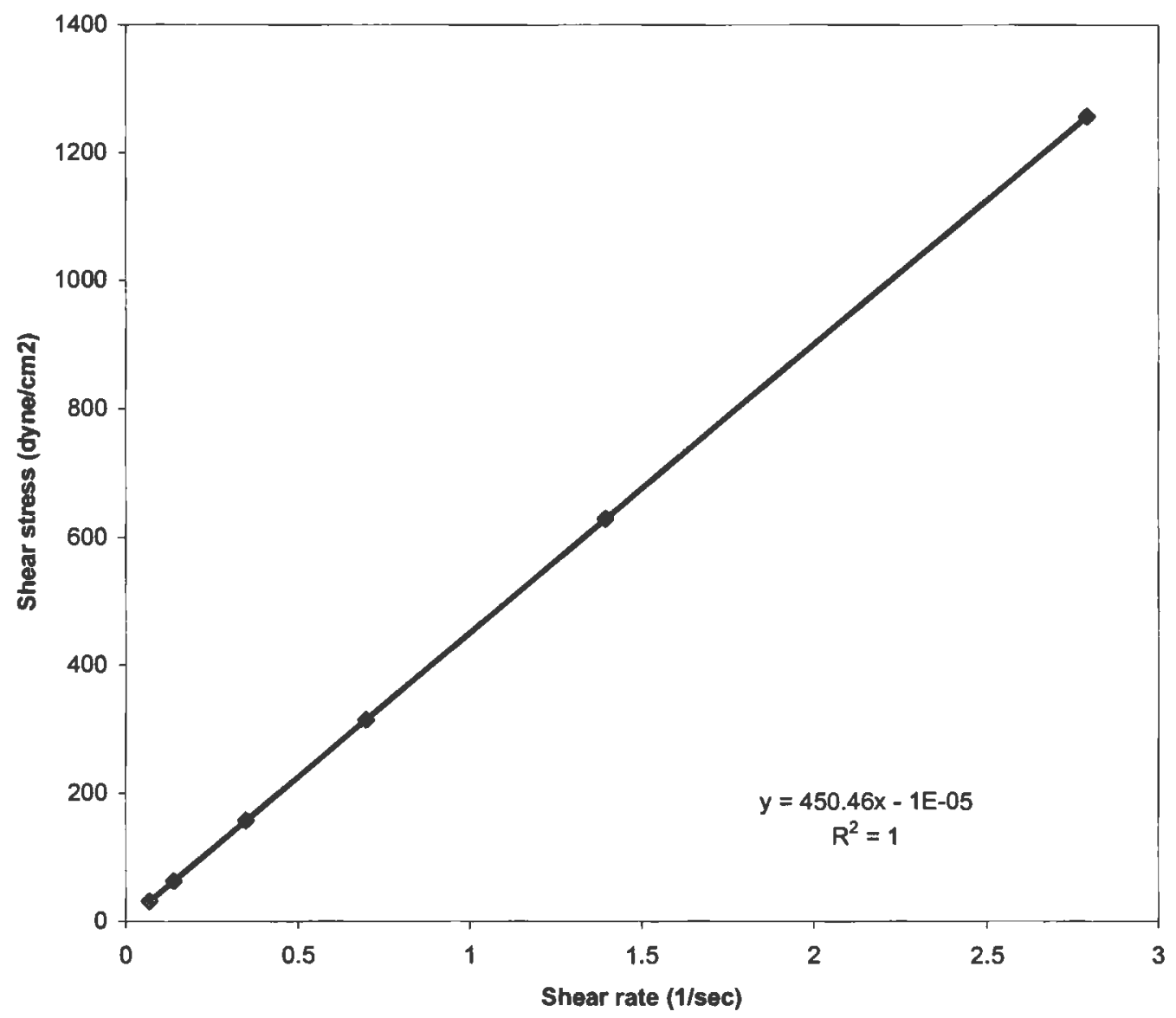

FIGURE 56. RHEOGRAM FOR LECITHIN:IPM (40:60) CONTAINING $0.1 \%$ WATER AND $6.5 \%$ KT BY CYLINDRICAL VISCOMETER 


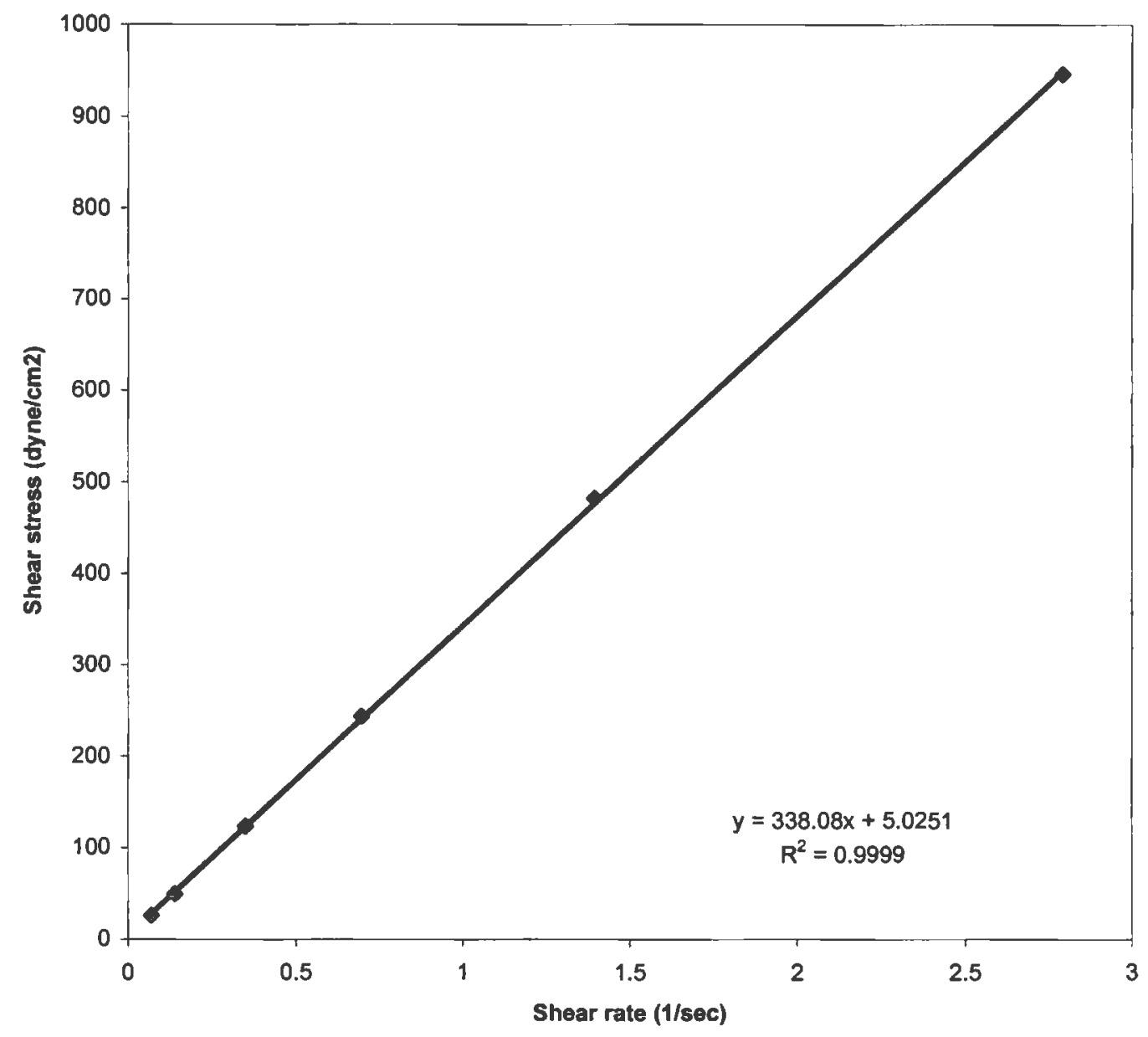

FIGURE 57. RHEOGRAM FOR LECITHIN:IPM (40:60) CONTAINING $0.25 \%$ WATER AND $6.5 \%$ KT BY CYLINDRICAL VISCOMETER 


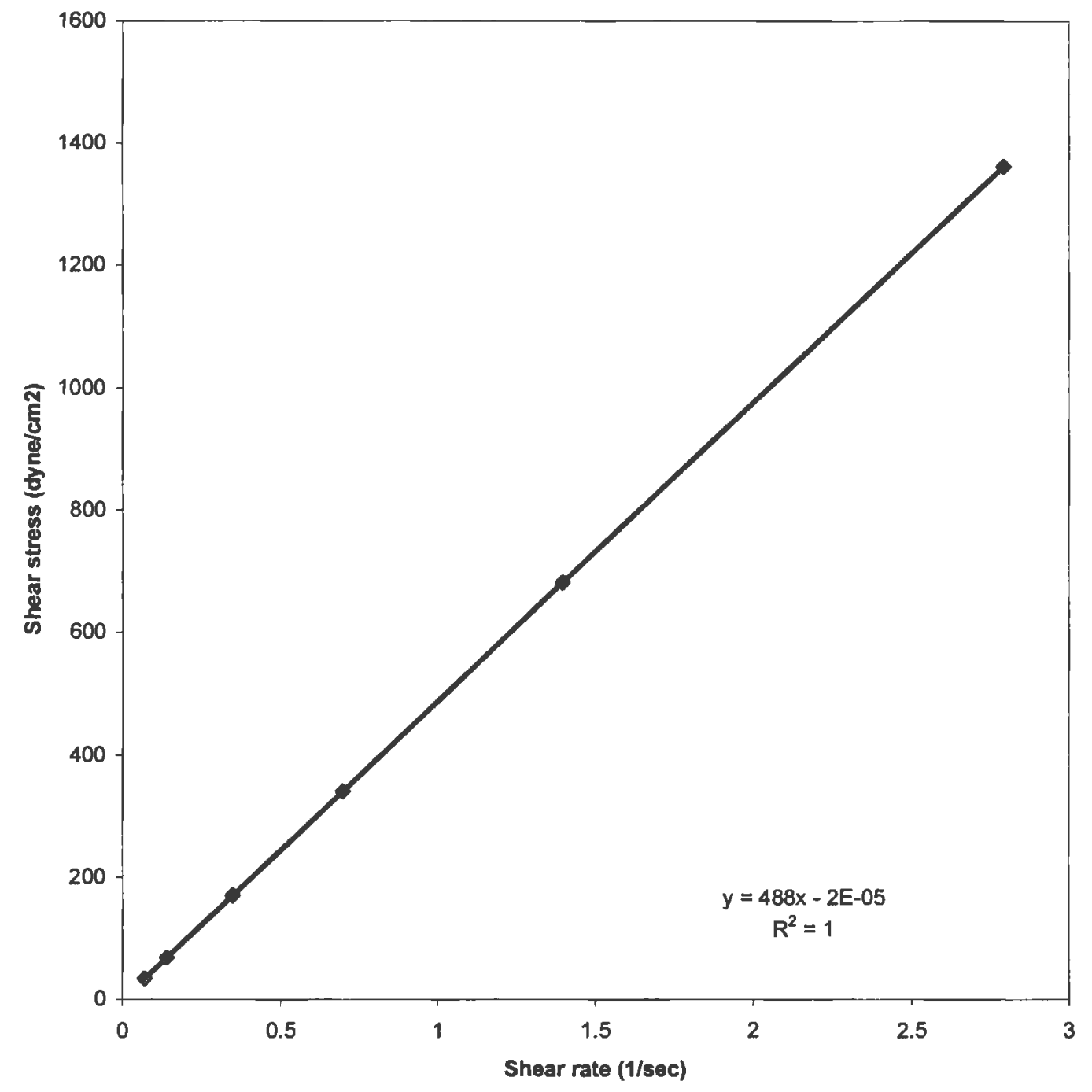

FIGURE 58. RHEOGRAM FOR LECITHIN:IPM (40:60) CONTAINING $0.5 \%$ WATER AND $6.5 \% \mathrm{KT}$ BY CYLINDRICAL VISCOMETER 


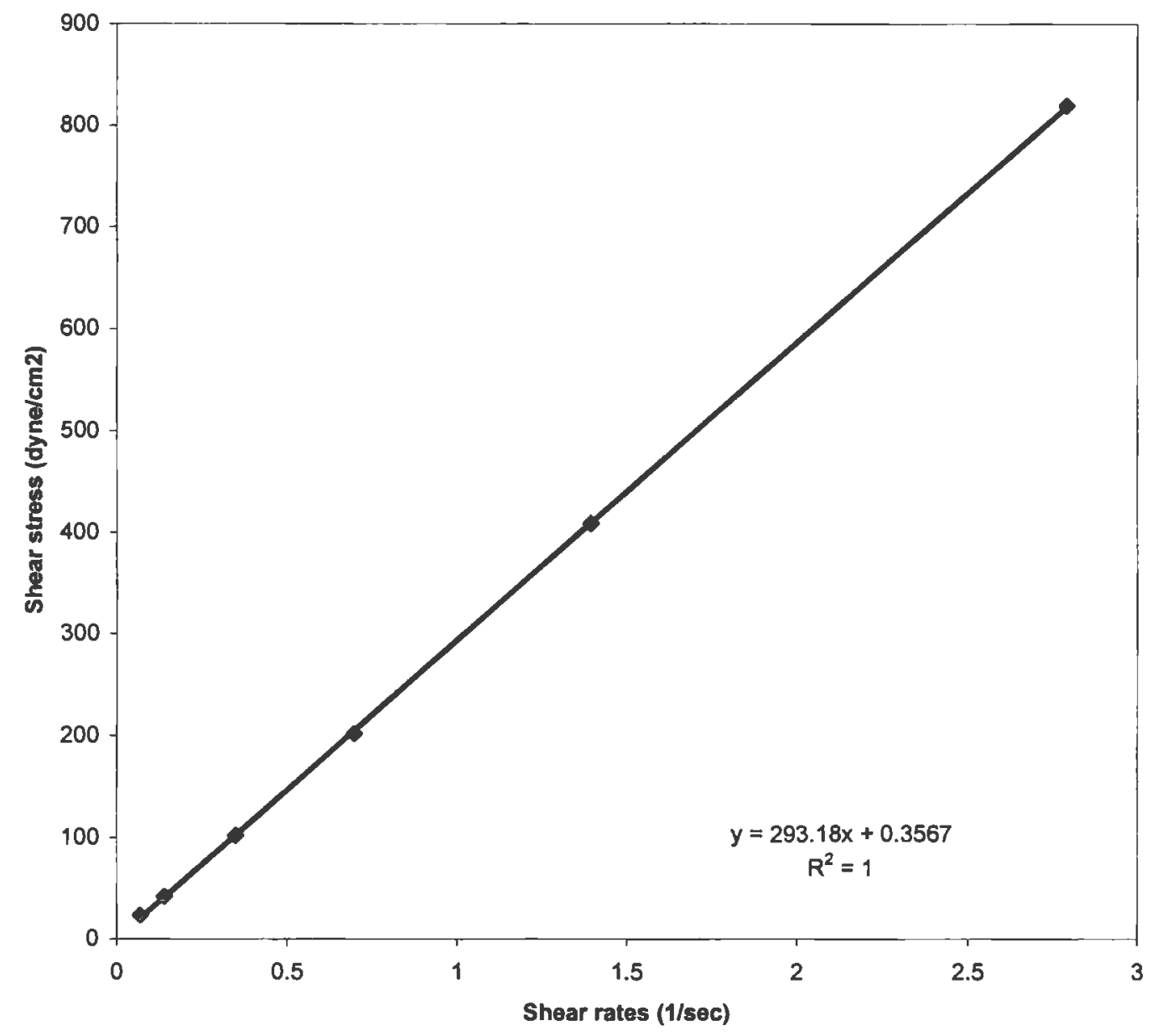

FIGURE 59. RHEOGRAM FOR LECITHIN:IPM (40:60) CONTAINING $0.7 \%$ WATER AND $6.5 \%$ KT BY CYLINDRICAL VISCOMETER 


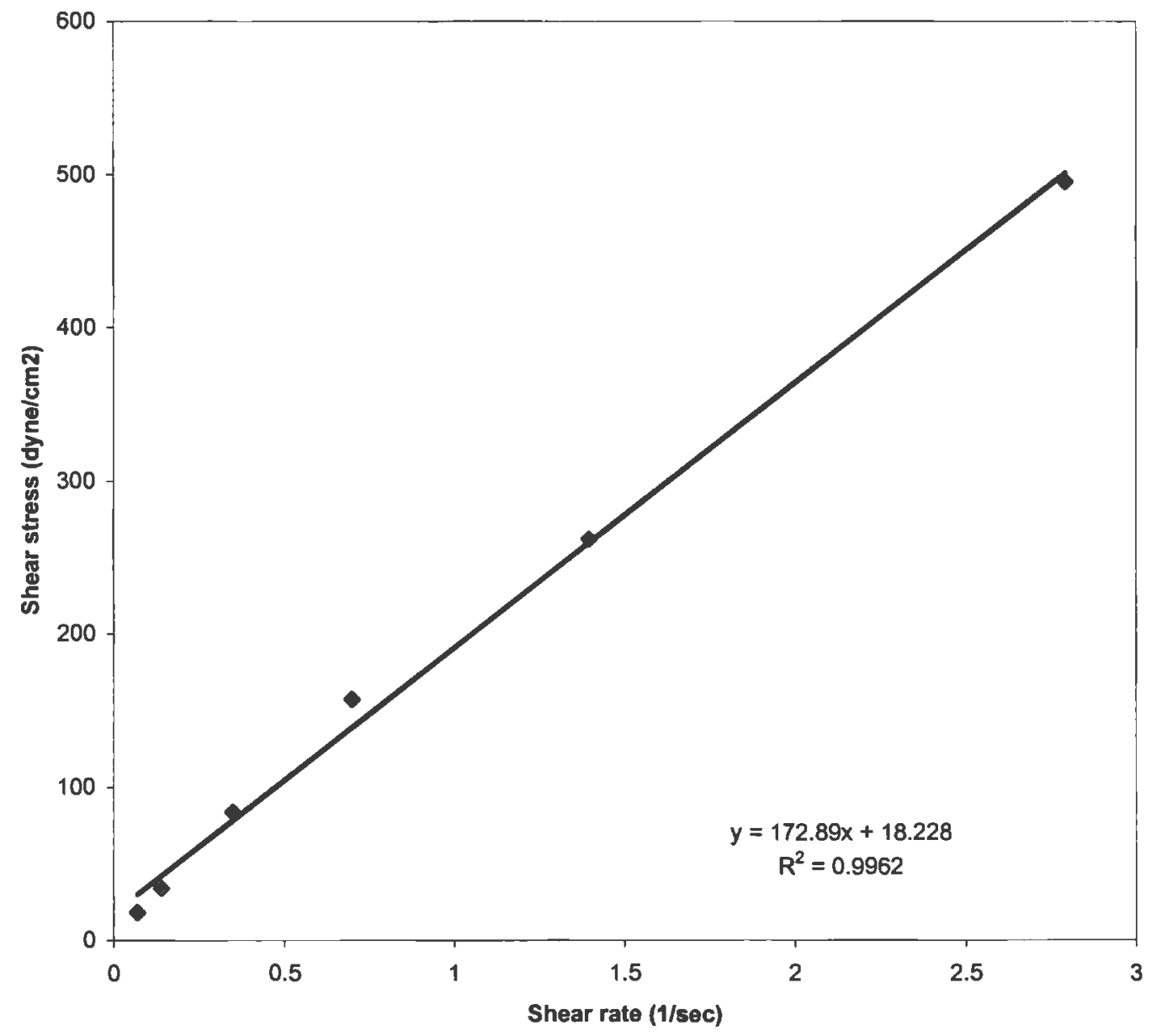

FIGURE 60. RHEOGRAM FOR LECITHIN:IPM (40:60) CONTAINING 0.8\% WATER AND 6.5\% KT BY CYLINDRICAL VISCOMETER 


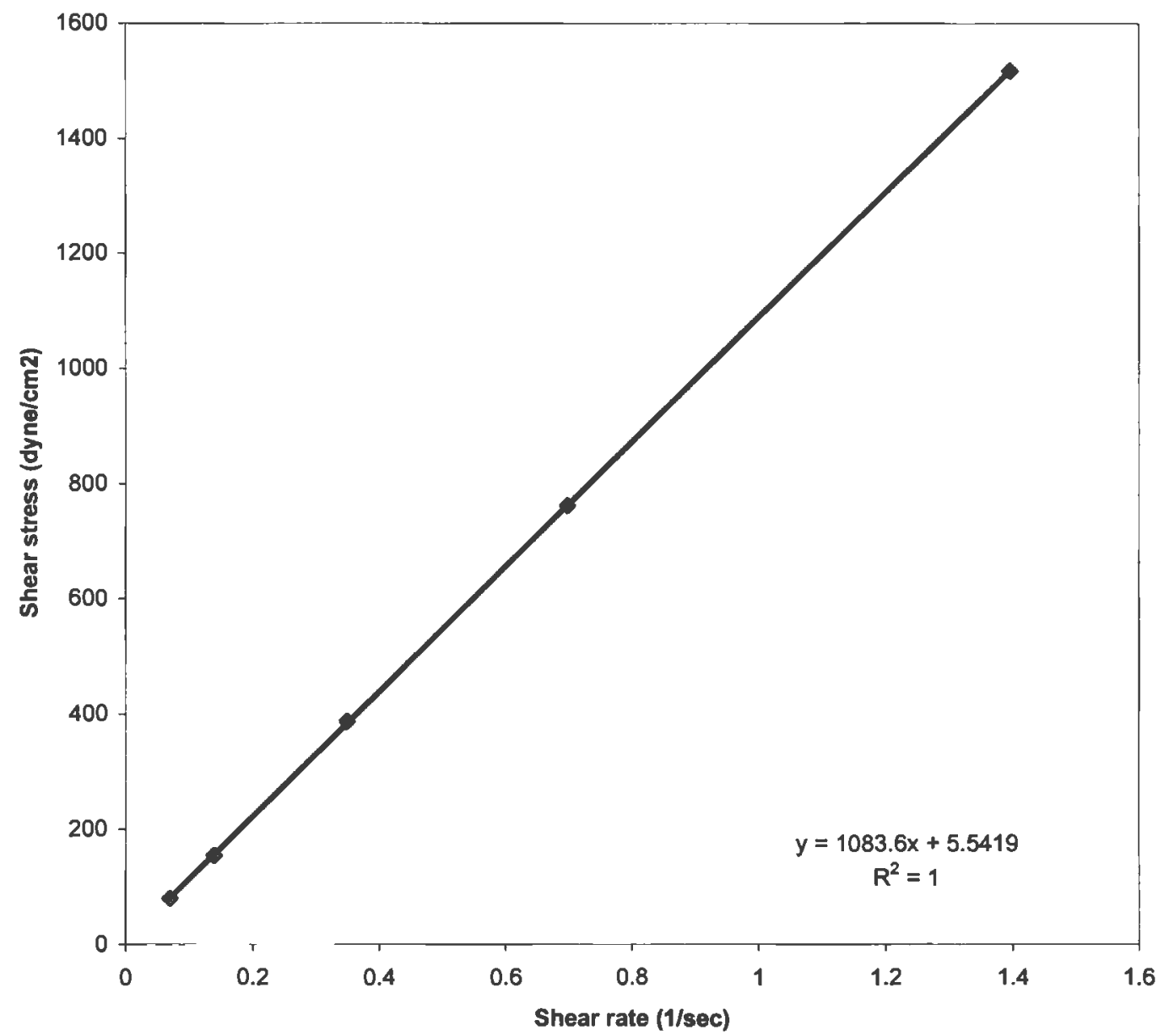

FIGURE 61. RHEOGRAM FOR LECITHIN:IPM (50:50) CONTAINING 0.1\% WATER AND 6.5\% KT BY CYLINDRICAL VISCOMETER 


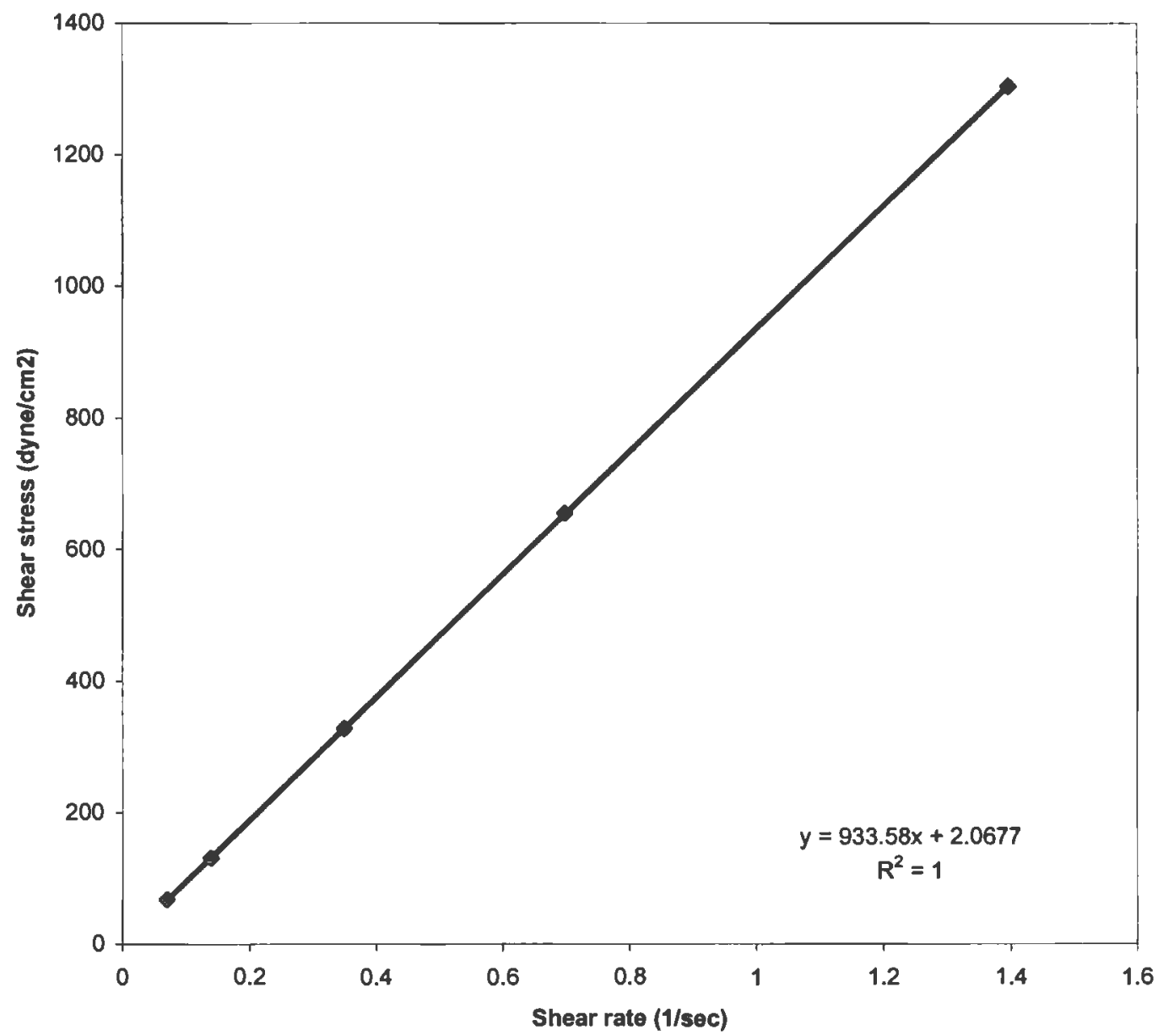

FIGURE 62. RHEOGRAM FOR LECITHIN:IPM (50:50) CONTAINING $0.25 \%$ WATER AND $6.5 \%$ KT BY CYLINDRICAL VISCOMETER 


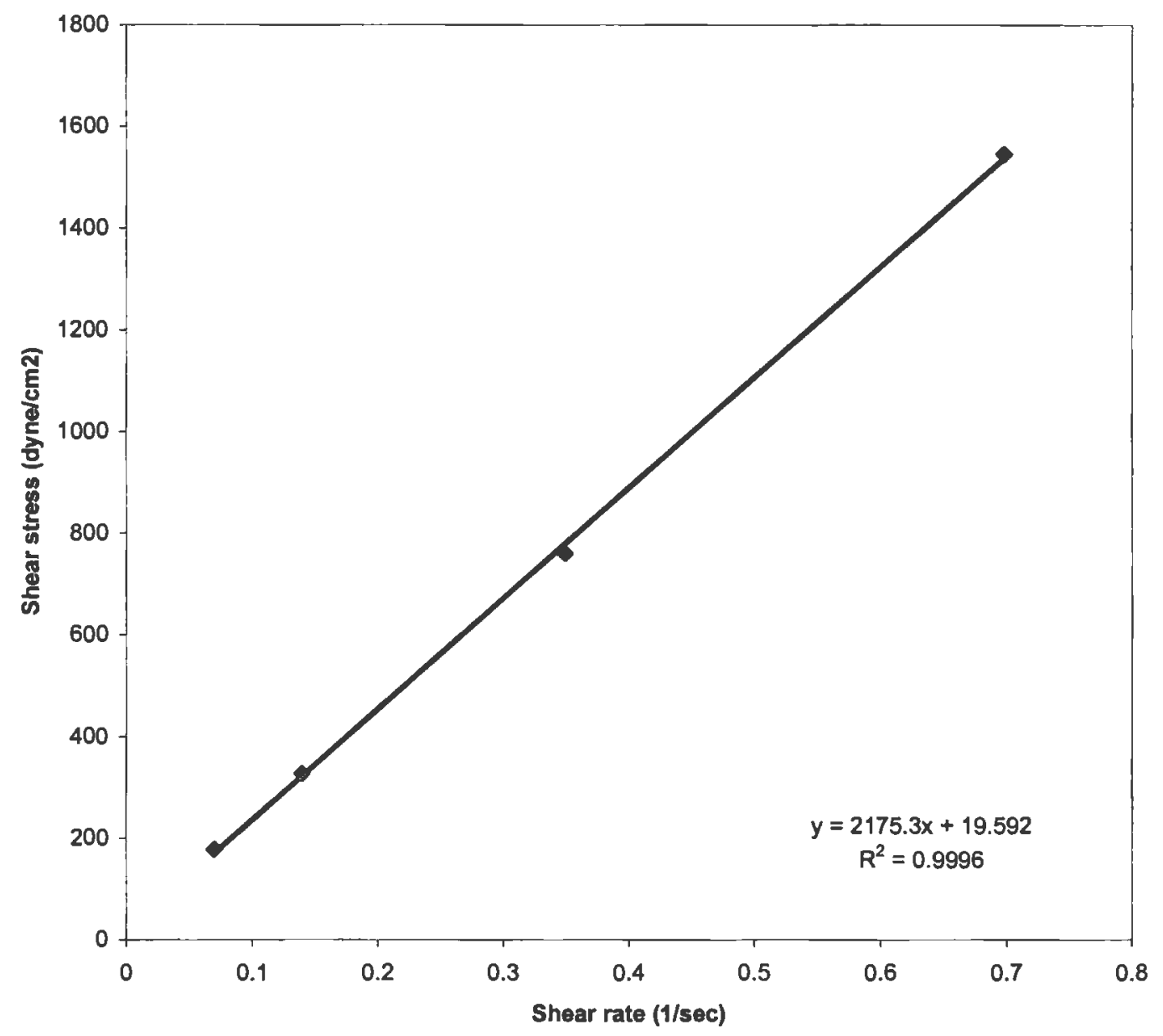

FIGURE 63. RHEOGRAM FOR LECITHIN:IPM $(60: 40)$ CONTAINING $0.1 \%$ WATER AND $6.5 \%$ KT BY CYLINDRICAL VISCOMETER 


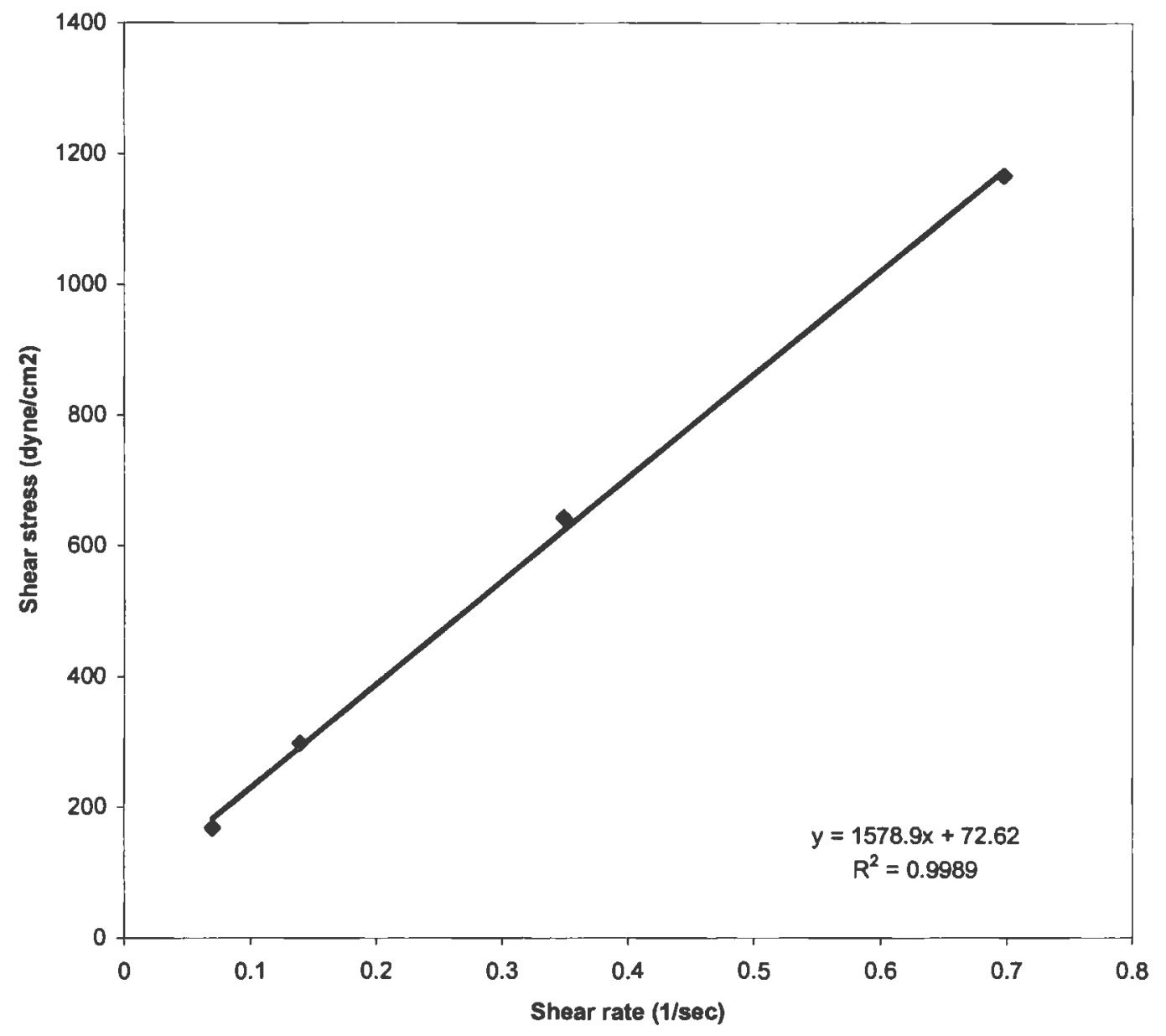

FIGURE 64. RHEOGRAM FOR LECITHIN:IPM (60:40) CONTAINING $0.25 \%$ WATER AND $6.5 \%$ KT BY CYLINDRICAL VISCOMETER 
TABLE 58. VALUES OF VISCOSITY FOR KT ORGANOGELS WITH DIFFERENT COMPOSITIONS BY CYLINDRICAL VISCOMETER (NO.2)

\begin{tabular}{|c|c|c|c|c|c|c|}
\hline \multicolumn{3}{|c|}{$40: 60 \quad 0.1 \% \quad L=1.6 \mathrm{~cm}$} & \multirow[b]{2}{*}{ Sh Rt } & \multirow[b]{2}{*}{ Viscosity } & \multirow[b]{2}{*}{ Reading Visco. } & \multirow[b]{2}{*}{$(3.1 / 1.6)^{\star}$ Reading Visco } \\
\hline Reading & Sh Str & RPM & & & & \\
\hline$(\%)$ & (dyne/cm2) & & (1/sec) & (p) & (cp) & \\
\hline 2.2 & 57.63 & 0.3 & 0.07 & 825.85 & 44000 & 85250 \\
\hline 4.3 & 112.63 & 0.6 & 0.14 & 807.08 & 43000 & 83312.5 \\
\hline 10.6 & 277.65 & 1.5 & 0.35 & 795.82 & 42400 & 82150 \\
\hline 21.1 & 552.69 & 3 & 0.70 & 792.07 & 42200 & 81762.5 \\
\hline 42 & 1100.13 & 6 & 1.40 & 788.31 & 42000 & 81375 \\
\hline 81 & 2121.68 & 12 & 2.79 & 760.16 & 42000 & 81375 \\
\hline & & & & & & \\
\hline $40: 60 \quad 0.25 \%$ & & & & & & \\
\hline & & & & & & \\
\hline Reading & Sh Str & RPM & Sh Rt & Viscosity & Reading Visco. & $(3.1 / 1.6)^{\star}$ Reading Visco. \\
\hline$(\%)$ & (dyne/cm2) & & $(1 / \mathrm{sec})$ & (p) & $(c p)$ & \\
\hline 1.7 & 44.53 & 0.3 & 0.07 & 638.16 & 34000 & 65875 \\
\hline 3.4 & 89.06 & 0.6 & 0.14 & 638.16 & 34000 & 65875 \\
\hline 8.3 & 217.41 & 1.5 & 0.35 & 623.14 & 33200 & 64325 \\
\hline 16.9 & 442.67 & 3 & 0.70 & 634.40 & 33800 & 65487.5 \\
\hline 33.8 & 885.34 & 6 & 1.40 & 634.40 & 33800 & 65487.5 \\
\hline 67.6 & 1770.69 & 12 & 2.79 & 634.40 & 33800 & 65487.5 \\
\hline & & & & & & \\
\hline \multicolumn{2}{|c|}{$40: 600.5 \%$} & & & & & \\
\hline & & & & & & \\
\hline Reading & Sh Str & RPM & Sh Rt & Viscosity & Reading Visco. & $(3.1 / 1.6)^{*}$ Reading Visco. \\
\hline$(\%)$ & (dyne/cm2) & & (1/sec) & (p) & (cp) & \\
\hline 1.5 & 39.29 & 0.3 & 0.07 & 563.08 & 30000 & 58125 \\
\hline 2.8 & 73.34 & 0.6 & 0.14 & 525.54 & 28000 & 54250 \\
\hline 6.8 & 178.12 & 1.5 & 0.35 & 510.53 & 27200 & 52700 \\
\hline 13.5 & 353.61 & 3 & 0.70 & 506.77 & 27000 & 52312.5 \\
\hline 26.7 & 699.37 & 6 & 1.40 & 501.14 & 26700 & 51731.25 \\
\hline 53.4 & 1398.74 & 12 & 2.79 & 501.14 & 26700 & 51731.25 \\
\hline & & & & & & \\
\hline \multicolumn{2}{|c|}{$40: 60 \quad 0.7 \%$} & & & & & \\
\hline & & & & & & \\
\hline Reading & Sh Str & RPM & Sh Rt & Viscosity & Reading Visco. & $(3.1 / 1.6)^{*}$ Reading Visco \\
\hline$(\%)$ & (dyne/cm2) & & (1/sec) & (p) & (cp) & \\
\hline 1 & 26.19 & 0.3 & 0.07 & 375.39 & 20000 & 38750 \\
\hline 1.9 & 49.77 & 0.6 & 0.14 & 356.62 & 19000 & 36812.5 \\
\hline 4.4 & 115.25 & 1.5 & 0.35 & 330.34 & 17600 & 34100 \\
\hline 8 & 209.55 & 3 & 0.70 & 300.31 & 16000 & 31000 \\
\hline 14 & 366.71 & 6 & 1.40 & 262.77 & 14200 & 27512.5 \\
\hline 26 & 681.03 & 12 & 2.79 & 244.00 & 13000 & 25187.5 \\
\hline
\end{tabular}


TABLE 58. CONT'D.

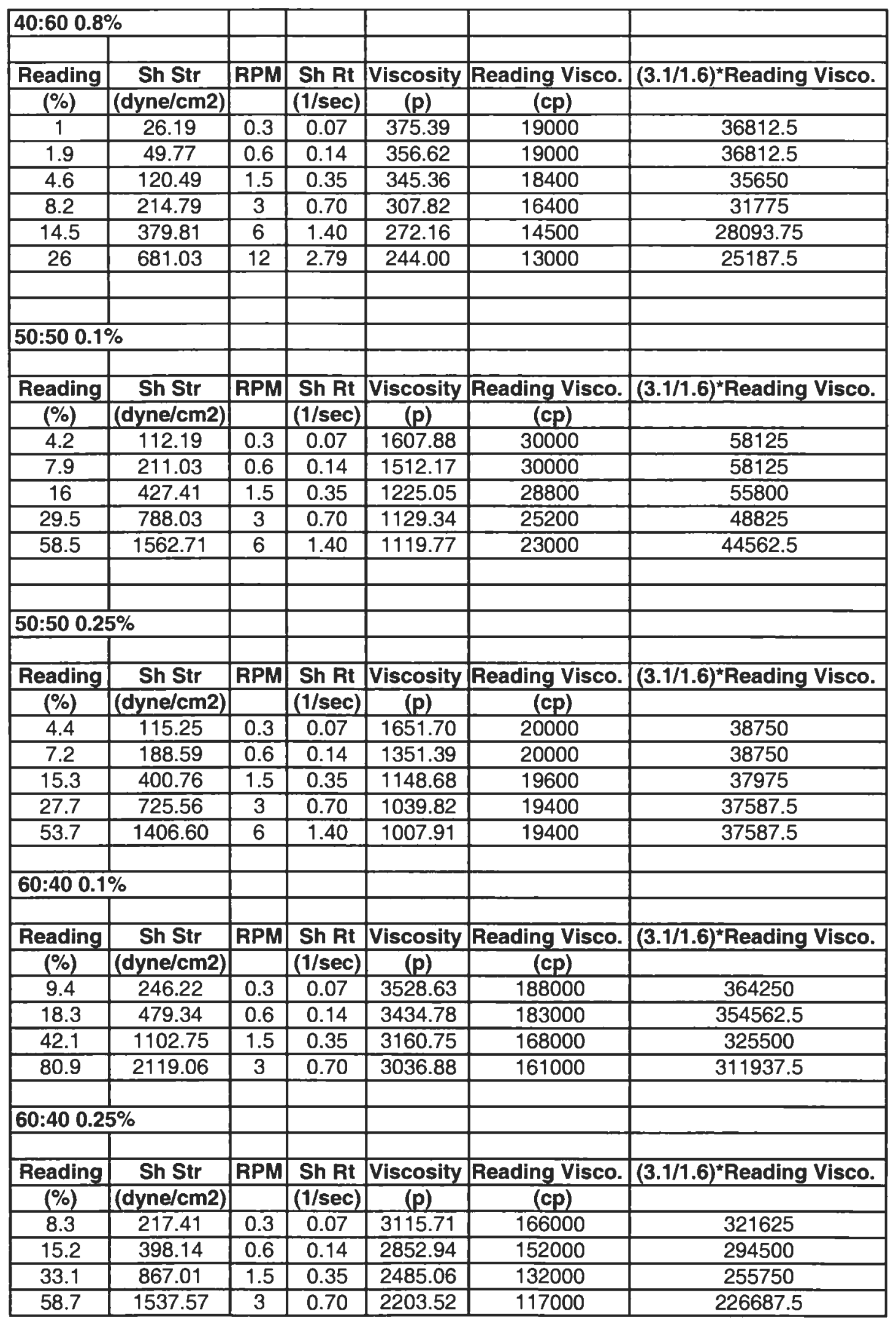




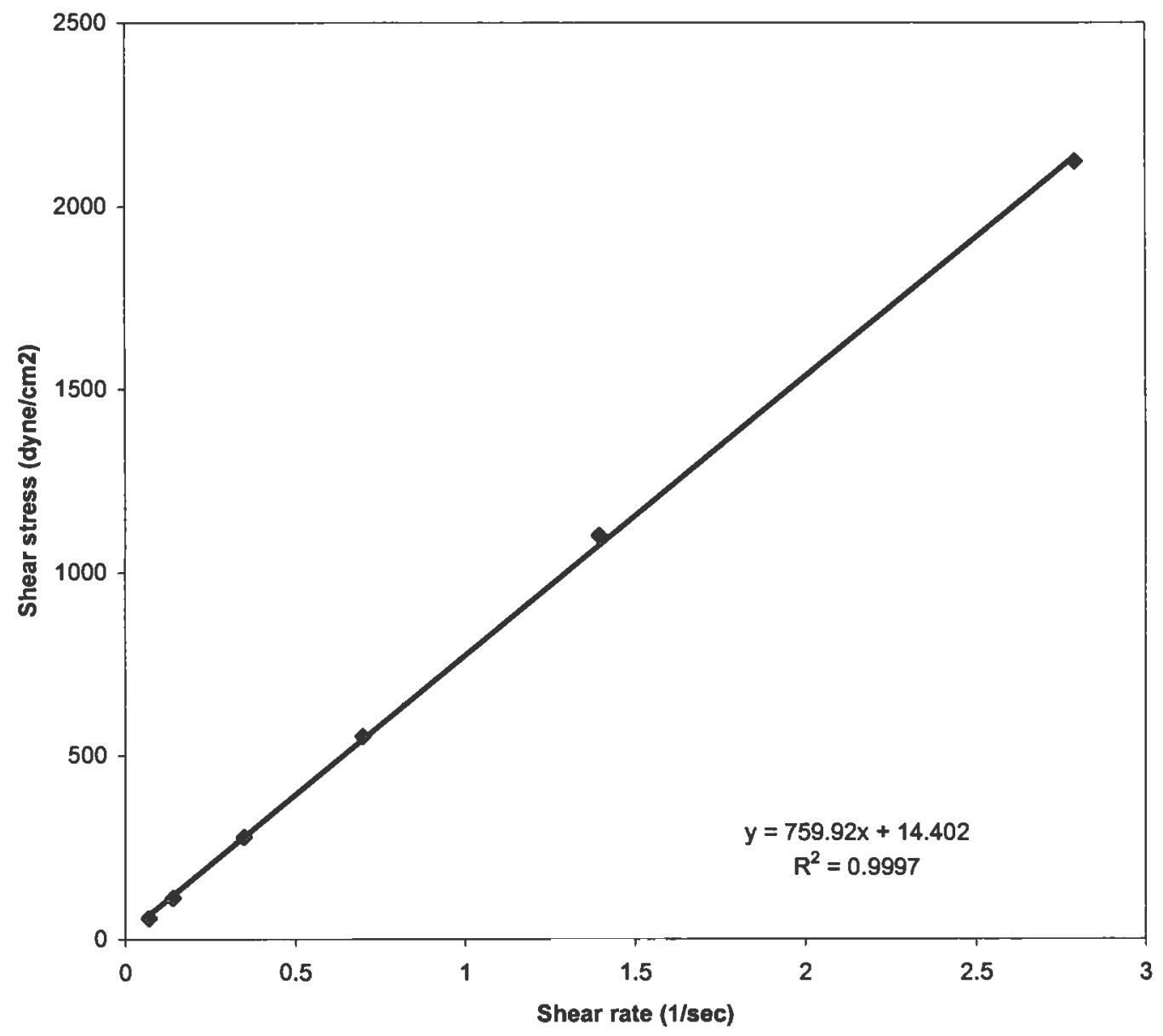

FIGURE 65. RHEOGRAM FOR LECITHIN:IPM (40:60) CONTAINING 0.1\% WATER AND 6.5\% KT BY CYLINDRICAL VISCOMETER 


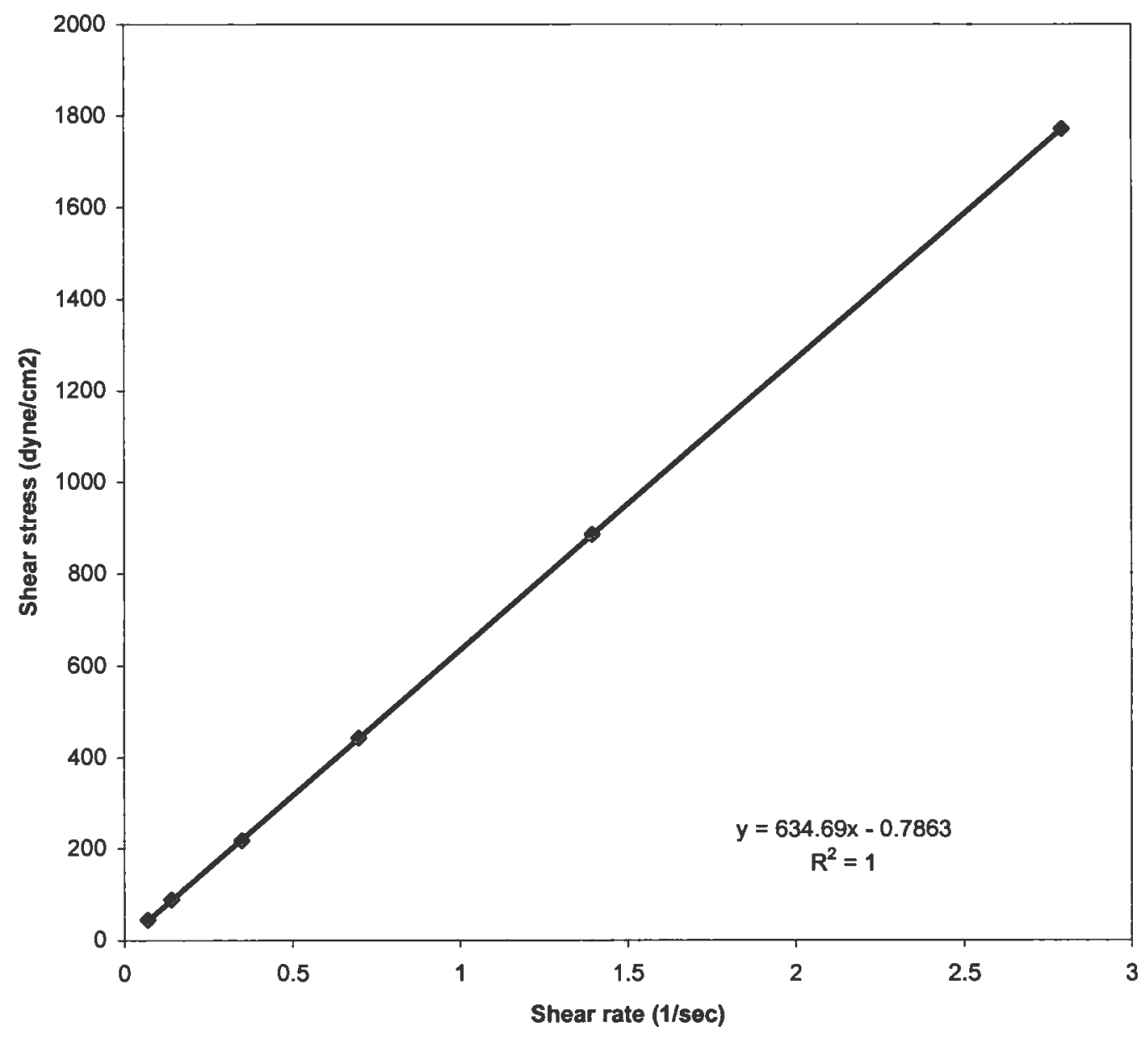

FIGURE 66. RHEOGRAM FOR LECITHIN:IPM (40:60) CONTAINING $0.25 \%$ WATER AND $6.5 \%$ KT BY CYLINDRICAL VISCOMETER 


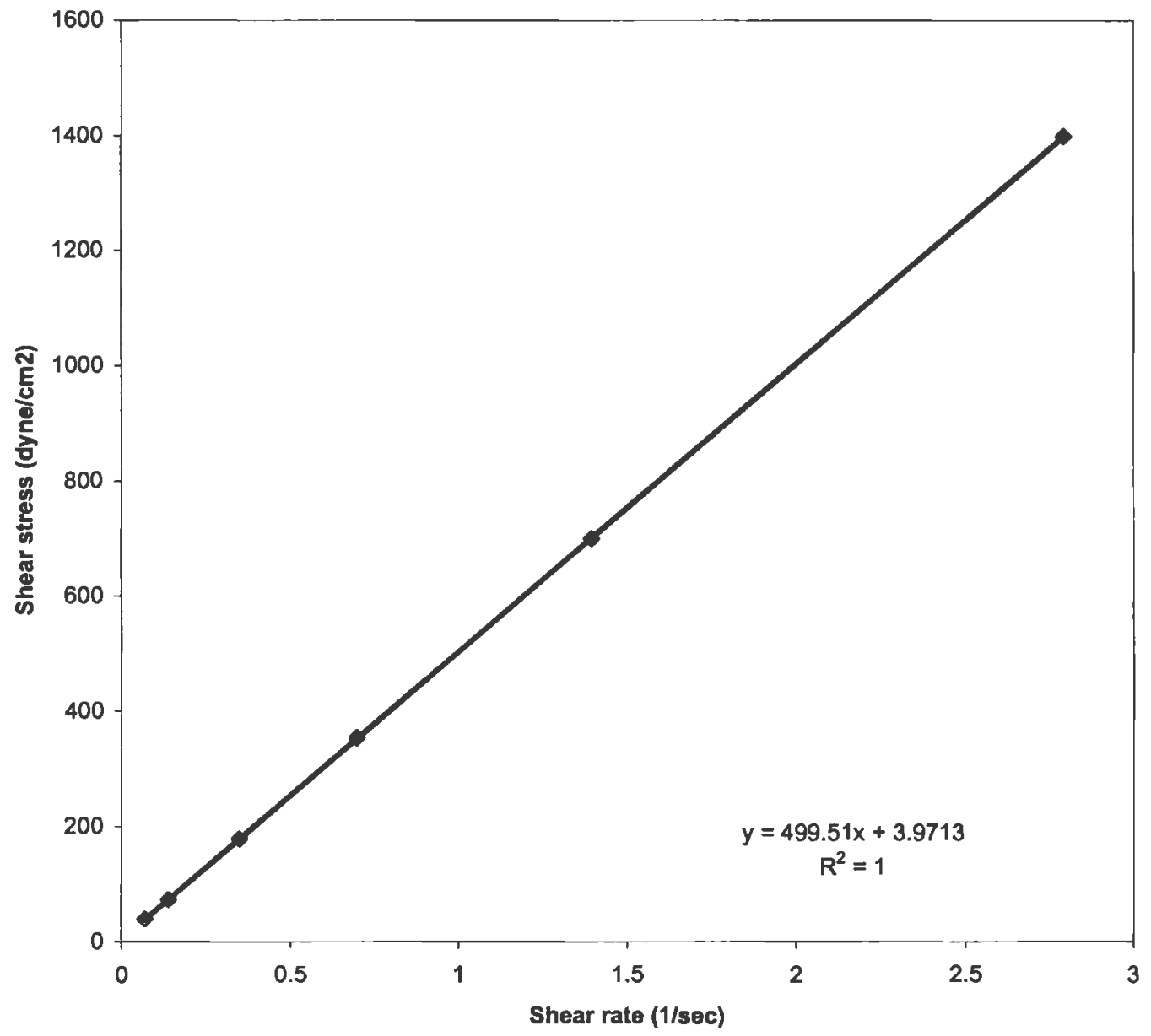

FIGURE 67. RHEOGRAM FOR LECITHIN:IPM (40:60) CONTAINING $0.5 \%$ WATER AND $6.5 \%$ KT BY CYLINDRICAL VISCOMETER 


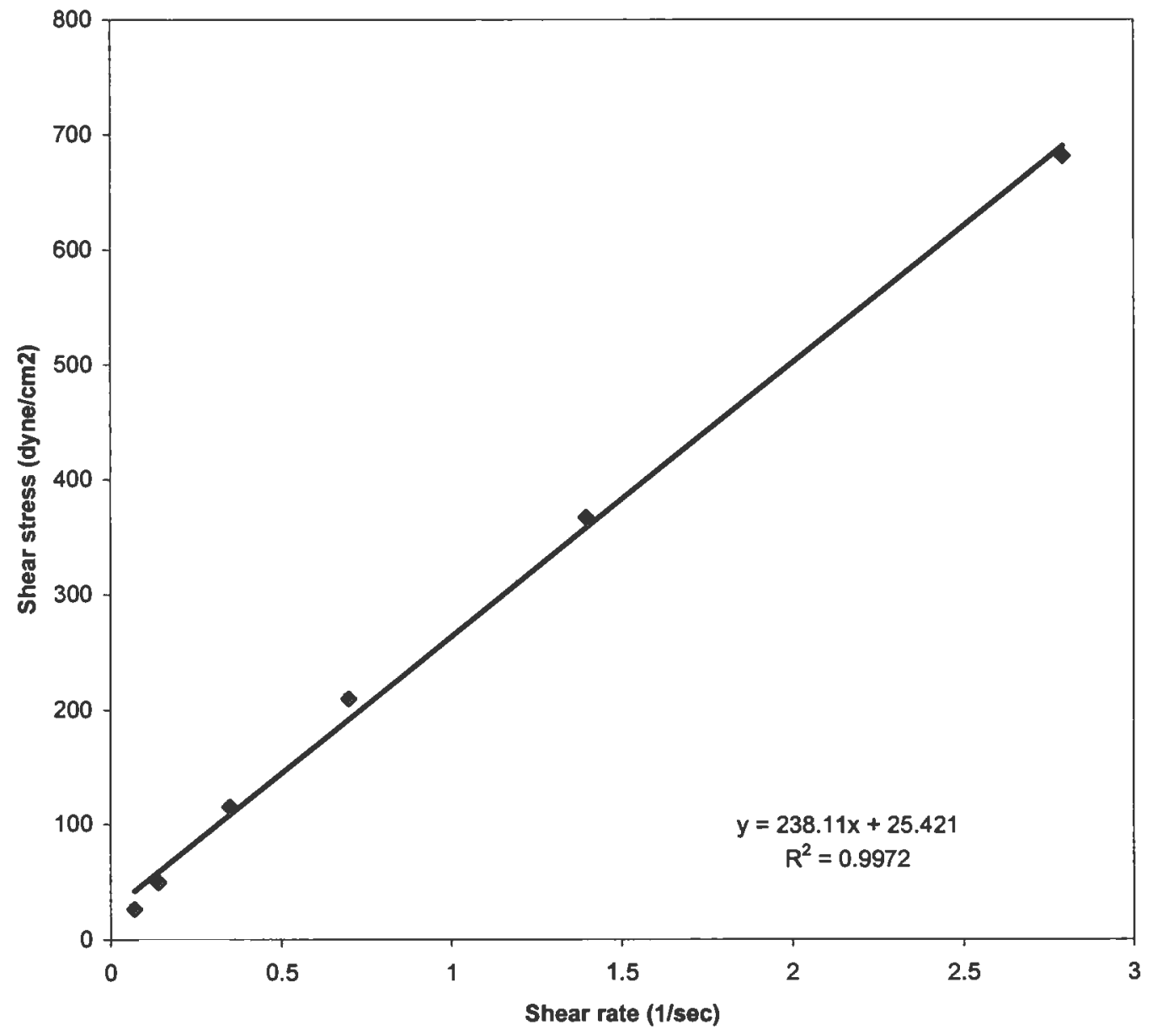

FIGURE 68. RHEOGRAM FOR LECITHIN:IPM (40:60) CONTAINING $0.7 \%$ WATER AND $6.5 \% \mathrm{KT}$ BY CYLINDRICAL VISCOMETER 


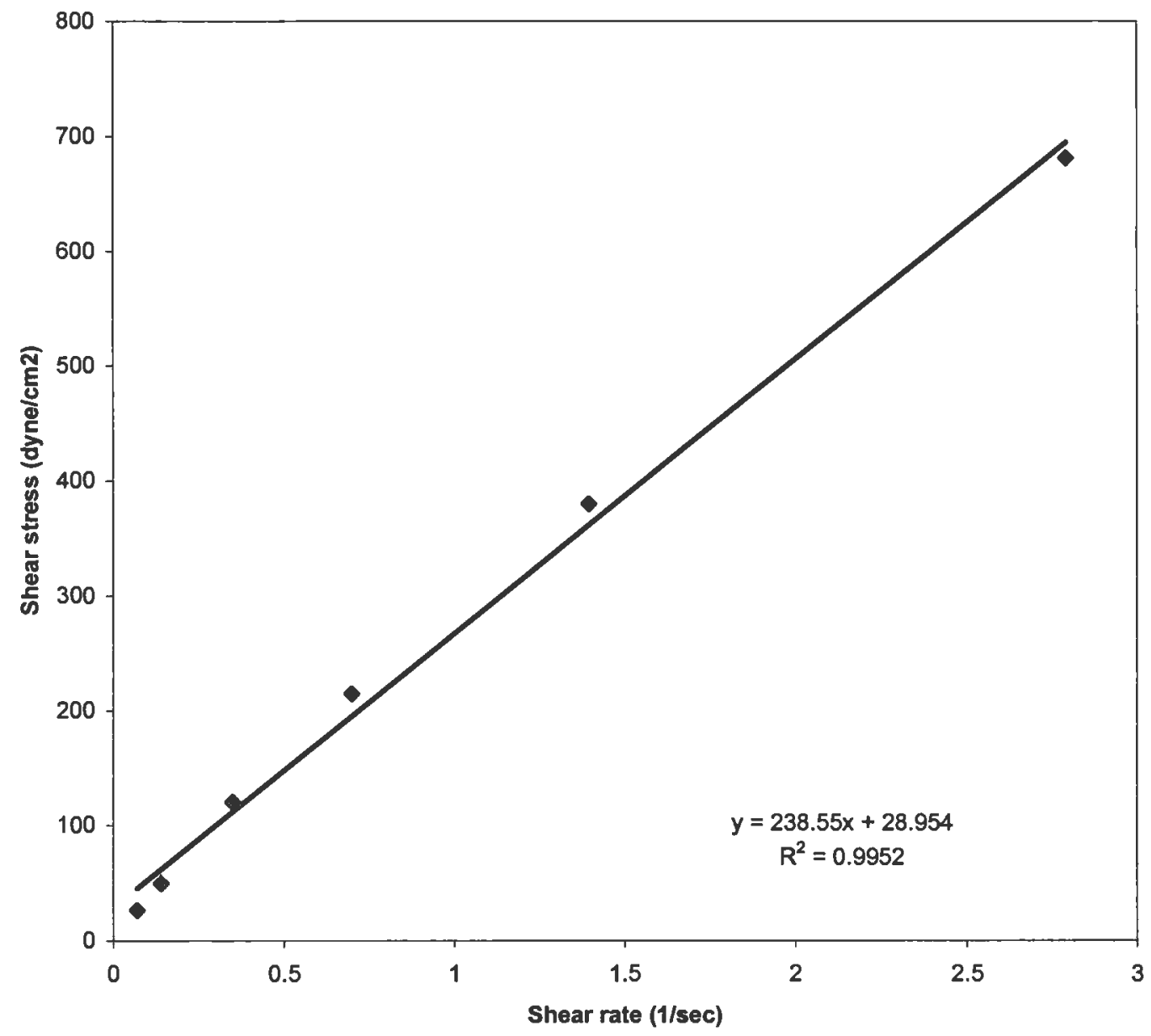

FIGURE 69. RHEOGRAM FOR LECITHIN:IPM (40:60) CONTAINING $0.8 \%$ WATER AND $6.5 \%$ KT BY CYLINDRICAL VISCOMETER 


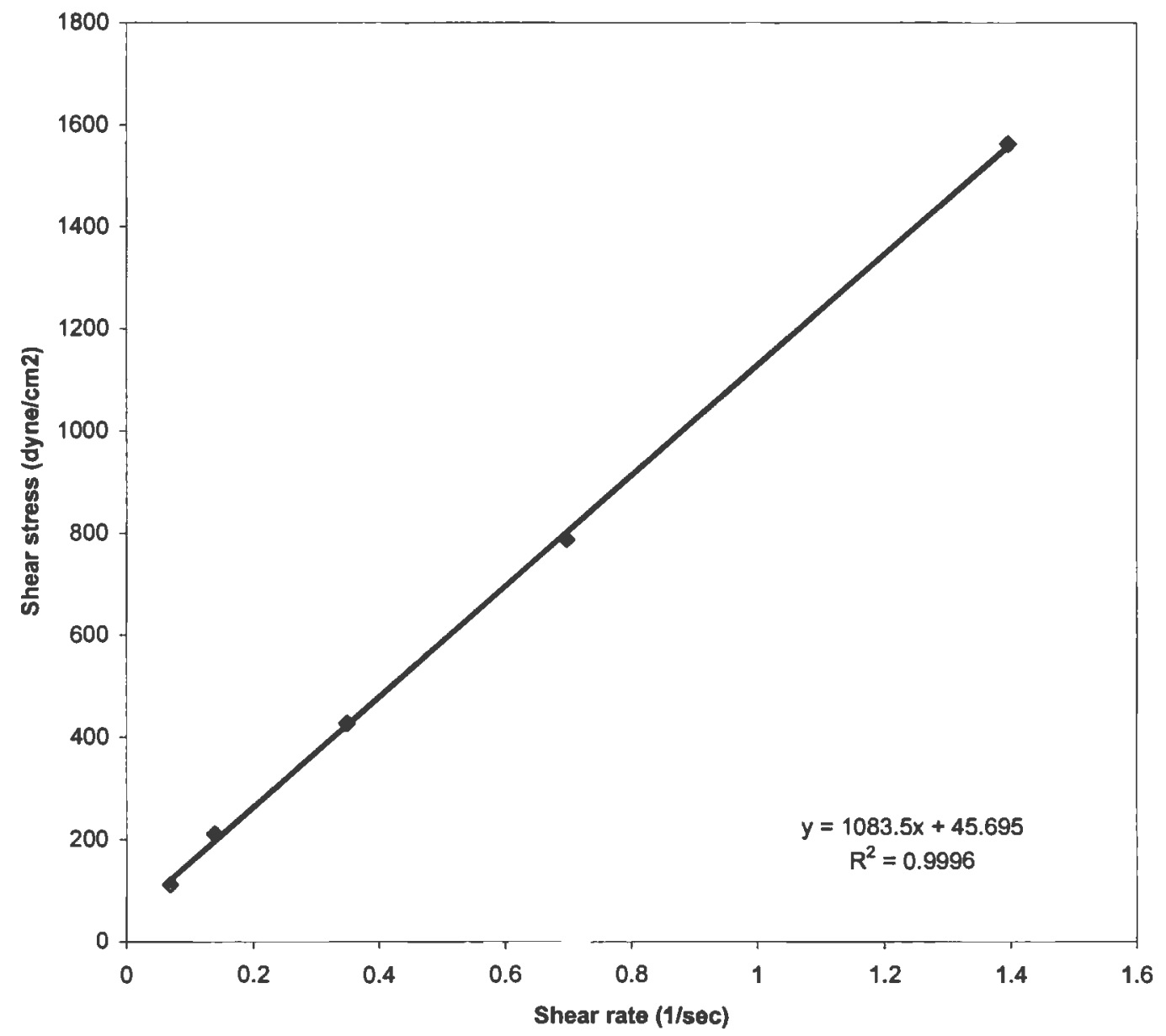

FIGURE 70. RHEOGRAM FOR LECITHIN:IPM (50:50) CONTAINING 0.1\% WATER AND 6.5\% KT BY CYLINDRICAL VISCOMETER 


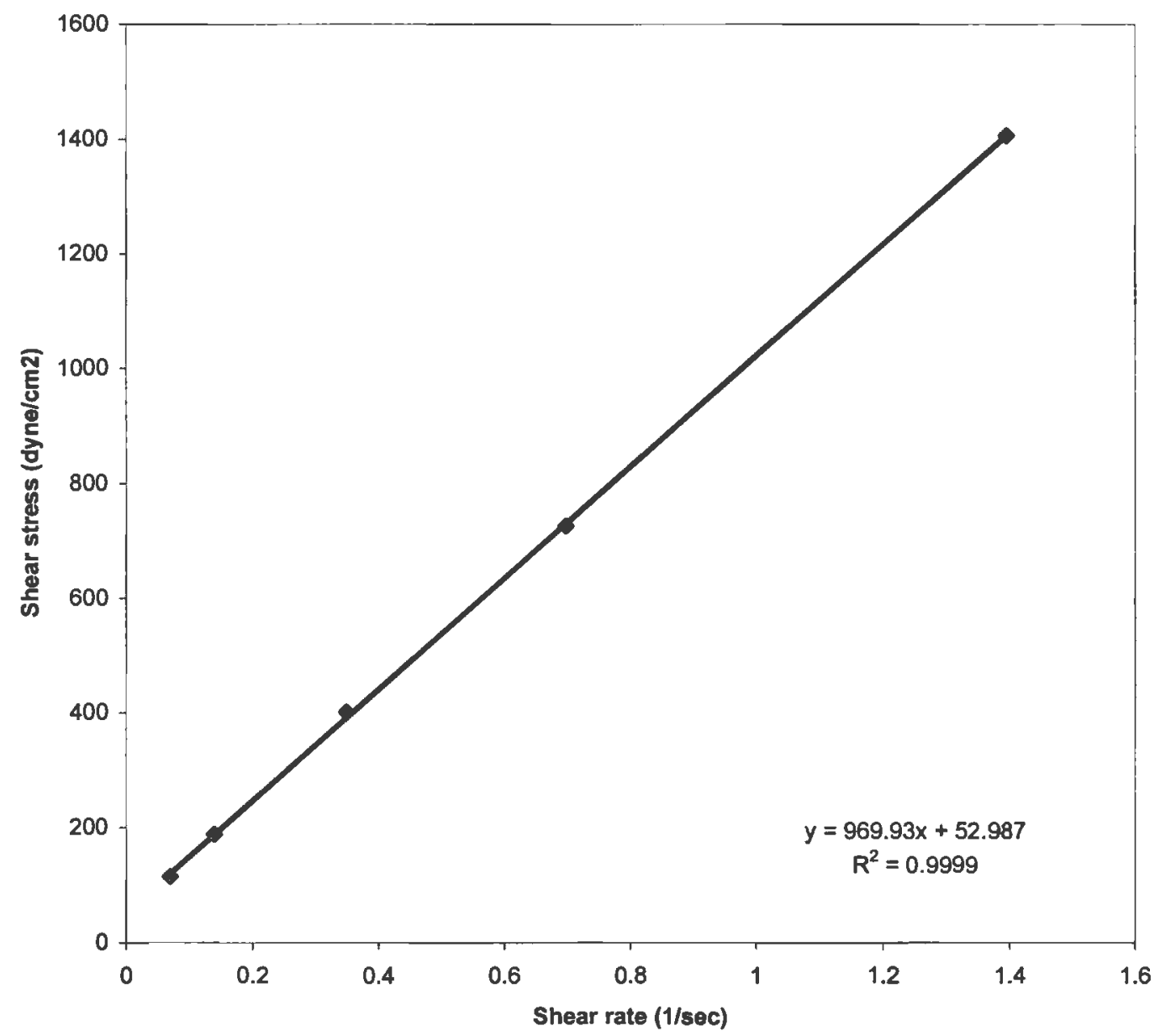

FIGURE 71. RHEOGRAM FOR LECITHIN:IPM (50:50) CONTAINING $0.25 \%$ WATER AND $6.5 \%$ KT BY CYLINDRICAL VISCOMETER 


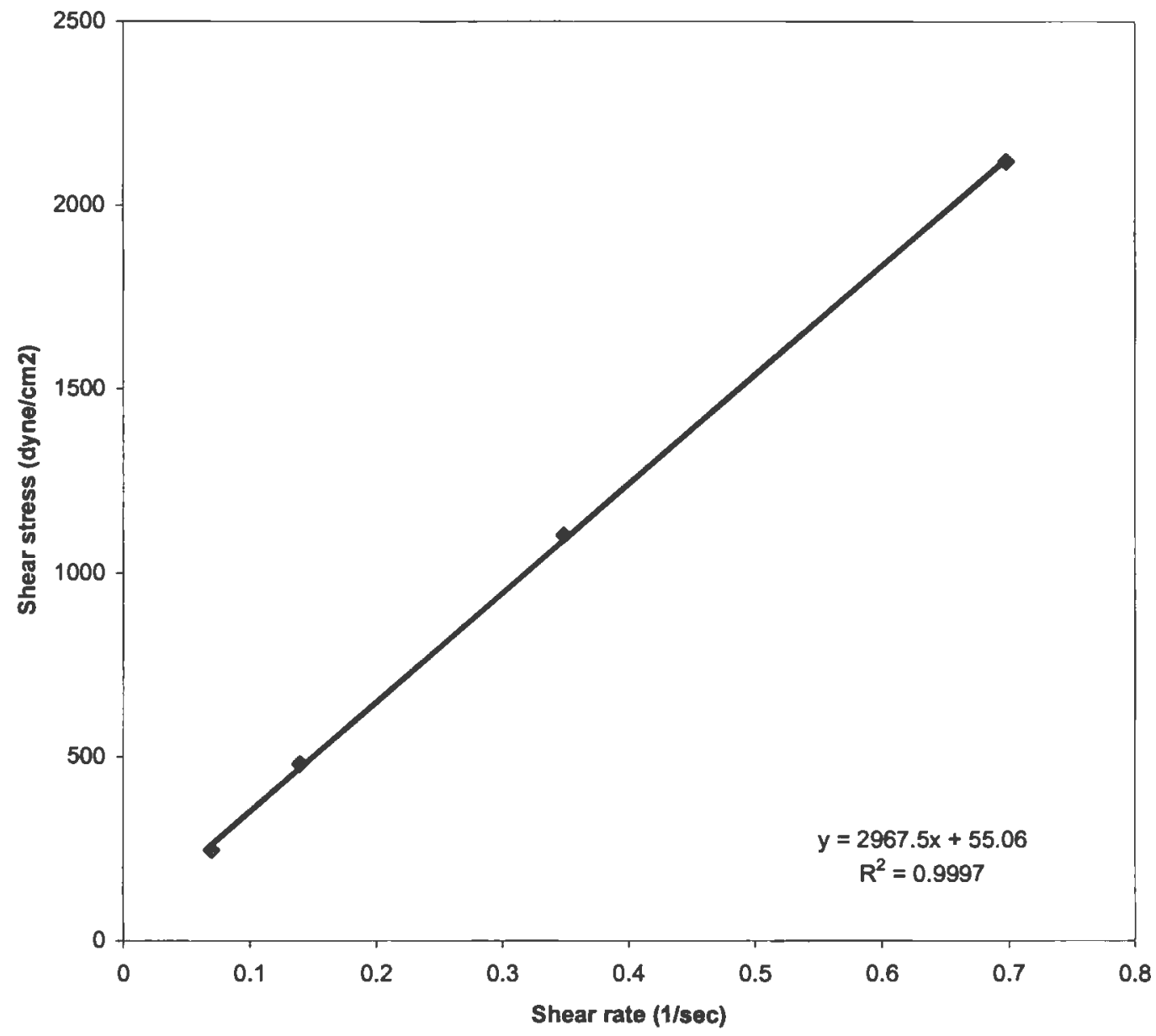

FIGURE 72. RHEOGRAM FOR LECITHIN:IPM $(60: 40)$ CONTAINING $0.1 \%$ WATER AND $6.5 \%$ KT BY CYLINDRICAL VISCOMETER 


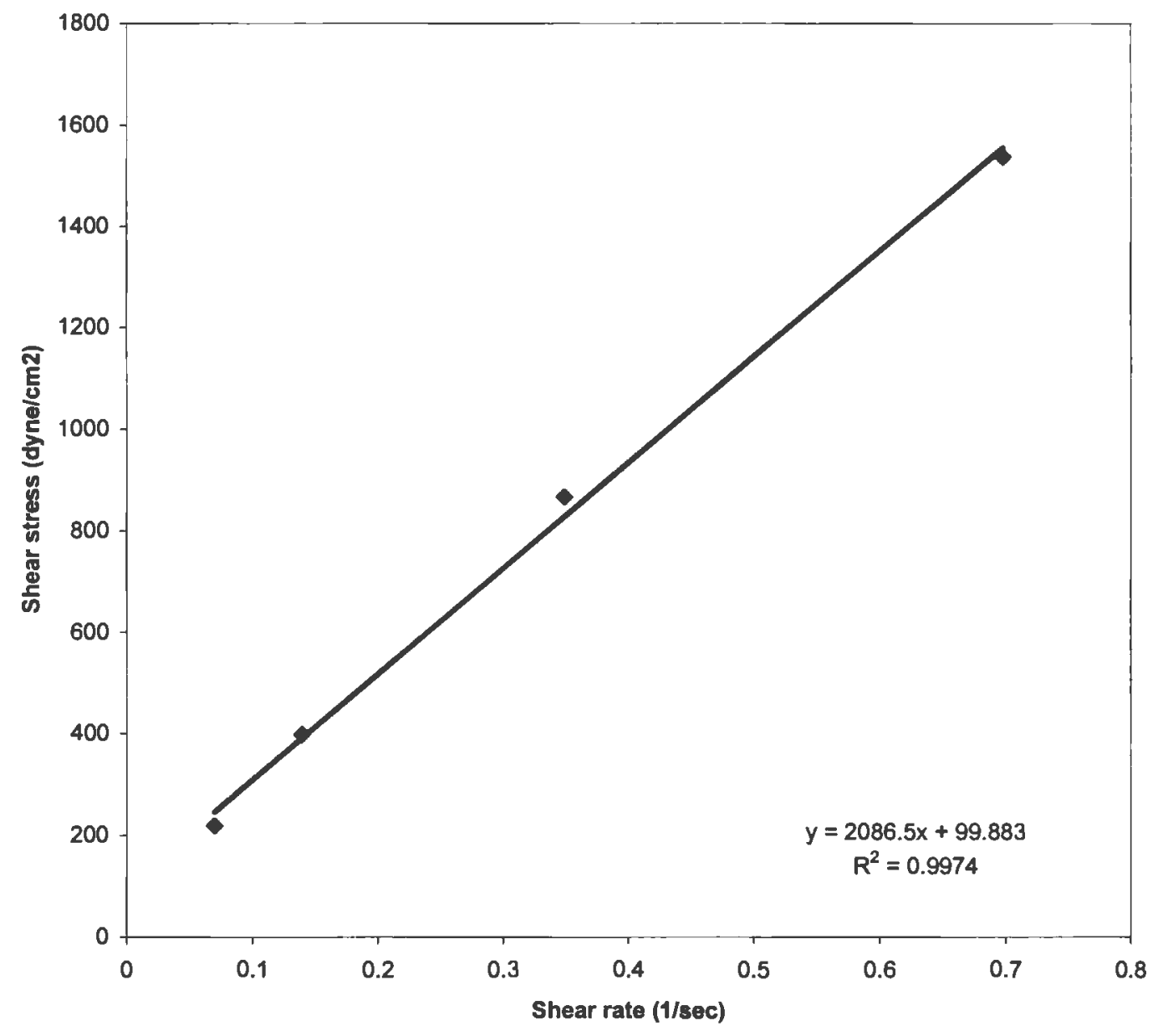

FIGURE 73. RHEOGRAM FOR LECITHIN:IPM (60:40) CONTAINING $0.25 \%$ WATER AND $6.5 \%$ KT BY CYLINDRICAL VISCOMETER 
TABLE 59. VISCOSITY OF LECITHIN:IPM (40:60) CONTAINING $0.1 \%$ WATER AND $6.5 \%$ KT BY CONE AND PLATE VISCOMETER

\begin{tabular}{|c|c|c|c|c|}
\hline RPM & Torque (\%) & Sh Str (N/m2) & Sh Rt (1/Sec) & Viscosity (mPas) \\
\hline & & & & \\
\hline 0.1 & 0.4 & 6.29 & 0.2 & 31456 \\
\hline 0.6 & 3.6 & 56.6 & 1.2 & 47184 \\
\hline 1.1 & 7.2 & 113.2 & 2.2 & 51473 \\
\hline 1.6 & 10.8 & 169.9 & 3.2 & 53082 \\
\hline 2.1 & 14.6 & 229.6 & 4.2 & 54674 \\
\hline 2.6 & 18.1 & 284.7 & 5.2 & 54746 \\
\hline 3.1 & 21.7 & 341.3 & 6.2 & 55048 \\
\hline 3.6 & 25.4 & 399.5 & 7.2 & 55485 \\
\hline 4.1 & 29 & 456.1 & 8.2 & 55623 \\
\hline 4.6 & 32.9 & 517.5 & 9.2 & 56245 \\
\hline 5.1 & 36.6 & 575.6 & 10.2 & 56436 \\
\hline 5.6 & 40.6 & 638.6 & 11.2 & 57014 \\
\hline 6.1 & 44.2 & 695.2 & 12.2 & 56982 \\
\hline 6.6 & 47.8 & 751.8 & 13.2 & 56954 \\
\hline 7.1 & 51.7 & 813.1 & 14.2 & 57263 \\
\hline 7.6 & 55.8 & 877.6 & 15.2 & 57738 \\
\hline 8.1 & 59.3 & 932.7 & 16.2 & 57572 \\
\hline 8.6 & 62.9 & 989.3 & 17.2 & 57517 \\
\hline 9.1 & 66.8 & 1051 & 18.2 & 57727 \\
\hline 9.6 & 70.8 & 1114 & 19.2 & 57997 \\
\hline 10 & 73.6 & 1158 & 20 & 57879 \\
\hline
\end{tabular}




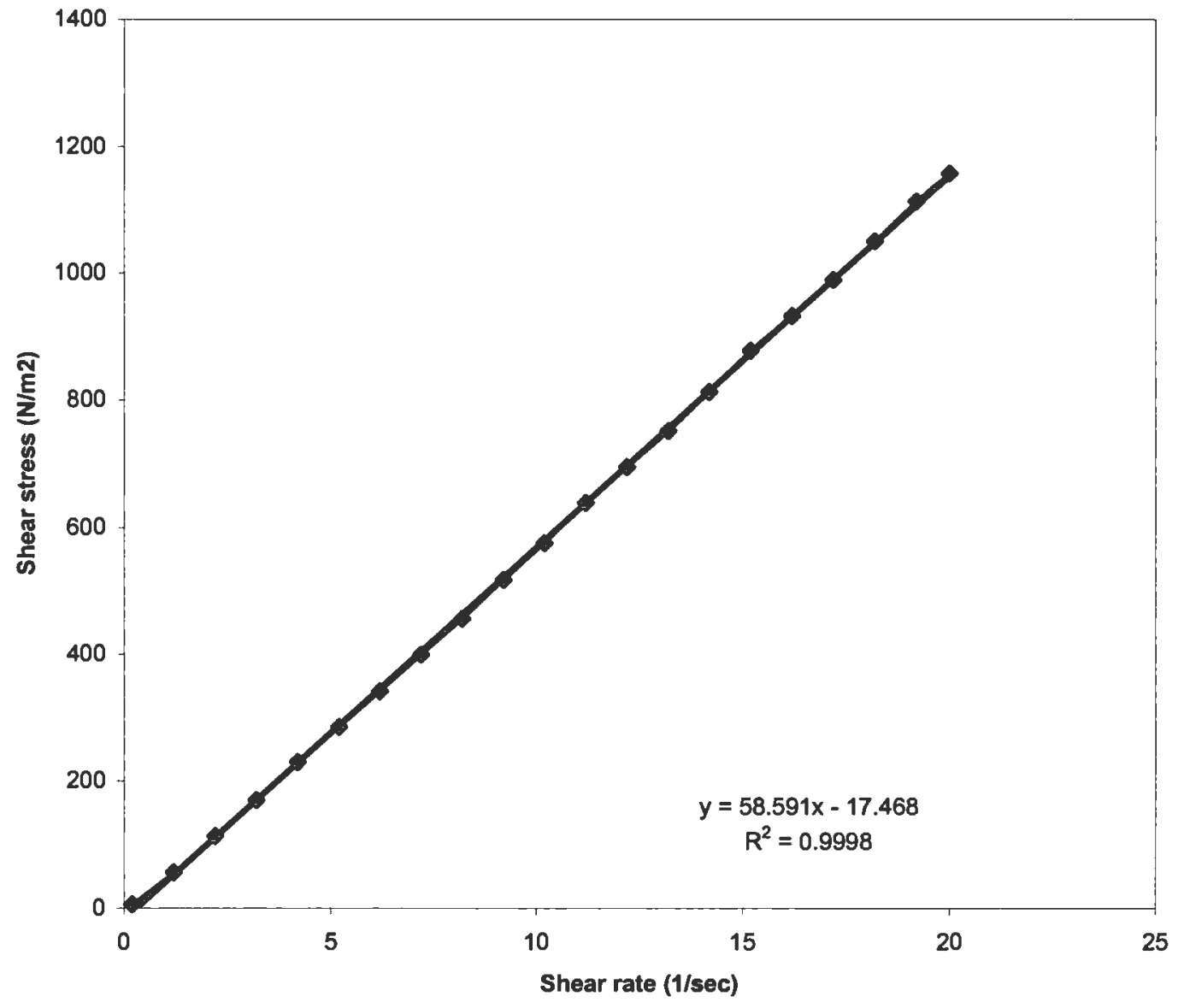

FIGURE 74. RHEOGRAM FOR LECITHIN:IPM (40:60) CONTAINING $0.1 \%$ WATER AND $6.5 \% \mathrm{KT}$ BY CONE AND PLATE VISCOMETER 
TABLE 60 . VISCOSITY OF LECITHIN:IPM (40:60) CONTAINING $0.25 \%$ WATER AND 6.5\% KT BY CONE AND PLATE VISCOMETER

\begin{tabular}{|c|c|c|c|c|}
\hline RPM & Torque (\%) & Sh Str (N/m2) & Sh Rt (1/Sec) & Viscosity (mPas) \\
\hline & & & & \\
\hline 0.1 & 0.6 & 9.44 & 0.2 & 47184 \\
\hline 0.6 & 4.2 & 66.1 & 1.2 & 55048 \\
\hline 1.1 & 8.9 & 140 & 2.2 & 63627 \\
\hline 1.6 & 13.7 & 215.5 & 3.2 & 67336 \\
\hline 2.1 & 18.5 & 291 & 4.2 & 69278 \\
\hline 2.6 & 23.3 & 366.5 & 5.2 & 70474 \\
\hline 3.1 & 28.2 & 443.5 & 6.2 & 71537 \\
\hline 3.6 & 33 & 519 & 7.2 & 72087 \\
\hline 4.1 & 37.5 & 589.8 & 8.2 & 71927 \\
\hline 4.6 & 42.5 & 668.4 & 9.2 & 72657 \\
\hline 5.1 & 47.5 & 747.1 & 10.2 & 73243 \\
\hline 5.6 & 51.9 & 816.3 & 11.2 & 72882 \\
\hline 6.1 & 56.6 & 890.2 & 12.2 & 72968 \\
\hline 6.6 & 61.6 & 968.8 & 13.2 & 73397 \\
\hline 7.1 & 66.8 & 1051 & 14.2 & 73988 \\
\hline 7.6 & 71.1 & 1118 & 15.2 & 73570 \\
\hline 8.1 & 75.6 & 1189 & 16.2 & 73397 \\
\hline 8.6 & 80.6 & 1268 & 17.2 & 73702 \\
\hline 9.1 & 85.3 & 1342 & 18.2 & 73714 \\
\hline 9.6 & 90.1 & 1417 & 19.2 & 73807 \\
\hline 10 & 94.1 & 1480 & 20 & 74000 \\
\hline
\end{tabular}




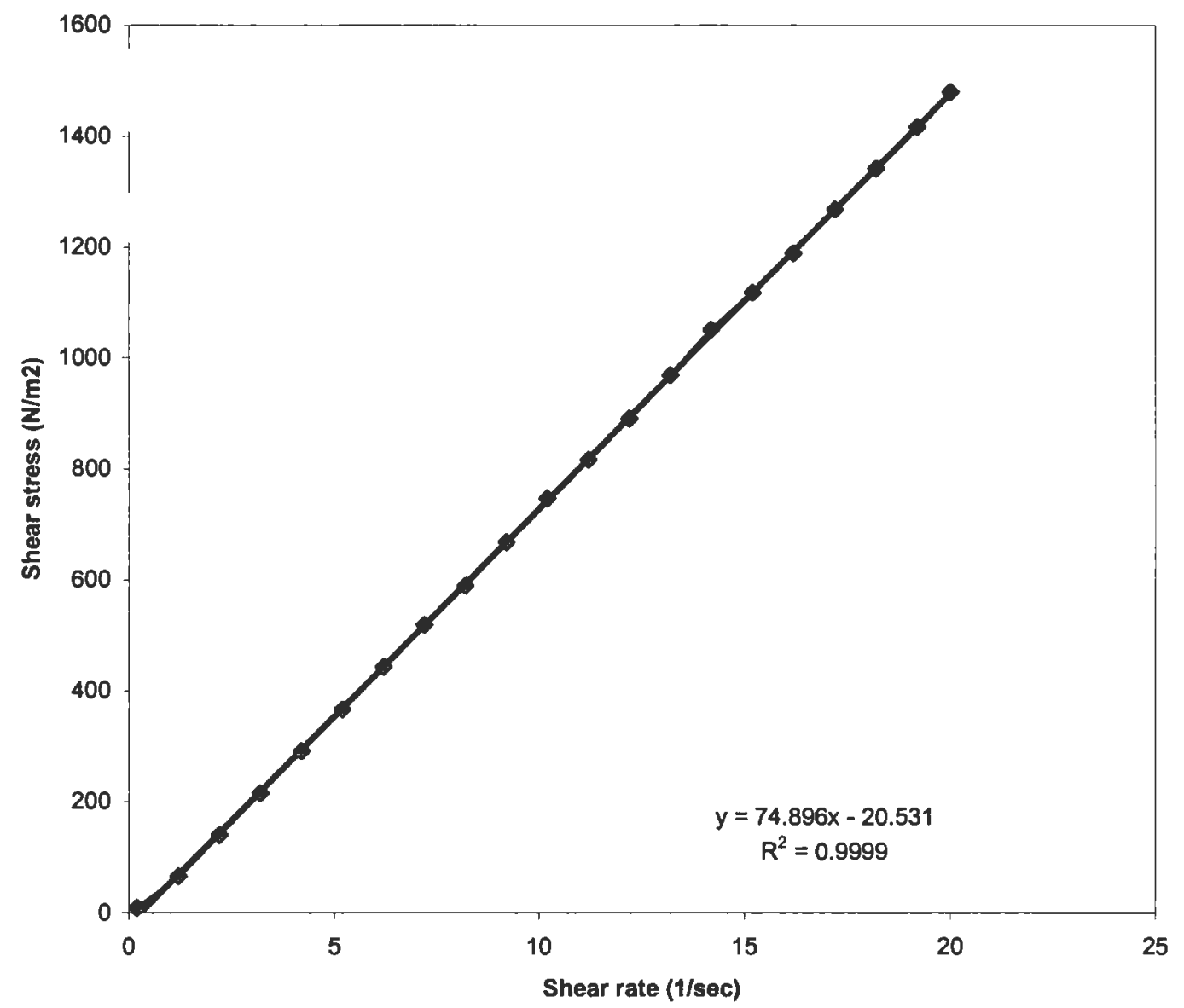

FIGURE 75. RHEOGRAM FOR LECITHIN:IPM (40:60) CONTAINING $0.25 \%$ WATER AND $6.5 \%$ KT BY CONE AND PLATE VISCOMETER 
TABLE 61. VISCOSITY OF LECITHIN:IPM (40:60) CONTAINING $0.5 \%$ WATER AND 6.5\% KT BY CONE AND PLATE VISOMETER

\begin{tabular}{|c|c|c|c|c|}
\hline RPM & Torque (\%) & Sh Str (N/m2) & Sh Rt (1/Sec) & Viscosity (mPas) \\
\hline & & & & \\
\hline 0.1 & 0.5 & 7.86 & 0.2 & 39320 \\
\hline 0.6 & 3.7 & 58.2 & 1.2 & 48495 \\
\hline 1.1 & 6.8 & 107 & 2.2 & 48614 \\
\hline 1.6 & 10.5 & 165.1 & 3.2 & 51608 \\
\hline 2.1 & 14.7 & 231.2 & 4.2 & 55048 \\
\hline 2.6 & 18.4 & 289.4 & 5.2 & 55653 \\
\hline 3.1 & 22.1 & 347.6 & 6.2 & 56063 \\
\hline 3.6 & 25.6 & 402.6 & 7.2 & 55922 \\
\hline 4.1 & 29.4 & 462.4 & 8.2 & 56391 \\
\hline 4.6 & 33.2 & 522.2 & 9.2 & 56758 \\
\hline 5.1 & 36.8 & 578.8 & 10.2 & 56744 \\
\hline 5.6 & 40.9 & 643.3 & 11.2 & 57435 \\
\hline 6.1 & 44.7 & 703 & 12.2 & 57626 \\
\hline 6.6 & 48.7 & 766 & 13.2 & 58027 \\
\hline 7.1 & 52.6 & 827.3 & 14.2 & 58260 \\
\hline 7.6 & 56 & 880.8 & 15.2 & 57945 \\
\hline 8.1 & 59.9 & 942.1 & 16.2 & 58155 \\
\hline 8.6 & 63.7 & 1002 & 17.2 & 58248 \\
\hline 9.1 & 67.5 & 1062 & 18.2 & 58332 \\
\hline 9.6 & 70.9 & 1115 & 19.2 & 58079 \\
\hline 10 & 74.4 & 1170 & 20 & 58508 \\
\hline
\end{tabular}




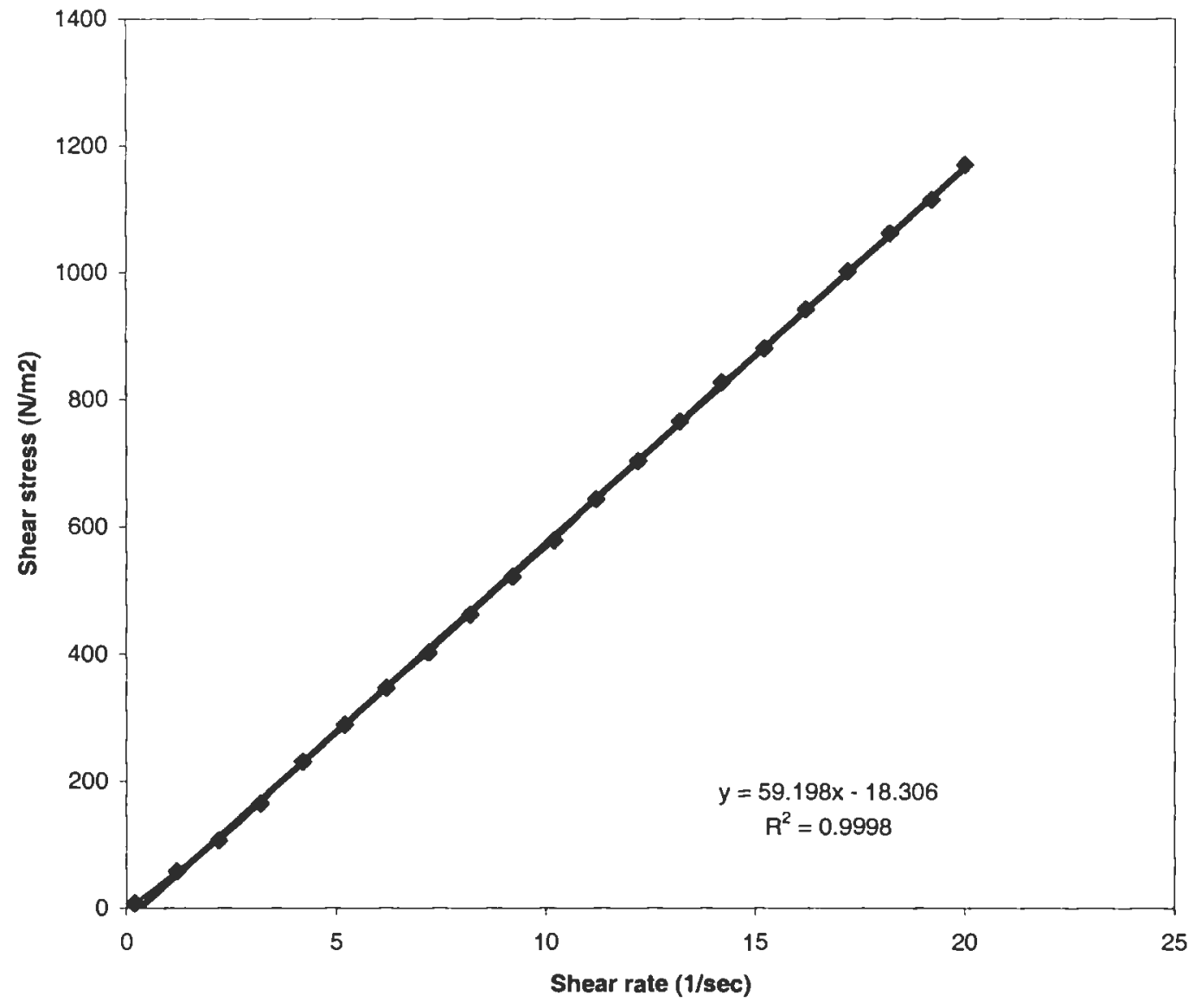

FIGURE 76. RHEOGRAM FOR LECITHIN:IPM (40:60) CONTAINING 0.5\% WATER AND 6.5\% KT BY CONE AND PLATE VISCOMETER 
TABLE 62. VISCOSITY OF LECITHIN:IPM (40:60) CONTAINING $0.6 \%$ WATER AND $6.5 \%$ KT BY CONE AND PLATE VISCOMETER

\begin{tabular}{|c|c|c|c|c|}
\hline RPM & Torque (\%) & Sh Str (N/m2) & Sh Rt (1/Sec) & Viscosity (mPas) \\
\hline & & & & \\
\hline 0.1 & 0.5 & 7.86 & 0.2 & 39320 \\
\hline 0.6 & 3.4 & 53.5 & 1.2 & 44563 \\
\hline 1.1 & 6.3 & 99.1 & 2.2 & 45039 \\
\hline 1.6 & 9.9 & 155.7 & 3.2 & 48658 \\
\hline 2.1 & 13.8 & 217 & 4.2 & 51678 \\
\hline 2.6 & 17.2 & 271.5 & 5.2 & 52023 \\
\hline 3.1 & 20.6 & 324 & 6.2 & 52258 \\
\hline 3.6 & 24 & 377.5 & 7.2 & 52427 \\
\hline 4.1 & 27.4 & 430.9 & 8.2 & 52555 \\
\hline 4.6 & 30.7 & 482.8 & 9.2 & 53484 \\
\hline 5.1 & 34.3 & 539.5 & 10.2 & 52889 \\
\hline 5.6 & 37.3 & 592.9 & 11.2 & 52942 \\
\hline 6.1 & 41.4 & 651.1 & 12.2 & 53372 \\
\hline 6.6 & 44.7 & 703 & 13.2 & 53261 \\
\hline 7.1 & 48.2 & 758.1 & 14.2 & 53387 \\
\hline 7.6 & 51.6 & 811.6 & 15.2 & 53392 \\
\hline 8.1 & 55.1 & 866.6 & 16.2 & 53495 \\
\hline 8.6 & 58.5 & 920.1 & 17.2 & 53493 \\
\hline 9.1 & 61.9 & 973.6 & 18.2 & 53492 \\
\hline 9.6 & 65.3 & 1027 & 19.2 & 53492 \\
\hline 10 & 68.1 & 1071 & 20 & 53554 \\
\hline
\end{tabular}




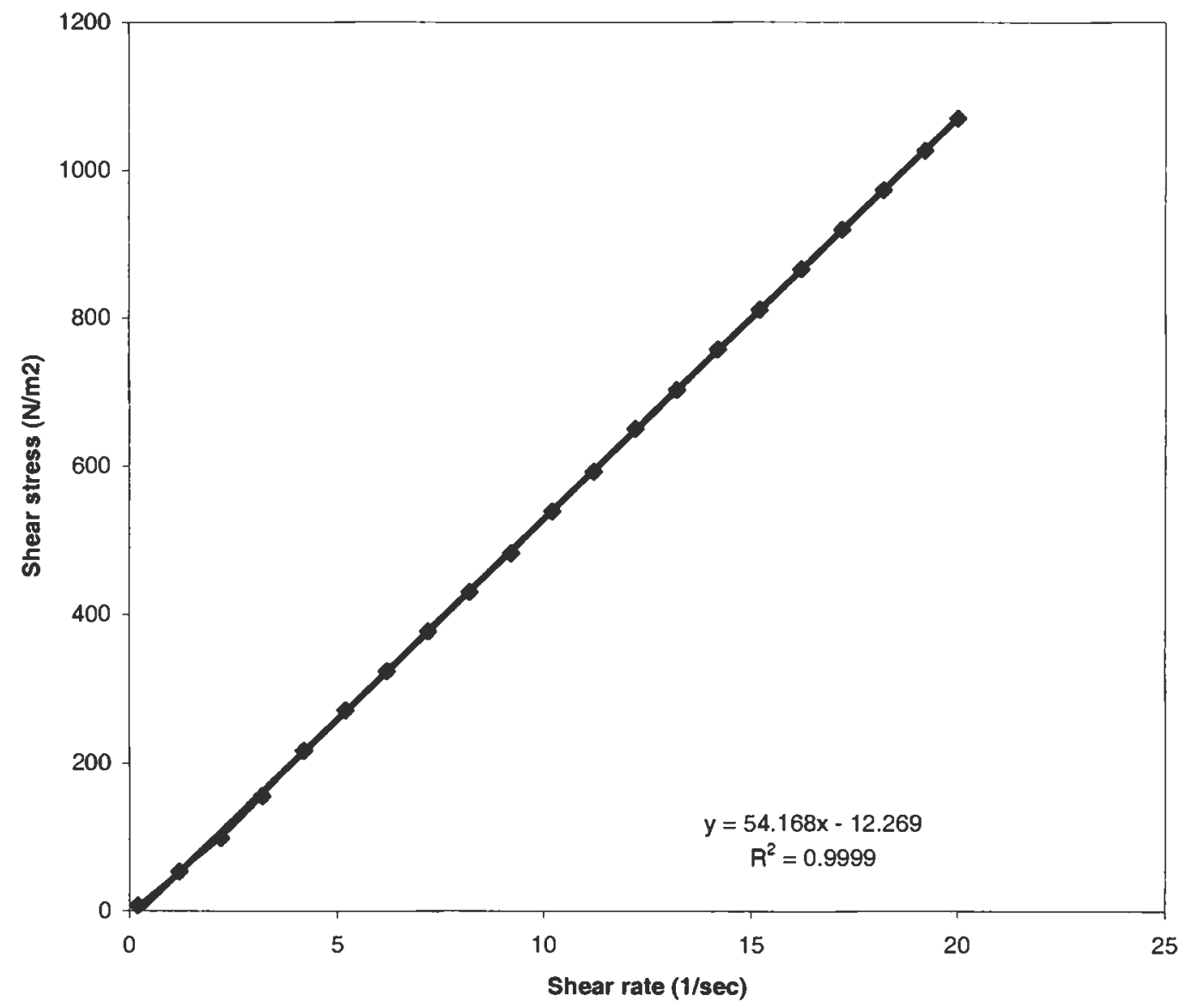

FIGURE 77. RHEOGRAM FOR LECITHIN:IPM (40:60) CONTAINING 0.6\% WATER AND 6.5\% KT BY CONE AND PLATE VISCOMETER 
TABLE 63. VISCOSITY OF LECIHTIN:IPM (40:60) CONTAINING $0.7 \%$ WATER AND $6.5 \%$ KT BY CONE AND PLATE VISCOMETER

\begin{tabular}{|c|c|c|c|c|}
\hline RPM & Torque (\%) & Sh Str (N/m2) & Sh Rt (1/Sec) & Viscosity (mPas) \\
\hline & & & & \\
\hline 0.1 & 0.6 & 9.44 & 0.2 & 47184 \\
\hline 0.6 & 3.5 & 55 & 1.2 & 45873 \\
\hline 1.1 & 7 & 110.1 & 2.2 & 50044 \\
\hline 1.6 & 10.4 & 163.6 & 3.2 & 51116 \\
\hline 2.1 & 14.1 & 221.8 & 4.2 & 52801 \\
\hline 2.6 & 17.6 & 276.8 & 5.2 & 53233 \\
\hline 3.1 & 21 & 330.3 & 6.2 & 53272 \\
\hline 3.6 & 24.5 & 385.3 & 7.2 & 53519 \\
\hline 4.1 & 28.1 & 442 & 8.2 & 53897 \\
\hline 4.6 & 31.5 & 495.4 & 9.2 & 53851 \\
\hline 5.1 & 34.9 & 548.9 & 10.2 & 53814 \\
\hline 5.6 & 38 & 597.7 & 11.2 & 53363 \\
\hline 6.1 & 41.4 & 651.1 & 12.2 & 53372 \\
\hline 6.6 & 45.2 & 710.9 & 13.2 & 53856 \\
\hline 7.1 & 48.4 & 761.2 & 14.2 & 53608 \\
\hline 7.6 & 51.9 & 816.3 & 15.2 & 53703 \\
\hline 8.1 & 14.9 & 863.5 & 16.2 & 53300 \\
\hline 8.6 & 58.4 & 918.5 & 17.2 & 53402 \\
\hline 9.1 & 62 & 975.1 & 18.2 & 53579 \\
\hline 9.6 & 64.8 & 1019 & 19.2 & 53082 \\
\hline 10 & 67.8 & 1066 & 20 & 53318 \\
\hline
\end{tabular}




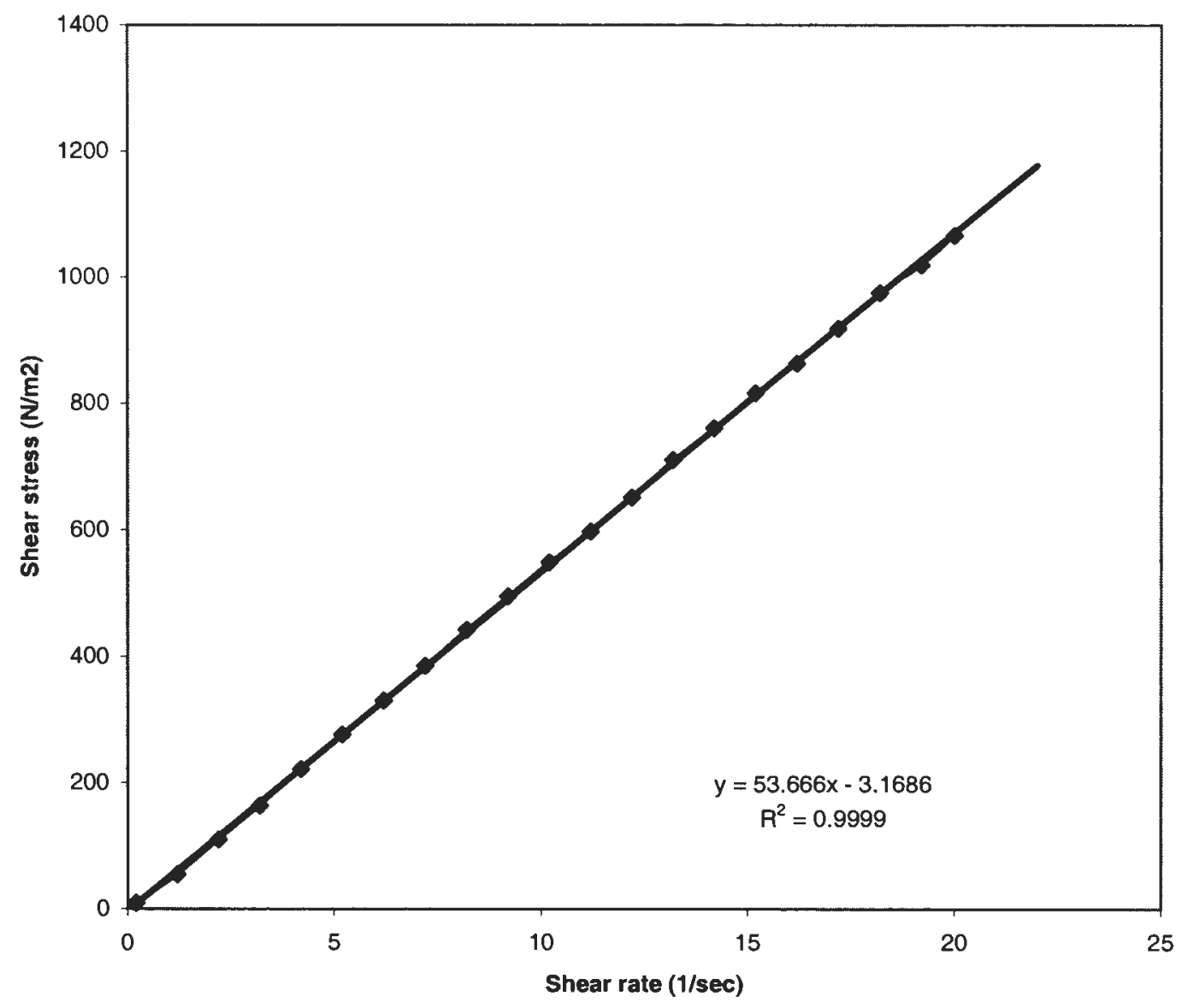

FIGURE 78. RHEOGRAM FOR LECITHIN:IPM (40:60) CONTAINING 0.7\% WATER AND 6.5\% KT BY CONE AND PLATE VISCOMETER 
TABLE 64. VISCOSITY OF LECITHIN:IPM (40:60) CONTAINING $0.8 \%$ WATER AND 6.5\% KT BY CONE AND PLATE VISCOMETER

\begin{tabular}{|c|c|c|c|c|}
\hline RPM & Torque (\%) & Sh Str (N/m2) & Sh Rt (1/Sec) & Viscosity (mPas) \\
\hline & & & & \\
\hline 0.1 & 0.4 & 6.29 & 0.2 & 31456 \\
\hline 0.6 & 2.9 & 45.6 & 1.2 & 38009 \\
\hline 1.1 & 5.8 & 91.2 & 2.2 & 41465 \\
\hline 1.6 & 8.5 & 133.7 & 3.2 & 41778 \\
\hline 2.1 & 11.3 & 177.7 & 4.2 & 42316 \\
\hline 2.6 & 14.1 & 221.8 & 5.2 & 42647 \\
\hline 3.1 & 16.9 & 265.8 & 6.2 & 42871 \\
\hline 3.6 & 19.6 & 308.3 & 7.2 & 42815 \\
\hline 4.1 & 22.3 & 350.7 & 8.2 & 42772 \\
\hline 4.6 & 25 & 393.2 & 9.2 & 42739 \\
\hline 5.1 & 27.9 & 438.8 & 10.2 & 43021 \\
\hline 5.6 & 30.5 & 479.7 & 11.2 & 42831 \\
\hline 6.1 & 33.3 & 523.7 & 12.2 & 42930 \\
\hline 6.6 & 36.2 & 569.4 & 13.2 & 43133 \\
\hline 7.1 & 39.3 & 618.1 & 14.2 & 43529 \\
\hline 7.6 & 42.6 & 670 & 15.2 & 44080 \\
\hline 8.1 & 45.7 & 718.8 & 16.2 & 44368 \\
\hline 8.6 & 48.4 & 761.2 & 17.2 & 44258 \\
\hline 9.1 & 51.6 & 811.6 & 18.2 & 44591 \\
\hline 9.6 & 54.5 & 857.2 & 19.2 & 44645 \\
\hline 10 & 57 & 896.5 & 20 & 44825 \\
\hline
\end{tabular}




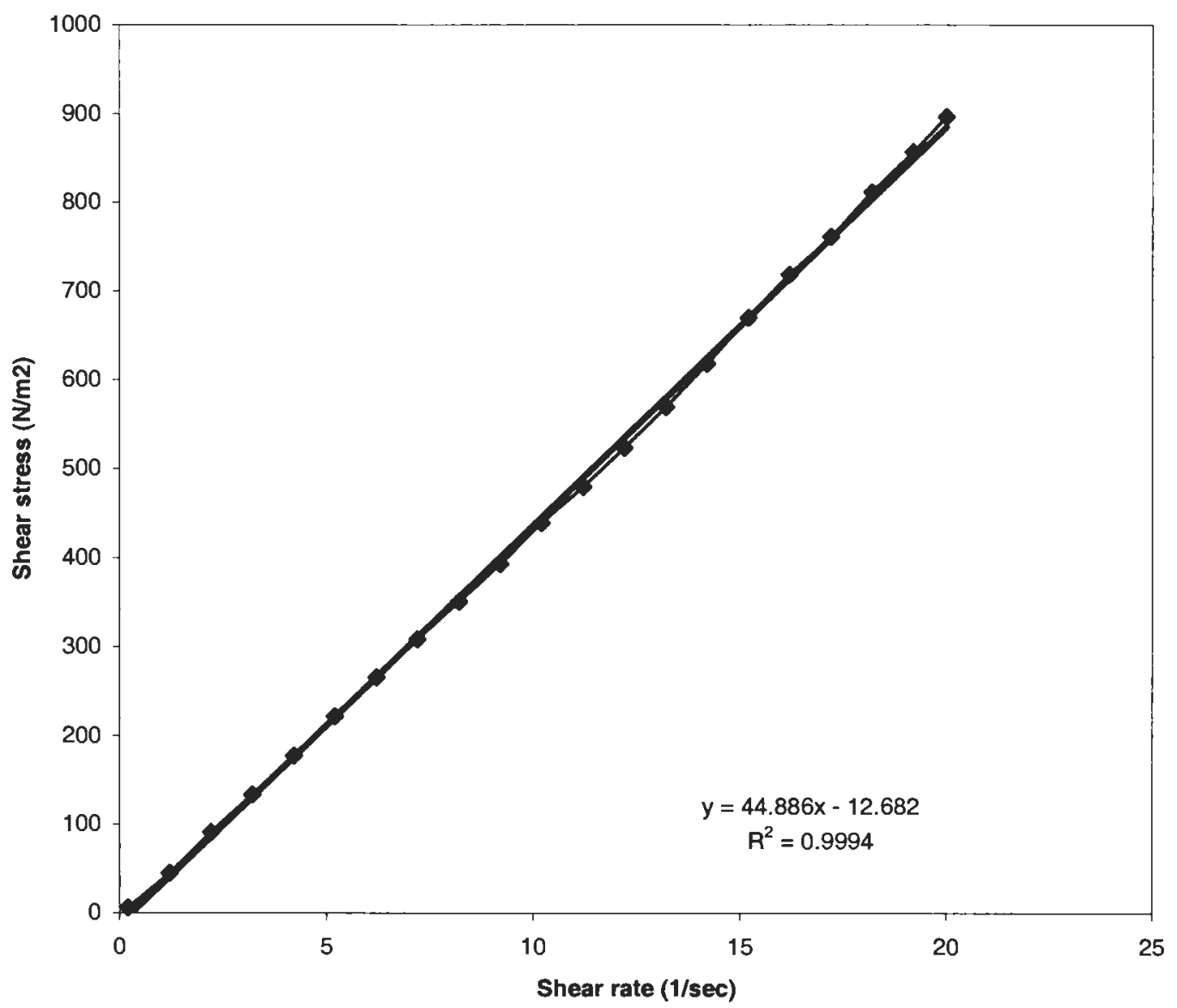

FIGURE 79. RHEOGRAM FOR LECITHIN:IPM (40:60) CONTAINING 0.8\% WATER AND 6.5\% KT BY CONE AND PLATE VISCOMETER 
TABLE 65. VISCOSITY OF LECITHIN:IPM (50:50) CONTAINING $0.1 \%$ WATER AND $6.5 \%$ KT BY CONE AND PLATE VISCOMETER

\begin{tabular}{|c|c|c|c|c|}
\hline RPM & Torque (\%) & Sh Str (N/m2) & Sh Rt (1/Sec) & Viscosity (mPas) \\
\hline & & & & \\
\hline 0.1 & 0.5 & 7.86 & 0.2 & 39320 \\
\hline 0.6 & 4.4 & 69.2 & 1.2 & 57669 \\
\hline 1.1 & 9.3 & 146.3 & 2.2 & 66487 \\
\hline 1.6 & 14.3 & 224.9 & 3.2 & 70285 \\
\hline 2.1 & 19.9 & 313 & 4.2 & 74521 \\
\hline 2.6 & 25.3 & 397.9 & 5.2 & 76523 \\
\hline 3.1 & 30.6 & 481.3 & 6.2 & 77625 \\
\hline 3.6 & 35.9 & 564.6 & 7.2 & 78422 \\
\hline 4.1 & 40.8 & 641.7 & 8.2 & 78256 \\
\hline 4.6 & 46.5 & 731.4 & 9.2 & 79495 \\
\hline 5.1 & 52.2 & 821 & 10.2 & 80490 \\
\hline 5.6 & 57.6 & 905.9 & 11.2 & 80887 \\
\hline 6.1 & 63.2 & 994 & 12.2 & 81476 \\
\hline 6.6 & 69.1 & 1087 & 13.2 & 82334 \\
\hline 7.1 & 74.9 & 1178 & 14.2 & 82960 \\
\hline 7.6 & 80.2 & 1261 & 15.2 & 82986 \\
\hline 8 & 85.3 & 1341 & 16 & 83850 \\
\hline
\end{tabular}




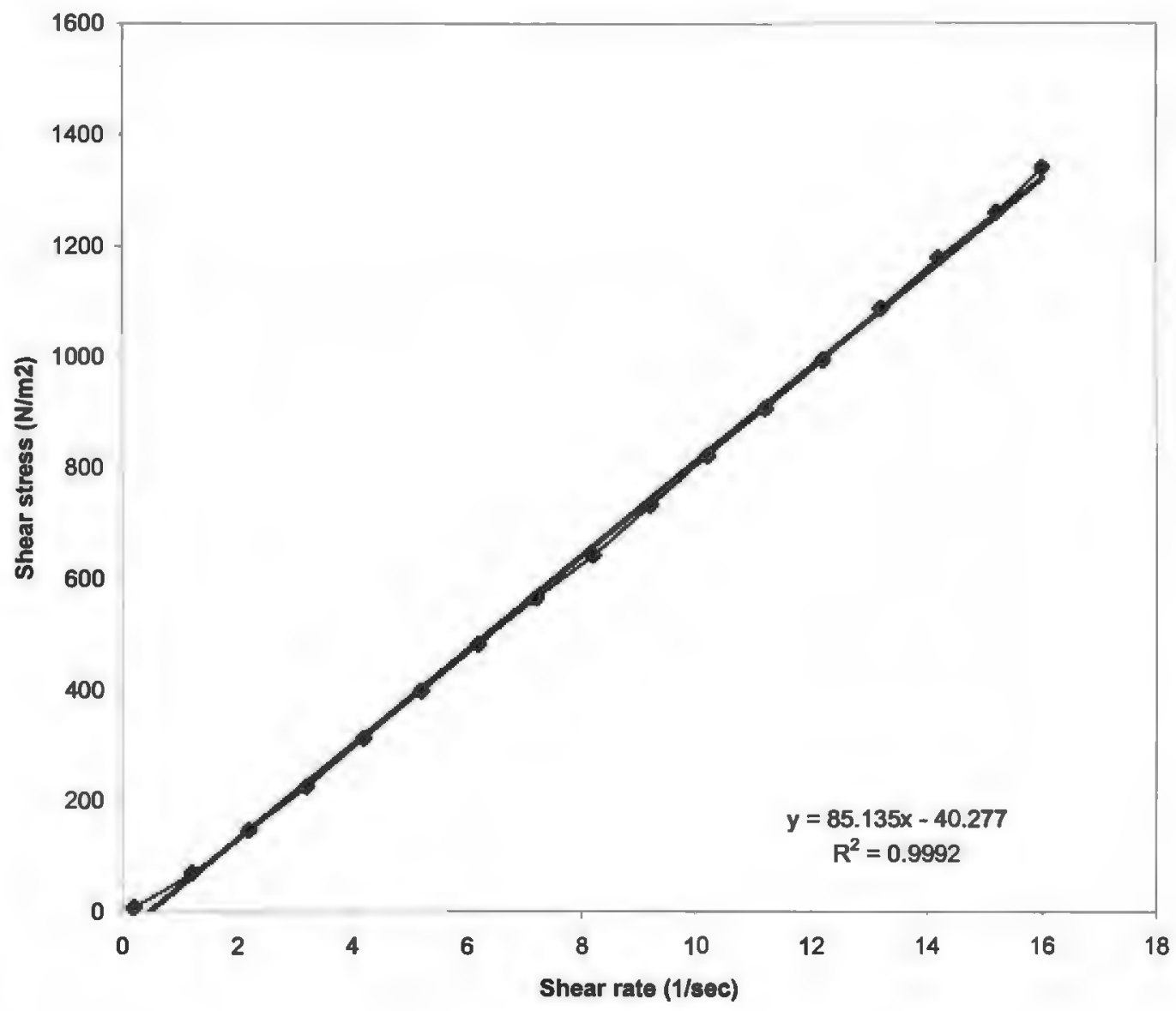

FIGURE 80. RHEOGRAM FOR LECITHIN:IPM (50:50) CONTAINING $0.1 \%$ WATER AND $6.5 \% \mathrm{KT}$ BY CONE AND PLATE VISCOMETER 
TABLE 66. VISCOSITY FOR LECITHIN:IPM (50:50) CONTAINING $0.25 \%$ WATER AND $6.5 \%$ KT BY CONE AND PLATE VISCOMETER

\begin{tabular}{|c|c|c|c|c|}
\hline RPM & Torque (\%) & Sh Str (N/m2) & Sh Rt (1/Sec) & Viscosity (mPas) \\
\hline & & & & \\
\hline 0.1 & 0.6 & 9.44 & 0.2 & 47184 \\
\hline 0.6 & 4.7 & 73.9 & 1.2 & 61601 \\
\hline 1.1 & 10.6 & 166.7 & 2.2 & 75780 \\
\hline 1.6 & 16.8 & 264.2 & 3.2 & 82572 \\
\hline 2.1 & 23 & 361.7 & 4.2 & 86130 \\
\hline 2.6 & 29.1 & 457.7 & 5.2 & 88016 \\
\hline 3.1 & 35.1 & 552.1 & 6.2 & 89041 \\
\hline 3.6 & 41.2 & 648 & 7.2 & 89999 \\
\hline 4.1 & 47.3 & 743.9 & 8.2 & 90724 \\
\hline 4.6 & 53.5 & 841.4 & 9.2 & 91462 \\
\hline 5.1 & 59.7 & 939 & 10.2 & 92055 \\
\hline 5.6 & 65.1 & 1024 & 11.2 & 91419 \\
\hline 6.1 & 71.1 & 1118 & 12.2 & 91661 \\
\hline 6.6 & 77.8 & 1224 & 13.2 & 92700 \\
\hline 7.1 & 83.2 & 1309 & 14.2 & 92153 \\
\hline 7.6 & 90.1 & 1417 & 15.2 & 93230 \\
\hline 8 & 94.1 & 1480 & 16 & 92500 \\
\hline
\end{tabular}




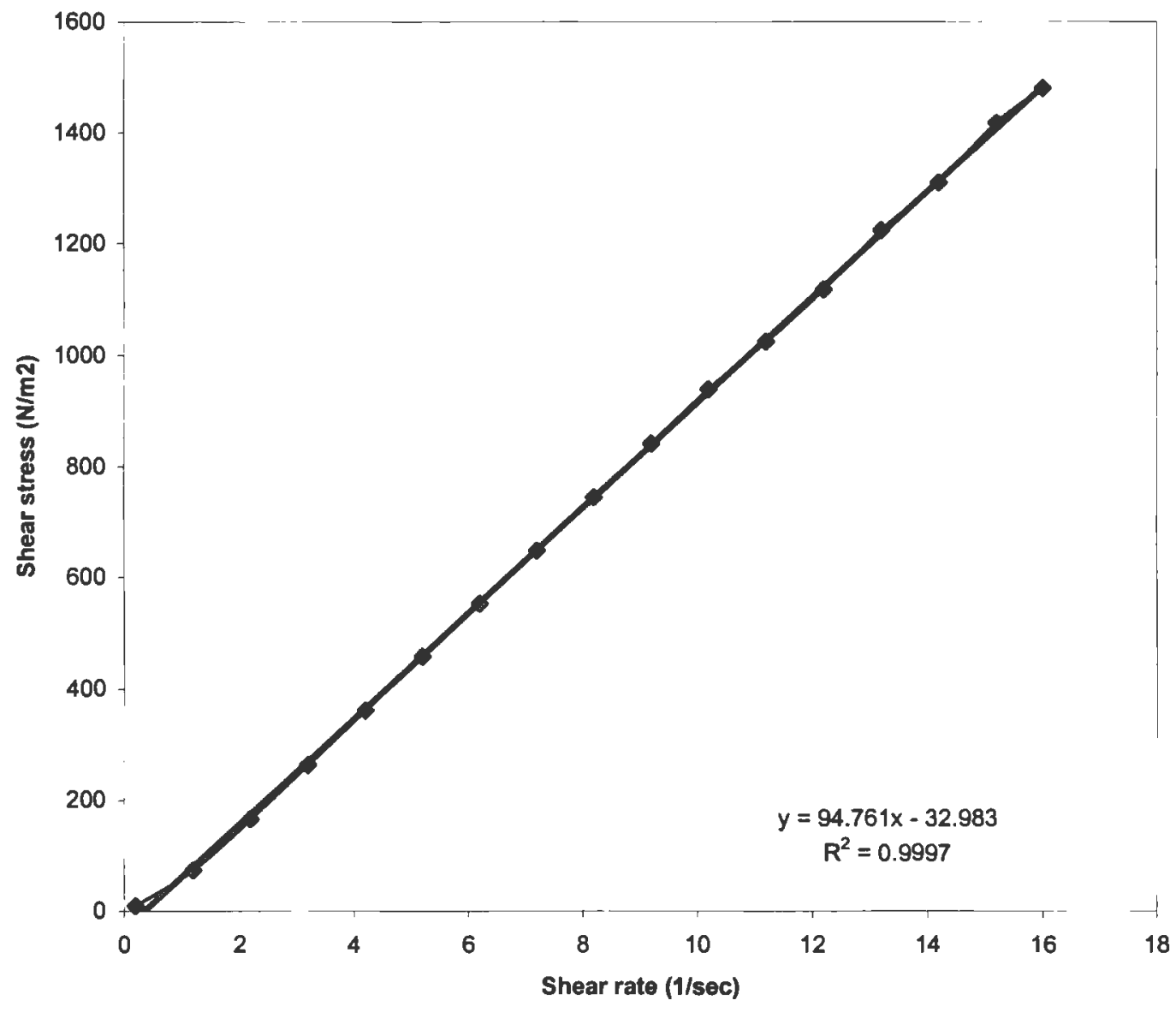

FIGURE 81. RHEOGRAM FOR LECITHIN:IPM (50:50) CONTAINING $0.25 \%$ WATER AND $6.5 \% \mathrm{KT}$ BY CONE AND PLATE VISCOMETER 
TABLE 67. VISCOSITY OF LECITHIN:IPM (50:50) CONTAINING $0.5 \%$ WATER AND $6.5 \% \mathrm{KT}$ BY CONE AND PLATE VISCOMETER

\begin{tabular}{|c|c|c|c|c|}
\hline RPM & Torque (\%) & Sh Str (N/m2) & Sh Rt (1/Sec) & Viscosity (mPas) \\
\hline & & & & \\
\hline 0.1 & 0.6 & 9.44 & 0.2 & 47184 \\
\hline 0.6 & 4.4 & 69.2 & 1.2 & 57669 \\
\hline 1.1 & 9.3 & 146.3 & 2.2 & 66487 \\
\hline 1.6 & 14 & 220.2 & 3.2 & 68810 \\
\hline 2.1 & 19.2 & 302 & 4.2 & 71899 \\
\hline 2.6 & 24.4 & 383.8 & 5.2 & 73801 \\
\hline 3.1 & 29.4 & 462.4 & 6.2 & 74581 \\
\hline 3.6 & 34.2 & 537.9 & 7.2 & 74708 \\
\hline 4.1 & 39.2 & 616.5 & 8.2 & 75188 \\
\hline 4.6 & 44.4 & 698.3 & 9.2 & 75905 \\
\hline 5.1 & 49.7 & 781.7 & 10.2 & 76635 \\
\hline 5.6 & 55.8 & 877.6 & 11.2 & 78359 \\
\hline 6.1 & 61.3 & 946.1 & 12.2 & 79027 \\
\hline 6.6 & 67.5 & 1062 & 13.2 & 80427 \\
\hline 7.1 & 73 & 1148 & 14.2 & 80855 \\
\hline 7.6 & 78.7 & 1238 & 15.2 & 81434 \\
\hline 8 & 83 & 1305 & 16 & 81589 \\
\hline
\end{tabular}




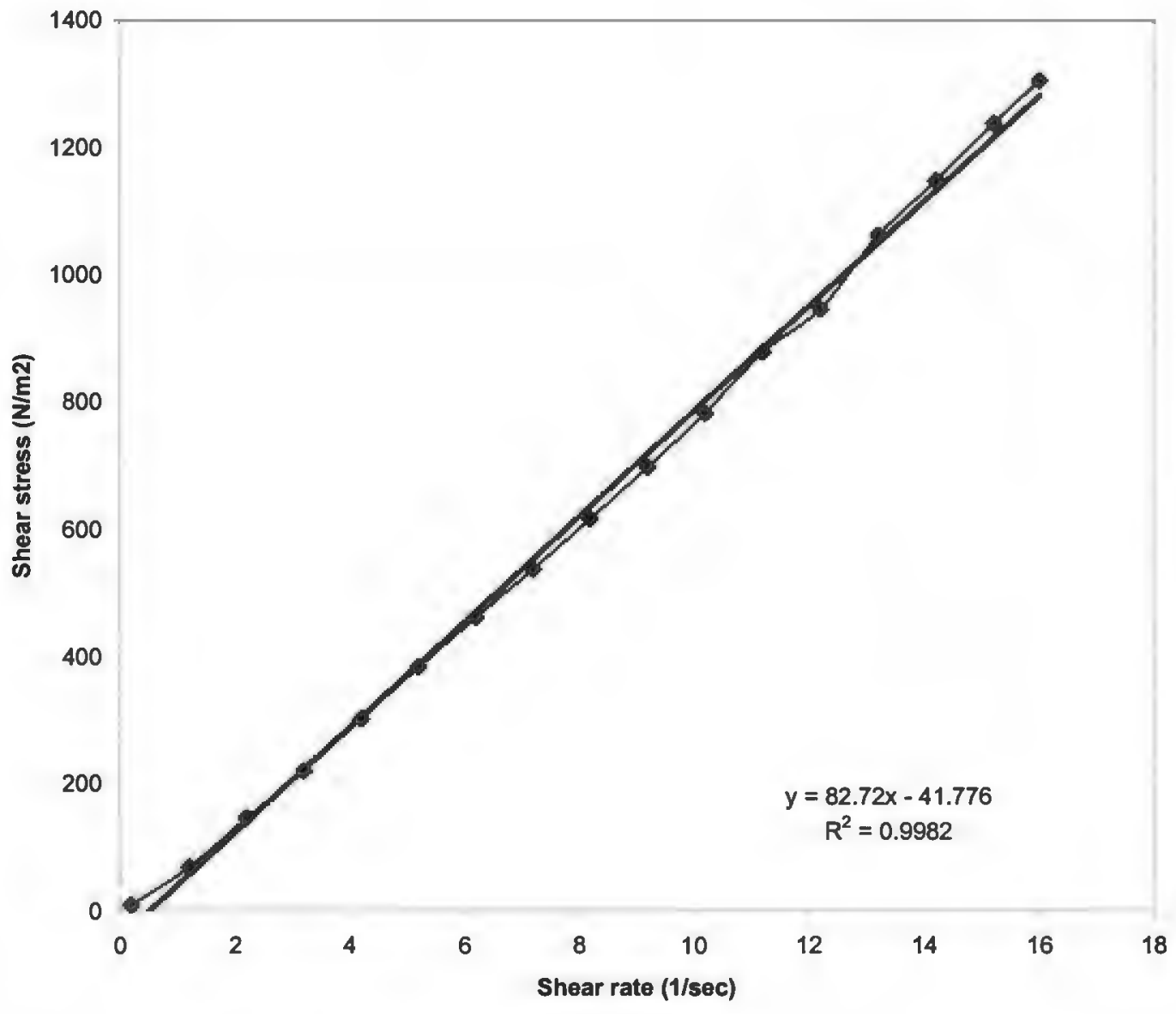

FIGURE 82. RHEOGRAM FOR LECITHIN:IPM (50:50) CONTAINING 0.5\% WATER AND 6.5\% KT BY CONE AND PLATE VISCOMETER 
TABLE 68. VISCOSITY OF LECITHIN:IPM (50:50)CONTAINING $0.6 \%$ WATER AND 6.5\% KT BY CONE AND PLATE VISCOMETER

\begin{tabular}{|c|c|c|c|c|}
\hline RPM & Torque (\%) & Sh Str (N/m2) & Sh Rt (1/Sec) & Viscosity (mPas) \\
\hline & & & & \\
\hline 0.1 & 0.4 & 6.29 & 0.2 & 31456 \\
\hline 0.6 & 3.6 & 56.6 & 1.2 & 47184 \\
\hline 1.1 & 9.4 & 147.8 & 2.2 & 67201 \\
\hline 1.6 & 14.6 & 229.6 & 3.2 & 71759 \\
\hline 2.1 & 20 & 314.6 & 4.2 & 74895 \\
\hline 2.6 & 25 & 393.2 & 5.2 & 75615 \\
\hline 3.1 & 30 & 471.8 & 6.2 & 76103 \\
\hline 3.6 & 34.6 & 544.2 & 7.2 & 75582 \\
\hline 4.1 & 40.4 & 635.4 & 8.2 & 77489 \\
\hline 4.6 & 45.8 & 720.3 & 9.2 & 78298 \\
\hline 5.1 & 51.6 & 811.6 & 10.2 & 79565 \\
\hline 5.6 & 56.9 & 894.9 & 11.2 & 79904 \\
\hline 6.1 & 63.1 & 992.4 & 12.2 & 81347 \\
\hline 6.6 & 68.9 & 1084 & 13.2 & 82095 \\
\hline 7.1 & 74.3 & 1169 & 14.2 & 82295 \\
\hline 7.6 & 79.8 & 1255 & 15.2 & 82572 \\
\hline 8 & 83.6 & 1315 & 16 & 82179 \\
\hline
\end{tabular}




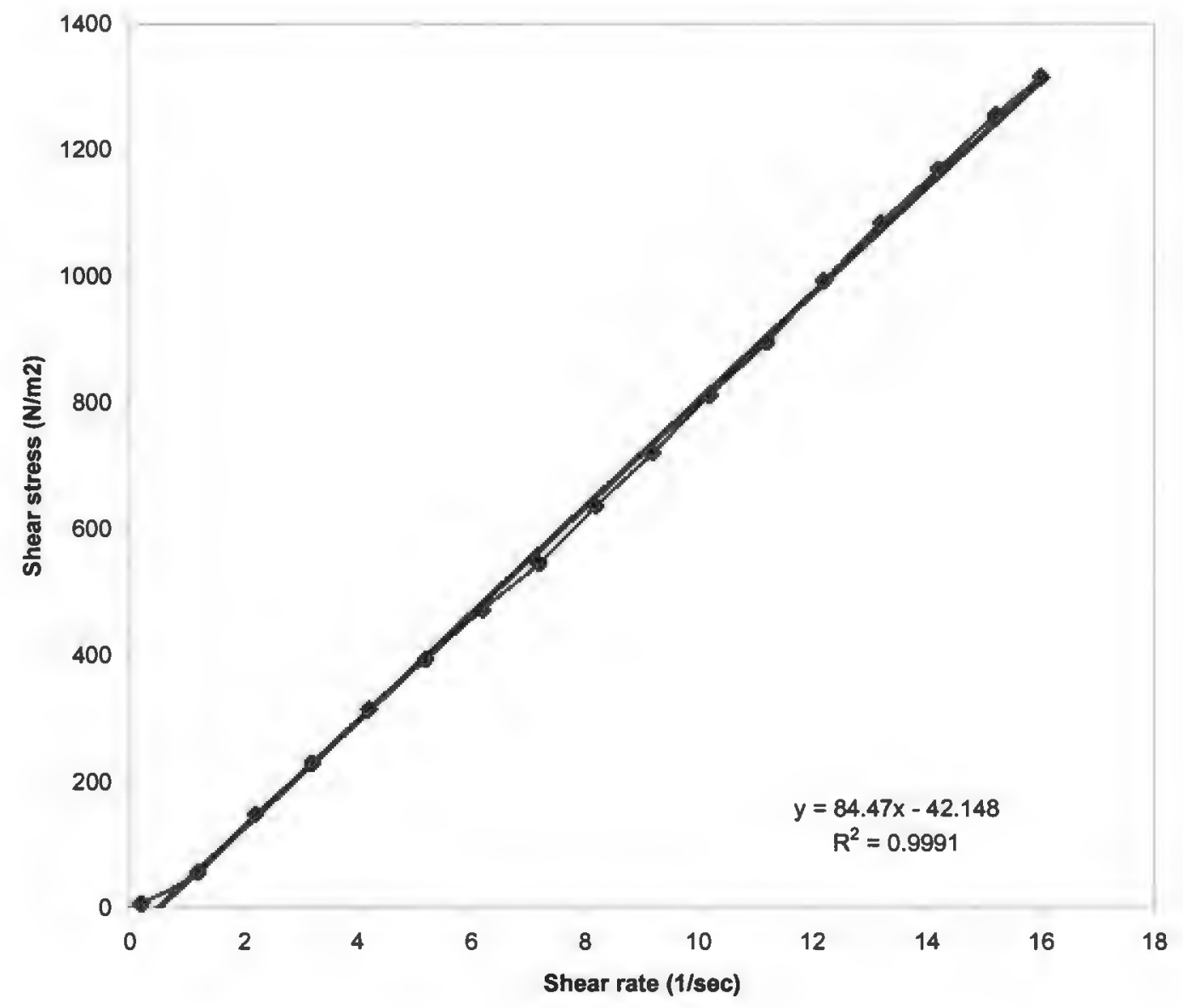

FIGURE 83. RHEOGRAM FOR LECITHIN:IPM (50:50) CONTAINING 0.6\% WATER AND $6.5 \% \mathrm{KT}$ BY CONE AND PLATE VISCOMETER 
TABLE 69. VISCOSITY OF LECITHIN:IPM (50:50) CONTAINING $0.7 \%$ WATER AND 6.5\% KT BY CONE AND PLATE VISCOMETER

\begin{tabular}{|c|c|c|c|c|}
\hline RPM & Torque (\%) & Sh Str (N/m2) & Sh Rt (1/Sec) & Viscosity (mPas) \\
\hline & & & & \\
\hline 0.1 & 0.4 & 6.29 & 0.2 & 31456 \\
\hline 0.6 & 4.7 & 73.9 & 1.2 & 61601 \\
\hline 1.1 & 10.2 & 160.4 & 2.2 & 72921 \\
\hline 1.6 & 15.8 & 248.5 & 3.2 & 77657 \\
\hline 2.1 & 22 & 364 & 4.2 & 82385 \\
\hline 2.6 & 27.5 & 432.5 & 5.2 & 83177 \\
\hline 3.1 & 33.6 & 528.5 & 6.2 & 85236 \\
\hline 3.6 & 39.1 & 615 & 7.2 & 85412 \\
\hline 4.1 & 44.9 & 706.2 & 8.2 & 86120 \\
\hline 4.6 & 50.5 & 794.3 & 9.2 & 86333 \\
\hline 5.1 & 56.4 & 887.1 & 10.2 & 86967 \\
\hline 5.6 & 62.1 & 976.7 & 11.2 & 87206 \\
\hline 6.1 & 68.1 & 1071 & 12.2 & 87793 \\
\hline 6.6 & 73.6 & 1158 & 13.2 & 87696 \\
\hline 7.1 & 79.4 & 1249 & 14.2 & 87944 \\
\hline 7.6 & 85.1 & 1338 & 15.2 & 88056 \\
\hline 8 & 90.2 & 1419 & 16 & 88667 \\
\hline
\end{tabular}




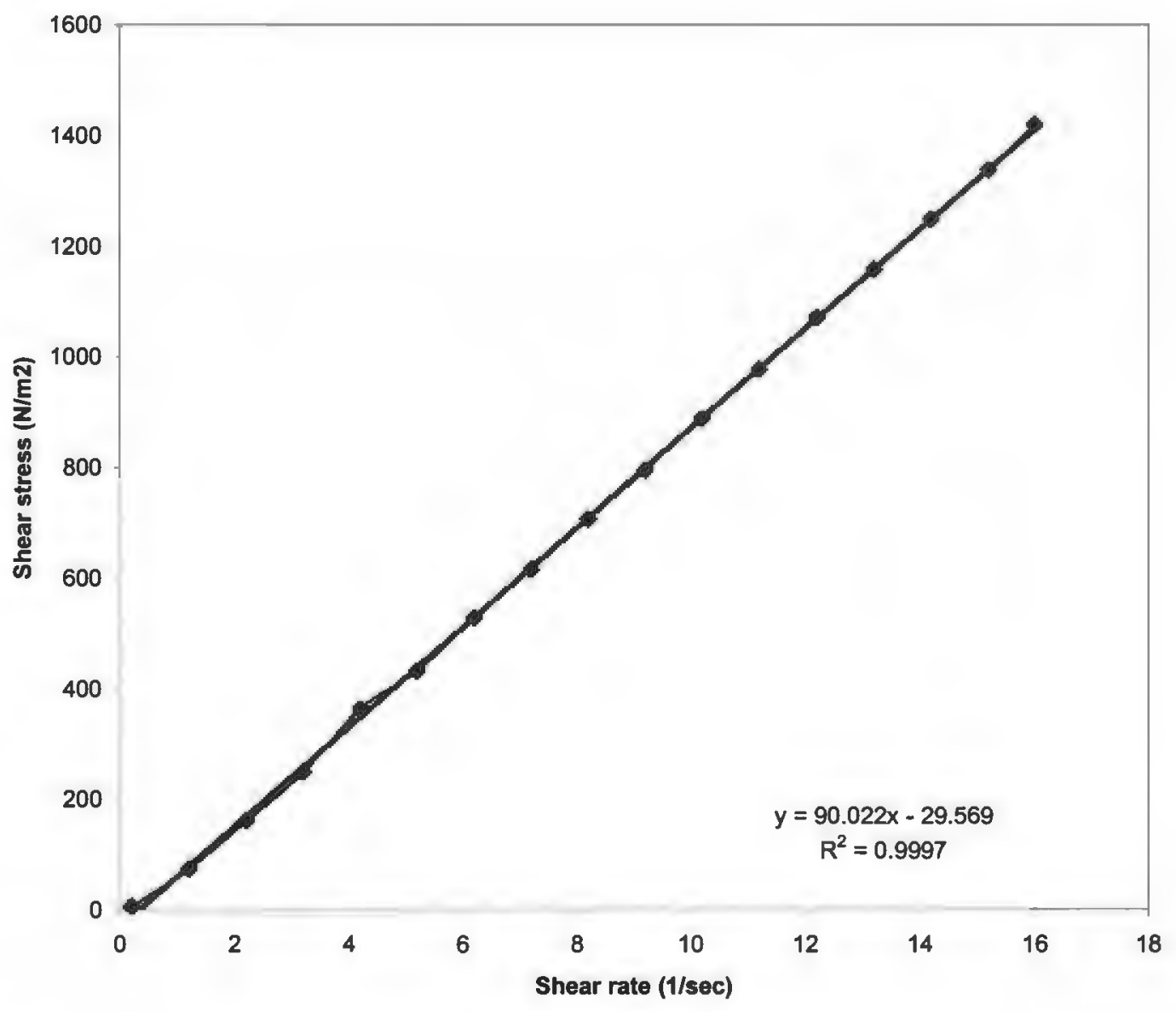

FIGURE 84. RHEOGRAM FOR LECITHIN:IPM (50:50) CONTAINING 0.7\% WATER AND 6.5\% KT BY CONE AND PLATE VISCOMETER 
TABLE 70. VISCOSITY OF LECITHIN:IPM (50:50) CONTAINING $0.8 \%$ WATER AND $6.5 \%$ KT BY CONE AND PLATE VISCOMETER

\begin{tabular}{|c|c|c|c|c|}
\hline RPM & Torque (\%) & Sh Str (N/m2) & Sh Rt (1/Sec) & Viscosity (mPas) \\
\hline & & & & \\
\hline 0.1 & 0.7 & 11 & 0.2 & 55048 \\
\hline 0.6 & 4.6 & 72.3 & 1.2 & 60291 \\
\hline 1.1 & 8.8 & 138.4 & 2.2 & 62912 \\
\hline 1.6 & 14.7 & 231.2 & 3.2 & 72251 \\
\hline 2.1 & 20.6 & 324 & 4.2 & 77142 \\
\hline 2.6 & 25.7 & 404.2 & 5.2 & 77733 \\
\hline 3.1 & 30.9 & 486 & 6.2 & 78386 \\
\hline 3.6 & 35.8 & 563.1 & 7.2 & 78203 \\
\hline 4.1 & 41.1 & 646.4 & 8.2 & 78832 \\
\hline 4.6 & 46.3 & 728.2 & 9.2 & 79153 \\
\hline 5.1 & 52.1 & 819.4 & 10.2 & 80336 \\
\hline 5.6 & 57.7 & 907.5 & 11.2 & 81027 \\
\hline 6.1 & 64.2 & 1010 & 12.2 & 82765 \\
\hline 6.6 & 69.9 & 1099 & 13.2 & 83287 \\
\hline 7.1 & 75.3 & 1184 & 14.2 & 83403 \\
\hline 7.6 & 79.1 & 1244 & 15.2 & 81848 \\
\hline 8 & 82.8 & 1302 & 16 & 81392 \\
\hline
\end{tabular}




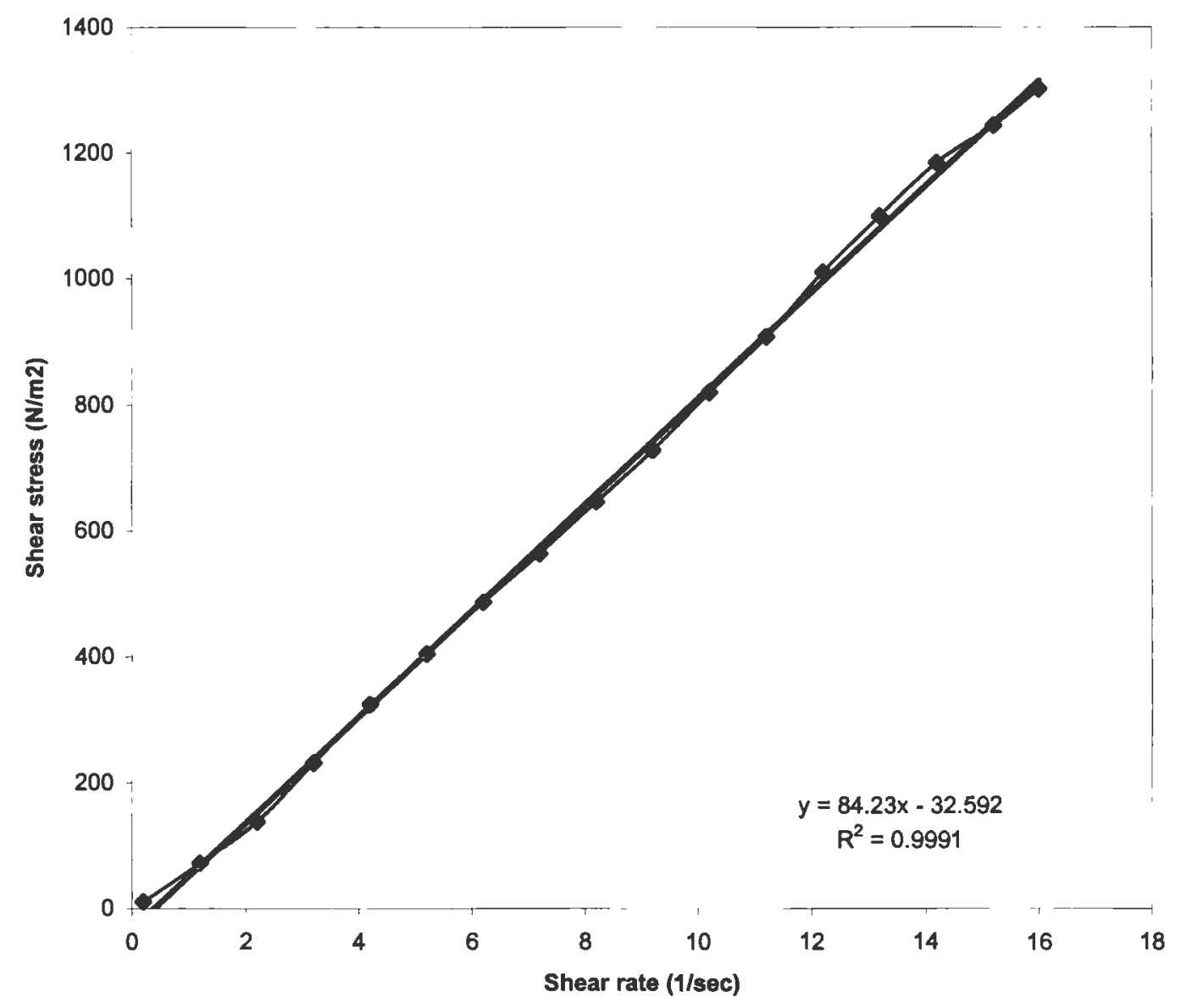

FIGURE 85. RHEOGRAM FOR LECITHIN:IPM (50:50) CONTAINING 0.8\% WATER AND 6.5\% KT BY CONE AND PLATE VISCOMETER 
TABLE 71. VISCOSITY OF LECITHIN:IPM $(60: 40)$ CONTAINING $0.1 \%$ WATER AND 6.5\%KT BY CONE AND PLATE VISCOMETER

\begin{tabular}{|c|c|c|c|c|}
\hline RPM & Torque (\%) & Sh Str (N/m2) & Sh Rt (1/Sec) & Viscosity (mPas) \\
\hline & & & & \\
\hline 0.1 & 1.2 & 18.9 & 0.2 & 94368 \\
\hline 0.3 & 4.2 & 66.1 & 0.6 & 110096 \\
\hline 0.5 & 8 & 125.8 & 1 & 125824 \\
\hline 0.7 & 14.6 & 229.6 & 1.4 & 164021 \\
\hline 0.9 & 21.7 & 341.3 & 1.8 & 189610 \\
\hline 1.1 & 29.2 & 459.3 & 2.2 & 208753 \\
\hline 1.3 & 37 & 581.9 & 2.6 & 223822 \\
\hline 1.5 & 44.2 & 695.2 & 3 & 231726 \\
\hline 1.7 & 52.2 & 821 & 3.4 & 241471 \\
\hline 1.9 & 60.7 & 954.7 & 3.8 & 251234 \\
\hline 2.1 & 68.2 & 1073 & 4.2 & 255393 \\
\hline 2.3 & 75.8 & 1192 & 4.6 & 259170 \\
\hline 2.5 & 84.4 & 1327 & 5 & 265489 \\
\hline
\end{tabular}




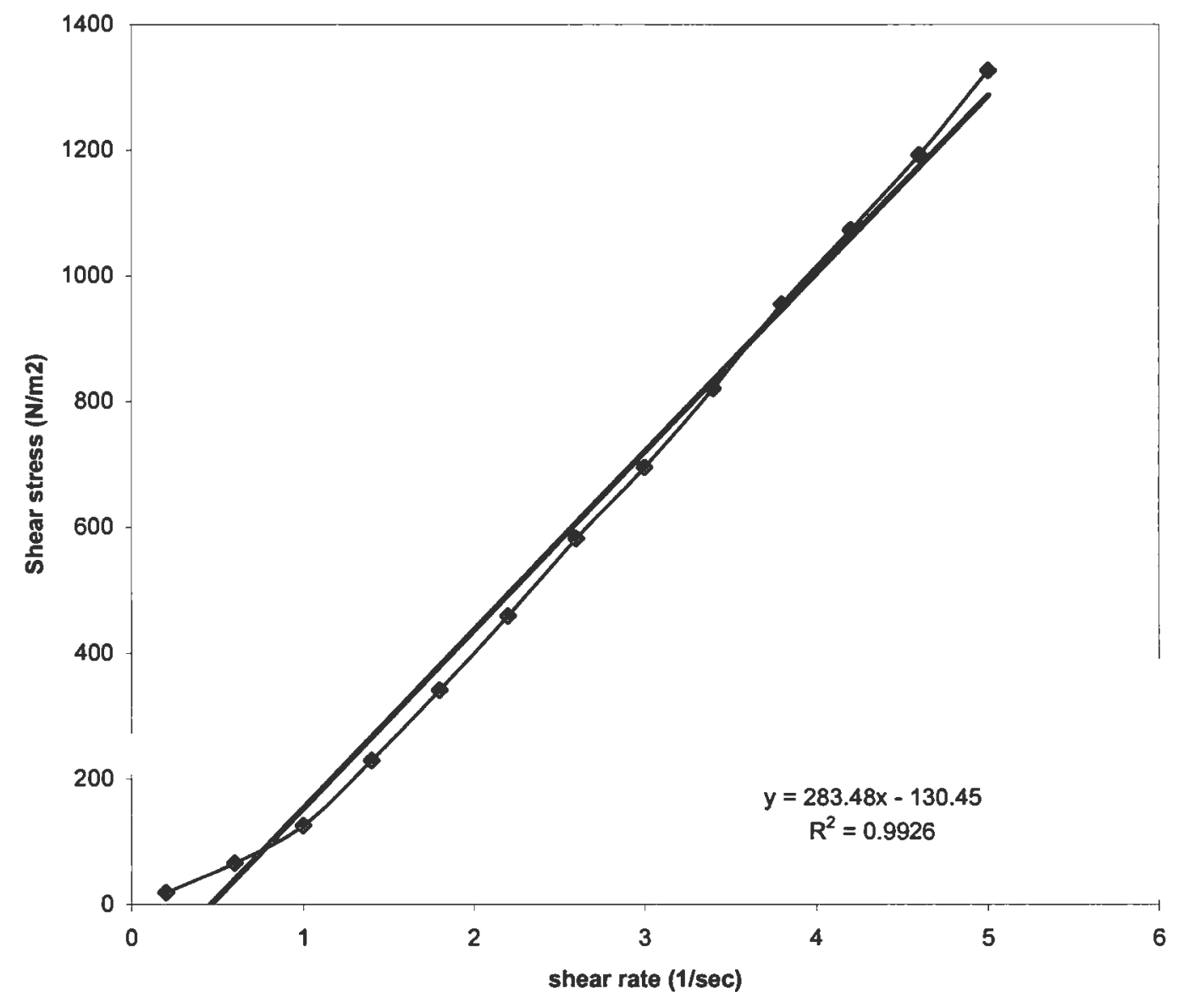

FIGURE 86. RHEOGRAM FOR LECITHIN:IPM (60:40) CONTAINING 0.1\% WATER AND 6.5\% KT BY CONE AND PLATE VISCOMETER 
TABLE 72. VISCOSITY OF LECITHIN:IPM (60:40) CONTAINING $0.25 \%$ WATER AND 6.5\% KT BY CONE AND PLATE VISCOMETER

\begin{tabular}{|c|c|c|c|c|}
\hline RPM & Torque (\%) & Sh Str (N/m2) & Sh Rt (1/Sec) & Viscosity (mPas) \\
\hline & & & & \\
\hline 0.1 & 1.3 & 20.4 & 0.2 & 102232 \\
\hline 0.3 & 3.6 & 56.6 & 0.6 & 94368 \\
\hline 0.5 & 8.6 & 135.3 & 1 & 135261 \\
\hline 0.7 & 15.7 & 246.9 & 1.4 & 176378 \\
\hline 0.9 & 22.7 & 357 & 1.8 & 198348 \\
\hline 1.1 & 30.4 & 478.1 & 2.2 & 217332 \\
\hline 1.3 & 37.7 & 592.9 & 2.6 & 228056 \\
\hline 1.5 & 45.8 & 720.3 & 3 & 240114 \\
\hline 1.7 & 53.7 & 844.6 & 3.4 & 248410 \\
\hline 1.9 & 60.8 & 956.3 & 3.8 & 251648 \\
\hline 2.1 & 68.6 & 1079 & 4.2 & 256891 \\
\hline 2.3 & 75.7 & 1191 & 4.6 & 258828 \\
\hline 2.5 & 83.7 & 1316 & 5 & 263287 \\
\hline
\end{tabular}




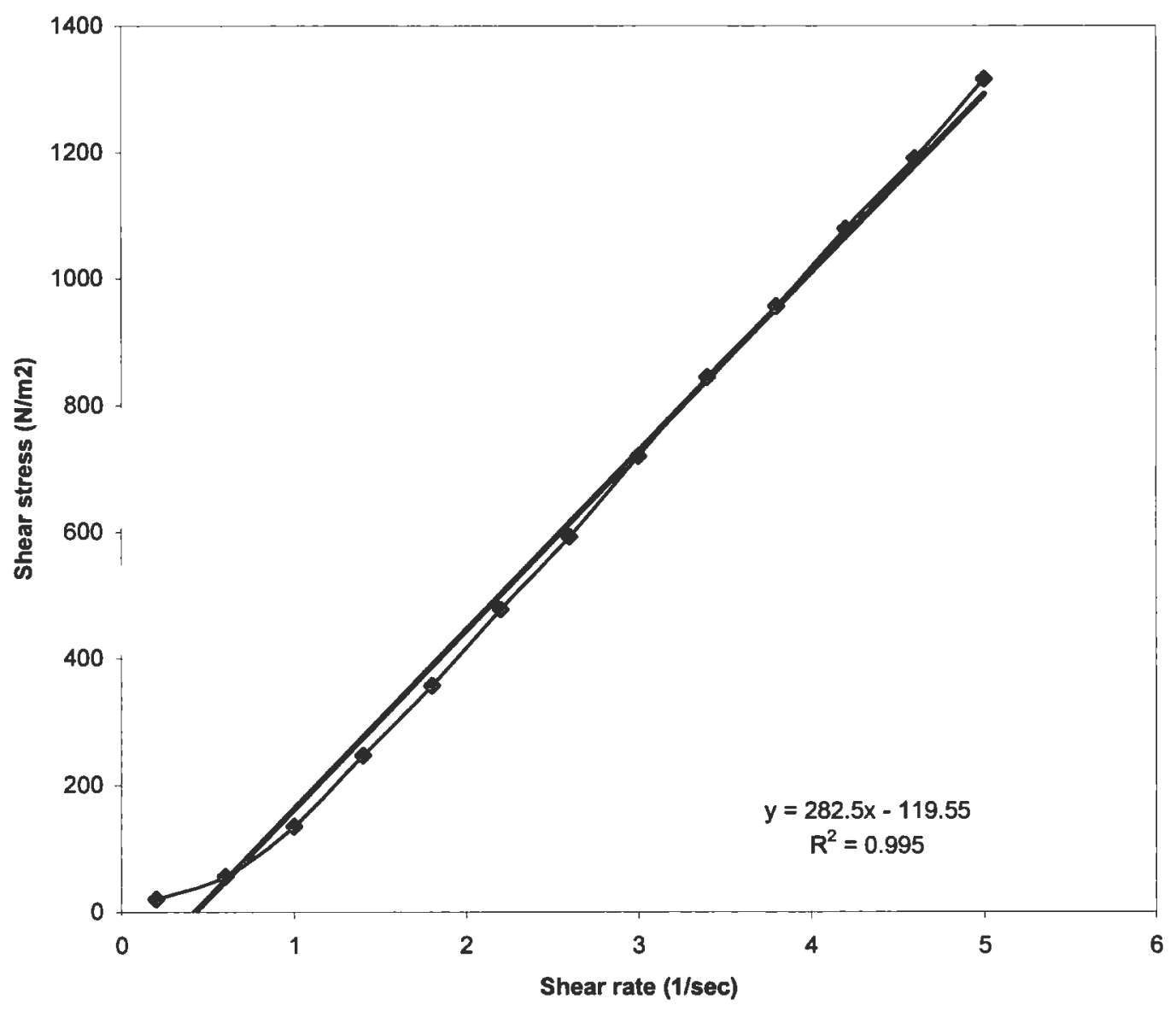

FIGURE 87. RHEOGRAM FOR LECITHIN:IPM (60:40) CONTAINING $0.25 \%$ WATER AND $6.5 \%$ KT BY CONE AND PLATE VISCOMETER 
TABLE 73. VISCOSITY OF LECITHIN:IPM $(60: 40)$ CONTAINING $0.5 \%$ WATER AND 6.5\% KT BY CONE AND PLATE VISCOMETER

\begin{tabular}{|c|c|c|c|c|}
\hline RPM & Torque (\%) & Sh Str (N/m2) & Sh Rt (1/Sec) & Viscosity (mPas) \\
\hline & & & & \\
\hline 0.1 & 0.8 & 12.6 & 0.2 & 62912 \\
\hline 0.3 & 3.8 & 59.8 & 0.6 & 99611 \\
\hline 0.5 & 7.3 & 114.8 & 1 & 114814 \\
\hline 0.7 & 13.3 & 209.2 & 1.4 & 149416 \\
\hline 0.9 & 19.3 & 303.6 & 1.8 & 168639 \\
\hline 1.1 & 25.5 & 401.1 & 2.2 & 182302 \\
\hline 1.3 & 31.3 & 492.3 & 2.6 & 189341 \\
\hline 1.5 & 37.8 & 594.5 & 3 & 198173 \\
\hline 1.7 & 44.2 & 695.2 & 3.4 & 204464 \\
\hline 1.9 & 50.3 & 791.1 & 3.8 & 208189 \\
\hline 2.1 & 57 & 896.5 & 4.2 & 513451 \\
\hline 2.3 & 63 & 990.9 & 4.6 & 215405 \\
\hline 2.5 & 69.7 & 1096 & 5 & 219248 \\
\hline
\end{tabular}




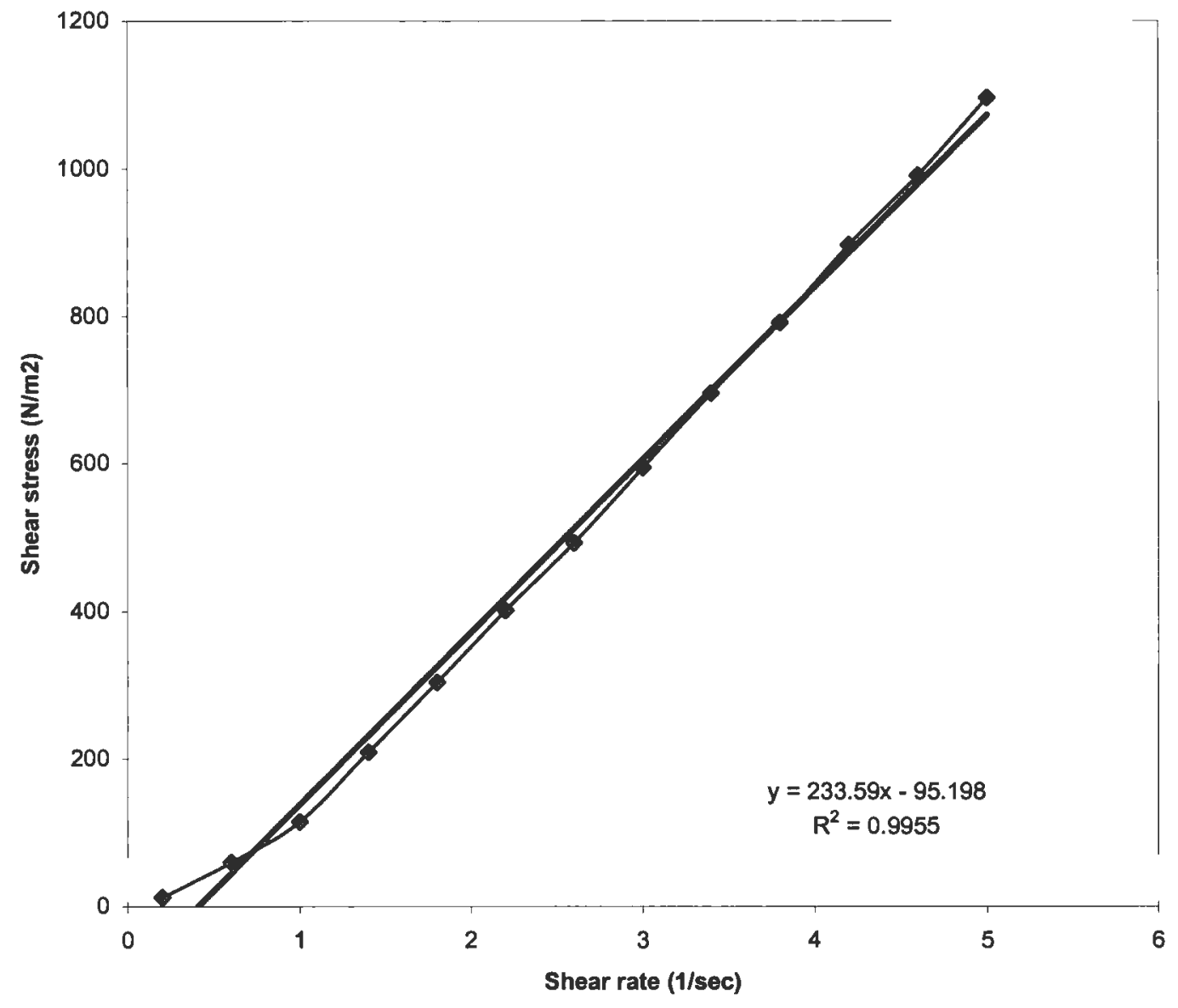

FIGURE 88. RHEOGRAM FOR LECITHIN:IPM (60:40) CONTAINING 0.5\% WATER AND 6.5\% KT BY CONE AND PLATE VISCOMETER 
TABLE 74. VISCOSITY OF LECITHIN:IPM (60:40) CONTAINING $0.6 \%$ WATER AND $6.5 \%$ KT BY CONE AND PLATE VISCOMETER

\begin{tabular}{|c|c|c|c|c|}
\hline RPM & Torque (\%) & Sh Str (N/m2) & Sh Rt (1/Sec) & Viscosity (mPas) \\
\hline & & & & \\
\hline 0.1 & 0.4 & 6.29 & 0.2 & 31456 \\
\hline 0.3 & 3.6 & 56.6 & 0.6 & 94368 \\
\hline 0.5 & 8.3 & 130.5 & 1 & 130542 \\
\hline 0.7 & 13.7 & 215.5 & 1.4 & 153910 \\
\hline 0.9 & 19.6 & 308.3 & 1.8 & 171260 \\
\hline 1.1 & 26.3 & 413.6 & 2.2 & 188021 \\
\hline 1.3 & 32.9 & 517.5 & 2.6 & 199020 \\
\hline 1.5 & 39.7 & 624.4 & 3 & 208134 \\
\hline 1.7 & 46.6 & 732.9 & 3.4 & 215566 \\
\hline 1.9 & 52.8 & 830.4 & 3.8 & 218536 \\
\hline 2.1 & 60.1 & 945.3 & 4.2 & 225060 \\
\hline 2.3 & 66.4 & 1044 & 4.6 & 227030 \\
\hline 2.5 & 73.5 & 1156 & 5 & 231202 \\
\hline
\end{tabular}




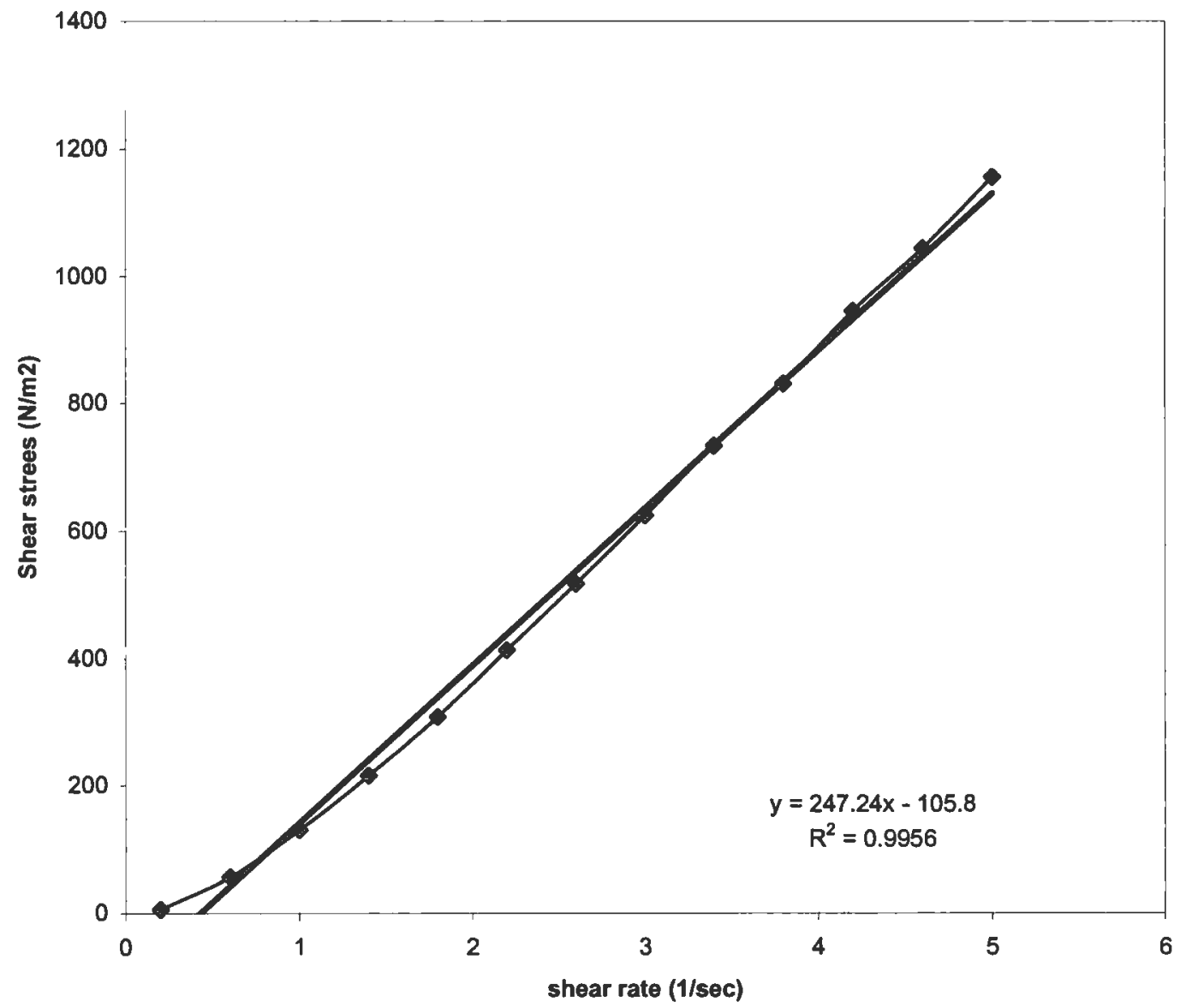

FIGURE 89. RHEOGRAM FOR LECITHIN:IPM (60:40) CONTAINING $0.6 \%$ WATER AND $6.5 \%$ KT BY CONE AND PLATE VISCOMETER 
TABLE 75. VISCOSITY OF LECITHIN:IPM (60:40) CONTAINING $0.7 \%$ WATER AND $6.5 \%$ KT BY CONE AND PLATE VISCOMETER

\begin{tabular}{|c|c|c|c|c|}
\hline RPM & Torque (\%) & Sh Str (N/m2) & Sh Rt (1/Sec) & Viscosity (mPas) \\
\hline & & & & \\
\hline 0.1 & 0.9 & 14.2 & 0.2 & 70776 \\
\hline 0.3 & 3.9 & 61.3 & 0.6 & 102232 \\
\hline 0.5 & 8.5 & 133.7 & 1 & 133688 \\
\hline 0.7 & 13.5 & 212.3 & 1.4 & 151663 \\
\hline 0.9 & 19.9 & 313 & 1.8 & 173882 \\
\hline 1.1 & 25.8 & 405.8 & 2.2 & 184447 \\
\hline 1.3 & 32.6 & 512.7 & 2.6 & 197205 \\
\hline 1.5 & 39.3 & 618.1 & 3 & 206037 \\
\hline 1.7 & 46 & 723.5 & 3.4 & 212791 \\
\hline 1.9 & 52.2 & 821 & 3.8 & 216053 \\
\hline 2.1 & 59.4 & 934.2 & 4.2 & 222439 \\
\hline 2.3 & 65.7 & 1033 & 4.6 & 224637 \\
\hline 2.5 & 72.8 & 1145 & 5 & 229000 \\
\hline
\end{tabular}




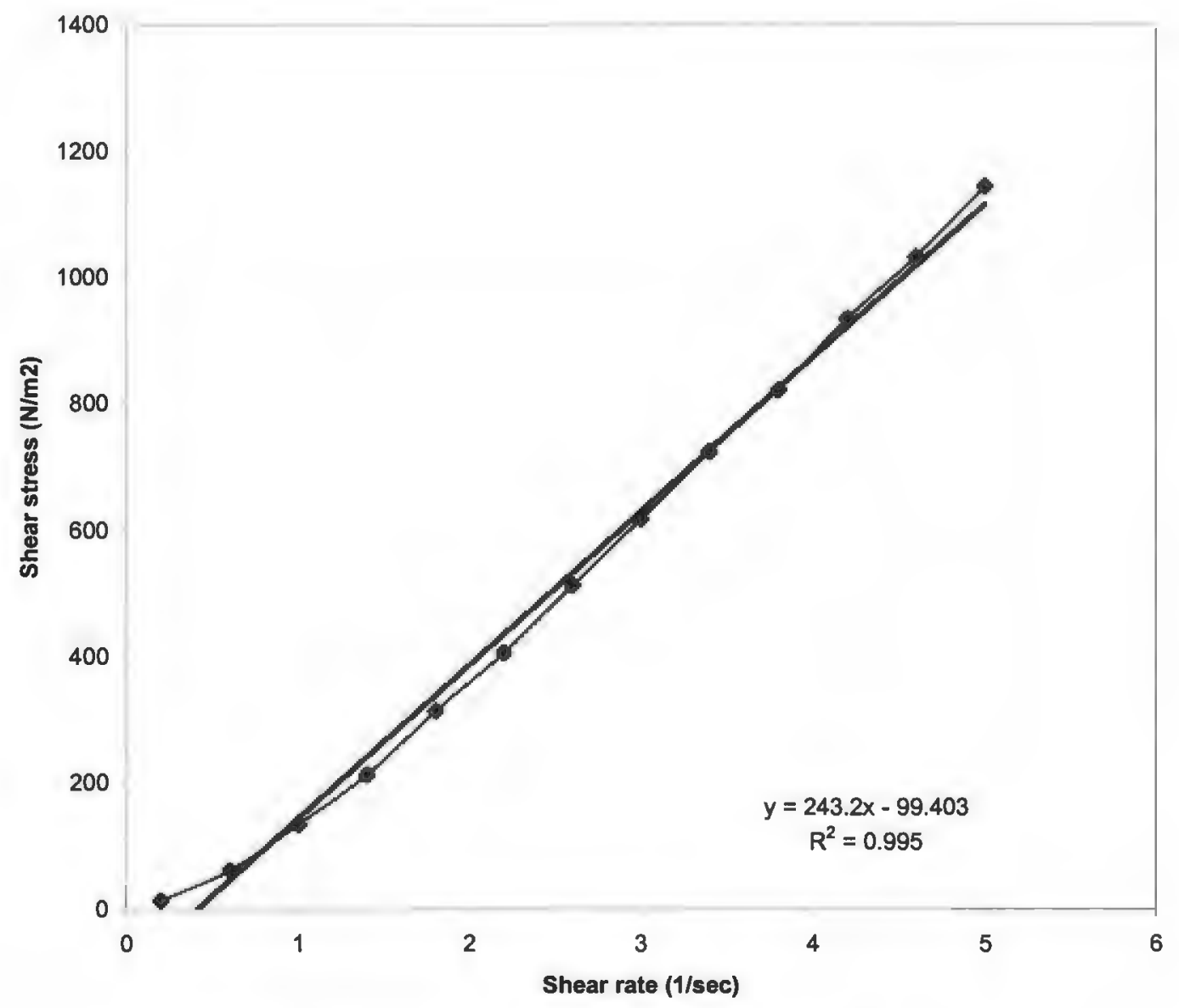

FIGURE 90. RHEOGRAM FOR LECITHIN:IPM (60:40)

CONTAINING 0.7\% WATER AND 6.5\% KT BY CONE AND PLATE VISCOMETER 
TABLE 76. VISCOSITY OF LECITHIN:IPM (60:40) CONTAINING $0.8 \%$ WATER AND 6.5\% KT BY CONE AND PLATE VISCOMETER

\begin{tabular}{|c|c|c|c|c|}
\hline RPM & Torque (\%) & Sh Str (N/m2) & Sh Rt (1/Sec) & Viscosity (mPas) \\
\hline & & & & \\
\hline 0.1 & 0.8 & 12.6 & 0.2 & 62912 \\
\hline 0.3 & 3 & 47.2 & 0.6 & 78640 \\
\hline 0.5 & 7.5 & 118 & 1 & 117960 \\
\hline 0.7 & 12.8 & 201.3 & 1.4 & 143799 \\
\hline 0.9 & 18.2 & 286.2 & 1.8 & 159028 \\
\hline 1.1 & 23.3 & 366.5 & 2.2 & 166574 \\
\hline 1.3 & 29.2 & 459.3 & 2.6 & 176638 \\
\hline 1.5 & 34.4 & 541 & 3 & 180348 \\
\hline 1.7 & 40.1 & 630.7 & 3.4 & 185498 \\
\hline 1.9 & 45.2 & 710.9 & 3.8 & 187080 \\
\hline 2.1 & 50.8 & 799 & 4.2 & 190234 \\
\hline 2.3 & 55.9 & 879.2 & 4.6 & 191129 \\
\hline 2.5 & 61.7 & 970.4 & 5 & 194084 \\
\hline
\end{tabular}




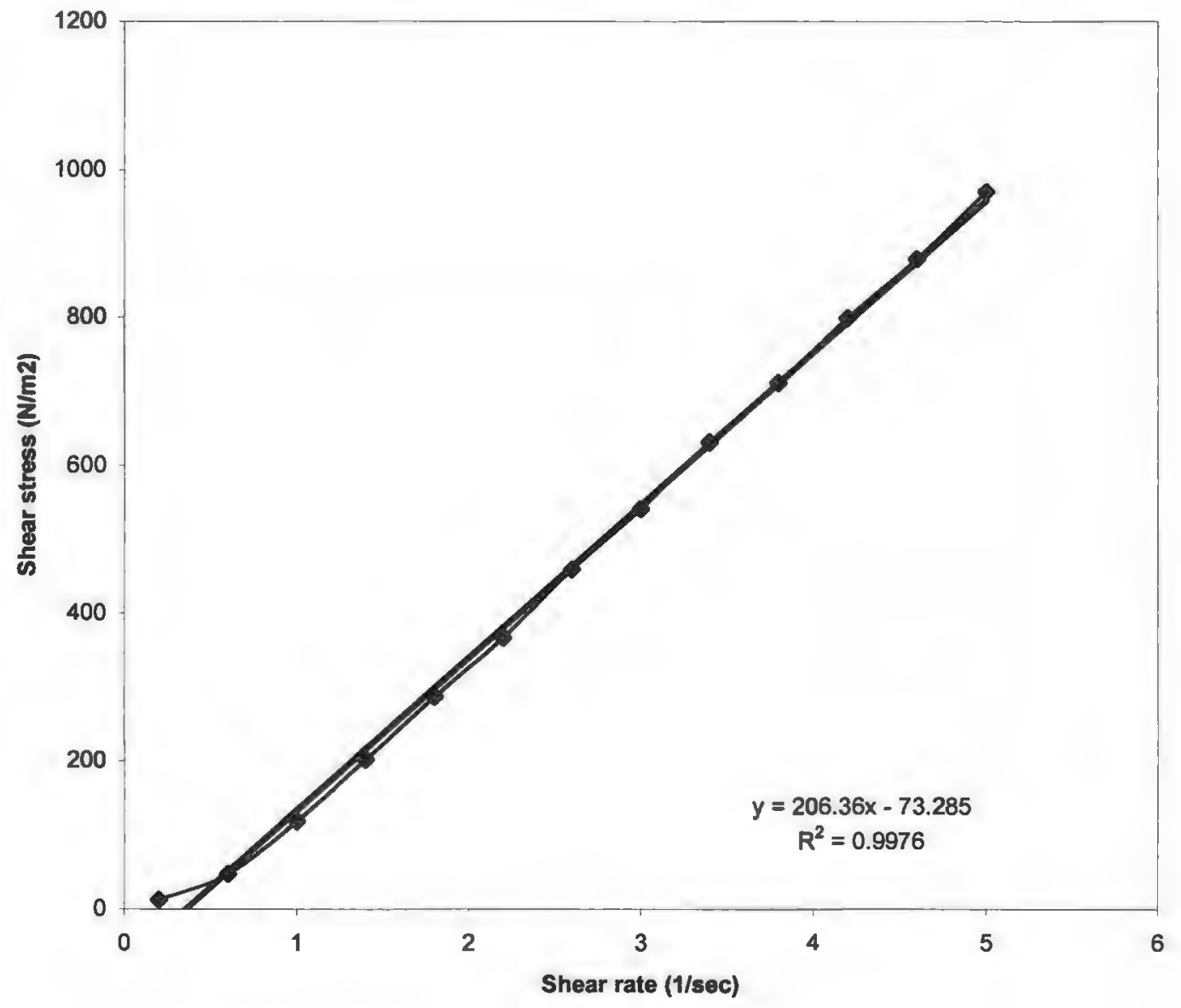

FIGURE 91. RHEOGRAM FOR LECITHIN:IPM (60:40) CONTAINING $0.8 \%$ WATER AND $6.5 \%$ KT BY CONE AND PLATE VISCOMETER 


\section{TABLE 77. RESULTS OF ONE-WAY ANOVA ON KT RELEASE FROM FORMULATIONS WITH DIFFERENT COMPOSITIONS}

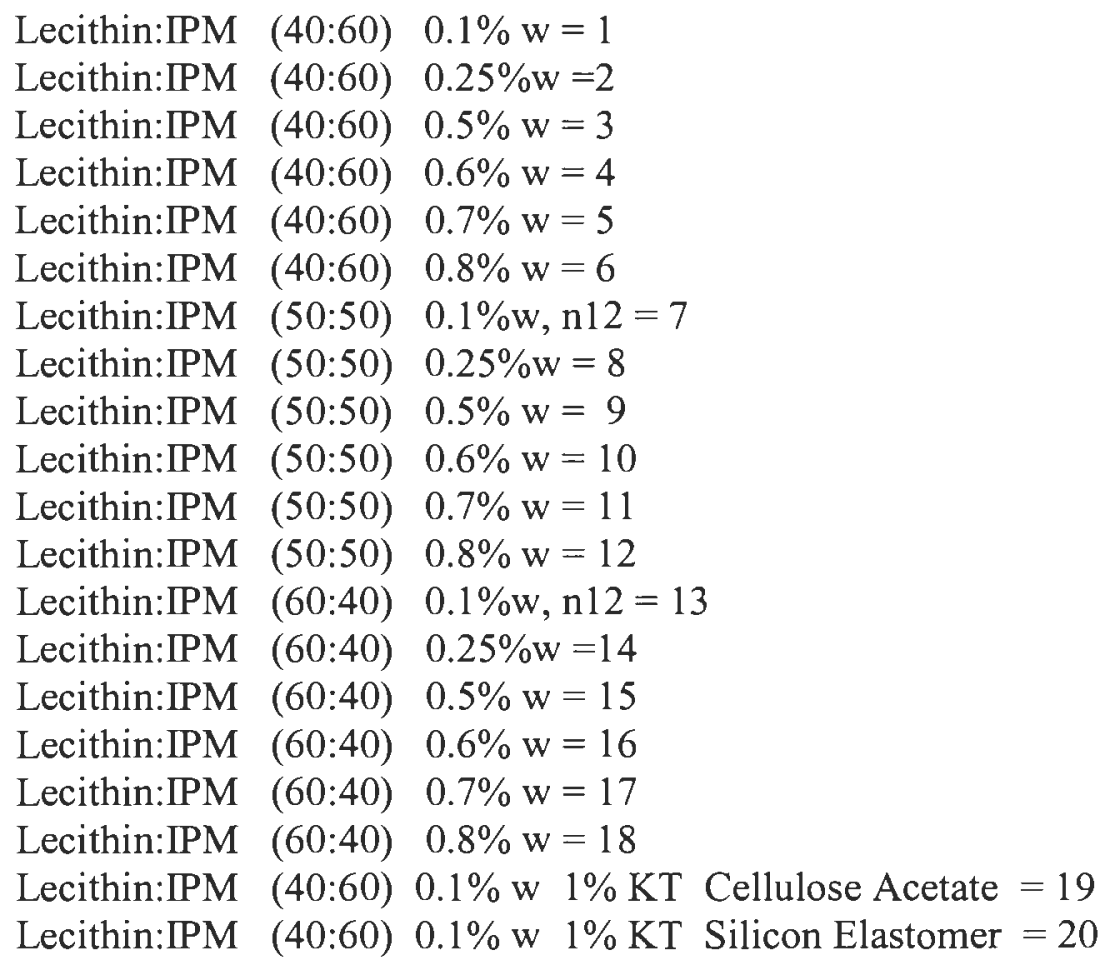

One-way ANOVA: release versus sample

Analysis of Variance for release

$\begin{array}{lcclll}\text { Source } & \text { DF } & \text { SS } & \text { MS } & \text { F } & \text { P } \\ \text { sample } & 17 & 203748 & 11985 & 86.04 & 0.000 \\ \text { Error } & 102 & 14208 & 139 & & \\ \text { Total } & 119 & 217955 & & & \end{array}$

Individual 95\% CIs For Mean Based on Pooled StDev

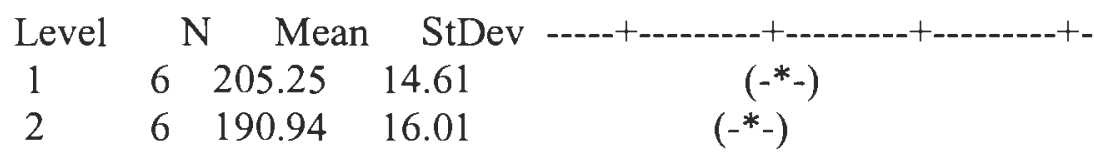




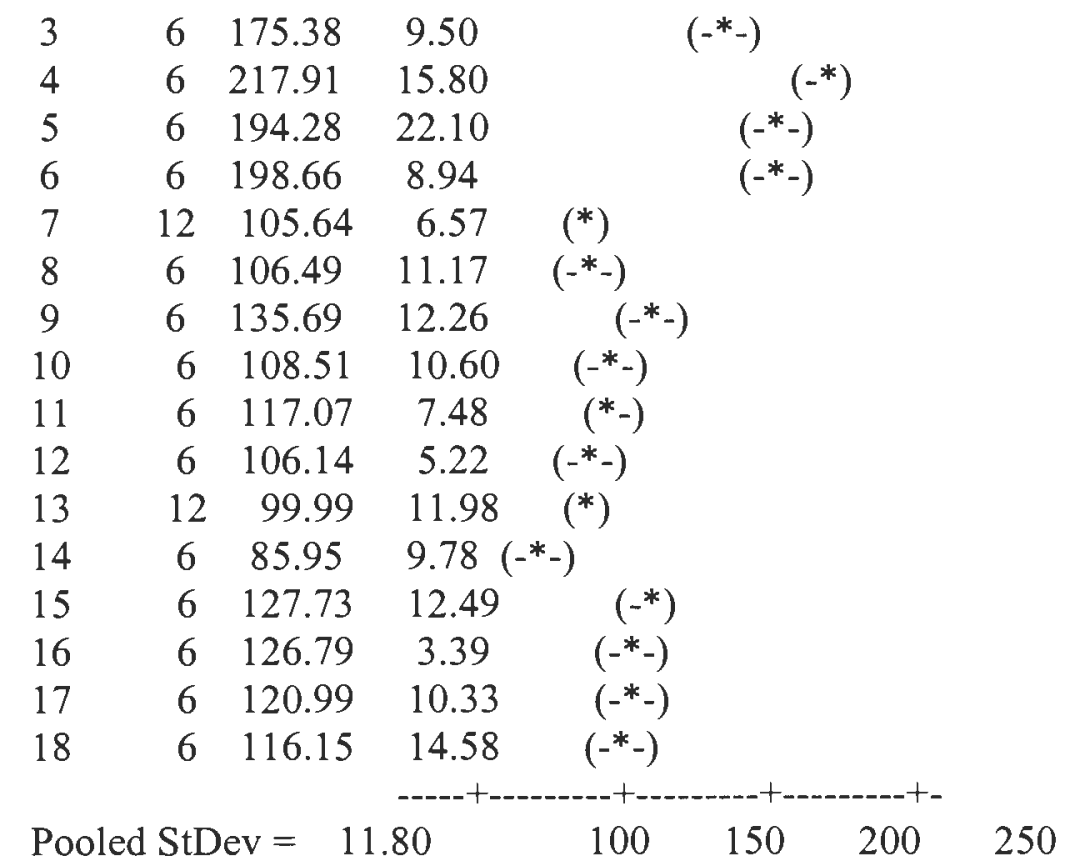

One-way ANOVA: release versus sample

Analysis of Variance for release

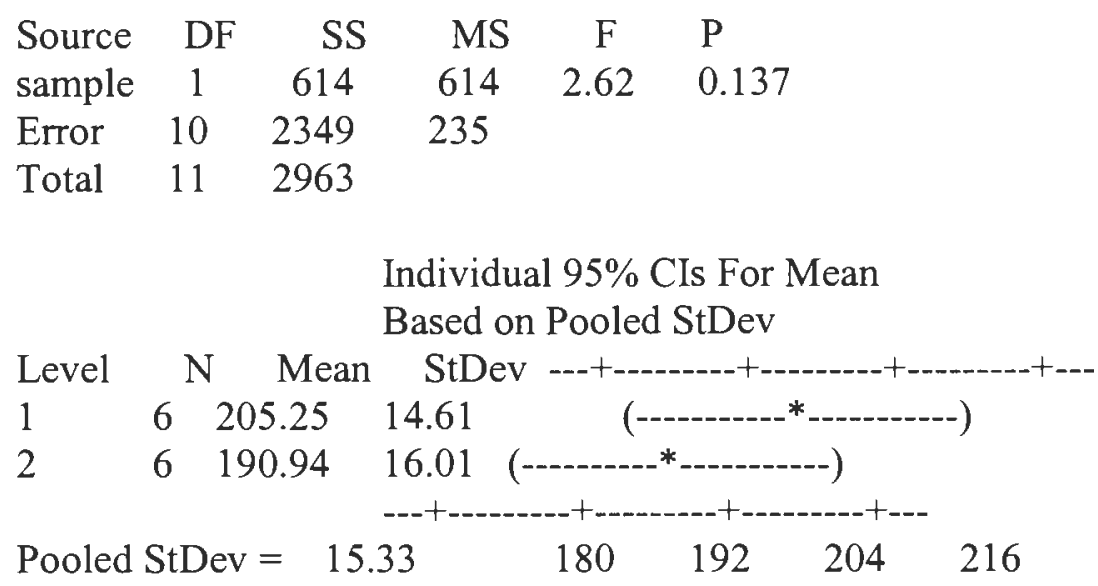

One-way ANOVA: release versus sample 
Analysis of Variance for release

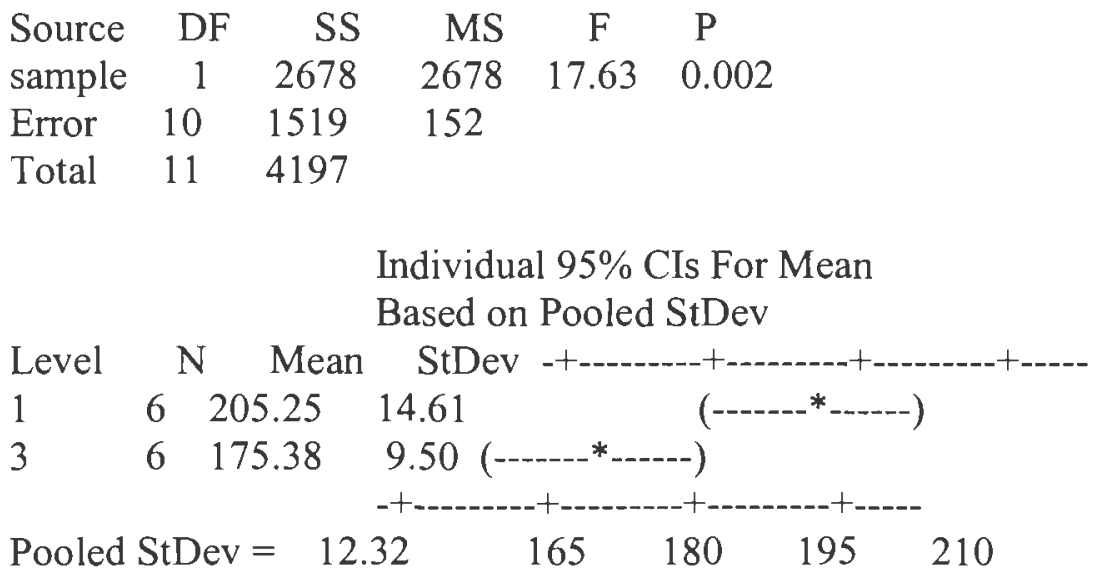

One-way ANOVA: release versus sample

Analysis of Variance for release

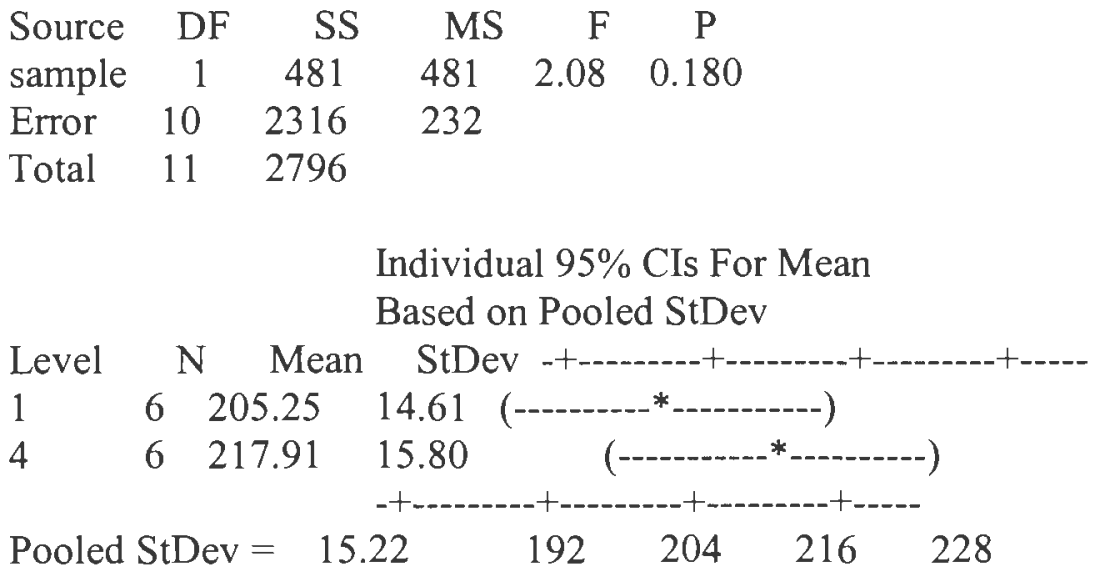

One-way ANOVA: release versus sample

Analysis of Variance for release

Source DF SS MS $\quad F \quad$ P 


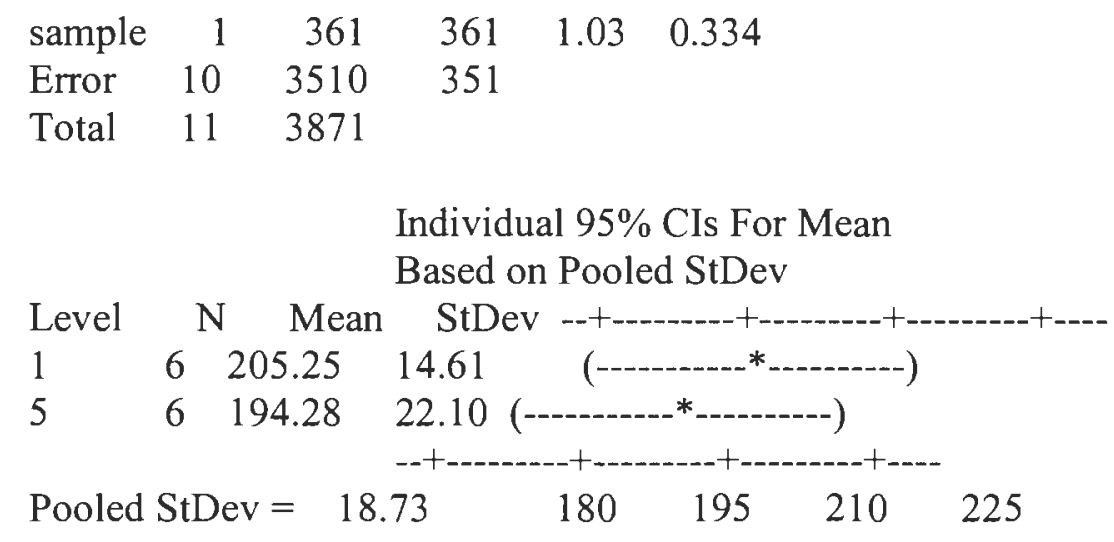

One-way ANOVA: release versus sample

Analysis of Variance for release

$\begin{array}{lcrcrc}\text { Source } & \text { DF } & \text { SS } & \text { MS } & \text { F } & \text { P } \\ \text { sample } & 1 & 130 & 130 & 0.89 & 0.368 \\ \text { Error } & 10 & 1467 & 147 & & \\ \text { Total } & 11 & 1598 & & & \end{array}$

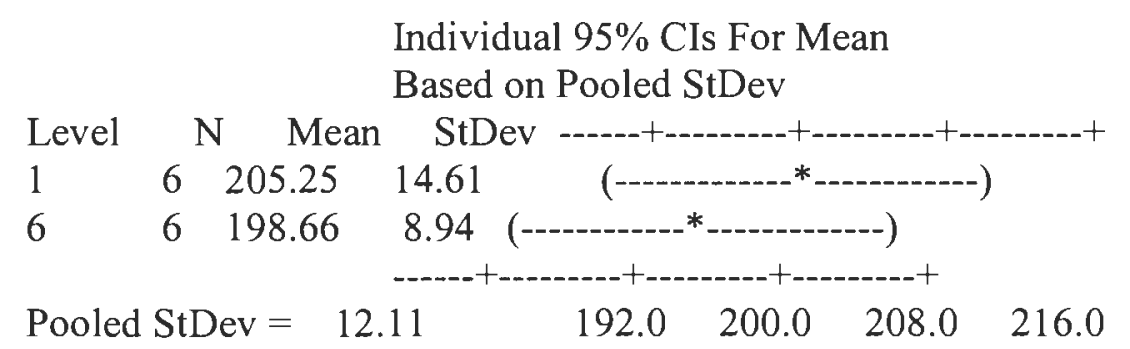

One-way ANOVA: release versus sample

Analysis of Variance for release

$\begin{array}{lcrcrc}\text { Source } & \text { DF } & \text { SS } & \text { MS } & \text { F } & \text { P } \\ \text { sample } & 1 & 727 & 727 & 4.20 & 0.068 \\ \text { Error } & 10 & 1732 & 173 & & \\ \text { Total } & 11 & 2459 & & & \end{array}$




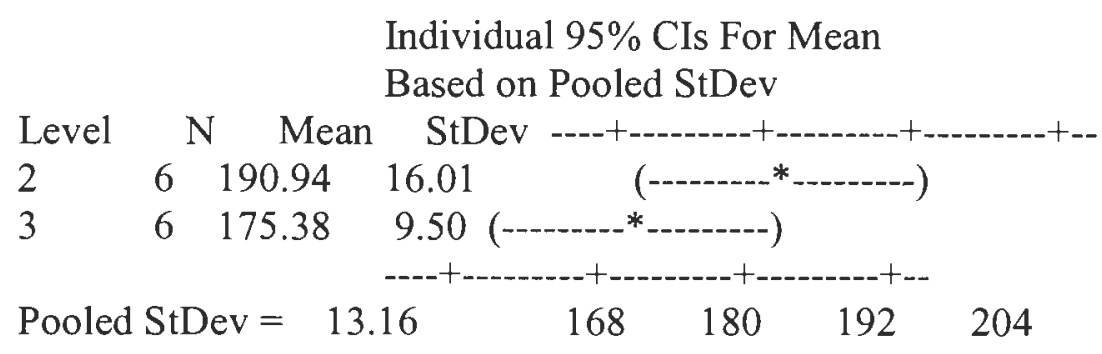

One-way ANOVA: release versus sample

Analysis of Variance for release

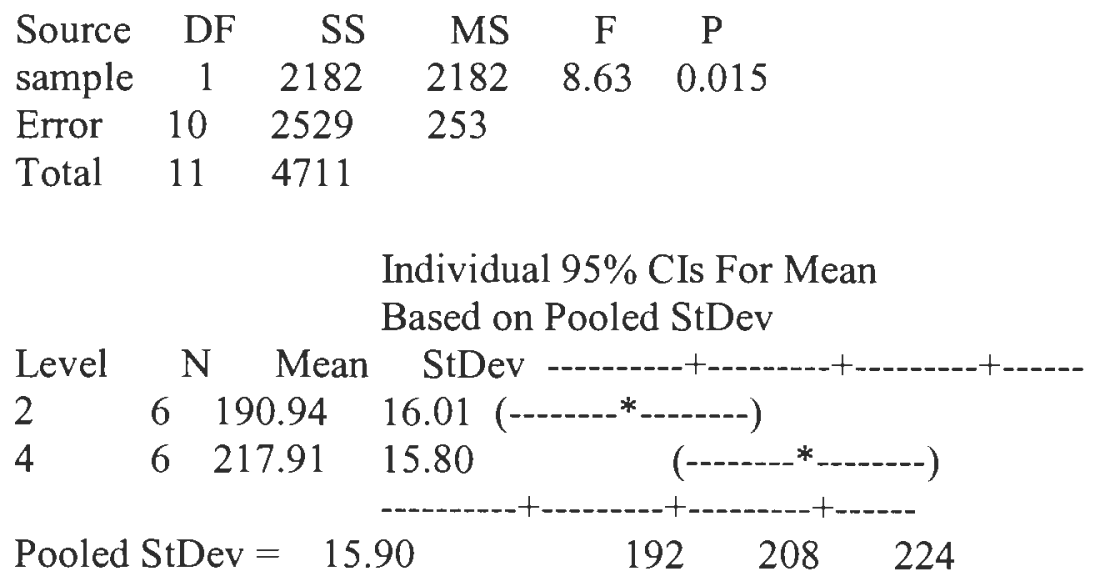

One-way ANOVA: release versus sample

Analysis of Variance for release

\begin{tabular}{|c|c|c|c|c|}
\hline Source & $\mathrm{DF}$ & SS & MS & \multirow{2}{*}{9} \\
\hline sample & 1 & 33 & 33 & \\
\hline Error & 10 & 3723 & 372 & \\
\hline Total & 11 & 3757 & & \\
\hline
\end{tabular}

Individual 95\% CIs For Mean

Based on Pooled StDev

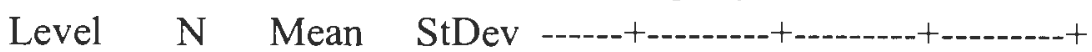




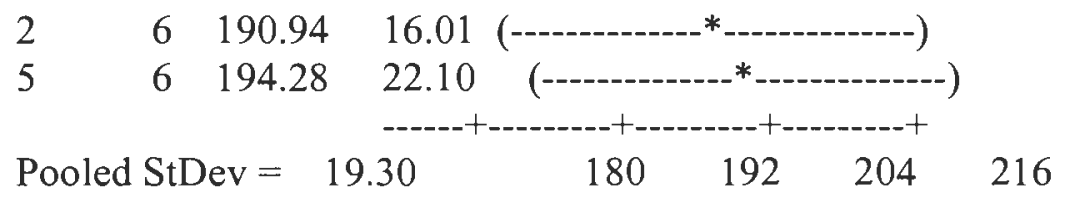

One-way ANOVA: release versus sample

Analysis of Variance for release

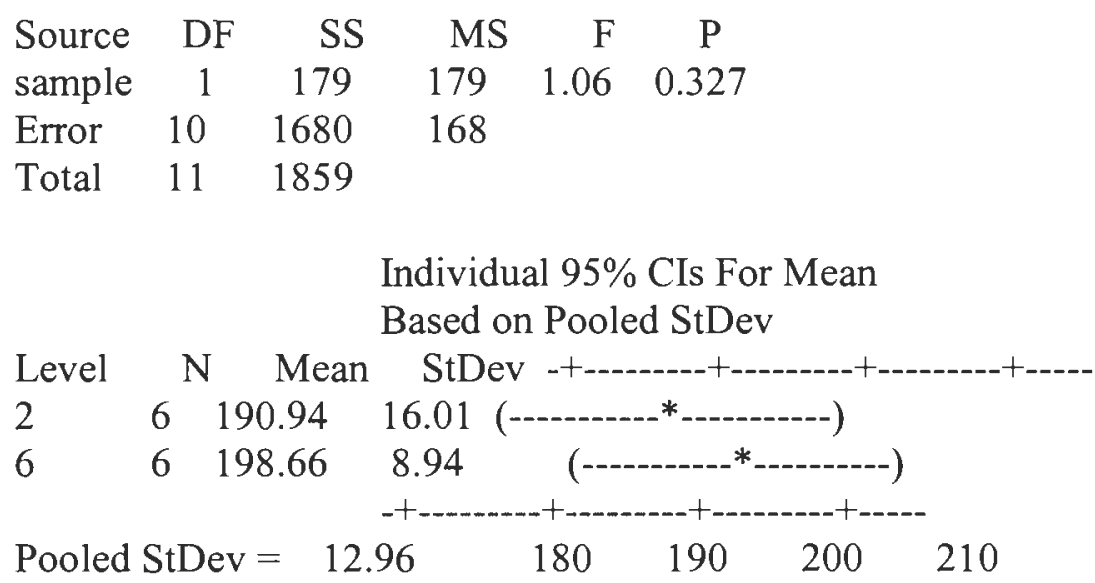

One-way ANOVA: release versus sample

Analysis of Variance for release

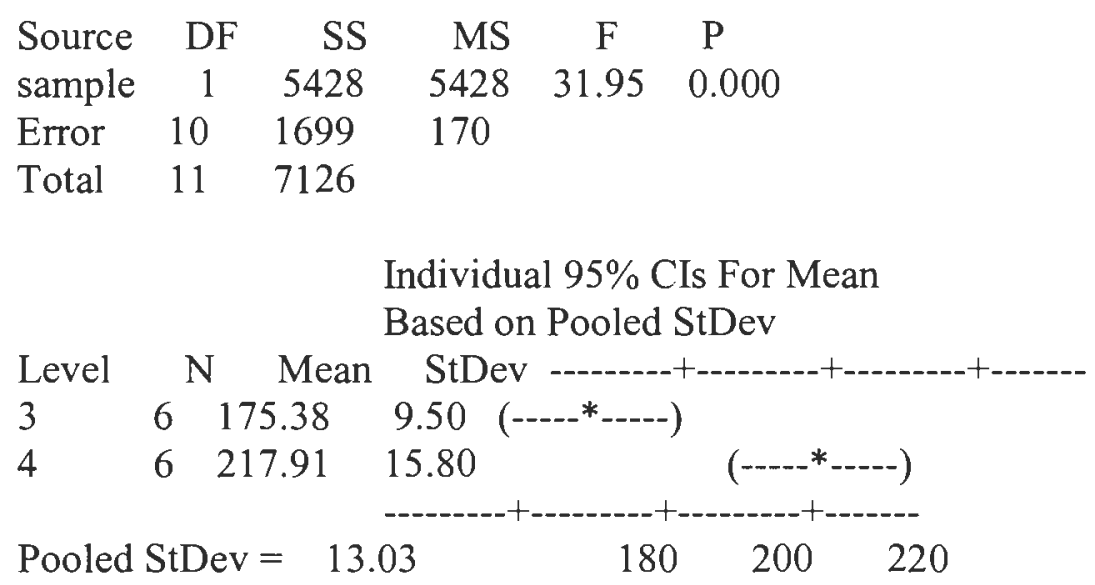


One-way ANOVA: release versus sample

Analysis of Variance for release

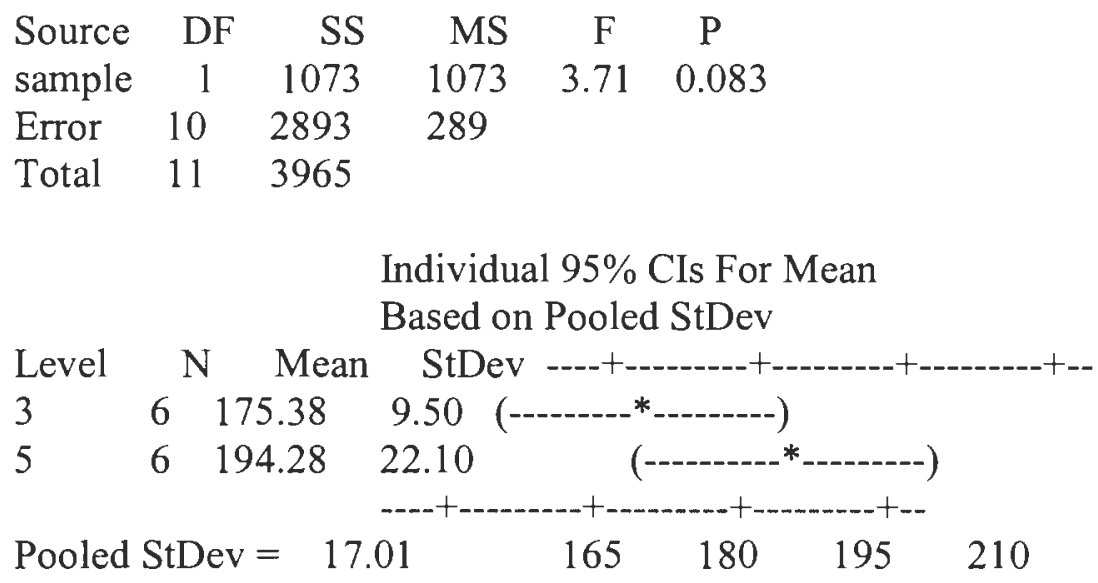

One-way ANOVA: release versus sample

Analysis of Variance for release

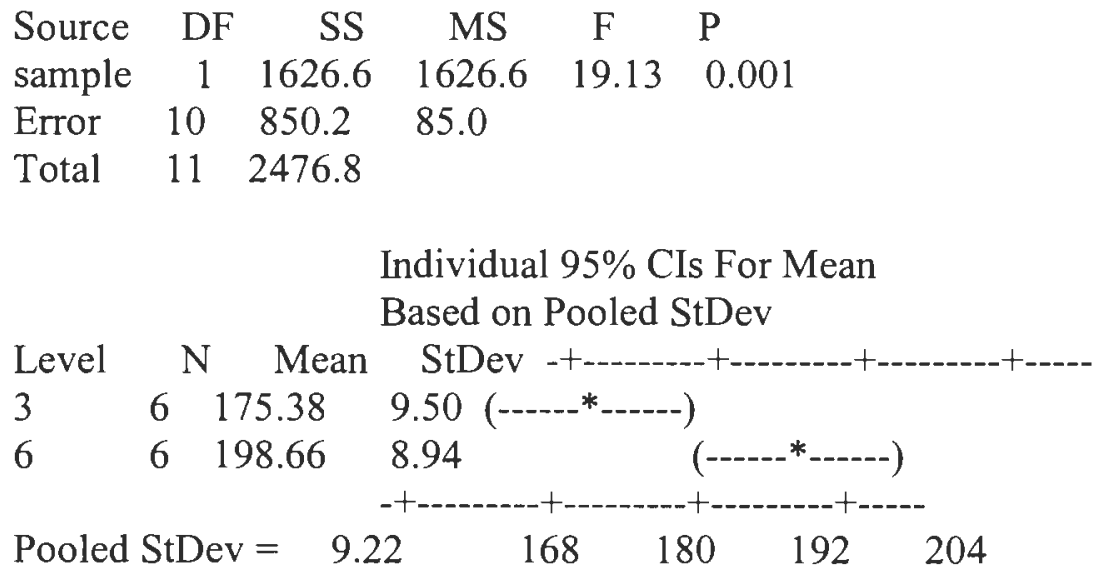

One-way ANOVA: release versus sample 
Analysis of Variance for release

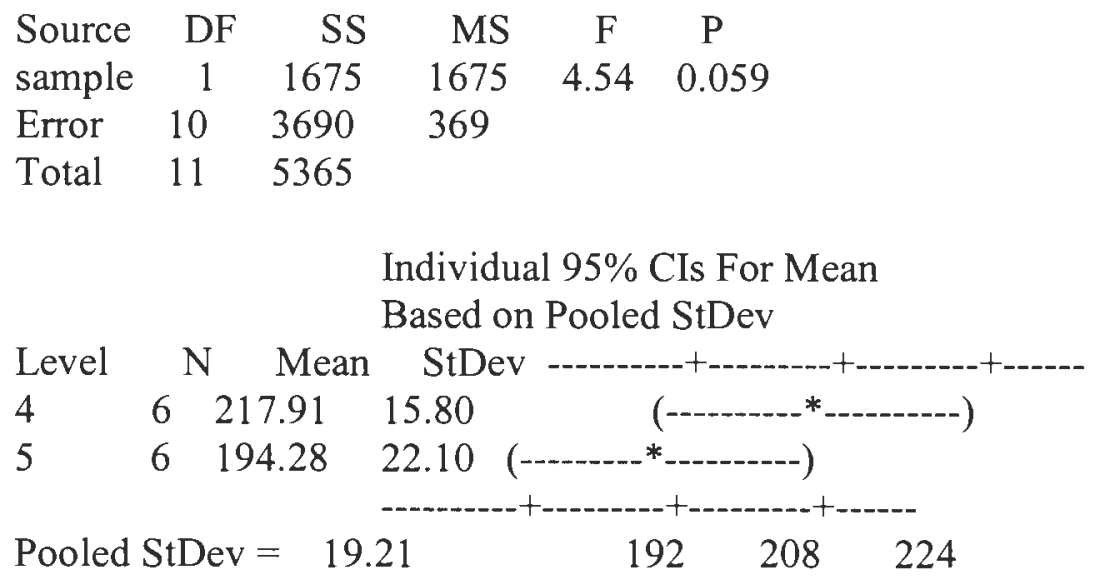

One-way ANOVA: release versus sample

Analysis of Variance for release

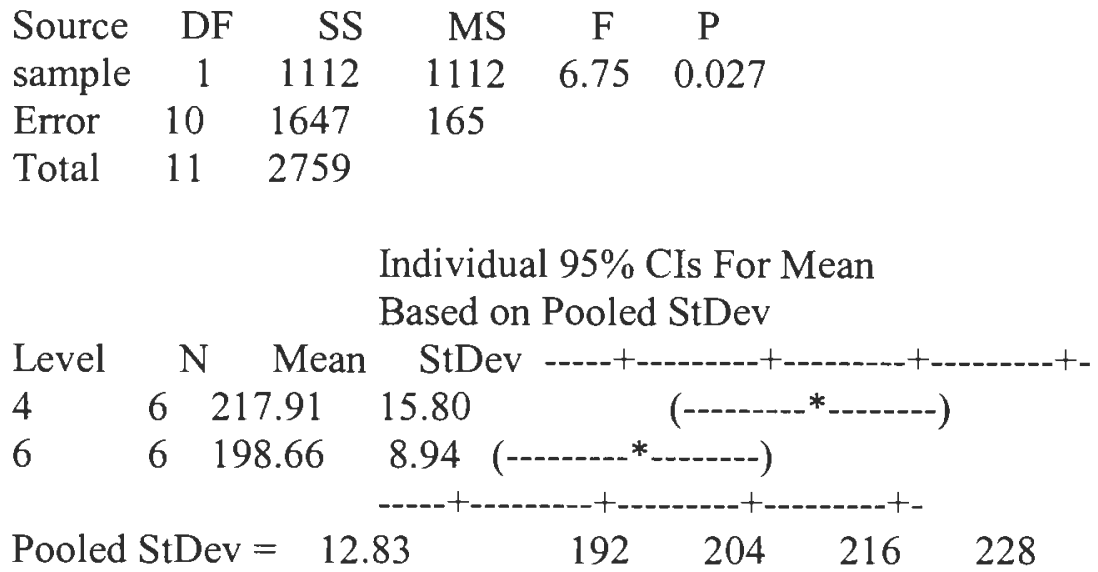

One-way ANOVA: release versus sample

Analysis of Variance for release 


\begin{tabular}{|c|c|c|c|c|c|}
\hline Source & DF & SS & MS & F & $\mathrm{P}$ \\
\hline sample & 1 & 57 & 57 & 0.20 & 0.662 \\
\hline Error & 10 & 2841 & 284 & & \\
\hline Total & 11 & 2899 & & & \\
\hline
\end{tabular}

Individual $95 \% \mathrm{CIs}$ For Mean

Based on Pooled StDev

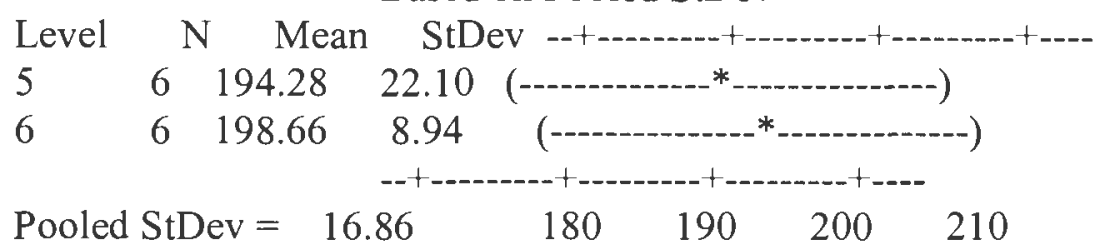

One-way ANOVA: release versus sample

Analysis of Variance for release

$\begin{array}{lccccr}\text { Source } & \text { DF } & \text { SS } & \text { MS } & \text { F } & \text { P } \\ \text { sample } & 1 & 2.9 & 2.9 & 0.04 & 0.839 \\ \text { Error } & 16 & 1098.7 & 68.7 & & \\ \text { Total } & 17 & 1101.6 & & & \end{array}$

Individual 95\% CIs For Mean

Based on Pooled StDev

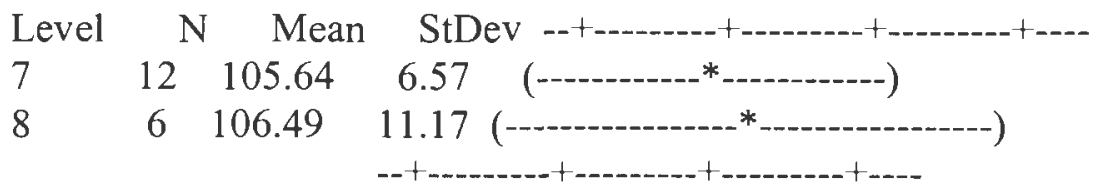

Pooled StDev $=\quad 8.29 \quad 100.0 \quad 104.0 \quad 108.0 \quad 112.0$

One-way ANOVA: release versus sample

Analysis of Variance for release

$\begin{array}{lccccc}\text { Source } & \text { DF } & \text { SS } & \text { MS } & \text { F } & \text { P } \\ \text { sample } & 1 & 3611.2 & 3611.2 & 47.12 & 0.000 \\ \text { Error } & 16 & 1226.3 & 76.6 & & \end{array}$


Total $\quad 17 \quad 4837.5$

Individual 95\% CIs For Mean

Based on Pooled StDev

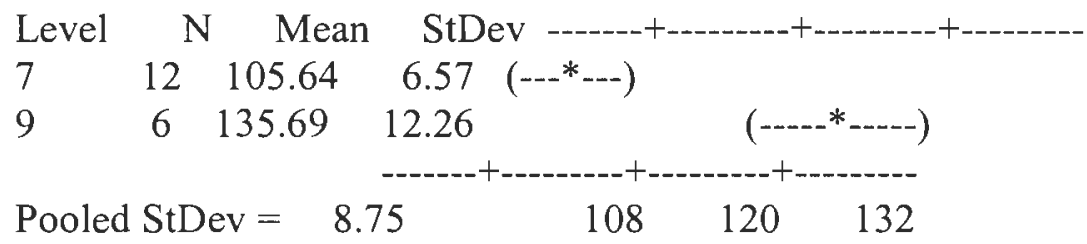

One-way ANOVA: release versus sample

Analysis of Variance for release

$\begin{array}{lrrrrr}\text { Source } & \text { DF } & \text { SS } & \text { MS } & \text { F } & \text { P } \\ \text { sample } & 1 & 32.9 & 32.9 & 0.51 & 0.486 \\ \text { Error } & 16 & 1036.1 & 64.8 & & \\ \text { Total } & 17 & 1069.1 & & & \end{array}$

Individual 95\% CIs For Mean

Based on Pooled StDev

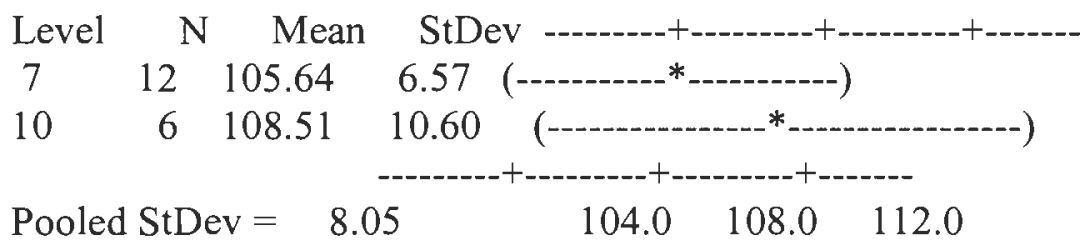

One-way ANOVA: release versus sample

Analysis of Variance for release

$\begin{array}{lcrrcc}\text { Source } & \text { DF } & \text { SS } & \text { MS } & \text { F } & \text { P } \\ \text { sample } & 1 & 522.5 & 522.5 & 11.08 & 0.004 \\ \text { Error } & 16 & 754.6 & 47.2 & & \\ \text { Total } & 17 & 1277.1 & & & \end{array}$

Individual $95 \%$ CIs For Mean

Based on Pooled StDev 


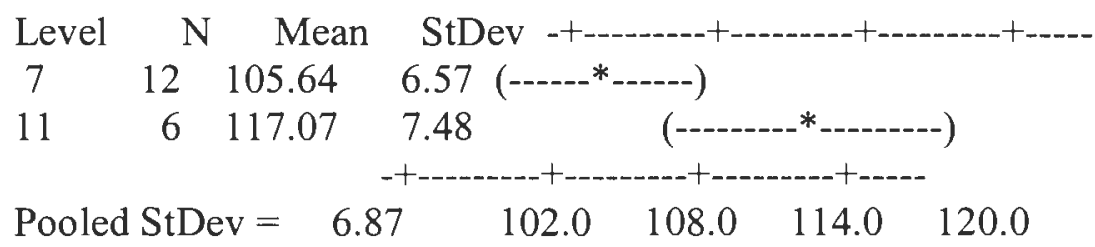

One-way ANOVA: release versus sample

Analysis of Variance for release

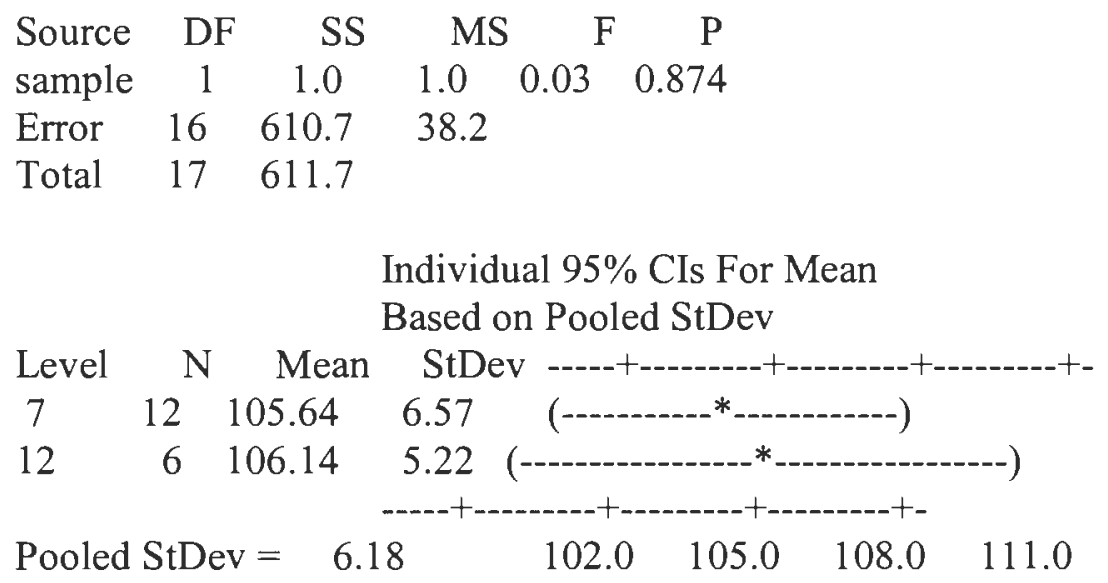

One-way ANOVA: release versus sample

Analysis of Variance for release

$\begin{array}{lcrccc}\text { Source } & \text { DF } & \text { SS } & \text { MS } & \text { F } & \text { P } \\ \text { sample } & 1 & 2557 & 2557 & 18.59 & 0.002 \\ \text { Error } & 10 & 1375 & 138 & & \\ \text { Total } & 11 & 3932 & & & \end{array}$

Individual 95\% CIs For Mean

Based on Pooled StDev

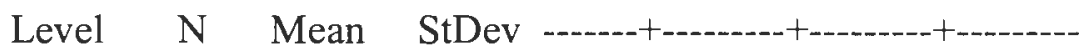

$8 \quad 6 \quad 106.49 \quad 11.17 \quad(-----* *-----)$

$9 \quad 6 \quad 135.69 \quad 12.26 \quad\left(--{ }^{-} * *_{-}^{*}-{ }^{---}\right)$ 
Pooled StDev $=\begin{array}{llll}11.73 & 105 & 120 & 135\end{array}$

One-way ANOVA: release versus sample

Analysis of Variance for release

\begin{tabular}{|c|c|c|c|c|c|}
\hline urce & DF & SS & MS & & \\
\hline $\mathrm{am}$ & 1 & 12 & 12 & 0.10 & 0.75 \\
\hline irro & 10 & 1185 & 119 & & \\
\hline ot & 11 & 1197 & & & \\
\hline
\end{tabular}

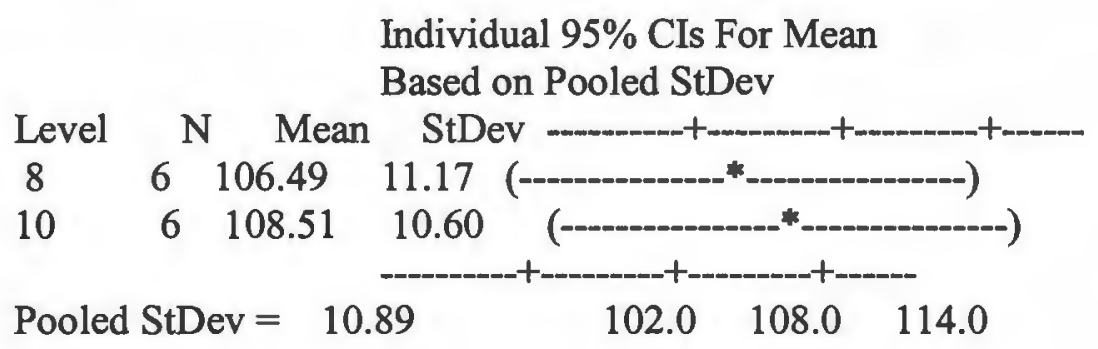

One-way ANOVA: release versus sample

Analysis of Variance for release

$\begin{array}{lcrccc}\text { Source } & \text { DF } & \text { SS } & \text { MS } & \text { F } & \text { P } \\ \text { sample } & 1 & 335.5 & 335.5 & 3.71 & 0.083 \\ \text { Error } & 10 & 903.8 & 90.4 & & \\ \text { Total } & 11 & 1239.3 & & & \end{array}$

Individual 95\% CIs For Mean Based on Pooled StDev

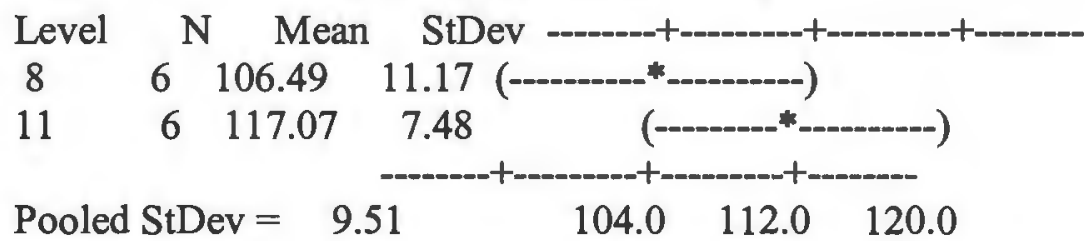


One-way ANOVA: release versus sample

Analysis of Variance for release

\begin{tabular}{|c|c|c|c|}
\hline Source & & SS & MS \\
\hline sample & & 0.4 & $\begin{array}{lll}0.4 & 0.00 & 0.945\end{array}$ \\
\hline Error & 10 & 759.9 & 76.0 \\
\hline \multirow[t]{2}{*}{ Total } & 11 & 760.3 & \\
\hline & & & $\begin{array}{l}\text { Individual } 95 \% \text { CIs For Mean } \\
\text { Based on Pooled StDev }\end{array}$ \\
\hline Level & $\Lambda$ & Mean & 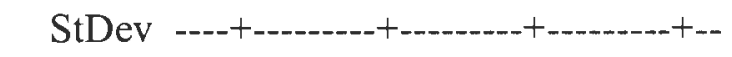 \\
\hline 8 & 6 & 106.49 & 11.17 (---------------*---------------) \\
\hline \multirow[t]{2}{*}{12} & 6 & 106.14 & 5.22 (-----on \\
\hline & StI & $=$ & 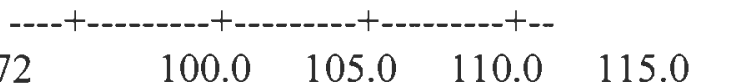 \\
\hline
\end{tabular}

One-way ANOVA: release versus sample

Analysis of Variance for release

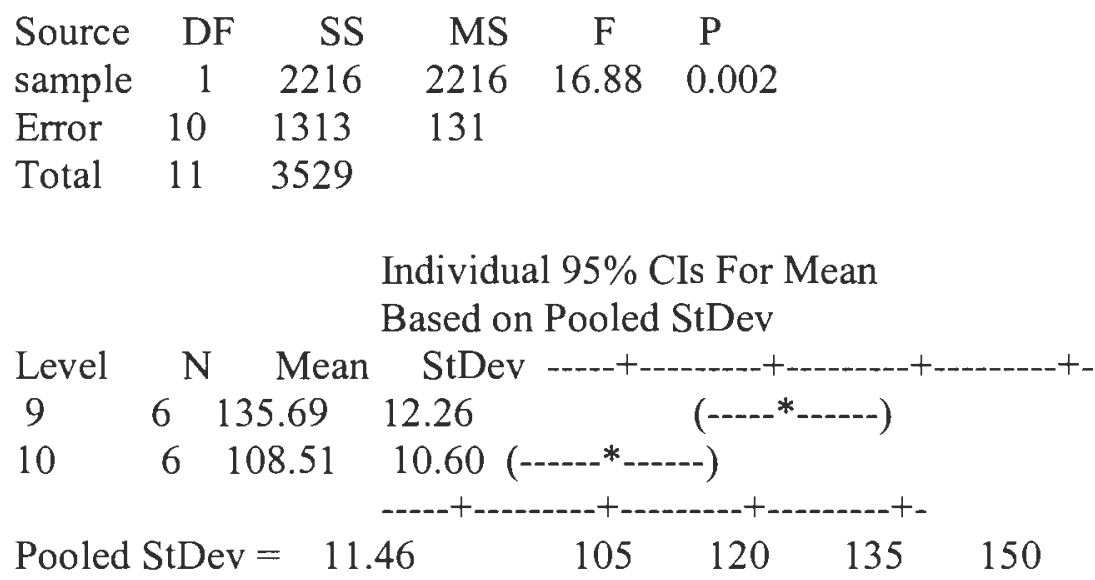

One-way ANOVA: release versus sample

Analysis of Variance for release 


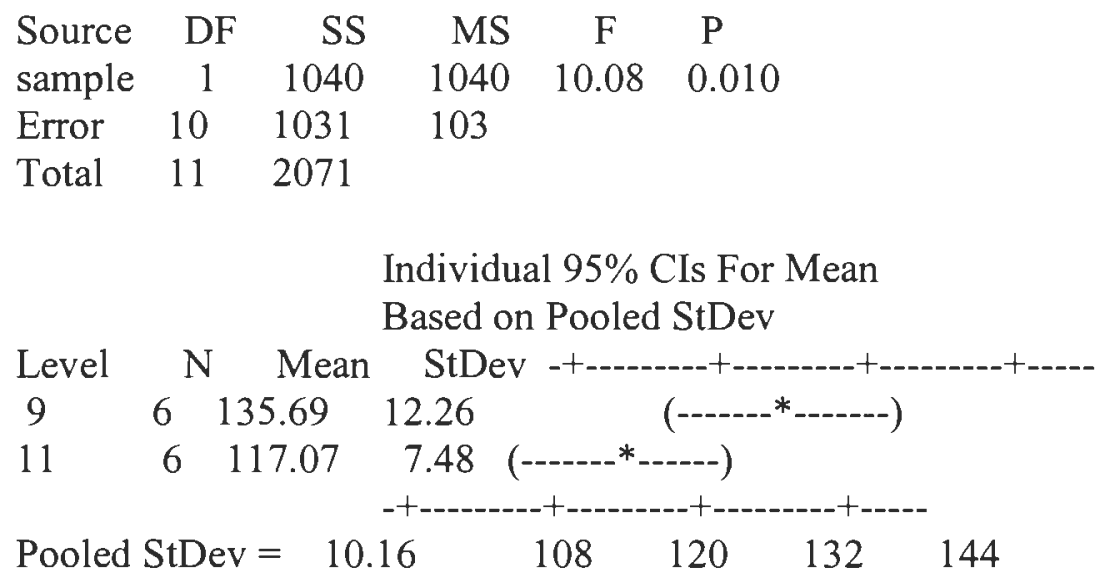

One-way ANOVA: release versus sample

Analysis of Variance for release

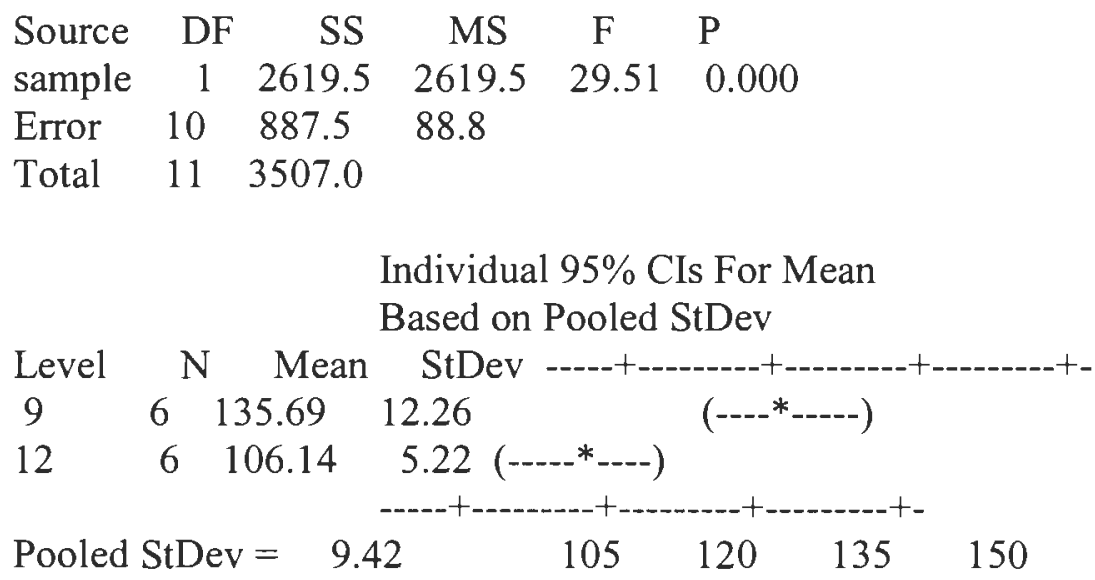

One-way ANOVA: release versus sample

Analysis of Variance for release

$\begin{array}{llllll}\text { Source } & \text { DF } & \text { SS } & \text { MS } & \text { F } & \text { P }\end{array}$ 


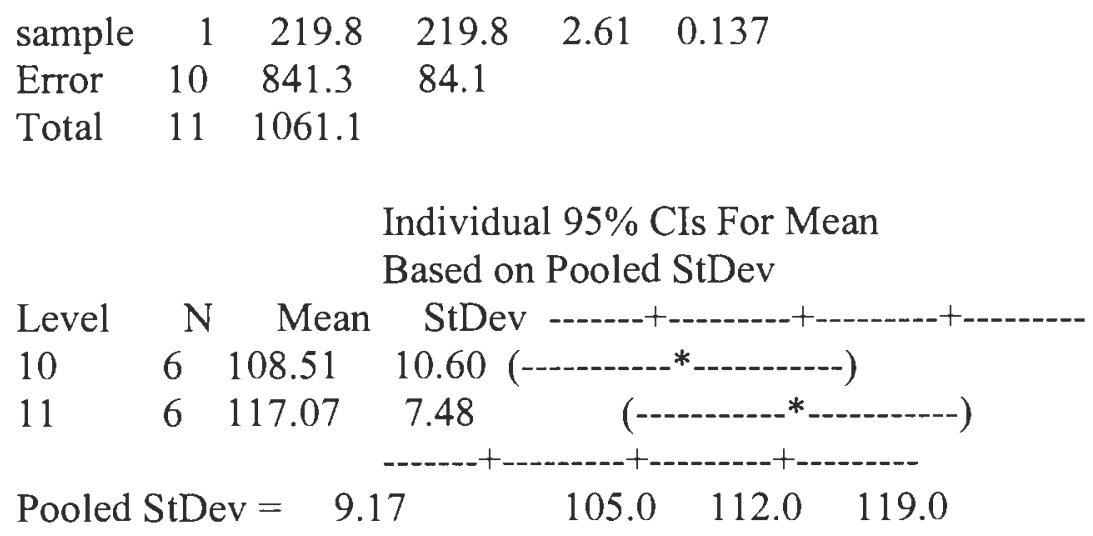

One-way ANOVA: release versus sample

Analysis of Variance for release

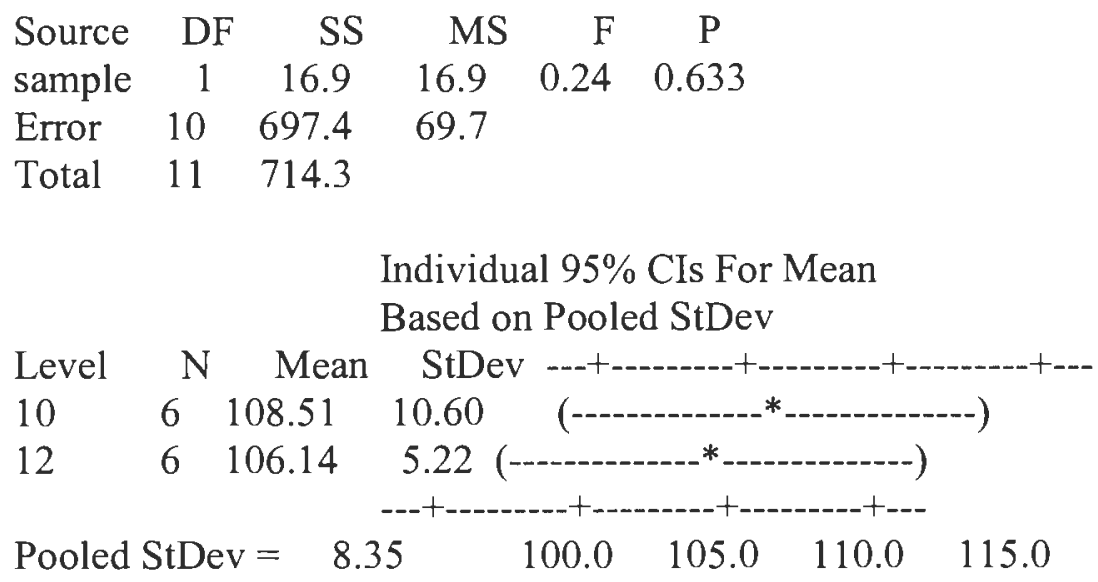

One-way ANOVA: release versus sample

Analysis of Variance for release

Source DF SS MS F $P$

$\begin{array}{llllll}\text { sample } & 1 & 358.5 & 358.5 & 8.62 & 0.015\end{array}$

Error $\quad 10 \quad 415.9 \quad 41.6$

Total $11 \quad 774.4$ 
Individual 95\% CIs For Mean

Based on Pooled StDev

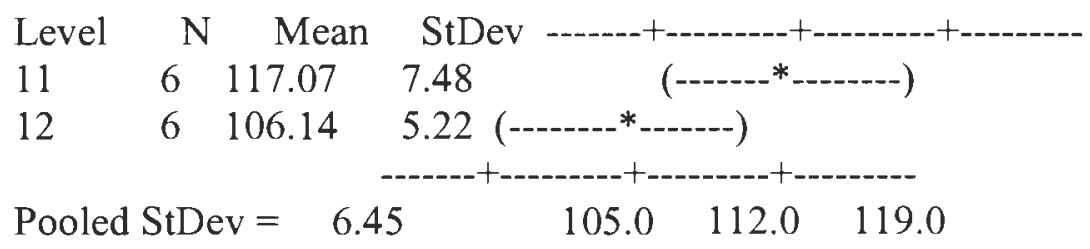

One-way ANOVA: release versus sample

Analysis of Variance for release

$\begin{array}{lcrrrr}\text { Source } & \text { DF } & \text { SS } & \text { MS } & \text { F } & \text { P } \\ \text { sample } & 1 & 789 & 789 & 6.13 & 0.025 \\ \text { Error } & 16 & 2058 & 129 & & \\ \text { Total } & 17 & 2847 & & & \end{array}$

Individual 95\% CIs For Mean

Based on Pooled StDev

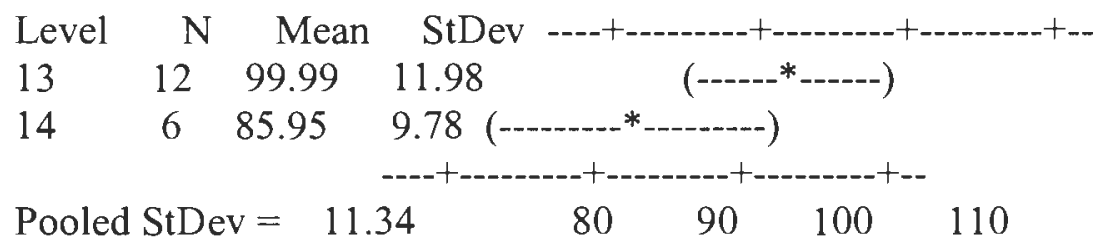

One-way ANOVA: release versus sample

Analysis of Variance for release

\begin{tabular}{lcrccc} 
Source & DF & SS & MS & F & P \\
sample & 1 & 3078 & 3078 & 20.88 & 0.000 \\
Error & 16 & 2359 & 147 & & \\
Total & 17 & 5438 & & \\
& & \multicolumn{4}{c}{$\begin{array}{l}\text { Individual 95\% CIs For Mean } \\
\end{array}$} \\
& \multicolumn{4}{c}{ Based on Pooled StDev }
\end{tabular}

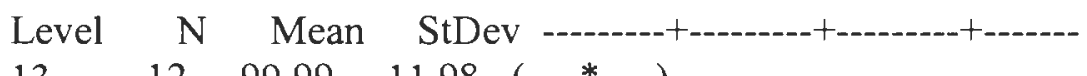

$13 \quad 1299.99 \quad 11.98 \quad(-\ldots *-\ldots--)$




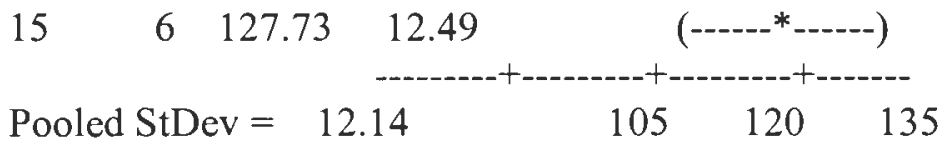

One-way ANOVA: release versus sample

Analysis of Variance for release

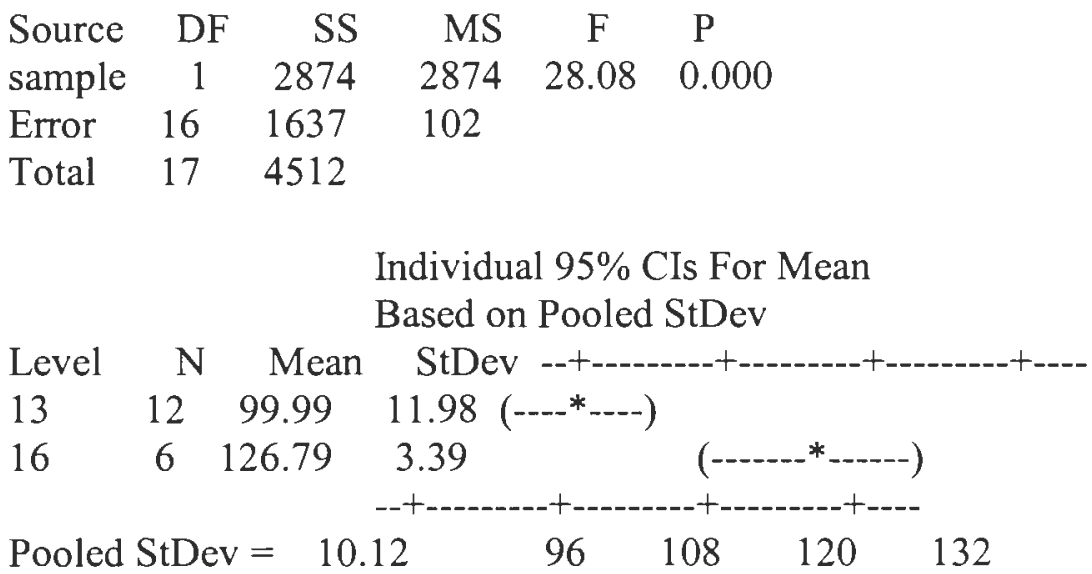

One-way ANOVA: release versus sample

Analysis of Variance for release

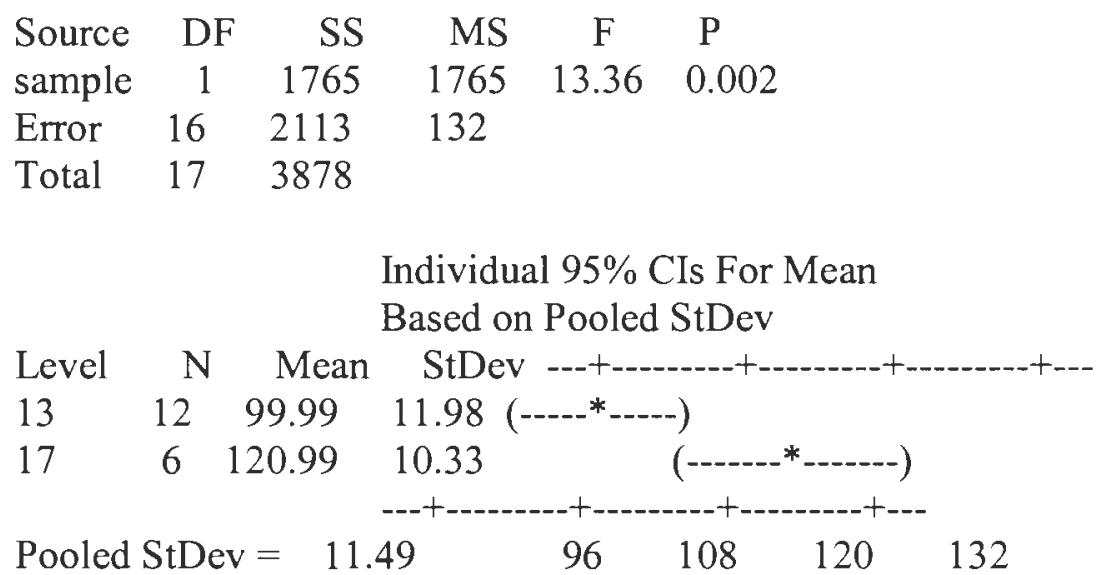


One-way ANOVA: release versus sample

Analysis of Variance for release

$\begin{array}{lrrrrc}\text { Source } & \text { DF } & \text { SS } & \text { MS } & \text { F } & \text { P } \\ \text { sample } & 1 & 1044 & 1044 & 6.32 & 0.023 \\ \text { Error } & 16 & 2642 & 165 & & \\ \text { Total } & 17 & 3686 & & & \end{array}$

Individual 95\% CIs For Mean

Based on Pooled StDev

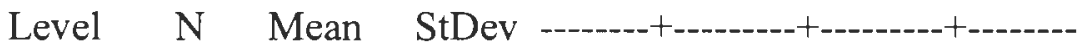

$13 \quad 12 \quad 99.99 \quad 11.98\left(-----*^{*}-\mathbf{-}^{----)}\right.$

$18 \quad 6 \quad 116.15 \quad 14.58 \quad$ (----------*----------)

$\begin{array}{llll}\text { Pooled StDev }= & 12.85 & 100 & 110\end{array}$

One-way ANOVA: release versus sample

Analysis of Variance for release

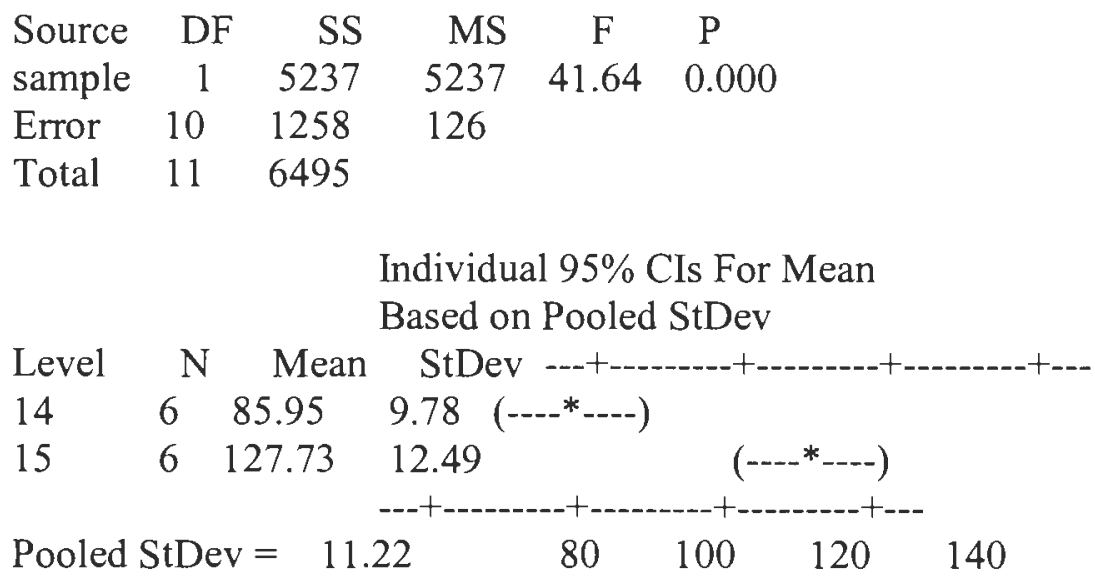

One-way ANOVA: release versus sample 
Analysis of Variance for release

\begin{tabular}{|c|c|c|c|c|}
\hline Source & $\mathrm{DF}$ & SS & MS & $\mathrm{P}$ \\
\hline sample & 1 & 5005.5 & 5005.5 & 0.000 \\
\hline Error & 10 & 536.0 & 53.6 & \\
\hline Total & 11 & 5541.5 & & \\
\hline \multicolumn{5}{|c|}{$\begin{array}{l}\text { Individual } 95 \% \text { CIs For Mean } \\
\text { Based on Pooled StDev }\end{array}$} \\
\hline Level & $\mathrm{N}$ & Mean & StDev ---.--+ & - \\
\hline 14 & 6 & 85.95 & 9.78 (---*----) & \\
\hline 16 & 6 & 126.79 & 3.39 & (----*---) \\
\hline Pooled & StD & $\mathrm{v}=$ & 90 & 120 \\
\hline
\end{tabular}

One-way ANOVA: release versus sample

Analysis of Variance for release

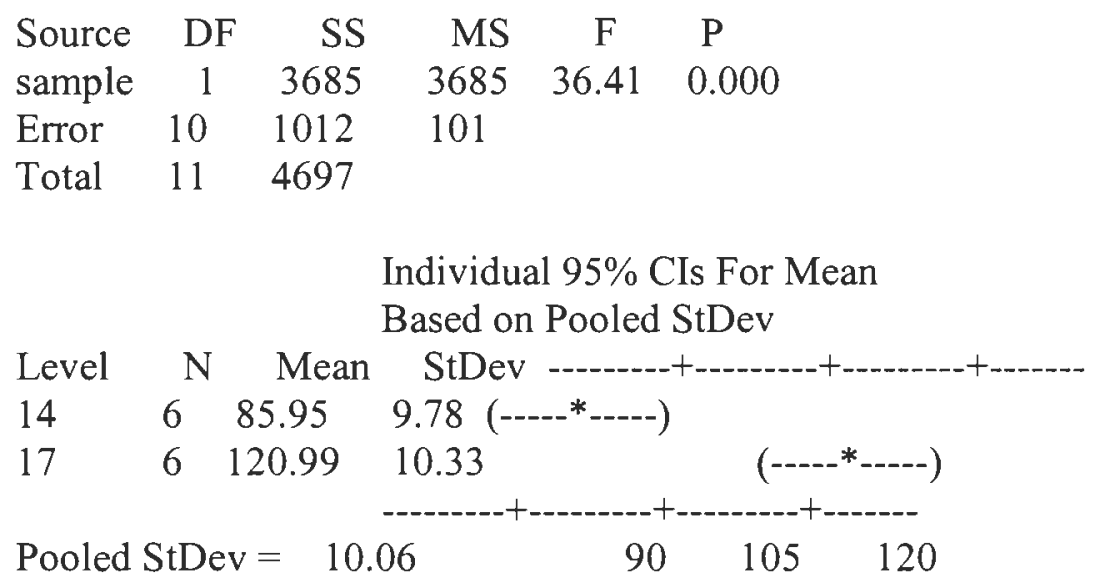

One-way ANOVA: release versus sample

Analysis of Variance for release 


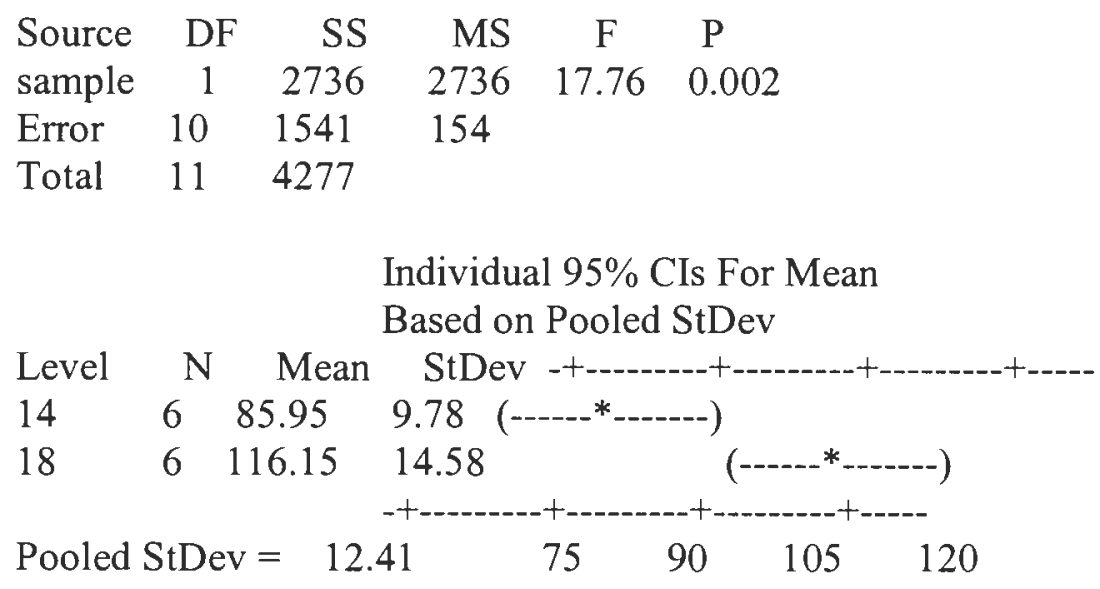

One-way ANOVA: release versus sample

Analysis of Variance for release

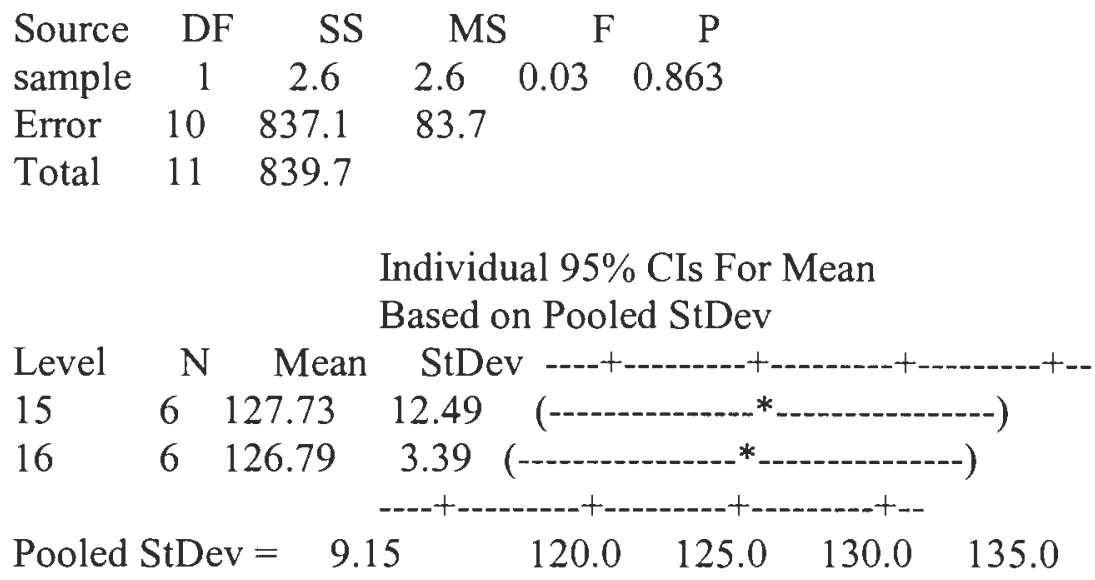

One-way ANOVA: release versus sample

Analysis of Variance for release

$\begin{array}{lcccrc}\text { Source } & \text { DF } & \text { SS } & \text { MS } & \text { F } & \text { P } \\ \text { sample } & 1 & 136 & 136 & 1.04 & 0.333 \\ \text { Error } & 10 & 1313 & 131 & & \\ \text { Total } & 11 & 1449 & & & \end{array}$




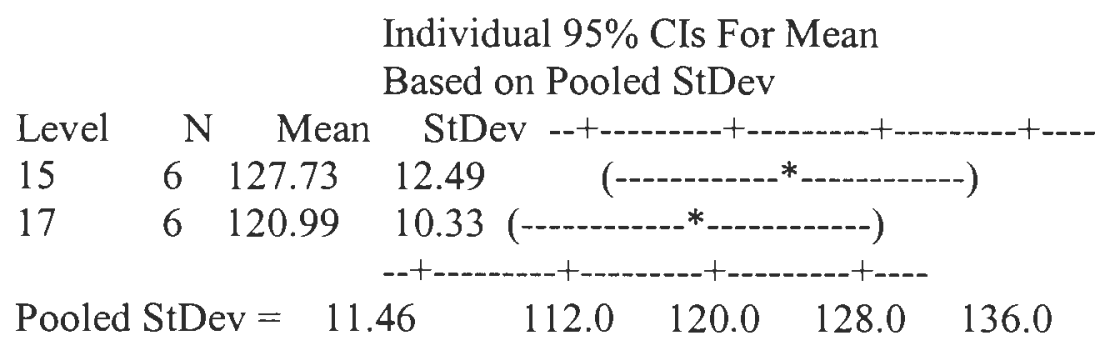

One-way ANOVA: release versus sample

Analysis of Variance for release

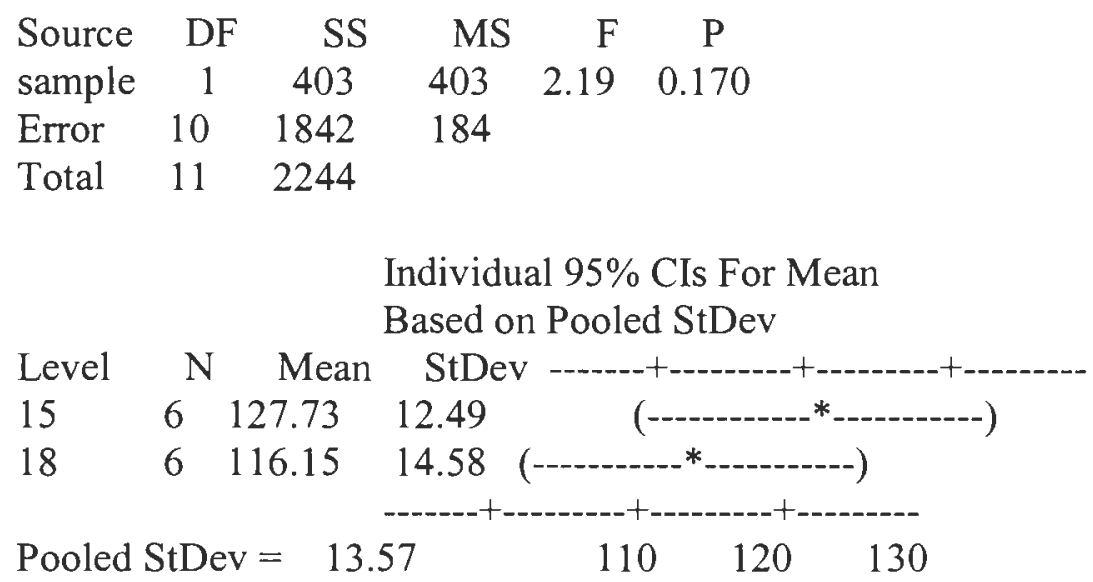

One-way ANOVA: release versus sample

Analysis of Variance for release

$\begin{array}{lcrrrc}\text { Source } & \text { DF } & \text { SS } & \text { MS } & \text { F } & \text { P } \\ \text { sample } & 1 & 100.9 & 100.9 & 1.71 & 0.221 \\ \text { Error } & 10 & 591.2 & 59.1 & & \\ \text { Total } & 11 & 692.1 & & & \end{array}$

Individual 95\% CIs For Mean

Based on Pooled StDev

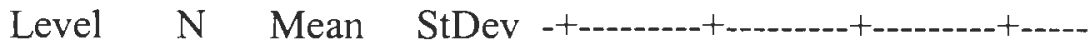




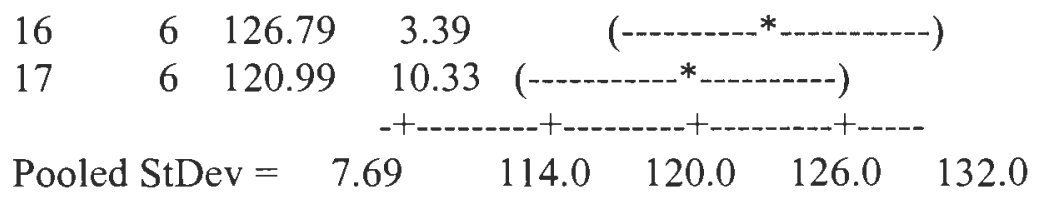

One-way ANOVA: release versus sample

Analysis of Variance for release

$\begin{array}{lrrrrr}\text { Source } & \text { DF } & \text { SS } & \text { MS } & \text { F } & \text { P } \\ \text { sample } & 1 & 485 & 485 & 3.88 & 0.077 \\ \text { Error } & 10 & 1250 & 125 & & \\ \text { Total } & 11 & 1735 & & & \end{array}$

Individual 95\% CIs For Mean

Based on Pooled StDev

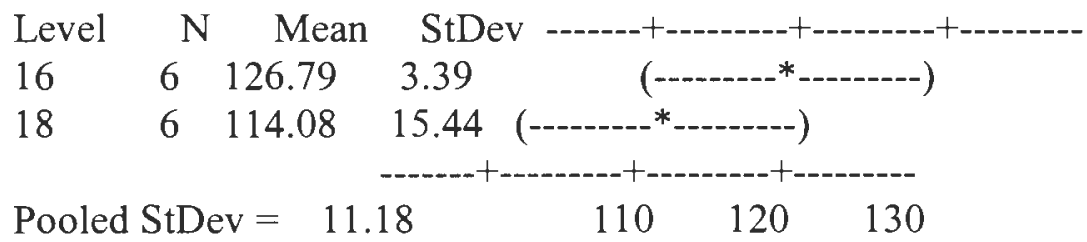

One-way ANOVA: release versus sample

Analysis of Variance for release

\begin{tabular}{lccccr} 
Source & DF & \multicolumn{1}{c}{ SS } & \multicolumn{1}{c}{ MS } & F & P \\
sample & 1 & 71 & 71 & 0.44 & 0.521 \\
Error & 10 & 1596 & 160 & & \\
Total & 11 & 1666 & & &
\end{tabular}

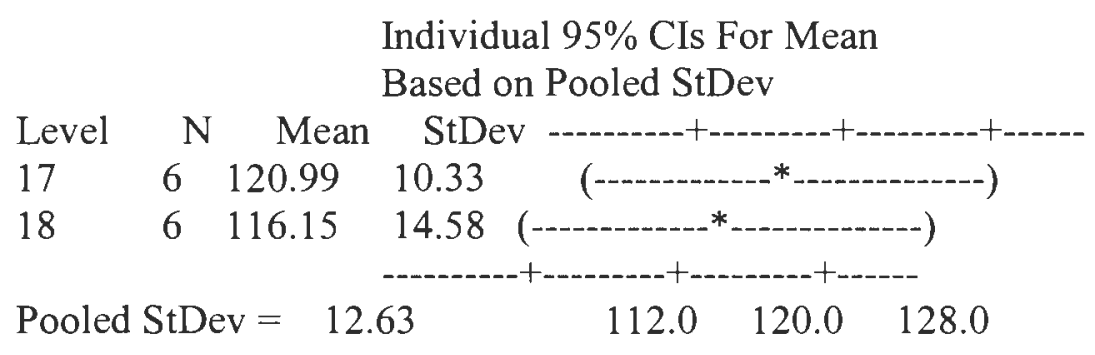


One-way ANOVA: release versus sample

Analysis of Variance for release

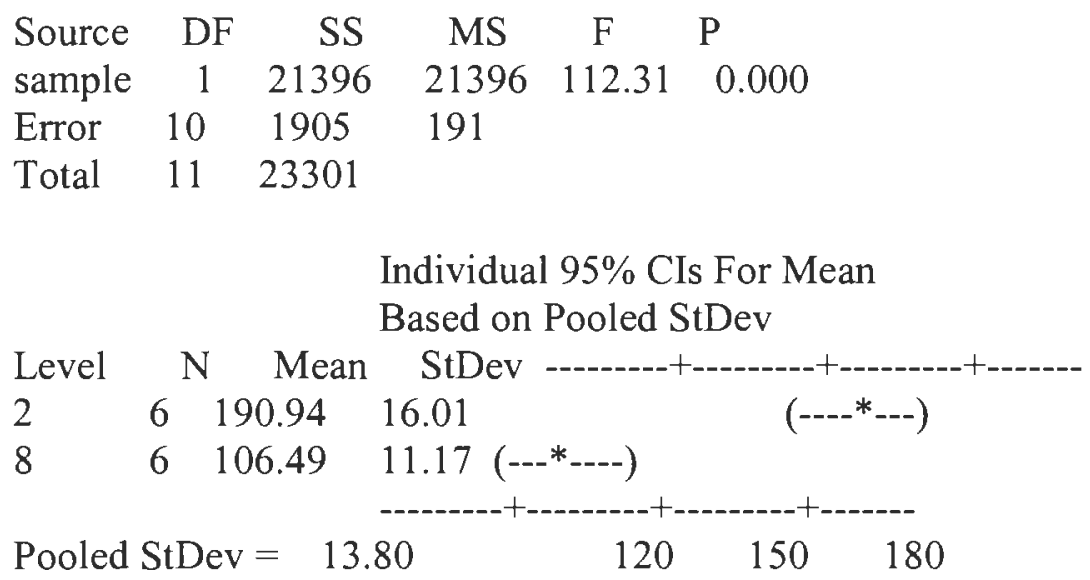

One-way ANOVA: release versus sample

Analysis of Variance for release

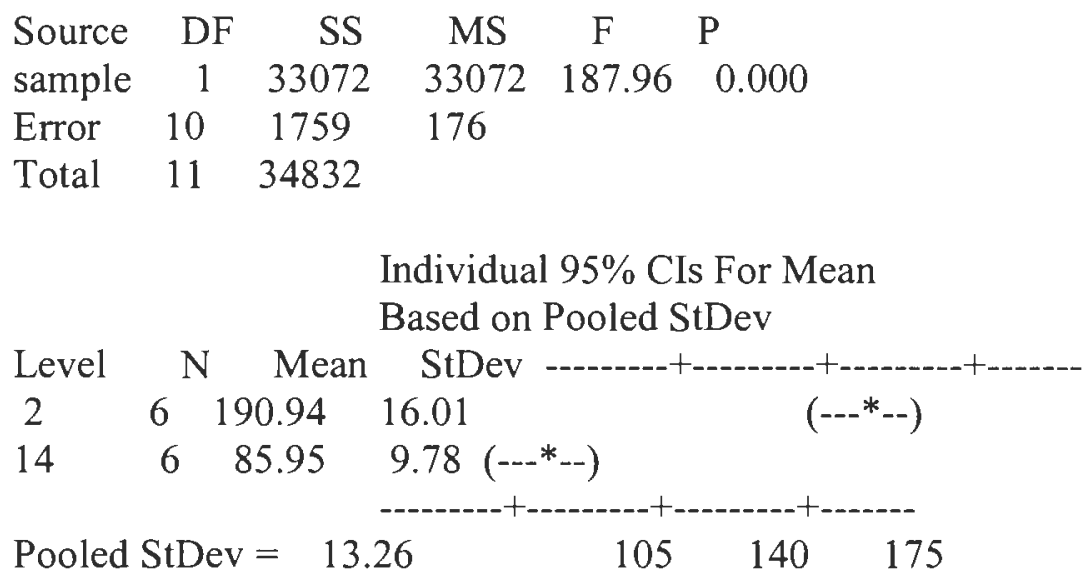

One-way ANOVA: release versus sample 
Analysis of Variance for release

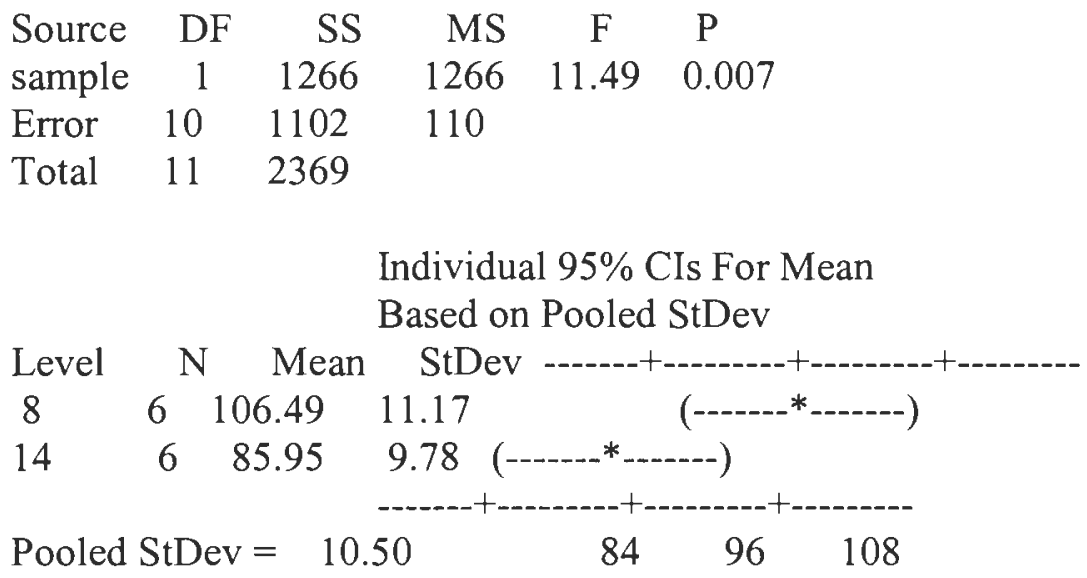

One-way ANOVA: release versus sample

Analysis of Variance for release

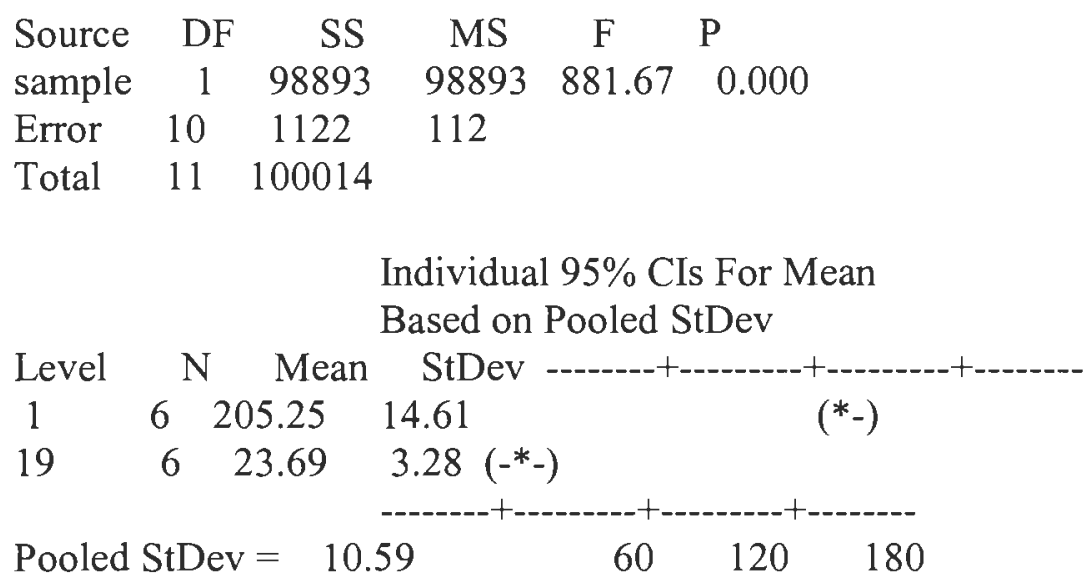

One-way ANOVA: release versus sample

Analysis of Variance for release 


\begin{tabular}{|c|c|c|c|c|}
\hline Source & $\mathrm{DH}$ & SS & MS & $\mathrm{P}$ \\
\hline sample & 1 & 727.24 & $727.24 \quad 134.42$ & 0.000 \\
\hline Error & 10 & 54.10 & 5.41 & \\
\hline Total & 11 & 781.35 & & \\
\hline \multicolumn{5}{|c|}{$\begin{array}{l}\text { Individual } 95 \% \text { CIs For Mean } \\
\text { Based on Pooled StDev }\end{array}$} \\
\hline Level & $\mathrm{N}$ & Mean & StDev --------- & †---------+-------. \\
\hline 19 & 6 & 23.692 & 3.277 & $(--*---)$ \\
\hline 20 & 6 & 8.122 & $0.281 \quad(---*--)$ & \\
\hline Pooled & StDe & $v=2.3$ & 12.0 & 18.0 \\
\hline
\end{tabular}


TABLE 77-1. RELEASE RATE VALUES OF KT FROM EIGHTEEN ORGANOGEL SAMPLES OF DIFFERENT COMPOSITIONS USING ANOVA ANALYSIS

\begin{tabular}{|c|c|}
\hline Sample & Release \\
\hline & \\
\hline 1 & 193.462 \\
\hline 1 & 189.029 \\
\hline 1 & 218.878 \\
\hline 1 & 201.939 \\
\hline 1 & 226.602 \\
\hline 1 & 201.607 \\
\hline 2 & 188.586 \\
\hline 2 & 212.267 \\
\hline 2 & 185.955 \\
\hline 2 & 205.616 \\
\hline 2 & 185.841 \\
\hline 2 & 167.392 \\
\hline 3 & 188.476 \\
\hline 3 & 172.851 \\
\hline 3 & 181.068 \\
\hline 3 & 179.897 \\
\hline 3 & 163.568 \\
\hline 3 & 166.396 \\
\hline 4 & 214.707 \\
\hline 4 & 229.885 \\
\hline 4 & 200.183 \\
\hline 4 & 207.001 \\
\hline 4 & 212.619 \\
\hline 4 & 243.068 \\
\hline 5 & 199.267 \\
\hline 5 & 228.531 \\
\hline 5 & 163.700 \\
\hline 5 & 204.391 \\
\hline 5 & 180.972 \\
\hline 5 & 188.843 \\
\hline 6 & 202.630 \\
\hline 6 & 199.084 \\
\hline 6 & 183.593 \\
\hline 6 & 207.560 \\
\hline 6 & 205.696 \\
\hline 6 & 193.403 \\
\hline 7 & 116.826 \\
\hline 7 & 103.124 \\
\hline 7 & 103.293 \\
\hline 7 & 116.732 \\
\hline 7 & 99.653 \\
\hline 7 & 101.051 \\
\hline 7 & 112.286 \\
\hline 7 & 99.690 \\
\hline & \\
\hline & 106.362 \\
\hline
\end{tabular}

\begin{tabular}{|c|c|}
\hline Sample & Release \\
\hline & \\
\hline 7 & 107.806 \\
\hline 7 & 97.370 \\
\hline 7 & 103.477 \\
\hline 8 & 112.276 \\
\hline 8 & 108.578 \\
\hline 8 & 93.037 \\
\hline 8 & 118.538 \\
\hline 8 & 114.197 \\
\hline 8 & 92.329 \\
\hline 9 & 129.893 \\
\hline 9 & 134.513 \\
\hline 9 & 114.461 \\
\hline 9 & 145.110 \\
\hline 9 & 145.842 \\
\hline 9 & 144.296 \\
\hline 10 & 100.848 \\
\hline 10 & 120.845 \\
\hline 10 & 114.105 \\
\hline 10 & 118.335 \\
\hline 10 & 101.666 \\
\hline 10 & 95.249 \\
\hline 11 & 105.571 \\
\hline 11 & 123.302 \\
\hline 11 & 110.272 \\
\hline 11 & 120.191 \\
\hline 11 & 124.084 \\
\hline 11 & 118.989 \\
\hline 12 & 109.824 \\
\hline 12 & 109.23 \\
\hline 12 & 105.747 \\
\hline 12 & 111.725 \\
\hline 12 & 97.945 \\
\hline 12 & 102.349 \\
\hline 13 & 104.238 \\
\hline 13 & 119.666 \\
\hline 13 & 117.554 \\
\hline 13 & 90.995 \\
\hline 13 & 108.509 \\
\hline 13 & 113.943 \\
\hline 13 & 90.983 \\
\hline 13 & 92.111 \\
\hline 13 & 93.054 \\
\hline 13 & 89.537 \\
\hline 13 & 88.406 \\
\hline 13 & 90.869 \\
\hline & \\
\hline 11
\end{tabular}

\begin{tabular}{|c|c|}
\hline Sample & Release \\
\hline & \\
\hline 14 & 91.258 \\
\hline 14 & 90.937 \\
\hline 14 & 96.537 \\
\hline 14 & 69.839 \\
\hline 14 & 78.962 \\
\hline 14 & 88.151 \\
\hline 15 & 133.435 \\
\hline 15 & 130.839 \\
\hline 15 & 102.449 \\
\hline 15 & 132.529 \\
\hline 15 & 135.439 \\
\hline 15 & 131.689 \\
\hline 16 & 130.506 \\
\hline 16 & 120.97 \\
\hline 16 & 125.567 \\
\hline 16 & 126.221 \\
\hline 16 & 129.214 \\
\hline 16 & 128.289 \\
\hline 17 & 133.056 \\
\hline 17 & 124.342 \\
\hline 17 & 104.021 \\
\hline 17 & 113.900 \\
\hline 17 & 126.031 \\
\hline 17 & 124.615 \\
\hline 18 & 136.014 \\
\hline 18 & 129.529 \\
\hline 18 & 114.354 \\
\hline 18 & 110.060 \\
\hline 18 & 95.513 \\
\hline 18 & 111.408 \\
\hline & \\
\hline
\end{tabular}


TABLE 77-1. CONT'D.

\begin{tabular}{|c|c|c|c|c|c|}
\hline Sample1,2 & Release1,2 & Sample1,3 & Release1,3 & Sample1,4 & Release 1,4 \\
\hline & & & & & \\
\hline 1 & 193.462 & 1 & 193.462 & 1 & 193.462 \\
\hline 1 & 189.029 & 1 & 189.029 & 1 & 189.029 \\
\hline 1 & 218.878 & 1 & 218.878 & 1 & 218.878 \\
\hline 1 & 201.939 & 1 & 201.939 & 1 & 201.939 \\
\hline 1 & 226.602 & 1 & 226.602 & 1 & 226.602 \\
\hline 1 & 201.607 & 1 & 201.607 & 1 & 201.607 \\
\hline 2 & 188.586 & 3 & 188.476 & 4 & 214.707 \\
\hline 2 & 212.267 & 3 & 172.851 & 4 & 229.885 \\
\hline 2 & 185.955 & 3 & 181.068 & 4 & 200.183 \\
\hline 2 & 205.616 & 3 & 179.897 & 4 & 207.001 \\
\hline 2 & 185.841 & 3 & 163.568 & 4 & 212.619 \\
\hline 2 & 167.392 & 3 & 166.396 & 4 & 243.068 \\
\hline
\end{tabular}

\begin{tabular}{|c|c|c|c|c|c|}
\hline Sample1,5 & Release1,5 & Sample1,6 & Release1,6 & Sample2,3 & Release2,3 \\
\hline & & & & & \\
\hline 1 & 193.462 & 1 & 193.462 & 2 & 188.586 \\
\hline 1 & 189.029 & 1 & 189.029 & 2 & 212.267 \\
\hline 1 & 218.878 & 1 & 218.878 & 2 & 185.955 \\
\hline 1 & 201.939 & 1 & 201.939 & 2 & 205.616 \\
\hline 1 & 226.602 & 1 & 226.602 & 2 & 185.841 \\
\hline 1 & 201.607 & 1 & 201.607 & 2 & 167.392 \\
\hline 5 & 199.267 & 6 & 202.630 & 3 & 188.476 \\
\hline 5 & 228.531 & 6 & 199.084 & 3 & 172.851 \\
\hline 5 & 163.700 & 6 & 183.593 & 3 & 181.068 \\
\hline 5 & 204.391 & 6 & 207.56 & 3 & 179.897 \\
\hline 5 & 180.972 & 6 & 205.696 & 3 & 163.568 \\
\hline 5 & 188.843 & 6 & 193.403 & 3 & 166.396 \\
\hline
\end{tabular}

\begin{tabular}{|c|c|c|c|c|c|}
\hline Sample2,4 & Release2,4 & Sample2,5 & Release2,5 & Sample2,6 & Release2,6 \\
\hline & & & & & \\
\hline 2 & 188.586 & 2 & 188.586 & 2 & 188.586 \\
\hline 2 & 212.267 & 2 & 212.267 & 2 & 212.267 \\
\hline 2 & 185.955 & 2 & 185.955 & 2 & 185.955 \\
\hline 2 & 205.616 & 2 & 205.616 & 2 & 205.616 \\
\hline 2 & 185.841 & 2 & 185.841 & 2 & 185.841 \\
\hline 2 & 167.392 & 2 & 167.392 & 2 & 167.392 \\
\hline 4 & 214.707 & 5 & 199.267 & 6 & 202.63 \\
\hline 4 & 229.885 & 5 & 228.531 & 6 & 199.084 \\
\hline 4 & 200.183 & 5 & 163.700 & 6 & 183.593 \\
\hline 4 & 207.001 & 5 & 204.391 & 6 & 207.56 \\
\hline 4 & 212.619 & 5 & 180.972 & 6 & 205.696 \\
\hline 4 & 243.068 & 5 & 188.843 & 6 & 193.403 \\
\hline
\end{tabular}


TABLE 77-1. CONT'D.

\begin{tabular}{|c|c|c|c|c|c|}
\hline Sample1,2 & Release1,2 & Sample1,3 & Release1,3 & Sample1,4 & Release 1,4 \\
\hline & & & & & \\
\hline 1 & 193.462 & 1 & 193.462 & 1 & 193.462 \\
\hline 1 & 189.029 & 1 & 189.029 & 1 & 189.029 \\
\hline 1 & 218.878 & 1 & 218.878 & 1 & 218.878 \\
\hline 1 & 201.939 & 1 & 201.939 & 1 & 201.939 \\
\hline 1 & 226.602 & 1 & 226.602 & 1 & 226.602 \\
\hline 1 & 201.607 & 1 & 201.607 & 1 & 201.607 \\
\hline 2 & 188.586 & 3 & 188.476 & 4 & 214.707 \\
\hline 2 & 212.267 & 3 & 172.851 & 4 & 229.885 \\
\hline 2 & 185.955 & 3 & 181.068 & 4 & 200.183 \\
\hline 2 & 205.616 & 3 & 179.897 & 4 & 207.001 \\
\hline 2 & 185.841 & 3 & 163.568 & 4 & 212.619 \\
\hline 2 & 167.392 & 3 & 166.396 & 4 & 243.068 \\
\hline
\end{tabular}

\begin{tabular}{|c|c|c|c|c|c|}
\hline Sample1,5 & Release1,5 & Sample1,6 & Release1,6 & Sample2,3 & Release2,3 \\
\hline & & & & & \\
\hline 1 & 193.462 & 1 & 193.462 & 2 & 188.586 \\
\hline 1 & 189.029 & 1 & 189.029 & 2 & 212.267 \\
\hline 1 & 218.878 & 1 & 218.878 & 2 & 185.955 \\
\hline 1 & 201.939 & 1 & 201.939 & 2 & 205.616 \\
\hline 1 & 226.602 & 1 & 226.602 & 2 & 185.841 \\
\hline 1 & 201.607 & 1 & 201.607 & 2 & 167.392 \\
\hline 5 & 199.267 & 6 & 202.630 & 3 & 188.476 \\
\hline 5 & 228.531 & 6 & 199.084 & 3 & 172.851 \\
\hline 5 & 163.700 & 6 & 183.593 & 3 & 181.068 \\
\hline 5 & 204.391 & 6 & 207.56 & 3 & 179.897 \\
\hline 5 & 180.972 & 6 & 205.696 & 3 & 163.568 \\
\hline 5 & 188.843 & 6 & 193.403 & 3 & 166.396 \\
\hline
\end{tabular}

\begin{tabular}{|c|c|c|c|c|c|}
\hline Sample2,4 & Release2,4 & Sample2,5 & Release2,5 & Sample2,6 & Release2,6 \\
\hline & & & & & \\
\hline 2 & 188.586 & 2 & 188.586 & 2 & 188.586 \\
\hline 2 & 212.267 & 2 & 212.267 & 2 & 212.267 \\
\hline 2 & 185.955 & 2 & 185.955 & 2 & 185.955 \\
\hline 2 & 205.616 & 2 & 205.616 & 2 & 205.616 \\
\hline 2 & 185.841 & 2 & 185.841 & 2 & 185.841 \\
\hline 2 & 167.392 & 2 & 167.392 & 2 & 167.392 \\
\hline 4 & 214.707 & 5 & 199.267 & 6 & 202.63 \\
\hline 4 & 229.885 & 5 & 228.531 & 6 & 199.084 \\
\hline 4 & 200.183 & 5 & 163.700 & 6 & 183.593 \\
\hline 4 & 207.001 & 5 & 204.391 & 6 & 207.56 \\
\hline 4 & 212.619 & 5 & 180.972 & 6 & 205.696 \\
\hline 4 & 243.068 & 5 & 188.843 & 6 & 193.403 \\
\hline
\end{tabular}


TABLE 77-1. CONT'D.

\begin{tabular}{|c|c|c|c|c|c|}
\hline Sample7,8 & Release7,8 & Sample7,9 & Release7,9 & Sample7,10 & Release7,10 \\
\hline & & & & & \\
\hline 7 & 116.826 & 7 & 116.826 & 7 & 116.826 \\
\hline 7 & 103.124 & 7 & 103.124 & 7 & 103.124 \\
\hline 7 & 103.293 & 7 & 103.293 & 7 & 103.293 \\
\hline 7 & 116.732 & 7 & 116.732 & 7 & 116.732 \\
\hline 7 & 99.653 & 7 & 99.653 & 7 & 99.653 \\
\hline 7 & 101.051 & 7 & 101.051 & 7 & 101.051 \\
\hline 7 & 112.286 & 7 & 112.286 & 7 & 112.286 \\
\hline 7 & 99.69 & 7 & 99.69 & 7 & 99.690 \\
\hline 7 & 106.362 & 7 & 106.362 & 7 & 106.362 \\
\hline 7 & 107.806 & 7 & 107.806 & 7 & 107.806 \\
\hline 7 & 97.370 & 7 & 97.37 & 7 & 97.370 \\
\hline 7 & 103.477 & 7 & 103.477 & 7 & 103.477 \\
\hline 8 & 112.276 & 9 & 129.893 & 10 & 100.848 \\
\hline 8 & 108.578 & 9 & 134.513 & 10 & 120.845 \\
\hline 8 & 93.037 & 9 & 114.461 & 10 & 114.105 \\
\hline 8 & 118.538 & 9 & 145.11 & 10 & 118.335 \\
\hline 8 & 114.197 & 9 & 145.842 & 10 & 101.666 \\
\hline 8 & 92.329 & 9 & 144.296 & 10 & 95.249 \\
\hline
\end{tabular}

\begin{tabular}{|c|c|c|c|c|c|}
\hline Sample7,11 & Release7,11 & Sample7,12 & Release7,12 & Sample8,9 & Release8,9 \\
\hline 7 & 116.826 & 7 & 116.826 & 8 & 112.276 \\
\hline 7 & 103.124 & 7 & 103.124 & 8 & 108.578 \\
\hline 7 & 103.293 & 7 & 103.293 & 8 & 93.037 \\
\hline 7 & 116.732 & 7 & 116.732 & 8 & 118.538 \\
\hline 7 & 99.653 & 7 & 99.653 & 8 & 114.197 \\
\hline 7 & 101.051 & 7 & 101.051 & 8 & 92.329 \\
\hline 7 & 112.286 & 7 & 112.286 & 9 & 129.893 \\
\hline 7 & 99.69 & 7 & 99.690 & 9 & 134.513 \\
\hline 7 & 106.362 & 7 & 106.362 & 9 & 114.461 \\
\hline 7 & 107.806 & 7 & 107.806 & 9 & 145.110 \\
\hline 7 & 97.370 & 7 & 97.370 & 9 & 145.842 \\
\hline 7 & 103.477 & 7 & 103.477 & 9 & 144.296 \\
\hline 11 & 105.571 & 12 & 109.824 & & \\
\hline 11 & 123.302 & 12 & 109.23 & & \\
\hline 11 & 110.272 & 12 & 105.747 & & \\
\hline 11 & 120.191 & 12 & 111.725 & & \\
\hline 11 & 124.084 & 12 & 97.945 & & \\
\hline 11 & 118.989 & 12 & 102.349 & & \\
\hline
\end{tabular}


TABLE 77-1. CONT'D.

\begin{tabular}{|c|c|c|c|c|c|}
\hline Sample8,10 & Release8,10 & Sample8,11 & Release8,11 & Sample8,12 & Release8,12 \\
\hline & & & & & \\
\hline 8 & 112.276 & 8 & 112.276 & 8 & 112.276 \\
\hline 8 & 108.578 & 8 & 108.578 & 8 & 108.578 \\
\hline 8 & 93.037 & 8 & 93.037 & 8 & 93.037 \\
\hline 8 & 118.538 & 8 & 118.538 & 8 & 118.538 \\
\hline 8 & 114.197 & 8 & 114.197 & 8 & 114.197 \\
\hline 8 & 92.329 & 8 & 92.329 & 8 & 92.329 \\
\hline 10 & 100.848 & 11 & 105.571 & 12 & 109.824 \\
\hline 10 & 120.845 & 11 & 123.302 & 12 & 109.23 \\
\hline 10 & 114.105 & 11 & 110.272 & 12 & 105.747 \\
\hline 10 & 118.335 & 11 & 120.191 & 12 & 111.725 \\
\hline 10 & 101.666 & 11 & 124.084 & 12 & 97.945 \\
\hline 10 & 95.249 & 11 & 118.989 & 12 & 102.349 \\
\hline
\end{tabular}

\begin{tabular}{|c|c|c|c|c|c|}
\hline Sample9,10 & Release9,10 & Sample9,11 & Release9,11 & Sample9,12 & Release9,12 \\
\hline 9 & 129.893 & 9 & 129.893 & 9 & 129.893 \\
\hline 9 & 134.513 & 9 & 134.513 & 9 & 134.513 \\
\hline 9 & 114.461 & 9 & 114.461 & 9 & 114.461 \\
\hline 9 & 145.11 & 9 & 145.110 & 9 & 145.110 \\
\hline 9 & 145.842 & 9 & 145.842 & 9 & 145.842 \\
\hline 9 & 144.296 & 9 & 144.296 & 9 & 144.296 \\
\hline 10 & 100.848 & 11 & 105.571 & 12 & 109.824 \\
\hline 10 & 120.845 & 11 & 123.302 & 12 & 109.230 \\
\hline 10 & 114.105 & 11 & 110.272 & 12 & 105.747 \\
\hline 10 & 118.335 & 11 & 120.191 & 12 & 111.725 \\
\hline 10 & 101.666 & 11 & 124.084 & 12 & 97.945 \\
\hline 10 & 95.249 & 11 & 118.989 & 12 & 102.349 \\
\hline
\end{tabular}

\begin{tabular}{|c|c|c|c|c|c|}
\hline Sample10,11 & Release10,11 & Sample10,12 & Release10,12 & Sample11,12 & Release11,12 \\
\hline 10 & 100.848 & 10 & 100.848 & 11 & 105.571 \\
\hline 10 & 120.845 & 10 & 120.845 & 11 & 123.302 \\
\hline 10 & 114.105 & 10 & 114.105 & 11 & 110.272 \\
\hline 10 & 118.335 & 10 & 118.335 & 11 & 120.191 \\
\hline 10 & 101.666 & 10 & 101.666 & 11 & 124.084 \\
\hline 10 & 95.249 & 10 & 95.249 & 11 & 118.989 \\
\hline 11 & 105.571 & 12 & 109.824 & 12 & 109.824 \\
\hline 11 & 123.302 & 12 & 109.230 & 12 & 109.23 \\
\hline 11 & 110.272 & 12 & 105.747 & 12 & 105.747 \\
\hline 11 & 120.191 & 12 & 111.725 & 12 & 111.725 \\
\hline 11 & 124.084 & 12 & 97.945 & 12 & 97.945 \\
\hline 11 & 118.989 & 12 & 102.349 & 12 & 102.349 \\
\hline
\end{tabular}


TABLE 77-1. CONT'D.

\begin{tabular}{|c|c|c|c|c|c|}
\hline Sample13,14 & Release13,14 & Sample13,15 & Release13,15 & Sampe13,16 & Release13,16 \\
\hline & & & & & \\
\hline 13 & 104.238 & 13 & 104.238 & 13 & 104.238 \\
\hline 13 & 119.666 & 13 & 119.666 & 13 & 119.666 \\
\hline 13 & 117.554 & 13 & 117.554 & 13 & 117.554 \\
\hline 13 & 90.995 & 13 & 90.995 & 13 & 90.995 \\
\hline 13 & 108.509 & 13 & 108.509 & 13 & 108.509 \\
\hline 13 & 113.943 & 13 & 113.943 & 13 & 113.943 \\
\hline 13 & 90.983 & 13 & 90.983 & 13 & 90.983 \\
\hline 13 & 92.111 & 13 & 92.111 & 13 & 92.111 \\
\hline 13 & 93.054 & 13 & 93.054 & 13 & 93.054 \\
\hline 13 & 89.537 & 13 & 89.537 & 13 & 89.537 \\
\hline 13 & 88.406 & 13 & 88.406 & 13 & 88.406 \\
\hline 13 & 90.869 & 13 & 90.869 & 13 & 90.869 \\
\hline 14 & 91.258 & 15 & 133.435 & 16 & 130.506 \\
\hline 14 & 90.937 & 15 & 130.839 & 16 & 120.970 \\
\hline 14 & 96.537 & 15 & 102.449 & 16 & 125.567 \\
\hline 14 & 69.839 & 15 & 132.529 & 16 & 126.221 \\
\hline 14 & 78.962 & 15 & 135.439 & 16 & 129.214 \\
\hline 14 & 88.151 & 15 & 131.689 & 16 & 128.289 \\
\hline
\end{tabular}

\begin{tabular}{|c|c|c|c|c|c|}
\hline Sample13,17 & Release13,17 & Sample13,18 & Release13,18 & Sample14,15 & Release14,15 \\
\hline & & & & & \\
\hline 13 & 104.238 & 13 & 104.238 & 14 & 91.258 \\
\hline 13 & 119.666 & 13 & 119.666 & 14 & 90.937 \\
\hline 13 & 117.554 & 13 & 117.554 & 14 & 96.537 \\
\hline 13 & 90.995 & 13 & 90.995 & 14 & 69.839 \\
\hline 13 & 108.509 & 13 & 108.509 & 14 & 78.962 \\
\hline 13 & 113.943 & 13 & 113.943 & 14 & 88.151 \\
\hline 13 & 90.983 & 13 & 90.983 & 15 & 133.435 \\
\hline 13 & 92.111 & 13 & 92.111 & 15 & 130.839 \\
\hline 13 & 93.054 & 13 & 93.054 & 15 & 102.449 \\
\hline 13 & 89.537 & 13 & 89.537 & 15 & 132.529 \\
\hline 13 & 88.406 & 13 & 88.406 & 15 & 135.439 \\
\hline 13 & 90.869 & 13 & 90.869 & 15 & 131.689 \\
\hline 17 & 133.056 & 18 & 136.014 & & \\
\hline 17 & 124.342 & 18 & 129.529 & & \\
\hline 17 & 104.021 & 18 & 114.354 & & \\
\hline 17 & 113.900 & 18 & 110.060 & & \\
\hline 17 & 126.031 & 18 & 95.513 & & \\
\hline 17 & 124.615 & 18 & 111.408 & & \\
\hline
\end{tabular}


TABLE 77-1. CONT'D.

\begin{tabular}{|c|c|c|c|c|c|}
\hline Sample14,16 & Release14,16 & Sample14,17 & Release14,17 & Sample14,18 & Release14,18 \\
\hline & & & & & \\
\hline 14 & 91.258 & 14 & 91.258 & 14 & 91.258 \\
\hline 14 & 90.937 & 14 & 90.937 & 14 & 90.937 \\
\hline 14 & 96.537 & 14 & 96.537 & 14 & 96.537 \\
\hline 14 & 69.839 & 14 & 69.839 & 14 & 69.839 \\
\hline 14 & 78.962 & 14 & 78.962 & 14 & 78.962 \\
\hline 14 & 88.151 & 14 & 88.151 & 14 & 88.151 \\
\hline 16 & 130.506 & 17 & 133.056 & 18 & 136.014 \\
\hline 16 & 120.970 & 17 & 124.342 & 18 & 129.529 \\
\hline 16 & 125.567 & 17 & 104.021 & 18 & 114.354 \\
\hline 16 & 126.221 & 17 & 113.900 & 18 & 110.060 \\
\hline 16 & 129.214 & 17 & 126.031 & 18 & 95.513 \\
\hline 16 & 128.289 & 17 & 124.615 & 18 & 111.408 \\
\hline
\end{tabular}

\begin{tabular}{|c|c|c|c|c|c|}
\hline Sample15,16 & Release15,16 & Sample15,17 & Release15,17 & Sample15,18 & Release15,18 \\
\hline & & & & & \\
\hline 15 & 133.435 & 15 & 133.435 & 15 & 133.435 \\
\hline 15 & 130.839 & 15 & 130.839 & 15 & 130.839 \\
\hline 15 & 102.449 & 15 & 102.449 & 15 & 102.449 \\
\hline 15 & 132.529 & 15 & 132.529 & 15 & 132.529 \\
\hline 15 & 135.439 & 15 & 135.439 & 15 & 135.439 \\
\hline 15 & 131.689 & 15 & 131.689 & 15 & 131.689 \\
\hline 16 & 130.506 & 17 & 133.056 & 18 & 136.014 \\
\hline 16 & 120.970 & 17 & 124.342 & 18 & 129.529 \\
\hline 16 & 125.567 & 17 & 104.021 & 18 & 114.354 \\
\hline 16 & 126.221 & 17 & 113.900 & 18 & 110.060 \\
\hline 16 & 129.214 & 17 & 126.031 & 18 & 95.513 \\
\hline 16 & 128.289 & 17 & 124.615 & 18 & 111.408 \\
\hline
\end{tabular}

\begin{tabular}{|c|c|c|c|c|c|}
\hline Sample16,17 & Release16,17 & Sample16,18 & Release16,18 & Sample17,18 & Release17,18 \\
\hline & & & & & \\
\hline 16 & 130.506 & 16 & 130.506 & 17 & 133.056 \\
\hline 16 & 120.97 & 16 & 120.97 & 17 & 124.342 \\
\hline 16 & 125.567 & 16 & 125.567 & 17 & 104.021 \\
\hline 16 & 126.221 & 16 & 126.221 & 17 & 113.900 \\
\hline 16 & 129.214 & 16 & 129.214 & 17 & 126.031 \\
\hline 16 & 128.289 & 16 & 128.289 & 17 & 124.615 \\
\hline 17 & 133.056 & 18 & 133.61 & 18 & 136.014 \\
\hline 17 & 124.342 & 18 & 124.639 & 18 & 129.529 \\
\hline 17 & 104.021 & 18 & 119.301 & 18 & 114.354 \\
\hline 17 & 113.900 & 18 & 107.949 & 18 & 110.060 \\
\hline 17 & 126.031 & 18 & 89.265 & 18 & 95.513 \\
\hline 17 & 124.615 & 18 & 109.717 & 18 & 111.408 \\
\hline
\end{tabular}


TABLE 77-1. CONT'D.

\begin{tabular}{|c|c|c|c|c|c|}
\hline Sample2,8 & Release2,8 & Sample2,14 & Release2,14 & Sample8,14 & Release8,14 \\
\hline & & & & & \\
\hline 2 & 188.586 & 2 & 188.586 & 8 & 112.276 \\
\hline 2 & 212.267 & 2 & 212.267 & 8 & 108.578 \\
\hline 2 & 185.955 & 2 & 185.955 & 8 & 93.037 \\
\hline 2 & 205.616 & 2 & 205.616 & 8 & 118.538 \\
\hline 2 & 185.841 & 2 & 185.841 & 8 & 114.197 \\
\hline 2 & 167.392 & 2 & 167.392 & 8 & 92.329 \\
\hline 8 & 112.276 & 14 & 91.258 & 14 & 91.258 \\
\hline 8 & 108.578 & 14 & 90.937 & 14 & 90.937 \\
\hline 8 & 93.037 & 14 & 96.537 & 14 & 96.537 \\
\hline 8 & 118.538 & 14 & 69.839 & 14 & 69.839 \\
\hline 8 & 114.197 & 14 & 78.962 & 14 & 78.962 \\
\hline 8 & 92.329 & 14 & 88.151 & 14 & 88.151 \\
\hline
\end{tabular}

\begin{tabular}{|c|c|c|c|}
\hline Sample1,19 & Release1,19 & Sample19,20 & Release19,20 \\
\hline & & & \\
\hline 1 & 193.462 & 19 & 27.174 \\
\hline 1 & 189.029 & 19 & 23.954 \\
\hline 1 & 218.878 & 19 & 27.424 \\
\hline 1 & 201.939 & 19 & 22.108 \\
\hline 1 & 226.602 & 19 & 18.781 \\
\hline 1 & 201.607 & 19 & 22.712 \\
\hline 19 & 27.174 & 20 & 8.163 \\
\hline 19 & 23.954 & 20 & 7.899 \\
\hline 19 & 27.424 & 20 & 8.602 \\
\hline 19 & 22.108 & 20 & 8.256 \\
\hline 19 & 18.781 & 20 & 7.8700 \\
\hline 19 & 22.712 & 20 & 7.945 \\
\hline
\end{tabular}




\section{TABLE 78. RESULTS OF ONE - WAY ANOVA ON KT RELEAES} THROUGH HAIRLESS GUINEA PIG SKIN

Lecithin:IPM (40:60) $0.1 \%$ water $\quad 6.5 \% \mathrm{KT} \quad$ Guinea pig skin $=1$

Lecithin:IPM $(40: 60) \quad 0.1 \%$ water $1 \%$ KT Guinea pig skin $=2$

One-way ANOVA: Release versus Sample

Analysis of Variance for Release

$\begin{array}{lrrrrc}\text { Source } & \text { DF } & \text { SS } & \text { MS } & \text { F } & \text { P } \\ \text { Sample } & 1 & 899 & 899 & 6.09 & 0.033 \\ \text { Error } & 10 & 1477 & 148 & & \\ \text { Total } & 11 & 2376 & & & \end{array}$

Individual 95\% CIs For Mean

Based on Pooled StDev

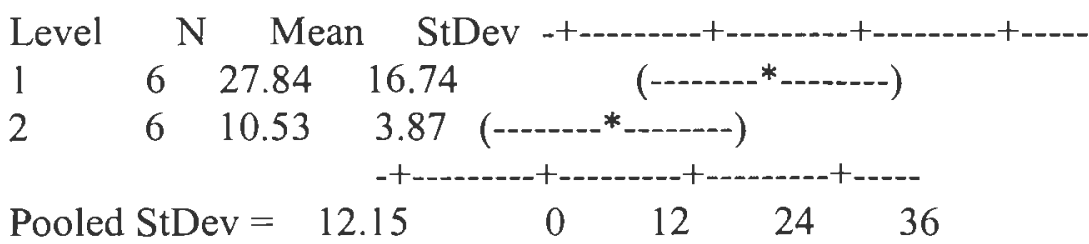


TABLE 78-1. RELEASE RATE VALUES OF KT THROUGH GUINEA PIG SKIN USING ONE-WAY ANOVA ANALYSIS

\begin{tabular}{|c|c|}
\hline Sample & Release \\
\hline & \\
\hline 1 & 18.77 \\
\hline 1 & 21.14 \\
\hline 1 & 51.06 \\
\hline 1 & 13.05 \\
\hline 1 & 47.17 \\
\hline 1 & 15.88 \\
\hline 2 & 10.68 \\
\hline 2 & 12.18 \\
\hline 2 & 10.37 \\
\hline 2 & 7.77 \\
\hline 2 & 5.46 \\
\hline 2 & 16.75 \\
\hline
\end{tabular}




\section{TABLE 79. RESULTS OF ONE-WAY ANOVA ON VISCOSITY OF FORMULATIONS WITH DIFFERENT COMPOSITIONS}

$$
\begin{aligned}
& \text { Lecithin:IPM (40:60) } 0.1 \% \mathrm{w}=1 \\
& \text { Lecithin:IPM (40:60) } 0.25 \% \mathrm{w}=2 \\
& \text { Lecithin:IPM (40:60) } 0.5 \% \mathrm{w}=3 \\
& \text { Lecithin:IPM (40:60) } 0.6 \% \mathrm{w}=4 \\
& \text { Lecithin:IPM }(40: 60) 0.7 \% \mathrm{w}=5 \\
& \text { Lecithin:IPM (40:60) } 0.8 \% \mathrm{w}=6 \\
& \text { Lecithin:IPM (50:50) } 0.1 \% \mathrm{w}=7 \\
& \text { Lecithin:IPM (50:50) } 0.25 \% \mathrm{w}=8 \\
& \text { Lecithin:IPM (50:50) } 0.5 \% \mathrm{w}=9 \\
& \text { Lecithin:IPM (50:50) } 0.6 \% \mathrm{w}=10 \\
& \text { Lecithin:IPM (50:50) } 0.7 \% \mathrm{w}=11 \\
& \text { Lecithin:IPM (50:50) } 0.8 \% \mathrm{w}=12 \\
& \text { Lecithin:IPM (60:40) } 0.1 \% \mathrm{w}=13 \\
& \text { Lecithin:IPM (60:40) } 0.25 \% \mathrm{w}=14 \\
& \text { Lecithin:IPM (60:40) } 0.5 \% \mathrm{w}=15 \\
& \text { Lecithin:IPM (60:40) } 0.6 \% \mathrm{w}=16 \\
& \text { Lecithin:IPM (60:40) } 0.7 \% \mathrm{w}=17 \\
& \text { Lecithin:IPM (60:40) } 0.8 \% \mathrm{w}=18
\end{aligned}
$$

\begin{tabular}{|c|c|c|c|}
\hline Level & & Mean & StDev -+--- \\
\hline 1 & 3 & 598.8 & $(--*--)$ \\
\hline 2 & 3 & 476.5 & $\left(--{ }^{*--}\right)$ \\
\hline 3 & 3 & 623.9 & 130.8 \\
\hline 5 & 3 & 355.9 & $158.9\left(\ldots * *_{--}\right)$ \\
\hline
\end{tabular}

One-way ANOVA: Viscosity versus Sample

Analysis of Variance for Viscosity

Source DF SS MS F P

Sample $\quad \begin{array}{lllll}8 & 16819301 & 2102413 & 27.23 & 0.000\end{array}$

Error $\quad 18 \quad 1389548 \quad 77197$

Total 2618208849

Individual 95\% CIs For Mean

Based on Pooled StDev 


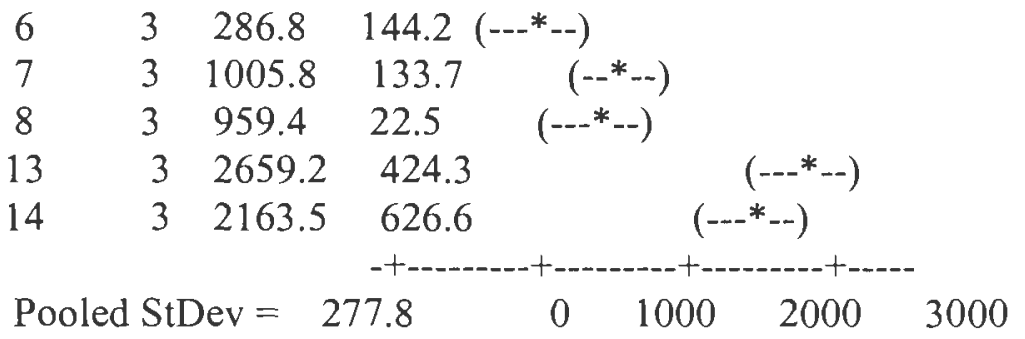

One-way ANOVA: viscosity versus sample

Analysis of Variance for viscosity

$\begin{array}{lccccl}\text { Source } & \text { DF } & \text { SS } & \text { MS } & \text { F } & \text { P } \\ \text { sample } & 1 & 22414 & 22414 & 1.10 & 0.353 \\ \text { Error } & 4 & 81156 & 20289 & & \\ \text { Total } & 5 & 103570 & & & \end{array}$

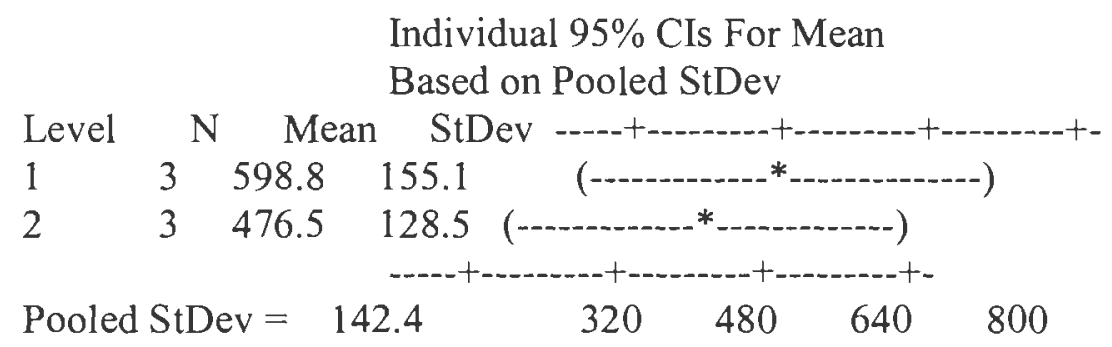

One-way ANOVA: viscosity versus sample

Analysis of Variance for viscosity

$\begin{array}{lcrcrc}\text { Source } & \text { DF } & \text { SS } & \text { MS } & \text { F } & \text { P } \\ \text { sample } & 1 & 947 & 947 & 0.05 & 0.841 \\ \text { Error } & 4 & 82356 & 20589 & & \\ \text { Total } & 5 & 83302 & & & \end{array}$

Individual $95 \%$ CIs For Mean Based on Pooled StDev 


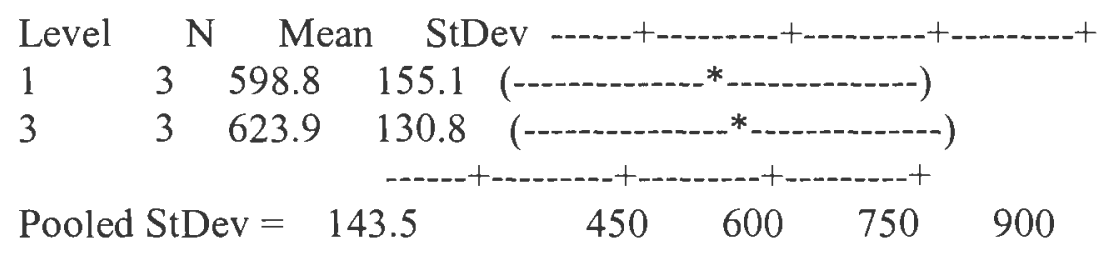

One-way ANOVA: viscosity versus sample

Analysis of Variance for viscosity

Source DF SS MS F $P$

$\begin{array}{lllllll}\text { sample } & 1 & 88457 & 88457 & 3.59 & 0.131\end{array}$

$\begin{array}{llll}\text { Error } \quad 4 & 98636 & 24659\end{array}$

Total $\quad 5 \quad 187093$

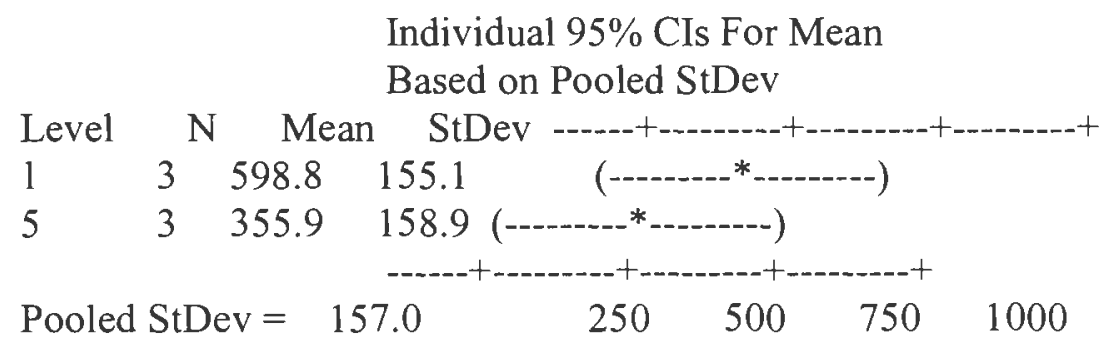

One-way ANOVA: viscosity versus sample

Analysis of Variance for viscosity

$\begin{array}{lccccc}\text { Source } & \text { DF } & \text { SS } & \text { MS } & \text { F } & \text { P } \\ \text { sample } & 1 & 146013 & 146013 & 6.51 & 0.063 \\ \text { Error } & 4 & 89698 & 22424 & & \\ \text { Total } & 5 & 235710 & & & \end{array}$

Individual 95\% CIs For Mean

Based on Pooled StDev

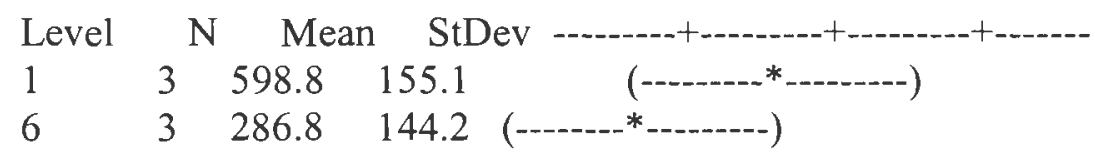


Pooled StDev $=\quad 149.7 \quad 250 \quad 500 \quad 750$

One-way ANOVA: Viscosity versus Sample

Analysis of Variance for Viscosity

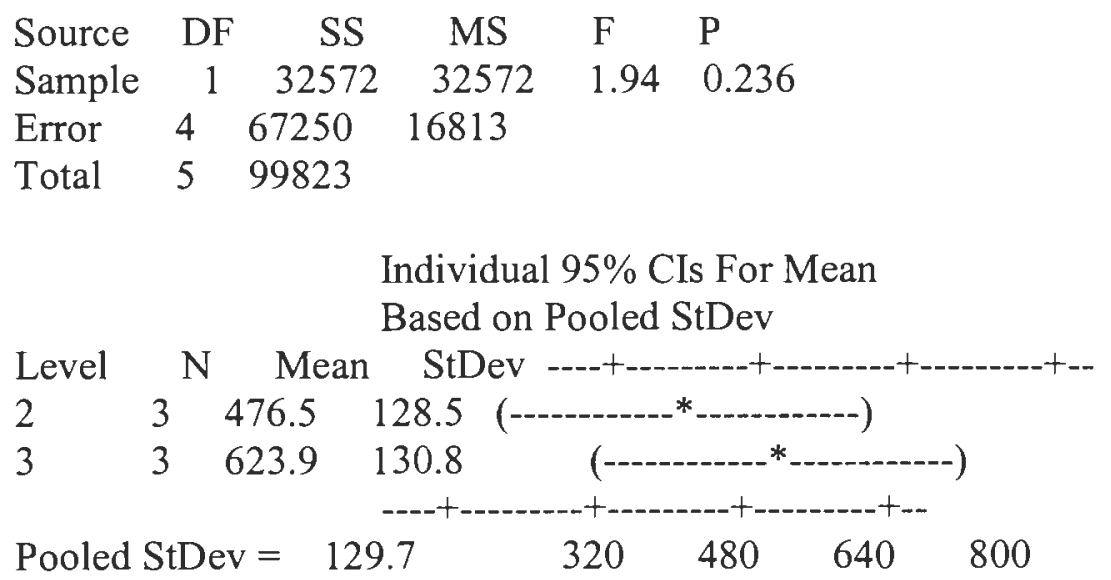

One-way ANOVA: Viscosity versus Sample

Analysis of Variance for Viscosity

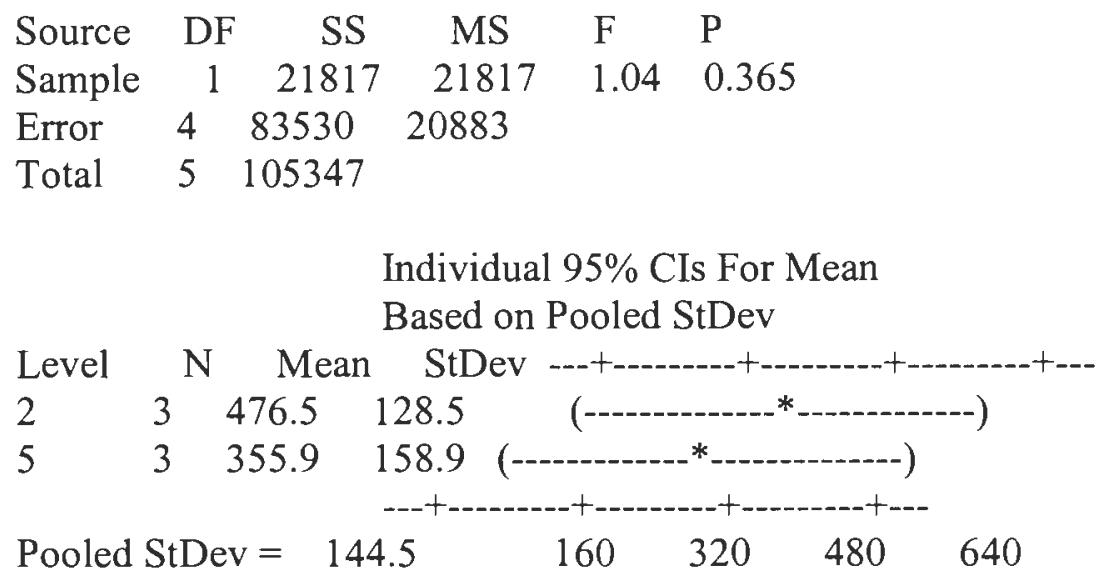


One-way ANOVA: Viscosity versus Sample

Analysis of Variance for Viscosity

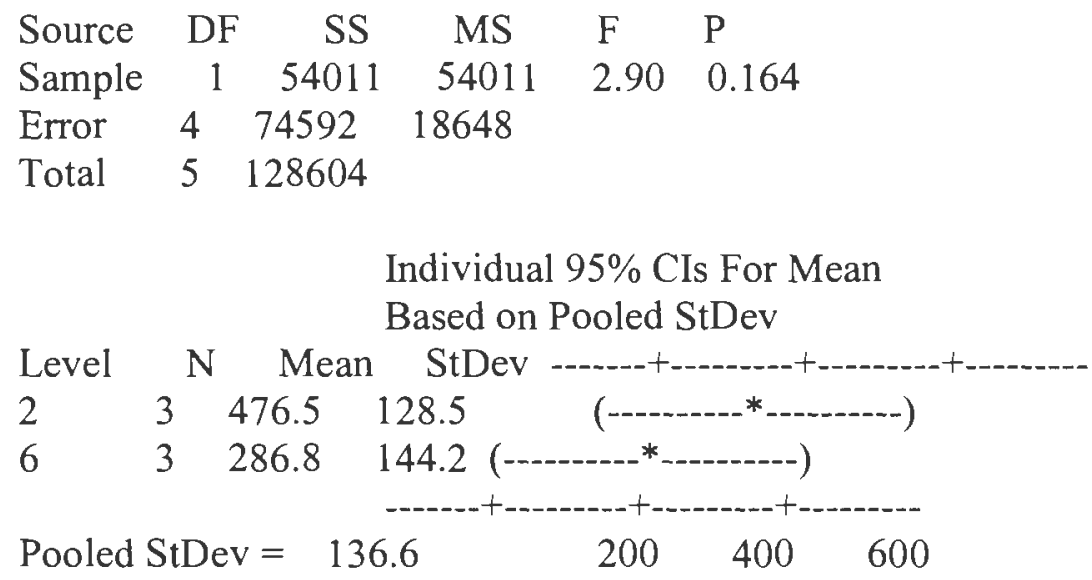

One-way ANOVA: Viscosity versus Sample

Analysis of Variance for Viscosity

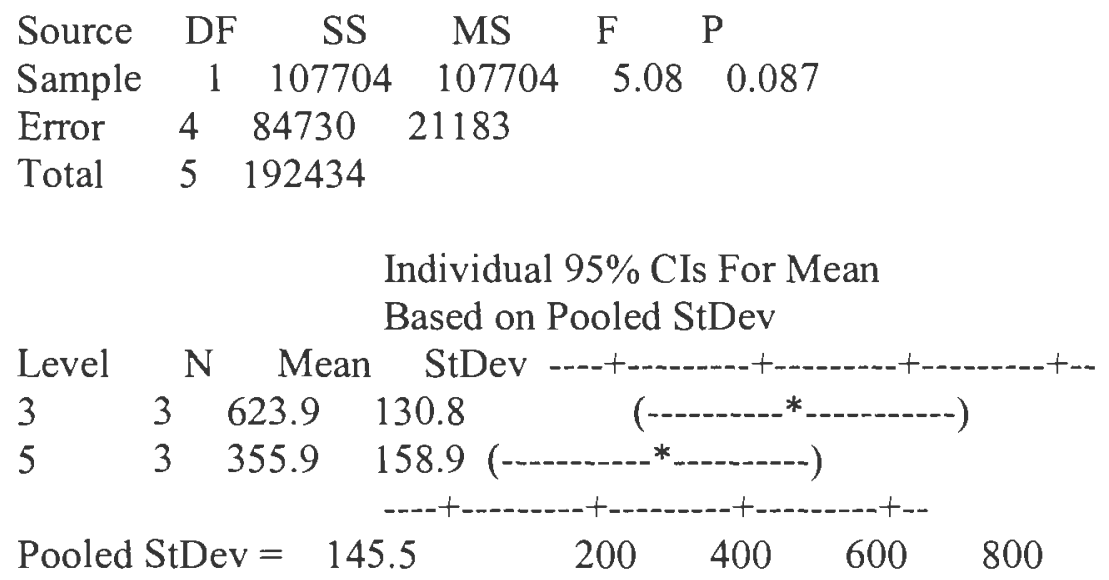

One-way ANOVA: Viscosity versus Sample 
Analysis of Variance for Viscosity

Source DF SS MS F P

$\begin{array}{llllll}\text { Sample } & 1 & 170471 & 170471 & 9.00 & 0.040\end{array}$

Error $\quad 4 \quad 75792 \quad 18948$

Total 5246264

Individual 95\% CIs For Mean

Based on Pooled StDev

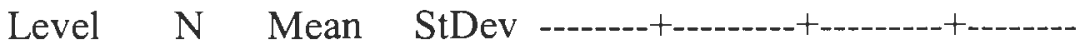

$3 \quad 3 \quad 623.9 \quad 130.8 \quad$ (--------*------)

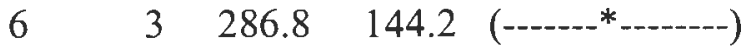

Pooled StDev $=137.7 \quad 250 \quad 500 \quad 750$

One-way ANOVA: Viscosity versus Sample

Analysis of Variance for Viscosity

Source DF SS MS F $\quad$ P

$\begin{array}{llllll}\text { Sample } & 1 & 7174 & 7174 & 0.31 & 0.606\end{array}$

Error $\quad 4 \quad 92072 \quad 23018$

Total 599246

Individual 95\% CIs For Mean

Based on Pooled StDev

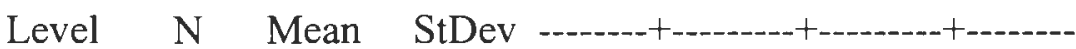

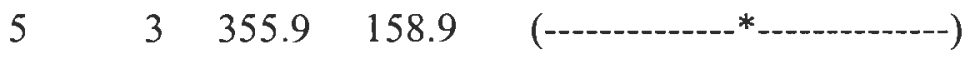

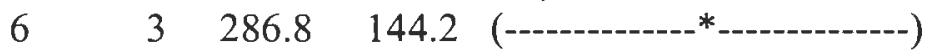

Pooled StDev $=\begin{array}{cccc}151.7 & 160 & 320 & 480\end{array}$

One-way ANOVA: Viscosity versus Sample

Analysis of Variance for Viscosity

Source DF $\mathrm{SS}$ MS F 


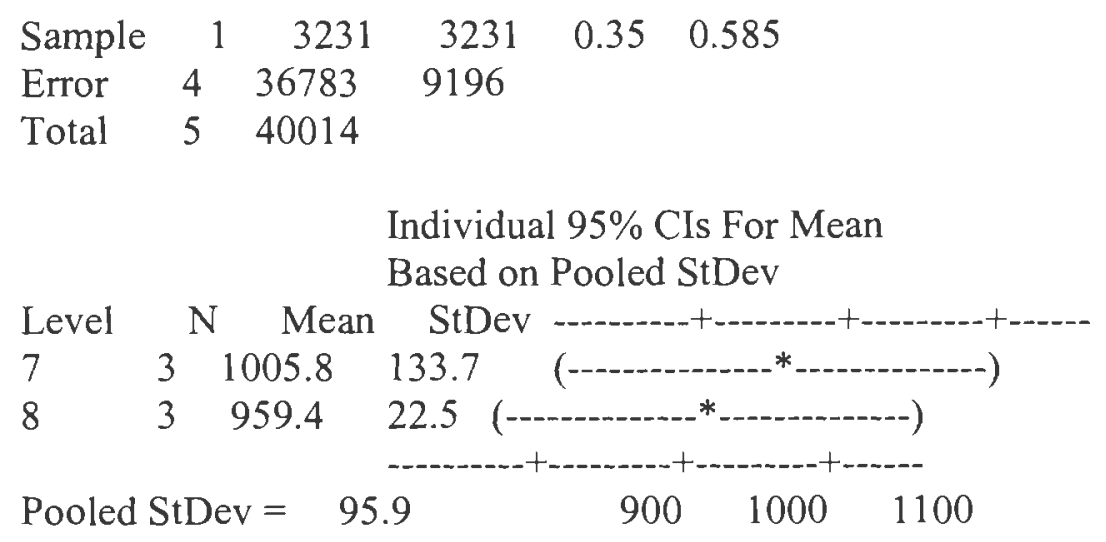

One-way ANOVA: Viscosity versus Sample

Analysis of Variance for Viscosity

$\begin{array}{lccccc}\text { Source } & \text { DF } & \text { SS } & \text { MS } & \text { F } & \text { P } \\ \text { Sample } & 1 & 368627 & 368627 & 1.29 & 0.320 \\ \text { Error } & 4 & 1145312 & 286328 & & \\ \text { Total } & 5 & 1513939 & & & \end{array}$

Individual 95\% CIs For Mean

Based on Pooled StDev

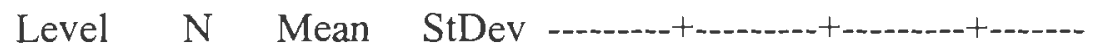

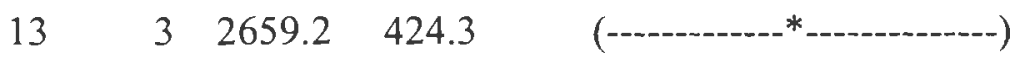

$1432163.5626 .6(-\cdots$

Pooled StDev $=535.1 \quad 1800 \quad 2400 \quad 3000$

One-way ANOVA: Viscosity versus Sample

Analysis of Variance for Viscosity 


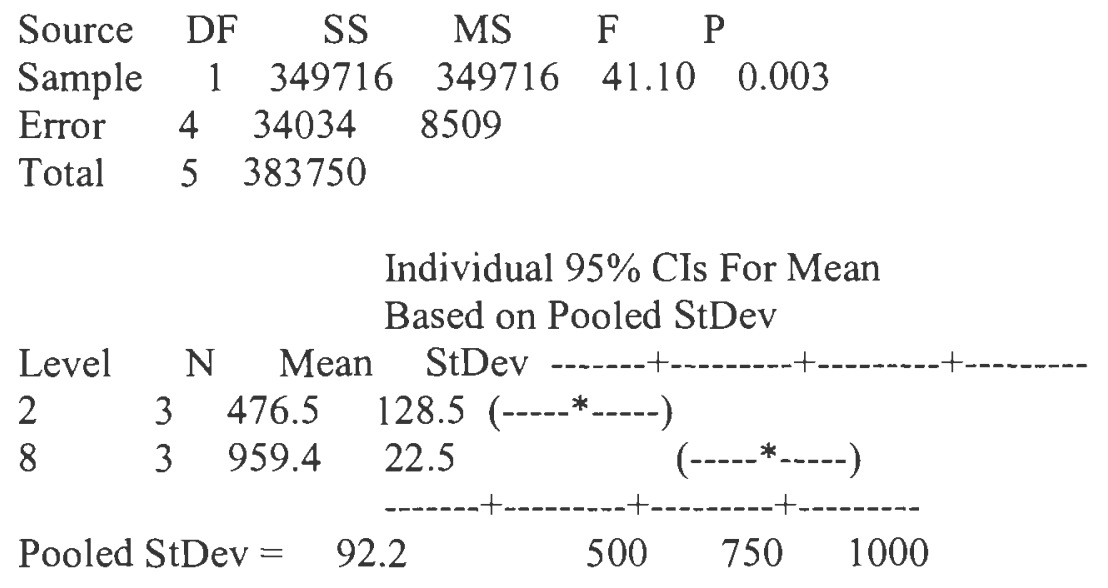

One-way ANOVA: Viscosity versus Sample

Analysis of Variance for Viscosity

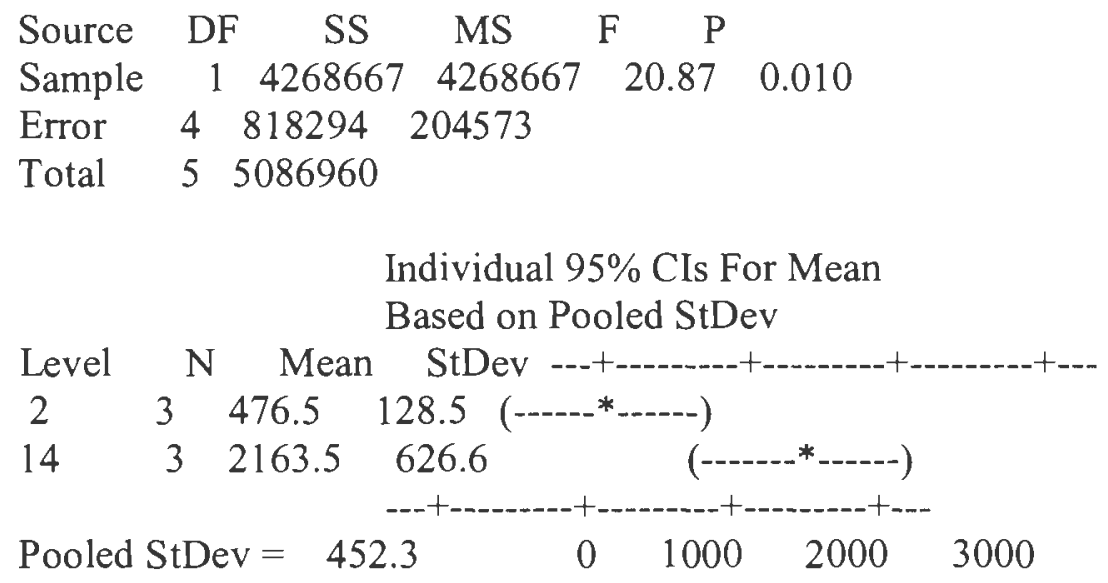

One-way ANOVA: Viscosity versus Sample

Analysis of Variance for Viscosity

$\begin{array}{lcccccc}\text { Source } & \text { DF } & \text { SS } & \text { MS } & \text { F } & \text { P } & \\ \text { Sample } & 1 & 2174761 & 2174761 & 11.06 & 0.029 \\ \text { Error } & 4 & 786277 & 196569 & & \\ \text { Total } & 5 & 2961038 & & & & \end{array}$


Individual 95\% CIs For Mean

Based on Pooled StDev

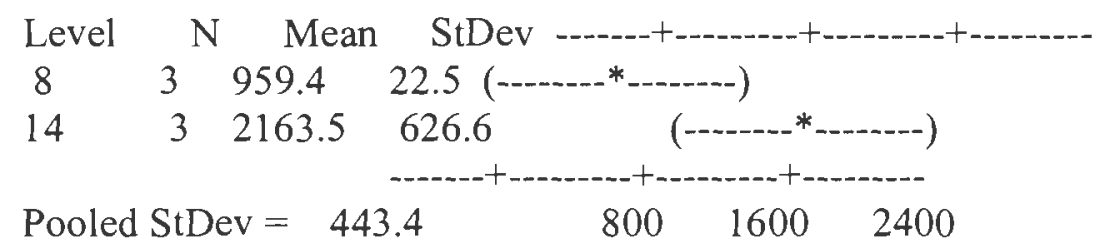

One-way ANOVA: Viscosity versus Sample

Analysis of Variance for Viscosity

\begin{tabular}{lcccll} 
Source & DF & SS & MS & F & \multicolumn{2}{c}{ P } \\
Sample & 1 & 349716 & 349716 & 41.10 & 0.003 \\
Error & 4 & 34034 & 8509 & & \\
Total & 5 & 383750 & & &
\end{tabular}

Individual 95\% CIs For Mean

Based on Pooled StDev

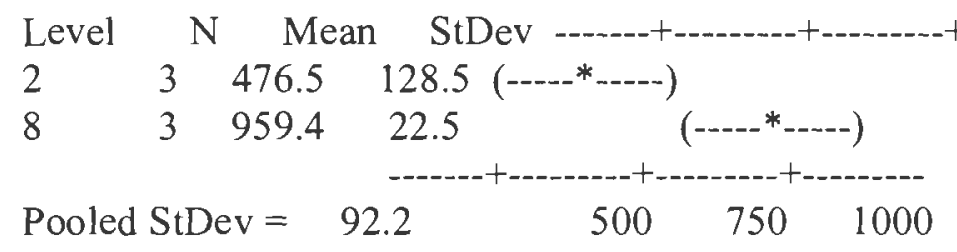

One-way ANOVA: Viscosity versus Sample

Analysis of Variance for Viscosity

\begin{tabular}{|c|c|c|c|}
\hline Source & SS & MS & \\
\hline Sample & 1426866 & $\begin{array}{lll}7 & 4268667 & 20.87\end{array}$ & 0.010 \\
\hline Error & $4 \quad 818294$ & 204573 & \\
\hline Total & 55086960 & & \\
\hline \multicolumn{4}{|c|}{$\begin{array}{l}\text { Individual } 95 \% \text { CIs For Mean } \\
\text { Based on Pooled StDev }\end{array}$} \\
\hline $\begin{array}{l}\text { Level } \\
2\end{array}$ & $\begin{array}{c}\mathrm{N} \text { Mean } \\
3476.5\end{array}$ & 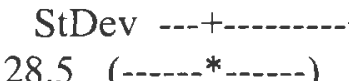 & \\
\hline
\end{tabular}




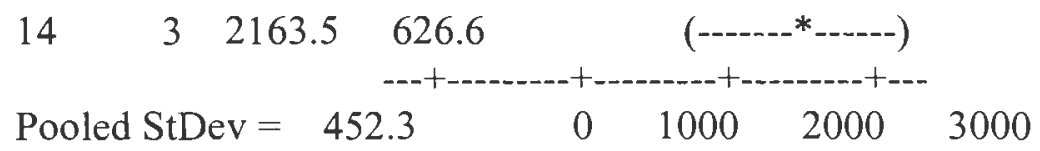

One-way ANOVA: Viscosity versus Sample

Analysis of Variance for Viscosity

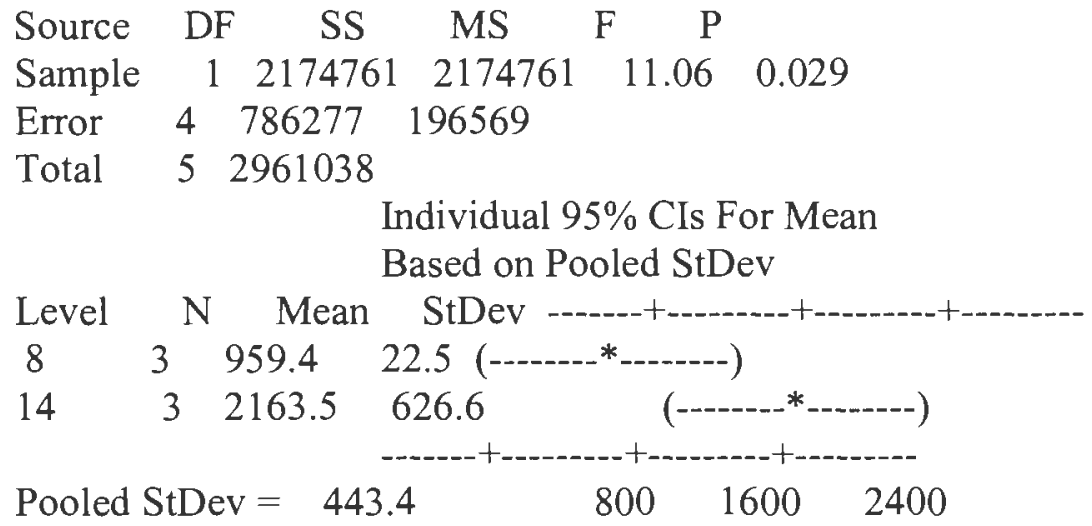


TABLE 79-1. VISCOSITY VALUES OF VARIOUS FORMULATIONS CONTAINING DIFFERENT COMPOSITIONS USING ONE-WY ANOVA ANALYSIS

\begin{tabular}{|c|c|c|c|c|c|}
\hline Sample & Viscosity & Sample1,2 & Viscosity1,2 & Sample1,3 & Viscosity1,3 \\
\hline & & & & & \\
\hline 1 & 585.91 & 1 & 585.91 & 1 & 585.91 \\
\hline 1 & 450.46 & 1 & 450.46 & 1 & 450.46 \\
\hline 1 & 759.92 & 1 & 759.92 & 1 & 759.92 \\
\hline 2 & 591.98 & 2 & 591.98 & 3 & 748.96 \\
\hline 2 & 338.08 & 2 & 338.08 & 3 & 488.00 \\
\hline 2 & 499.51 & 2 & 499.51 & 3 & 634.69 \\
\hline 3 & 748.96 & & & & \\
\hline 3 & 488.00 & & & & \\
\hline 3 & 634.69 & & & & \\
\hline 5 & 536.66 & & & & \\
\hline 5 & 293.00 & & & & \\
\hline 5 & 238.11 & & & & \\
\hline 6 & 448.86 & & & & \\
\hline 6 & 172.89 & & & & \\
\hline 6 & 238.55 & & & & \\
\hline 7 & 851.35 & & & & \\
\hline 7 & 1083.00 & & & & \\
\hline 7 & 1083.00 & & & & \\
\hline 8 & 974.61 & & & & \\
\hline 8 & 933.58 & & & & \\
\hline 8 & 969.93 & & & & \\
\hline 13 & 2834.8 & & & & \\
\hline 13 & 2175.3 & & & & \\
\hline 13 & 2967.5 & & & & \\
\hline 14 & 2825.00 & & & & \\
\hline 14 & 1578.9 & & & & \\
\hline 14 & 2086.5 & & & & \\
\hline
\end{tabular}


TABLE 79-1. CONT'D.

\begin{tabular}{|c|c|c|c|c|c|}
\hline Sample1,5 & Viscosity,1,5 & Sample1,6 & Viscosity1,6 & Sample2,3 & Viscosity2,3 \\
\hline & & & & & \\
\hline 1 & 585.91 & 1 & 585.91 & 2 & 591.98 \\
\hline 1 & 450.46 & 1 & 450.46 & 2 & 338.08 \\
\hline 1 & 759.92 & 1 & 759.92 & 2 & 499.51 \\
\hline 5 & 536.66 & 6 & 448.86 & 3 & 748.96 \\
\hline 5 & 293.00 & 6 & 172.89 & 3 & 488.00 \\
\hline 5 & 238.11 & 6 & 238.55 & 3 & 634.69 \\
\hline
\end{tabular}

\begin{tabular}{|c|c|c|c|c|c|}
\hline Sample2,5 & Viscosity2,5 & Sample2,6 & Viscosity2,6 & Sample3,5 & Viscosity3,5 \\
\hline & & & & & \\
\hline 2 & 591.98 & 2 & 591.98 & 3 & 748.96 \\
\hline 2 & 338.08 & 2 & 338.08 & 3 & 488.00 \\
\hline 2 & 499.51 & 2 & 499.51 & 3 & 634.69 \\
\hline 5 & 536.66 & 6 & 448.86 & 5 & 536.66 \\
\hline 5 & 293.00 & 6 & 172.89 & 5 & 293.00 \\
\hline 5 & 238.11 & 6 & 238.55 & 5 & 238.11 \\
\hline
\end{tabular}

\begin{tabular}{|c|c|c|c|c|c|}
\hline Sample3,6 & Viscosity3,6 & Sample5,6 & Viscosity5,6 & Sample7,8 & Viscosity7,8 \\
\hline & & & & & \\
\hline 3 & 748.96 & 5 & 536.66 & 7 & 851.35 \\
\hline 3 & 488.00 & 5 & 293.00 & 7 & 1083.00 \\
\hline 3 & 634.69 & 5 & 238.11 & 7 & 1083.00 \\
\hline 6 & 448.86 & 6 & 448.86 & 8 & 974.61 \\
\hline 6 & 172.89 & 6 & 172.89 & 8 & 933.58 \\
\hline 6 & 238.55 & 6 & 238.55 & 8 & 969.93 \\
\hline
\end{tabular}

\begin{tabular}{|c|c|c|c|c|c|}
\hline Sample13,14 & Viscosity13,14 & Sample2,8 & Viscosity2,8 & Sample2,14 & Viscosity2,14 \\
\hline & & & & & \\
\hline 13 & 2834.8 & 2 & 591.98 & 2 & 591.98 \\
\hline 13 & 2175.3 & 2 & 338.08 & 2 & 338.08 \\
\hline 13 & 2967.5 & 2 & 499.51 & 2 & 499.51 \\
\hline 14 & 2825.00 & 8 & 974.61 & 14 & 2825.00 \\
\hline 14 & 1578.9 & 8 & 933.58 & 14 & 1578.9 \\
\hline 14 & 2086.5 & 8 & 969.93 & 14 & 2086.5 \\
\hline
\end{tabular}

\begin{tabular}{|c|c|}
\hline Sample8,14 & Viscosity8,14 \\
\hline & \\
\hline 8 & 974.61 \\
\hline 8 & 933.58 \\
\hline 8 & 969.93 \\
\hline 14 & 2825.00 \\
\hline 14 & 1578.9 \\
\hline 14 & 2086.5 \\
\hline
\end{tabular}


TABLE 80. VISCOSITY VALUES FOR LECITHIN:IPM (40:60) CONTAINING $0.1 \%$ WATER AND $6.5 \%$ KT BY CONE AND PLATE VISCOMETER

RHEOCALC V1.40 BROOKFIELD ENGINEERING LABS

\begin{tabular}{|c|c|c|c|c|c|c|c|}
\hline \multirow{2}{*}{$\begin{array}{l}\text { Mode I: } \\
\text { Sample } \\
\end{array}$} & \multirow{2}{*}{$\begin{array}{l}: \quad 4060 \\
\text { RPM }\end{array}$} & \multicolumn{2}{|c|}{$\begin{array}{l}\text { Spindle: CP52 } \\
01 \mathrm{~W}\end{array}$} & \multirow{2}{*}{\multicolumn{2}{|c|}{ 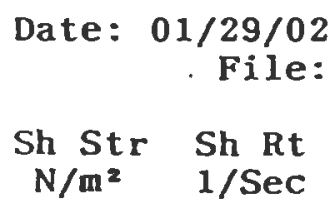 }} & \multicolumn{2}{|c|}{$\begin{array}{l}\text { Time: } 04: 23 \\
40601 \mathrm{~W} . \text { DV } 3\end{array}$} \\
\hline & & $\underset{\%}{\text { Torque }}$ & $\begin{array}{l}\text { Viscosity } \\
\text { mPas }\end{array}$ & & & $\underset{{ }^{\circ} \mathrm{C}}{\text { Temp }}$ & $\begin{array}{l}\text { Time } \\
M M: S S\end{array}$ \\
\hline 001 & 0.1 & 0.4 & 31456 & 6.29 & 0.20 & 25.0 & $00: 02$ \\
\hline 002 & 0.6 & 3.6 & 47184 & 56.6 & 1.20 & 25.0 & $00: 02$ \\
\hline 003 & 1.1 & 7.2 & 51473 & 113.2 & 2.20 & 25.0 & $00: 02$ \\
\hline 004 & 1.6 & 10.8 & 53082 & 169.9 & 3.20 & 25.0 & $00: 02$ \\
\hline 005 & 2.1 & 14.6 & 54674 & 229.6 & 4.20 & 25.0 & $00: 02$ \\
\hline 006 & 2.6 & 18.1 & 54746 & 284.7 & 5.20 & 25.0 & $00: 02$ \\
\hline 007 & 3.1 & 21.7 & 55048 & 341.3 & 6.20 & 25.0 & $00: 02$ \\
\hline 008 & 3.6 & 25.4 & 55485 & 399.5 & 7.20 & 25.0 & $00: 02$ \\
\hline 009 & 4.1 & 29.0 & 55623 & 456.1 & 8.20 & 25.0 & $00: 02$ \\
\hline 010 & 4.6 & 32.9 & 56245 & 517.5 & 9.20 & 25.0 & $00: 02$ \\
\hline 011 & 5.1 & 36.6 & 56436 & 575.6 & 10.2 & 25.0 & $00 \vdots 02$ \\
\hline 012 & 5.6 & 40.6 & 57014 & 638.6 & 11.2 & 25.0 & $00: 02$ \\
\hline 013 & 6.1 & 44.2 & 56982 & 695.2 & 12.2 & 25.0 & $00: 02$ \\
\hline 014 & 6.6 & 47.8 & 56954 & 751.8 & 13.2 & 25.0 & $00: 02$ \\
\hline 015 & 7.1 & 51.7 & 57263 & 813.1 & 14.2 & 25.0 & $00: 02$ \\
\hline 016 & 7.6 & 55.8 & 57738 & 877.6 & 15.2 & 25.0 & $00: 02$ \\
\hline 017 & 8.1 & 59.3 & 57572 & 932.7 & 16.2 & 25.0 & $00: 02$ \\
\hline 018 & 8.6 & 62.9 & 57517 & 989.3 & 17.2 & 25.0 & $00: 02$ \\
\hline 019 & 9.1 & 66.8 & 57727 & 1051 & 18.2 & 25.0 & $00: 02$ \\
\hline 020 & 9.6 & 70.8 & 57997 & 1114 & 19.2 & 25.0 & $00: 02$ \\
\hline 021 & 10.0 & 73.6 & 57879 & 1158 & 20.0 & 24.9 & $00: 02$ \\
\hline 022 & 9.5 & 71.4 & 59104 & 1123 & 19.0 & 25.0 & $00: 02$ \\
\hline 023 & 9.0 & 67.9 & 59330 & 1068 & 18.0 & 25.0 & $00: 02$ \\
\hline 024 & 8.5 & 64.2 & 59396 & 1010 & 17.0 & 25.0 & $00: 02$ \\
\hline 025 & 8.0 & 60.5 & 59472 & 951.5 & 16.0 & 25.0 & $00: 02$ \\
\hline 026 & 7.5 & 56.9 & 59662 & 894.9 & 15.0 & 25.0 & $00: 02$ \\
\hline 027 & 7.0 & 53.1 & 59654 & 835.2 & 14.0 & 25.0 & $00: 02$ \\
\hline 028 & 6.5 & 49.4 & 59766 & 777.0 & 13.0 & 25.0 & $00: 02$ \\
\hline 029 & 6.0 & 45.6 & 59766 & 717.2 & 12.0 & 25.0 & $00: 02$ \\
\hline 030 & 5.5 & 42.0 & 60052 & 660.6 & 11.0 & 25.0 & $00: 02$ \\
\hline 031 & 5.0 & 38.3 & 60238 & 602.4 & 10.0 & 25.0 & $00: 02$ \\
\hline 032 & 4.5 & 34.7 & 60640 & 545.8 & 9.00 & 25.0 & $00: 02$ \\
\hline 033 & 4.0 & 30.8 & 60553 & 484.4 & 8.00 & 25.0 & $00: 02$ \\
\hline 034 & 3.5 & 27.1 & 60890 & 426.2 & 7.00 & 25.0 & $00: 02$ \\
\hline 035 & 3.0 & 23.1 & 60553 & 363.3 & 6.00 & 25.0 & $00: 02$ \\
\hline 036 & 2.5 & 19.5 & 61339 & 306.7 & 5.00 & 25.0 & $00: 02$ \\
\hline 037 & 2.0 & 15.6 & 61339 & 245.4 & 4.00 & 25.0 & $00: 02$ \\
\hline 038 & 1.5 & 12.1 & 63436 & 190.3 & 3.00 & 25.0 & $00: 02$ \\
\hline 039 & 1.0 & 8.3 & 65271 & 130.5 & 2.00 & 25.0 & $00: 02$ \\
\hline 040 & 0.5 & 4.6 & 72349 & 72.3 & 1.00 & 25.0 & $00: 02$ \\
\hline 041 & 0.1 & 1.9 & 149416 & 29.9 & 0.20 & 25.0 & $00: 02$ \\
\hline
\end{tabular}


FIGURE 92! RHEOGRAM SHOWING RHEOPEXY BEHAVIOR FOR LECITHIN:IPM (40:60) CONTAINING 0.1\% WATER AND 6.5\% KT BY CONE AND PLATE VISCOMETER

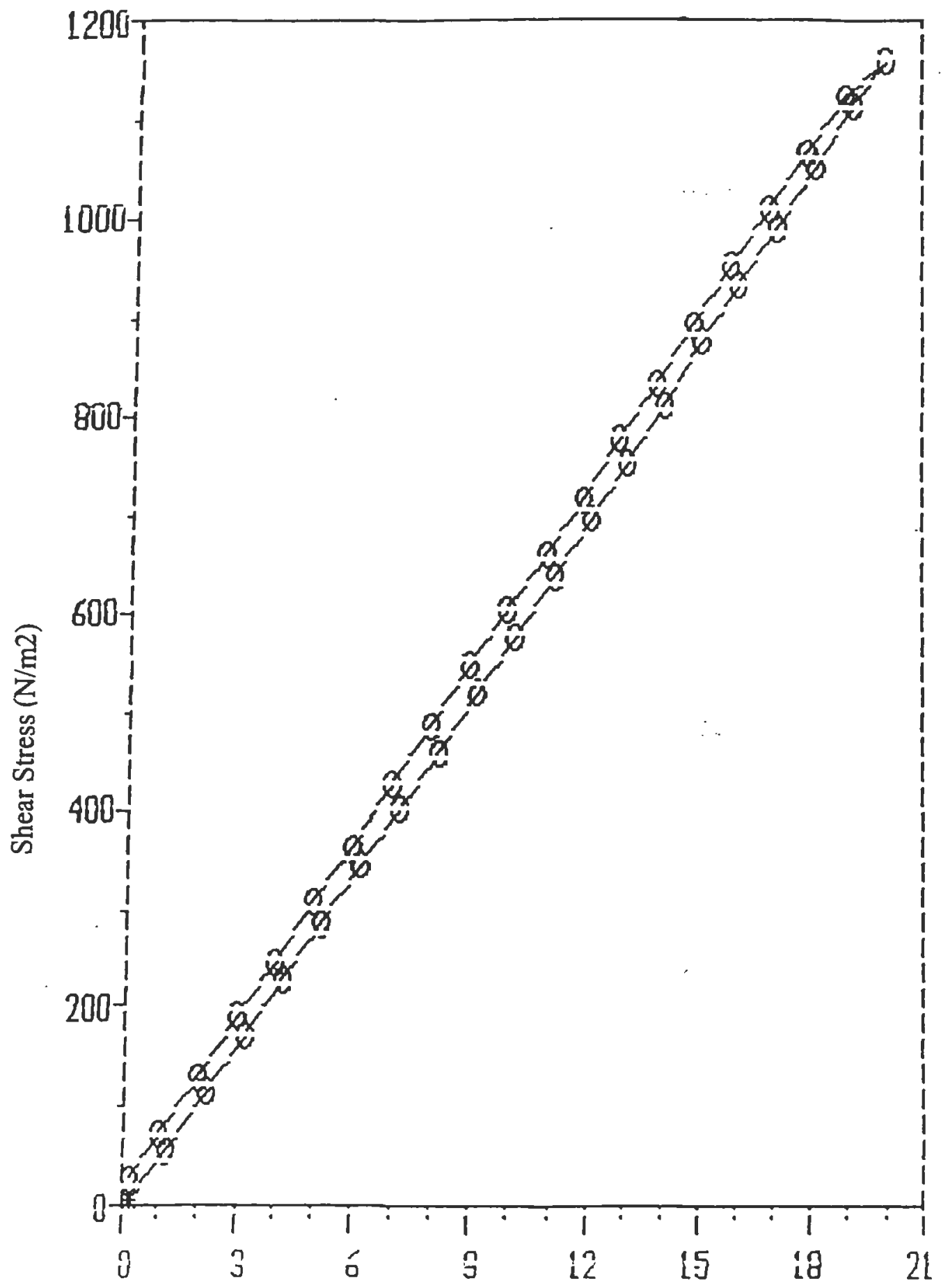

Shear Rate (1/Sec) 
TABLE 81. VISCOSITY VALUES FOR LECITHIN:IPM (40:60) CONTAINING $0.25 \%$ WATER AND $6.5 \% \mathrm{KT}$ BY CONE AND PLATE VISCOMETER

RHEOCALC V1.40 BROOKFIELD ENGINEERING LABS

\begin{tabular}{|c|c|c|c|c|c|c|c|}
\hline \multirow{2}{*}{$\begin{array}{l}\text { Model: } \\
\text { Sample: } \\
\\
\#\end{array}$} & \multirow{2}{*}{$\begin{array}{l}\text { HB } \\
: \quad 4060 \\
\text { RPM }\end{array}$} & \multirow{2}{*}{$\begin{array}{l}\text { Spindle } \\
25 w \\
\text { Torque } \\
\frac{\alpha}{2}\end{array}$} & \multirow{2}{*}{$\begin{array}{l}\text { : CP52 } \\
\text { viscosity } \\
\text { mPas }\end{array}$} & \multirow{2}{*}{$\begin{array}{l}\text { Date: } \\
\text { Sh Str } \\
N / m^{2}\end{array}$} & \multirow{2}{*}{$\begin{array}{c}1 / 29 / 02 \\
\text { File: } \\
\text { Sh Rt } \\
1 / \text { Sec }\end{array}$} & \multicolumn{2}{|c|}{$\begin{array}{l}\text { Time : } 04: 15 \\
406025 W . \text { DV3 }\end{array}$} \\
\hline & & & & & & $\begin{array}{l}\text { Temp } \\
{ }^{\circ} \mathrm{C}\end{array}$ & $\begin{array}{l}\text { Time } \\
M M: S S\end{array}$ \\
\hline 001 & 0.1 & 0.6 & 47184 & 9.44 & 0.20 & 25.0 & $00: 02$ \\
\hline 002 & 0.6 & 4.2 & 55048 & 66.1 & 1.20 & 25.0 & $00: 02$ \\
\hline 003 & 1.1 & 8.9 & 63627 & 140.0 & 2.20 & 25.1 & $00: 02$ \\
\hline 004 & 1.6 & 13.7 & 67336 & 215.5 & 3.20 & 25.0 & $00: 02$ \\
\hline 005 & 2.1 & 18.5 & 69278 & 291.0 & 4.20 & 25.0 & $00: 02$ \\
\hline 006 & 2.6 & 23.3 & 70474 & 366.5 & 5.20 & 25.0 & $00: 02$ \\
\hline 007 & 3.1 & 28.2 & 71537 & 443.5 & 6.20 & 25.0 & $00: 02$ \\
\hline 008 & 3.6 & 33.0 & 72087 & 519.0 & 7.20 & 25.0 & $00: 02$ \\
\hline 009 & 4.1 & 37.5 & 71927 & 589.8 & 8.20 & 25.0 & $00: 02$ \\
\hline 010 & 4.6 & 42.5 & 72657 & 668.4 & 9.20 & 25.0 & $00: 02$ \\
\hline 011 & 5.1 & 47.5 & 73243 & 747.1 & $10 . .2$ & 25.0 & $00: 02$ \\
\hline 012 & 5.6 & 51.9 & 72882 & 816.3 & 11.2 & 25.0 & $00: 02$ \\
\hline 013 & 6.1 & 56.6 & 72968 & 890.2 & 12.2 & 25.0 & $00: 02$ \\
\hline 014 & 6.6 & 61.6 & 73397 & 968.8 & 13.2 & 25.0 & $00: 02$ \\
\hline 015 & 7.1 & 66.8 & 73988 & 1051 & 14.2 & 25.0 & $00: 02$ \\
\hline 016 & 7.6 & 71.1 & 73570 & 1118 & 15.2 & 25.0 & $00: 02$ \\
\hline 017 & 8.1 & 75.6 & 73397 & 1189 & 16.2 & 25.0 & $00: 02$ \\
\hline 018 & 8.6 & 80.6 & 73702 & 1268 & 17.2 & 25.0 & $00: 02$ \\
\hline 019 & 9.1 & 85.3 & 73714 & 1342 & 18.2 & 25.0 & $00: 02$ \\
\hline 020 & 9.6 & $90 \ldots$ & 73807 & 1417 & 19.2 & 25.0 & $00: 02$ \\
\hline 021 & 10.0 & 94.1 & 74000 & 1480 & 20.0 & 25.0 & $00: 02$ \\
\hline 022 & 9.5 & 92.5 & 76571 & 1455 & 19.0 & 25.0 & $00: 02$ \\
\hline 023 & 9.0 & 87.7 & 76630 & 1379 & 18.0 & 25.0 & $00: 02$ \\
\hline 024 & 8.5 & 82.7 & 76512 & 1301 & 17.0 & 25.0 & $00: 02$ \\
\hline 025 & 8.0 & 78.1 & 76772 & 1228 & 16.0 & 25.0 & $00: 02$ \\
\hline 026 & 7.5 & 73.6 & 77172 & 1158 & 15.0 & 25.0 & $00: 02$ \\
\hline 027 & 7.0 & 68.7 & 77180 & 1081 & 14.0 & 25.0 & $00: 02$ \\
\hline 028 & 6.5 & 63.9 & 77309 & 1005 & 13.0 & 25.0 & $00: 02$ \\
\hline 029 & 6.0 & 59.0 & 77329 & 928.0 & 12.0 & 25.0 & $00: 02$ \\
\hline 030 & 5.5 & 54.7 & 78211 & 860.3 & 11.0 & 25.0 & $00: 02$ \\
\hline 031 & 5.0 & 49.9 & 78483 & 784.8 & 10.0 & 25.0 & $00: 02$ \\
\hline 032 & 4.5 & 44.9 & 78465 & 706.2 & 9.00 & 25.0 & $00: 02$ \\
\hline 033 & 4.0 & 40.2 & 79033 & 632.3 & 8.00 & 25.0 & $00: 02$ \\
\hline 034 & 3.5 & 35.3 & 79314 & 555.2 & 7.00 & 25.0 & $00: 02$ \\
\hline 035 & 3.0 & 30.7 & 80475 & 482.8 & 6.00 & 25.0 & $00: 02$ \\
\hline 036 & 2.5 & 25.8 & 81156 & 405.8 & 5.00 & 25.0 & $00: 02$ \\
\hline 037 & 2.0 & 21.2 & 83358 & 333.4 & 4.00 & 25.0 & $00: 02$ \\
\hline 038 & 1.5 & 16.2 & 84931 & 254.8 & 3.00 & 25.0 & $00: 02$ \\
\hline 039 & 1.0 & 11.5 & 90436 & 180.9 & 2.00 & 25.0 & $00: 02$ \\
\hline 040 & 0.5 & 6.7 & 105378 & 105.4 & 1.00 & 25.0 & $00: 02$ \\
\hline 041 & 0.1 & 2.4 & 188736 & 37.7 & 0.20 & 25.0 & $00: 02$ \\
\hline
\end{tabular}


FIGURE 93. RHEOGRAM SHOWING RHEOPEXY BEHAVIOR FOR LECITHIN:IPM (40:60) CONTAINING 0.25\% WATER AND $6.5 \%$ KT BY CONE AND PLATE VISCOMETER

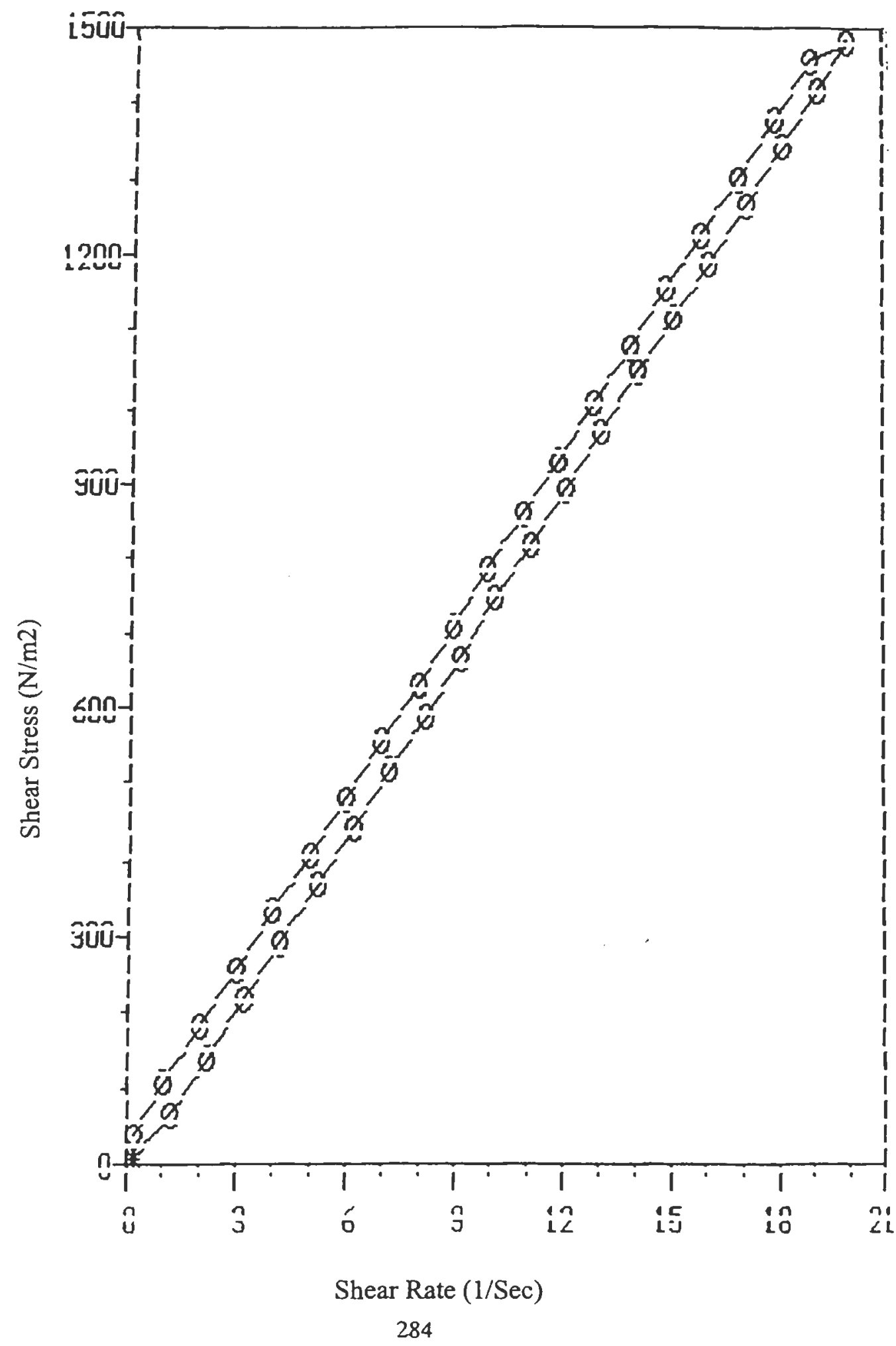


TABLE 82. VISCOSITY VALUES FOR LECITHIN:IPM (40:60) CONTAINING $0.5 \%$ WATER AND $6.5 \%$ KT BY CONE AND PLATE VISCOMETER

RHEOCALC V1.40 BROOKFIELD ENGINEERING LABS

\begin{tabular}{|c|c|c|c|c|c|c|c|}
\hline \multirow{2}{*}{$\begin{array}{l}\text { Model: } \\
\text { Sample } \\
\qquad\end{array}$} & \multirow{2}{*}{$\begin{array}{l}\mathrm{HB} \\
: 4060 \\
\mathrm{RPM}\end{array}$} & \multicolumn{2}{|c|}{$\begin{array}{l}\text { Spindle: CP52 } \\
05 W\end{array}$} & \multirow{2}{*}{\multicolumn{2}{|c|}{$\begin{array}{rr}\text { Date: } & 01 / 29 / 02 \\
\text { File: } & \\
\text { Sh Str } & \text { Sh Rt } \\
N / m^{2} & 1 / \text { Sec }\end{array}$}} & \multicolumn{2}{|c|}{$\begin{array}{l}\text { Time: } 04: 08 \\
\text { 40605W. DV3 }\end{array}$} \\
\hline & & $\underset{\%}{\text { Torque }}$ & $\begin{array}{l}\text { Viscosity } \\
\text { mPas }\end{array}$ & & & ${ }^{T} \mathrm{C} C$ & $\begin{array}{l}\text { Time } \\
M M: S S\end{array}$ \\
\hline 001 & 0.1 & 0.5 & 39320 & 7.86 & 0.20 & 25.0 & $00: 02$ \\
\hline 002 & 0.6 & 3.7 & 48495 & 58.2 & 1.20 & 25.0 & $00: 02$ \\
\hline 003 & 1.1 & 6.8 & 48614 & 107.0 & 2.20 & 25.0 & $00: 02$ \\
\hline 004 & 1.6 & 10.5 & 51608 & 165.1 & 3.20 & 25.0 & $00: 02$ \\
\hline 005 & 2.1 & 14.7 & 55048 & 231.2 & 4.20 & 25.0 & $00: 02$ \\
\hline 006 & 2.6 & 18.4 & 55653 & 289.4 & 5.20 & 25.0 & $00: 02$ \\
\hline 007 & 3.1 & 22.1 & 56063 & 347.6 & 6.20 & 25.0 & $00: 02$ \\
\hline 008 & 3.6 & 25.6 & 55922 & 402.6 & 7.20 & 25.0 & $00: 02$ \\
\hline 009 & 4.1 & 29.4 & 56391 & 462.4 & 8.20 & 25.0 & $00: 02$ \\
\hline 010 & 4.6 & 33.2 & 56758 & 522.2 & 9.20 & 25.0 & $00: 02$ \\
\hline 011 & 5.1 & 36.8 & 56744 & 578.8 & 10.2 & 25.0 & $00: 02$ \\
\hline 012 & 5.6 & 40.9 & 57435 & 643.3 & 11.2 & 25.0 & $00: 02$ \\
\hline 013 & 6.1 & 44.7 & 57626 & 703.0 & 12.2 & 25.0 & $00: 02$ \\
\hline 014 & 6.6 & 48.7 & 58027 & 766.0 & 13.2 & 25.0 & $00: 02$ \\
\hline 015 & 7.1 & 52.6 & 58260 & 827.3 & 14.2 & 25.0 & $00: 02$ \\
\hline 016 & 7.6 & 56.0 & 57945 & 880.8 & 15.2 & 25.0 & $00: 02$ \\
\hline 017 & 8.1 & 59.9 & 58155 & 942.1 & 16.2 & 25.0 & $00: 02$ \\
\hline 018 & 8.6 & 63.7 & 58248 & 1002 & 17.2 & 25.0 & $00: 02$ \\
\hline 019 & 9.1 & 67.5 & 58332 & 1062 & 18.2 & 25.0 & $00: 02$ \\
\hline 020 & 9.6 & 70.9 & 58079 & 1115 & 19.2 & 25.1 & $00: 02$ \\
\hline 021 & 10.0 & 74.4 & 58508 & 1170 & 20.0 & 25.0 & $00: 02$ \\
\hline 022 & 9.5 & 72.0 & 59601 & 1132 & 19.0 & 25.0 & $00: 02$ \\
\hline 023 & 9.0 & 68.2 & 59592 & 1073 & 18.0 & 25.0 & $00: 02$ \\
\hline 024 & 8.5 & 64.9 & 60044 & 1021 & 17.0 & 25.0 & $00: 02$ \\
\hline 025 & 8.0 & 61.0 & 59963 & 959.4 & 16.0 & 25.0 & $00: 02$ \\
\hline 026 & 7.5 & 57.3 & 60081 & 901.2 & 15.0 & 25.0 & $00: 02$ \\
\hline 027 & 7.0 & 53.6 & 60216 & 843.0 & 14.0 & 25.0 & $00: 02$ \\
\hline 028 & 6.5 & 50.2 & 60734 & 789.5 & 13.0 & 25.0 & $00: 02$ \\
\hline 029 & 6.0 & 46.3 & 60684 & 728.2 & 12.0 & 25.0 & $00: 02$ \\
\hline 030 & 5.5 & 42.7 & 61053 & 671.6 & 11.0 & 25.0 & $00: 02$ \\
\hline 031 & 5.0 & 38.9 & 61182 & 611.8 & ro.o & 25.0 & $00: 02$ \\
\hline 032 & 4.5 & 35.1 & 61339 & 552.1 & 9.00 & 25.0 & $00: 02$ \\
\hline 033 & 4.0 & 31.2 & 61339 & 490.7 & 8.00 & 25.1 & $00: 02$ \\
\hline 034 & 3.5 & 27.7 & 62238 & 435.7 & 7.00 & 25.0 & $00: 02$ \\
\hline 035 & 3.0 & 23.7 & 62126 & 372.8 & 6.00 & 25.0 & $00: 02$ \\
\hline 036 & 2.5 & 20.1 & 63227 & 316.1 & 5.00 & 25.0 & $00: 02$ \\
\hline 037 & 2.0 & 16.0 & 62912 & 251.6 & 4.00 & 25.0 & $00: 02$ \\
\hline 038 & 1.5 & 12.5 & 65533 & 196.6 & 3.00 & 25.0 & $00: 02$ \\
\hline 039 & 1.0 & 8.5 & 66844 & 133.7 & 2.00 & 25.0 & $00: 02$ \\
\hline 040 & 0.5 & 5.1 & 80213 & 80.2 & 1.00 & 25.0 & $00 \vdots 02$ \\
\hline 041 & 0.1 & 1.6 & 125824 & 25.2 & 0.20 & 25.0 & $00: 02$ \\
\hline
\end{tabular}


FIGURE 94: RHEOGRAM SHOWING RHEOPEXY BEHAVIOR FOR LECITHIN:IPM (40:60) CONTAINING 0.5\% WATER AND 6.5\% KT BY CONE AND PLATE VISCOMETER

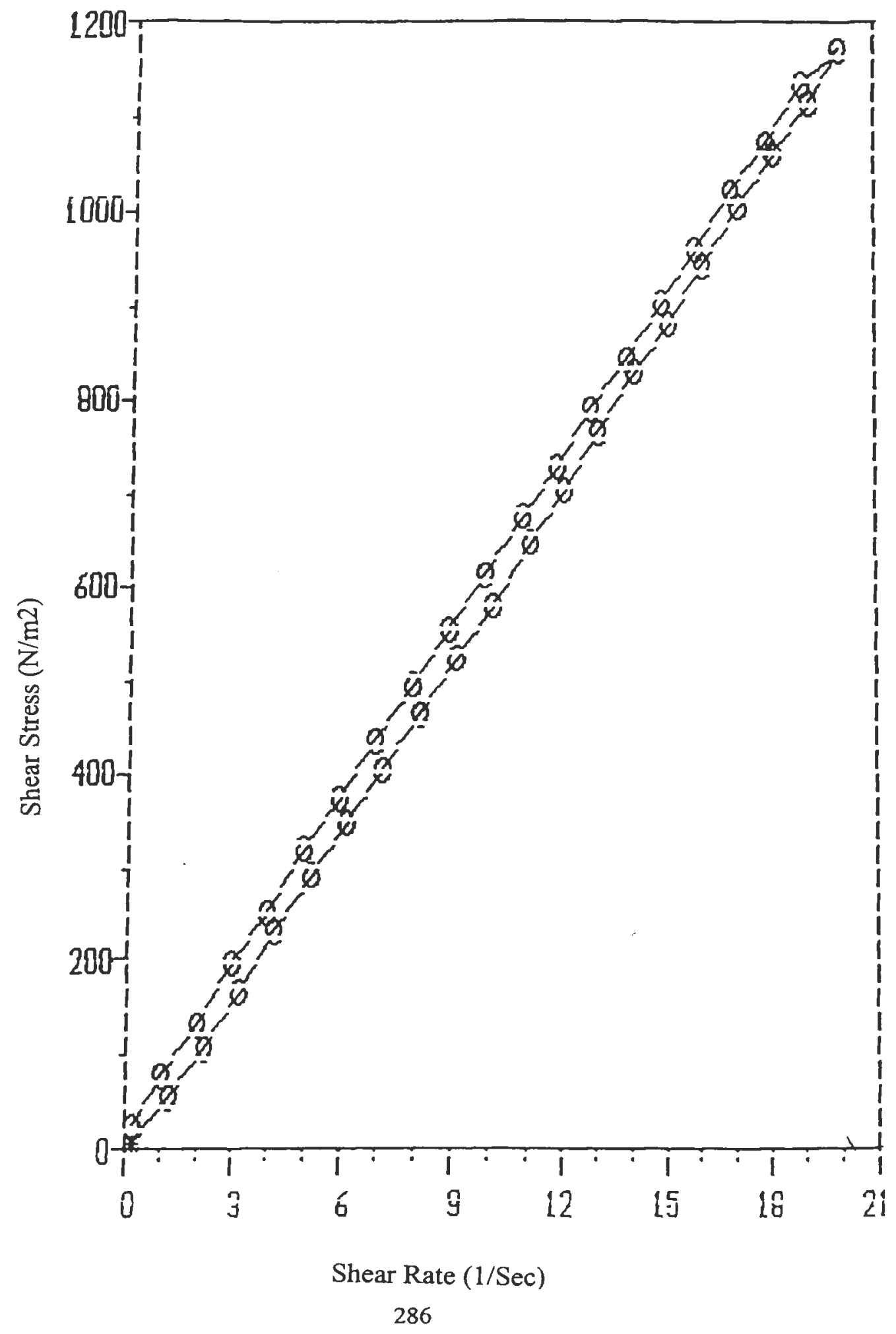


TABLE 83!: VISCOSITY VALUES FOR LECITHIN:IPM (40:60) CONTAINING $0.6 \%$ WATER AND $6.5 \% \mathrm{KT}$ BY CONE AND PLATE VISCOMETER

RHEOCALC V1.40 BROOKFIELD ENGINEERING LABS

\begin{tabular}{|c|c|c|c|c|c|c|c|}
\hline \multirow{2}{*}{$\begin{array}{l}\text { Mode 1: } \\
\text { Sample } \\
\qquad\end{array}$} & \multirow{2}{*}{$\begin{array}{l}\mathrm{HB} \\
: \quad 4060 \\
\text { RPM }\end{array}$} & \multicolumn{2}{|c|}{$\begin{array}{l}\text { Spindle: CP52 } \\
06 \mathrm{~W}\end{array}$} & \multicolumn{2}{|c|}{$\begin{array}{r}\text { Date: } 01 / 29 / 02 \\
\text { File: }\end{array}$} & \multicolumn{2}{|c|}{$\begin{array}{l}\text { Time: } 04: 01 \\
\text { 40606W. DV3 }\end{array}$} \\
\hline & & $\begin{array}{c}\text { Torque } \\
\%\end{array}$ & $\begin{array}{l}\text { Viscosity } \\
\text { mPas }\end{array}$ & $\begin{array}{l}\text { Sh Str } \\
\mathrm{N} / \mathrm{m}^{2}\end{array}$ & $\begin{array}{l}\text { Sh Rt } \\
1 / \text { Sec }\end{array}$ & $\underset{{ }^{\circ} \mathrm{C}}{\text { Temp }}$ & $\begin{array}{l}\text { Time } \\
M M: S S\end{array}$ \\
\hline 001 & 0.1 & 0.5 & 39320 & 7.86 & 0.20 & 25.0 & $00: 02$ \\
\hline 002 & 0.6 & 3.4 & 44563 & 53.5 & 1.20 & 25.0 & $00: 02$ \\
\hline 003 & 1.1 & 6.3 & 45039 & 99.1 & 2.20 & 25.0 & $00: 02$ \\
\hline 004 & 1.6 & 9.9 & 48658 & 155.7 & 3.20 & 25.0 & $00: 02$ \\
\hline 005 & 2.1 & 13.8 & 51678 & 217.0 & 4.20 & 25.0 & $00: 02$ \\
\hline 006 & 2.6 & 17.2 & 52023 & 270.5 & 5.20 & 25.0 & $00: 02$ \\
\hline 007 & 3.1 & 20.6 & 52258 & 324.0 & 6.20 & 25.0 & $00: 02$ \\
\hline 008 & 3.6 & 24.0 & 52427 & 377.5 & 7.20 & 25.0 & $00: 02$ \\
\hline 009 & 4.1 & 27.4 & 52555 & 430.9 & 8.20 & 25.0 & $00: 02$ \\
\hline 010 & 4.6 & 30.7 & 52484 & 482.8 & 9.20 & 25.0 & $00 \vdots 02$ \\
\hline 011 & 5.1 & 34.3 & 52889 & 539.5 & 10.2 & 25.0 & $00: 02$ \\
\hline 012 & 5.6 & 37.7 & 52942 & 592.9 & 11.2 & 25.0 & $00: 02$ \\
\hline 013 & 6.1 & 41.4 & 53372 & 651.1 & 12.2 & 25.0 & $00: 02$ \\
\hline 014 & 6.6 & 44.7 & 53261 & 703.0 & 13.2 & 25.0 & $00: 02$ \\
\hline 015 & 7.1 & 48.2 & 53387 & 758.1 & 14.2 & 25.0 & $00: 02$ \\
\hline 016 & 7.6 & 51.6 & 53392 & 811.6 & 15.2 & 25.0 & $00: 02$ \\
\hline 017 & 8.1 & 55.1 & 53495 & 866.6 & 16.2 & 25.0 & $00: 02$ \\
\hline 018 & 8.6 & 58.5 & 53493 & 920.1 & 17.2 & 25.0 & $00: 02$ \\
\hline 019 & 9.1 & 61.9 & 53492 & 973.6 & 18.2 & 25.1 & $00: 02$ \\
\hline 020 & 9.6 & 65.3 & 53492 & 1027 & 19.2 & 25.0 & $00: 02$ \\
\hline 021 & 10.0 & 68.1 & 53554 & 1071 & 20.0 & 25.0 & $00: 02$ \\
\hline 022 & 9.5 & 65.7 & 54386 & 1033 & 19.0 & 25.0 & $00: 02$ \\
\hline 023 & 9.0 & 62.6 & 54698 & 984.6 & 18.0 & 25.0 & $00: 02$ \\
\hline 024 & 8.5 & 59.4 & 54955 & 934.2 & 17.0 & 25.0 & $00: 02$ \\
\hline 025 & 8.0 & 56.0 & 55048 & 880.8 & 16.0 & 25.0 & $00: 02$ \\
\hline 026 & 7.5 & 52.6 & 55153 & 827.3 & 15.0 & 25.0 & $00: 02$ \\
\hline 027 & 7.0 & 49.5 & 55610 & 778.5 & 14.0 & 25.0 & $00: 02$ \\
\hline 028 & 6.5 & 45.9 & 55532 & 721.9 & 13.0 & 25.0 & $00: 02$ \\
\hline 029 & 6.0 & 42.5 & 55703 & 668.4 & 12.0 & 25.0 & $00: 02$ \\
\hline 030 & 5.5 & 39.0 & 55763 & 613.4 & 21.0 & 25.0 & $00: 02$ \\
\hline 031 & 5.0 & 35.7 & 56149 & 561.5 & 10.0 & 25.0 & $00: 02$ \\
\hline 032 & 4.5 & 32.2 & 56271 & 506.4 & 9.00 & 25.0 & $00: 02$ \\
\hline 033 & 4.0 & 28.9 & 56817 & 454.5 & 8.00 & 25.0 & $00: 02$ \\
\hline 034 & 3.5 & 25.3 & 56845 & 397.9 & 7.00 & 25.0 & $00: 02$ \\
\hline 035 & 3.0 & 21.9 & 57407 & 344.4 & 6.00 & 25.0 & $00: 02$ \\
\hline 036 & 2.5 & 18.2 & 57250 & 286.2 & 5.00 & 25.0 & $00: 02$ \\
\hline 037 & 2.0 & 14.8 & 58194 & 232.8 & 4.00 & 25.0 & $00: 02$ \\
\hline 038 & 1.5 & 11.2 & 58718 & 176.2 & 3.00 & 25.0 & $00: 02$ \\
\hline 039 & 1.0 & 7.9 & 62126 & 124.3 & 2.00 & 25.0 & $00: 02$ \\
\hline 040 & 0.5 & 4.2 & 66058 & 66.1 & 1.00 & 25.0 & $00: 02$ \\
\hline 041 & 0.1 & 1.4 & 110096 & 22.0 & 0.20 & 25.0 & $00: 02$ \\
\hline
\end{tabular}


FIGURE 95! RHEOGRAM SHOWING RHEOPEXY BEHAVIOR FOR LECITHIN:IPM (40:60) CONTAINING 0.6\% WATER AND 6.5\% KT BY CONE AND PLATE VISCOMETER

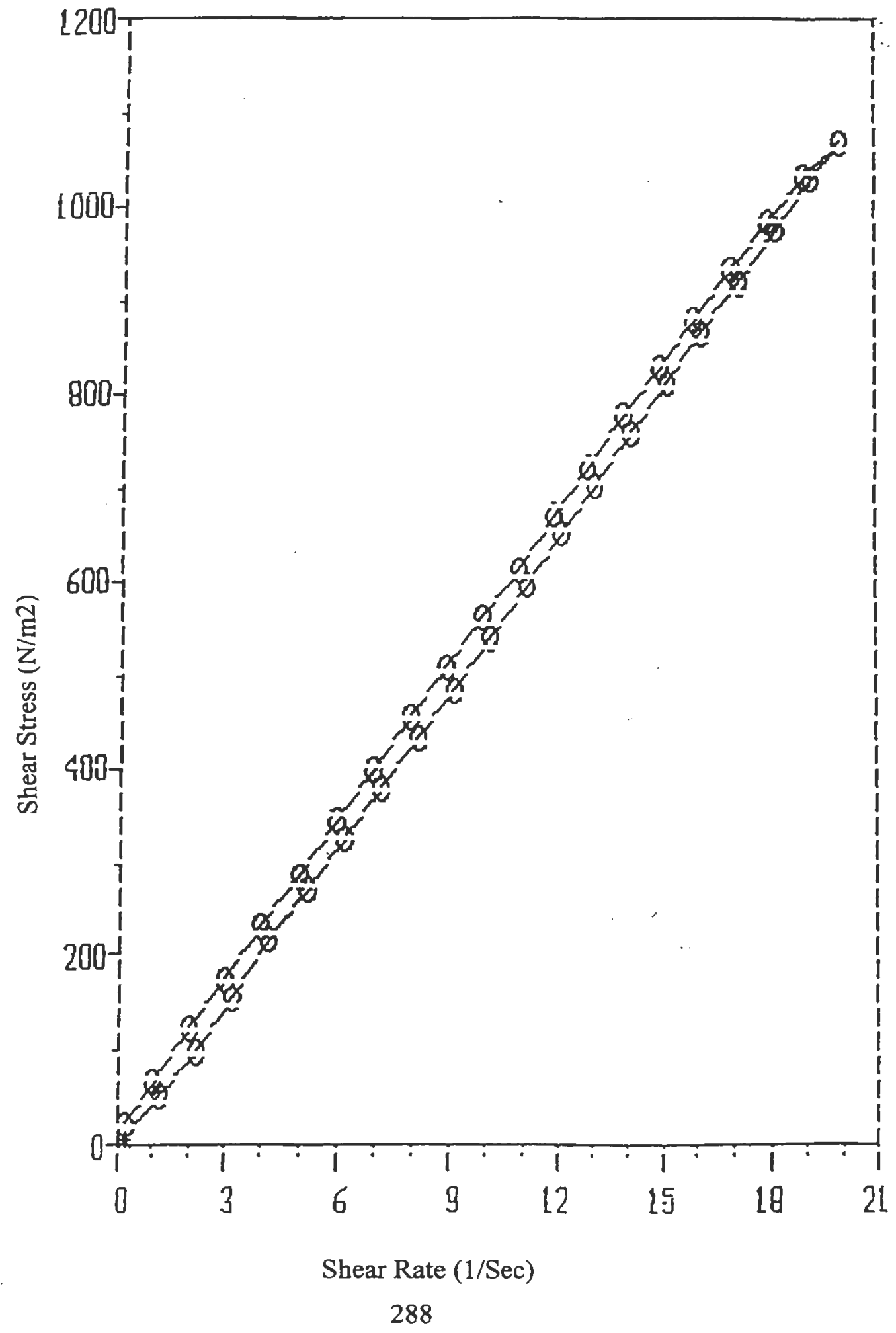


TABLE 84: VISCOSITY VALUES FOR LECITHIN:IPM (40:60) CONTAINING $0.7 \%$ WATER AND 6.5\% KT BY CONE AND PLATE VISCOMETER

RHEOCALC V1.40 BROOKFIELD ENGINEERING LABS

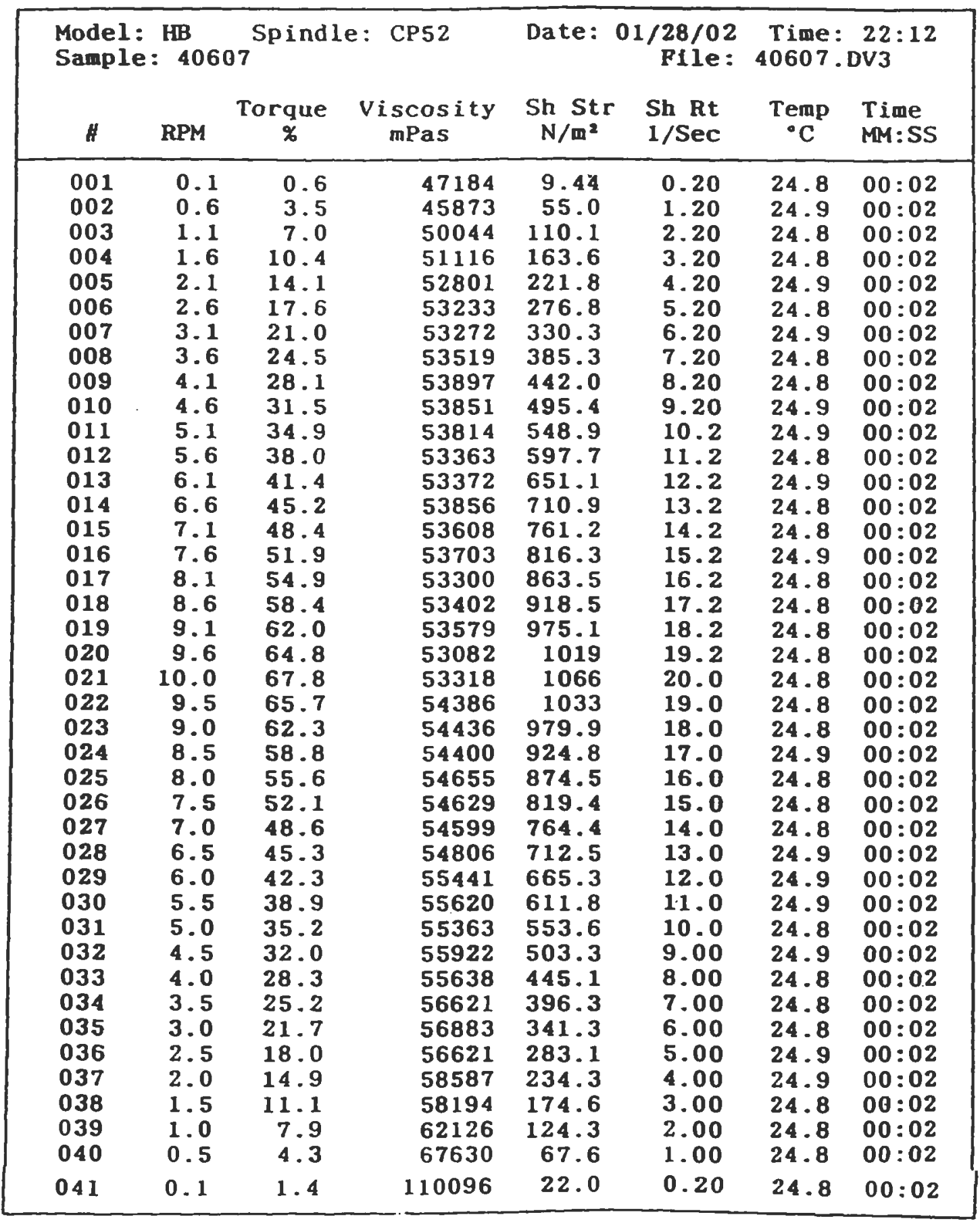


FIGURE 96; RHEOGRAM SHOWING RHEOPEXY BEHAVIOR FOR LECITHIN:IPM (40:60) CONTAINING 0.7\% WATER AND $6.5 \% \mathrm{KT}$ BY CONE AND PLATE VISCOMETER

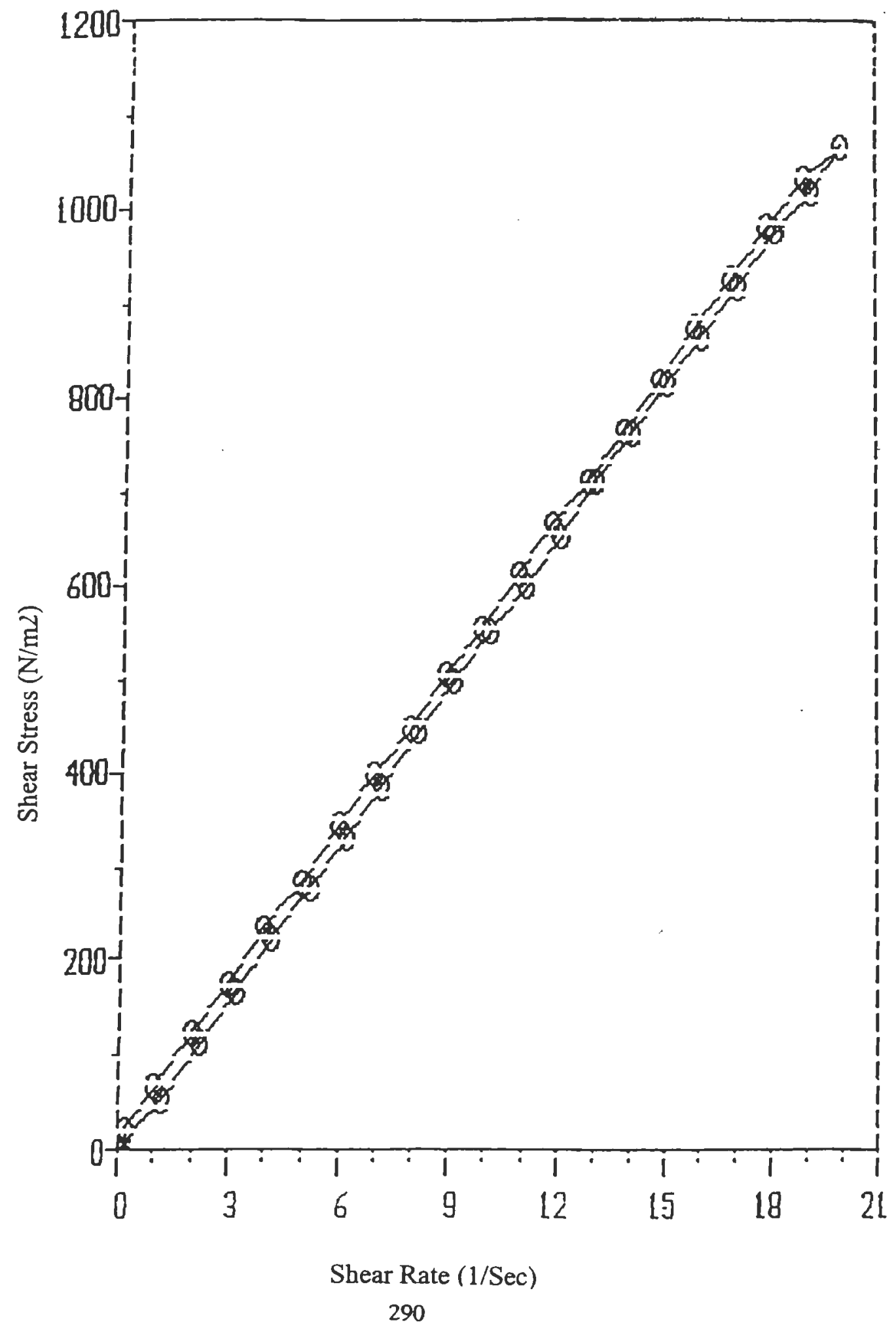


TABLE 85; VISCOSITY VALUES FOR LECITHIN:IPM (40:60) CONTAINING $0.8 \%$ WATER AND $6.5 \%$ KT BY CONE AND PLATE VISCOMETER

RHEOCALC V1.40 BROOKFIELD ENGINEERING LABS

\begin{tabular}{|c|c|c|c|c|c|c|c|}
\hline \multirow{2}{*}{$\begin{array}{l}\text { Model: } \\
\text { Sample } \\
\qquad H\end{array}$} & \multirow{2}{*}{$\begin{array}{l}\mathrm{HB} \\
: 4060 \\
\text { RPM }\end{array}$} & \multicolumn{2}{|c|}{$\begin{array}{l}\text { Spindle: CP52 } \\
\text { Dow }\end{array}$} & \multicolumn{2}{|c|}{$\begin{array}{r}\text { Date: } 01 / 29 / 02 \\
\text { File: }\end{array}$} & \multicolumn{2}{|c|}{$\begin{array}{l}\text { Time: } 03: 54 \\
\text { 40608W. DV3 }\end{array}$} \\
\hline & & $\underset{\mathscr{x}}{\text { Torque }}$ & $\begin{array}{l}\text { Viscosity } \\
\text { mPas }\end{array}$ & $\begin{array}{l}\mathrm{Sh} S t r \\
\mathrm{~N} / \mathrm{m}^{2}\end{array}$ & $\begin{array}{l}\text { Sh Rt } \\
1 / \text { Sec }\end{array}$ & $\begin{array}{l}\text { Temp } \\
\cdot \mathrm{C}\end{array}$ & $\begin{array}{l}\text { Time } \\
M M: S S\end{array}$ \\
\hline 001 & 0.1 & 0.4 & 31456 & 6.29 & 0.20 & 25.0 & $00: 02$ \\
\hline 002 & 0.6 & 2.9 & 38009 & 45.6 & 1.20 & 25.0 & $00: 02$ \\
\hline 003 & 1.1 & 5.8 & 41465 & 91.2 & 2.20 & 25.0 & $00: 02$ \\
\hline 004 & 1.6 & 8.5 & 41778 & 133.7 & 3.20 & 25.0 & $00: 02$ \\
\hline 005 & 2.1 & 11.3 & 42316 & 177.7 & 4.20 & 25.0 & $00: 02$ \\
\hline 006 & 2.6 & 14.1 & 42647 & 221.8 & 5.20 & 25.0 & $00: 02$ \\
\hline 007 & 3.1 & 16.9 & 42871 & 265.8 & 6.20 & 25.0 & $00: 02$ \\
\hline 008 & 3.6 & 19.6 & .42815 & 308.3 & 7.20 & 25.0 & $00: 02$ \\
\hline 009 & 4.1 & 22.3 & 42772 & 350.7 & 8.20 & 25.0 & $00: 02$ \\
\hline 010 & 4.6 & 25.0 & 42739 & 393.2 & 9.20 & 25.0 & $00: 02$ \\
\hline 011 & 5.1 & 27.9 & 43021 & 438.8 & 10.2 & 25.0 & $00: 02$ \\
\hline 012 & 5.6 & 30.5 & 42831 & 479.7 & 11.2 & 25.0 & $00: 02$ \\
\hline 013 & 6.1 & 33.3 & 42930 & 523.7 & 12.2 & 25.0 & $00: 02$ \\
\hline 014 & 6.6 & 36.2 & 43133 & 569.4 & 13.2 & 25.0 & $00: 02$ \\
\hline 015 & 7.1 & 39.3 & 43529 & 618.1 & 14.2 & 25.0 & $00: 02$ \\
\hline 016 & 7.6 & 42.6 & 44080 & 670.0 & 15.2 & 25.0 & $00: 02$ \\
\hline 017 & 8.1 & 45.7 & 44368 & 718.8 & 16.2 & 25.0 & $00: 02$ \\
\hline 018 & 8.6 & 48.4 & 44258 & 761.2 & 17.2 & 25.0 & $00: 02$ \\
\hline 019 & 9.1 & 51.6 & 44591 & 811.6 & 18.2 & 25.0 & $00: 02$ \\
\hline 020 & 9.6 & 54.5 & 44645 & 857.2 & 19.2 & 25.0 & $00: 02$ \\
\hline 021 & 10.0 & 57.0 & 44825 & 896.5 & 20.0 & 25.0 & $00: 02$ \\
\hline 022 & 9.5 & 55.0 & 45528 & 865.0 & 19.0 & 25.0 & $00: 02$ \\
\hline 023 & 9.0 & 52.5 & 45873 & 825.7 & 18.0 & 25.0 & $00: 02$ \\
\hline 024 & 8.5 & 49.6 & 45889 & 780.1 & 17.0 & 25.0 & $00: 02$ \\
\hline 025 & 8.0 & 47.1 & 46299 & 740.8 & 16.0 & 25.0 & $00: 02$ \\
\hline 026 & 7.5 & 44.3 & 46450 & 696.8 & 15.0 & 25.0 & $00: 02$ \\
\hline 027 & 7.0 & 41.6 & 46735 & 654.3 & 14.0 & 25.0 & $00: 02$ \\
\hline 028 & 6.5 & 38.7 & 46821 & 608.7 & 13.0 & 25.0 & $00: 02$ \\
\hline 029 & 6.0 & 35.9 & 47053 & 564.6 & 12.0 & 25.0 & $00: 02$ \\
\hline 030 & 5.5 & 33.0 & 47184 & 519.0 & 11.0 & 25.0 & $00: 02$ \\
\hline 031 & 5.0 & 30.3 & 47656 & 476.6 & 10.0 & 25.0 & $00: 02$ \\
\hline 032 & 4.5 & 27.4 & 47883 & 430.9 & 9.00 & 25.0 & $00: 02$ \\
\hline 033 & 4.0 & 24.4 & 47970 & 383.8 & 8.00 & 25.0 & $00: 02$ \\
\hline 034 & 3.5 & 21.4 & 48083 & 336.6 & 7.00 & 25.0 & $00: 02$ \\
\hline 035 & 3.0 & 18.3 & 47970 & 287.8 & 6.00 & 25.0 & $00: 02$ \\
\hline 036 & 2.5 & 15.5 & 48757 & 243.8 & 5.00 & 25.0 & $00: 02$ \\
\hline 037 & 2.0 & 12.5 & 49150 & 196.6 & 4.00 & 25.0 & $00: 02$ \\
\hline 038 & 1.5 & 9.7 & 50854 & 152.6 & 3.00 & 25.0 & $00: 02$ \\
\hline 039 & 1.0 & 6.7 & 52689 & 105.4 & 2.00 & 25.0 & $00: 02$ \\
\hline 040 & 0.5 & 3.5 & 55048 & 55.0 & 1.00 & 25.0 & $00: 02$ \\
\hline 041 & 0.1 & 1.0 & 78640 & 15.7 & 0.20 & 25.0 & $00: 02$ \\
\hline
\end{tabular}


FIGURE 97| RHEOGRAM SHOWING RHEOPEXY BEHAVIOR FOR LECITHIN:IPM (40:60) CONTAINING 0.8\% WATER AND $6.5 \%$ KT BY CONE AND PLATE VISCOMETER

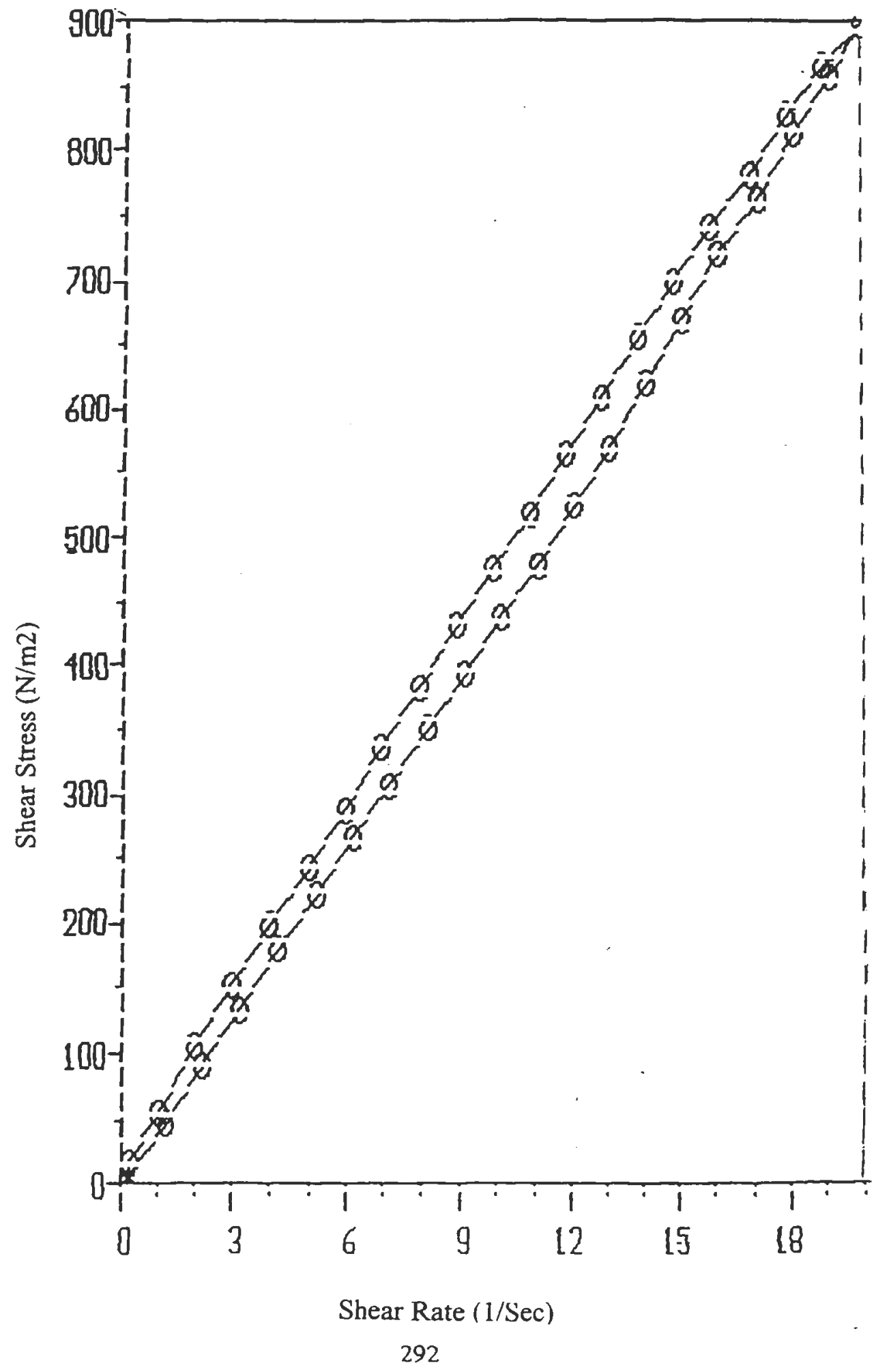


TABLE 86. VISCOSITY VALUES FOR LECITHIN:IPM (50:50) CONTAINING $0.1 \%$ WATER AND $6.5 \% \mathrm{KT}$ BY CONE AND PLATE VISCOMETER

RHEOCALC V1.40 BROOKFIELD ENGINEERING LABS

\begin{tabular}{|c|c|c|c|c|c|c|c|}
\hline $\begin{array}{l}\text { Model: } \\
\text { Sample }\end{array}$ & $\begin{array}{l}\mathrm{HB} \\
: 505\end{array}$ & \multicolumn{2}{|c|}{$\begin{array}{l}\text { Spindle: CP52 } \\
01 \mathrm{w}\end{array}$} & \multicolumn{2}{|c|}{$\begin{array}{r}\text { Date: } 01 / 29 / 02 \\
\text { File: }\end{array}$} & \multicolumn{2}{|c|}{$\begin{array}{l}\text { Time: } 03: 47 \\
\text { 50501W.DV3 }\end{array}$} \\
\hline$H$ & RPM & $\begin{array}{c}\text { Torque } \\
\boldsymbol{x}\end{array}$ & $\begin{array}{l}\text { Viscosity } \\
\text { mPas }\end{array}$ & $\begin{array}{l}\text { Sh Str } \\
N / \mathrm{m}^{2}\end{array}$ & $\begin{array}{l}\text { Sh Rt } \\
1 / \text { Sec }\end{array}$ & $\underset{{ }^{T} \mathrm{C}}{\text { Temp }}$ & $\begin{array}{l}\text { Time } \\
\text { MM:SS }\end{array}$ \\
\hline 001 & 0.1 & 0.5 & 39320 & $7: 86$ & 0.20 & 25.0 & $00: 02$ \\
\hline 002 & 0.6 & 4.4 & 57669 & 69.2 & 1.20 & 25.0 & $00: 02$ \\
\hline 003 & 1.1 & 9.3 & 66487 & 146.3 & 2.20 & 25.0 & $00: 02$ \\
\hline 004 & 1.6 & 14.3 & 70285 & 224.9 & 3.20 & 25.0 & $00: 02$ \\
\hline 005 & 2.1 & 19.9 & 74521 & 313.0 & 4.20 & 25.0 & $00: 02$ \\
\hline 006 & 2.6 & 25.3 & 76523 & 397.9 & 5.20 & 25.0 & $00: 02$ \\
\hline 007 & 3.1 & 30.6 & 77625 & 481.3 & 6.20 & 25.0 & $00: 02$ \\
\hline 008 & 3.6 & 35.9 & 78422 & 564.6 & 7.20 & 25.0 & $00: 02$ \\
\hline 009 & 4.1 & 40.8 & 78256 & 641.7 & 8.20 & 25.0 & $00: 02$ \\
\hline 010 & 4.6 & 46.5 & 79495 & 731.4 & 9.20 & 25.0 & $00: 02$ \\
\hline 011 & 5.1 & 52.2 & 80490 & 821.0 & 10.2 & 25.0 & $00: 02$ \\
\hline 012 & 5.6 & 57.6 & 80887 & 905.9 & 11.2 & 25.0 & $00: 02$ \\
\hline 013 & 6.1 & 63.2 & 81476 & 994.0 & 12.2 & 25.0 & $00: 02$ \\
\hline 014 & 6.6 & 69.1 & 82334 & 1087 & 13.2 & 25.0 & $00: 02$ \\
\hline 015 & 7.1 & 74.9 & 82960 & 1178 & 14.2 & 25.0 & $00: 02$ \\
\hline 016 & 7.6 & 80.2 & 82986 & 1261 & 15.2 & 25.0 & $00: 02$ \\
\hline 017 & 8.0 & 85.3 & 83850 & 1342 & 16.0 & 25.0 & $00: 02$ \\
\hline 018 & 7.5 & 83.4 & 87448 & 1312 & 15.0 & 25.0 & $00: 02$ \\
\hline 019 & 7.0 & 78.5 & 88189 & 1235 & 14.0 & 25.0 & $00: 02$ \\
\hline 020 & 6.5 & 73.8 & 89287 & 1161 & 13.0 & 25.0 & $00: 02$ \\
\hline 021 & 6.0 & 68.6 & 89912 & 1079 & 12.0 & 25.0 & $00: 02$ \\
\hline 022 & 5.5 & 63.3 & 90507 & 995.6 & 11.0 & 25.0 & $00: 02$ \\
\hline 023 & 5.0 & 58.0 & 91222 & 912.2 & 10.0 & 25.0 & $00: 02$ \\
\hline 024 & 4.5 & 52.3 & 91397 & 822.6 & 9.00 & 25.0 & $00: 02$ \\
\hline 025 & 4.0 & 47.0 & 92402 & 739.2 & 8.00 & 25.0 & $00: 02$ \\
\hline 026 & 3.5 & 41.4 & 93020 & 651.1 & 7.00 & 25.0 & $00: 02$ \\
\hline 027 & 3.0 & 36.2 & 94892 & 569.4 & 6.00 & 25.0 & $00: 02$ \\
\hline 028 & 2.5 & 30.3 & 95312 & 476.6 & 5.00 & 25.0 & $00: 02$ \\
\hline 029 & 2.0 & 25.1 & 98693 & 394.8 & 4.00 & 25.0 & $00: 02$ \\
\hline 030 & 1.5 & 19.4 & 101708 & 305.1 & 3.00 & 25.0 & $00: 02$ \\
\hline 031 & 1.0 & 14.0 & 110096 & 220.2 & 2.00 & 25.0 & $00: 02$ \\
\hline 032 & 0.5 & 8.6 & 135261 & 135.3 & 1.00 & 25.0 & $00: 02$ \\
\hline 033 & 0.1 & 3.3 & 259512 & 51.9 & 0.20 & 25.0 & $00: 02$ \\
\hline
\end{tabular}


FIGURE 98, RHEOGRAM SHOWING RHEOPEXY BEHAVIOR FOR LECITHIN:IPM (50:50) CONTAINING 0.1\% WATER AND 6.5\% KT BY CONE AND PLATE VISCOMETER

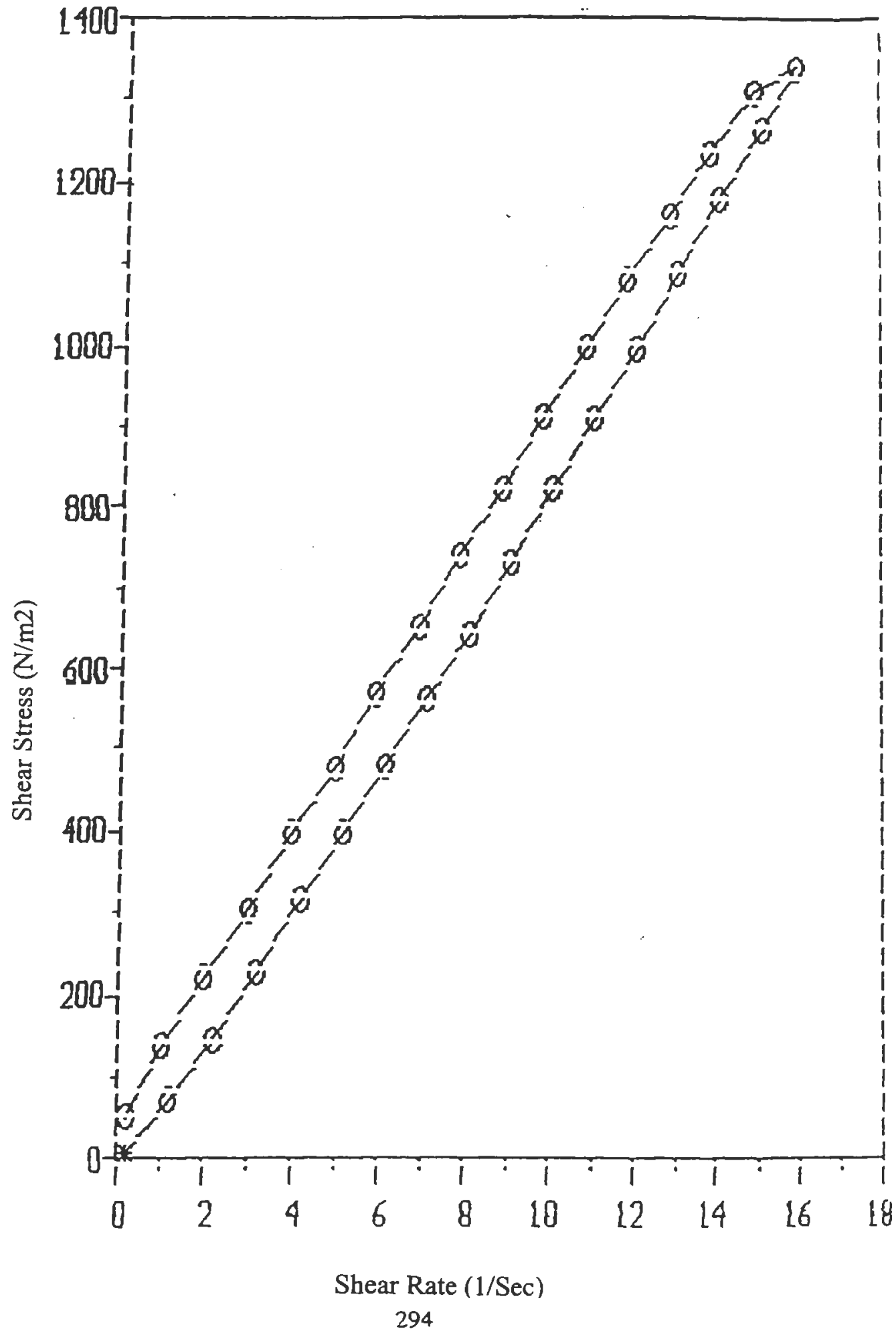


TABLE 87' VISCOSITY VALUES FOR LECITHIN:IPM (50:50) CONTAINING $0.25 \%$ WATER AND $6.5 \% \mathrm{KT}$ BY CONE AND PLATE VISCOMETER

RHEOCALC V1.40 BROOKFIELD ENGINEERING LABS

\begin{tabular}{|c|c|c|c|c|c|c|c|}
\hline \multirow{2}{*}{$\begin{array}{c}\text { Mode l: } \\
\text { Sample } \\
H\end{array}$} & \multirow{2}{*}{$\begin{array}{l}\mathrm{HB} \\
: 5050 \\
\mathrm{RPM}\end{array}$} & \multicolumn{2}{|c|}{$\begin{array}{l}\text { Spindle: CP5 } 2 \\
25\end{array}$} & \multicolumn{2}{|c|}{$\begin{array}{r}\text { Date: } 01 / 28 / 02 \\
\text { File: }\end{array}$} & \multicolumn{2}{|c|}{$\begin{array}{l}\text { Time: } 22: 49 \\
505025 . \text { DV3 }\end{array}$} \\
\hline & & $\underset{\%}{\text { Torque }}$ & $\begin{array}{l}\text { Viscosity } \\
\text { mPas }\end{array}$ & $\begin{array}{l}\text { Sh Str } \\
\mathrm{N} / \mathrm{m}^{2}\end{array}$ & $\begin{array}{l}\text { Sh Rt } \\
1 / \text { Sec }\end{array}$ & $\underset{{ }^{\circ} \mathrm{C}}{\text { Temp }}$ & $\begin{array}{l}\text { Time } \\
M M: S S\end{array}$ \\
\hline 001 & 0.1 & 0.6 & 47184 & 9.44 & 0.20 & 24.9 & $00: 02$ \\
\hline 002 & 0.6 & 4.7 & 61601 & 73.9 & 1.20 & 24.8 & $00: 02$ \\
\hline 003 & 1.1 & 10.6 & 75780 & 166.7 & 2.20 & 24.8 & $00: 02$ \\
\hline 004 & 1.6 & 16.8 & 82572 & 264.2 & 3.20 & 24.9 & $00: 02$ \\
\hline 005 & 2.1 & 23.0 & 86130 & 361.7 & 4.20 & 24.8 & $00: 02$ \\
\hline 006 & 2.6 & 29.1 & 88016 & 457.7 & 5.20 & 24.8 & $00: 02$ \\
\hline 007 & 3.1 & 35.1 & 89041 & 552.1 & 6.20 & 24.9 & $00: 02$ \\
\hline 008 & 3.6 & 41.2 & 89999 & 648.0 & 7.20 & 24.9 & $00: 02$ \\
\hline 009 & 4.1 & 47.3 & 90724 & 743.9 & 8.20 & 24.9 & $00: 02$ \\
\hline 010 & 4.6 & 53.5 & 91462 & 841.4 & 9.20 & 24.8 & $00: 02$ \\
\hline 011 & 5.1 & 59.7 & 92055 & 939.0 & 10.2 & 24.8 & $00: 02$ \\
\hline 012 & 5.6 & 65.1 & 91419 & 1024 & 11.2 & 24.9 & $00: 02$ \\
\hline 013 & 6.1 & 71.1 & 91661 & 1118 & 12.2 & 24.8 & $00: 02$ \\
\hline 014 & 6.6 & 77.8 & 92700 & 1224 & 13.2 & 24.9 & $00: 02$ \\
\hline 015 & 7.1 & 83.2 & 92153 & 1309 & 14.2 & 24.8 & $00: 02$ \\
\hline 016 & 7.6 & 90.1 & 93230 & 1417 & 15.2 & 24.8 & $00: 02$ \\
\hline 017 & 8. 0 & 94.1 & 92500 & 1480 & 16.0 & 24.8 & $00: 02$ \\
\hline 018 & 7.5 & 92.9 & 97409 & 1461 & 15.0 & 24.8 & $00: 02$ \\
\hline 019 & 7.0 & 88.3 & 99199 & 1389 & 14.0 & 24.8 & $00: 02$ \\
\hline 020 & 6.5 & 82.3 & 99570 & 1294 & 13.0 & 24.9 & $00: 02$ \\
\hline 021 & 6.0 & 76.0 & 99611 & 1195 & 12.0 & 24.8 & $00: 02$ \\
\hline 022 & 5.5 & 69.8 & 99801 & 1098 & 11.0 & 24.8 & $00: 02$ \\
\hline 023 & 5.0 & 63.8 & 100345 & 1003 & 10.0 & 24.8 & $00: 02$ \\
\hline 024 & 4.5 & 58.4 & 102057 & 918.5 & 9.00 & 24.8 & $00: 02$ \\
\hline 025 & 4.0 & 52.4 & 103018 & 824.1 & 8.00 & 24.9 & $00: 02$ \\
\hline 026 & 3.5 & 45.7 & 102681 & 718.8 & 7.00 & 24.8 & $00: 02$ \\
\hline 027 & 3.0 & 40.3 & 105640 & 633.8 & 6.00 & 24.8 & $00: 02$ \\
\hline 028 & 2.5 & 33.4 & 105063 & 525.3 & 5.00 & 24.9 & $00: 02$ \\
\hline 029 & 2.0 & 28.0 & 110096 & 440.4 & 4.00 & 24.8 & $00: 02$ \\
\hline 030 & 1.5 & 21.9 & 114814 & 344.4 & 3.00 & 24.8 & $00: 02$ \\
\hline 031 & 1.0 & 15.0 & 117960 & 235.9 & 2.00 & 24.8 & $00: 02$ \\
\hline 032 & 0.5 & 9.7 & 152562 & 152.6 & 1.00 & 24.8 & $00: 02$ \\
\hline 033 & 0.1 & 4.0 & 314560 & 62.9 & 0.20 & 24.8 & $00: 02$ \\
\hline
\end{tabular}


FIGURE 99! RHEOGRAM SHOWING RHEOPEXY BEHAVIOR FOR LECITHIN:IPM (50:50) CONTAINING 0.25\% WATER AND 6.5\% KT BY CONE AND PLATE VISICOMETER

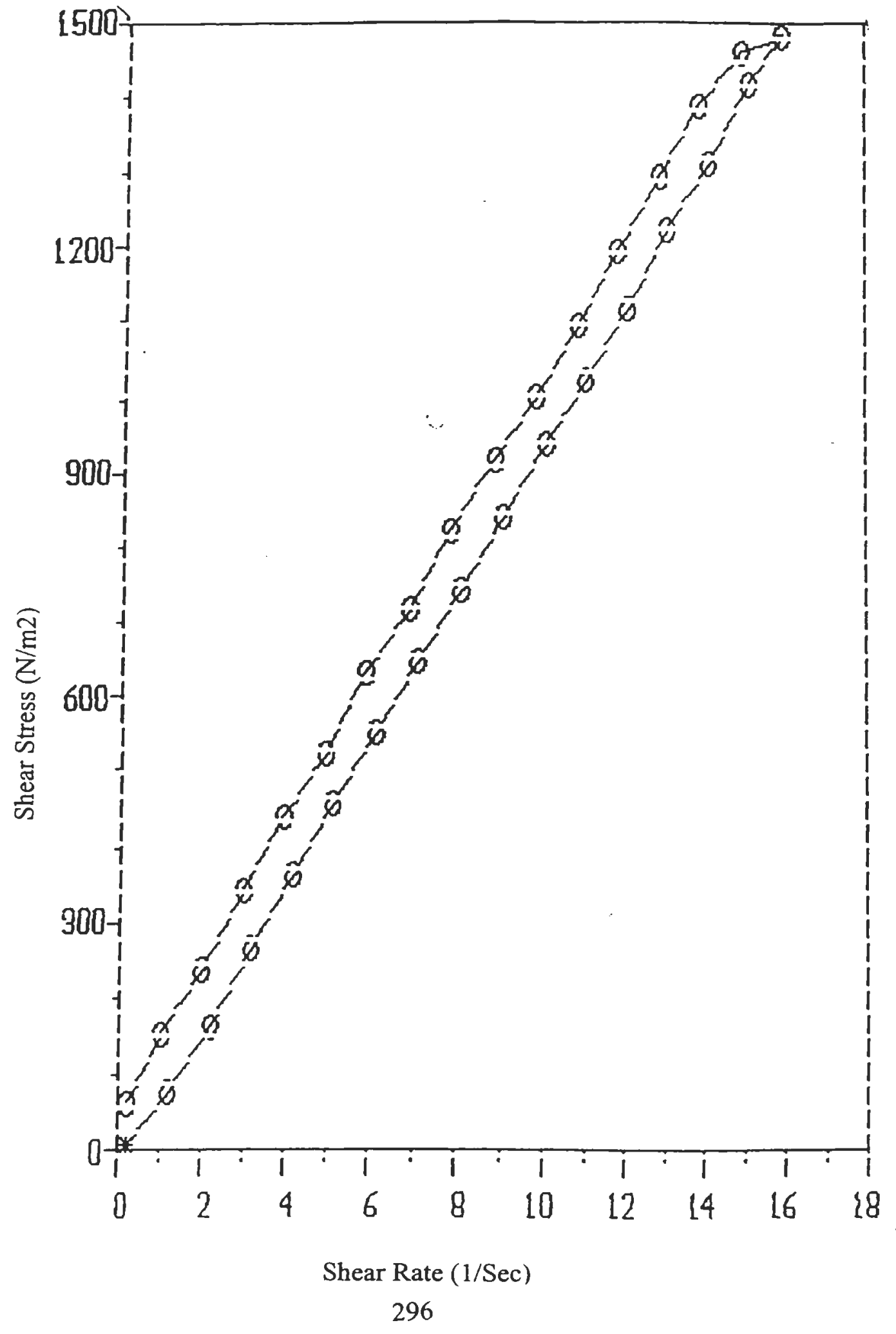


TABLE 88. VISCOSITY VALUES FOR LECITHIN:IPM (50:50) CONTAINING $0.5 \%$ WATER AND $6.5 \%$ KT BY CONE AND PLATE VISCOMETER

RHEOCALC V1.40 BROOKFIELD ENGINEERING LABS

\begin{tabular}{|c|c|c|c|c|c|c|c|}
\hline \multirow{2}{*}{$\begin{array}{c}\text { Model: } \\
\text { Sample } \\
\#\end{array}$} & \multirow{2}{*}{$\begin{array}{l}\mathrm{HB} \\
: 5050 \\
\mathrm{RPM}\end{array}$} & \multicolumn{2}{|c|}{ Spindle: CP52 } & \multicolumn{2}{|c|}{$\begin{array}{r}\text { Date: } 01 / 29 / 02 \\
\text { File: }\end{array}$} & \multicolumn{2}{|c|}{$\begin{array}{l}\text { Time: } 01: 15 \\
\text { 50505.DV3 }\end{array}$} \\
\hline & & $\underset{\mathscr{x}}{\text { Torque }}$ & $\begin{array}{l}\text { Viscosity } \\
\text { mPas }\end{array}$ & $\begin{array}{l}\text { Sh Str } \\
\mathrm{N} / \mathrm{m}^{2}\end{array}$ & $\begin{array}{l}\text { Sh Rt } \\
1 / \text { Sec }\end{array}$ & $\underset{{ }^{\circ} \mathrm{C}}{\text { Temp }}$ & $\begin{array}{l}\text { Time } \\
\text { MM:SS }\end{array}$ \\
\hline 001 & 0.1 & 0.6 & 47184 & 9.44 & 0.20 & 25.1 & $00: 02$ \\
\hline 002 & 0.6 & 4.4 & 57669 & 69.2 & 1.20 & 25.1 & $00: 02$ \\
\hline 003 & 1.1 & 9.3 & 66487 & 146.3 & 2.20 & 25.1 & $00: 02$ \\
\hline 004 & 1.6 & 14.0 & 68810 & 220.2 & 3.20 & 25.1 & $00: 02$ \\
\hline 005 & 2.1 & 19.2 & 71899 & 302.0 & 4.20 & 25.0 & $00: 02$ \\
\hline 006 & 2.6 & 24.4 & 73801 & 383.8 & 5.20 & 25.1 & $00: 02$ \\
\hline 007 & 3.1 & 29.4 & 74581 & 462.4 & 6.20 & 25.1 & $00: 02$ \\
\hline 008 & 3.6 & 34.2 & 74708 & 537.9 & 7.20 & 25.1 & $00: 02$ \\
\hline 009 & 4.1 & 39.2 & 75188 & 616.5 & 8. 20 & 25.1 & $00: 02$ \\
\hline 010 & 4.6 & 44.4 & 75905 & 698.3 & 9.20 & 25.1 & $00: 02$ \\
\hline 011 & 5.1 & 49.7 & 76635 & 781.7 & 10.2 & 25.1 & $00: 02$ \\
\hline 012 & 5.6 & 55.8 & 78359 & 877.6 & 11.2 & 25.1 & $00: 02$ \\
\hline 013 & 6.1 & 61.3 & 79027 & 964.1 & 12.2 & 25.1 & $00: 02$ \\
\hline 014 & 6.6 & 67.5 & 80427 & 1062 & 13.2 & 25.1 & $00: 02$ \\
\hline 015 & 7.1 & 73.0 & 80855 & 1148 & 14.2 & 25.1 & $00: 02$ \\
\hline 016 & 7.6 & 78.7 & 81434 & 1238 & 15.2 & 25.1 & $00: 02$ \\
\hline 017 & 8.0 & 83.0 & 81589 & 1305 & 16.0 & 25.0 & $00: 02$ \\
\hline 018 & 7.5 & 80.8 & 84721 & 1271 & 15.0 & 25.1 & $00: 02$ \\
\hline 019 & 7.0 & 76.9 & 86392 & 1209 & 14.0 & 25.1 & $00: 02$ \\
\hline 020 & 6.5 & 71.5 & 86504 & 1125 & 13.0 & 25.1 & $00: 02$ \\
\hline 021 & 6.0 & 66.7 & 87421 & 1049 & 12.0 & 25.1 & $00: 02$ \\
\hline 022 & 5.5 & 61.5 & 87934 & 967.3 & 11.0 & 25.1 & $00: 02$ \\
\hline 023 & 5.0 & 56.2 & 88391 & 883.9 & 10.0 & 25.0 & $00: 02$ \\
\hline 024 & 4.5 & 51.3 & 89650 & 806.8 & 9.00 & 25.0 & $00: 02$ \\
\hline 025 & 4.0 & 45.9 & 90239 & 721.9 & 8.00 & 25.1 & $00: 02$ \\
\hline 026 & 3.5 & 40.6 & 91222 & 638.6 & 7.00 & 25.0 & $00: 02$ \\
\hline 027 & 3.0 & 35.0 & 91747 & 550.5 & 6.00 & 25.1 & $00: 02$ \\
\hline 028 & 2.5 & 29.7 & 93424 & 467.1 & 5.00 & 25.1 & $00: 02$ \\
\hline 029 & 2.0 & 24.2 & 95154 & 380.6 & 4.00 & 25.1 & $00: 02$ \\
\hline 030 & 1.5 & 18.8 & 98562 & 295.7 & 3.00 & 25.1 & $00: 02$ \\
\hline 031 & 1.0 & 13.2 & 103805 & 207.6 & 2.00 & 25.0 & $00: 02$ \\
\hline 032 & 0.5 & 8.0 & 125824 & 125.8 & 1.00 & 25.1 & $00: 02$ \\
\hline 033 & 0.1 & 3.1 & 243784 & 48.8 & 0.20 & 25.1 & $00: 02$ \\
\hline
\end{tabular}


HIGUHETUU,RHEUGRAM SHOWING RHEOPEXY BEHAVIOR FOR LECITHIN:IPM (50:50) CONTAINING 0.5\% WATER AND 6.5\% KT BY CONE AND PLATE VISCOMETER

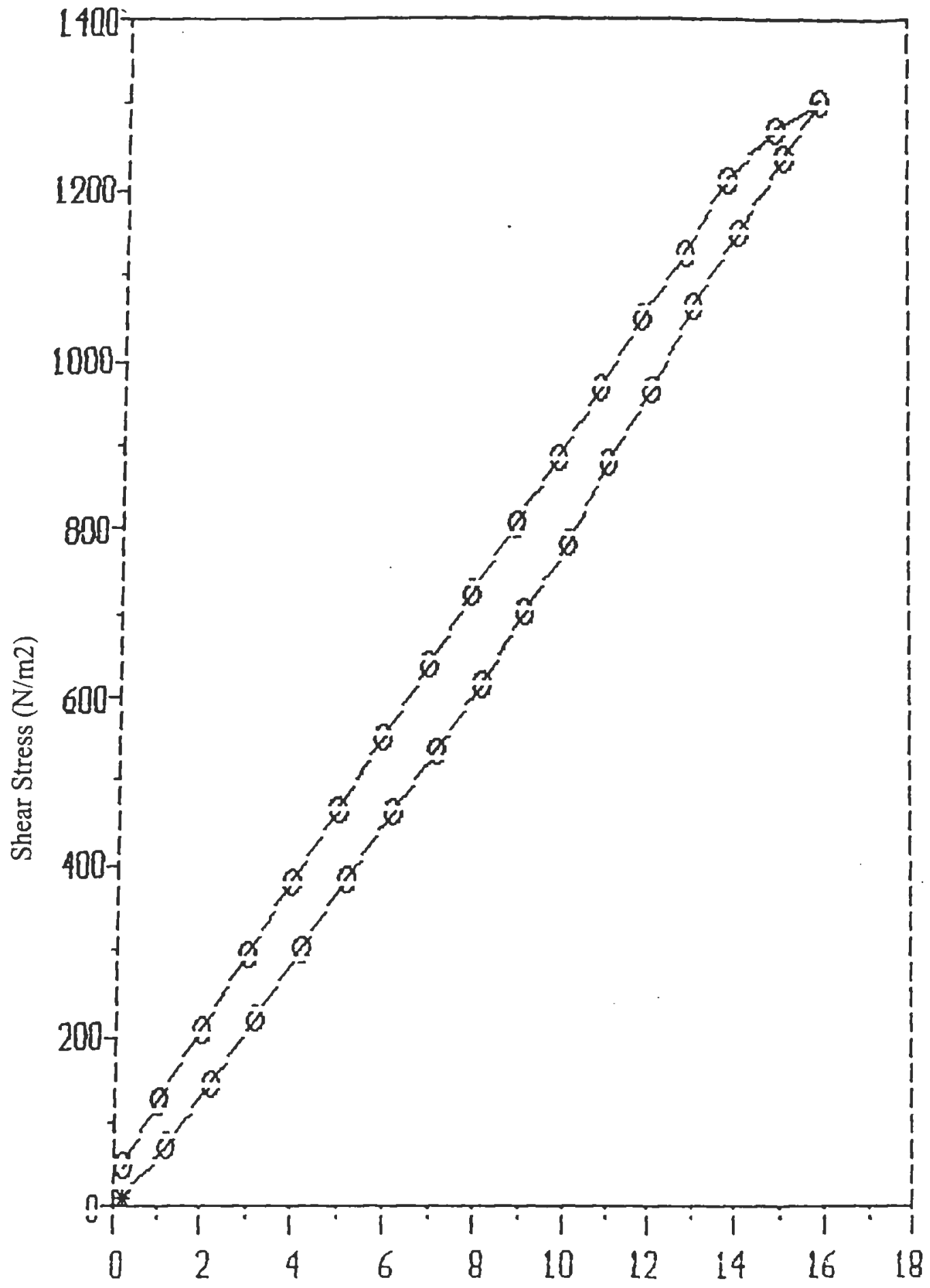

Shear Rate (1/Sec) 
TABLE 89. VISCOSITY VALUES FOR LECITHIN:IPM (50:50) CONTAINING $0.6 \%$ WATER AND $6.5 \% \mathrm{KT}$ BY CONE AND PLATE VISCOMETER

RHEOCALC V1.40 BROOKFIELD ENGINEERING LABS

\begin{tabular}{|c|c|c|c|c|c|c|c|}
\hline \multirow{2}{*}{$\begin{array}{l}\text { Model: } \\
\text { Sample: } \\
\qquad \#\end{array}$} & \multirow{2}{*}{ 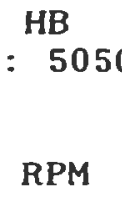 } & \multicolumn{2}{|c|}{ Spindle: CP52 } & \multicolumn{2}{|c|}{$\begin{array}{r}\text { Date: } 01 / 29 / 02 \\
\text { File: }\end{array}$} & \multicolumn{2}{|c|}{$\begin{array}{l}\text { Time: } 01: 29 \\
50506 W . \text { DV3 }\end{array}$} \\
\hline & & $\underset{x}{\text { Torque }}$ & $\begin{array}{l}\text { Viscosity } \\
\text { mPas }\end{array}$ & $\underset{N / m^{2}}{S h ~ S t r}$ & $\begin{array}{l}\text { Sh Rt } \\
1 / \operatorname{Sec}\end{array}$ & ${ }^{\text {Temp }}$ & $\begin{array}{l}\text { Time } \\
\text { MM:SS }\end{array}$ \\
\hline 001 & 0.1 & 0.4 & 31456 & 6.29 & 0.20 & 25.1 & $00: 02$ \\
\hline 002 & 0.6 & 3.6 & 47184 & 56.6 & 1.20 & 25.0 & $00: 02$ \\
\hline 003 & 1.1 & 9.4 & 67201 & 147.8 & 2.20 & 25.0 & $00: 02$ \\
\hline 004 & 1.6 & 14.6 & 71759 & 229.6 & 3.20 & 25.0 & $00: 02$ \\
\hline 005 & 2.1 & 20.0 & 74895 & 314.6 & 4.20 & 25.1 & $00: 02$ \\
\hline 006 & 2.6 & 25.0 & 75615 & 393.2 & 5.20 & 25.0 & $00: 02$ \\
\hline 007 & 3.1 & 30.0 & 76103 & 471.8 & 6.20 & 25.1 & $00: 02$ \\
\hline 008 & 3.6 & 34.6 & 75582 & 544.2 & 7.20 & 25.1 & $00: 02$ \\
\hline 009 & 4.1 & 40.4 & 77489 & 635.4 & 8.20 & 25.1 & $00: 02$ \\
\hline 010 & 4.6 & 45.8 & 78298 & 720.3 & 9.20 & 25.1 & $00: 02$ \\
\hline 011 & 5.1 & 51.6 & 79565 & 811.6 & 10.2 & 25.1 & $00: 02$ \\
\hline 012 & 5.6 & 56.9 & 79904 & 894.9 & 11.2 & 25.0 & $00: 02$ \\
\hline 013 & 6.1 & 63.1 & 81347 & 992.4 & 12.2 & 25.1 & $00: 02$ \\
\hline 014 & 6.6 & 68.9 & 82095 & 1084 & 13.2 & 25.1 & $00: 02$ \\
\hline 015 & 7.1 & 74.3 & 82295 & 1169 & 14.2 & 25.1 & $00: 02$ \\
\hline 016 & 7.6 & 79.8 & 82572 & 1255 & 15.2 & 25.1 & $00: 02$ \\
\hline 017 & 8.0 & 83.6 & 82179 & 1315 & 16.0 & 25.1 & $00: 02$ \\
\hline 018 & 7.5 & 81.1 & 85036 & 1276 & 15.0 & 25.1 & $00: 02$ \\
\hline 019 & 7.0 & 76.9 & 86392 & 1209 & 14.0 & 25.1 & $00: 02$ \\
\hline 020 & 6.5 & 71.5 & 86504 & 1125 & 13.0 & 25.1 & $00: 02$ \\
\hline 021 & 6.0 & 67.0 & 87815 & 1054 & 12.0 & 25.1 & $00: 02$ \\
\hline 022 & 5.5 & 61.8 & 88363 & 972.0 & 11.0 & 25.1 & $00: 02$ \\
\hline 023 & 5.0 & 57.0 & 89650 & 896.5 & 10.0 & 25.0 & $00: 02$ \\
\hline 024 & 4.5 & 51.5 & 89999 & 810.0 & 9.00 & 25.0 & $00: 02$ \\
\hline 025 & 4.0 & 46.5 & 91419 & 731.4 & 8.00 & 25.0 & $00: 02$ \\
\hline 026 & 3.5 & 41.2 & 92571 & 648.0 & 7.00 & 25.0 & $00: 02$ \\
\hline 027 & 3.0 & 35.7 & 93582 & 561.5 & 6.00 & 25.1 & $00: 02$ \\
\hline 028 & 2.5 & 30.5 & 95941 & 479.7 & 5.00 & 25.0 & $00: 02$ \\
\hline 029 & 2.0 & 24.8 & 97514 & 390.1 & 4.00 & 25.0 & $00: 02$ \\
\hline 030 & 1.5 & 19.5 & 102232 & 306.7 & 3.00 & 25.1 & $00: 02$ \\
\hline 031 & 1.0 & 13.7 & 107737 & 215.5 & 2.00 & 25.0 & $00: 02$ \\
\hline 032 & 0.5 & 8.5 & 133688 & 133.7 & 1.00 & 25.0 & $00: 02$ \\
\hline 033 & 0.1 & 3.3 & 259512 & 51.9 & 0.20 & 25.1 & $00: 02$ \\
\hline
\end{tabular}


FIGURE101LRHEOGRAM SHOWING RHEOPEXY BEHAVIOR FOR LECITHIN:IPM (50:50) CONTAINING 0.6\% WATER AND $6.5 \%$ KT BY CONE AND PLATE VISCOMETER

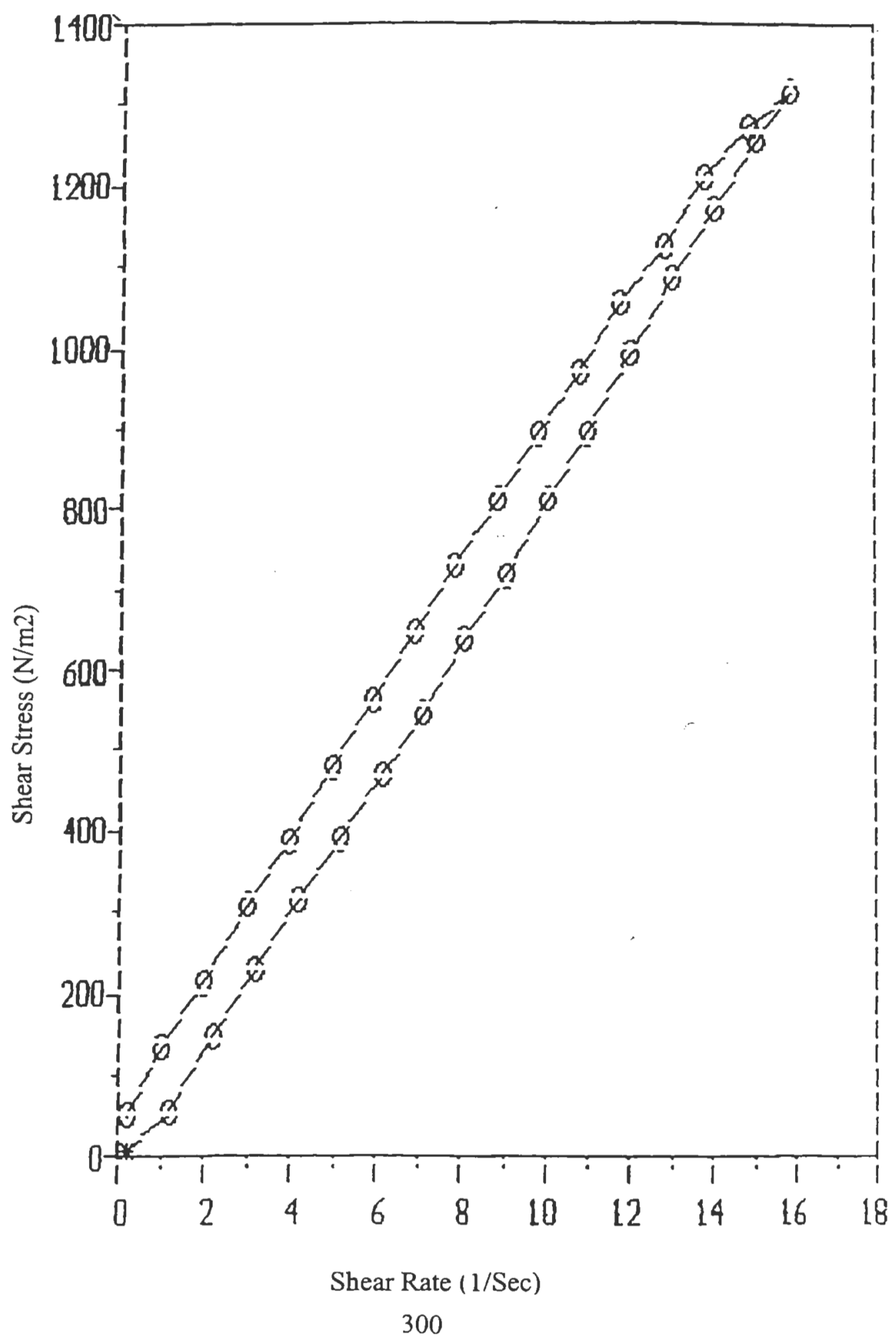


TABLE 90! VISCOSITY VALUES FOR LECITHIN:IPM (50:50) CONTAINING $0.7 \%$ WATER AND $6.5 \%$ KT BY CONE AND PLATE VISCONETER

RHEOCALC V1.40 BROOKFIELD ENGINEERING LABS

\begin{tabular}{|c|c|c|c|c|c|c|c|}
\hline \multirow{2}{*}{$\begin{array}{l}\text { Model: } \\
\text { Sample } \\
\end{array}$} & \multirow{2}{*}{$\begin{array}{l}\text { HB } \\
5050 \\
\text { RPM }\end{array}$} & \multicolumn{2}{|c|}{$\begin{array}{l}\text { Spindle: CP52 } \\
7 W\end{array}$} & \multicolumn{2}{|c|}{$\begin{array}{r}\text { Date: } 01 / 29 / 02 \\
\text { File: }\end{array}$} & \multicolumn{2}{|c|}{$\begin{array}{l}\text { Time: } 01: 38 \\
\text { 50507W. DV } 3\end{array}$} \\
\hline & & $\underset{\mathscr{x}}{\text { Torque }}$ & $\begin{array}{l}\text { Viscosity } \\
\text { mPas }\end{array}$ & $\begin{array}{l}\text { Sh Str } \\
\mathrm{N} / \mathrm{m}^{2}\end{array}$ & $\begin{array}{l}\text { Sh Rt } \\
1 / \text { Sec }\end{array}$ & $\begin{array}{l}\text { Temp } \\
{ }^{\circ} \mathrm{C}\end{array}$ & $\begin{array}{l}\text { Time } \\
\text { MM:SS }\end{array}$ \\
\hline 001 & 0.1 & 0.4 & 31456 & 6.29 & 0.20 & 25.0 & $00: 02$ \\
\hline 002 & 0.6 & 4.7 & 61601 & 73.9 & 1.20 & 25.0 & $00: 02$ \\
\hline 003 & 1.1 & 10.2 & 72921 & 160.4 & 2.20 & 25.0 & $00: 02$ \\
\hline 004 & 1.6 & 15.8 & 77657 & 248.5 & 3.20 & 25.0 & $00: 02$ \\
\hline 005 & 2.1 & 22.0 & 82385 & 346.0 & 4.20 & 25.0 & $00: 02$ \\
\hline 006 & 2.6 & 27.5 & 83177 & 432.5 & 5.20 & 25.0 & $00: 02$ \\
\hline 007 & 3.1 & 33.6 & 85236 & 528.5 & 6.20 & 25.0 & $00: 02$ \\
\hline 008 & 3.6 & 39.1 & 85412 & 615.0 & 7.20 & 25.0 & $00: 02$ \\
\hline 009 & 4.1 & 44.9 & 86120 & 706.2 & 8.20 & 25.1 & $00: 02$ \\
\hline 010 & 4.6 & 50.5 & 86333 & 794.3 & 9.20 & 25.0 & $00: 02$ \\
\hline 011 & 5.1 & 56.4 & 86967 & 887.1 & 10.2 & 25.0 & $00: 02$ \\
\hline 012 & 5.6 & 62.1 & 87206 & 976.7 & 11.2 & 25.0 & $00: 02$ \\
\hline 013 & 6.1 & 68.1 & 87793 & 1071 & 12.2 & 25.1 & $00: 02$ \\
\hline 014 & 6.6 & 73.6 & 87696 & 1158 & 13.2 & 25.1 & $00: 02$ \\
\hline 015 & 7.1 & 79.4 & 87944 & 1249 & 14.2 & 25.0 & $00: 02$ \\
\hline 016 & 7.6 & 85.1 & 88056 & 1338 & 15.2 & 25.0 & $00: 02$ \\
\hline 017 & 8.0 & 90.2 & 88667 & 1419 & 16.0 & 25.0 & $00: 02$ \\
\hline 018 & 7.5 & 88.0 & 92271 & 1384 & 15.0 & 25.0 & $00: 02$ \\
\hline 019 & 7.0 & 82.8 & 93020 & 1302 & 14.0 & 25.0 & $00: 02$ \\
\hline 020 & 6.5 & 77.8 & 94126 & 1224 & 13.0 & 25.0 & $00: 02$ \\
\hline 021 & 6.0 & 71.9 & 94237 & 1131 & 12.0 & 25.1 & $00: 02$ \\
\hline 022 & 5.5 & 66.6 & 95226 & 1047 & 11.0 & 25.0 & $00: 02$ \\
\hline 023 & 5.0 & 60.6 & 95312 & 953.1 & 10.0 & 25.1 & $00: 02$ \\
\hline 024 & 4.5 & 55.3 & 96640 & 869.8 & 9.00 & 25.1 & $00: 02$ \\
\hline 025 & 4.0 & 49.7 & 97710 & 781,7 & 8.00 & 25.0 & $00: 02$ \\
\hline 026 & 3.5 & 43.8 & 98412 & 688.9 & 7.00 & 25.0 & $00: 02$ \\
\hline 027 & 3.0 & 38.2 & 100135 & 600.8 & 6.00 & 25.0 & $00: 02$ \\
\hline 028 & 2.5 & 32.3 & 101603 & 508.0 & 5.00 & 25.0 & $00: 02$ \\
\hline 029 & 2.0 & 26.6 & 104591 & 418.4 & 4.00 & 25.1 & $00: 02$ \\
\hline 030 & 1.5 & 20.5 & 107475 & 322.4 & 3.00 & 25.1 & $00: 02$ \\
\hline 031 & 1.0 & 14.7 & I 15601 & 231.2 & 2.00 & 25.0 & $00: 02$ \\
\hline 032 & 0.5 & 8.8 & 138406 & 138.4 & 1.00 & 25.0 & $00: 02$ \\
\hline 033 & 0.1 & 3.6 & 283104 & 56.6 & 0.20 & 25.0 & $00: 02$ \\
\hline
\end{tabular}


FIGURE 102, RHEOGRAM SHOWING RHEOPEXY BEHAVIOR FOR LECITHIN:IPM (50:50) CONTAINING 0.7\% WATER AND $6.5 \%$ KT BY (:ONE AND PLATE VISCOMETER

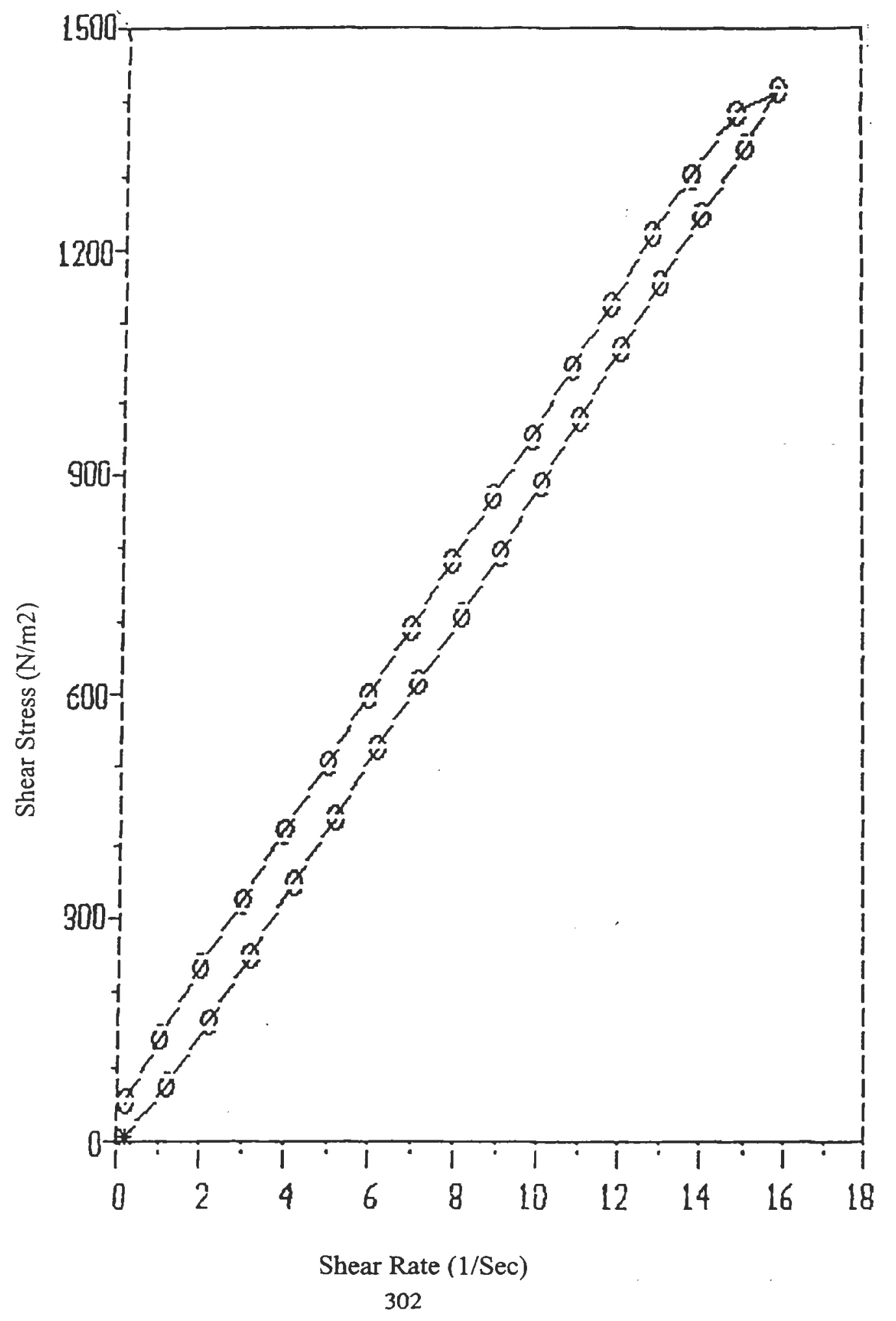


TABLE 91. VISCOSITY VALUES FOR LECITHIN:IPM (50:50) CONTAINING $0.8 \%$ WATER AND $6.5 \%$ KT BY CONE AND PLATE VISCOMETER

RHEOCALC V1.40 BROOKFIELD ENGINEERING LABS

\begin{tabular}{|c|c|c|c|c|c|c|c|}
\hline \multirow{2}{*}{$\begin{array}{l}\text { Model: } \\
\text { Sample } \\
\end{array}$} & \multirow{2}{*}{$\begin{array}{l}\mathrm{HB} \\
: 5050 \\
\mathrm{RPM}\end{array}$} & \multicolumn{2}{|c|}{$\begin{array}{l}\text { Spindle: CP52 } \\
08 W\end{array}$} & \multirow{2}{*}{\multicolumn{2}{|c|}{$\begin{array}{rr}\text { Date: } & 01 / 29 / 02 \\
\text { File: } \\
\text { Sh Str } & \text { ShRt } \\
N / m^{2} & 1 / \operatorname{Sec}\end{array}$}} & \multicolumn{2}{|c|}{$\begin{array}{l}\text { Time: } 01: 50 \\
50508 \mathrm{~W} . \mathrm{DV} 3\end{array}$} \\
\hline & & $\underset{\%}{\text { Torque }}$ & $\begin{array}{l}\text { Viscosity } \\
\text { mPas }\end{array}$ & & & $\begin{array}{l}\text { Temp } \\
{ }^{\circ} \mathrm{C}\end{array}$ & $\begin{array}{l}\text { Time } \\
\text { MM:SS }\end{array}$ \\
\hline 001 & 0.1 & 0.7 & 55048 & 11.0 & 0.20 & 25.0 & $00: 02$ \\
\hline 002 & 0.6 & 4.6 & 60291 & 72.3 & 1.20 & 25.0 & $00: 02$ \\
\hline 003 & 1.1 & 8.8 & 62912 & 138.4 & 2.20 & 25.1 & $00: 02$ \\
\hline 004 & 1.6 & 14.7 & 72251 & 231.2 & 3.20 & 25.0 & $00: 02$ \\
\hline 005 & 2.1 & 20.6 & 77142 & 324.0 & 4.20 & 25.1 & $00: 02$ \\
\hline 006 & 2.6 & 25.7 & 77733 & 404.2 & 5.20 & 25.0 & $00: 02$ \\
\hline 007 & 3.1 & 30.9 & 78386 & 486.0 & 6.20 & 25.0 & $00: 02$ \\
\hline 008 & 3.6 & 35.8 & 78203 & 563.1 & 7.20 & 25.1 & $00: 02$ \\
\hline 009 & 4.1 & 41.1 & 78832 & 646.4 & 8.20 & 25.0 & $00: 02$ \\
\hline 010 & 4.6 & 46.3 & 79153 & 728.2 & 9.20 & 25.0 & $00: 02$ \\
\hline 011 & 5.1 & 52.1 & 80336 & 819.4 & 10.2 & 25.0 & $00: 02$ \\
\hline 012 & 5.6 & 57.7 & 81027 & 907.5 & 11.2 & 25.0 & $00: 02$ \\
\hline 013 & 6.1 & 64.2 & 82765 & 1010 & 12.2 & 25.0 & $00: 02$ \\
\hline 014 & 6.6 & 69.9 & 83287 & 1099 & 13.2 & 25.0 & $00: 02$ \\
\hline 015 & 7.1 & 75.3 & 83403 & 1184 & 14.2 & 25.0 & $00: 02$ \\
\hline 016 & 7.6 & 79.1 & 81848 & 1244 & 15.2 & 25.0 & $00: 02$ \\
\hline 017 & 8.0 & 82.8 & 81392 & 1302 & 16.0 & 25.0 & $00: 02$ \\
\hline 018 & 7.5 & 79.8 & 83673 & 1255 & 15.0 & 25.1 & $00: 02$ \\
\hline 019 & 7.0 & 74.7 & 83920 & 1175 & 14.0 & 25.0 & $00: 02$ \\
\hline 020 & 6.5 & 69.4 & 83963 & 1092 & 13.0 & 25.1 & $00: 02$ \\
\hline 021 & 6.0 & 64.0 & 83883 & 1007 & 12.0 & 25.1 & $00: 02$ \\
\hline 022 & 5.5 & 59.7 & 85360 & 939.0 & 11.0 & 25.0 & $00: 02$ \\
\hline 023 & 5.0 & 54.9 & 86347 & 863.5 & 10.0 & 25.1 & $00: 02$ \\
\hline 024 & 4.5 & 50.8 & 88776 & 799.0 & 9.00 & 25.0 & $00: 02$ \\
\hline 025 & 4.0 & 46.1 & 90633 & 725.1 & 8.00 & 25.0 & $00: 02$ \\
\hline 026 & 3.5 & 40.8 & 91672 & 641.7 & 7.00 & 25.0 & $00: 02$ \\
\hline 027 & 3.0 & 35.6 & 93319 & 559.9 & 6.00 & 25.1 & $00: 02$ \\
\hline 028 & 2.5 & 30.3 & 95312 & 476.6 & 5.00 & 25.1 & $00: 02$ \\
\hline 029 & 2.0 & 25.2 & 99086 & 396.3 & 4.00 & 25.1 & $00: 02$ \\
\hline 030 & 1.5 & 19.6 & 102756 & 308.3 & 3.00 & 25.1 & $00: 02$ \\
\hline 031 & 1.0 & 14.2 & 111669 & 223.3 & 2.00 & 25.1 & $00: 02$ \\
\hline 032 & 0.5 & 8.5 & 133688 & 133.7 & 1.00 & 25.0 & $00: 02$ \\
\hline 033 & 0.1 & 4.2 & 330288 & 66.1 & 0.20 & 25.0 & $00: 02$ \\
\hline
\end{tabular}


FIGURE 103. RHEOGRAM SHOWING RHEOPEXY BEHAVIOR FOR LECITHIN:IPM (50:50) CONTAINING 0.8\% WATER AND 6.5\% KT BY CONE AND PLATE VISCOMETER

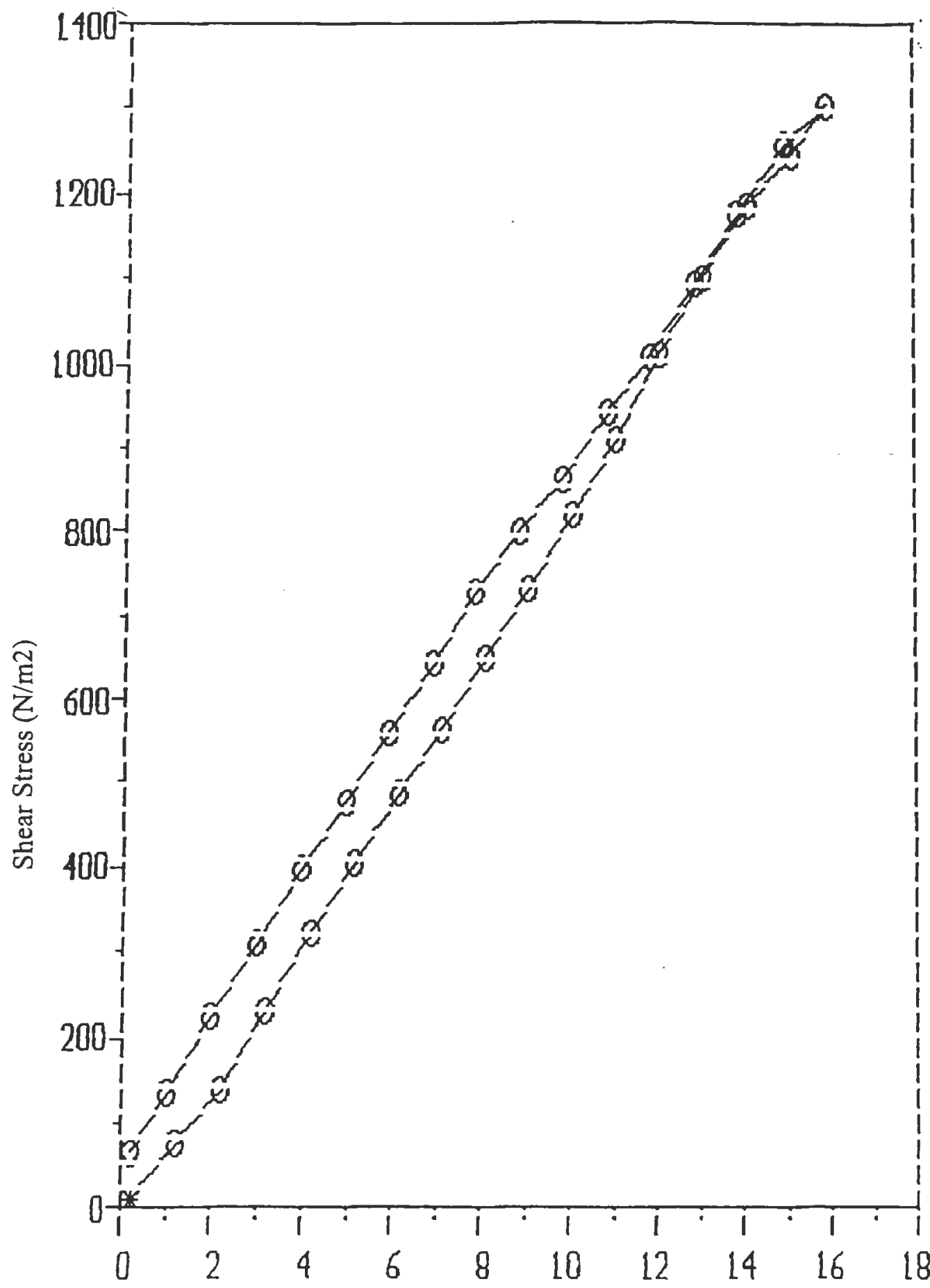

Shear Rate (1/Sec) 
TABLE 92. VISCOSITY VALUES FOR LECITHIN:IPM (60:40) CONTAINING $0.1 \%$ WATER AND $6.5 \%$ KT BY CONE AND PLATE VISCOMETER

RHEOCALC V1.40 BROOKFIELD ENGINEERING LABS

\begin{tabular}{|c|c|c|c|c|c|c|c|}
\hline \multirow{2}{*}{$\begin{array}{c}\text { Model: } \\
\text { Sample } \\
\#\end{array}$} & \multirow{2}{*}{$\begin{array}{l}\mathrm{HB} \\
: \quad 6040 \\
\mathrm{RPM}\end{array}$} & \multicolumn{2}{|c|}{$\begin{array}{l}\text { Spindle: CP52 } \\
\text { 01W }\end{array}$} & \multicolumn{4}{|c|}{$\begin{array}{c}\text { Date: } 01 / 29 / 02 \text { Time: } 02: 11 \\
\text { File: } 60401 \mathrm{~W} . \text { DV } 3\end{array}$} \\
\hline & & $\underset{\%}{\text { Torque }}$ & $\begin{array}{l}\text { Viscosity } \\
\text { mPas }\end{array}$ & $\underset{N / m^{2}}{S h S t r}$ & $\begin{array}{l}\text { Sh Rt } \\
1 / \operatorname{Sec}\end{array}$ & $\underset{\circ}{\text { Temp }}$ & $\begin{array}{l}\text { Time } \\
M M: S S\end{array}$ \\
\hline 001 & 0.1 & 1.2 & 94368 & 18.9 & 0.20 & 25.0 & $00: 02$ \\
\hline 002. & 0.3 & 4.2 & 110096 & 66.1 & 0.60 & 25.0 & $00: 02$ \\
\hline 003 & 0.5 & 8.0 & 125824 & 125.8 & 1.00 & 25.0 & $00: 02$ \\
\hline 004 & 0.7 & 14.6 & 164021 & 229.6 & 1.40 & 25.1 & $00: 02$ \\
\hline 005 & 0.9 & 21.7 & 189610 & 341.3 & 1.80 & 25.1 & $00: 02$ \\
\hline 006 & 1.1 & 29.2 & 208753 & 459.3 & 2.20 & 25.0 & $00: 02$ \\
\hline 007 & 1.3 & 37.0 & 223822 & 581.9 & 2.60 & 25.1 & $00: 02$ \\
\hline 008 & 1.5 & 44.2 & 231726 & 695.2 & 3.00 & 25.0 & $00: 02$ \\
\hline 009 & 1.7 & 52.2 & 241471 & 821.0 & 3.40 & 25.0 & $00: 02$ \\
\hline 010 & 1.9 & 60.7 & 251234 & 954.7 & 3.80 & 25.0 & $00: 02$ \\
\hline 011 & 2.1 & 68.2 & 255393 & 1073 & 4.20 & 25.1 & $00: 02$ \\
\hline 012 & 2.3 & 75.8 & 259170 & 1192 & 4.60 & 25.0 & $00: 02$ \\
\hline 013 & 2.5 & 84.4 & 265489 & 1327 & 5.00 & 25.0 & $00: 02$ \\
\hline 014 & 2.3 & 87.8 & 300200 & 1381 & 4.60 & 25.1 & $00: 02$ \\
\hline 015 & 2.1 & 87.8 & 328790 & 1381 & 4.20 & 25.0 & $00: 02$ \\
\hline 016 & 1.9 & 85.0 & 351811 & 1337 & 3.80 & 25.0 & $00: 02$ \\
\hline 017 & 1.7 & 80.2 & 370996 & 1261 & 3.40 & 25.1 & $00: 02$ \\
\hline 018 & 1.5 & 74.6 & 391103 & 1173 & 3.00 & 25.1 & $00: 02$ \\
\hline 019 & 1.3 & 67.6 & 408928 & 1063 & 2.60 & 25.0 & $00: 02$ \\
\hline 020 & 1.1 & 60.9 & 435380 & 957.8 & 2.20 & 25.1 & $00: 02$ \\
\hline 021 & 0.9 & 52.9 & 462228 & 832.0 & 1.80 & 25.0 & $00: 02$ \\
\hline 022 & 0.7 & 45.4 & 510037 & 714.1 & 1.40 & 25.0 & $00: 02$ \\
\hline 023 & 0.5 & 36.9 & 580363 & 580.4 & 1.00 & 25.0 & $00: 02$ \\
\hline 024 & 0.3 & 29.4 & 770672 & 462.4 & 0.60 & 25.0 & $00: 02$ \\
\hline 025 & 0.1 & 21.1 & 1659304 & 331.9 & 0.20 & 25.1 & $00: 02$ \\
\hline
\end{tabular}


FIGURE 104 RHEOGRAM SHOWING RHEOPEXY BEHAVIOR FOR LECITHIN:IPM (60:40) CONTAINING 0.1\% WATER AND $6.5 \% \mathrm{KT}$ BY CONE AND PLATE VISCOMETER

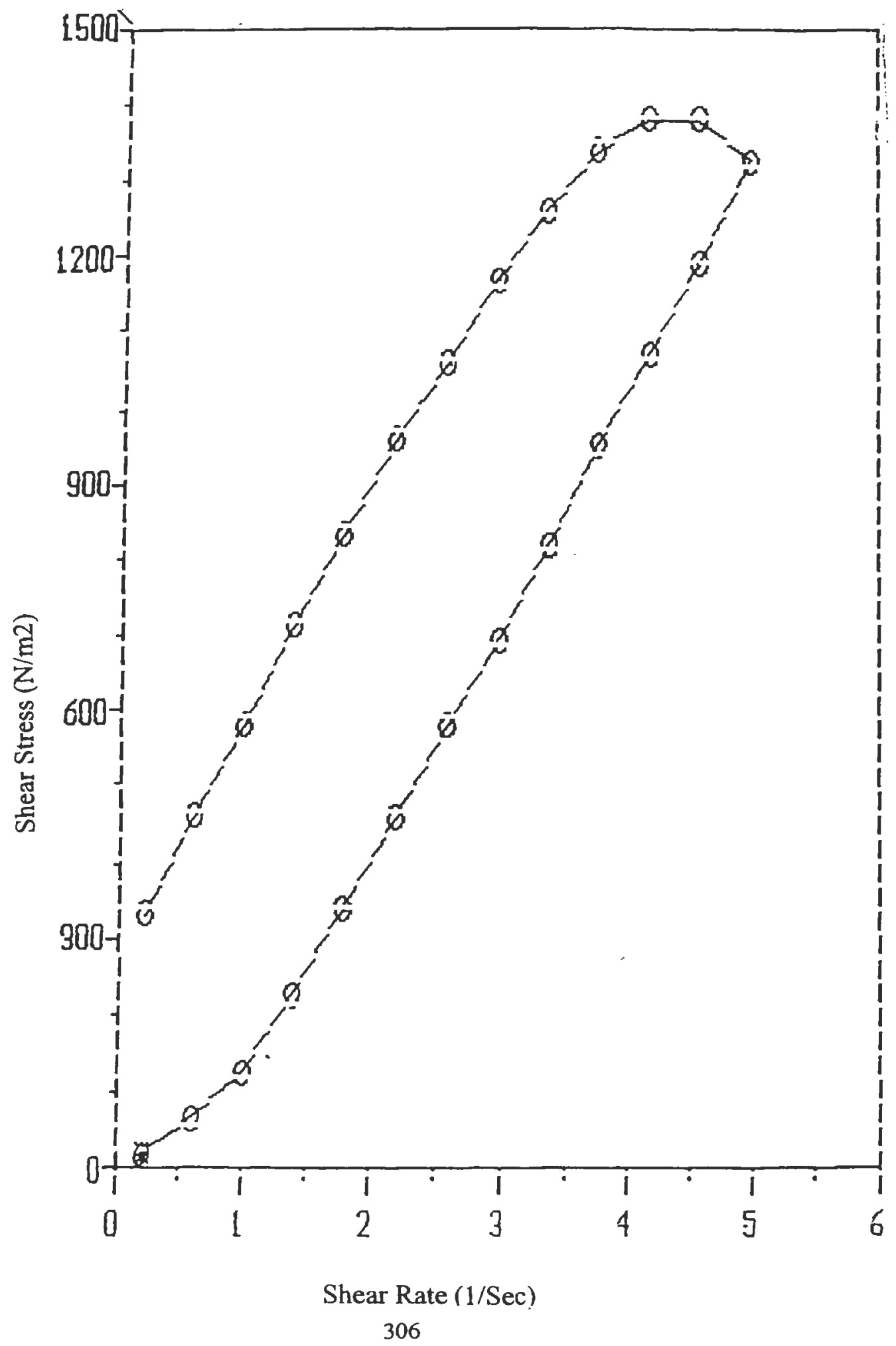


TABLE 93, VISCOSITY VALUES FOR LECITHIN:IPM (60:40) CONTAINING $0.25 \%$ WATER AND $6.5 \% \mathrm{KT}$ BY CONE AND PLATE VISCOMETER

RHEOCALC VI.40 BROOKFIELD ENGINEERING LABS

\begin{tabular}{|c|c|c|c|c|c|c|c|}
\hline \multirow{2}{*}{$\begin{array}{l}\text { Model: } \\
\text { Sample } \\
H\end{array}$} & \multirow{2}{*}{$\begin{array}{l}\mathrm{HB} \\
: 604 \mathrm{C} \\
\mathrm{RPM}\end{array}$} & \multicolumn{2}{|c|}{$\begin{array}{l}\text { Spindle: CP52 } \\
025 W\end{array}$} & \multicolumn{2}{|c|}{$\begin{array}{r}\text { Date: } 01 / 29 / 02 \\
\text { File: }\end{array}$} & \multicolumn{2}{|c|}{$\begin{array}{l}\text { Time: } 02: 38 \\
604025 W . \text { DV3 }\end{array}$} \\
\hline & & $\underset{\mathscr{x}}{\text { Torque }}$ & $\begin{array}{l}\text { Viscosity } \\
\text { mPas }\end{array}$ & $\begin{array}{l}\text { Sh Str } \\
\mathrm{N} / \mathrm{m}^{2}\end{array}$ & $\begin{array}{l}\text { Sh Rt } \\
1 / \text { Sec }\end{array}$ & $\begin{array}{l}\text { Temp } \\
{ }^{\circ} \mathrm{C}\end{array}$ & $\begin{array}{l}\text { Time } \\
M M: S S\end{array}$ \\
\hline 001 & 0.1 & 1.3 & 102232 & 20.4 & 0.20 & 25.0 & $00: 02$ \\
\hline 002 & 0.3 & 3.6 & 94368 & 56.6 & 0.60 & 25.0 & $00: 02$ \\
\hline 003 & 0.5 & 8.6 & 135261 & 135.3 & 1.00 & 25.0 & $00: 02$ \\
\hline 004 & 0.7 & 15.7 & 176378 & 246.9 & 1.40 & 25.0 & $00: 02$ \\
\hline 005 & 0.9 & 22.7 & 198348 & 357.0 & 1.80 & 25.0 & $00: 02$ \\
\hline 006 & 1.1 & 30.4 & 217332 & 478.1 & 2.20 & 25.0 & $00: 02$ \\
\hline 007 & 1.3 & 37.7 & 228056 & 592.9 & 2.60 & 25.0 & $00: 02$ \\
\hline 008 & 1.5 & 45.8 & 240114 & 720.3 & 3.00 & 25.0 & $00: 02$ \\
\hline 009 & 1.7 & 53.7 & 248410 & 844.6 & 3.40 & 25.0 & $00: 02$ \\
\hline 010 & 1.9 & 60.8 & 251648 & 956.3 & 3.80 & 25.1 & $00: 02$ \\
\hline 011 & 2.1 & 68.6 & 256891 & 1079 & 4.20 & 25.0 & $00: 02$ \\
\hline 012 & 2.3 & 75.7 & 258828 & 1191 & 4.60 & 25.0 & $00: 02$ \\
\hline 013 & 2.5 & 83.7 & 263287 & 1316 & 5.00 & 25.0 & $00: 02$ \\
\hline 014 & 2.3 & 86.7 & 296439 & 1364 & 4.60 & 25.0 & $00: 02$ \\
\hline 015 & 2.1 & 86.1 & 322424 & 1354 & 4.20 & 25.0 & $00: 02$ \\
\hline 016 & 1.9 & 82.9 & 343119 & 1304 & 3.80 & 25.0 & $00: 02$ \\
\hline 017 & 1.7 & 77.8 & 359894 & 1224 & 3.40 & 25.0 & $00: 02$ \\
\hline 018 & 1.5 & 72.7 & 381142 & 1143 & 3.00 & 25.0 & $00: 02$ \\
\hline 019 & 1.3 & 66.1 & 399854 & 1040 & 2.60 & 25.0 & $00: 02$ \\
\hline 020 & 1.1 & 59.9 & 428231 & 942.1 & 2.20 & 25.0 & $00: 02$ \\
\hline 021 & 0.9 & 52.4 & 457860 & 824.1 & 1.80 & 25.1 & $00: 02$ \\
\hline 022 & 0.7 & 45.7 & 513407 & 718.8 & 1.40 & 25.0 & $00: 02$ \\
\hline 023 & 0.5 & 37.9 & 596091 & 596.1 & 1.00 & 25.0 & $00: 02$ \\
\hline 024 & 0.3 & 30.8 & 807371 & 484.4 & 0.60 & 25.0 & $00: 02$ \\
\hline 025 & 0.1 & 22.5 & 1769400 & 353.9 & 0.20 & 25.0 & $00: 02$ \\
\hline
\end{tabular}


FIGURE 105, RHEOGRAM SHOWING RHEOPEXY BEHAVIOR FOR LECITHIN:IPM (60:40) CONTAINING 0.25\% WATER AND 6.5\% KT BY CONE AND PLATE VISCOMETER

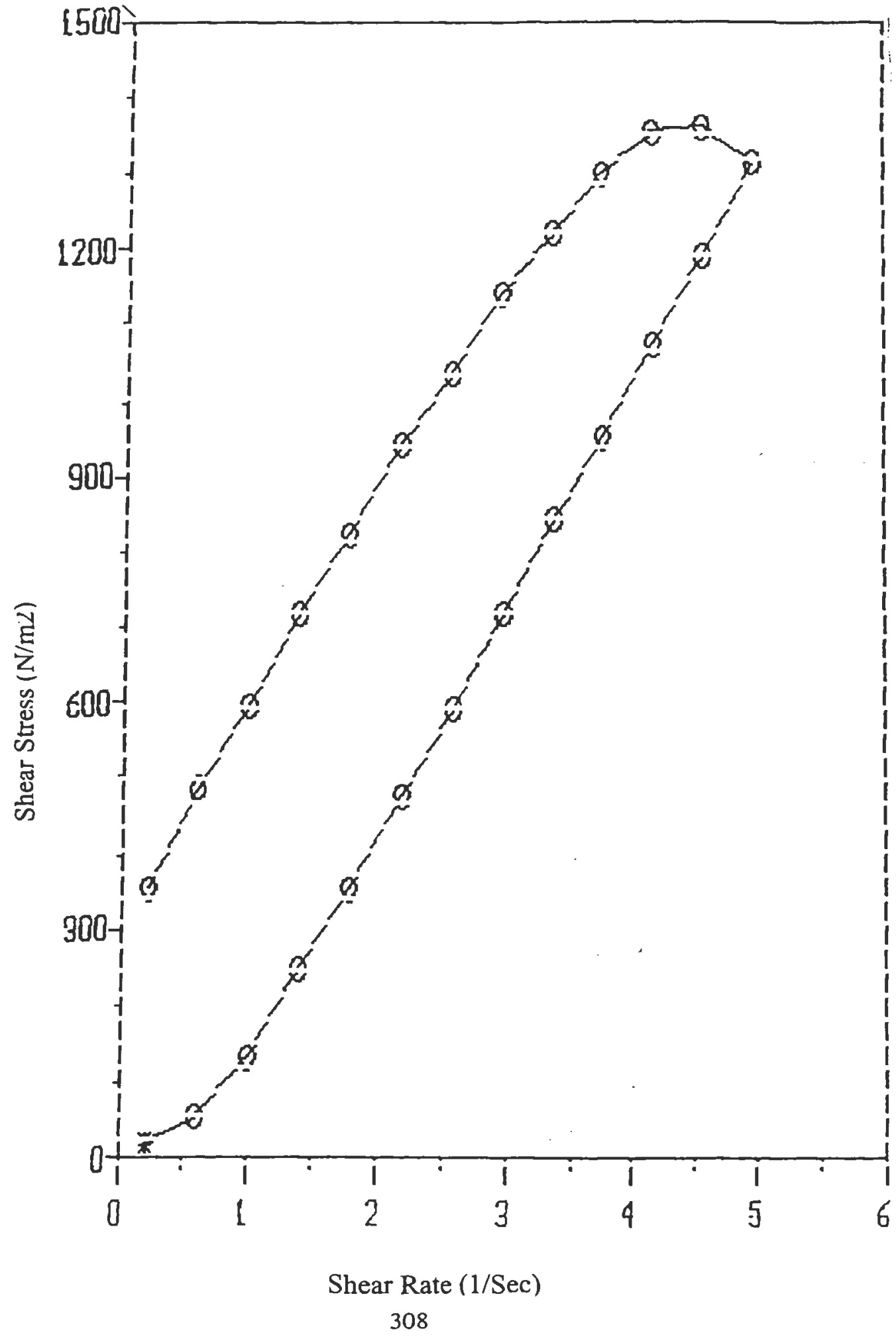


TABLE 94! VISCOSITY VALUES FOR LECITHIN:IPM (60:40) CONTAINING $0.5 \%$ WATER AND $6.5 \%$ KT BY CONE AND PLATE VISCOMETER

RHEOCALC V1.40 BROOKFIELD ENGINEERING LABS

\begin{tabular}{|c|c|c|c|c|c|c|c|}
\hline \multirow{2}{*}{$\begin{array}{c}\text { Model: } \\
\text { Sample } \\
\#\end{array}$} & \multirow{2}{*}{$\begin{array}{l}\mathrm{HB} \\
: \quad 6040 \\
\mathrm{RPM}\end{array}$} & \multicolumn{2}{|c|}{$\begin{array}{l}\text { Spindle: CP52 } \\
05 W\end{array}$} & \multicolumn{2}{|c|}{$\begin{array}{r}\text { Date: } 01 / 29 / 02 \\
\text { File: }\end{array}$} & \multicolumn{2}{|c|}{$\begin{array}{l}\text { Time: } 02: 55 \\
60405 W . \text { DV3 }\end{array}$} \\
\hline & & $\underset{x}{\text { Torque }}$ & $\begin{array}{l}\text { Viscosity } \\
\text { mPas }\end{array}$ & $\underset{N / m^{2}}{S h ~ S t r}$ & $\begin{array}{l}\text { Sh Rt } \\
1 / \text { Sec }\end{array}$ & $\stackrel{\text { Temp }}{ }^{\circ} \mathrm{C}$ & $\begin{array}{l}\text { Time } \\
\text { MM:SS }\end{array}$ \\
\hline 001 & 0.1 & 0.8 & 62912 & 12.6 & 0.20 & 25.0 & $00: 02$ \\
\hline 002 & 0.3 & 3.8 & 99611 & 59.8 & 0.60 & 25.0 & $00: 02$ \\
\hline 003 & 0.5 & 7.3 & 114814 & 114.8 & 1.00 & 25.0 & $00: 02$ \\
\hline 004 & 0.7 & 13.3 & 149416 & 209.2 & 1.40 & 25.0 & $00: 02$ \\
\hline 005 & 0.9 & 19.3 & 168639 & 303.6 & 1.80 & 25.0 & $00: 02$ \\
\hline 006 & 1.1 & 25.5 & 182302 & 401.1 & 2.20 & 25.0 & $00: 02$ \\
\hline 007 & 1.3 & 31.3 & 189341 & 492.3 & 2.60 & 25.0 & $00: 02$ \\
\hline 008 & 1.5 & 37.8 & 198173 & 594.5 & 3.00 & 25.1 & $00: 02$ \\
\hline 009 & 1.7 & 44.2 & 204464 & 695.2 & 3.40 & 25.0 & $00: 02$ \\
\hline 010 & 1.9 & 50.3 & 208189 & 791.1 & 3.80 & 25.0 & $00: 02$ \\
\hline 011 & 2.1 & 57.0 & 213451 & 896.5 & 4.20 & 25.0 & $00: 02$ \\
\hline 012 & 2.3 & 63.0 & 215405 & 990.9 & 4.60 & 25.0 & $00: 02$ \\
\hline 013 & 2.5 & 69.7 & 219248 & 1096 & 5.00 & 25.0 & $00: 02$ \\
\hline 014 & 2.3 & 71.6 & 244810 & 1126 & 4.60 & 25.0 & $00: 02$ \\
\hline 015 & 2.1 & 70.4 & 263631 & 1107 & 4.20 & 25.0 & $00: 02$ \\
\hline 016 & 1.9 & 67.2 & 278137 & 1057 & 3.80 & 25.0 & $00: 02$ \\
\hline 017 & 1.7 & 62.4 & 288655 & 981.4 & 3.40 & 25.0 & $00: 02$ \\
\hline 018 & 1.5 & 57.3 & 300405 & 901.2 & 3.00 & 25.0 & $00: 02$ \\
\hline 019 & 1.3 & 51.1 & 309116 & 803.7 & 2.60 & 25.0 & $00: 02$ \\
\hline 020 & 1.1 & 45.5 & 325284 & 715.6 & 2.20 & 25.0 & $00: 02$ \\
\hline 021 & 0.9 & 39.1 & 341647 & 615.0 & 1.80 & 25.0 & $00: 02$ \\
\hline 022 & 0.7 & 33.1 & 371855 & 520.6 & 1.40 & 25.0 & $00: 02$ \\
\hline 023 & 0.5 & 26.4 & 415219 & 415.2 & 1.00 & 25.0 & $00: 02$ \\
\hline 024 & 0.3 & 20.6 & 539995 & 324.0 & 0.60 & 25.0 & $00: 02$ \\
\hline 025 & 0.1 & 13.9 & 1093096 & 218.6 & 0.20 & 25.0 & $00: 02$ \\
\hline
\end{tabular}


FIGURE 106. RHEOGRAM SHOWING RHEOPEXY BEHAVIOR FOR LECITHIN:IPM (60:40) CONTAINING 0.5\% WATER AND 6.5\% KT BY CONE AND PLATE VISCOMETER

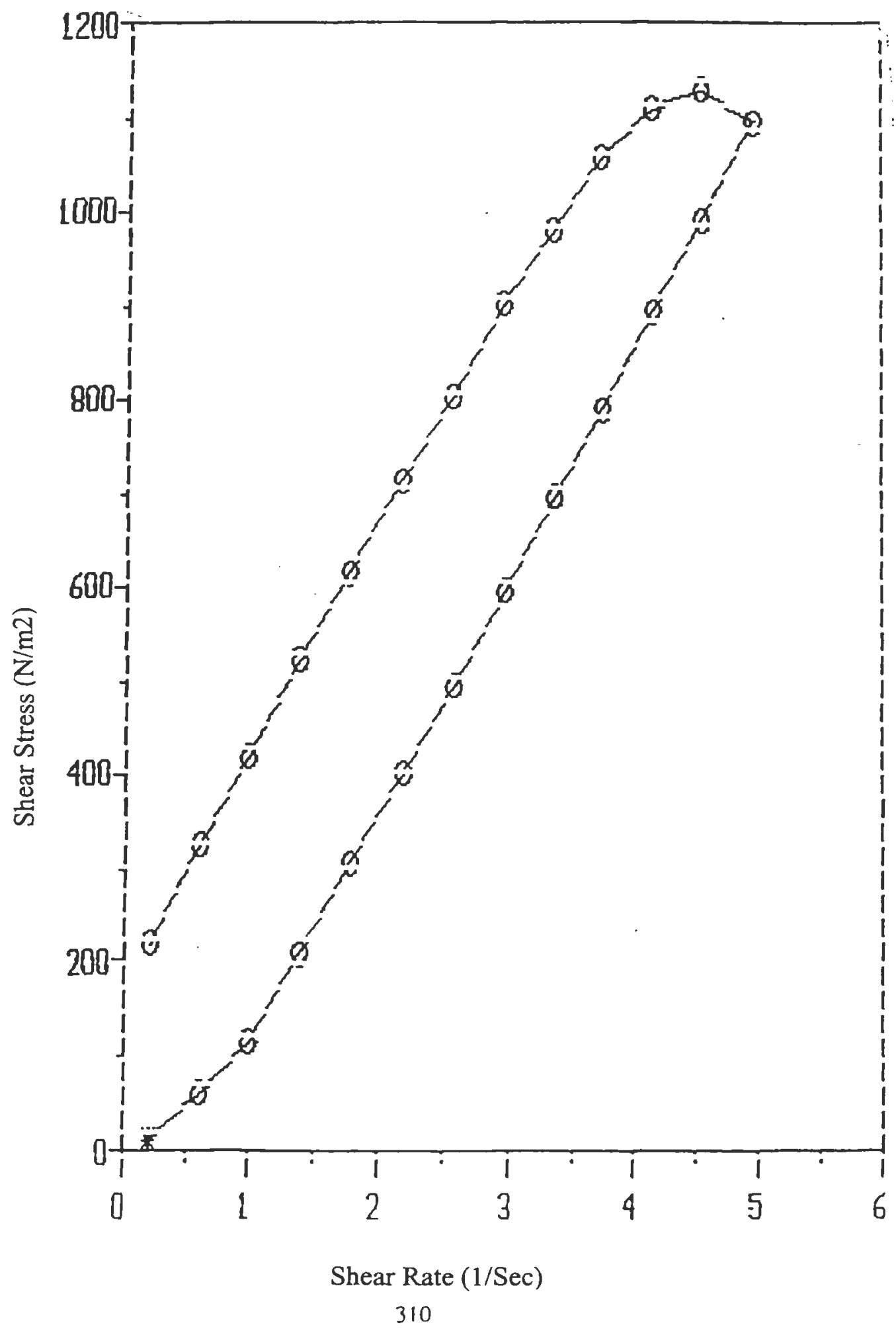


TABLE 95: VISCOSITY VALUES FOR LECITHIN:IPM (60:40) CONTAINING $0.6 \%$ WATER AND $6.5 \%$ KT BY CONE AND PLATE VISCOMETER

\author{
RHEOCALC V1. 40 BROOKFIELD ENGINEERING LABS
}

\begin{tabular}{|c|c|c|c|c|c|c|c|}
\hline \multirow{2}{*}{$\begin{array}{l}\text { Model: } \\
\text { Sample } \\
\#\end{array}$} & \multirow{2}{*}{$\begin{array}{l}\mathrm{HB} \\
: 6040 \\
\mathrm{RPM}\end{array}$} & \multicolumn{2}{|c|}{$\begin{array}{l}\text { Spindle: CP52 } \\
06 w\end{array}$} & \multicolumn{2}{|c|}{$\begin{array}{r}\text { Date: } 01 / 29 / 02 \\
\text { File: }\end{array}$} & \multicolumn{2}{|c|}{$\begin{array}{l}\text { Time: } 03: 07 \\
\text { 60406W.DV3 }\end{array}$} \\
\hline & & $\underset{\mathscr{x}}{\text { Torque }}$ & $\begin{array}{l}\text { Viscosity } \\
\text { mPas }\end{array}$ & $\begin{array}{l}\text { Sh Str } \\
N / \mathbf{m}^{2}\end{array}$ & $\begin{array}{l}\text { Sh Rt } \\
1 / \operatorname{Sec}\end{array}$ & $\begin{array}{l}\text { Temp } \\
{ }^{\circ} \mathrm{C}\end{array}$ & $\begin{array}{l}\text { Time } \\
\text { MM:SS }\end{array}$ \\
\hline 001 & 0.1 & 0.4 & 31456 & 6.29 & 0.20 & 25.0 & $00: 02$ \\
\hline 002 & 0.3 & 3.6 & 94368 & 56.6 & 0.60 & 25.0 & $00: 02$ \\
\hline 003 & 0.5 & 8.3 & 130542 & 130.5 & 1.00 & 25.0 & $00: 02$ \\
\hline 004 & 0.7 & 13.7 & 153910 & 215.5 & 1.40 & 25.1 & $00: 02$ \\
\hline 005 & 0.9 & 19.6 & 171260 & 308.3 & 1.80 & 25.1 & $00: 02$ \\
\hline 006 & 1.1 & 26.3 & 188021 & 413.6 & 2.20 & 25.1 & $00: 02$ \\
\hline 007 & 1.3 & 32.9 & 199020 & 517.5 & 2.60 & 25.1 & $00: 02$ \\
\hline 008 & 1.5 & 39.7 & 208134 & 624.4 & 3.00 & 25.1 & $00: 02$ \\
\hline 009 & 1.7 & 46.6 & 215566 & 732.9 & 3.40 & 25.1 & $00: 02$ \\
\hline 010 & 1.9 & 52.8 & 218536 & 830.4 & 3.80 & 25.0 & $00: 02$ \\
\hline 011 & 2.1 & 60.1 & 225060 & 945.3 & 4.20 & 25.1 & $00: 02$ \\
\hline 012 & 2.3 & 66.4 & 227030 & 1044 & 4.60 & 25.1 & $00: 02$ \\
\hline 013 & 2.5 & 73.5 & 231202 & 1156 & 5.00 & 25.1 & $00: 02$ \\
\hline 014 & 2.3 & 75.7 & 258828 & 1191 & 4.60 & 25.1 & $00: 02$ \\
\hline 015 & 2.1 & 74.3 & 278236 & 1169 & 4.20 & 25.1 & $00: 02$ \\
\hline 016 & 1.9 & 71.2 & 294693 & 1120 & 3.80 & 25.0 & $00: 02$ \\
\hline 017 & 1.7 & 66.1 & 305771 & 1040 & 3.40 & 25.1 & $00: 02$ \\
\hline 018 & 1.5 & 61.0 & 319803 & 959.4 & 3.00 & 25.1 & $00: 02$ \\
\hline 019 & 1.3 & 54.5 & 329683 & 857.2 & 2.60 & 25.1 & $00: 02$ \\
\hline 020 & 1.1 & 48.8 & 348876 & 767.5 & 2.20 & 25.0 & $00: 02$ \\
\hline 021 & 0.9 & 42.5 & 371356 & 668.4 & 1.80 & 25.1 & $00: 02$ \\
\hline 022 & 0.7 & 35.5 & 398817 & 558.3 & 1.40 & 25.0 & $00: 02$ \\
\hline 023 & 0.5 & 29.3 & 460830 & 460.8 & 1.00 & 25.0 & $00: 02$ \\
\hline 024 & 0.3 & 22.2 & 581936 & 349.2 & 0.60 & 25.1 & $00: 02$ \\
\hline 025 & 0.1 & 15.7 & 1234648 & 246.9 & 0.20 & 25.1 & $00: 02$ \\
\hline
\end{tabular}


FIGURE 107. RHEOGRAM SHOWING RHEOPEXY BEHAVIOR FOR LECITHIN:IPM (60:40) CONTAINING 0.6\% WATER AND 6.5\% KT BY CONE AND PLATE VISCOMETER

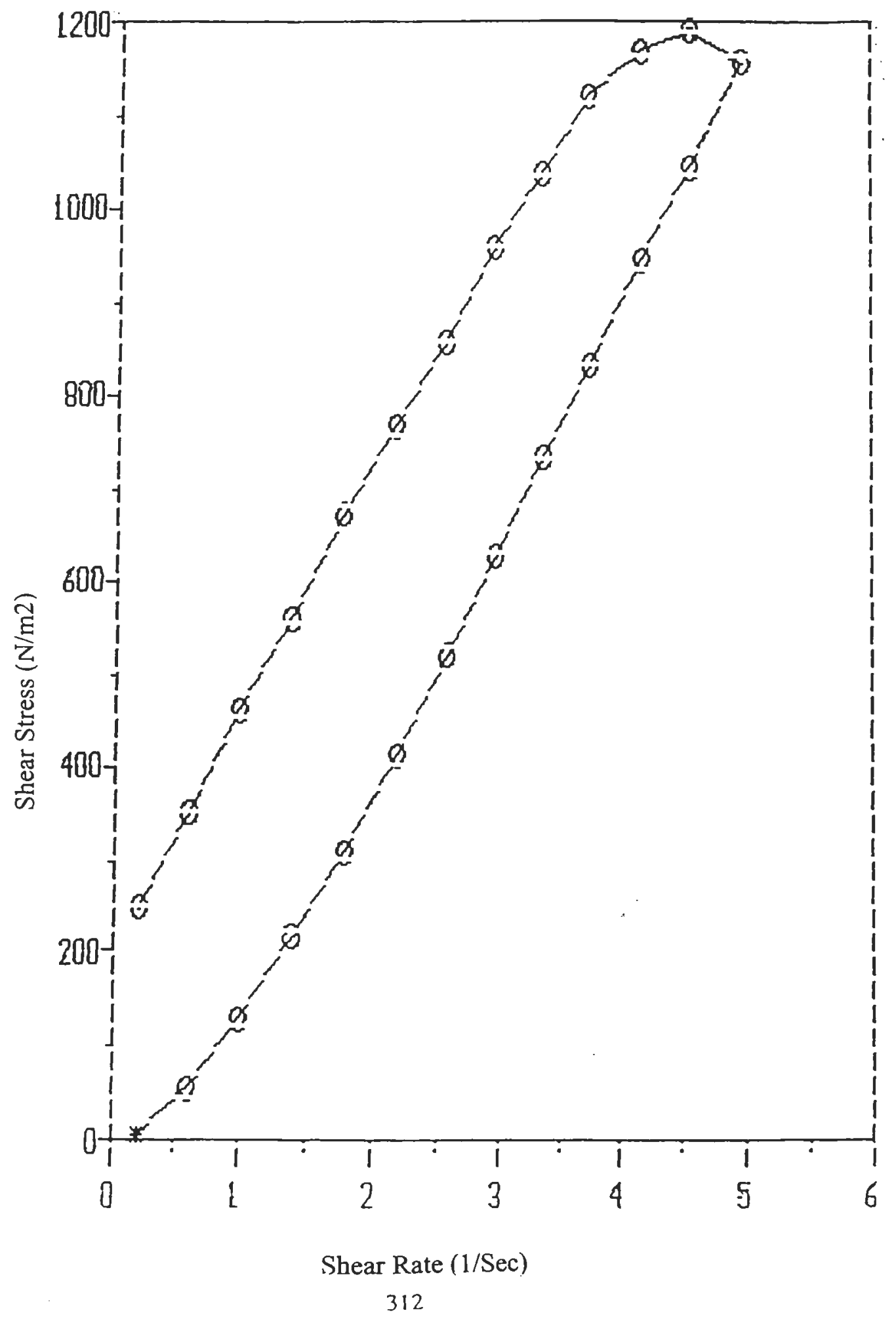


TABLE 96:. VISCOSITY VALUES FOR LECITHIN:IPM (60:40) CONTAINING $0.7 \%$ WATER AND $6.5 \%$ KT BY CONE AND PLATE VISCOMETER

RHEOCALC V1.40 BROOKFIELD ENGINEERING LABS

\begin{tabular}{|c|c|c|c|c|c|c|c|}
\hline \multirow{2}{*}{$\begin{array}{l}\text { Mode 1: } \\
\text { Sample } \\
\#\end{array}$} & \multirow{2}{*}{$\begin{array}{l}\mathrm{HB} \\
: 6040 \\
\mathrm{RPM}\end{array}$} & \multicolumn{2}{|c|}{$\begin{array}{l}\text { Spindle: CP52 } \\
07 W\end{array}$} & \multicolumn{2}{|c|}{$\begin{array}{r}\text { Date: } 01 / 29 / 02 \\
\text { File: }\end{array}$} & \multicolumn{2}{|c|}{$\begin{array}{l}\text { Time: } 03: 15 \\
60407 W . \text { DV3 }\end{array}$} \\
\hline & & $\begin{array}{c}\text { Torque } \\
\%\end{array}$ & $\begin{array}{l}\text { Viscosity } \\
\text { mPas }\end{array}$ & $\underset{N / m^{2}}{\operatorname{Sh} S t r}$ & $\begin{array}{l}\text { Sh Rt } \\
1 / \text { Sec }\end{array}$ & ${ }^{\text {Temp }}$ & $\begin{array}{l}\text { Time } \\
M M: S S\end{array}$ \\
\hline 001 & 0.1 & 0.9 & 70776 & 14.2 & 0.20 & 25.0 & $00: 02$ \\
\hline 002 & 0.3 & 3.9 & 102232 & 61.3 & 0.60 & 25.0 & $00: 02$ \\
\hline 003 & 0.5 & 8.5 & 133688 & 133.7 & 1.00 & 25.1 & $00: 02$ \\
\hline 004 & 0.7 & 13.5 & 151663 & 212.3 & 1.40 & 25.1 & $00: 02$ \\
\hline 005 & 0.9 & 19.9 & 173882 & 313.0 & 1.80 & 25.1 & $00: 02$ \\
\hline 006 & 1.1 & 25.8 & 184447 & 405.8 & 2.20 & 25.0 & $00: 02$ \\
\hline 007 & 1.3 & 32.6 & 197205 & 512.7 & 2.60 & 25.0 & $00: 02$ \\
\hline 008 & 1.5 & 39.3 & 206037 & 618.1 & 3.00 & 25.0 & $00: 02$ \\
\hline 009 & 1.7 & 46.0 & 212791 & 723.5 & 3.40 & 25.0 & $00: 02$ \\
\hline 010 & 1.9 & 52.2 & 216053 & 821.0 & 3.80 & 25.1 & $00: 02$ \\
\hline 011 & 2.1 & 59.4 & 222439 & 934.2 & 4.20 & 25.0 & $00: 02$ \\
\hline 012 & 2.3 & 65.7 & 224637 & 1033 & 4.60 & 25.1 & $00: 02$ \\
\hline 013 & 2.5 & 72.8 & 229000 & 1145 & 5.00 & 25.0 & $00: 02$ \\
\hline 014 & 2.3 & 74.9 & 256093 & 1178 & 4.60 & 25.0 & $00: 02$ \\
\hline 015 & 2.1 & 73.5 & 275240 & 1156 & 4.20 & 25.1 & $00: 02$ \\
\hline 016 & 1.9 & 70.3 & 290968 & 1106 & 3.80 & 25.1 & $00: 02$ \\
\hline 017 & 1.7 & 65.2 & 301608 & 1025 & 3.40 & 25.0 & $00: 02$ \\
\hline 018 & 1.5 & 60.1 & 315084 & 945.3 & 3.00 & 25.0 & $00: 02$ \\
\hline 019 & 1.3 & 53.9 & 326054 & 847.7 & 2.60 & 25.0 & $00: 02$ \\
\hline 020 & 1.1 & 48.2 & 344586 & 758.1 & 2.20 & 25.0 & $00: 02$ \\
\hline 021 & 0.9 & 41.2 & 359996 & 648.0 & 1.80 & 25.1 & $00: 02$ \\
\hline 022 & 0.7 & 35.2 & 395447 & 553.6 & 1.40 & 25.1 & $00: 02$ \\
\hline 023 & 0.5 & 28.2 & 443530 & 443.5 & 1.00 & 25.1 & $00: 02$ \\
\hline 024 & 0.3 & 22.0 & 576693 & 346.0 & 0.60 & 25.1 & $00: 02$ \\
\hline 025 & 0.1 & 14.8 & 1163872 & 232.8 & 0.20 & 25.1 & $00: 02$ \\
\hline
\end{tabular}


FIGURE 108: RHEOGRAM SHOWING RHEOPEXY BEHAVIOR FOR LECITHIN:IPM (60:40) CONTAINING 0.7\% WATER AND $6.5 \% \mathrm{KT}$ BY CONE AND PLATE VISCOMETER

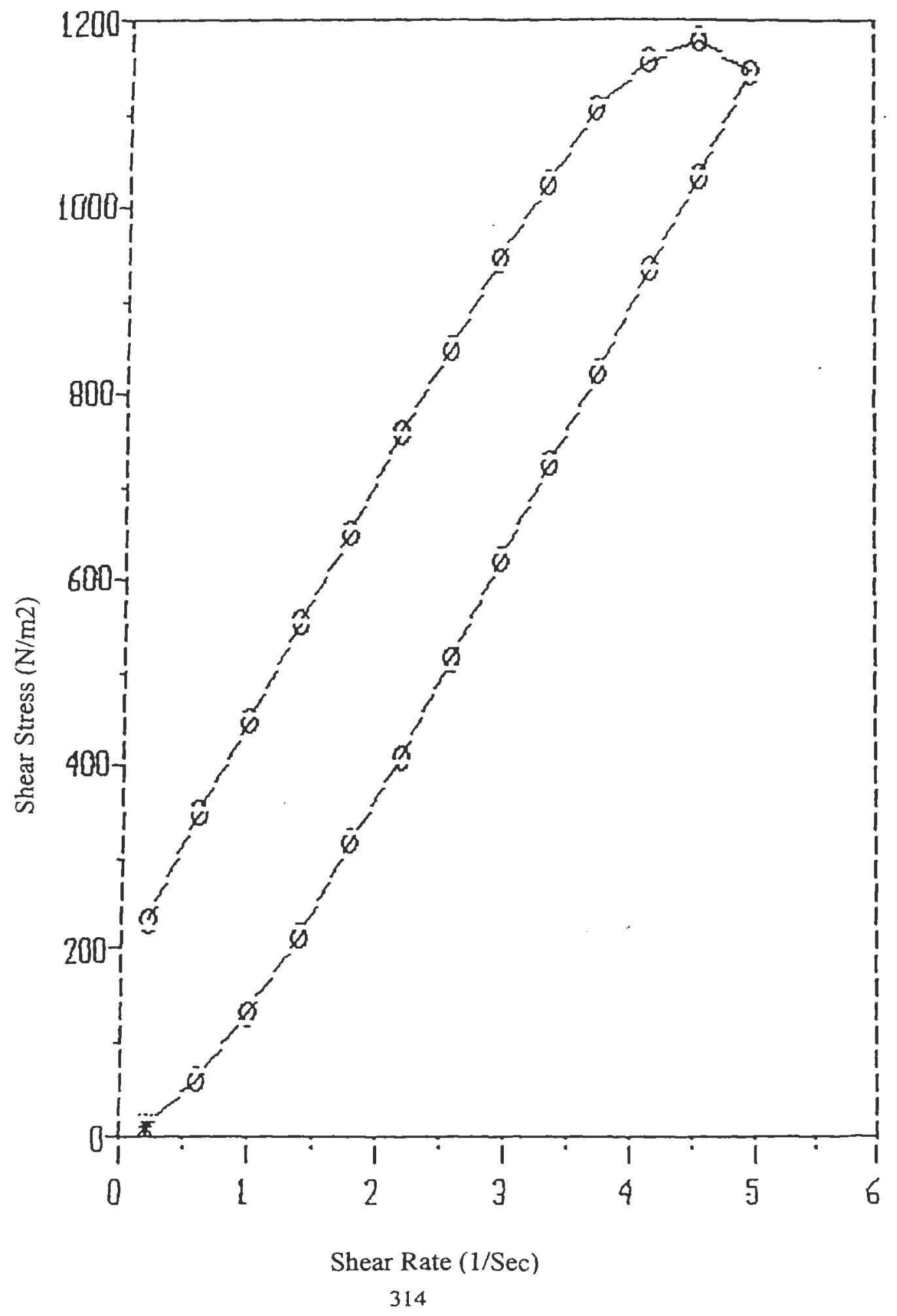


TABLE 97. VISCOSITY VALUES FOR LECITHIN:IPM (60:40) CONTAINING $0.8 \%$ WATER AND $6.5 \%$ KT BY CONE AND PLATE VISCOMETER

RHEOCALC V1.40 BROOKFIELD ENGINEERING LABS

\begin{tabular}{|c|c|c|c|c|c|c|c|}
\hline \multirow{2}{*}{$\begin{array}{l}\text { Model: } \\
\text { Sample } \\
\text { \# }\end{array}$} & \multirow{2}{*}{$\begin{array}{l}\mathrm{HB} \\
: \quad 604 \mathrm{C} \\
\mathrm{RPM}\end{array}$} & \multicolumn{2}{|c|}{$\begin{array}{l}\text { Spindle: CP52 } \\
\text { 08w }\end{array}$} & \multicolumn{2}{|c|}{$\begin{array}{r}\text { Date: } 01 / 29 / 02 \\
\text { File: }\end{array}$} & \multicolumn{2}{|c|}{$\begin{array}{l}\text { Time: } 03: 21 \\
60408 W . \text { DV3 }\end{array}$} \\
\hline & & $\underset{\%}{\text { Torque }}$ & $\begin{array}{l}\text { Viscosity } \\
\text { mPas }\end{array}$ & $\underset{N / m^{2}}{\operatorname{Sh} S t r}$ & $\begin{array}{l}\text { Sh Rt } \\
\text { 1/Sec }\end{array}$ & $\stackrel{\text { Temp }}{\cdot \mathbf{C}}$ & $\begin{array}{l}\text { Time } \\
M M: S S\end{array}$ \\
\hline 001 & 0.1 & 0.8 & 62912 & 12.6 & 0.20 & 25.0 & $00: 02$ \\
\hline 002 & 0.3 & 3.0 & 78640 & 47.2 & 0.60 & 25.0 & $00: 02$ \\
\hline 003 & 0.5 & 7.5 & 117960 & 118.0 & 1.00 & 25.0 & $00: 02$ \\
\hline 004 & 0.7 & 12.8 & 143799 & 201.3 & 1.40 & 25.0 & $00: 02$ \\
\hline 005 & 0.9 & 18.2 & 159028 & 286.2 & 1.80 & 25.0 & $00: 02$ \\
\hline 006 & 1.1 & 23.3 & 166574 & 366.5 & 2.20 & 25.0 & $00: 02$ \\
\hline 007 & 1.3 & 29.2 & 176638 & 459.3 & 2.60 & 25.0 & $00: 02$ \\
\hline 008 & 1.5 & 34.4 & 180348 & 541.0 & 3.00 & 25.0 & $00: 02$ \\
\hline 009 & 1.7 & 40.1 & 185498 & 630.7 & 3.40 & 25.0 & $00: 02$ \\
\hline 010 & 1.9 & 45.2 & 187080 & 710.9 & 3.80 & 25.0 & $00: 02$ \\
\hline 011 & 2.1 & 50.8 & 190234 & 799.0 & 4.20 & 25.0 & $00: 02$ \\
\hline 012 & 2.3 & 55.9 & 191129 & 879.2 & 4.60 & 25.0 & $00: 02$ \\
\hline 013 & 2.5 & 61.7 & 194084 & 970.4 & 5.00 & 25.0 & $00: 02$ \\
\hline 014 & 2.3 & 63.0 & 215405 & 990.9 & 4.60 & 25.0 & $00: 02$ \\
\hline 015 & 2.1 & 61.3 & 229554 & 964.1 & 4.20 & 25.0 & $00: 02$ \\
\hline 016 & 1.9 & 58.1 & 240473 & 913.8 & 3.80 & 25.0 & $00: 02$ \\
\hline 017 & 1.7 & 53.5 & 247485 & 841.4 & 3.40 & 25.0 & $00: 02$ \\
\hline 018 & 1.5 & 48.9 & 256366 & 769.1 & 3.00 & 25.0 & $00: 02$ \\
\hline 019 & 1.3 & 43.4 & 262537 & 682.6 & 2.60 & 25.0 & $00: 02$ \\
\hline 020 & 1.1 & 38.6 & 275955 & 607.1 & 2.20 & 25.0 & $00: 02$ \\
\hline 021 & 0.9 & 33.2 & 290094 & 522.2 & 1.80 & 25.0 & $00: 02$ \\
\hline 022 & 0.7 & 28.0 & 314560 & 440.4 & 1.40 & 25.0 & $00: 02$ \\
\hline 023 & 0.5 & 22.2 & 349162 & 349.2 & 1.00 & 25.1 & $00: 02$ \\
\hline 024 & 0.3 & 17.1 & 448248 & 268.9 & 0.60 & 25.0 & $00: 02$ \\
\hline 025 & 0.1 & 11.1 & 872904 & 174.6 & 0.20 & 25.0 & $00: 02$ \\
\hline
\end{tabular}


FIGURE 109'. RHEOGRAM SHOWING RHEOPEXY BEHAVIOR FOR LECITHIN:IPM (60:40) CONTAINING 0.8\% WATER AND 6.5\% KT BY CONE AND PLATE VISCOMETER

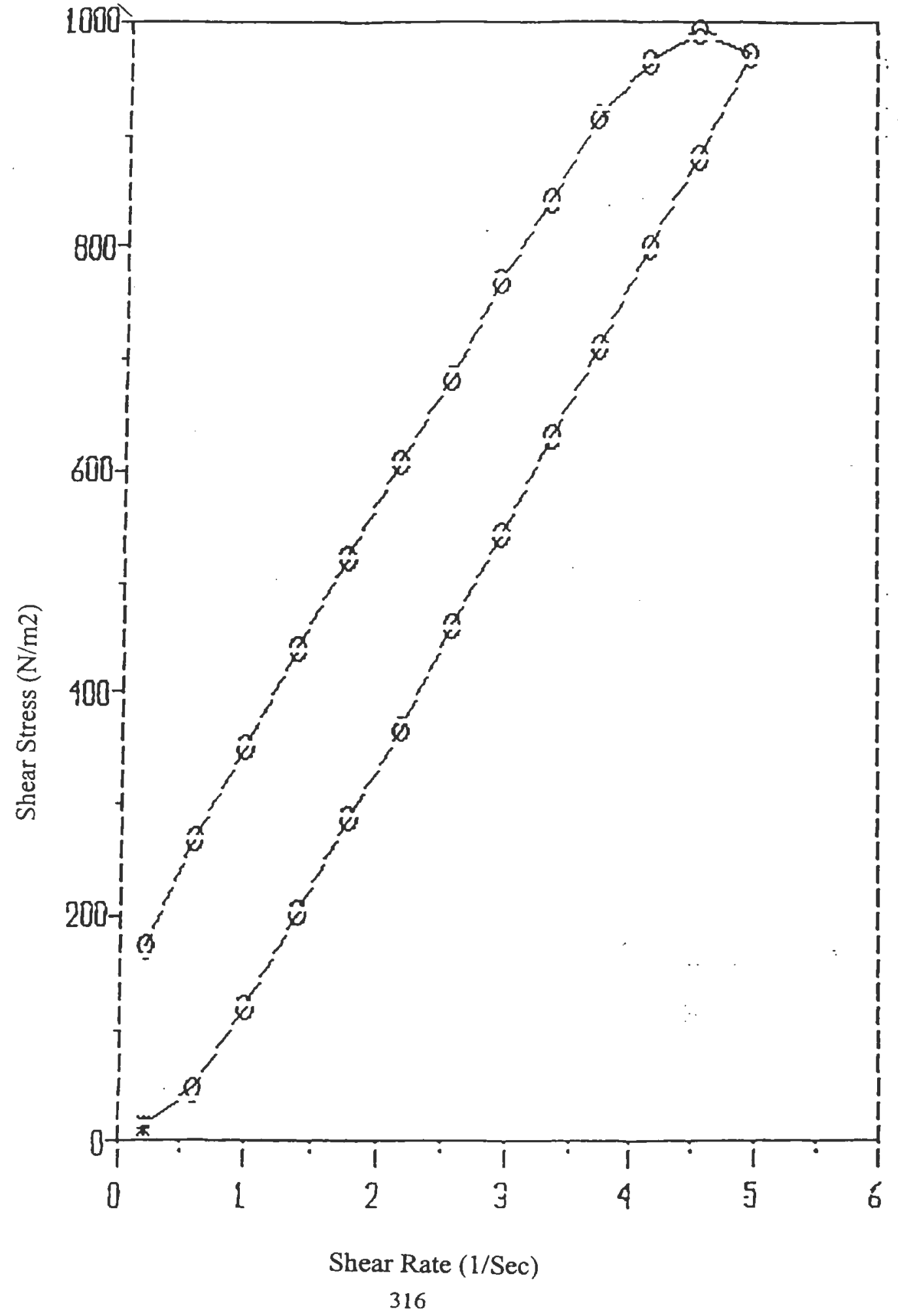




\section{BIBLIOGRAPHY}

Attwood, D., In Colloidal Drug Delivery Systems, Kreuter, J., Ed., Marcel Dekker: New York, 1994, 31-72.

Bhatnagar, S., Vyas, S. P., Organogel-based system for transdermal delivery of propranolol, Journal of Microencapsulation, 1994, 11(4), 431-438.

Cordero, J. A., Alarcon, L., Escribano, E., Obach, R., Domenech, J., A comparative study of the transdermal penetration of a series of nonsteroidal antiinflamatory drugs, Journal of Pharmaceutical Sciences, 1997, 86(4), 503-507.

Delgado-Charro, M. B., Iglesias-Vilas, G., Blanco-Mendez, J., Lopez-Quintela, M. A., Marty, J. P., Guy, R. H., Delivery of a hydrophilic solute through the skin from novel microemulsion systems, European Journal of Pharmaceutics and Biopharmaceutics, $1997,43,37-42$.

Dreher, F., Walde, P., Luisi, P. L., Elsner, P., Human skin irritation studies of a lecithin microemulsion gel and of lecithin liposomes, Skin Pharmacology, 1996, 9, 124-129.

Dreher, F., Walde, P., Walther, P., Wehrli, E., Interaction of a lecithin microemulsion gel with human stratum corneum and its effect on transdermal transport, Journal of Controlled Release, 1997, 45, 131-140. 
Gurol, Z., Hekimoglu, S., Demirdamar, R., Sumnu, M., Percutaneous absorption of ketoprofen: In vitro release and percutaneous absorption of ketoprofen from different ointment bases, Pharmaceutica Acta Helvetiae, 1996, 71, 205-212.

Haering, G., Luisi, P. L., Hydrocarbon gels from water-in-oil microemulsions, The Journal of Physical Chemistry, 1986, 90(22), 5892-58-95.

Henmi, T., Fujii, M., Kikuchi, K., Yamanobe, N., Matsumoto, M., Application of an oily gel formed by hydrogenated soybean phospholipids as a percutaneous absiorptiontype ointment base, Chemical and Pharmaceutical Bulletin, 1994, 42(3), 651-655.

Hinze, W. L., Uemasu, I., Dai, F., Braun, J. M., Analytical and related applications of organogels, Current Opinion in Colloid \& Interface Science, 1996, 1, 502-513.

Ho, H. O., Hsiao, C. C., Sheu, M. T., Preparation of microemulsions using polyglycerol fatty acid esters as surfactant for the delivery of protein drugs, Journal of Pharmaceutical Sciences, 1996, 85(2), 138-143.

Kantaria, S., Rees, G. D., Lawrence, M. J., Gelatin-stabilised microemulsion-based organogels: theology and application in iontophoretic transdermal drug delivery, Journal of Controlled Release, 1999, 60, 355-365. 
Lawrence, M. J., Rees, G. D., Microemulsion-based media as novel drug delivery systems, Advanced Drug Delivery Reviews, 2000, 45, 89-121.

McDaid, D. M., Deasy, P. B., An investigation into the transdermal delivery of nifedipine, Pharmeceutica Acta Helvetiae, 1996, 71, 253-258.

Murdan, S., Bergh, B., Gregoriadis, G., Florence, A. T., Water-in-sorbitan monostearate organogels (water-in-oil gels), Journal of Pharmaceutical Sciences, $1999,88(6), 615-619$.

Murdan, S., Bergh, B., Gregoriadis, G., Florence, A. T., Novel sorbitan monostearate organogels, Journal of Pharmaceutical Sciences, 1999, 88(6), 608-614.

Murdan, S., Bergh, B., Gregoriadis, G., Florence, A. T., Interaction of a nonionic surfactant-based organogel with aqueous media, International Journal of Pharmaceutics, 1999, 180, 211-214.

Osborne, D. W., Ward, A. J. I., O’Neill, K. J., Microemulsions as topical drug delivery vehicles: in-vitro transdermal studies of a model hydrophilic drug. The Journal of Pharmacy and Pharmacology, 1991, 43, 451-454.

Quadir, M., Zia, H., Needham, T. E., Development and evaluation of nasal formulations of ketorolac, Drug Delivery, 2000, 7, 223-229. 
Quellet, C., Eicke, H. F., Sager, W., Formation of microemulsion-based gelatin gels, The Journal of Physical Chemistry, 1991, 95, 5642-5655.

Rhee, Y. S., Choi, J. G., Park, E. S., Chi, S. C., Transdermal delivery of keoprofen using microemulsions, International Journal of Pharmaceutics, 2001, 228, 161-170.

Santoyo, S., Arellano, A., Ygartua, P., Martin, C., In vitro percutaneous absorption of piroxicam through synthetic membranes and abdominal rat skin, Pharmeceutica Acta Helvetiae, 1996, 71, 141-146.

Scartazzini, R., Luisi, P. L., Organogels from lecithins, The Journal of Physical Chemistry, 1988, 92, 829-833.

Schurtenberger, P., Scartazzini, R., Magid, L. J., Leser, M. E., Luisi, P. L., Structural and dynamic properties of polymer-like reverse micelles, The Journal of Physical Chemistry, 1990, 94, 3695-3701.

Shchipunov, Y. A., Lecithin organogel: A micellar system with unique properties, Colloids and Surfaces A: Physicochemical and Engineering Aspects, 2001(183-185), 541-554. 
Shchipunov, Y. A., Durrschmidt, T., Hoffman, H., Electrorheological effects in lecithin organogels with water and glycerol, Journal of Colloid and Interface Science, $1999,212,390-401$

Shchipunov, Y. A., Shumilina, E. V., Lecithin bridging by hydrogen bonds in the organogel, Materials Science and Engineering: C3, 1995, 43-50.

Tenjarla, S., Microemulsions: An overview and pharmaceutical applications, Critical Reviews in Therapeutic Drug Carrier Systems, 1999, 16(5), 461-521.

Trotta, M., Morel, S., Gasco, M. R., Effect of oil phase composition on the skin permeation of felodipine from o/w microemulsions, Pharmazie, 1997, 52, 50-53.

Trotta, M., Pattarino, F., Gasco, M. R., Influence of counter ions on the skin permeation of methotrexate from water-oil microemulsions, Pharmaceutica Acta Helvetiae, 1996, 71, 135-140.

Valenta, C., Wanka, M., Heidlas, J., Evaluation of novel soya-lecithin formulations for dermal use containing ketoprofen as a model drug Journal of Controlled Release, $2000,63,165-173$. 
Willimann, H., Walde, P., Luisi, P. L., Gazzaniga, A., Stroppolo, F., Lecithin organogel as matrix for transdermal transport of drugs, Journal of Pharmaceutical Sciences, 1992, 81(9), 871-874.

Yokomizo, Y., Sagitani, H., Effects of Phospholipids on the percutaneous penetration of indomethacin through the dorsal skin of guinea pigs in vitro, Journal of Controlled Release, 1996, 38, 267-274.

Yokomizo, Y., Sagitani, H., The effects of Phospholipids on the percutaneous penetration of indomethacin through the dorsal skin of guinea pigs in vitro. 2 . The effects of the hydrophobic group in phospholipids and a comparison with general enhancers. Journal of Controlled Release, 1996, 42, 37-46.

Yokomizo, Y., Effects of Phospholipids on the percutaneous penetration of drugs through the dorsal skin of the guinea pig, in vitro. 3. The effects of phospholipids on several drugs having different polarities. Journal of Controlled Release, 1996, 42 , 217-228. 